\title{
Scientia Media
}

\section{Der Molinismus}

\section{und das Faktenwissen}

Mit einer Edition des

Ms. BU Salamanca 156 von 1653

Sven K. Knebel 
SCIENTIA MEDIA 
BOCHUMER STUDIEN ZUR PHILOSOPHIE (BSP)

ISSN $1384-668 \mathrm{x}$

Herausgegeben von

Kurt Flasch - Ruedi Imbach

Burkhard Mojsisch $\dagger-$ Olaf Pluta

For an overview of all books published in this series, please see benjamins.com/catalog/bsp

Band 60

SVEN K. KNEBEL

Scientia Media

Der Molinismus und das Faktenwissen

Mit einer Edition des Ms. BU Salamanca 156 von 1653

JOHN BENJAMINS PUBLISHING COMPANY

AMSTERDAM / PHILADELPHIA 


\section{Scientia Media}

Der Molinismus und das Faktenwissen

Mit einer Edition des Ms. BU Salamanca 156 von 1653

SVEN K. KNEBEL

JOHN BENJAMINS PUBLISHING COMPANY

AMSTERDAM / PHILADELPHIA 
The paper used in this publication meets the minimum requirements of the American National Standard for Information Sciences - Permanence of Paper for Printed Library Materials, ANSI z39.48-1984.

DOI 10.1075/bsp.6o

Cataloging-in-Publication Data available from Library of Congress: LCCN 2021005954

ISBN 9789027208514 (нB)

ISBN 9789027260079 (Е-воOK)

(C) 2021 - John Benjamins B.V.

The electronic edition of this book is Open Access under the CC BY-NC-ND 4.o license. https://creativecommons.org/licenses/by-nc-nd/4.o/

This license permits reuse, distribution and reproduction in any medium, provided that the original author(s) and source are credited, for non-commercial purposes only. It does not permit the creation of derivative works without prior permission from the publisher.

This work may contain content reproduced under license from third parties. Permission to reproduce this third-party content must be obtained from these third parties directly.

John Benjamins Publishing Company · https://benjamins.com 


\section{Inhalt}

Einführung

I. Die nächste Etappe im Historikerstreit über die Gnadenstreitigkeiten

II. Die Systematisierung der Scientia Media im XVII. Jahrhundert

III. Luke Wadding SJ. (1593-1651/52) und sein Traktat über Gottes Wissen vom kontingent Zukünftigen

IV. Edmund Hogan SJ. (1831-1917): Luke Wadding, SJ.

\section{EDITION}

\section{Luke Wadding SJ.: Tractatus de scientia Dei futurorum contingentium}

Richardus Lynceus SJ.: Ad Lectorem

Liber quartus

1. An futura contingentia praesciantur a Deo in causis 191

2. Secunda sententia proponitur et probatur esse Sancti Thomae 196

3. Obiectiones contra mentem S. Thomae 202

4. Futura contingentia in solis causis omnino antecedentibus non posse a Deo determinate cognosci $\mathbf{2 1 2}$

5. An, et quo sensu, futura contingentia cognoscantur a Deo in ideis et in divina essentia $\mathbf{2 1 8}$

6. An, et quo sensu, futura contingentia cognoscuntur a Deo „in se ipsis“ 224

7. Probatur contingentium futurorum cognoscibilitas in se ipsis, ut obiecto terminativo, concurrente divina essentia ut obiecto motivo, sine ullo praedeterminante decreto $\mathbf{2 2 7}$

8. Quomodo motivum indifferens ad esse et non-esse futuri obiecti possit esse motivum sufficiens ad cognoscendum determinate, illud esse futurum $\mathbf{2 3 4}$

9. De prioritate obiecti libere futuri ad divinam eius praescientiam 237

10. Principium, cui innititur prioritas obiecti creati liberi ad divinam praescientiam $\mathbf{2 4 1}$

11. Ex superiori principio deducitur et probatur actus liberi creati prioritas et determinatio obiectiva respectu divinae praescientiae 
12. Explicatur nonnullis obiectionibus praecedentis capitis doctrina $\mathbf{2 4 8}$

13. An prioritas obiectivae determinationis exerceatur ab obiecto creato libero respectu divinae praescientiae ab aeterno vel in tempore? $\mathbf{2 5 4}$

14. Solutio obiectorum capite $9^{\circ}$, et compendium doctrinae eiusdem capitis et quinque sequentium 266

15. Determinata cognoscibilitas futuri sine decreto illud praedeterminante explicatur $\mathbf{2 7 1}$

16. Explicatur futuritio contingentium et veritas huius causalis „Ideo scit Deus liberum actum nostrum esse futurum, quia futurus est“ 277

17. Obiectio nova contra doctrinam capitum praecedentium $\quad \mathbf{2 8 5}$

18. An Deus cognoscat futura contingentia ut futura sibi, vel aliis? 292

19. Quae sit futurorum contingentium in aeternitate praesentia, et quid conferat ad divinam illorum cognitionem 299

20. Iudicium fertur de aliorum sententiis circa futurorum praesentiam in aeternitate $\mathbf{3 1 1}$

21. Explicatur, quomodo divina scientia futurorum contingentium non sit actus Deo formaliter liber, si ad illam non praecedit decretum praedeterminativum $\mathbf{3 2 1}$

22. Explicatur, quomodo praedeterminatio obiectiva obstet formali libertati scientiae de futuro contingenti, quamvis illam non praecedat natura 329

23. An ad hoc, quod scientia futurorum contingentium non sit formaliter libera, opus sit, illam non esse formaliter volitionem? 337

24. Concordia certitudinis divinae praescientiae futurorum contingentium cum creata libertate 344

25. Praecedentem rationem probandi concordiam certitudinis praescientiae cum libertate obiecti familiarem esse Patribus et Theologis 355

26. Eandem concordiae rationem probarunt antiqui Scholastici 363

27. Aliae probationes concordiae praescientiae cum libertate ex Patribus et Scholasticis proferuntur 369

28. De scientia absoluta futurorum contingentium eiusque formali obiecto

29. An scientia absoluta futurorum cognoscat divinum decretum

ad futura necessarium, ut existens prius ratione, aut etiam natura, quam ipsa scientia? 379

30. Tres aliae quaestiones solvuntur $\mathbf{3 8 4}$

31. De obiecto determinativo divinae scientiae absolutae futurorum contingentium 388

32. An futura contingentia absoluta cognoscat Deus in se ipsis, vel in divinis praedefinitionibus et permissionibus? 397

33. De scientiae absolutae futurorum contingentium libertate 404 
34. De concordia praescientiae absolutae cum libertate obiecti liberi, quod praescit esse futurum $\quad \mathbf{4 1 0}$

35. Appendix de divina voluntate praedefiniente actum liberum disiunctive ut efficiendum per aliquod medium indifferens 411

Index scholasticus 431

Index nominum 435 



\section{Einführung}

Der Jesuit Luis de Molina ist heute der international beststudierte Scholastiker des 16. Jahrhunderts. Teile seines Euvres sind inzwischen auch übersetzt, sogar ins Deutsche. ${ }^{1}$ Nicht nur deswegen, aber vor allem wegen seiner Scientia Media-Hypothese von 1588 ist Molina berühmt. Die Scientia Media-Hypothese war der Keim der Gnadenstreitigkeiten. Kirchengeschichtlich wird ihre Wirkung als die Geschichte der Erregung eines Ärgernisses und der darauf erfolgten Reaktionen beschrieben. Entstanden in spanischen Dominikanerzirkeln, habe der Skandal sich von dort fortgepflanzt, einen ersten Höhepunkt in den Aktenbergen der römischen Congregationes de auxiliis, einen zweiten in der sich noch viel höher stapelnden Literatur zum Jansenismus erreicht und am Ende, 1773, den erheblichsten Anteil an der Befriedigung über die Aufhebung der Gesellschaft Jesu gehabt.

Für ein historisches Studium von Molinas Ruhmestitel qualifiziert sich die kirchengeschichtliche Perspektive mit Sicherheit nicht. Aus dieser Perspektive hat die Frage nie eine Rolle gespielt, in welchem Umfang Molinas Theologie für den sog. Molinismus überhaupt repräsentativ ist. Molina und der Molinismus sind aber nicht dasselbe. Andererseits läßt sich beides auch nicht voneinander trennen. Inzwischen haben wir zwar gelernt, Molinas Theologie sowohl zum 14. Jahrhundert ${ }^{2}$ als auch punktuell zur Geschichte der Philosophie in Beziehung zu setzen. Solange die Wahl dieses oder jenes philosophischen Bezugspunkts, z.B. Leibniz, die scholastische Theologie nicht einbezieht, sind solche Vergleiche aber arbiträr, zwecklos und steril. Molina und Leibniz begegnen sich ja als - durch ein volles Jahrhundert voneinander getrennte - Konstrukteure von Gnadensystemen.

Aus kirchengeschichtlicher Sicht haben wir einen engen, einen allzu engen Begriff des Molinismus, aus philosophiehistorischer Sicht ein zu wenig trennscharfes Bild von Molina. Da paßt etwas nicht zusammen, und die Inkongruenz hat Folgen. Eine davon ist, daß uns jeder Begriff davon fehlt, wie die Scientia Media-Hypothese

1. L. DE Molina Göttlicher Plan und menschliche Freiheit. Concordia, Disputation 52, Lateinisch-Deutsch. Eingeleitet, übersetzt und kommentiert von Christoph Jäger, Hans Kraml und Gerhard Leibold (= Philosophische Bibliothek Nr. 695), Hamburg 2018. Wenigen Autoren der Vergangenheit glückt es, in unserer Inflation der Sammelbände so hochkarätige Beiträge auf sich zu vereinigen wie in M. Kaufmann / A. Aichele (Hgg.): A Companion to Luis de Molina, Leiden 2014.

2. J.P. AnfraY: „Molina and John Duns Scotus“, in A Companion to Luis de Molina, 325-64. 
auf ihr Entstehungsmilieu zurückgewirkt hat. Dabei gibt es kaum eine scholastische Systemstelle, auf welche sie nicht Auswirkungen gehabt hat. Sie hat die Lage gründlicher verändert als die Entdeckung Amerikas. Erst als das Produkt dieser Lageveränderung tritt die ,Jesuitenscholastik' aus dem Schatten der ,mittelalterlichen' Scholastik.

In der philosophiehistorischen Forschung lassen sich die zwei losen Enden nur so miteinander verknüpfen, daß sie sich aus der Kirchengeschichte die Kategorie ,Molinismus' aneignet: nicht, um damit eine bestimmte Doktrin zu bezeichnen, geschweige denn eine bestimmte Partei, sondern, auch konfessionell ganz neutral, eine scholastische Gruppierung. Innerhalb einer noch größeren Umwälzung, deren Zeugen wir derzeit in der Philosophiegeschichtsschreibung sind, ${ }^{3}$ folgt daraus ein Programm, welches hier nicht im Einzelnen entwickelt werden muß. Das hat Francesco Piro neulich in wünschenswerter Deutlichkeit getan. ${ }^{4}$ Zur Abarbeitung dieses Programms leistet dieses Buch einen Beitrag, zu anderem nicht: weder zur modernen Molinaliteratur noch zu der modernen, vorwiegend englischsprachigen, Literatur zum Thema Middle Knowledge. Dieses Buch handelt also von der Rezeption der Scientia Media-Hypothese im Molinismus. Es untersucht die Beziehung zwischen dem Molinismus und dem durch ihn auf den Prüfstand gestellten Begriff des Faktenwissens.

Epoche gemacht hat die Scientia Media-Hypothese zunächst dadurch, daß sie die intellektuelle Phantasie beflügelt. Gott weiß, welcher Partei der Verfasser dieser Zeilen bei den Reichstagswahlen vom 5. März 1933 seine Stimme gegeben hätte. Aus dem skeptischen, Gott weiß’ schlägt Molinas Hypothese Funken. Die Herausforderung zu einer bestimmten intellektuellen Integrationsleistung ist uns erst infolge dieser Hypothese in Fleisch und Blut übergegangen. Am besten lassen wir uns von einem Sevillaner Molinisten um 1600 einmal auseinandersetzen, was Gott - Gott! - alles zu berücksichtigen hat, um zu wissen, wie Er es anstellen müßte, daß ein junger Mann dieser Hafenstadt, Francisco, sich nach Amerika einschifft:

Wenn Gott ihm die Idee zu reisen und die Lust dazu eingibt, dann wird Francisco nach Westindien reisen. In diesem Fall ist das Reisen, eine freie Handlung, durch den Einfall und die Reiselust zweifellos kausal stark determiniert. Nichtsdestoweniger würde mein Francisco keineswegs reisen, wenn nicht sein Vater gestorben

3. P. Dvořák / J. Schmutz: „Introduction: Special Issue on Baroque Scholasticism“, American Catholic Philosophical Quarterly 93 (2019), 187-89.

4. F. PIRo: „Per una mappa delle discussioni sul molinismo nel XVII. secolo“ (https://www. academia.edu/2107645), besonders 24ff. Vgl. Ders.: „The Philosophical Impact of Molinism in the 17th Century“, in A Companion to Luis de Molina, besonders 389ff.; J. Schmutz: „Molina retourne à Paris“, in L. DE Molina: Des secours de la grâce, frz. Teilübersetzung von Paola Nicolas, Paris 2016. 
wäre, er nicht sein Vermögen verloren hätte und ihm nicht eine Einladung von seiten eines verwandten Bischofs oder reichen Onkels in Westindien vorläge. Die Ursache für den Tod seines Vaters wäre nun entweder ein Duell oder ein Raubmord oder ein ärztlicher Kunstfehler oder ein Schlaganfall nach einer Prasserei gewesen. Daß er sein Vermögen verloren hat, dafür die Ursache wäre wiederum ein betrügerischer Bankrott oder eine übernommene Bürgschaft oder Piraterie oder Schiffbruch gewesen. Sein Onkel mag als Höfling oder wegen seines heiligmäßigen Lebenswandels Bischof geworden oder durch gute Geschäfte in Westindien zu Reichtum gelangt sein. Es gibt fast unzählig viele derartiger Umstände, welche dazu beitragen, daß der Einfall, zu reisen, und die Lust dazu, anstatt wirkungslos zu bleiben, in die Tat umgesetzt werden. Untereinander stehen diese Umstände in überhaupt keinem Zusammenhang, sie haben nichts miteinander zu tun. Gott seinerseits würde den hypothetischen Zusammenhang der Reise mit diesem Einfall und dieser Neigung nun gar nicht erkennen, wenn Er nicht erkennen würde, daß zugleich alle Umstände gegeben sind, welche in dem Sinne förderlich sind, daß dadurch Hinderungsgründe für eine solche Handlungsweise wegfallen. [...] Wann immer Gott also irgendeinen hypothetischen Sachverhalt von der Art sieht, daß die Bedingung kausal mit der betreffenden freien Handlung zusammenhängt, sieht Gott notwendig auch eine Masse freier, untereinander überhaupt nicht zusammenhängender Handlungen daran mit beteiligt. ${ }^{5}$

Kurz: einen ganzen Roman. Der Aufwand an Verwicklungen zur Erzielung eines beabsichtigten Erfolgs tendiert aus theologischer Sicht gegen Unendlich. Ohne eine Unendlichkeit ,möglicher Welten' wäre Gott nicht imstande, für jeden Menschen das passende Prädestinationsszenario zu finden, eines, in dem der einzelne auch mitspielt. Die Verabreichung eines bestimmten Gnadenimpulses reicht dazu nicht. Die iberische Welt beginnt sich erst neuerdings, etwa in der Zeitschrift Anuario Filosófico, als die intellektuelle Heimat des Kapitalismus zu begreifen. ${ }^{6} \mathrm{Daß}$ aber Molina dazugehört, hat man schon längst vermutet. ${ }^{7}$ Auch wenn andere Teile seines literarischen CEuvres ${ }^{8}$ dieser Vermutung noch wichtigere Gründe leihen als die Liberi arbitrii cum gratiae donis, divina praescientia, providentia, praedestinatione et reprobatione Concordia: Wäre es so ganz von ungefähr, daß die spezifisch

5. D. Ruiz de Montoya SJ.: Commentarii ac Disputationes de scientia, de ideis, de veritate, ac de vita Dei 78, 2, 7, Paris 1629, 822a/b. Dasselbe Beispiel unter einem anderen Aspekt ebd. 73, 6, 2, p. $768 \mathrm{a}$.

6. J. Barrientos García: Repertorio de moral económica (1526-1670). La Escuela de Salamanca y su proyección, Colección de Pensamiento Medieval y Renacentista 124, Pamplona 2011.

7. F. Borkenau: Der Übergang vom feudalen zum bürgerlichen Weltbild. Studien zur Geschichte der Philosophie der Manufakturperiode, Paris 1934 / Repr. Darmstadt 1980, 215-37.

8. R. SchüssLer: „The Economic Thought of Luis de Molina“, in A Companion to Luis de Molina, 257-90. 
neuzeitliche literarische Kunstform, der Roman, just aus der Zeit datiert, als alles sich über Molinas Buch aufregte? Die Romane im Verständnis der Zeit waren so etwas wie Gottes Planspiele en miniature. An die Stelle Gottes trat nur ,der allwissende Erzähler'. In der gleichen Umständlichkeit, mit der der Allwissende auf den Prädestinationserfolg hinarbeitet, arbeitet der Romanautor auf das happy end hin. Als sich erzähltechnisch im 18. Jahrhundert die Forderung durchsetzte, nur ja keinen Umstand auszulassen, aus dem hervorgeht, „warum die Sache vielmehr so als anders erfolgt ist" ${ }^{9}$ war das gebildete Publikum durch die Gnadentheologie des 17. Jahrhunderts an den intellektuellen Umgang mit dieser Komplexität und an eine gewisse Strenge gewöhnt, mit der aus der Kontingenz Konsequenzen zu ziehen sind.

Nicht nur die politischen oder technischen Utopien der Vergangenheit können den Historiker beschäftigen. Der Philosophiehistoriker wird sich vorrangig um die erkenntnismetaphysischen Utopien kümmern. Deren gibt es nämlich auch. Wenn ,Psychologie', ,Erkenntnistheorie, ,Wissenschaftstheorie und ,Wissenschaftsgeschichte in je verschiedener Hinsicht das Zustandekommen kognitiver Leistungen untersuchen, bleibt doch immer die Frage, ob Erkenntnis nicht auch würde prinzipiell anders funktionieren können als unter den immer unterstellten Bedingungen. Aus dieser Frage muß nicht das Bedürfnis nach esoterischer Überwindung der Schranken unserer Erkenntnis sprechen. Instruktiver als die Esoterik ist, wie von Denkern der Vergangenheit akademisch reputierlich sich die Möglichkeit solcher kognitiver Leistungen gedacht worden ist, welche die condition humaine übersteigen. Wenn man sich das alte Lehrstück von der Erkenntnis der reinen Geister - im christlichen Kulturraum: der ,Engel - vornimmt und die scholastischen Spekulationen studiert, wie Erkenntnis oder Kommunikation unter der Hypothese funktionieren könnten, daß wir uns unsere Sinnesausstattung wegdenken, ergibt sich der Bezug zu den modernen Theorien der ,künstlichen Intelligenz' von selbst.

Unter den erkenntnismetaphysischen Utopien obenan gestanden hat in der Vergangenheit das ideale Faktenwissen. Als dessen Träger kam nur einer in Betracht, der Allwissende. Dafür mußte Gott es auch haben. Man muß nicht der Ansicht sein, die Stoffhuberei des Faktenwissens wäre das Ideal eines Wissens. Der klassische Begriff des ,Wissens' ist ein anderer: Scientia est cognitio per causas. Nichtsdestoweniger haben die Gottesgelehrten Veranlassung gehabt, sich auszudenken, wie ein Faktenwissen idealerweise beschaffen wäre. Auf die Idealvorstellung davon angewiesen war der christliche Supranaturalismus.

Ein ideales Faktenwissen müßte vor allem die Forderung erfüllen, daß alles auf dieselbe Weise gewußt wird, wie wir uns ausschließlich von Gegenwärtigem und Vergangenem vorstellen können, daß es so gewußt wird. Von den Vorhersagen der Naturwissenschaft ist klar, daß sie diese Forderung nicht erfüllen. Die Entwicklung

9. (Ch.F. von Blanckenburg:) Versuch über den Roman, Leipzig-Liegnitz 1774, 279. 
der Stichprobentechnik und die darauf gestützten Erfolge der Wahlforschung zeigen, wie mächtig der Impuls ist, der Erfüllung dieser Forderung dennoch näherzukommen und auch solches vorhersagen zu können, das unter Benutzung kausalanalytischer Modelle nicht mit hinlänglicher Bestimmtheit prognostizierbar wäre. Bei allem Aufwand gelingt das trotzdem nur innerhalb engster zeitlicher Schranken. Durch technische Simulierbarkeit ernstlich bedroht wäre das Monopol von Gottes Vorherwissen erst dann, wenn das Ergebnis einer erst noch stattfindenden empirischen Erhebung vorher schon fertig abrufbar wäre.

Das aufgeklärte Écrasez l'infâme wußte schon, was es an dem Supranaturalismus so unausstehlich fand:

Der subjektive oder persönliche Gott war das Universalprinzip - kein Funke von Verstand, von Sinn [...] für das göttliche Wesen, ohne einen persönlichen Träger desselben -, verständlich, begreiflich war nur, was im Sinne der Subjektivität, der absichtlichen Zweckmäßigkeit oder der mechanischen Werkmeisterei begreiflich war $[\ldots]^{10}$

Gott als der große Macher. Nun dreht zwar diese Anthropomorphismuskritik das biblische Et fecit Deus hominem ad imaginem Dei einfach nur um: Fecit homo Deum ad imaginem hominis. Trotzdem ist Feuerbachs Bemerkung nicht ohne Pfiff. Die philosophische Beschäftigung mit diesem Gott hätte es offenbar nicht nötig gehabt, sich von Hegel erst belehren zu lassen, daß Gott nicht nur „als Substanz“, sondern auch „als Subjekt“ zu denken ist. Der Gott des Supranaturalismus war von vornherein Subjekt, allerdings nicht irgendein beschränktes Subjekt, sondern das Subjekt, um für das ihrerseits eine Unterbringungsmöglichkeit zu haben, die Philosophen würden hochstapeln und mit nichts Geringerem aufwarten müssen als mit einem transzendentalen Ich.

Der Gottesbegriff des Supranaturalismus hatte drei Attribute: Verstand, Wille und Allmacht. Gelehrt wurde ein Gott, der alles weiß und alles kann und nur nicht alles will. Die kritische Frage war, ob und inwiefern dieser Gott auch anderes hätte wissen können, als er faktisch weiß; ob er auch anderes hätte wollen können, als er faktisch will. Die scholastische Theologie erstreckt sich historisch genau so weit, wie beides mit Ja beantwortet wird. Die Freiheit Gottes war das Schibboleth des scholastischen Gottesbegriffs. ${ }^{11}$ In der Geschichte der scholastischen Theologie sind der Tractatus de scientia Dei und der Tractatus de voluntate Dei nicht nur stetig angeschwollen, sie sind in der theologischen Systematik auch nach vorn gewandert.

10. L. Feuerbach: Pierre Bayle. Ein Beitrag zur Geschichte der Philosophie und Menschheit ( $\left.{ }^{1} 1838\right)$ (= Gesammelte Werke, hg. W. Schuffenhauer, Bd. 4), Berlin 1989, 236.

11. S.K. Knebel: „Sebastián Izquierdo (1601-1681) und die Zeitlichkeit des Bewußtseins“, Freiburger Zeitschrift für Philosophie und Theologie 65 (2018) 401-42, hier 431-34. 
Während die betreffenden Distinktionen in der Sentenzenkommentierung ziemlich weit hinten kamen, nach dem Dogma von der Dreifaltigkeit, zog die Summa theologica des Thomas von Aquin diese Fragen vor. Der Tractatus de scientia Dei umfaßte in der Summenkommentierung die Quaestiones 14-17 des ersten Teils, der Tractatus de voluntate Dei die Quaestio 19. Im Zeitalter der Gnadenstreitigkeiten sind die beiden Traktate nicht selten ausgegliedert und zum Stoff für Monographien geworden.

Von dem Inhalt des Tractatus de voluntate Dei sei hier abgesehen. ${ }^{12}$ Was die Philosophiehistoriker längst hätte beunruhigen müssen, ist, daß sie von den Quellen der unablässig fortgesetzten scholastischen Theoriebildung zum göttlichen Wissen nicht annähernd einen Begriff haben. Erst neuerdings beginnt sie im Zusammenhang studiert zu werden. ${ }^{13}$ Hier der durch Thomas von Aquin kanonisch gewordene Fragenkatalog:

\section{Quaestio 14}

1. Gibt es in Gott Wissen?

2. Erkennt Gott sich selber?

3. Begreift Gott sich selber?

4. Ist sein Erkennen seine Wesenheit?

5. Erkennt Gott außerdem noch anderes?

6. Hat Gott von den Dingen Erkenntnis im eigentlichen Sinn?

7. Ist Gottes Wissen diskursiv strukturiert?

8. Ist Gottes Wissen kausal strukturiert?

9. Gibt es davon, was nicht ist, ein Wissen Gottes?

10. Gibt es davon, was übel ist, ein Wissen Gottes?

11. Gibt es ein Wissen Gottes vom Individuellen?

12. Gibt es ein Wissen Gottes vom Unendlichen?

13. Gibt es ein Wissen Gottes vom Freizukünftigen?

14. Hat Gottes Wissen propositionale Form?

15. Ist Gottes Wissen veränderlich?

16. Hat Gott von den Dingen ein kontemplatives oder ein praktisches Wissen?

12. Einiges dazu bei S.K. Knebel: Wille, Würfel und Wahrscheinlichkeit. Das System der moralischen Notwendigkeit in der Jesuitenscholastik (1550-1700). Hamburg 2000.

13. Vgl. O. Boulnois / J. Schmutz / J.-L. Solère (Hgg.): Le Contemplateur et les idées. Modèles de la science divine du néoplatonisme au XVIII ${ }^{\mathrm{e}}$ siècle, Paris 2002. Zusätzlich das z.T. vortrefflich eingeleitete Lesebuch von J.-C. Bardout / O. BoulnoIs (Hgg.): Sur la Science divine, Paris 2002. Aus der Scholastik bis zum 14. Jh. sind berücksichtigt: Avicenna, Averroes, Hugo von St. Viktor, Petrus Abaelardus, Robert von Melun, Petrus Lombardus, Alexander von Hales, Thomas von Aquin, Petrus Iohannis Olivi, Heinrich von Gent, Johannes Duns Scotus, Wilhelm von Ockham, Thomas Bradwardine und Gregor von Rimini. Die posttridentinische Scholastik ist vertreten durch einen Beitrag zu Molina (von V. Aubin), zu Vázquez (von J. Schmutz) und zu Izquierdo (von J. Schmutz). 


\section{Quaestio 15}

1. Gibt es Ideen?

2. Gibt es eine Mehrzahl von Ideen oder nur eine einzige?

3. Gibt es von allem, was Gott erkennt, Ideen?

Quaestio 16

1. Steckt die Wahrheit in der Sache oder nur im Verstand?

2. Steckt die Wahrheit im Urteilsakt des Verstandes?

3. Wie verhält sich das Wahre zum Seienden?

4. Wie verhält sich das Wahre zum Guten?

5. Ist Gott die Wahrheit?

6. Was auch immer wahr ist, ist es das aufgrund einer Wahrheit oder einer Mehrzahl von Wahrheiten?

7. Ist die Wahrheit ewig?

8. Ist die Wahrheit keinem Wechsel unterworfen?

Quaestio 17

1. Steckt die Falschheit in den Sachen?

2. Geht Falschheit mit der Sinneswahrnehmung einher?

3. Steckt die Falschheit im Verstand?

4. Sind Wahr und Falsch Gegenteile?

Das sind Fragen, welche offenbar das Interesse keineswegs ,nur' des Theologen finden. Und das, muß man sich vorstellen, ist über zweieinhalb Jahrhunderte, zwischen dem 16. und dem 18., tausendfach kommentiert worden. ${ }^{14}$ Die Tatsache, daß die Fragestellungen der Summa theologica vom 16. bis zum 18. Jahrhundert das theologische Kurrikulum strukturiert haben, ist ihrer Wirkung nach kaum zu überschätzen. Selten macht man sich klar, daß der unverhältnismäßig große Anteil natürlicher Theologie in dem Philosophiebegriff der ,Frühen Neuzeit' sich nur aus diesem Kurrikulum und damit aus dem Aufbau der Summa theologica erklärt. Die Philosophiegeschichtsschreibung tut beharrlich so, als ließe sich die Philosophie der Frühen Neuzeit unter Ausblendung der Theologie studieren. Obwohl die Digitalisierung der Bibliotheken die verstaubten Folianten inzwischen allgemein zugänglich macht, ist in der historischen Forschung die Neigung nach wie vor

14. „La doctrine de Thomas d'Aquin a [...] acquis un poids institutionnel dont elle n'a jamais joui au Moyen Âge. Elle joua un rôle central au Concile de Trente, et a inspiré les fondements d'une doctrina communis. [...] C'est à la même époque, que la Summa theologiae est finalement adoptée comme manuel de texte dans plusieurs universités [...]. Mais le phénomène le plus important est l'adoption de la philosophie de Thomas d'Aquin par un grand nombre d'ordres et de congrégations, en particulier les nouvelles [...]“ J. Schmutz: „Bellum scholasticum. Thomisme et Antithomisme dans les débats doctrinaux modernes“, Revue thomiste 2008, 131-82, hier 141. 
verschwindend gering, nach dem bestenfalls absolvierten Cursus philosophicus ${ }^{15}$ sich etwa noch erst durch den Cursus theologicus fressen zu sollen. ${ }^{16}$ Vielleicht ist man zugunsten Molinas bereit, eine Ausnahme zu machen. Aber die ganze Scientia Media-Hypothese ist historisch ein Ableger der Kommentierung des Artikels 13 der Quaestio 14. „Das Problem, das in diesem einen Artikel angeschnitten wird“, bezeugt der zitierte Sevillaner Molinist, also das Problem des Vorherwissens, „,bereitet den Theologen der Gegenwart mehr Kopfzerbrechen als die restlichen fünfzehn Artikel zusammen. ${ }^{\text {"17 }}$

Bei der Ausweitung des Interesses an Molinas Wirkung ins Philosophie- und Kulturgeschichtliche ist zu beachten, daß die Scientia Media-Hypothese, die den Anstoß dazu gibt, nicht mit den Resultaten eines individuellen Denkens verwechselt wird. Der Autor Molina und die Scientia Media-Hypothese sind, wie gesagt, zweierlei. Nur wenn die fachtheologische Perspektive auf Molinas Wirkung beibehalten wird, bleibt auch im Blick, ein wie wichtiger Teil dieser Wirkung in der Erscheinung eines Diskurses bestanden hat, welcher der systematischen Ausarbeitung der Scientia Media-Hypothese gewidmet war. Tatsächlich ist es eine ganze Autorenklasse, in welcher wir, über mehrere Generationen hin, den Träger des Scientia Media-Diskurses zu sehen haben.

Dieses Buch wirbt für die Unhintergehbarkeit des Scientia Media-Diskurses. Es vereint drei aufeinander aufbauende Studien mit einer Textedition.

Die erste Studie führt eine Kontroverse. Die Theologie, welche unmittelbar unter dem Eindruck von Molinas Hypothese gestanden hat, war die katholische des 17. Jahrhunderts. Historisch einen befriedigenden Zugang zu ihr zu finden, ist schwierig; die Diskussion mit dem Historiker Sylvio De Franceschi (Paris, Ecole Pratique des Hautes Etudes, section des Sciences religieuses) zeigt, wie schwierig auf einem prononciert christlichen Standpunkt - also gerade auf dem Standpunkt, welcher dadurch scheinbar im Vorteil ist, daß er noch ein Verhältnis zu dem verhandelten dogmatischen Stoff hat. Franceschis jüngstes Buch weckt Zweifel daran,

15. Am bereitwilligsten natürlich in der Logik. Zur Physik CH. Lütнy: „What To Do With Seventeenth-Century Natural Philosophy? A Taxonomic Problem“, Perspectives on Science 8 (2000) 164-95. Zur Metaphysik die Pioniertat von P. Di Vona: Studi sulla Scolastica della Controriforma. L'esistenza e la sua distinzione metafisica dall' essenza, Florenz 1968; I concetti trascendenti in Sebastián Izquierdo e nella Scolastica del Seicento, Neapel 1994.

16. Freimütig z.B. R. ARIEw: „Descartes and the First Cartesians Revisited“, Perspectives on Science 26 (2018) 599-617, hier 606. Einen textgestützten Einwand gegen seine Thesen zu Descartes' scholastischem Hintergrund wehrt Ariew mit dem Argument ab, daß das schmale Sortiment der von ihm konsultierten Philosophiekurse des 17. Jahrhunderts (Conimbricenses, Eustachius a S. Paulo, Arriaga) zu dem strittigen Punkt nicht mehr hergibt.

17. Ruiz de Montoya, De scientia Dei, $165 \mathrm{~b}$. 
daß seit dem 18. Jahrhundert die Geschichtsschreibung der Gnadenstreitigkeiten eigentlich Fortschritte gemacht hat. Ein Wust jansenistischer Vorurteile behindert die Entwicklung einer angemessenen historischen Perspektive. ${ }^{18}$ Hermeneutisch überwindungsbedürftig sind nicht nur Befangenheiten aller Art. Vor allem wäre endlich zu begreifen, daß sich im Zeitalter der Gnadenstreitigkeiten durchaus nicht nur die Frage gestellt hat, ob die Scientia Media-Hypothese mit einer an Augustin geschulten Christlichkeit vereinbar war. Um ihre metaphysischen Konsequenzen, die für den monotheistischen Gottesbegriff, ist es nicht weniger gegangen.

Die zweite Studie widmet sich Gottes ,Wachstum' im 17. Jahrhundert. Sie entwickelt die Scientia Media-Hypothese als ein philosophisches Lehrstück und wählt dazu einen begriffsgeschichtlichen Ansatz. Der 1905 abgebrochene ${ }^{19}$ Versuch wird wieder aufgenommen, einen latent normativen durch einen rigoros historischen Begriff der Scientia Media zu ersetzen. Aus philosophiehistorischer Perspektive wird das Ereignis beschrieben, das diese Hypothese für das 17. Jahrhundert gewesen ist. Zu diesem Zweck werden aus dem gesamten Quellencorpus einschlägige Thesen zusammengetragen. Zum erstenmal ist die gedruckte Literatur des 17. und frühen 18. Jahrhunderts, die für Anfänger wie die für Fortgeschrittene, in erreichbarer Vollständigkeit ausgewertet. Schon in der Verwendung des Begriffs ,Scientia Media' und von einigem, was mit ihm zusammenhängt, zeigt diese Synopse wichtige Konfliktlinien.

Die dialektische Evolution des Gottesbegriffs ist auch das Thema der dritten Studie. Analysiert wird, von einem bisher nicht weiter bekannten Molinisten aus Salamanca, dessen ungedruckter Traktat über Gottes Vorherwissen. In diesem Text spielt die Scientia Media-Hypothese nicht die große Rolle, die nach den Entstehungsumständen für sie zu erwarten gewesen wäre. Warum nicht? Weil sie in mancher Beziehung nur eine Lösung unter anderen gewesen ist, auch im Molinismus. Die Studie dient der Einleitung in die Textedition. Ergänzt wird sie durch ein biographisches Dossier zu dem irischstämmigen Verfasser.

Das Buch folgt auf zwei schon früher vorgelegte Texteditionen aus der Jesuitentheologie des 17. Jahrhunderts. In den Einleitungen zu Auszügen aus den Gnadentraktaten von Juan Perlín und Diego del Mármol wurden zum einen die

18. Zur Information über die Gnadenstreitigkeiten immer noch unübertroffen ist die über dreihundert Jahre alte, auf französisch abgefaßte Darstellung des Pariser Jesuiten G. DANIEL: Lettres au R.P. Alexandre, où se fait le parallèle de la Doctrine des Thomistes avec celle des Jésuites, sur la Probabilité et sur la Grace, in: Recueil de divers ouvrages philosophiques, théologiques, historiques, apologétiques, et de Critique, Paris 1724, t.2, 96-213.

19. Ich beziehe mich auf die Scholien des Jesuiten Marcel Chossat zu seiner Ausgabe von Vázquez' Opera omnia, von der anscheinend nicht mehr als der erste Band erschienen ist. Deswegen wird im Folgenden daneben auf die Ausgabe Lyon 1620 zurückgegriffen. 
Leistungsfähigkeit des menschlichen Willens, zum andern die kongruistische Interpretation des Begriffs ,Gnadenwirksamkeit' thematisiert. ${ }^{20}$ Abschließend geht es jetzt also noch darum, wie in diesem handlungsmetaphysischen Spannungsfeld sich von Gottes Faktenwissen gedacht worden ist, daß es interveniert.

Sowohl der Begriff der Zeit als auch der Begriff der Ewigkeit sind zu sehr belastet, als daß an den Zufluchtsstätten der vita contemplativa Gottes Vorherwissen als Gegenstand des Nachdenkens noch viel Kredit hätte. Es ist möglich, daß es ein Hirngespinst ist. Trotzdem, wird man sagen, wäre es ein Akt der Barbarei, die diesem Kapitel gewidmete kolossale okzidentale Vernunftanstrengung aus dem historischen Gedächtnis zu streichen. Es hängt zuviel daran. Aus Falschem kann auch Wahres folgen.

Der Mediävistik mag mit derlei Beschwichtigung gedient sein. Bücher und Fachzeitschriften reißen sich um die Ausgrabungen, durch die in dem letzten Vierteljahrhundert Chris Schabel fast im Alleingang dafür gesorgt hat, daß es bei einem Schlüsselthema für die Geschichte der Scholastik aufhört, daß wir bezogen auf die Pariser Szene des 14. Jahrhunderts weiter im Nebel stochern müssen. Unnachgiebig Historismus wäre auch in bezug auf die Scientia Media die einzig adäquate Einstellung. Da es in dem vorliegenden Fall jedoch so ist, daß diese spezielle Art des Vorherwissens schon aus der christlichen Vergangenheit übel beleumdet ist, führt die Hinfälligkeit der dogmatischen Glaubensgrundlage leicht zu dem Schluß, hier wäre nun wirklich etwas zu Recht vergessen.

Von der Exekution dieses Urteils sind wir nicht weit entfernt. Das konfessionelle Christentum - Biotope immer ausgenommen - winkt bei dem Thema ab, denn das Gesäusel in Richtung Judentum und Islam fühlt sich dadurch nur geniert. Mit den umworbenen Dialogpartnern gibt es hier nichts zu konferieren. Was akademisch heute den Ton angibt, winkt erst recht ab. Die kulturpolitisch eingeleitete Revision des Kanons hat hier nichts zu gewinnen. Es wimmelt von toten weißen Männern. Auch die Institutionen der Forschung winken ab, das ist am bedenklichsten. Das Thema stört die seit der gesichtswahrenden Beendigung des Kulturkampfs eingespielte Arbeitsteiligkeit des geisteswissenschaftlichen Forschungsbetriebs. An der Periodisierung , Mittelalter' / ,Neuzeit' wird ja nur aus diesem Grund so fanatisch festgehalten. Man mag es drehen und wenden, eine Erfindung von 1588, obwohl

20. S.K. Knebel: „Willensfreiheit und Willensschwäche bei dem Molinisten Juan Perlin (15691638) [mit Edition Ioannes Perlin: Tractatus de exteriori principio humanorum actuum controv. V. MS. Köln, Historisches Archiv GB $4^{\circ}{ }^{1}$ “, Freiburger Zeitschrift für Philosophie und Theologie 52 (2005) 680-720. - „Diego del Mármol SJ. (1590-1664): Tractatus De Auxilio efficaci divinae Gratiae, ac eius cum libero arbitrio creato concordia, eingeleitet, herausgegeben und kommentiert“, in: U.L. LeHner (Hg.): Die scholastische Theologie im Zeitalter der Gnadenstreitigkeiten I, Nordhausen 2007, 7-131. 
lateinischsprachig, paßt nicht in die Mediävistik. Also wohin damit? Nur gut, daß es der Abneigung vorläufig an dem Mut und der geistigen Klarheit fehlt, deren es auch zu Akten der Barbarei bedarf.

Henao, der erste Historiker des Scientia Media-Diskurses, erzählt von sich, daß er von Beginn seines Philosophiestudiums an, 1629, fast ein halbes Jahrhundert lang Gelegenheit gehabt habe, alles zu verfolgen, was auf diesem Sektor akademisch vor sich ging. ${ }^{21}$ Daran kann ein Historiker heute nicht klingeln. Hinter einer historischen Befassung mit dem Thema steckt heute banal der Zufall privater Bildungsumstände. Daß die Scientia Media jedoch ein dickes Brett ist, von dem jeder sich fragen muß, ob er es bohren will, daran hat sich seit Henaos Zeiten nichts geändert. Ihr Studium braucht Zeit. Die Neigung zu den Forschungen zu diesem Buch, so viel sei gesagt, verdankt der Verfasser seiner Alma Mater, der Freien Universität Berlin, dort der Fachrichtung Hermeneutik des Philosophischen Instituts. In den achtziger Jahren war die Arbeit an dem Historischen Wörterbuch der Philosophie in vollem Gang. In den Seminaren seines Lehrers Wolfgang Hübener (1934-2007) erfuhr ein Hans Castorp von der Logomachie um das System der physischen Prädetermination. Er genoß die Freiheit, sich in die Gnadenstreitigkeiten des 17. Jahrhunderts zu vertiefen. Allerdings trieb es ihn auf diesem Zauberberg bald ins Lager der von Hübener bespöttelten „Lojoliten“. Rührend, wie es nach der ,Bologna’ genannten Roßkur, welcher die deutsche Universität seitdem unterzogen worden ist, gar nicht mehr vorstellbar wäre, hat ihn die Alma Mater auch gewarnt. Am 17. Februar 1987 schrieb der andere verehrte Lehrer, Jacob Taubes (1923-87), in seinen Abschiedszeilen: „... Ich begleite Sie trotz tödlicher Linie auf meinem Antlitz... Ich fürchte, Sie versteigen sich in Gebirge, wo Ihnen nur Hübener und S.M. folgen können... Kehren Sie zurück zur Philosophie nach dem Weltbegriff und lassen Sie die Schulbegriffe. Das sagt Ihnen der todkranke J.T." Von den Ansprüchen der Philosophie nach dem Weltbegriff leuchtete dem jungen Castorp indessen nicht ein, wie er sich denen hätte fügen sollen, ohne den von beiden seiner Lehrer über den Münsteraner Neuzeitpanegyriker Blumenberg damals errungenen Vorteil wieder fahren zu lassen.

Vier Männern verdankt dieses Buch seine Entstehung: Ruedi Imbach, Georg Miczka, Martin Stone und Olaf Pluta. Der Mediävist Ruedi Imbach (Fribourg) hat den Verfasser auf die Neuerscheinung von Franceschi hingewiesen und das Ergebnis, obwohl gewiß polemischer Natur, ohne Wenn und Aber für den Rezensionsteil der Freiburger Zeitschrift für Philosophie und Theologie akzeptiert. Wäre Georg Miczka, seinerzeit Bibliotheksdirektor der Jesuitenhochschule Sankt Georgen in Frankfurt a.M., 1988 dreisten Bitten nicht ungewöhnlich entgegengekommen, dann

21. G. DE Henao SJ.: Scientia Media theologice defensata $\$ 6264$, Lyon 1674-76, t.2, 823. 
wäre nicht, vor inzwischen einem Menschenalter, die Urfassung des Leitfadens durch die Scientia Media-Literatur erschienen. ${ }^{22}$ Manches Gute hat sie bewirkt. Dem Hüter der 1872 ins Exil verfrachteten und 1926 zurückgekehrten Schätze (Bibliothek Valkenburg) war vermutlich bewußt, daß deren Exil in dem entscheidenden Sinn noch nicht zu Ende war. Der Historiker Martin Stone hat es auf einer dem Wirken der irischen Franziskaner im 17. Jahrhundert gewidmeten Löwener Tagung 2007 gestattet, über einen Wadding vorzutragen, der kein Franziskaner war. Weil unser Gastgeber bald darauf über eine scheinheilige Intrige akademisch gestolpert ist, ist diese Tagung nicht weniger unvergeßlich. Der Mediävist Olaf Pluta (Bochum) schließlich hat durch seine Herausgebertätigkeit dem Verfasser bewiesen, daß auch in der Stockfinsternis der blind peer review das Licht der Caritas leuchtet.

Das Buch ist literaturintensiv. Um dem Leser lästiges Herumblättern zu ersparen, ist auf ein abgetrenntes Literaturverzeichnis verzichtet und die Bibliographie in den Fußnotenapparat integriert. Auf diese Weise ist jedes Kapitel, sonst unter Vermeidung überflüssiger Wiederholungen, bibliographisch in sich abgeschlossen. Jeweils bei der ersten Erwähnung werden die vollständigen Angaben geboten, anschließend nur der abgekürzte Titel, die innere Gliederung und die Seitenangabe. Etwas weniger sparsam angelegt ist der Apparat zu der Textedition.

22. S.K. KNEBEL: „Scientia media. Ein diskursarchäologischer Leitfaden durch das XVII. Jahrhundert", Archiv für Begriffsgeschichte 34 (1991) 262-94. Eine unautorisierte, soweit der Verfasser das beurteilen kann, indessen sehr sorgfältige, russische Übersetzung stammt von W.L. Iwanowa: Einai 4 (2015) 310-73. Einai ist das Organ des geisteswissenschaftlichen Instituts der Staatlichen Universität für Luft- und Raumfahrttechnik (SUAI) in St. Petersburg. 


\section{Die nächste Etappe im Historikerstreit über die Gnadenstreitigkeiten}

Anzuzeigen ist von Sylvio Hermann de Franceschi Thomisme et théologie moderne. L'école de saint Thomas à l'épreuve de la querelle de la grâce (xvii ${ }^{e}-x v i i{ }^{e}$ siècles). ${ }^{1}$

Die Gnadenstreitigkeiten sind in der römischen Congregatio de auxiliis seinerzeit unentschieden geblieben, geistesgeschichtlich sind sie immer noch unverdaut. Dabei hat der Katholizismus über nichts sonst so eifrig und anhaltend gestritten (237). Auch hundert Jahre nach Schluß der Congregatio de auxiliis, 1607, war das Problem einer Lösung nicht näher gerückt (426). 1748 definierte der Hl. Stuhl den Status quo durch einen Pluralismus, der drei katholische Gnadensysteme unterschied und vor gegenseitiger Verketzerung schützte: das der „Thomisten“, das der „Augustiner“ und das der „Anhänger von Molina und Suárez“. Ein Teil des Problems bestand in der Unklarheit über die Position des Thomismus. Vfr. nennt das "la question thomiste“ (455, 501, 707). Um „das thomistische Paradigma“ (715) in den Gnadenstreitigkeiten geht es. Wie ist es zu definieren, was fällt darunter? In der Antwort auf diese Frage liege der Schlüssel zu dem ganzen Problem.

Die Deutungshoheit über den Thomismus, welche die Theologen des Dominikanerordens bis an die Schwelle des 20. Jahrhunderts leidenschaftlich verteidigt haben („leur prétendu monopole thomasien“, 746), gesteht Vfr. ihnen nicht zu. Schon die Congregatio de auxiliis ,läßt sich als die Sternstunde der erbitterten Konkurrenz zweier Orden lesen, die beide den hl. Thomas für sich reklamieren“" (281). Zu tief ist der Thomismus in die Entstehung einer Pluralität katholischer Gnadensysteme involviert, als daß nicht endgültig zu akzeptieren wäre, daß durch das institutionelle Bekenntnis zum Aquinaten nichts geklärt ist (76). Die Entinstitutionalisierung des Thomismus begünstigt eine Historisierung der Gnadenstreitigkeiten. Hinter dem Plädoyer für Historisierung steckt indessen noch ein anderes Motiv, das geradezu entgegengesetzte: die zum Schluß (769f.) noch einmal beschworene Erinnerung an Pascals Mahnung, daß der Dominikanerorden eine Mission hat und intellektuell identifizierbar bleiben muß. Diese Mission sei ihm nur unter Vorbehalt

1. S.H. De Franceschi: Thomisme et théologie moderne. L'école de saint Thomas à l'épreuve de la querelle de la grâce (xvii ${ }^{\mathrm{e}}$-xviii ${ }^{\mathrm{e}}$ siècles), Paris: Lethielleux 2018. Kart. 793 S. Die vorliegende Rezension erschien zuerst in der Freiburger Zeitschrift für Philosophie und Theologie 65 (2018) 213-35. Die elfte Fußnote ist leicht überarbeitet. 
anvertraut - unter dem Vorbehalt, daß er die reine Lehre nicht durch Zugeständnisse an den Zeitgeist veruntreut: „La grâce peut bien n'avoir plus les dominicains pour défenseurs; mais elle ne manquera jamais de défenseurs." Insofern fungiert der titelgebende ,Thomismus' zugleich als massiv normativer Begriff, und „épreuve“ bezeichnet eine Bewährungsprobe.

Die Thomisten (l'École de saint Thomas) haben die Sache Augustins zu ihrer gemacht (247), so die These. Den âge classique, mit Jean Dagens 1951, das goldene Zeitalter Augustins zu nennen, ist zu eng. Er war auch das goldene Zeitalter des Thomismus (9off., 127, 200). Im Lichte dieser These widmet sich das neue Buch des gewandten Historikers dem weiteren Kontext einer 2009 von ihm edierten Archivalie, des Examen des deux méthodes quón peut prendre pour justifier Jansénius von 1659. Wenn Pierre Nicole ( $\dagger 1695$ ), von ihm ist der Text, zu der ersten Generation gehört, welche das Wort ,Thomismus' überhaupt verwendet hat, ${ }^{2}$ dann ist in dem vorliegenden Buch dieses Wort das Sesam öffne dich zu einer versunkenen Welt.

Das Buch, in der von den Dominikanern Grégory Woimbée und Philippe-Marie Margelidon herausgegebenen Reihe Sed contra erschienen, ist nicht systematisch aufgebaut, es ist eine Aufsatzsammlung, erweitert um eine ausführliche Einleitung. Die 16 Einzelstudien erschienen zwischen 2006 und 2014. Vfr. hat sie überarbeitet und unter drei Rubriken gebracht: I. Spannungen in der Orthodoxie des Thomismus. II. Die Jansenismuskrise. III. Das Spätstadium der Gnadenstreitigkeiten.

Der erste Teil ist eine tour d'horizon, die gewisse Abstraktionen zueinander in Beziehung setzt. Das erste Kapitel (81-127) legt die speziell historischen Gründe für die Skepsis dar, mit welcher der Beschwörung einer thomistischen Identität zu begegnen ist. Von der Philosophie ist hier nicht die Rede, nur von der Theologie. Das betrifft dann die Verhältnisbestimmung von Thomismus und Augustinismus. Sie ist diffizil. Manche (Arnauld, Bossuet) haben beides forciert miteinander identifiziert, andere (Malebranche, Fénelon) hatten hier ihre Zweifel. Die Frage wurde praktisch in dem Aufruhr um die Rezeption der Bulle Unigenitus 1713. Durch sie entstand zeitweilig der Eindruck einer Solidarität des Thomismus (Massoulié, Noël Alexandre, Amat de Graveson) mit dem verketzerten Augustinismus. Erst mit mehr als zehnjähriger Verzögerung wurde dieser Eindruck aus Rom, durch das Breve Demissas preces, korrigiert. Näheres dazu folgt im vierzehnten Kapitel (6o8ff.).

Das zweite und das dritte Kapitel verstehen sich als Beiträge zu der gegenwärtig wieder flotten (23) historischen Erforschung der römischen Congregatio de auxiliis. Das zweite Kapitel (129-163) disjungiert Thomismus und Calvinismus. Wie der Thomismus sich gegen den von den Jesuiten erhobenen Calvinismusvorwurf zur Wehr setzte, wird an dem darüber zwischen dem Jesuiten Bastida und dem

2. P. Nicole an P. Quesnel (ca. 1693), in P. NICOLE: Traité de la grace generale, hgg. von J. Fouillou / N. Petitpied, s.l. 1715, t.2, 12. 
Dominikaner Lemos geführten Disput gezeigt, in einem späteren Stadium der Congregatio (1605/06). Der Calvinismustopos hat auch in der Folgezeit seine Aktualität behalten. Zu der Situation unmittelbar am Vorabend der Jansenismuskrise bringt das sechste Kapitel noch Ergänzungen (318ff.). In der Jansenismuskrise kehrte sich der Topos vorwiegend gegen den Jansenismus. Der verschanzte sich hinter dem Thomismus. Damit war die Situation für die nächsten Jahrzehnte gegeben.

Das dritte Kapitel (165-98) verknüpft Thomismus und Augustinismus. Zu diesem Zweck analysiert es den in Rom ausgetragenen Wettbewerb im Fach Augustinexegese, in der ersten Runde zwischen Lemos und Gregor von Valencia, dann, nachdem der k.o. war, zwischen Lemos und Bastida. In der zweiten Runde war Stellung zu nehmen zu einem von dem inzwischen verstorbenen Schiedsrichter, Papst Clemens VIII., hinterlassenen Resümee der Thesen Augustins. Lemos unterstützte im vollen Umfang dieses Positionspapier, Bastida durfte es unter Papst Paul V. wagen, sich in einigen Punkten davon zu distanzieren. Lemos hat die strategische Partnerschaft von Thomismus und Augustinismus auf den Weg gebracht. Erst dieser „thomisme augustinien des Dominicains espagnols“ hat dem Jansenismus Deckung gewähren können.

Das vierte Kapitel (199-235) untersucht die Störanfälligkeit des augustinisierenden Thomismus. Gegen die Philologen war sowohl die Echtheit der Summa theologica (Launoy) als auch die von der Bibelkritik (Simon) angezweifelte Legitimität der scholastischen Bibelkommentierung zu verteidigen. Die Diskussion dieser Fragen war von dem Gerangel in Prestigefragen belastet. Das wird an dem von der Franziskanerkonkurrenz (Alva y Astorga) munter unterhaltenen Störfeuer gegen den von maßgeblicher Seite begünstigten Versuch gezeigt, die Autorität des Aquinaten bis zur Ranggleichheit mit Augustin hochzuschrauben. Virtueller Fluchtpunkt dieses Kapitels ist die in dem 16. Kapitel referierte Auseinandersetzung um die These eines Dominikaners: „Augustinus eget Thoma interprete.“

Das fünfte Kapitel (237-73) disjungiert Augustinismus und Molinismus. Die Jesuiten haben die von ihnen fast (243) ausnahmslos verteidigte Scientia Media-Hypothese in der Theologie zwar für einen Traditionsbruch, trotzdem für mit Augustin vereinbar gehalten. Die Thomisten bestritten das. Konfrontiert werden Molina einerseits und Alvarez und Antonio de la Madre de Dios (Karmeliterkurs von Salamanca) andererseits. Mit letzteren wird die Scientia Media-Hypothese als semipelagianisch qualifiziert.

Der zweite Teil wechselt das Thema. Die beschriebene Konstellation wird nicht weiter zu dem Streit über die Ursache der Gnadenwirksamkeit verfolgt, sondern zu der Frage in Beziehung gesetzt, ob die Unterscheidung zwischen wirksamer und unwirksamer Gnade (gratia efficiens / sufficiens) überhaupt zulässig ist. Hier kommt eine neue Größe ins Spiel: der augustinische Gnadenpartikularismus (,Jansenismus'), der die Frage verneint. 
Das sechste Kapitel (277-328) ist ein Beitrag zur Pascalforschung. Pascals Entwicklung dokumentiert die auf jansenistischer Seite bestehenden Vorbehalte gegen den Thomismus. „Als der Gnadenstreit bereits eine beispiellose Komplexität und Insichreflektiertheit erreicht hat, ordnet sich Pascals Intervention sehr präzise in das Endstadium einer wichtigen Etappe ein. Seine Texte spiegeln das Patt wider, in dem sich die Kontroverse befindet." (324) Gemeint ist die Phase zwischen dem Schluß der Congregatio de auxiliis 1607, die den Konflikt der beiden Parteien unentschieden gelassen hatte, und der römischen Verurteilung des Jansenismus 1653. Beleuchtet werden diverse theologische Optionen, die in dieser Zeit bestanden haben, teils in der Absicht, damit die Alternative von Thomismus und Molinismus zu unterlaufen (Bereur de Dôle), teils in der, zwischen den Lagern zu vermitteln. Um eine dieser Kompromißlösungen, die des Sorbonniten Alphonse Le Moyne († 1659), geht es speziell. Dessen Thesen zur Gebetsgnade haben ab 1649 die Gruppe um Arnauld, darunter Pascal, zur Bildung eines Lagers provoziert, das sich für Äquidistanz zu Calvinismus und Molinismus entschied. Pseudoaugustinismus und Kryptomolinismus waren die Schlagworte. Wie es sich zum Thomismus stellte, blieb vorläufig offen.

Das siebente Kapitel (329-50) zeigt an Quesnel ( $†$ 1719), daß es zum Zweck der Disjunktion von Jansenismus und Calvinismus dem Jansenisten unter Umständen sogar gelegen kam, daß Augustin mit thomistischen Augen („avec des yeux Thomistes") gelesen wurde. Es behandelt eine Episode aus Quesnels Kontroverse mit dem Jesuiten Dechamps, Autor des gelehrten Standardwerks De haeresi Janseniana. Quesnel benutzte 1689 die Herausgabe des Briefwechsels zwischen Dechamps und einem verstorbenen vornehmen Jesuitenzögling, der nachher zum System der physischen Prädetermination konvertiert war, für die Zwecke der jansenistischen Propaganda. Bei dieser Gelegenheit wird auf die den Jansenisten von Anfang an wichtige Öffentlichkeitsarbeit eingegangen. Die literarische Gattung des Briefwechsels war überhaupt ein Hauptmittel der Popularisierung der Gnadenstreitigkeiten.

Das achte Kapitel (351-87) kommt zur Hauptthese, zu der Affinität von Jansenismus und Thomismus. Die Ausbildung des ,Philothomismus' als jansenistischer Defensivposition ist das Thema in Nicoles Strategiepapier Examen des deux méthodes qu’on peut prendre pour justifier Jansénius von 1659. Dem jansenistischen Lager wurde darin geraten, die eigene Verteidigung besser nicht auf das Argument aufzubauen, man stehe doch auf dem Boden Augustins. Die Beweislast sei zu groß, der Erfolg ungewiß. Gescheiter sei es, sich auf den Boden der Orthodoxie zu stellen und dazu den Thomismus für sich zu reklamieren. Der Thomismus, brachte Quesnel diese Hermeneutik auf eine Formel, „läßt Augustin Schuljargon sprechen, aber ohne ihn deswegen seine eigene Sprache vergessen $\mathrm{zu}$ machen" (542). Zu den kirchengeschichtlichen Folgen dieses, von Arnauld auch befolgten, Ratschlags folgen in späteren Kapiteln noch Ausführungen. Durch 
seine Aufrichtigkeit unterschied sich Nicoles Philothomismus von dem anderer Jansenisten. Aus deren Sicht bestätigte Nicoles, bald nach seinem Tod ruchbar gewordener, Gnadenuniversalismus den Argwohn, daß schon in der Hinwendung zur Scholastik der Verrat an Augustin steckt.

Das neunte und das zehnte Kapitel untersuchen die Störanfälligkeit des Philothomismus. Das neunte (389-427) beschreibt die Affäre um die Maurinerausgabe von Augustins gnadentheologischen Schriften. Der Versuch des Herausgebers Mabillon, die jansenistische Verteidigungsstrategie zu adoptieren, mißlang, denn auf der einen Seite sah er sich von Quesnel desavouiert, auf der anderen stöberte Fénelon ( $\dagger 1715)$ die Mauriner hinter ihrer Verschanzung auf. Umgekehrt wird an dem Benediktiner François Gesvres ( $†$ 1705) deutlich, wie versucht wurde, Thomismus und Molinismus durch die These auseinanderzudividieren, der Gnadenuniversalismus werde dem Thomismus lediglich unterschoben.

Das zehnte Kapitel (429-61) beschreibt den Streit um die Klausel „in sensu thomistico“, mit der die Jansenisten innerkirchlich dem ihnen abverlangten Bekenntnis zum Gnadenuniversalismus auszuweichen versuchten. Fénelon ließ ihnen das nicht durchgehen: „Ce sens est devenu comme le centre de la dispute.“ Den renitenten Augustinverehrern wurde von dem scholastisch erzogenen Episkopat die Distinktionsbereitschaft zwischen Akt und Potenz, zwischen Erstakt und Zweitakt, zugemutet. Immer müsse gewährleistet sein, daß der Mensch in der betreffenden Situation auch hätte anders handeln können. Daß die Amtskirche hier unbeugsam blieb (Affäre Couet), zeigte die Grenzen der philothomistischen Strategie.

Das elfte und das zwölfte Kapitel beleuchten die Eskalation des Streits am Vorabend des Erscheinens der Bulle Unigenitus (1713), d.h. der abschließenden Verketzerung des Jansenismus. Das elfte (463-91) führt den Nachweis, daß der Philothomismus dogmatisch immerhin keine Totgeburt war. Der Jansenismus hat nie verschwiegen, daß trotz der gemeinsamen Überzeugung, daß Gott am längeren Hebel sitzt (gratia per se efficax), es in den anthropologischen Grundlagen zwischen ihm und dem Thomismus Differenzen gab: Das System der physischen Prädetermination nivelliert Unschuldsstand und Sündenstand, während Augustin die Gnadenbedürftigkeit strikt durch den Sündenstand bedingt sein läßt. Daher wurde es sowohl von Jansenisten (Henricus a S. Ignatio OC. $\dagger 1719$ ) als auch von Dominikanern (Norbert d'Elbecque $\dagger 1714$ ) mit Erleichterung aufgenommen, daß ein Jansenist, Francois-Laurent Boursier ( $† 1749)$, in seinem Traité de l'action de Dieu sur les créatures (1713) die physische Prädetermination schon bei Augustin nachweisen zu können behauptete. Dann hätte die Übereinstimmung zwischen Augustin und dem Thomismus viel weiter gereicht als angenommen. Von hier aus fällt ein Seitenblick auf die Theologie der Übernatur im 2o. Jahrhunderts (Lubac, Maritain u.a.).

Im Zentrum des dritten Teils steht Fénelon, der Erzbischof von Cambray, hier als streitbarer Antijansenist. Dargestellt wird das Stadium der totalen Politisierung 
des Streits um die philothomistische Option. Beide Lager bezichtigen einander, die Begriffe zu fälschen und die Öffentlichkeit irrezuführen. Gegenseitig wird sich dialektisch überboten und mit Denunziationen überzogen.

Das zwölfte Kapitel (495-553) beschreibt die Umstände der zehnjährigen Entstehungsgeschichte von Fénelons Hauptwerk, der Instruction pastorale en forme de dialogues von 1714. Es beschreibt sie als die Entstehung einer Obsession wegen vermuteter Konspiration von Dominikanern und Jansenisten. Quesnel, Jacques Fouillou († 1736) und im Episkopat der Pariser Erzbischof Noailles sind Fénelons Gegenspieler. Fénelon bezweckte die Zementierung des Ergebnisses der Congregatio de auxiliis: Mehr als zwei katholische Gnadensysteme gebe es nicht. Um die Grenzen des innerkatholischen Pluralismus aufzuzeigen, setzte er die Inkompatibilität von Thomismus und Jansenismus auseinander. Sie unterscheiden sich „wie Tag und Nacht“ (518), weil das System der physischen Prädetermination handlungsmetaphysisch beim Zweitakt ansetzt, das der delectatio victrix dagegen beim Erstakt. Was Fénelons Hommage an Unigenitus als die Verketzerung des Systems der delectatio victrix interpretierte, interpretierte die Gegenseite als die Verketzerung des Thomismus.

Das dreizehnte Kapitel (555-87), das die Fénelondiskussion fortsetzt, ist dem an den Gnadenstreitigkeiten mehr systematisch interessierten Leser überhaupt zum Einstieg zu empfehlen. Es ist überschrieben „Le thomisme moderne au tribunal du molinisme“, d.h. des „molinisme fénelonien“ (553). Das große Argument, mit dem Fénelon die jansenistische Strategie durchkreuzt, wird immanent studiert: daß die physische Prädetermination und die delectatio victrix metaphysisch konträre Grundlagen haben. Alles dreht sich um die Unterscheidung von Erstakt und Zweitakt. Darum läuft Fénelons Interpretation des thomistischen Systems darauf hinaus, daß sich die physische Prädetermination nur unter der Bedingung im Rahmen der Orthodoxie hält, daß sie sich von dem suarezischen Simultankonkurs gar nicht unterscheidet. Fénelons theologisches Profil ist nicht so vieldeutig, wie manchmal behauptet. Er ist Kongruist.

Das vierzehnte Kapitel (589-635) schließt die Diskussion ab. Es behandelt Fénelons Versuch, das Lager der physischen Prädeterministen zu spalten, sowie die gereizten Reaktionen darauf in dem Zeitraum 1721/26. Bis in die Spitzen des französischen Episkopats lief gegen den toten Fénelon eine Diskreditierungskampagne (Noailles, La Broue, Billuart, Fouillou). Die Gegner beschworen, unter Berufung auf Massoulié († 1706), die Identität von gratia efficax, praemotio physica und delectatio victrix. Es wurde gestreut, Fénelon hätte behauptet, in der Verdammung des Jansenismus sei von Rom die gratia efficax der Thomisten verdammt. Die Richtigstellung, daß Fénelon die physische Prädetermination lediglich für das weniger probable katholische Gnadensystem gehalten hat, wurde nicht akzeptiert. Er sei zu der alten, nur zwischenzeitlich von den Molinisten aufgegebenen, Taktik 
zurückgekehrt, es direkt auf die Verketzerung des Thomismus anzulegen. „Die Debatte über Fénelons Antithomismus war ein wichtiges Kapitel im Gnadenstreit unmittelbar im Anschluß an die Publikation des Breve Demissas preces. Es galt, auf seiner Hut zu sein, daß die Molinisten nicht durch die Hintertür und gegen den Willen des Hl. Stuhls doch noch, zu ihrem Vorteil, über den Ausgang der Congregatio de auxiliis befanden." (627)

Das fünfzehnte Kapitel (637-705) charakterisiert die Situation in den Jahrzehnten nach Demissas preces, d.h. zu der Zeit, als die Dominikaner kirchenpolitisch obenauf waren. Dazu greift es, gestützt auch auf Archivstudien, die Affäre Viou heraus, den aktenkundigen Fall eines jansenistischen Dominikaners. Viou ( $† 1780$ ) war ein widerspenstiger Professor, sein Bischof, Yse de Saléon ( $† 1751$ ), ein Anhänger Fénelons. Die Wirksamkeit der Gnade, behauptete Viou, sei ein Prädikat, welches sich auch auf den Erstakt bezieht. Wer das leugnet, setze die Dominikanertheologie generell (Lemos, Gonet, Regnault, Massoulié, Alexandre, Elbecque, Serry, Amat de Graveson) unter Jansenismusverdacht. Obwohl von seinem Orden schließlich doch gemaßregelt, wurde ihm in dogmatischer Hinsicht lediglich vorgeworfen, daß seine Interpretation Massouliés von dem Augustiner Berti ( $\dagger 1766)$ inspiriert sei. Bertis Gnadensystem wurde von Saléon als jansenistisch qualifiziert, aber in der 1744/47 darüber zwischen ihm und Berti geführten Kontroverse hat er den Kürzeren gezogen. Das Resultat der Affäre Viou stellt sich so dar: „Indem er hinter einer taktisch günstigen Bezugnahme auf den Augustinismus in Deckung ging, dennoch eingeklemmt zwischen Jansenismus und Molinismus, hat sich der Thomismus auf einen Standpunkt gestellt, der mit Ländern eine Ähnlichkeit hat, welche zwischen zwei feindlichen Nationen liegen: Was immer geschieht, es geht sie unweigerlich alle an.“ (705)

Das Schlußkapitel (707-73) beschreibt aus französischer Sicht, hin und wieder mit einem Blick über die Grenze, die „Dämmerung“ der Gnadenstreitigkeiten bis zum Vorabend der Französischen Revolution. Dazu schlägt es drei Pflöcke ein, Benedikts XIV. Sendschreiben Dum praeterito mense von 1748, die Aufhebung der Gesellschaft Jesu 1773 und die Théologie de Lyon von 1780, den „Schwanengesang des schulmäßigen Jansenismus in Frankreich" (765). Nach einigen Bemerkungen zur irenischen Kommentierung des pluralistischen Status quo (Nicolas Jamin $\dagger$ 1768) wird die Möglichkeit erwogen, daß 1773 die Gnadenstreitigkeiten praktisch beendet gewesen sein könnten, denn der Störenfried war weg: „Sans Molina, pas de Jansénius.“ (742) Die übrigen beiden Parteien, Dominikaner und Augustiner, hätten sich unter dem Beifall der Jansenisten miteinander verständigt. Für das Unionsprojekt wurden unterschiedliche Vorschläge gemacht. Der Benediktiner Pierre Mougenot († 1797) schlug den „Augustiniens-Thomistes“ vor, die Gnadenwirksamkeit auf die delectatio victrix und die ,moralische ${ }^{`}$ Prädetermination zu gründen. Die Théologie de Lyon kombinierte dagegen praedeterminatio physica und delectatio victrix, und zwar mit dem Akzent auf jener. Das war auch die von den 
Nouvelles Ecclésiastiques vorgezogene Lösung. Auf beiden Seiten gab es indessen Widerstand gegen das Unionsprojekt. Die Augustinerschule (Berti) wehrte sich gegen die von der Dominikanerschule (Mamachi) für Thomas beanspruchte Deutungshoheit über Augustin. Die Dominikaner wehrten sich gegen den antischolastischen, augustinisierenden Geist der Studienreform, wie sie zur Flankierung der Jesuitenvertreibung von den absolutistischen Höfen (Madrid, Wien) verordnet wurde. Das alte jansenistische Mißtrauen, dem schon früher im 18. Jahrhundert der Abbé Racine in seinem Abrégé de l'histoire ecclésiastique Ausdruck verliehen hatte (37), sah die Dominikaner, vom Ultramontanismus bis zur Anthropologie, Positionen besetzen, für welche in der Vergangenheit die Jesuiten gut gewesen waren (734ff.). In der Gnadenlehre wollten die Nouvelles Ecclésiastiques bei ihnen Zeichen der Erschlaffung feststellen $(736,743)$. Trotz der für den Philothomismus an sich günstigen Konjunktur widerspricht Vfr. dem Eindruck nicht, daß von seiten der Dominikaner abermals habe „Verrat“ $(735,767,770)$ befürchtet werden müssen. Das Buch schließt mit einigen allgemeinen Überlegungen zu dem historiographischen Verifikationsproblem der Aussage, eine Kontroverse habe irgendwann , aufgehört'.

\section{Kritik}

Vfr. behandelt einen großen Gegenstand aus dem Überschneidungsbereich von Theologie- und Kirchengeschichte, doch (286f.) innerhalb der dem Historiker gezogenen Schranken. Der historische Horizont dieses Buches ist außergewöhnlich, ebenso der Sinn für die Dramatik seines Gegenstandes. Insofern dabei die Rekonstruktion des Geschichtsbilds herausgekommen ist, von welchem der redaktionelle Kurs der Nouvelles Ecclésiastiques bestimmt war, ist das Ergebnis auch uneingeschränkt als gelungen zu bezeichnen. Das jansenistische Wochenblatt, das 1728 das Zeitalter der Parteipresse einleitete, wird viel zu selten studiert. Deswegen und auch, weil beide Werke den Zusammenhang des 17. mit dem 18. Jahrhundert festhalten, empfiehlt sich aus Sicht des deutschen Lesers das hier zu besprechende als die dringend nötige Ergänzung zu der soziologisch inspirierten Weltanschauungsanalyse des Jansenismus in Bernhard Groethuysens Klassiker von 1927. Wo sich auf den Standpunkt gestellt wird, in Frankreich habe die Schaffung einer Welt auf der Tagesordnung gestanden, welche „die Sünde nicht mehr kennt und der Gnade nicht mehr bedarf ", 3 waren Verzeichnungen unvermeidlich, um die zu korrigieren

3. B. Groethuysen: Die Entstehung der bürgerlichen Welt-und Lebensanschauung in Frankreich, Frankfurt a.M. 1978, Bd. 1, 237. Mit den späteren Exzessen der Weltanschauungsanalyse verglichen (L. Goldmann: Der verborgene Gott, dt. Übers. von H. Baum, Neuwied-Darmstadt 1973) verkehren sich allerdings auch die Schwächen dieses Buchs in Stärken. 
Nachhilfeunterricht in Theologiegeschichte schon guttut. Gallikanismus und Jansenismus bedingen die idiosynkratische Mischung des französischen Katholizismus. Vfr. ist Spezialist für die eine wie für die andere der im 17. Jahrhundert gestellten großen Machtfragen. Ob nun zwischen Staat und Kirche oder zwischen Gott und freiem Willen, stets ging es ja um das: Wer wen?

Ein Historiker muß sich der Masse von Namen stellen, die ihm sein Gegenstand darbietet. Dieses Verhältnis zu einer Masse von Namen hat der Vfr. Weder gibt es für ihn zu recht vergessene Autoren noch ist er für bestimmte Namen besonders eingenommen. Die Autorenindividualität ist ihm überhaupt nicht übermäßig wichtig. Interessiert wird sich für die großen Ideen, für die durch die Institutionen und die Lagerbildung der Vergangenheit bedingte Verteilung der Massen. Die gewählte Kapitelfolge lehnt sich an die Zeitfolge an, aber Vfr. hat der Versuchung widerstanden, diese zum Leitfaden der Darstellung zu nehmen. Statt dessen überläßt er sich, zeitlich im Vor und Zurück, frei dem Duktus seines Themas. Stets werden wirklich geführte Kontroversen identifiziert, das ist viel erhellender als das Ziehen abstrakter Vergleiche, geschweige denn als die Manier der ,immanenten' Interpretation. Die formalen Kompositionsmängel, Vorgriffe und Wiederholungen, erklären sich zum Teil daraus, zum Teil aus der Entstehungsweise des Buchs. Dem Leser bleiben überflüssige Informationen, anekdotische Details usw., erspart. Die Aussagen im Text sind hinlänglich belegt. Die Sorgfalt, mit der der gelehrte Apparat lateinischen Quellentext bietet, ist nicht selbstverständlich.

Die in Anspruch genommene Freiheit gegenüber einer äußerst weitschichtigen Materie macht das historische Argument auch angreifbar. Die Plausibilität des Gedankengangs einmal zugestanden bleiben doch Einwände. Ein erster betrifft die Literaturverarbeitung, ein zweiter die Darlegung der Streitsache, ein dritter die Nomenklatur der Beweismittel.

\section{Erster Einwand}

Deutschsprachige Literatur ist nicht verarbeitet, obwohl die Existenz einer Literatur zu diesem Forschungszweig von Karl Werners Geschichte des Thomismus von 1859 datiert. Wenn in dem Kapitel „Fénelon et la définition du vrai thomisme“ versichert wird, dieses Thema sei noch unbehandelt („aucun travail“, 498), dann weiß der Leser nicht, woran er mit einer solchen Feststellung ist. Auf der einen Seite ist z.B. Spaemanns Habilitationsschrift über Fénelon gar nicht erwähnt, auf der anderen muß der Hinweis erlaubt sein, daß das Historische Wörterbuch der Philosophie in dem Artikel „Thomismus“ schon vor zwanzig Jahren auf eine sogar noch weitergehende Vermutung gekommen ist: „Wahrscheinlich gehört Fénelon zu den ersten, 
die den Begriff eigens thematisieren."4 Das heißt nicht, daß von deutschsprachiger Literatur gar nicht Notiz genommen wäre. Vfr. hat aber die Unsitte, Forschungsliteratur summarisch in den Fußnoten beizusetzen. Auf diese Weise läuft etliches mit, was vermutlich doch nur aus zweiter Hand bekannt ist. Obwohl es sich in diesem Fall sogar um den einzigen Literaturhinweis handelt, der gegeben ist (31), hat z.B. der Artikel „Praedeterminatio physica“, aus demselben Standardwerk, in dem Gedankengang nicht die mindeste Spur hinterlassen.

Auch die Sorgfalt im Umgang mit den Quellentexten ist nicht überall gleichmäßig. Molinas Concordia $\left({ }^{1} 1588,{ }^{2} 1595\right)$ ist der Stein, der alles ins Rollen gebracht hat. Mehr ist sie für den Vfr. allerdings nicht. Seine Bekanntschaft mit ihr ist oberflächlich. Ihm zufolge hätte Molina „rigoureusement“ (263) deduziert, daß die Futuribilien „,von ewigkeither eine objektive Wahrheit“ haben. Das Gegenteil ist der Fall: Molina hat es bekämpft, die Scientia Media-Hypothese auf den festen Wahrheitswert in einem zweiwertigen Aussagenkalkül zurückzuführen. Das ist freilich nur einer der Gründe, warum sich innerhalb der Jesuiten Molinas Variante der Scientia Media-Hypothese gerade nicht durchgesetzt hat. Für seine Behauptung, die Concordia wäre „certainement“ (238) einer der meistkommentierten Texte der posttridentinischen Theologie gewesen, bleibt Vfr. den Beweis schuldig. Die Concordia wird offenbar mit Suárez' Opusculum De scientia quam Deus habet de futuris contingentibus (1599) verwechselt. Suárez' Version der Scientia Media-Hypothese ist die klassisch gewordene, sie unterscheidet sich von Molinas grundlegend, und zumindest der eben berührte Unterschied war jedem damals geläufig, auch den Dominikanern. ${ }^{5}$ Dieser für die Traditionsbildung schlechterdings maßgebliche Text, der von Suárez, ist dem Vfr. nicht unbekannt, aber von ihm ebensowenig studiert. In seiner Darlegung des Verlaufsprofils der Kontroverse um die Scientia Media-Hypothese fällt er schlicht aus. Das hat dann zur Folge, daß sein Referat der von den Thomisten an dieser Hypothese geübten Kritik streckenweise (249ff., 255ff.) die Orientierung verliert.

4. Historisches Wörterbuch der Philosophie, hgg. von J. Ritter / K. Gründer / G. Gabriel, s.v. ,Thomismus' (H. Schmidinger), Basel 1971-2004, Bd. 10 (1998), 1184-87.

5. „Discordant [...] principaliter tres Authores, nempe Molina, Vasques et Suarius, et se mutuo destruunt, in assignando fundamento principali talis scientiae mediae. Molina namque constanter negat, illam posse fundari in veritate obiectiva ipsius futuri, quae est ratio totalis Suarii [...]. Vasques autem [...], quem sequitur ibi Arrubal [...], requirunt ad fundamentum huius scientiae, moralem saltem connexionem in obiecto futuro ad conditionem, cum qua efficitur. Unde negant, pure disparata sciri posse a Deo [...]. Suarius [...] recurrit ad veritatem obiectivam [...]. [...] quoniam hic modus Suarii praevalet magis hac tempestate apud Authores Societatis, ideo illum ex professo impugnabimus." P. Magalhaes OP. ( $† 1672)$ : Tractatus theologicus de scientia Dei, Lissabon 1666, 375f. Vgl. E. VAnsteenberGhe: „Molinisme“, DThCX (1928), 2094-2187, hier 2169. 


\section{Zweiter Einwand}

Der Historiker muß nicht unbedingt unparteilich sein. In dem Historikerstreit, der seit dreihundert Jahren die Gnadenstreitigkeiten überlagert, steht Vfr. auf den Schultern des Dominikaners Serry. Sein Beweis (244ff.) für den Bruch mit der katholischen Tradition, den die Jesuiten nach eigenem Bekunden mit der Scientia Media-Hypothese vollzogen hätten, ist Punkt für Punkt aus Serry geschöpft, möglicherweise aus zweiter Hand, ${ }^{6}$ und schon Serry haben die Kritiker damals diesen Beweis nicht abgenommen, sondern, bis auf einen der dafür angeführten Texte, fehlende Autopsie zu rügen gehabt. ${ }^{7}$ Wenn den Molinisten in ihrem Disput mit den Dominikanern nicht nur Skrupellosigkeit (323) und Augustinverachtung (186, 268) attestiert wird, sondern Unaufrichtigkeit $(139,143)$ und Inkohärenz $(161)$, dann würden solche Urteile jedoch voraussetzen, daß in die Streitsache tiefer eingetreten ist, als es Vfr. für seine Zwecke vorgehabt hat. Es gibt Gründe, um an seiner richterlichen Kompetenz zu zweifeln.

Was er ,Molinismus' nennt, bleibt vage. Manchmal (552) hat es den Anschein, als wäre die Prädestination post praevisa merita ein Merkmal dieses Begriffs. Das stünde dann im Widerspruch zu Molinas erklärter Doktrin. Es würde der Verständigung dienen, nicht nur zwischen dem Molinismus und dessen vermeintlich pelagianischen Konsequenzen, sondern sogar zwischen ihm und der Scientia Media-Hypothese zu unterscheiden und bezogen auf die Gnadenstreitigkeiten den Begriff ,Molinismus 'terminologisch dem Gnadenmolinismus vorzubehalten. Die Scientia Media-Hypothese diente ja dazu, diesen mit bestimmten Gottesattributen (der Unfehlbarkeit des Vorherwissens, der Unfrustrierbarkeit des Prädestinationswillens) auszugleichen. Dann ist, was gemeint ist, eindeutig: daß die Wirksamkeit einer Gnadenhilfe kein Ausstattungsmerkmal derselben ist (gratia [... quantum est ex se, agit necessitate naturae), ${ }^{8}$ sondern davon abhängt, was heute als compliance in aller Munde ist: auxilia gratiae non habere ex sua natura, quod efficacia sint aut non sint, sed id pendere ex eo, quod arbitrium [...] consentire et cooperari velit aut non velit. ${ }^{9}$ Ob es mit dieser Abhängigkeit vom Zweitakt vereinbar ist, die Gnadenhilfen auf der Basis der Scientia Media spezialangefertigt zu denken, davon leuchtet es

6. J.H. SERry OP.: Historia Congregationum de auxiliis divinae gratiae 1, 13, Antwerpen 1709, 72f.; A.M. Dummermuth OP. (†1918): S. Thomas et doctrina Praemotionis Physicae, seu Responsio ad R.P. Schneemann S.J. aliosque doctrinae Scholae Thomisticae impugnatores, Paris 1886, 750ff.

7. (B. Germon SJ. [† 1718]:) Errata de l'Histoire des Congregations de auxiliis composée par l'abbé Le Blanc, Lüttich 1702, 98-101.

8. L. Molina: Concordia, hg. von J. Rabeneck, Oña-Madrid 1953, 504.

9. Ebd. 361 . 
dann ein, daß diese These - es ist die des von Suárez entwickelten ,Kongruismus ‘ das Lager der Gnadenmolinisten hat spalten müssen. Vfr., der Le Bachelets kostbare Dokumentation dieses Streits von 1931 kennt, hält den Kongruismus übrigens immer noch für eine taktische Konzession (27, 284f.). „Molinisme congruiste“ (329) ist jedenfalls Nonsens, entweder ein hölzernes Eisen oder ein weißer Schimmel, je nachdem.

Da der Streit zwischen den Molinisten und den Dominikanern bzw. Jansenisten sich darum dreht, ob deren Hypothesen für die Gnadenwirksamkeit mit dem Neinsagenkönnen, mit dem posse dissentire, si velit der Konzilsdefinition, ${ }^{10}$ vereinbar sind, hätte es bei der Darlegung des polemischen Schlagabtauschs nicht sein Bewenden haben dürfen. Speziell von dem Calvinismustopos, der den Vfr. angelegentlich beschäftigt, war den streitenden Parteien damals bewußt, daß der nicht mehr als eine Retourkutsche war. ${ }^{11}$ Erst im dreizehnten Kapitel, im Rahmen des Fénelonreferats, d.h. bezogen auf ein viel späteres Diskursstadium, bekommt der Leser das thomistische Gnadensystem ordentlich auseinandergesetzt. Vorher wird er, wie gesagt, mit dem Hinweis auf den Wörterbuchartikel „Praedeterminatio physica" von dem Berliner Philosophiehistoriker Wolfgang Hübener abgefunden. Der Artikel ist grundlegend wichtig, aber nicht in der Absicht, in der Vfr. auf ihn verweist. Der Autor hatte damit seinerzeit ausdrücklich nur die Klärung einer begriffsgeschichtlichen Vorfrage bezweckt.

Einer Beantwortung der Frage, ob Fénelons ebenso instruktive wie paradoxe Interpretation des Systems der physischen Prädetermination historisch zutrifft, hätte nicht ausgewichen werden dürfen. Solange die Möglichkeit nicht ausgeschlossen ist, daß Fénelon mit seiner Interpretation recht hat, die von dem älteren Stadium der Gnadenstreitigkeiten nur viel Lärm um nichts übrigläßt, hängt die Hauptthese des Buches, die von der Wahlverwandtschaft von Augustinismus und Thomismus, in der Luft. Aus Fénelons Interpretation spreche eine „diskrete Feindseligkeit“ (586). Vielleicht, aber damit ist sie nicht widerlegt. Vfr. zeigt nur, daß die forcierte Interpretation den sehr praktischen Zweck gehabt hat, den Dominikanerorden unter Zugzwang zu setzen, damit er einen Unvereinbarkeitsbeschluß gegen die Fraktion

10. Enchiridion symbolorum, definitionum et declarationum de rebus fidei et morum $\$ 1554$, hgg. von H. Denzinger / A. Schönmetzer, Freiburg i. Br. ${ }^{32} 1963,378$ (Canon 4 de iustificatione).

11. „[...] ut illi [sc. Thomistae] doctrinam de Scientia Media eo nomine improbant, quod favere videatur Semipelagianismo, ita ipsi nobis licere putamus exquirere, quantum contraria distet a Calvinismo.“ F. Annat SJ.: Scientia media contra novos eius impugnatores defensa $4,93,\left({ }^{1} 1645\right)$ Paris ${ }^{2} 1662$, 539. - „Ce prétendu soupçon de Calvinisme contre les Thomistes n'est, au sentiment de Ripalda Jesuite, qu' une recrimination des Jesuites, pour opposer à l'accusation de Pélagianisme que les Dominicains faisoient contre eux." (CH. BILluaRT OP. $\dagger$ 1757:) Le Thomisme triomphant, s.l. (1725) 18. Wiederholt von (B. RAcINE † 1755:) Abrégé de l'histoire ecclésiastique XVII ${ }^{\text {mè }}$ siècle 2, 2, Paris (Cologne) 1754, t.10, 8 o. 
Massoulié faßte. Die diesem Theologen gewidmeten Bemerkungen (106ff.) sind, beiläufig bemerkt, gar zu dürftig, Massouliés Position in dem kritischen Punkt bleibt unklar (662f.). Es wäre zu prüfen gewesen - denn das behauptet Fénelon (583) -, ob die Interpretationsspielräume, die das thomistische Gnadensystem ließ („la relative obscurité de la théorie de la praemotio physica“, 601), wirklich erst da angefangen haben, wo es sich bei der physischen Prädetermination um die Spezifikation der näheren Umstände von deren Bezogenheit auf den Zweitakt handelt. Einmal klingt es so, als pflichtete Vfr. Fénelon bei (,justement“, 566), dann wieder so, als hätte er seine Zweifel (594f.). Für seine Person trägt er Zweifelsgründe aber nicht vor. Die Interpretationskritik überläßt er den jansenistischen Gegnern Fénelons (603ff.), übrigens auch wieder nicht, ohne sich davon zu distanzieren („mauvaise foi“, 625). Nur in bezug auf Fénelons Vereinnahmung von Lemos (516, 595) läßt sich aus dem Bericht über Lemos' Auftreten in der Congregatio de auxiliis (182f.) sicher schließen, daß Vfr. diese Kritik teilt. Fénelons Persilschein für seinen anderen Gewährsmann, Alvarez (581ff.), bleibt unerörtert.

Die Zweifel hätten bei dem Begriff der Freiheit anzusetzen. Fénelons Behauptung, es gebe keinen echten Thomisten (,aucun vrai Thomiste“), der in bezug auf den Begriff der Freiheit („sur la notion de liberté") mit den Antijansenisten, auch mit den sog. Molinisten, nicht übereinstimmte, pariert Vfr. mit Ironie. Er nennt sie vielleicht doch etwas kühn, „probablement un peu vite en besogne“ (592). Sie riskiere, durch die Tatsachen widerlegt zu werden (594). Mit Tatsachen wird auch aufgewartet. Nur ist durch die Tatsache, daß die Thomisten damals nur sehr ausnahmsweise für die Molinisten Sympathien gezeigt haben, nichts bewiesen. Der Punkt ist, ob man lagerübergreifend von derselben Sache sprach, wenn man über die Vereinbarkeit bzw. Unvereinbarkeit dieser oder jener Hypothese mit der Freiheit stritt. Jeder Streit setzt voraus, daß die Parteien sich zumindest darin einig sind, worüber sie streiten. Fénelon behauptet lediglich, den orthodoxen Gnadenstreitigkeiten habe es an einer solchen Verständigungsbasis nicht gefehlt, nämlich an dem Begriff der libertas indifferentiae. Andere damals hätten das bestritten. ${ }^{12}$ Das ist der Punkt, zu welchem Vfr. hätte Stellung nehmen müssen. Über diesen Begriff, den der libertas indifferentiae $(161,301 f ., 586)$, schweigt sich das Buch nun aus. Es hätte sich angeboten, ihn begriffsgeschichtlich zu erörtern, dann wäre über eine nette, schon von den Zeitgenossen darüber geführte, Kontroverse zu berichten gewesen. ${ }^{13}$

12. „Molinistae $[\ldots]$ indifferentiam ad agendum et non agendum, in qua libertas arbitrii consistit, [...] longe aliter intelligunt quam Thomistae recentiores.“ L. LE BLANC BEAULIEU († 1675): „Theses theologicae de libero hominis arbitrio absolute et in se spectato" 3,32 , in Theses theologicae variis temporibus in Academia Sedanensi editae, London 1675, 427.

13. Zur Bibliographie: P. Sherlog SJ. (Pseudonym: Paulus Leonardus, $\dagger 1646$ ): Responsiones ad expostulationes recentiorum quorumdam Theologorum contra Scientia Mediam 2, 15-16, Lyon 1644, 
Ein schönes Dokument für die vom Vfr. herausgearbeitete Wahlverwandtschaft ist die Reaktion auf die Begriffsbestimmung der Indifferenzfreiheit, welche den Jesuiten zum Lackmustest der posttridentinischen Orthodoxie gedient hat. Von dieser Begriffsbestimmung, die auch Fénelon (563) seiner Argumentation zugrundelegt, haben nämlich der Augustinverehrer Jansenius und der Thomasverehrer Massoulié übereinstimmend betont, wie fremd sie ihren jeweiligen Hausgöttern sei. ${ }^{14}$ Sie lautet: „Illa causa libera est, quae positis omnibus requisitis ad agendum, potest agere, et non agere. ${ }^{\text {15 }}$ Der Unterschied zwischen dem freien Willen und einer natürlichen Ursache besteht exakt darin: Auch wenn alle Voraussetzungen dafür gegeben sind, daß diese Art Ursache eine bestimmte Wirkung tut, kann sie diese tun oder auch nicht. Also Indeterminismus. Allen Beteiligten an den Gnadenstreitigkeiten war klar, daß die Formel weder auf Aristoteles noch auf den Aquinaten zurückgeht. In einer Monographie zur Scientia Media-Hypothese, welche Vfr. bei anderer Gelegenheit auch heranzieht (321), hat der Jesuit François Annat $(\dagger 1670)$ darauf aufmerksam gemacht, daß die Formel in Teilen der theologischen Kontroversliteratur für eine Erfindung der Nominalisten (Nominales) ausgegeben wurde. Obwohl die von den Jesuiten damals zu diesem Punkt umgehend angestellten Recherchen tatsächlich nicht über das 14. Jahrhundert zurückführten, ${ }^{16}$ hatte Annat ganz recht, wenn er diese Filiation als eine Diskreditierungsstrategie zurückwies. Mit dem Argument, sie sei scholastisch von schlechten Eltern, werde die Formel madig zu machen versucht. Den Nominalisten werde etwas in die Schuhe

106-09; Annat, Scientia media defensa 1, 109, [nt. 11] 138-39; M. Sснооск († 1669): Diatriba academica explicans naturam et conditionem liberi arbitrii $\$ 15$, Groningen 1659, 20-24; S. IzQUIERDO SJ. († 1681): Opus theologicum iuxta atque philosophicum de Deo uno 30, 442, Rom 1664-70, t.2, $281 \mathrm{~b} / 82 \mathrm{a}$.

14. „Nam Augustino, discipulis et posteris eius, definitio ista liberi arbitrii, qua nunc Scholastici quidam id esse volunt, ,quod positis omnibus ad agendum requisitis potest agere et non agere, $[\ldots]$ ad multa saecula fuit ignotissima, sicut etiamnum ab omnibus, qui gratiam physice determinantem liberum arbitrium tuentur, velut Christi gratiae capitaliter inimica reprobatur.“ C. Jansenius: Augustinus: De gratia Christi Salvatoris 8, 19, Löwen 1640, t.3, 866. - „[...] manifeste colligitur, eam libertatis definitionem, quae celebris est apud Recentiores, alienam esse a D. Thomae sententia." A. MAssoulié OP.: Divus Thomas sui interpres de divina motione et libertate creata 2, 1, 3, Rom 1692, 251a.

15. „Definitio illa libertatis est tanquam lapis aliquis Lydius, quo facillime exploramus, utrum doctrina aliqua libertatis sit eversiva. “T. González de SAnTAlla SJ.: Selectae Disputationes in Theologiam Scholasticam 4, 4, 843, Salamanca 1680-86, t.4, $290 a$.

16. D. Ruiz de Montoya SJ. (†1632): Commentarii ac Disputationes de scientia, de ideis, de veritate, ac de vita Dei 50, 4, Paris 1629, 472b-477a. Eine Standardreferenz in der scholastischen Theologie (Izquierdo, De Deo uno 30, 453, [nt. 13] t.2, 283b) und Philosophie (F. Oviedo SJ.: Cursus philosophicus: De anima 12, 2, 5, Lyon 1640, t.2, 202b). 
geschoben, was akademisch Gemeingut war. ${ }^{17}$ Annat nannte im Zusammenhang mit dieser Legende drei Namen: Diego Alvarez ( $\uparrow 1635)$, Guillaume Gibieuf ( $† 1650$ ) und William Twisse ( $\dagger 1645$ ). Bei Alvarez steht die Behauptung an herausragender Stelle, gleich einleitend in dem Kapitel Quaenam sit legitima definitio ac propria natura liberi arbitrii. ${ }^{18}$ Die Zuversicht, mit der Alvarez manchmal geradezu als der Urheber der Legende bezeichnet worden ist, ${ }^{19}$ hält einer Prüfung jedoch nicht stand. Auch in den anderen zeitgenössischen Gnadentraktaten der Dominikanerschule wird sie erzählt. ${ }^{20}$ Bei Lemos liegt auf der Datierung des Zeitpunktes, zu dem die Scholastik auf Abwege geraten sein soll, sogar ein besonderer Nachdruck. ${ }^{21}$ In Paris interpretierten die Molinisten die verblüffende These als ein Paris gemachtes Kompliment, ${ }^{22}$ sonst war das Echo, schon bevor sie dann von einem spanischen

17. „[...] Caeterum circa illam liberi agentis definitionem, inprimis immerito attribuit solis Nominalibus quod debetur potius Scholae Parisiensi, a qua in caeteras Academias ita est propagata, nulla ut sit vel natio vel secta quae non eam facile admittat." AnNAT, Scientia media defensa 1, 110, [nt. 11] 139.

18. „Haec definitio liberi arbitrii sub hac forma neque apud Aristotelem neque apud Magistrum Sententiarum neque apud S, Thomam invenitur, sed apud aliquos nominales. “ D. Alvarez OP.: De auxiliis divinae gratiae et humani arbitrii viribus et libertate, ac legitima eius cum efficacia eorundem auxiliorum Concordia 115, 1, Rom 1610, 756a.

19. „Primus ergo de eius definitionis bonitate legitimae [...] dubitare coepit Magister Illustriss. Alvarez [...]. Eum postea imitati sunt Ledesma [...], Nunnius Cabezudo [...] “ C. DE OrTEga SJ. († 1686): De Deo uno controversiae scholasticae 3, 1, 7, 1, 2, Lyon 1671, t.1, 501 b.

20. „[...] respondemus [...] negantes istam esse definitionem liberi arbitrii. Quia neque illa invenitur apud Magistrum Sententiarum neque apud D. Thomam neque apud alios Theologos antiquos et graves, sed solum apud aliquos Nominales et apud aliquos Modernos. “D. NuÑo CABEzudo OP. ( $\dagger$ 1614): Commentarii et Disputationes in Tertiam partem D. Thomae Aquinatis Q. 62 art. 5, Valladolid 1601, 174b. (Zur antimolinistischen Aktivität von Nuño Cabezudo 1594 vgl. SERry, Historia Congregationum de auxiliis divinae gratiae 1, 20, [nt. 6] 106-10; [GERMon,] Errata, [nt. 7] 149-57; L. Meyer SJ. [Ps.: Theodorus Eleutherius]: Historiae Controversiarum de divinae gratiae auxiliis 2, 23-24, Antwerpen 1705, 167b-73a). - „Haec tamen definitio neque apud Aristotelem neque apud D. Thomam neque apud aliquem gravem authorem nisi apud Almainum et alios nominales invenitur." P. DE Ledesma OP.: Tractatus de divinae gratiae auxiliis, Salamanca 1611, 205bC.

21. „Hanc definitionem [...] non ex Aristotele aut doctrina eius, non ex Augustino aut Sanctis Patribus, non ex Magistro Sententiarum, S. Thoma, aut Doctore aliquo ex gravioribus, sed ex Almayno in suis Moralibus didicerunt praedicti authores [...]“ T. DE Lemos OP. († 1629): Panoplia Gratiae 3, 2, 29, Lüttich 1676, t.3, 98b/99a.

22. Ph. Gamaché († 1624): Summa theologica: In Primam Secundae Q. 13, 2, Paris 1634, t.2, 127aB; N. Ysambert († 1642): Disputationes in Primam Secundae S. Thomae 2, 4, Paris 1648, 7b. Daher, bei entgegengesetzter Wertung, G. Gibieuf: De libertate Deo et creaturae 1, 32, 9, Paris 1630, 239 (über sich als Schüler von Gamaché ibid. 257). 
Gelehrten gründlich widerlegt war, skeptisch ${ }^{23}$ bis ablehnend. ${ }^{24}$ Die Recherchen bestätigten, daß es sich um eine gezielte Desinformation mitten aus dem Entstehungsmilieu des Systems der physischen Prädetermination handelte. ${ }^{25}$ Die Spur führt zu den Dominikanern in Valladolid. Die Schulhäupter in Salamanca, Francisco de Vitoria ( $† 1540)$ und Domingo de Soto ( $† 1560)$, waren daran unbeteiligt, vielleicht sogar Báñez († 1604), zumindest vor Ausbruch der Gnadenstreitigkeiten. ${ }^{26}$ Die Dominikaner scheinen sich, murrend, ${ }^{27}$ in die historische Wahrheit gefügt

23. G. Coninck SJ.: De moralitate, natura, et effectibus actuum supernaturalium 2, 3, Lyon 1623, 5a.

24. „[...] nescio, quid in mentem venerit Didaco Alvarez, viro alioqui eruditissimo et de Theologia optime merito, ut dixerit [...], eam [sc. propositionem] neque apud Aristotelem neque apud Magistrum neque apud D. Thomam reperiri, sed solum apud quosdam nominales." G. Рennotto CR.: Propugnaculum humanae libertatis 1, 13, 2, Lyon 1624, 28a. - „Imo existimo, ante nuperas controversias circa auxilium efficax gratiae exertas, descriptionem illam fuisse a doctoribus, et in scholis communiter probatam. “F. SuÁrez SJ. († 1617): Tractatus de gratia Dei P.I: Prol. 1, 3, 4, in: Opera omnia, Paris: Vivès 1856-78, t.7, 11a. - Außerdem: „[...] Didacus Alvarez [...] quia vidit illam definitionem causae suae non commodare, oblique illam elevarit, dicens esse tantum Nominalium.“ TH. Raynaud SJ. († 1663): Moralis disciplina 2, 76, ( $\left.{ }^{1} 1629\right)$, Lyon 1665, 225b.

25. „Exceptis physicae praedeterminationis authoribus, qui sunt numero pauci, et praesentis aetatis, nullus omnino author, sive antiquior, sive praesenti aetati proximior reperitur, qui neget de ratione libertatis esse, quod positis omnibus requisitis ad operandum, possit volitionem elicere, aut cohibere. Hoc autem absque temeritate possum attestari, quoniam omnes Doctores [...] citatos et alios multos magno cum otio et attentione perlegi, non solum loca, quae notavi [...] Facile poterit lector colligere, verumne sit, an falsum, quod multi Doctores contrariae sententiae testantur, a nullo gravi et antiquo Doctore, sed a solis Nominalibus definiri libertatem esse, quae positis omnibus requisitis ad operandum, possit operari, et non operari. "RuIZ DE MonTOYA, De scientia Dei 50, 4, 35, [nt. 16] 477a. - Damit war für die spanische Scholastik die Sache geklärt: „Rationem huius asserti nullam aliam [sc. Alvarez, Ledesma, Nuño Cabezudo] excogitarunt, nisi visum fuit illis talem libertatis definitionem physicae praedeterminationi adversari, quam ipsi pro viribus tueri conantur.“ J. SENDIN CALDERON OFM. († 1676): Opus posthumum aliquot tractatus theologicos exhibens 4, 1, 9, hg. von J. Bernique, Alcalá 1699, 189a.

26. D. Soto OP.: De natura et gratia 1, 16, Paris 1549, 58r; D. BAÑEz OP.: Scholastica Commentaria in Primam partem Angelici Doctoris D. Thomae Aquinatis Q. 83 art. 1, Venedig ${ }^{2}$ 1591, t.2, 1363aD. Über den Hinweis auf die Stelle bei Soto (F. Zumel OM. [† 1607]: Variae disputationes ad Primam Secundae S. Thomae, 5, 4, Salamanca 1608, t.3, 217b) wollte der physische Prädeterminist sich vor Lachen ausschütten: A. Regnault (Reginaldus) OP. († 1676): De mente S. Concilii Tridentini circa gratiam se ipsa efficacem opus posthumum 2, 67, Antwerpen 1706, 1426-27.

27. „Hanc definitionem ita extollunt moderni, quod [...] usque ad sacietatem refferant authores, qui istam tradiderunt et approbarunt, ut videri potest in P. Ruiz de Scientia Dei disp. 50 sectione 4, ex quo alii sumpserunt.“ J. MARTínez de Prado OP. († 1668): Controversiae metaphysicales 2, 11, 80, Alcalá 1649, 486b. In Antwort auf Suárez: „Doctores antiqui, qui descriptionem illam tradiderunt [...], explicandi sunt in pio sensu [...], ne forte, dum quis vult explicare et defendere libertatem Christianam, defendat libertatem Ciceronianam. “D. Alvarez: Responsiones ad obiectiones adversus Concordiam 4, 1, 14, Lyon 1622, 804f. 
und die Legende fallengelassen zu haben. ${ }^{28}$ Bei dem aus Salamanca nach Löwen heimgekehrten Alexandre Sébille („un thomisme qui s'accorde avec le molinisme“, 659f.) war zur Zeit der Jansenismuskrise jede Erinnerung an sie wie getilgt. ${ }^{29} \mathrm{Da}$ für nahmen sich ihrer jetzt die Calvinisten ${ }^{30}$ und die Jansenisten ${ }^{31}$ an. Zweifellos geschickter als der Versuch, sich gegen die Widerlegung einfach zu immunisieren, war es von demjenigen jansenistischen Kollegen, gegen den Sébille disputierte, daß er Buridans Esel sprichwörtlich zu machen verstanden hat. ${ }^{32}$ Das hat den verachteten Begriff der libertas indifferentiae auf andere Weise diskreditiert, nämlich durch dessen Verengung auf die These von der Unmotiviertheit des Handelns, auf die Freiheit der Willkür. Das war eine Verwechslung, ${ }^{33}$ aber diese Verwechslung hat dann im 18. Jahrhundert die Literatur zum philosophischen Determinismus

28. Nicht mehr wiederholt von José DE S. MARIA OP.: Tractatus thomisticus de libero arbitrio 4, 6, Lissabon 1625, 653ff.; M. SERRA OP. († 1647): Summa commentariorum in Primam partem S. Thomae Q. 83 art. 1, Valencia 1630-40, t.2, 500 ff.

29. „[...] definitio libertatis, tam trita, tamque in Scholis recepta [...] [...] usque ad haec nostra tempora, nulla unquam alia in Schola audita fuerit [...]“ A. SÉBILle OP. († 1657): Divi Augustini et SS. Patrum de libero arbitrio interpres thomisticus adversus Cornelii Iansenii doctrinam prout defensatam in Theriaca Vincentii Lenis 2, 4, 1, Mainz 1652, 99a.

30. W. Twisse: Dissertatio de scientia media 2, 1, 3, Arnheim 1639, 265a; J. Strang († 1654): De voluntate et actionibus Dei circa peccatum 3, 15. Amsterdam 1657, 694; ScHOоск, Diatriba $\$ 15$, [nt. 13] 21.

31. Aus Lemos schöpfte die Legende der Jansenist Henricus a S. Ignatio OC.: Ethica Amoris 2, 59, Venedig 1771, t.1, 107b. Ansonsten die historischen Bemerkungen von J. MarTinez DE Ripalda SJ.: Adversus Baium et Baianos 2, 15, 132 (= De ente supernaturali t.5), Paris 1872, 465b; González de Santalla, Sel. Dispp. in Theol. Schol. 4, 4, 839-40, [nt. 15] t.4, 288b/89a (daher noch L. VeITh SJ. [†1796]: De gemina delectatione, caelesti ac terrena, relative victrice 1,4 , Mecheln 1826, 5). Auch in der Polemik des 19. Jahrhunderts war die Legende noch präsent. Vgl. z.B. V. Gioberti: Il gesuita moderno cap. 7, Lausanne 1846, t.2, 453.

32. L. Froidmont (Ps.: V. Lenis, $\dagger 1653$ ): Theriaca adv. D. Petavii et A. Ricardi de libero arbitrio libros 1, 27, Paris (1648), 132. Denn daß ,Buridans Esel' seinerseits eine Legende ist, ist seit langem bekannt. Vgl. D. Tiedemann: Geist der spekulativen Philosophie, Marburg 1791-97, Bd. 5, 228; P.

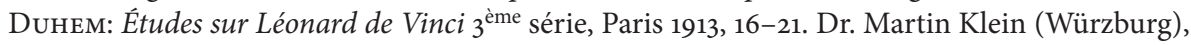
der soeben (2019) eine große Abhandlung über Buridan veröffentlicht hat, weist mich darauf hin, daß die Sprichwörtlichkeit von ,Buridans Esel' genau für Froidmonts Zeit bezeugt ist, durch den Löwener Bibliothekar W. Driessens (Valerius Andreas, † 1655): Bibliotheca Belgica s.v. ,Ioannes Buridanus', Löwen ${ }^{3} 1643,471$. Sprichwörtlich ist er z.B. noch nicht bei RuIz DE MonToya, De scientia Dei 22, 2, 10, [nt. 16] 168a.

33. Vgl. z.B. Dictionnaire des sciences philosophiques, hg. von A. Franck, s.v. ,Liberté' (E. Saisset), Paris 1844-52, t.3, 565f. Äquivokationskritisch gab es Übereinstimmung zwischen den molinistischen und thomistischen Verteidigern der Indifferenzfreiheit. Vgl. D. Petau (Petavius) SJ. (†1652): Dogmata theologica: De opificio sex dierum 5, 11, 2-3, Paris 1866, t.4, 494a/b; J.B. GoneT OP.: Clypeus Theologiae Thomisticae 2, 2, 2, 264, Paris 1669, t.3, 132a/b. 
dermaßen anschwellen lassen. Leibniz ( $† 1716)$, der die „chimère d'une indifférence d'Équilibre" bekämpft, kommt bezeichnenderweise genau deswegen auch wieder auf die angestaubte Legende zurück. ${ }^{34}$

Alvarez, Gibieuf, Twisse: der erste Dominikaner, der zweite Jansenist, der dritte Calvinist. ${ }^{35}$ Eins, zwei, drei. Den von der Gegenseite festgehaltenen Streitpunkt als ein scholastisches Dekadenzphänomen zu schmähen, ist von Anfang an und überkonfessionell eine Waffe in den Gnadenstreitigkeiten gewesen, eine von interessierter Seite lancierte Legende. Ob die Augustinexegese mit der von dieser Legende attackierten Formel zu bewältigen war, ob es nicht etwas viel verlangt war, die ganze Hypothesenbildung für die christliche Heilsökonomie auf diese Spitze zu stellen, dieser Zweifel ist durch die Kritikwürdigkeit einer proliferierenden Geschichtslegende gewiß nicht gehoben. Philosophisch läßt sich den Molinisten jedoch nichts weiter vorwerfen, als daß sie auch im 17. Jahrhundert unbeirrt an den Errungenschaften des 14. Jahrhunderts festgehalten haben. Wo würde in der Mediävistik heute denn noch auf das 14. Jahrhundert geschimpft?

Alvarez, Gibieuf, Twisse: Auch an der von den Molinisten vorgenommenen Zusammenstellung ihrer Gegner gibt es so gesehen sachlich nichts auszusetzen. Sie trifft den Nagel auf den Kopf. Alle drei Parteien sind damals, so wie noch im rechtswie linkstraditionalistischen Diskurs des 19. Jahrhunderts, ${ }^{36}$ über das , pelagianische Idol der Indifferenzfreiheit hergefallen. Auf dem Standpunkt der Verteidiger war es legitim, das System der physischen Prädetermination der Ketzerei zu verdächtigen. Das findet Vfr. nicht. Zu diesem Zweck hätte er etwa auf Pedro de Ledesma (†1616) verweisen können, der, von Suárez bedrängt, in der wünschenswerten Deutlichkeit die physische Prädetermination vom Erstakt abgebogen hat. ${ }^{37}$ Anstatt jedoch diese

34. G.W. Leibniz: Opuscules et fragments inédits, hg. von L. Couturat, Paris 1903/Repr. 1961, 25; auch in Philosophische Schriften, Ak.-Ausg. VI/4, Berlin 1999, 1380. Von Leibniz aus in die Philosophiegeschichtsschreibung übergegangen. Vgl. W.L.G. FreiherR von Eberstein: „Übersicht der scholastischen Freyheits-Lehre“ in Natürliche Theologie der Scholastiker, Leipzig 1803, 221-36.

35. „[...] coepit illa definitio liberi agentis in dubium revocari, primum a Didaco Alvarez, deinde a Gibieufo, quorum suspicionem TVissius avide amplexus est.“ Annat, Scientia media defensa 1, 109, [nt. 11] 138. Gibieuf einen Jansenisten zu nennen, hat Annat übrigens gezögert: F. AnNAT: De incoacta libertate contra Apologistam Iansenii 3, 1, in Opuscula theologica ad gratiam spectantia, Paris 1666, t.3, 209f.

36. L.G.A. Vicomte DE Bonald: Théorie du pouvoir politique et religieux dans la société civile 6, 6, in Euvres complètes, Paris 1859, t.1, 671-72; GIOBERTI, Il gesuita moderno cap. 7, [nt. 31] t.2, 462 (Hinweis auf Lemos und Massoulié); J. Donoso CoRTEs: Ensayo sobre el catolicismo, el liberalismo y el socialismo 2, 1, in Obras completas, hg. von C. Valverde, Madrid 1970, t.2, 549; G. VenturA DE RAulicA: La Tradition et les semi-pélagiens de la philosophie, Paris 1856, 31f.

37. „Auxilium [...] praedeterminans physice voluntatem, quod est requisitum ad operationem, non se tenet ex parte potentiae, neque constituit illam in actu primo, neque complet actum 
Tradition zu registrieren, sie abzuklopfen ${ }^{38}$ und auf diese Weise Fénelons Interpretation (583) kritisch zu stützen, wird nur wieder auf die Gehässigkeit des Calvinismustopos zurückgelenkt $(597,608)$, den ewigen Joker in der Hand der Molinisten, der sich beliebig habe ausspielen lassen (414f.).

Das ist larmoyant. Während die Calvinisten die Legende taktisch dazu benutzten, um 1653 in der Verdammung des zweiten der fünf Sätze des Jansenius ${ }^{39}$ die Erhebung eines scholastischen Dekadenzphänomens zum Glaubensartikel anzuprangern, ${ }^{40}$ hat die antijansenistische Polemik der Molinisten - Annat, Martinon ( $\dagger$ 1662), Dechamps ( $\dagger$ 1701) -, mit der Existenz der Legende diskret hinterm Berg gehalten. Eine vielbewunderte Dialektik wollte ja gerade die Gruppe der physischen Prädeterministen - Alvarez, Nuño Cabezudo, Ledesma (Lemos war noch nicht ediert) ${ }^{41}$ - für das Zeugnis reklamieren, daß zwischen der katholischen Position

primum [...], sed tenet se ex parte ipsius actus, et est veluti initium ipsius actus." Ledesma, De divinae gratiae auxiliis, [nt. 20] 223bB. Die Stelle bei F. Annat: Iansenius a Thomistis Gratiae per seipsam efficacis defensoribus condemnatus, in Opuscula theologica [nt. 35] t.3, 555.

38. „Habent [...] Thomistae: concursum istum Dei non se tenere ex parte actus primi, nec complere virtutem aut potestatem quoad sufficientiam, sed esse puram applicationem se tenentem praecise ex parte actus secundi." Collegium Complutense OP.: In octo libros Physicorum Aristotelis quaestiones 2, 11, 149, Alcalá ${ }^{2} 1695,466 \mathrm{~b} / 67 \mathrm{a}$. Weder die externen Kritiker (P. ALER SJ. [†1727]: Philosophia tripartita: Physica $\$ 573$ C, Köln 1710-24, t.2, 615a/b) hat diese Erklärung befriedigt noch war damit intern die Sache geklärt. Manche haben nämlich daraus gefolgert: „[...] dico, quod, cum praemotio physica non se teneat ex parte actus primi constituendo illud, sed ex parte actus secundi, non ponit in numero cum illo, et ideo talis praemotio est in potestate nostra." J. DE PARRA OP.: In octo libros Physicorum Aristotelis commentaria 2, 6, 3, 34, Alcalá 1657, 375a. Andere (X. MARIALES OP. [† 1660]: Bibliotheca interpretum ad universam Summam Theologiae D. Thomae 9, 3, Venedig 166o, t.4, 277bA-78aB; A. Goudin OP. [† 1695]: Philosophia iuxta inconcussa tutissimaque D. Thomae dogmata: Metaphysica 4, 4, 9, Lyon 1678, t.4, 276f.) haben das nicht daraus gefolgert.

39. Enchiridion symbolorum $\$ 2002$, [nt. 10] 445.

40. „Et denique in Canonem recipitur illa Liberi Arbitrii definitio falsa, erronea, certitudinis praescientiae et decretorum Dei eversiva, et ex qua homo constituitur in agendo independens a Deo, quam , neque apud Aristotelem, neque apud Magistrum Sententiarum, neque apud Thomam, sed tantum apud aliquos Nominales' inveniri, testatur Didacus Alvarez disp. 115 De Auxiliis $\$_{1}[\ldots]$ “. S. Desmarets (MAResius $† 1673$ ): Apologia novissima pro S. Augustino, Jansenio et Jansenitis, contra Pontificem et Jesuitas, sive Examen Theologicum tripertitum Constitutionis nuperae Innocentii X. P.R. qua in gratiam Jesuitarum et Pelagianorum contra Augustini et Jansenii sequaces declarantur et definiuntur quinque Propositiones in materia fidei 2, 55, Groningen 1654, 52.

41. Annat, Iansenius a Thomistis condemnatus, [nt. 35] t.3, 522. Von den Dominikanern auch dankbar quittiert: „Doctissimi Societatis Jesu Scriptores Annatus, Stephanus Dechamps, et [...] Martinonus, in libris non minus mole quam eruditione immensis, quos contra Jansenium eiusque discipulos publicarunt, omni argumentorum genere probant, Thomistarum doctrinam de Gratia per se efficaci non tollere hominis libertatem, et a doctrina des Gratia necessitante, quam 
und dem Jansenismus Welten liegen. Im Disput mit den Ketzern mußte der Molinist es sich verkneifen, eine die Dominikaner kompromittierende Intimität auszuplaudern, also machte er seinem Ärger durch Witze Luft. Wenn auch in der Sache kein Unterschied zwischen Thomisten, Jansenisten und Calvinisten sei, gebe es schon einen Unterschied, einen im Argumentationsverhalten. Die Calvinisten leugnen weder A noch B, weder den Determinismus noch die Aufhebung der Freiheit. Die Jansenisten leugnen B, nicht A. Die Thomisten leugnen sowohl A als auch B. Den Calvinisten fehlt's an der Gesinnung, nicht an Logik, den Jansenisten sowohl an dem einen als auch an dem andern, den Thomisten nur an Logik. ${ }^{42}$

\section{Dritter Einwand}

Die Rekonstruktion eines bestimmten Geschichtsbilds, wie gesagt, und eines sehr zählebigen. "And the true reason“, wurde in der heterodoxen Alvarezgemeinde gegen 1680 gemunkelt, „why the Jansenists do not maintain greater correspondence with the Dominicans, is, not their difference in doctrine, but because many of the Dominicans have by a Spirit of Cabal, or of Faction joined with the Jesuites. "43 Das Buch endet damit, daß die Nouvelles Ecclésiastiques auch gegen 1780 Grund gehabt haben, sich über die Dominikaner deswegen zu beschweren.

Gesetzt den Fall, an dem Anspruch des Buches gemessen wäre es ein Mißverständnis, daß es das jansenistische Geschichtsbild von um 1780 rekonstruiert, dann läge das Mißverständnis an der Nomenklatur der Beweismittel. Sie hat klaffende Lücken, und dieser Einwand erledigt sich weder durch den Hinweis auf den Charakter einer Aufsatzsammlung und den schon dadurch bedingten Verzicht auf Vollständigkeit noch durch die Idee, der Begriff, Thomismus' bezeichnete eine überzeitliche Verpflichtung. Diese Idee beherrscht das Buch zwar, da sie sich aber nicht zu einer These verdichtet, ist sie der Diskussion entzogen. Mit einem Historiker kann nur darüber gestritten werden, ob er dem Thomismus als einer historischen Realität gerecht wird. Darüber aber mit ihm zu streiten, wäre in diesem Fall unerläßlich.

Außerhalb der Franziskanerschule ist im 16. Jahrhundert der theologische Lehrbetrieb überall auf die Kommentierung der Summa theologica umgestellt worden (278ff.). Seine Anerkennung dieser Tatsache, d.h. der akademischen Institutionalisierung des Thomismus, bleibt bei dem Vfr. Lippenbekenntnis. Er hat es unterlassen, sich bezogen auf die neue theologische Systematik den Ort der von

Jansenius eiusque discipuli propugnant, longe lateque discrepare." I.H. AMAT DE Graveson OP.: Epistolae theologico-historico-polemicae 5, 3, Rom 1728, 162.

42. González de Santalla, Sel. Dispp. in Theol. Schol. 4, 4, 696, [nt. 15] t.4, 246b/47a.

43. Th. Gale († 1677): The Court of the Gentiles 4, 3, 4, London 1678, 127. 
ihm angeschnittenen Fragen über den Umfang und die Tiefe der menschlichen Gnadenbedürftigkeit klarzumachen. Wenn er sein sehr gemischtes Quellencorpus ernstlich zu dem akademisch über diese Materien geführten Disput, also zu dem historisch gelebten Thomismus, hätte in Beziehung setzen wollen, dann wären die zum Teil doch sehr speziellen Theologumena, unter anderem, auf die zehn Artikel der Q. 109 der Prima Secundae hin erst einmal zu ordnen gewesen. Erst so hätte man verstanden, wieso Nicole eigensinnig auf der Sicherstellung der , potentia physica' bestanden hat. Ohne die Einordnung in den akademischen Diskurs bleibt sein für das jansenistische Lager so verstörender Gnadenuniversalismus (8. Kapitel) historisch steril und die zwischen ihm und Arnauld darüber eingetretene Entfremdung „quelque chose de tragique“ (367).

Da Vfr. den Fehdehandschuh, den Pascal 1656 der Sorbonne hinwarf, für ein einschneidendes Ereignis hält, wundert es, daß der Leser weder etwas über den an der Sorbonne gelehrten Thomismus noch über die von der Sorbonne zu den Gnadenstreitigkeiten eingenommene Stellung erfährt. Der älteren Literatur ist das Thema nicht so gleichgültig gewesen. ${ }^{44}$ Hier dagegen tritt die Sorbonnetheologie zwar individuell in Erscheinung, aber weder korporativ noch in ihren Thomaskommentatoren. Die beiden Habert, Isaac $(\dagger 1668)$ und Louis ( $\uparrow 1718)$, beides Sorbonniten, sind in dem Personenverzeichnis sogar vermengt.

Nun hat, was diese posttridentinische Scholastik betrifft, die Musik allerdings nicht in Paris gespielt. „Tota philosophia recens, tota Theologia bellatrix, hispanica plane est", ließ ein darüber verschnupfter Pariser Cartesianer seinen spanischen Gesprächspartner auftrumpfen. Beherrschten Alvarez und Molina denn nicht die theologischen Fakultäten von ganz Europa?45 Vfr. würde nicht widersprechen. Den Theologiekurs der Karmeliter von Salamanca, der $1631 \mathrm{zu}$ erscheinen anfing und ab 1870 in Paris nachgedruckt worden ist, stilisiert er zur „,incarnation du thomisme authentique pour les théologiens catholiques“ (247). Spätestens seit den Forschungen von Jacob Schmutz („Scholasticon“), auf die er sich wiederholt beruft, ist die von der Aufklärung betriebene und von Gilson und M.-D. Chenu noch einmal bekräftigte (95) Verdrängung (dévalorisation) dieses spanisch dominierten Stadiums der Scholastik obsolet. So abwegig war der, jetzt fünfundzwanzig

44. F. Annat SJ. (Ps.: Eugenius Philadelphus): Exercitatio scholastica contra novam rationem tuendi physicas praemotiones liberorum agentium, Cahors 1632, 268f.; G. DE HenAo SJ. († 1704): Scientia Media historice propugnata $\$ \$ 1094-1101$, Salamanca ${ }^{2} 1665$, 305a-o7a; SERRY, Historia Congregationum 2, 26, [nt. 6] 264-69; MEyer, Historiae Controversiarum 2, 14, [nt. 20] 13ob-33a. Bei Georg Pfeilschifter in Freiburg ist 1908 eine Dissertation zur Stellung der Sorbonne zum Jansenismus in dem Zeitraum 1681/1729 entstanden: J. HILD: Honoré Tournely und seine Stellung zum Jansenismus mit besonderer Berücksichtigung der Stellung der Sorbonne zum Jansenismus, Freiburg i. Br. 1911.

45. Anonymus: Philosophia vulgaris refutata, Paris 169o, if. 
Jahre alte, Vorschlag nicht, die Revisionsbedürftigkeit auch unserer Periodisierung der Philosophiegeschichte, die daraus folgt, durch die Einrichtung einer Abteilung „Hispanic Philosophy“ anzuerkennen: nämlich mit Blick auf Lateinamerika. ${ }^{46}$ Trotzdem nun vereinnahmt Vfr. diese gewaltige Diskursformation, die kulturgeographisch übrigens doch besser dem habsburgischen Commonwealth zugeordnet wäre, für den âge classique, um dann aus der Konfrontation dieses Thomismus mit den Idiosynkrasien der französischen Szene sein Thema überhaupt erst zu gewinnen.

Die Spanier können da wieder sehen, wo sie bleiben. Aus der Zunft der spanischen Thomaskommentatoren kommen nur einige physische Prädeterministen (Alvarez, Ioannes a S. Thoma, Ioannes ab Annunciatione) zu Wort, selbst die Koryphäen der Gegenseite nicht, Suárez ( $† 1617$ ) und Vázquez († 1604), geschweige denn die großen Antijansenisten: Martínez de Ripalda ( $\uparrow 1648)$, der spätere Jesuitengeneral González de Santalla ( $†$ 1705). Andere kommen freilich auch nicht besser weg, weder die Jansenisten, selbst wenn sie sich philothomistisch in die französische Diskussion eingeschaltet haben (González de Rosende $† 1681), 47$ noch die Antijansenisten anderer Couleur, darunter der Benediktinerkardinal Saénz de Aguirre ( $\uparrow 1699$ ) oder gerade auch die Augustiner. ${ }^{48}$ Von dem Kongruismus, dem offiziellen Gnadensystem der Jesuiten, erfährt man, daß er innerjesuitisch Gegner gehabt hat, aber weder, daß Vázquez diese angeführt hat, noch, daß Vázquez trotzdem mit der Attitüde „el Agustín español“ punktete. ${ }^{49}$ Da bei ihm der Antipelagianismus folglich anders gepolt gewesen sein muß als bei seinem Zeitgenossen Lemos, hätte Vázquez' eigentümliche Stellung zu Bajus bedacht und, wenn es darum geht, die Gnadensysteme richtig zu justieren, in die Beschreibung der Gemengelage unbedingt mit aufgenommen werden müssen: nicht nur zur Vervollständigung des Spektrums der zwischen Augustin und Molina vermittelnden Positionen (303ff.),

46. J.J.E. Gracia: „Hispanic Philosophy: Its Beginning and Golden Age“, Review of Metaphysics 46 (1993) 475-502.

47. Über ihn Salamancas führender Dominikaner zu der Zeit: „[...] utrumque Parentem Augustinum et Thomam [...] sub tenebris Iansenismi involuit, eorumque doctrinam, dum praemit, usque ad succum Iansenismi detorquet." V. Ferre OP. († 1682): Tractatus theologici in Primam Secundae D. Thomae $\$ 683$, Salamanca 1679, t.1, 354a.

48. „Dicendum, gratiam Dei per Jesum Christum D.N. dividi in ,sufficientem et ,efficacem؛ et huiusmodi divisionem esse clavem ad aperiendum omnes errores antiquos et recentes contra gratiam Dei." P. MANso OSA. (†1729): S. Augustinus Gratiae sufficientis assertor et vindex contra Jansenistas, Quesnellianos ac novissimos Gratiae sufficientis osores 1, 13, Salamanca 1719, 16a.

49. Ph. Alegambe SJ.: Bibliotheca Scriptorum Societatis Iesu s.v. ,Gabriel Vasquez', Antwerpen 1643, 146b; Diccionario de historia eclesiástica de España s.v. ,Vázquez' (E. Elorduy), Madrid 197287, t.4, 2716b. Von den Jansenisten auch ernstgenommen: J.B. Sinnich (Ps.: Aurelius Avitus, $\dagger$ 1666): Molinomachia 12, 2-3, Paris 1650, 65-68. 
sondern auch, um die feinen Unterschiede im jansenistischen Lager begreifen zu können, also z.B. im Hinblick auf die vermeintliche Inkohärenz in der Position des Pariser Erzbischofs Noailles (537) oder im Hinblick auf den Supranaturalismus des gefeierten Boursier („brillante conclusion“, 490).

Ripalda, das ist wahr, wird einmal erwähnt (656), aber aus zweiter Hand. Dabei ist er im Paris der siebziger Jahre des 19. Jahrhunderts genauso nachgedruckt worden wie der Theologiekurs der Karmeliter von Salamanca. Es hätte lediglich Fénelons für den Hl. Stuhl bestimmte Dissertatio de physica praemotione (1713), die wir in dem dreizehnten Kapitel vorgestellt bekommen, neben Ripaldas Kapitel „Quibus Baiani a Praedeterminatoribus dissideant in concilianda libertate cum gratia ${ }^{\text {}}{ }^{\circ}$ gehalten werden müssen, und man hätte gesehen, woher der gelehrte Prälat die „stratégie fénelonienne" (544) gehabt hat: von den Jesuiten in Salamanca. Schon Ripalda hatte in derselben scholastischen Bestimmtheit Punkt für Punkt die Täuschung auseinandergesetzt, welche für ihn darin lag, daß die Jansenisten sich hinter den Dominikanern versteckten. Schon Ripalda hatte in dieser Absicht Alvarez sogar dessen Bekenntnis zur Indifferenzfreiheit abgekauft. Vfr. selber zitiert Ripaldas Zeugnis aus dem Dominikaner Gonet $(\dagger 1681) .{ }^{51}$ In der Apologetik der Dominikaner, gerade auch der französischen, kursierte dieser Persilschein. Noch zu Fénelons Zeit z.B. hat kein geringerer als Serry ihn abgedruckt. ${ }^{52}$ Nicht jedem gefiel das. ${ }^{53}$

Ripalda war längst tot, als Fénelon das Licht der Welt erblickte. Ripaldas französischer Partner, Annat, spießte schon 1664 den Mißbrauch der Salvationsformel „in sensu thomistico“ auf,54 die eine Quelle von so viel Hader wurde, deren Denunziation um die Jahrhundertwende das zehnte Kapitel daher aber doch überdramatisiert. Wenn das alles schon durchgekaut war, dann war die in dem Buch beschriebene krisenhafte Zuspitzung des Disputs um die philothomistische Option

50. Martinez de Ripalda, Adversus Baium et Baianos 2, 14, 34-41 (= De ente supernaturali t.5), [nt. 31] 378ff. Vgl. ibid. 2, 24, 16, (= De ente supernaturali t.6), [nt. 31] 382a/b. In der jansenistischen Geschichtsschreibung war Ripalda für die Ungeniertheit seines Semipelagianismus berüchtigt: (RACINE:) Abrégé de l'histoire ecclésiastique XVII ème siècle 10, 2, [nt. 11] t.11, 75; CH. CLÉMENCET OSB. (Ps.: Eusèbe Philalèthe, $\dagger 1778$ ): Lettres à M. François Morenas sur son prétendu Abrégé de l'Histoire Ecclésiastique de M. Fleuri 7, 27-30, Lüttich 1757, 181-83.

51. Gonet, Apologia Thomistarum $\$ 139$, in Clypeus Theol. Thomist., Antwerpen 1725, t.1, 478507, hier 506a.

52. J.H. SERry: Schola thomistica vindicata, seu Gabr. Danielis e Soc. Jesu Tractatus theologicus adversus Gratiam se ipsa efficacem censoriis animadversionibus confutatus, Venedig (Coloniae) 1706, 209ff. (wieder in: Praelectiones theologicae, Venedig 1742, t.2, 627ff.).

53. D. DE Quadros SJ. (Ps.: M. Ortiz, † 1746): Caduceus theologicus et crisis pacifica de Examine Thomistico 1, 218, Madrid 1733, 158.

54. Annat, Iansenius a Thomistis condemnatus, [nt. 35] t.3, 518f. 
zu Beginn des 18. Jahrhunderts nicht mehr als ein Epilog. Was Vfr. den „Schwanengesang der französischen Gnadentheologie des klassischen Zeitalters" (602) nennt - Fénelons Instruction pastorale en forme de dialogues -, war spanische Jesuitenscholastik in französischer Übersetzung.

Sei's drum, könnte man sagen. Die Seite, nach der hin bei dem Buch die Versäumnisse liegen, belastet indessen auch die analytische Erschließungskraft. Die logische Systematisierung der Gnadensysteme, eine intellektuelle Leistung, auf die Vfr. Gewicht legt, fällt eben nicht, wie er annimmt (115ff.), erst in die Zeit nach Unigenitus, sondern war in Spanien gang und gäbe. Die scholastische Übung, sich über den status quaestionis zu verständigen, zwang dazu. Das Ignorieren der spanischen Szene ist nicht wegen an sich gleichgültiger Prioritätsfragen ein so ernstes Kapitel, sondern wegen der Verzerrungen, die dann fast zwangsläufig aus der unterstellten unaufhörlichen („sans cesse“) Komplexitätssteigerung (701) und der Vermutung folgen, die jeweils erfolgte Positionierung in dem Diskurs wäre daher wohl auch gar nicht mehr restlos durchsichtig (568).

Der Anlage des Buchs fehlt es also an ein paar mehr Koordinaten. Im Hinblick auf Fénelons maßlose Aufregung über Louis Haberts „langweiliges“ (591) Theologiekompendium - weil es einer ,moralischen' Notwendigkeit das Wort redete - wäre das Gnadensystem des Sevillaner Thomaskommentators Diego Ruiz de Montoya († 1632) zu konsultieren gewesen. Es hätte den Vfr. für seine Zwecke interessieren müssen, daß dieses System, die hedonistische Erklärung der Gnadenwirksamkeit durch einen auf der Bewußtseinsebene (568) spielenden Motivkalkül,55 in der spanischen Szene sogar ziemlich verbreitet war: schon darum interessieren müssen, weil Kongruisten und physische Prädeterministen auf die ,praedeterminatio moralis' gemeinsam einhackten. Daß sie im 18. Jahrhundert von gewisser Seite als die gefundene Lösung für eine Verständigung zwischen Augustinismus und Thomismus präsentiert wurde, lenkt ja auch ganz zuletzt (718ff.) in dem Buch die Aufmerksamkeit auf sie. Da ist es indessen zu spät, um von der großen Literatur zum Thema Notiz zu nehmen. Was das 19. Jahrhundert an Kenntnissen darüber erreicht hat, waren auch schon nicht mehr solche über das scholastische Original, sondern von der französischen Schwundstufe, auf der aber immerhin Namen, die zur Nomenklatur des Buchs gehören: Vincent Contenson ( $\uparrow 1674)$, Louis Thomassin († 1695) und eben der bewußte Habert. ${ }^{56}$

55. S.K. KnebeL: Wille, Würfel und Wahrscheinlichkeit. Das System der moralischen Notwendigkeit in der Jesuitenscholastik 1550-1700, Hamburg 2000, 221ff. Auf dieser Basis, gegen Berti, wird die Orthodoxie des augustinischen Gnadensystems verteidigt noch von J.N. SCHAD CR. († 1777): Concordia delectationis victricis vere Augustinianae cum libertate indifferentiae, Günzburg a.D. 1770, 239.

56. Veith, De gemina delectatione 2, 45-46. 103, [nt. 31] 74f. $239 \mathrm{f}$. 
Die historische Textur der Beweisführung löst sich auf, der Spannungsbogen hält nicht. Der Kardinalfehler ist, daß der Diversität der Positionen nicht hinlänglich Rechnung getragen werden kann, weil die Positionsbezeichnung ,Molinismus aus den Kontroversen der Vergangenheit in das deskriptive Besteck des Historikers unkritisch übernommen wird. Es ist die Kehrseite der affirmativ besetzten Abstraktion ,Thomismus‘. Obwohl Vfr. den Alleinvertretungsanspruch der Dominikaner selber zurückweist und sogar von dem Protest berichtet (679), den die Molinisten seinerzeit gegen ihre Ausgrenzung aus dem Thomismus erhoben hätten, bekommen diese keinen Einfluß auf das Verlaufsprofil des Diskurses und damit auf den Zuschnitt des Gegenstands zugestanden, in bezug auf den er seine Aufgabe, davon abgesehen, vortrefflich auffaßt. Von dem alten Klagelied über eine Inflationierung der ,Jansenisten ' wird Notiz genommen (658), von Fénelons Bemerkung über die Inflation der ,Molinisten' (616) aber nicht. 1732 machte der Jesuit und Fénelonleser darüber noch seine Scherze, ${ }^{57} 1762$ war ihm das Lachen vergangen, denn inzwischen befaßten sich die gallikanischen Staatsanwälte mit dem Verrat an dem hl. Augustin und dem hl. Thomas..$^{58}$ In dem Buch spielt die Einmischung der Justiz in

57. „Mais ne commençons point par une équivoque. Il y en a une, ce me semble, dans le nom de ,moliniste, que M. Bayle et ceux de votre parti donnent généralement à tous les vrais catholiques qui ont du respect pour les décisions de l'Eglise. J'ai vu le temps, qu'on appelait seulement ainsi les théologiens qui se sont attachés aux sentiments particuliers de Molina. Mais maintenant un docteur a beau réfuter Molina, suivre une autre route et une autre méthode que la sienne pour expliquer les matières de la prédestination et de la grâce, s'il reçoit les constitutions des papes qui avec le corps épiscopal ont condamné le jansénisme, il est moliniste malgré lui... Cependant les véritables molinistes protestent contre l'excès d'honneur que la haine aveugle des hérétiques leur fait. Ils déclarent franchement et ingénument que la fortune de leur nom, quón veut bien donner à tous les prélats et à toutes les personnes orthodoxes de l'univers, a été portée plus loin que celle de leurs opinions; et que si les autres écoles catholiques ont par hasard quelque jalousie de ce qu'il n'y a point de seigneur ni de dame qu'on appelle ,thomiste, ,scotiste ' ou ,sorboniste, et qu'il y en a pourtant un bon nombre qu'on appelle ,molinistes'; si, en un mot, ces respectables écoles prennent l'alarme, et on lieu de craindre quà la faveur du nom la doctrine moliniste ne fasse trop de progrès, on les prie de considérer que les molinistes proprement dits nén sont point responsables, et qu'il y aurait de l'injustice à leur en faire un crime, puisqu'ils nont point ambitionné cet avantage, qui leur vient uniquement, dirais-je de la malice ou de l'imprudence des ennemis communs de la catholicité." CH. Merlin SJ. († 1747): Réfutation des critiques de M. Bayle ( $\left.{ }^{1} 1732\right)$, PL (Migne) 47, Paris 1877, 888-89.

58. „Lorsque Molina mit au jour son système, il déclara lui-même qu'il étoit nouveau et contraire à l'enseignement commun. [...] Quelle foule de maux a produit la passion uniforme et constante de faire prévaloir ces dogmes Jésuitiques à la doctrine de S. Augustin et de S. Thomas!“ J.P.F. De Ripert de Monclar: Compte rendu des Constitutions des Jésuites (Parlement de Provence, 28.5.-4.6.1762), in Supplément au Recueil par ordre de dates sur l'affaire des ci-devant soi-disans Jésuites, Paris 1766, t.1, Sonderpaginierung 34b/35a. Worauf die Jesuiten trocken erwiderten: „Que fait le système de Molina à la morale des Jésuites?" (J.N. Grou SJ.:) Reponse au livre intitulé: 
innerkirchliche Angelegenheiten - vorgeblich zur Sicherstellung der Meinungsfreiheit in den religiösen Orden (7o1f.) - eine nur untergeordnete Rolle. An dem Politikum hätte jedoch nicht vorbeigelesen werden dürfen, zumal heute nicht, wo sich über nichts so leidenschaftlich aufgeregt wird wie über ,Kategorisierungen' Wohl möglich, daß seine Parteilichkeit dem Historiker also doch einen Streich gespielt hat.

Gewiß, es wird sich darüber mokiert (62), daß in den 1880er Jahren eine Renaissance des Molinismus manchem Thomisten nach dem Fanfarengeschmetter („Paradmarch“) der ,jésuites prussiens“ geklungen hat. Die waren damals exiliert. Wo wäre der Molinismus heute noch politisch suspekt? Wo würde andererseits noch über eine jansenistische Geschichtsklitterung gezetert? So werden Choreographie und Literaturverarbeitung lediglich Zweifel daran wecken, daß der von Colbert in die Kulturpolitik eingeführte chauvinistische Standpunkt restlos überwunden ist. Seine Historisierung der Gnadenstreitigkeiten fällt für diesen Gelehrten zusammen mit deren Einordnung in die französische Geistesgeschichte. Der âge classique annektiert den siglo d'oro. Was läßt auch die französische Kirchengeschichte als Sieger aus dem Spanischen Erbfolgekrieg hervorgegangen sein? War es wirklich das Fehlen einer Behörde, welche anderswo dafür sorgte, daß es in den Gnadenstreitigkeiten vernünftig zuging, mit paritätisch besetzten Kommissionen und geregelten Verfahren? Und nicht jeder Bischof mit seinen eigenen Bücherverboten (536ff.) fuchtelte und jeder Geck mit theologischen Broschüren die Boudoirs stürmte?59

Die Unlust zum Studium der Spanier rührt vermutlich einfach daher, daß scholastische Systemansprüche nun einmal ihre Sprödigkeit haben. So gesehen fiele dem Bourbonenprinzen Conti, in dem siebenten Kapitel, choreographisch die Rolle zu, der Unlust eine Stimme zu geben. Seinen intelligenten Auftritt in den Gnadenstreitigkeiten („non sans raison ni prudence polémique“) bestritt der jugendliche Prinz, so hören wir aus dessen Munde, ohne schweres Geschütz: Thomas, Augustins De gratia et libero arbitrio „et un ou deux Thomistes. Voilà toutes mes munitions.“

Extraits des assertions dangereuses et pernicieuses en tout genre que les soi-disans Jésuites ont, dans tous les tems et persévéramment soutenues, enseignées et publiées dans leurs Livres [...]. Troisième Partie, s.l. 1763-65, t.II/1, 123.

59. $\mathrm{Zu}$ diesem Aspekt der Jansenismusstreitigkeiten: Linda Timmermans: L'accès des femmes à la culture (1598-1715), Paris 1993, 663-700. Auch schon zeitgenössisch ein Topos: (F. DE LAviLlE:) Prejugés legitimes contre le Jansénisme, Köln 1686, 149f.; (J.PH. LaLlemant SJ.:) De véritable esprit des nouveaux disciples de S. Augustin, Brüssel ${ }^{2} 1709$, t.3, $153 \mathrm{ff}$. 


\section{Die Systematisierung der Scientia Media im XVII. Jahrhundert}

\section{$\$$ 1. [Definition]}

,Scientia Media' nennt die christliche Theologie dasjenige Gott beigelegte Wissen, durch welches der Allwissende Fragen des Typs Was wäre, wenn...? gewachsen ist.

$\mathrm{Zu}$ unterscheiden ist zwischen der Worterklärung und der Sacherklärung. ${ }^{1}$ Die Worterklärung von ,Scientia Media' bezieht sich auf traditionelle scholastische Einteilungsweisen des göttlichen Wissens ( $\$ \$ 20-21)$. In der Hinsicht wird selten daran gezweifelt, daß diese auf ihre Weise erschöpfend sind. Daher zählt die Scientia Media nur vereinzelt ${ }^{2}$ als drittes Einteilungsglied.

In der Sache hat der Begriff zwei Bedeutungen, eine erstintentionale und eine zweitintentionale. Erstintentional wird damit Gottes Notiz von denjenigen kontingenten Tatsachen bezeichnet, bei welchen die Notiznahme von ihnen nicht davon

1. „... per ,scientiam mediam' duo posse significari, inter se valde diversa... Alterum reale, nempe scientiam futurorum contingentium conditionalium ante ullum liberum decretum divinum praedeterminans. Alterum nominale, nempe scientiam quamdam, quae neque sit simplicis intelligentiae tantum, neque visionis tantum; neque tantum naturalis, neque tantum libera." G. Fasulo (Fasolus) SJ. († 1639): In Primam partem Summae D. Thomae commentaria Q. 14, art. 13, 501, Lyon 1623-36, t.2, p. 285b. Von einer wissenschaftstheoretischen Sonderbedeutung, nämlich als scholastischer Oberbegriff für eine Gruppe von Wissenschaften (Optik, Musik und Astronomie) zwischen Mathematik und Physik, ist hier ganz abzusehen. In dieser Bedeutung bezieht sich das ,media’ auf die aristotelischen Kategorien Quantität und Qualität.

2. Richtig B. Mastri da Meldola OFMConv. (†1673): Disputationes theologicae in Primum librum Sententiarum 3, 279, ( $\left.{ }^{1} 1655\right)$ Venedig 1731, p. 162b. Vgl. jedoch G. VÁzQUEz SJ. († 1604): Commentaria ac Disputationes in Primam partem S. Thomae 67, 27, ( $\left.{ }^{1} 1598\right)$, Opera omnia, hg. von M. Chossat, Paris 1905, t.1, p. 562 a („tertium membrum“). Zustimmend M. Becanus (VAN DER BEECK) SJ. († 1624): Summa theologiae scholasticae 1, 1, 10, 1, 5, ( $\left.{ }^{1} 1612\right)$ Rouen 1657, p. 6oa; PH. Moncé SJ. († 1619): Disputationes theologicae in aliquot selectas D. Thomae quaestiones 3 , 16, Paris 1622, p. 214; N. Martínez SJ. († 1676): Deus Sciens, sive de scientia Dei 2, 5, 4, München 1678, pp. 198-99; P.G. Antolne SJ. († 1743): Theologia universa: De Deo uno 5, 5, 6, $\left({ }^{1} 1723\right)$ Augsburg-Krakau 1762, t.1, p. 264a. 
abhängt, daß der Akt interveniert hat, durch den sie in der Zeitordnung zur Verwirklichung bestimmt sind. ${ }^{3}$

Die zweitintentionale Verwendungsweise abstrahiert von der Streitfrage, ob es ein solches Wissen gibt. Dann bezeichnet der Begriff eine Hypothese (die „sententia de scientia media"), ${ }^{4}$ d.h. dasjenige, das mit dem Namen Molina verknüpfte, System ${ }^{5}$ der posttridentinischen Theologie, welches dogmatisch im Zentrum der Jesuitentheologie gestanden hat.

Dieser Bedeutungsunterschied wird auch durch die Unterscheidung zwischen der ,Existenz' der Scientia Media und deren ,Unentbehrlichkeit' ausgedrückt. ${ }^{6}$ Dabei schließt die behauptete Unentbehrlichkeit manchmal das Fach Philosophie mit ein. ${ }^{7}$

\section{\$2. [Problem]}

Gott weiß alles, was der Fall ist. Gott muß aber auch auf jede hypothetische Frage die Antwort haben. Auch von etwas, das nicht der Fall ist, kann es wahr sein, daß es unter dieser oder jener Bedingung der Fall wäre. ${ }^{8}$ Daß Gott diese Antwort hat,

3. „... patet, scientiam mediam sic definiendam esse: Est notitia divina infallibilis et immediata earum veritatum contingentium, quae non petunt decretum actuale Dei." G. DE Rivadeneyra SJ. († 1675): Tractatus de scientia Dei 23, 39, Alcalá 1653, p. 515b. - „... hoc nomine , scientiae mediae’... cognitio quaedam futurorum conditionatorum certa et infallibilis, quae omne absolutum Dei decretum antecedat..."H. DE BASTIDA SJ. († 1637): Sermo de scientia media [5.11.1604-12.2.1605], hg. von L. Meyer (Pseudonym: Theodorus Eleutherius) SJ. († 1730): Historiae Controversiarum de Divinae Gratiae auxiliis 5, 43-51, Antwerpen 1705, pp. 489-529, hier p. 49ob. Ein Experte, über den das Spottwort kursierte (G. DE Henao SJ. [ $†$ 1704]: Scientia media theologice defensata $\$ 1850$, Lyon 1674-76, t.1, p. 420a) „Videtur Bastida nihil nisi Scientiam Mediam et Auxilia scire“. Weitere Definitionen bei Henao, Scientia media theologice $\$ 1493$, t.1, p. 342b; F. Aranda SJ. († 1695): Schola Scientiae Mediae 5, 137, Saragossa 1693, p. 354b; J. DE UlloA SJ. († 1723): Theologia scholastica 1, 3, 23, Augsburg-Graz 1719, t.1, p. $99 \mathrm{~b}$.

4. P. De Ledesma OP. (†1616): Tractatus de divinae gratiae auxiliis: Difficultas de scientia Dei, Salamanca 1611, p. $580 a D$. Der Text ist von 1601.

5. „... le système de la Science moyenne... “G. DANIEL SJ. († 1728): Remonstrance à Monseigneur l'archevêque de Reims sur son Ordonnance du quinzième de Juillet 1697, in: Recueil de divers ouvrages, Paris 1724, t.3, p. 433; Lettres au R.P. Alexandre, ou se fait le parallèle de la Doctrine des Thomistes avec celle des Jésuites, s.l. 1698, p. 98.

6. „Aliud est usus, aliud existentia scientiae mediae." UlloA, Theol. 1, 3, 149, t.1, p. 153b.

7. F. SoAres SJ. († 1659): Cursus philosophicus: De anima 5, 3, 171, Coimbra 1651, t.3, p. 266a.

8. „Et de rebus nunquam futuris dici potest ,Existerent, si haec vel illa conditio poneretur'، R. DE Arriaga SJ. († 1667): Cursus philosophicus: Logica 14, 132, Lyon 1669, p. 246a. Ohne das (ebd. 14, 134, p. 246b) kein Begriff der Gefahr. 
ist common sense. ${ }^{9}$ In der Konkurrenz mit den heidnischen Orakeln sichert die Scientia Media-Hypothese also die Überlegenheit des Monotheismus. ${ }^{10}$ In bezug auf die kausaldeterminierten Naturvorgänge ${ }^{11}$ besteht hier theologisch kein Problem. Auch die sublunarische Welt (Meteorologie) meldet sich nicht einmal von fern als ein möglicher Einwand dagegen, daß die Verwaltung des Kosmos an Gottes Wissenshaushalt nicht viel größere Ansprüche stellt als der Bereich der analytischen Wahrheiten. Das Problem liegt darin, daß, um jedem Was wäre, wenn...? gewachsen zu sein, der Allwissende den,Gebrauch ${ }^{\prime 12}$ kennen muß, der unter jeder erdenklichen Hypothese vom freien Willen gemacht sein würde. „Wenn Peter jetzt hier wäre, täte er das. ${ }^{\text {"13 }}$ Dieses Wissen könnte auf Gottes Anordnung beruhen. Der Gedanke, daß es das tut, liegt bei etlichen der biblischen Orakel auch nahe. ${ }^{14}$

9. „... communis hominum sensus...“ BASTIDA, [De scientia media] pp. 494b. 501a (unter Berufung auf ein geflügeltes Wort von Luis de León OSA.).

10. L. Lessius SJ. († 1623): De gratia efficaci, decretis divinis, libertate arbitrii et praescientia Dei conditionata, Disputatio apologetica 19, 12, Antwerpen 1610, pp. 223-24; G. Pennotto CR.: Propugnaculum humanae libertatis 3, 29, 10, Lyon 1624, p. 166b; B. Aldrete SJ. († 1657): Commentaria ac Disputationes in Primam partem D. Thomae 27, 2, 17, Lyon 1662, t.1, p. 396a; ebd. 27, 5, 18, t.1, p. 407a; T. GonzÁlez de SANTAlla SJ. († 1705): Selectae disputationes ex universa theologia scholastica: In Primam partem 14, 24, Salamanca 168o-86, t.1, p. 223b; ArAndA, Schola Scientiae Mediae 5, 27, p. 328a; A. Cienfuegos SJ. († 1739): Aenigma Theologicum 12, 2, 11-19, Wien 1717, t.2, pp. 418b-24a. Verspottet von Henricus a S. Ignatio OC. († 1719): Theologia Veterum fundamentalis 8, 726, Lüttich 1677, t.1, p. 544b.

11. Zur „scientia de futuris conditionatis necessariis“: S. IzQUIERDo SJ. ( $†$ 1681): Opus theologicum iuxta atque philosophicum de Deo uno 28, 87-105, Rom 1664-70, t.2, pp. 109-13; J. Saguens O. Minim. († 1718): De perfectionibus divinis opus theologicum 2, 1, 5, 8-40, Köln 1718, t.2, pp. 82-93.

12. „Praescientia usus liberi arbitrii“: L. Molina SJ. (†160o): Liberi arbitrii cum gratiae donis, divina praescientia, providentia, praedestinatione et reprobatione Concordia Q. 23 art. 4-5, 1, 11, 33, hg. von J. Rabeneck, Oña-Madrid 1953, p. 557; F. SuÁrez SJ. († 1617): Un tratado inédito sobre la Ciencia Media (1585/86) \$64, hg. von S. Gonzalez Rivas, Miscelanea Comillas 9 (1948) pp. 59-132, hier p. 124; Varia opuscula theologica $\left({ }^{1} 1599\right)$ 2, 1, 6, 12, Opera omnia, Paris 1856-78, t.11, p. 317b. Die Formel stammt vermutlich aus der Pariser Theologie des 14. Jahrhunderts (Thomas Wylton, Thomas von Straßburg). Vgl. Chris Schabel: Pierre Ceffons et le déterminisme radical au temps de la peste noire, Paris 2019, pp. 174. 181.

13. „Si Petrus hic nunc adesset, hoc faceret.“ SuÁrez, Varia opusc. theol., t.11, p. 343a. - „Deus non solum cognoscit futura contingentia de facto futura, sed etiam cognoscit quid unaquaeque voluntas esset operatura seu volitura, si cum iis vel illis conditionibus applicaretur ad operandum, etsi de facto applicanda non sit, nec sit illud operatura." SuÁrez, Tratado inédito $\$ 17$, p. 91.

14. D. Alarcón SJ. († 1634): Prima pars theologiae scholasticae 2, 4, 10, 6-11, Lyon 1633, pp. 148b-49b. - „... an seinem (sc. Gottes) Schluß hängt nicht allein die Wahrheit der Dinge, die geschehen sollen, sondern auch selbst der Dinge, die nicht geschehen sollen, aber doch unter dieser oder jener Condition geschehen seyn würden; ob sie schon zu keinem wahrhafftigen 
Trotzdem schließt die Scientia Media-Hypothese einen Rekurs auf Vicos Axiom Verum et factum convertuntur aus. Bezogen auf ein Kondizionalgefüge $p / q$ soll die Wahrheit darüber kein Machtspruch sein.

\section{\$3. [Voraussetzungen]}

Die Einführung der Scientia Media in Gottes Wissenshaushalt hat Vorurteile in bezug auf die Form von Gottes Wissen zu überwinden gehabt. Die Einbeziehung der hypothetischen Form trifft auf Hemmungen aus der monotheistischen Anthropomorphismuskritik. Es fällt nicht leicht, sich Gott als Hypothesenschmied zu denken. ${ }^{15}$ Während die Scientia Media in diesem Punkt in der christlichen Theologie des 17. Jahrhunderts jedoch kaum noch auf Widerstand gestoßen ist ${ }^{16}$ und besonders die Jesuiten dazu provokante Thesen vertreten haben, ${ }^{17}$ war ein anderes Vorurteil zäher: Gottes Vorherwissen gebe es grammatisch nur im Indikativ. Im Spektrum der Ordensschulen wurde das von dem konservativen Flügel der Benediktinertheologie behauptet. ${ }^{18}$ Dann würde das Vorherwissen sich in

Effect und Werck kommen, dieweil die Condition, an welcher sie hangen, nicht gestellet wird.“ F. Burman († 1679): Alle Biblische Wercke, Frankfurt-Leipzig 1709, S. 86ob.

15. „Sed dicere scientiam Dei ,conditionatam', dicit imperfectionem. Iam enim divinus intellectus non esset perfectissimus, si dependeret ab aliquo alio in sua cognitione, innitendo videlicet conditioni.“ J. EcK († 1543): Chrysopassus 4, 45, Augsburg 1514, fol. M5r. - „Scientia Dei media... et ,conditionata' scientia nominatur, non subiective quidem, et quasi conditio, a qua denominatur ita, (suppl.: ut) afficiat Deum eiusque... scientiam, sed obiective et per extrinsecam denominationem, quia terminatur ad futura conditionata." J.P. Hebenstreit ( $\dagger 1718$ ): Theologia naturalis 15, 13, 7, Jena ${ }^{2} 1696$, p. 634. - „... res ,conditionate’ cognoscibiles non sunt nisi per ordinem ad nostrum intellectum, et prout de illis potest formare propositiones conditionatas." (C. TIPHAINE SJ. [† 1641]:) De ordine deque priori et posteriori 25, 9, Reims 1640, p. 156. Der wichtigste Kritiker der Scientia Media-Hypothese aus der Gesellschaft Jesu.

16. „Qui... scientiam conditionalium huiusmodi negaverit, contra torrentem doctorum huius temporis niteret.“ L. SANTI (SANCTIUS) SJ. († 1651/52): An Societatis nostrae magistri docere publice possint ac propositis conclusionibus defendere, scientiam, quam ,mediam' vocant, in Deo non dari, hg. von X.-M. LE BACHelet SJ.: Prédestination et grâce efficace. Controverses dans la Compagnie de Jésus au temps d'Aquaviva (1610-1613) doc. 149, Louvain 1931, t.2, p. 376.

17. „Hic actus scientiae conditionatae existit in Deo: ,Si ego essem, ego crearem mundum.“

D. Granado SJ. (†1632): Commentarii in Summam Theologiae D. Thomae: In Primam partem 2, 5, 4, 6, Sevilla 1623, t.1, p. 262a. - „Hypotheses impossibiles nequit facere Deus..., at bene possibiles hypotheses.“ A. Bernaldo DE Quirós SJ. († 1668): Selectae disputationes theologicae de praedestinatione 9, 69, Lyon 1658, p. 69a.

18. „... Authores utriusque scholae supponunt, dari futura, conditionata', et ex hac suppositione falsa nascitur tota difficultatis occasio.“D. DE Silva y Pacheco OSB. († 1677): Commentaria theologica in Primam partem D. Thomae Q. 14 art. 13, 12, 40, Madrid 1663-65, t.2, p. 398b. 
dem Wissen um den faktischen Weltlauf erschöpfen. Daß es sich für die ältere katholische Tradition darin erschöpft hat, wird auf dem Standpunkt der Scientia Media-Hypothese bezweifelt. ${ }^{19}$

Entstanden ist die Scientia Media-Hypothese aus der erst spätmittelalterlichen Rehabilitierung des Satzes des Origenes, ${ }^{20}$ daß etwas nicht darum ,zukünftig' ist, weil es von Gott vorhergewußt ist, sondern, vorhergewußt' ist etwas, weil es zukünftig ist. ${ }^{21}$ Das so gefaßte Abhängigkeitsverhältnis abstrahiert von Gottes Willen. ${ }^{22}$ Die Scientia Media-Hypothese überbietet das noch durch die Annahme, auch von

19. SuÁrez, Varia opusc. theol. 2, 2, 3, 5, t.11, p. 353b; Aldrete, In Primam partem 26, 2, 6, t.1, p. $358 \mathrm{~b}$.

20. Origenes: Comment. in Epist. ad Rom. PG (Migne) 14, 1126. Zur Tradition: Henao, Scientia media theologice $\$ \$ 4598-605$, t.2, pp. 373-76.

21. „... non quia cognoscit aliquid esse futurum, ideo illud futurum, sed e contrario, quia illud futurum est ex suis causis, ideo (sc. Deum) cognoscere illud esse futurum. "Molina, Concordia Q. 14 art. 13, 52, 19, p. 347, und öfter. - „Non quia Deus praescit futura, idcirco illa futura esse: sed contra, quia illa futura sunt, idcirco Deum ea praescire. “P. DA FonsecA SJ. († 1596): Commentaria in Metaphysicorum libros 6, 2, 4, 11, ( $\left.{ }^{1} 1604\right)$ Köln 1615, t.3, p. 131bC. - „Fatemur futura ideo praesciri, quia futura sunt, non e contrario; et eodem modo de iis conditionatis dicimus, ideo cognosci quod futura essent, quia re vera ita futura essent, non e contrario." SuÁrez, Tratado inédito $\$ 67$, p. 127; Varia opusc. theol. 2, 1, 5, 7, t.11, pp. 310a-11a; Tractatus de gratia Dei Prol. 2, 10, 25, t.7, pp. 124-26. - „Eo quod res futura est, a Deo cognoscitur, non eo quod cognoscitur, futura est.“ VÁzQuez, In Primam partem 68, 24, t.1, 571a. - Ebenso L. Lessius: Responsio ad Antapologiam Ven. Facultatis S. Theologiae Universitatis Lovaniensis (1588) cap. 10, hg. von G. SchneEMAnN SJ.: Controversiarum de divinae gratiae liberique arbitrii concordia initia et progressus, Freiburg i. Br. 1881, pp. 369-462, hier pp. 419-21; BeCAnUs, Summa Theol. schol. 1, 1, 10, 12, 4, p. 68a. - „Est haec assertio universae Societatis contra Patres Dominicanos. Quare Authores referre, supervacaneum puto.“ A. Perez SJ. († 1649): In Primam partem D. Thomae Opus posthumum: De scientia Dei 6, 74, Rom 1656, p. 197b. - Aus kritischer Sicht bestätigt von F. Zumel OM. († 1607): In Primam D. Thomae partem commentaria Q. 14, 1, Salamanca 1590, t.1, pp. 364b/65a; B. NAvarrete OP.: Controversiae in D. Thomae eiusque scholae defensionem 32, 4, Valladolid 1605-09, t.2, p. 693b; T. DE Lemos OP. († 1629): Panoplia Gratiae 1, 5, 13, Liège 1676, t.1, p. 233 b („unum fundamentum... illius mediae scientiae"); IoAnnes a S. Thoma OP. († 1644): Cursus theologicus: In Primam partem D. Thomae 20, 4, 26, Paris-Tournai-Rom 1934, t.2, p. 489b; J. Lalemandet O. Minim. († 1647): Cursus theologicus: De Deo uno 8, 83, Lyon 1656, t.1, p. 277 a.

22. „Si per impossibile Deus non esset volens, esset autem intelligens, sicut est, et futura essent futura, adhuc Deus propter excellentiam suae intelligentiae nosset quaecumque futura... Non ideo res sunt futurae, quia Deus praescit illas esse futuras... Quia res futurae sunt, et Dei scientiam nihil potest latere, ideo praescit Deus illas esse futuras, et sic puto, quod intellexerit Origenes." Gregor von Rimini OSA. († 1358): In Primum Sententiarum, Venedig 1522, fol. 152vM. 155vN/156rA. Vgl. A. DE Mendoza OSA. († 1596): Quaestiones quodlibeticae 7, 6, Salamanca 1588, p. 538; Aldrete, In Primam partem 28, 5, 7, t.1, p. 438b; Henao, Scientia media theologice $\$ 5019$, t.2, p. 469b; A. HöFlER OSA. († 1713): Sapientia et providentia Dei in gubernanda republica humana, München 1685, p. 40. 
dem Vorherwissen selbst, ja von der Scientia Media, wäre Abstraktion möglich. ${ }^{23}$ Dadurch läßt sich das Vorherwissen in einer bestimmten Beziehung: gegenständlich („obiective“), von außen bestimmt denken. ${ }^{24}$ Das ist skandalös. ${ }^{25}$ Nur wenn das Vorherwissen so rigoros kontemplativ gefaßt wird, ist es aber ohne den Rekurs auf das Willensregime möglich, den fraglichen Aussagenbereich in Gottes Wissenshaushalt aufzunehmen. Sonst ist er kein möglicher Wissensgegenstand, auch nicht aus der Perspektive der Allwissenheit. ${ }^{26}$

\section{$\$ 4$. [These]}

Die ,hypothetische' Ansetzung eines $p$ hat auch im Wissenshaushalt des Allwissenden ihren Platz. Gott urteilt in der Form ,Wenn $p$, dann $q{ }^{\text {'. }}{ }^{27}$

23. „... ac si in Deo nulla esset praescientia circa eventus futuros“ Molina, Concordia Q.14 art. $13,52,29$, p. 350 et passim. - „... etsi per impossibile, nulla esset in Deo contingentium futurorum praescientia..." Fonseca, In Metaph. 6, 2, 4, 11, t.3, p. 131bA. Vgl. S. Mauro SJ. († 1687): Opus theologicum 1, 85, 8, Rom 1687, t.1, pp. 251b/52a.

24. „Praescientiae tota ratio infallibilitatis est certa futuritio contingentis, non quidem causaliter, sed obiective." Thomas Waldensis OC. († 1430): Doctrinale antiquitatum fidei catholicae Ecclesiae, Venedig 1757, col. 144C (zitiert von Henao, Scientia media theologice $\$ 5185$, t.2, p. 497a). „Haec praescientia non determinat libertatem, sed ab ipsa potius (ut ita dicam) obiective determinatur." F. Diotallevi (†1620): De Concursu Dei ad actus liberos voluntatis creatae, ac De scientia quam Deus habet de contingentibus sub conditione futuris prius ratione quam libere quidquam decernat, Opuscula theologica, Lyon 1611, p. 248. Vgl. SuÁrez, Varia opusc. theol. 2, 1, 5, 10, t.11, p. $311 b$.

25. „Facit haec scientia intellectum Dei pendere ab obiecto externo... creaturamque hic non dependere a Deo..., sed Deum dependere a creaturis tamquam suo exemplari. Quae omnino absurdissima sunt... “G. voet $(\dagger 1676)$ \& M. Nethen ( $† 1686)$ : De conditionata seu media in Deo scientia $\$ 26$, in G. VoET: Selectae disputationes theologicae, Utrecht 1648-67, t.1, pp. 264-339, hier p. 326.

26. „... potest Deus per coniecturas aliquo modo cognoscere, quid causa libera faceret, si in tali occasione cum istis, vel illis conditionibus constitueretur; non tamen potest certa et infallibili scientia id cognoscere, atque adeo potest quidem Deus iudicare quid foret verosimilius, vel probabilius in tali eventu, non tamen potest definitum iudicium ferre." LEDESMA, De auxiliis, p. 579bA/D. - „Dico..., ea (sc. futura sub conditione) ... nonnisi tamquam probabilia perspici.“ G. Gibieuf OF. († 1650): De libertate Dei et creaturae, Paris 1630, pp. 154-56.

27. Izquierdo, De Deo uno 28, 2, t.2, p. 92b. - „'Scientia media' est, qua Deus novit res futuras sub conditione, quae numquam ponetur.“ J. BoudarT ( $\dagger 1702$ ): Manuale theologicum 1, 25, Tournai ${ }^{4} 1710$, t.1, p. 15 b. 
Gott muß nicht alles entscheiden, aber alles wissen. ${ }^{28}$ Über die Wahrheit jedes Kondizionalgefüges hat Gott nicht die Macht, ${ }^{29}$ aber kennen muß Er sie. Der durch die Scientia Media erfüllte Informationszweck übersteigt die Faktizität. ${ }^{30}$ Es ist ein Tatsachenwissen eigener Art, ${ }^{31}$ dasjenige im Konjunktiv, ${ }^{32}$ auch in der Vergangenheitsform..$^{33}$ Sein Stoffgebiet sind die Fälle von freier Willensbetätigung, ${ }^{34}$ sowohl

28. R. de Arriaga: Disputationes theologicae in Primam partem D. Thomae 25, 18, Antwerpen 1643, t.1, p. 256a; González de Santalla, In Primam partem 36, 6, 26, t.1, p. 521b; V. Ramirez SJ. (†1721): Tractatus de scientia Dei 17, 151, Madrid 1708, t.2, p. 163b. - Anders z.B. MASTRI DA Meldola, In I Sent. 3, 244, p. 155b; Gabriele di SAN Vincenzo OCD. († 1671): In universam Primam partem Summae Angelicae 14, 254, Rom 1664, p. 264 b.

29. „Potestne Deus per suam infinitam et efficacissimam voluntatem impedire hanc veritatem conditionalem ,Si Petro detur auxilium A, dissentiet'? Certe non potest, iuxta omnes Auctores Societatis." Martínez, Deus Sciens 4, 6, 2, p. 747.

30. „Scientia stricte media ex proprio munere destinata est, ut informet intellectum divinum de operatione libera creaturae sub hypothesi.“ Ramirez, De scientia Dei 23, 28, t.2, p. 391b. - „... ut aliquid cognoscatur determinate, non est necesse, ut sit de facto.“ A. MADERNI CRSP. († 1685): Cursus theologicus 1, 4, 16, 10, t.1, Rom 1671-75, t.1, p. 193 b.

31. „Suppono tamquam certum... in Deo esse praescientiam seu scientiam omnium conditionalium liberarum... Idque... scit..., quia de facto creatura... se ad hoc flecteret et determinaret.“ Lessius, Resp. ad Antapologiam cap. 2, p. 391. - „... scientia qua Deus cognoscit praedicata contingentia, quae de facto convenirent subiecto, si in talibus vel talibus circumstantiis poneretur..." P. Luis SJ. hg. von K. ReInHARDT: Pedro Luis SJ (1538-1602) und sein Verständnis der Kontingenz, Praescienz und Prädestination, Münster i.W. 1965, S. 131. Vgl. BAstida, [De scientia media] p. 491b; D. RuIz De Montoya SJ. († 1632): Commentarii ac Disputationes de scientia, de ideis, de veritate, ac de vita Dei 68, 2, 1, Paris 1629, p. 678a.

32. „... modus cognoscendi modo subiunctivo...“ A. Perez, Opus posth.: De intelligentia Dei 6, 112, p. 205a. Vgl. Ruiz de Montoya, De scientia Dei 68, 9, 15-16, p. 691 b.

33. "Scientia media non solum ad futura conditionata terminatur, sed etiam ad praesentia, et praeterita conditionata. “ MANUEL DE LA CONCEPCIón O.SS.T. (†1701): Tractatus de inscrutabili scientia Dei 5, 273, Bayonne 1698, p. 541. Vgl. FonsecA, In Metaph. 6, 2, 4, 9, t.3, pp. 122b/23a; Arriaga, In Primam partem 21, 2, t.1, p. 215a; Aldrete, In Primam partem 27, 1, 13, t.1, p. 392b; A. Bernaldo De Quirós: Selectae Disputationes de Deo 51, 2, Lyon 1654, p. 345b; Ders.: Opus philosophicum 99, 29, Lyon 1666, p. 692b; Henao, Scientia media theologice $\$$ 3, t.1, p. 34a/b; Ramirez, De scientia Dei 16, 10, t.2, p. 6oa. Ein Beispiel für die Alleinzulässigkeit des Irrealis der Vergangenheit bei G. DE Rhodes SJ. ( $†$ 1661): Disputationes Theologiae scholasticae 1, 3, 4, 3, 1, Lyon 1661, t.1, p. 102a.

34. „Quotquot exercitia libertatis creatae unquam fuerunt, sunt, aut erunt, praenoscuntur a Deo conditionate per scientiam mediam." J. DE UlloA: De anima 3, 2, 27, Rom 1715, p. 320. 
profane als auch heilsrelevante, ${ }^{35}$ sein Gegenstand ist das kontingente Ereignis als solches, ${ }^{36}$ auch in der Fehlanzeige. ${ }^{37}$

Grundlegend ist die Unterscheidung zwischen dem kategorisch (oder ,absolut') und dem hypothetisch (oder, bedingt') Freizukünftigen. Von Fonseca stammt die Unterscheidung der zwei Betrachtungsweisen desselben Seesiegs bei Lepanto, dem ,status conditionatus' und dem ,status absolutus'. ${ }^{38}$ Dieser impliziert jenen, wenn auch nicht einen bestimmten. ${ }^{39}$ Für einen auf das Kontrafaktische verengten Begriff des Freizukünftigen ${ }^{40}$ bürgert sich im Lauf des 17. Jahrhunderts ${ }^{41}$ der Ausdruck, Futuribilien' ein..$^{42}$ Zur Bezeichnung des Gegenstandes der Scientia Media übernimmt die Jesuitenscholastik diesen, von ihr importierten, Ausdruck aber nur unter der

35. UlloA, Theol. 1, 3, 26, t.1, p. 100 .

36. „... scientia de effectu contingente, ut contingens est et vere liber... “F. SuÁrez: Tractatus de Deo uno et trino: De praedest. 1, 7, 8, t.1, p. 255b. Vgl. Aranda, Schola Scientiae Mediae 5, 142, p. 355 b.

37. „Deus iudicat per scientiam mediam, rem conditionate futuram, vel non.“ A. MAYr SJ. († 1749): Theologia scholastica 1, 389, Ingolstadt 1732, t.1, p. 306. Vgl. Ledesma, De auxiliis, p. 573bA; I. Der-Kennis SJ. († 1656): De Deo uno 8, 58, Bruxelles 1655, p. 177; Martínez, Deus Sciens 4, 3, 3, p. 628; A. Erath CRA. († 1719): Conciliatio Praedeterminationis Physicae... cum Scientia Media $\$ 189$, Augsburg 1689, p. 66.

38. FonsecA, In Metaph. 6, 2, 4, 7, t.3, p. 116aE; ebd. 6, 2, 4, 8, t.3, p. 119aB/C. Vgl. V. Herice SJ. († 1626): Quatuor tractatus in Primam partem S. Thomae 7, 4, Pamplona 1623, p. 129a; RuIZ DE Montoya, De scientia Dei 61, 1, 4, p. 568b; P. Hurtado de Mendoza SJ. († 1641): Disputationes de Deo Homine 13, 320, Antwerpen 1634, t.1, p. 174b.

39. Hurtado de Mendoza, De Deo Homine 13, 85, t.1, p. 143b; Aldrete, In Primam partem 31, 6, 7, t.1, 629a. - „Cuilibet... eventui absoluto correspondent varii status conditionati, sub quibus etiam esset, si tales conditiones ponerentur.“ T. MuniesA SJ. († 1696): Disputationes scholasticae de providentia Dei 9, 53, Saragossa 1700, p. 217a.

40. Molina, Concordia Q. 14 art. 13, 53, 1, 5, p. 360; Zumel, In Primam partem Q. 14 art. 13, 8, Venedig ${ }^{2} 1597$, p. 353b; P. DE CABRERA († 1616): In Tertiam partem S. Thomae commentarii et disputationes Q. 1, art. 3, $\$ \$ 338-40$, Cordoba 1602, t.1, p. 295b; Silva y Pacheco, In Primam partem Q. 14 art. 13, 11, 1-2, t.2, p. 369a/b. Anders Herice, In Primam partem 7, 5, p. 129 a.

41. Von einer bemerkenswerten, aber etwas zweifelhaften Okkurrenz abgesehen (Molina an Lessius, Cuenca 4.7.1594, ed. Le Bachelet, Prédestination doc. 6, t.1, p. 38) findet sich in der katholischen Theologie der Ausdruck erst bei F. Bonae Spei (Crespin) OC. († 1677): Commentarii tres in Universam Theologiam Scholasticam 11, 7, Antwerpen 1662, t.1, p. 112 b.

42. „Nonnulli (sc. scientiae mediae obiectum) ad sola futuribilia sub conditione (licet revera nunquam futura sint) restringunt, quidam etiam ad omnia futura sub conditione... ampliant." J.A. Schertzer ( $\dagger 1683$ ): Ad Salvatoris oraculum Vae tibi Chorazin etc. exercitatio theologica $\$ 72$, Leipzig ${ }^{1}$ 1666. Vgl. J.A. QuenstedT (†1688): Theologia didactico-polemica 1, 8, 7, Wittenberg 1691, t.1, p. 315b. 
Bedingung, daß er nicht auf diese Bedeutung verengt wird. ${ }^{43}$ Nur in der weiteren Bedeutung ${ }^{44}$ ersetzt er den sperrigen und auch weiterhin üblichen Ausdruck, futura contingentia conditionata'.

Normalerweise ist $p$ eine typmäßig bestimmte Situation und $q$ ein Ereignis des Typs Entscheidung oder eine äußere Handlung, ${ }^{45}$ nicht: eine kontingente Folge davon. Welchen Gewinn ich erzielen würde, wenn ich jetzt verkaufte, ist auch mir bekannt. Das Hauptmotiv, um $q$ doch manchmal dafür zu öffnen, ${ }^{46}$ ist die Einkalkulierbarkeit der demographischen Folgen bestimmter Handlungen. ${ }^{47}$

Gottes hypothetische Urteile haben immer nur individuelle Tatsachen zum Gegenstand. ${ }^{48}$ Daher impliziert die Scientia Media eine vollständige Fallspezifikation. ${ }^{49}$

43. „Futuribile est id, quod futurum esset, si futura esset aliqua conditio... Duplex est... Futuribile tantum est illud, quod aliquando esset, si esset aliqua conditio, sed nunquam erit, quia nunquam erit illa conditio... Futuribile simul et futurum est illud, de quo verum est dicere ,esset', si esset talis conditio, et reipsa erit, quia erit talis conditio."Antorne, De Deo uno 5, 5, 1, p. 248b. Vgl. E. Simonnet SJ. († 1732): Institutiones theologicae, Nancy 1721, t.1, p. 238.

44. J.W. JÄGER († 1720): Systema theologicum, Tübingen 1715, p. 76. - „Quae... esset utilitas scientiae mediae, si solum ad actus numquam futuros poneretur?“ A. DE PERALTA SJ. († 1736): Dissertationes scholasticae de divina scientia media 1, 1, Antwerpen ${ }^{2} 1734$, p. 6.

45. „... scientia media, qua cognoscit quid in quavis rerum coniugatione quaevis voluntas creata electura, volitura et factura sit..." G. RAGUSA SJ. († 1624): Commentaria ac Disputationes in Tertiam partem D. Thomae 30, 5, Lyon 1619, col. 270B. - „... ipsa electio est eventus, qui conditionate praevidetur.“ ARANDA, Schola Scientiae Mediae 5, 222, p. 371b. - „... scientia media debet habere ex parte conditionati aliquem actum subiective liberum respectu voluntatis, cuius est actus.“ $\mathrm{B}$. DE VARGas SJ. († 1752): Cursus theologicus: De Deo sciente 4, 2, 12, Granada 1751, t.2, p. 509.

46. G. Agostini SJ. († 1643): Commentarii in Primam partem Summae S. Thomae Q. 14 art. 13, $\$ 136$, Palermo 1639-43, t.2, p. 113a; P. WAdDING SJ. († 1644): Tractatus de Incarnatione 3, 27, Antwerpen 1636, p. 97; GonZÁlez de Santalla, In Primam partem 14, 6, t.1, p. 219 b.

47. Molina, Concordia Q. 14 art. 13, 53, 2, 15, p. 374; Hurtado de Mendoza, De Deo Homine 13, $82-85$, t.1, pp. 142 b/43a.

48. „Scientia media contemplatur diversos eventus liberos singulares pendentes ex conditionibus diversis singularibus.“ Hurtado de Mendoza, De Deo Homine 13, 119, t.1, p. 149b. - „Veritas... pertinens obiective ad scientiam mediam et per eam formaliter adstructa, est semper singularis." A. Junius (Young) SJ. ( $†$ 1679): De providentia et praedestinatione meditationes scholasticae 11, 7, 7, Lyon 1678, p. 33ob. Vgl. A. TANner SJ. († 1632): Universa theologia scholastica 2, 8, 5, 21, Ingolstadt 1626-27, t.1, col. 457 .

49. „... distinctissime praevidens omnes hos actus in specie et in individuo, quos haec voluntas humana in hoc momento cum hoc obiecto aliisque circumstantiis efficere potest... "SUÁrEZ, Varia opusc. theol. 1, 1, 15, 3, t.11, 77a. 
Das Kondizionalgefüge $p / q$ steht für eine transfinite Klasse..$^{50}$ Diese zerfällt im Ergebnis in zwei Teilklassen, in die mit dem Ergebnis A und in die mit non A. ${ }^{51} \mathrm{Ob}$ und inwiefern es ausgeschlossen ist, daß eine Teilklasse leer bleibt, veranlaßt ausführliche Erörterungen..$^{2}$

\section{\$5. [Mögliche Welten]}

Diese Lösung stattet den Schöpfer mit einem kontemplativen Wissen um eine kombinatorische Unendlichkeit aus. ${ }^{53}$ Wenn der Schöpfer Serien durchmustert und Ihm

50. „... per scientiam mediam videt in particulari, quid in omni casu possibili facturus esset... Lucifer...“"Mauro, Opus theol. 1, 46, 24, t.1, p. 154b. - „... semper verum erit dicere: Si Petrus poneretur in his circumstantiis, hoc erit; si in aliis, erit hoc aliud; et sic de singulis, nulla excepta..." Agostini, In Primam partem Q. 14 art. 13, $\$ 140$, t.2, p. 114b. - „... scientia media ut talis... habet pro hypothesi singularem libertatem totam et solam. “ Junius, De provid. 11, 5, 1, p. 322b. - „... ,casus vocationis... debet sumi singulariter, ut sensus sit , hic casus vocationis etc.'“ MAYR, Theol. 1, 390, p. 306. - „... possibiles sunt infinitae conditiones categorematice, sub quibus potest simultate potentiae poni et constitui quaelibet libertas et... conditionari ad aliquid faciendum, vel non." G.B. Tolomei (Ptolemaeus) SJ. († 1726): Philosophia mentis et sensuum: Theol. nat. 6, 4, 18, 4, Augsburg-Dillingen 1698, p. 734a.

51. „... actus scientiae mediae sunt infiniti, uni affirmativi quoad conditionatum, alii negativi.“ UlloA, Theol. 1, 3, 29, t.1, p. 102a. - „Certum est in auxiliorum possibilium cumulo infinities infinita contineri... Separemus ergo ex auxiliorum possibilium infinitissimo cumulo aliquod infinitum, relinquendo alia infinita. Vel, si mavis, cum certum sit Deum mente discernere, quae auxilia efficacia, quae inefficacia forent, si conferrentur: loquamur de cumulo auxiliorum efficacium, quem cumulum appellemus cumulum $A$ ad distinctionem cumuli auxiliorum, quae Deus inefficacia praevidet, quem appellabimus cumulum B..." A. DE Herrera SJ. († 1684): Tractatus de praedestinatione sanctorum 16, 17, Alcalá 1671, p. 401.

52. „Communiter... supponunt Jesuitae istum casum esse ,moraliter' impossibilem, et totam controversiam in eo esse sitam existimant, an saltim ,metaphysice' sit possibilis." MANUEL DE LA Concepción, De scientia Dei 5, 156, p. 439. - „Est impossibile saltem moraliter..., ut Deus per scientiam mediam non videat in tota collectione auxiliorum aliqua fore efficacia, aliqua inefficacia, pro quocunque puro homine, pro quocunque actu, pro quocunque momento et loco." J. Morawski SJ. († 170o): Quaestiones theologicae selectae ad totam Summam D. Thomae. Ad Primam partem, Kalisch 1681, p. 63. - „An sit possibilis creatura omnibus auxiliis indifferentibus consensura, et creatura omnibus dissensura?" J. MARÍn SJ. († 1725): Theologia speculativa et moralis 8,3 , Venedig 1720, t.1, pp. 516b-32b.

53. „... per... mediam scientiam agnovit (sc. Deus), quid futurum esset... ex hypothesi quod hunc vel illum ordinem rerum eligeret, ex infinities infinitis quos condere poterat." Molina an Lessius, Lissabon 9.10.1590, ed. Le BACHelet, Prédestination doc. 5, t.1, p. 31. - „In obiecto scientiae mediae, ut Molina dedit, amplectuntur infinitae combinationes, in quibus humana voluntas potest collocari... Ita ut haec scientia non videatur absimilis arti et scientiae Lullianae..."A. GonzÁlez de Rosende CRM. (†1681): Disputationes theologicae 3, 5, 59. 75, Lyon 1677, 
die Wahl zwischen verschiedenen möglichen Welten beigelegt wird, ${ }^{54}$ dann hat sich damit die scholastische Streitfrage, ob der Allmächtige auch Macht über die Vergangenheit hat, in dem Sinn, in welchem sie früher diskutiert worden ist, erledigt. ${ }^{55}$ Die Popularisierung der Scientia Media-Hypothese ist nicht davon zu trennen, daß sich unter ,Scientia Media’ der Browser solcher komplexer Möglichkeiten vorgestellt wird. Bei KANT ist sie auf die „Einsicht bloss möglicher Welten " ${ }^{\text {“6 }}$ sogar geschrumpft. Nun ist in mancher Hinsicht die modale Differenz $(\$ 21)$ zwischen dem Möglichen und dem bedingt Zukünftigen vernachlässigbar, ${ }^{57}$ semantisch besteht jedoch ein Unterschied. ${ }^{58}$

Klassisch bezieht sich der Ausdruck ,mögliche Welten' in der Regel auch gerade nicht auf die Scientia Media-Szenarien. Um auf diese Bezug zu nehmen, wird sich anders ausgedrückt. ${ }^{59}$ Die Scientia Media informiert darüber, was in jeder der möglichen Welten, die hätten erschaffen werden können, die als solche aber in Gottes Wissenshaushalt der Gegenstand eines von ihr zu unterscheidenden Wissenstyps sind, die in diesen Welten jeweils erschaffenen Vernunftwesen (Engel und

pp. 379a. 385b. - Vgl. Molina, Concordia Q. 14 art. 13, 53, 3, 11, p. 390; Lessius, De praescientia Dei cond. 20, 3, p. 231; Aranda, Schola Scientiae Mediae 4, 206, p. 291a; SAguens, De perfectionibus divinis $2,1,5,1$, t.2, p. 80 .

54. „Prius ratione, imo et prius duratione, quam Deus produxerit hunc mundum, venerunt ipsi in mentem omnes mundi possibiles. “L. Bereur De Dôle OFMCap. (†1636): Disputatio quadripartita de modo coniunctionis concursuum Dei et creaturae 2, 12, 3, Lyon 1634, p. 180. Vgl. MolinA, Concordia Q. 23 art. 4-5, 1, 8, 15, p. 516.

55. „... licet potuerit Deus pro sua libertate non condere hunc rerum ordinem, tamen ex suppositione, quod illum condidit, non potuit facere nisi illa eadem quae per scientiam mediam facta invenit in illo obiective." Gabriele di San Vincenzo, In Primam partem 14, 294, p. 274a. Ein Einwand gegen die Scientia Media-Hypothese. Zur Diskussion über die Macht über die Vergangenheit in der Scholastik des 14. Jahrhunderts Schabel, Pierre Ceffons, pp. 59-93.

56. A.G. Baumgarten ( $† 1762)$ : Metaphysica $\$ 876$, Halle ${ }^{71779}$, p. 357 . Daher I. Kant $(\dagger 1804)$ : Ak.-Ausg. Bd. 17, Berlin-Leipzig 1926, S. 171.

57. „... Deus cognoverit omnes creaturas possibiles, et quid ab unaquaque, quavis conditione posita, esset futurum. Quamvis enim hae duae cognitiones non sint ratione simul, sed una virtualiter sit prior altera,... computantur, ac si essent simul.“ G. DE ConINCK SJ. ( $\uparrow 1633$ ): Disputationes theologicae de Divini Verbi Incarnatione 4, 93, Antwerpen 1645, p. 442a. Identifiziert auch bei Silva y Pacheco, In Primam partem Q. 14 art. 13, 13, 128-29, t.2, pp. 446b/47a.

58. „... futuritio ipsa conditionalis ex positione causae oriunda aliquid distinctum est a possibilitate pura.“ Alarcón, Theol. schol. 2, 4, 2, 2, p. 13ob. - „Omnes possibiles divisive possunt cognosci simul ut futurae sub conditione." ArriagA, In Primam partem 22, 11, t.1, p. 226b. Also nicht: collective.

59. Zum Beispiel B. Aldrete: Commentaria ac Disputationes in Tertiam partem S. Thomae 21, 3, 1, Lyon 1652, t.1, p. 230 („tota illa series scientiae mediae“). 
Menschen) mit ihrer Freiheit anfangen würden. ${ }^{60}$ Die ,möglichen Welten' bilden also nur die Folie für die gemeinte Erkenntnisleistung, es sind die kosmischen Schauplätze der Dramen, welche die Scientia Media aufführt. ${ }^{61}$ Erst im metaphysischen Optimismus, dem die Scientia Media-Hypothese ein Argument für die Mutmaßung liefert, daß die existente Welt auch die beste aller möglichen Welten ist, ${ }^{62}$ wird der Weltbegriff zu einer Funktion der Erkenntnisleistung der Scientia Media. ,Welt' ist seitdem eine endliche Serie freier Willensakte unter Einschluß ihrer, vom jeweiligen Indexstand abhängigen, daher sich fortlaufend ändernden, hypothetischen Zukunftspotentiale. ${ }^{63}$ Auch im Optimismus der Jesuitenscholastik, der intern übrigens kontrovers ist, ${ }^{64}$ haben die möglichen Welten jedoch nicht notwendig denselben Substanzenbestand und unterscheiden sie sich daher nicht ausschließlich durch ihre Ordnungsbeziehungen voneinander. ${ }^{65}$

Umgekehrt signalisiert ein Rekurs auf die Unendlichkeit möglicher Welten im Optimismus auch nicht immer die Übernahme der Scientia Media-Hypothese. LEIBNIZ steht zwar „dem Molinismus ungleich näher"66 als dem System der phy-

6o. „... ex infinitis hominibus et angelis et mundis possibilibus, quos Deus cognovit in sua simplici intelligentia..."SUÁrEz, Tratado inédito $₫ 60$, p. 122. - „... praevidisse non solum scientia simplicis intelligentiae infinitos mundos, quos condere poterat..., inter quos praevidit hunc, quem de facto condidit, sed etiam scientia conditionata praecognovisse, quid singulae creaturae... operaturae essent... “F. Amico SJ. ( $\uparrow 1651)$ : Cursus theologicus: De Incarnationis mysterio 7, 76, Antwerpen 1650, t.6, p. 97a. Vgl. Becanus, Summa Theol. schol. 1, 1, 10, 1, 3, p. 60 .

61. „Deus scit futura conditionata circa mundos possibiles.“ G.C. ReCUPITo SJ. († 1647): Theologia 2, 1, 28, 14, Neapel 1642, t.2, p. 149 b.

62. D. Ruiz de Montoya: Commentaria ac Disputationes in Primam partem S. Thomae: De voluntate Dei 9, 8, 3, Lyon 1630, p. 87b; G. Estrix SJ. († 1694): Diatriba theologica de sapientia Dei benefica optimi mundi architecta et gubernatrice optima $\$ 38$, Antwerpen 1672, pp. 22-23.

63. „Deus... ad decretum creandi Mundum et ponendi hanc seriem rerum directus fuisset a scientia media directa, qua ab aeterno cognoscit, quid essent facturi homines et Angeli, si ponerentur in iis circumstantiis..." Mauro, Opus theol. 1, 46, 19, t.1, p. 153b. Der Optimismus betont (Ruiz De Montoya, De volunt. 9, 1, 10, p. 73a; ebd. 10, 7, 18, p. 121a/b) seinen durchgängig temporalisierten Weltbegriff, d.h. unter Einschluß der gesamten Vergangenheit und Zukunft.

64. „Inter mundos possibiles non datur optimus omnium, sed quolibet posito posset creari melior." J. DE Lugo SJ. († 1660): Disputationes scholasticae et morales: De mysterio Incarnationis dominicae 2, 15, Paris 1868-69, t.2, p. 233a. Vgl. ebd. 2, 32, t.2, p. 238a/b. Das haben selbst Optimisten eingeräumt: IzQUiERdo, De Deo uno 32, 120, t.2, pp. 465b/66a.

65. „... supponendo possibiles esse creaturarum series et coordinationes infinitas, non solum in aliis mundis infinitis possibilibus, sed etiam in hoc unico mundo. "RuIz DE Montoya, De scientia Dei 78, 3, 3, p. 823b.

66. W. HüBenER: „Notio completa. Die theologischen Voraussetzungen von Leibniz’ Postulat der Unbeweisbarkeit der Existentialsätze und die Idee des logischen Formalismus“, in: Leibniz: Questions de logique (= Studia Leibnitiana Sonderheft 15), Stuttgart 1988, S. 107-16, hier 114. 
sischen Prädetermination, aber zu dem Kalkül mit unendlich vielen möglichen Welten („mon principe d'une infinité de mondes possibles“) bekennt er sich unter gleichzeitiger Absage an die „Molinisten “ ${ }^{67}$ Dieser Kalkül ist folglich kein spezifisches Merkmal von Molinas Hypothese. Als diese im Druck erscheint, 1588, ist von dem thomistischen Gegenentwurf schon bekannt, daß der ebenso mit einer kombinatorischen Unendlichkeit aufwartet. ${ }^{68}$ In den Reihen der Gegner zieht namentlich ZumeL daraus unerschrocken Konsequenzen ${ }^{69}$ - ohne faule Kompromisse ${ }^{70}$-, deswegen aber keineswegs zur Zufriedenheit der Scientia Media-Theologie. Obwohl sie selber, in bezug auf Gottes Wissenshaushalt, durchaus keinen Sparsamkeitsgrundsätzen huldigt, ${ }^{71}$ beunruhigt sie die von Zumels Thesen ausgehende Inflationswirkung. ${ }^{72}$

67. G.W. Leibniz († 1716): Théodicée 1, 42, Die philosophischen Schriften, hg. von C.I. Gerhardt, Berlin 1875-9o / Repr. Hildesheim 1965, Bd. 6, S. 126.

68. „... alter (sc. modus)..., quo Deus certo cognoscere potest illos eventus, videlicet in libera praedeterminatione suae voluntatis. Quod ut intelligas, reduc in memoriam eam doctrinam, quam Thomistae nostri temporis tam mordicus tenent... Et sic infinitas rerum possibilium combinationes non futuras, possibiles tamen et conditionatas, Deus... comprehendit." MendozA, Quodl. 7, 11, pp. 544-45.

69. F. Zumel OM. († 1607): Utrum Deus habeat praescientiam futurorum contingentium (= Opuscula, Salamanca 1608, t.2), pp. 173aB/74aA. 187aB. Vgl. F. ZumeL: Informe sobre las doctrinas del P. Luis Molina SJ., presentado en julio de 1595, hg. von V. Muñoz Delgado: „Zumel y el molinismo“, Estudios 7 (1951), pp. 521ff., hier p. 550. Zustimmend Cabrera, In Tertiam partem Q. 1 art. 3, $\$ \$ 383-84$, t.1, p. 303b („,solutio probabilis“); IoAnnes a S. ThомA, In Primam partem 20, 5, 39, t.2, pp. 513b/14a; Gabriele di san Vincenzo, In Primam partem 14, 260, p. 265b; V. Sedlmayr OSB.: Deus unus in se et attributis suis 4, 4, 16, Regensburg 1735, pp. 407b-o9a.

70. Die Kompromißlinie bei Ledesma, De auxiliis, pp. 582aA (Bezug: 577aB-bA). 586bB-87bA; Lemos, Panoplia Gratiae 1, 5, 23, t.1, p. 263b; D. Alvarez OP. († 1635): Responsiones ad obiectiones adversus Concordiam liberi arbitrii cum efficacia praevenientis gratiae 1, 4, 10, Lyon 1622, p. 143; Modestus a S. Amabili OC. († 1684): Theologia Thom-Augustiniana: De Deo uno 13, 1, 2, Lyon 1684, t.1, pp. 29ob/91a.

71. Pennotto, Propugnaculum humanae libertatis 3, 30, 10, p. 169a/b. Vgl. Martínez, Deus Sciens 4, 1, 5, p. 586.

72. Bastida, [De scientia media] p. 511a; Herice, In Primam partem 7, 38, p. 151b; Alarcón, Theol. schol. 3, 5, 8, 10-11, p. 232a; Arriaga, In Primam partem 21, 17, t.1, p. 218a; F. van der VeKen SJ. († 1664): Disputationes theologicae de Deo uno et trino 19, 13. 17, Antwerpen 1655, pp. 332a/b. 334b; Izquierdo, De Deo uno 28, 441, t.2, pp. 184b/85a; Martínez, Deus Sciens 4, 3, 4, p. 643; Saguens, De perfectionibus divinis 2, 1, 6, 20-22, t.2, pp. 124-25. Anders RuIz De Montoya, De scientia Dei 71, 10, 11, p. 751b. Ganz taub gegen solche Bedenken stellt sich der Skotismus: F. Felix OFMObs.: Primum Principium Complutense 1, 6, 3, 2-4, Alcalá 1646, pp. 18ob/82a; Mastri da Meldola, In I Sent. 3, 266, p. 159b. Darüber wundert sich G. Buontempi OFMCap. (†1672): Palladium theologicum 1, 13, 367, Lyon 1676, t.1, p. 234 b. 
Insofern der Kalkül mit den unendlich vielen möglichen Welten im Christentum des 17. Jahrhunderts das Potenzial gehabt hätte, als eine ,narzißtische Kränkung' erfahren zu werden, welche die durch das Weltbild der modernen Astronomie angeblich erlittene weit in den Schatten stellt, bildet er also kein Alleinstellungsmerkmal der Scientia Media-Hypothese. ${ }^{73}$

\section{\$6. [Erkenntnisgrund]}

Gott kennt das bedingt Freizukünftige. Wie ist das möglich?74 Die Scientia Media-Hypothese hat eine Metaphysik des Erkenntnisgrundes hervorgerufen. ${ }^{75}$ Die Mehrheitsposition in der christlichen Theologie setzt diesen in Gottes Dekret. ${ }^{76}$ Sie besagt: Worauf der Begriff, Futuribilien' auch immer referiert, ob auf ein intentionales Objekt oder auf eine Klasse von Dingen, ${ }^{77}$ sofern nicht über dessen Wahrheitswert durch Gottes Willen vorweg entschieden ist, ist er ohne Referenz. ${ }^{78}$

73. Dieses Motiv klingt erst im 19. Jahrhundert an: „Die Kenntniß nun dieser unendlich mal unendlich vielen und auch unendlich oft immer anders sich wiederholenden (2. Aufl.: gestaltenden) Welten ist der Gegenstand der scientia media, in welcher die Kenntniß der wirklichen Welt sich als ein unendlich kleines verliert..." F.D.E. SCHLEIERMACHER: Der christliche Glaube nach den Grundsätzen der evangelischen Kirche im Zusammenhange dargestellt (1821/22). Kritische Gesamtausgabe Abt. I Bd. 7,1, Berlin 1980, S. 216.

74. Das ist der Kontroverspunkt: SuÁrez, De praedest. 1, 7, 1, t.1, p. 254a; IoAnnes A S. Thoma, In Primam partem 20, 1, 1, t.2, p. 433a.

75. „Inquiro ... ab his authoribus, ut assignent primam omnium radicem a priori ob quam Deus praesciverit liberum arbitrium creatum hoc facturum, si in tali rerum ordine collocetur." LEMOs, Panoplia Gratiae 1, 5, 14, t.1, p. 235b.

76. „Deus non cognoscit futura conditionata per scientiam mediam ante omne decretum actu positum. Haec est Scotistarum et Thomistarum quasi omnium (sc. sententia) contra Patres Societatis.“ A. Hermann OFM. († 1700): Tractatus theologici de Deo uno et trino 4, 2, 5, 7, Köln 169o, p. 267b. So z.B. auch J. CARAmuel y Lobkowitz O.Cist. (†1682): Leptotatos $\$ 524$, Vigevano 1681, p. $271 \mathrm{a} / \mathrm{b}$.

77. „... quomodocunque sumatur , futurum contingens conditionale', hoc est, sive obiective, sive existentialiter, semper est posterius decreto.“ Lalemandet, De Deo uno 8, 59, t.1, p. 255 a.

78. „Obiectum scientiae mediae non est scibile.“ D. Alvarez OP.: De auxiliis divinae gratiae et humani arbitrii viribus et libertate, ac legitima eius cum efficacia eorundem auxiliorum Concordia 7, 17, Rom 1610, p. 67a. Zustimmend: J. Prideaux ( $†$ 1650): Lectio de scientia media $\$ 10$ (Oxford 12.7.1617), Opera theologica omnia, Zürich 1672, pp. 14-28, hier p. 23. Bekräftigt in Alvarez, Responsiones 1, 1, 8, p. 12. - „Obiectum scientiae mediae est simpliciter nonens et nihil. Ergo ipsa scientia non scientia." Voet \& Nethen, De scientia media $\$ 23$, p. 316 . Vgl. Navarrete, Controversiae 56, 4, t.1, fol. 354va/b; Collegium Salmanticense OCD.: Cursus theologicus 3, 12, 1, ( $\left.{ }^{1} 1631\right)$ Paris-Rom 1870, t.1, p. 662b; Gabriele di SAN Vincenzo, In Primam partem 14, 289, p. 273 a. 
Dem opponiert die Scientia Media-Hypothese:79 Daß über eine Teilmenge des $\mathrm{Zu}$ künftigen allerdings so entschieden ist, verringert bei dieser gar nicht die Schwierigkeit, welche die Angabe des Erkenntnisgrundes bereitet. ${ }^{80}$

Endox sind auch skeptische Positionen vertreten worden. ${ }^{81}$ In der Jesuitenscholastik überwiegt jedoch ein dogmatischer Prinzipiendualismus. ${ }^{82}$ Ein (a) subjektives (ex parte virtutis cognoscentis) und ein (b) objektives Prinzip (ex parte obiecti cognoscibilis $)^{83}$ konkurrieren miteinander:

a. Den Futuribilien fehlt die Erkennbarkeit, aber dieser Mangel wird kompensiert durch die überragende Leistungsfähigkeit des Verstandes, welcher der Träger der Scientia Media ist. ${ }^{84}$ Die Hypothesenbildung dazu macht, unterschiedlich massiv, Anleihen bei der natürlichen Theologie. Eine solche Hilfshypothese ist

79. „... affirmant scientiae mediae assertores, decreta Divina nihil influere in futuritionem conditionatam actuum liberorum, sed e contra illam decreta Divina omnia praevenire... "SAGUENS, De perfectionibus divinis 2, 1, 7, 2, t.2, p. 136.

8o. SuÁrez, Varia opusc. theol. 2, 2, 7, 16, t.11, p. 370a; De praedest. 1, 7, 8, t.1, p. 255b.

81. „Ego... id solum firmum reddere conatus sum, quod Deus contingentia illa conditionata certo ac determinate cognoscat. Modum vero inquirere et deprehendere, quo Deus illa cognoscat, ego non solum non promisi, verum dicere me non posse, testatus sum. "MendozA, Quodl. 7, 10, p. 543. Vgl. E. Vansteenberghe: „Molinisme“, Dictionnaire de Théologie Catholique t.10, Paris 1929, coll. 2094-2187, hier 2169.

82. „Primum... principium non probatur per secundum, nec secundum per primum, sed unumquodque per diversa seorsim principia ostenditur." Martínez, Deus Sciens 4, 5, 2, pp. 718-19.

83. „... quando Deus ab aeterno affirmat futurum contingens conditionatum, datur duplex determinativum: alterum quidem subiectivum... alterum vero obiectivum... "J.B. Gormaz SJ. († 1708): Cursus theologicus 1, 722, Augsburg 1707, t.1, pp. 153b/54a. Vgl. Bernaldo de Quirós, De Deo 53, 17, p. 356b; González de Santalla, In Primam partem 19, 6, t.1, p. 352b; Ulloa, Theol. 1, 3, 94, t.1, pp. 129b/30a; M. Wietrowski SJ. ( $†$ 1737): Selectae conclusiones theologicae 1, 368, Praha 1726, t.2, p. 58; F. Miranda SJ. ( $\dagger 1744)$ : Tractatus de scientia media 6, 2, 20, in Collectio ex variis autographis theologicis Collegii Salmantini et Vallisoletani Societatis Iesu, hg. von B. Rada, Villagarcia 1766, pp. 401-536, hier p. 503b. - Ebenso die Gegner: CABRERA, In Tertiam partem Q. 1 art. 3, \$390, t.1, p. 304b; AlvareZ, De auxiliis divinae gratiae 7, 12, p. 62a; Ledesma, De auxiliis, pp. 577bC. 581aD; FAsulo, In Primam partem Q. 14, art. 13, 426. 462, t.2, pp. 253b. 268b. - „Jesuitae confugiunt ad scientiam mediam, qua Deus vel in se, vel in re (nam hic inter se non conveniunt) futura conditionata praecognoscit." PrIDEAUX, De scientia media $\$$ 9, p. 23.

84. „... ex altitudine... divini intellectus, qua quod incertum ancepsque omnino in se est certo cognovit futurum...“ Molina, Concordia Q. 23 art. 4-5, 1, 11, 29, p. 555. - „Quod non est, sed esset,... potest determinare intellectum divinum..., quia... obiectum extrinsecum determinans intellectum divinum est pura conditio, ita ut tota virtus sit infinitum lumen cognoscitivum Dei.“ Mauro, Opus theol. 1, 45, 23, t.1, p. 149a. 
die Adaption des thomistischen Lehrstücks von der ewigen Realpräsenz des Zukünftigen. ${ }^{85}$

b. Die Frage nach einem Erkenntnismedium erübrigt sich, weil die Futuribilien ihrer Struktur nach erkennbar, ${ }^{86}$ vielleicht sogar Gegenstand eines intuitiven Wissens, sind. ${ }^{87}$

Fonseca, SuÁrez und Vázquez haben sich gegen Molina ${ }^{88}$ damit durchgesetzt, den Vernunftbeweis für die Existenz der Scientia Media über deren Erkenntnisgrund ex parte obiecti zu führen, ${ }^{89}$ über den festen Wahrheitswert singulärer Sätze über kontingent Zukünftiges. Endliche Geister kennen diesen zwar nicht, aber das

85. Ruiz de Montoya, De scientia Dei 75, 1-7, pp. 786-99; M. de Esparza SJ. († 1689): Cursus theologicus 1, 18, 11-14, Lyon 1666, t.1, p. 62a/b; J. Channevelle SJ. († 1699): Metaphysica, Paris 1677, t.2, pp. 371-75. Dagegen: Ledesma, De auxiliis, p. 594bC/D; Alvarez, Responsiones 1, 5, 15, pp. 169 ff.; Moncé, Disputationes theol. 3, 16, p. 210; Granado, In Primam partem 2, 5, 6, 7, t.1, p. 266a; Alarcón, Theol. schol. 2, 4, 7, 4, p. 146a; D. DE Avendaño SJ. († 1688): Problemata theologica 1, 924-25, Antwerpen 1668, t.1, p. 258a.

86. SuÁrez, Varia opusc. theol. 2, 2, 7, 15, t.11, pp. 369b/70a. - „... constat Deum... cognoscere contingentia conditionata... in se ipsis, quatenus scilicet fertur ad illa sine medio cognoscendi... In hac illatione re ipsa conveniunt omnes assertores scientiae mediae." GonzÁlEz dE SANTALlA, In Primam partem 14, 82, t.1, p. 236a/b. Vgl. Hurtado de Mendoza, De Deo Homine 55, 57, t.1, p. 397b; Aldrete, In Primam partem 28, 14, 3, t.1, p. 496a; Martínez, Deus Sciens 4, 4, 2, p. 670. Auch in der philosophischen Literatur: BERnaldo DE Quirós, Opus philos. 99, 38, p. 695a; O. Cattaneo SJ. († 1679): Cursus philosophicus: Logica 12, 3, 8, Rom 1677, t.1, p. 779. Für die Kritiker das Asyl des Nichtwissens: „Isti autores... nullo modo possunt intelligere, quomodo illa futura conditionata sint cognoscibilia, quoniam ignorant modum cognoscibilitatis. "LeDEsma, De auxiliis, p. 602aD. - „Scientia media nullum habet medium, in quo suum obiectum cognoscat: Ergo talis scientia fictitia et chimaerica est. “J.B. Gonet OP. ( $\dagger$ 1681): Clypeus theologiae thomisticae 3, 6, 66, Köln 1671, t.1, p. 298a. - „... recursum facere ad veritatem talis obiecti in se spectati, idem est ac quaerere latibulum in delusione, quia... est propositio de subiecto non supponente." González de Rosende, Disputationes theol. 4, 1, 16, p. 506b.

87. Suárez, Varia opusc. theol. 2, 2, 7, 16, t.11, p. 370a; De gratia Prol. 2, 7, 21, t.7, p. 94a/b; ebd. 2, 9, 6, t.7, p. 11ob. Anders z.B. Granado, In Primam partem 2, 5, 6, 7, t.1, p. 266a. Vgl. Ledesma, De auxiliis, pp. 579aB/D. 601bC/D; W. Twisse ( $\dagger 1645)$ : Dissertatio de scientia media, Arnheim 1639 , p. 446 a.

88. Molina, Concordia Q. 14 art. 13, 52, 15, pp. 344-45; ebd. 53, 1, 12, p. 362. - „... Molinae... principium, futura... contingentia non habere determinatam veritatem, ac proinde non posse cognosci, nisi supercomprehendantur ab intellectu infinito... “F. Albertini SJ. († 1619): Corollaria, seu quaestiones theologicae quae deducuntur ex principiis Philosophicis complexis 4, Coroll. 3, 2, Lyon 1610, p. 287a. Vgl. P. Sherlog (Pseudonym: LeonARdus) SJ. (†1646): Responsiones ad expostulationes recentium quorundam Theologorum contra Scientiam Mediam 3, 31, Lyon 1644, p. 280; HenaO, Scientia media theologice $\$ \$ 5912-14$, t.2, pp. 721b-22a.

89. SuÁrez, Varia opusc. theol. 2, 1, 8, 5, t.11, p. 328b; 2, 2, 8, 3, t.11, p. 371a. Originell ist nur diese Gewichtung, nicht die Doktrin an sich. Vgl. z.B. schon MendozA, Quodl. 7, 4, pp. 527-31. 
Bewußtsein, in dem geurteilt wird, ist generell nicht der Maßstab für Wahrheit und Falschheit eines Urteils..$^{90}$ Die Scientia Media-Hypothese ist damit eine philosophische. Sie ordnet sich in die ,nominalistische' ${ }^{91}$ Tradition oder, richtiger, in Chrysipps $^{92}$ zweiwertigen Aussagenkalkül ein.

Seitdem wird von beiden Lagern die Logik des bedingt Freizukünftigen korollarisch zu den Lösungen für Aristoteles' berühmte Problemstellung abgehandelt, entweder auf der Basis der Wahrheitsneutralität, ${ }^{93}$ die auf das bedingt Freizukünftige übertragen wird, ${ }^{94}$ oder umgekehrt auf der Basis der Wahrheitsdefinitheit. ${ }^{95}$ Die Futuribilien sind dann etwas an und für sich Bestimmtes. ${ }^{96}$ Das erhöht die

90. „... ratio veritatis, vel falsitatis in propositionibus formaliter, non sumitur a proferente, sed potius adaequate et totaliter a conformitate cum suo obiecto." I. DE PEÑAFIEL SJ. († 1657): Cursus integer philosophicus: Logica 9, 83, Lyon 1653-55, t.1, p. 411a. Vgl. Boethius: In librum De interpr. ed. sec., PL (Migne) 64, col. 49oD.

91. SuÁrez, Varia opusc. theol. 2, 2, 3, 3, t.11, p. 352b; VÁzQueZ, In Primam partem 65, 1, t.1, p. 53ob; Zumel, Utrum Deus habeat praescientiam (= Opuscula t.2) p. 159aC; Lemos, Panoplia Gratiae 1, 5, 34, t.1, p. 285a; Ledesma, De auxiliis, p. 578aB-bB (Ockham); Aldrete, In Primam partem 28, 4, 14-18, t.1, p. 435a/36b (Ockham); HenaO, Scientia media theologice $\$ 1816$, t.1, p. 411a.

92. Ruiz de Montoya, De scientia Dei 68, 3, 6, p. 68ob. Chrysipp als Ahnherr der Scientia Media: S. Piccinardi OP. (†1693): De approbatione doctrinae S. Thomae Aquinatis 6, 2, 1, Padua 1683, t.3, pp. 165-66; M. Leydecker (†1721): Historia Ecclesiae Africanae: Diss. de Stoicorum fato, Utrecht 1690, t.2, p. 658.

93. „Futura contingentia ex vi obiecti sui, seu veritatis obiectivae, non habent determinatam veritatem, nec sunt cognoscibilia ut determinate futura." IoAnnes a S. Thомa, In Primam partem 19, 2, 2, t.2, p. 411a. Vgl. Lemos, Panoplia Gratiae 1, 5, 36, t.1, pp. 29ob-91b; Voet \& Nethen, De scientia media $\$ 20$, pp. 310-11; Th. White (Albus, † 1676): Sonus Buccinae: Quaestio theologica de Gratia et Libero Arbitrio $₫$ 7, Köln 1659, pp. 223-317, hier pp. 254-58.

94. Ledesma, De auxiliis, pp. 624aA. 632aB/C; Mastri da Meldola, In I Sent. 3, 230, p. 151b; P. DE Godoy OP. ( $\dagger 1677)$ : Disputationes theologicae in Primam partem D. Thomae 35, 30-31, $\left({ }^{1} 1670\right)$ Venedig 1696, t.2, p. 29a; F. PAlanco O. Minim. († 1720): Cursus philosophicus: Metaphysica 16, 40, Madrid ${ }^{4} 1718$, t.3, p. 533a/b.

95. „Ut autem in contingentibus absolutis altera contradictionis pars determinate vera est, altera determinate falsa:... ita et in conditionatis." Fonseca, In Metaph. 6, 2, 4, 9, t.3, p. 123a. Vgl. VÁzquez, In Primam partem 67, 12, t.1, p. 553a; SuÁrez, Varia opusc. theol. 2, 2, 5, 13, t.11, p. 359b; Albertini, Corollaria 4, Coroll. 4, 7, p. 292b; J. Durelle O. Minim.: Dialecticothaea, sive Dialectica supernaturalis 2, 8, Lyon 1626, p. 490; F. DE Oviedo SJ. († 1651): Cursus philosophicus: De anima 7, 6, 11, Lyon ${ }^{2} 1651$, t.2, p. 113a; TH. DEL Bene CR. († 1673): Summa theologica 4, 12, Lyon 1655, t.1, p. 170a/b; B. DE Benjumea OFMObs.: Opera theologica: Tractatus de scientia Dei (1654) $\$ 1026$, Leiden 1677 , t.3, p. 141b; ErATH, Conciliatio $\$ \$ 344-46$, pp. 119-20 (ablehnend); SAGUENS, De perfectionibus divinis 2, 1, 6, 3-4, t.2, p. 117 .

96. „Nego... futura ex hypothesi non esse determinata in seipsis obiective: quia posita hypothesi determinate essent secutura ex parte rei." Lessius, De praescientia Dei cond. 20, 7, p. 234. 
Durchsichtigkeit des kombinatorischen Ansatzes. ${ }^{97}$ Obwohl diese Radikalisierung der zweiwertigen Logik auch intern vielfach abgelehnt worden ist, nicht nur von Molina, ${ }^{98}$ und obwohl die Ordensleitung ${ }^{99}$ und selbst Suárez ${ }^{100}$ das philosophische Kurrikulum mit dieser Innovation nicht haben belasten wollen, ist es nicht gelungen, sie da herauszuhalten. Ordensintern und -extern ist sie ein Thema auch der ,barockscholastischen' Philosophie. ${ }^{101}$

Theologisch spitzt sich die Metaphysik des Erkenntnisgrundes auf die Frage zu: Gibt es die von der Mehrheitsposition postulierten Dekrete, oder gibt es sie nicht? ${ }^{102}$ Die Wahrheitsdefinitheit beansprucht nicht, genau dasselbe zu leisten wie das Dekret, ${ }^{103}$ sie opponiert nur der Dekretlösung. ${ }^{104}$ Beide Seiten haben sich auf einen

97. „... tot varietatibus, quot omnium quae sunt in rerum natura variae sunt combinationes. Absque hoc enim non consistit ratio scientiae conditionatae, cuius fundamentum est ea contradictio, quae in affirmante et negante sub conditione propositionibus apparet et cogere determinatam earumdem veritatem creditur." White, Sonus Buccinae: De Gratia et Lib. Arb. \$ 7, p. 258.

98. P. Vallio SJ. († 1622): Logica, Lyon 1622, t.1, pp. 671bE. 683aA; C. Knittel SJ. († 1702): Ars universalis: Mantissa thesium $\$ 3$, Praha 1691, fol. N2v.

99. Ordinatio pro Studiis Superioribus $(1651) \S 4$, in: Institutum Societatis Jesu, Prag 1705, t.2, p. 110a. Daher z.B. nur als Merkposten in dem Philosophiekurs von Th. Compton-Carleton 1649.

100. F. SUÁREZ: Disputationes metaphysicae 30, 15, 33, t.26, p. 180 .

101. P. Hurtado de Mendoza: Universa philosophia: De anima 9, 150, Lyon 51624, p. 594b; R. De Arriaga: Cursus philosophicus: Logica 14, 106, Antwerpen ${ }^{1} 1632$, p. 207a; P. DE LA SERnA OM. († 1642): Commentaria in Logicam Aristotelis 3, 8, 4, 2, 3, Sevilla 1624, fol. 440vb; P. CoMagère (Petrus a S. Ioseph) O.Cist. († 1662): Idea philosophiae rationalis, seu Logica 2, 4, 4-5, ( $\left.{ }^{1} 1654\right)$ Köln 1671, pp. 210-14; Casimirus Tolosanus OFMCap. ( $\dagger$ 1674): Atomi peripateticae: Metaphysica realis 1, 2, 2, 8, Beziers 1674, t.5, p. 102; C. Meron OFMObs.: Philosophia scoto-peripatetica 2, 1, 2, 4, 5, Paris 1675, t.2, p. 907a/b. Ebenso im Luthertum an der Universität Jena: P. Slevogt († 1655): Disputationes academicae 1, 17, 50, Jena 1656, p. 407; F. BeChmanN († 1703): Dissertatio philosophica de scientia Dei 2, 133, Jena 1657.

102. „Hoc decretum totis viribus contendunt exterminare assertores scientiae mediae, et circa hanc quaestionem mutuo utraque Doctorum acies in alteram toto impetu irruunt." OviEdo, Physica 10, 1, 18, t.1, p. 243b. - „Eo... tota haec controversia vergit, sintne an non sint isthaec decreta." F. Annat SJ. († 1670): Scientia media contra novos eius impugnatores defensa: Epilog. $\S 2,\left({ }^{1} 1645\right)$ Paris ${ }^{2} 1662$, p. 586.

103. „Communiter Nostri, ut probent veritatem obiectivam et fundamentalem determinate futuram ex hypothesi in contingenti conditionato... solent uti argumento desumpto ex lege illa contradictoriarum propositionum... Sed neque per somnium volumus, illam legem, aut propositiones ipsas esse medium, in quo a Deo praesciantur contingentia conditionata." HenAO, Scientia media theologice $\$ 1517$, t.1, p. 348a.

104. GonzÁlez de Santalla, In Primam partem 36, 7, 38, t.1, pp. 526b/27a. 
Slogan verständigt, um damit die Gegenposition sowohl zu der Dekretlösung ${ }^{105}$ als auch zu Molinas Primat des subjektiven Erkenntnisprinzips ${ }^{106}$ zu bezeichnen: Auf diesem Standpunkt werde der Grund für die Erkennbarkeit der Futuribilien in deren objektive Wahrheit gesetzt. ${ }^{107}$

\section{\$7. [Veritas obiectiva]}

Die Scientia Media steht und fällt mit der objektiven Wahrheit ihres Gegenstandes. Sie hat kondizionale objektive Wahrheiten zum Gegenstand. ${ }^{108}$ Daß besonders

105. „... observandum est, medullam controversiae sitam esse in medio, in quo Numen certo et perfecte attingit futura libera conditionata, an videlicet ea in se ipsis cognoscat ratione veritatis obiectivae determinatae, quam in se habent independenter a decreto Dei praedeterminativo, vel potius ratione praedefinitionis divinae..." SHERLOG (LeONARDUs), Responsiones 2, 17, p. 110. Vgl. Alarcón, Theol. schol. 2, 4, 6, 13, p. 144a; ebd. 3, 5, 8, 2, p. 231a. - Die Gegenthese: „Deus non cognoscit futura contingentia conditionata in ipsorum veritate obiectiva, independenter a propriis decretis ex parte actus absolutis." G. CACHERANO CRSP. ( $\dagger$ 1685): Theologia assertiva 1, 3, 4, 21, Lyon 1673-85, t.1, p. 286a; D. Perez OP. († 1724): Tractatus de scientia Dei 3, 2, 2, Madrid 1747, p. 239b; V. Gufl OSB.: Philosophia scholastica universa: Metaphysica $\$ 1139$, München 1753, t.2, p. 696.

106. „... ratio determinans divinum intellectum ad cognoscendos independenter a decreto actus liberos creatos non est divina supercomprehensio..., sed veritas obiectiva et cognoscibilitas ipsorum actuum.“ Peralta, De scientia media 4, 2, p. 388. - „Supereminentia scientiae Dei... non... facit, ut, si obiectum non habeat veritatem obiectivam determinatam in se, possit terminare scientiam divinam. “F. DE LUGo SJ. († 1652): Theologia scholastica in Primam partem D. Thomae 1, 29, 3, 4, Lyon 1647, p. 32 ob.

107. „... inquiro, cur... eam (sc. scientiam mediam) ut a Molina per supercomprehensionem, et non alio modo, defensam iidem postea Societatis Theologi derelinquerunt, recurrentes ad obiectivam veritatem...?" Piccinardi OP., De approb. doctrinae S. Thomae 7, 6, 1, t.3, p. 452. Vgl. P. Magalhaes OP. (†1672): Tractatus theologicus de scientia Dei 2, 11, 3, Lissabon 1666, p. 375; Henao, Scientia media theologice $\$ 1580$, t.1, p. 36ob; ebd. $\$ 4582$, t.2, p. 368a. Irreführend Сн. Pesch SJ. († 1925): Compendium theologiae dogmaticae 2, 91, Freiburg i. Br. 1913, t.2, p. 48. Richtig Vansteenberghe, „Molinisme“, DThC t.10, col. 2169; A. MiChel: „Science de Dieu“, ebd. t.14, Paris 1941, coll. 1598-1620, hier 1613.

108. „Per illam scientiam cognoscit Deus... veritates obiectivas conditionales de libertate creata.“ Ramirez, De scientia Dei 20, 41, t.2, p. 281a. - „... sublata hac veritate obiectiva tollitur obiectum scientiae mediae.“ L. BAbenstuber OSB. († 1726): Deus unus 7, 4, 13, Salzburg 17o6, p. 337a. - Vgl. Diotallevi, De scientia quam Deus habet de contingentibus, p. 232; IzQuierdo, De Deo uno 28, 257, t.2, p. 147b; D. DE Avendaño SJ.: Recognitio tomi I Problematum theologicorum $\$$ 596, in Auctarium Indicum t.4, Antwerpen 1686, p. 214b; TolomeI, Theol. nat. 6, 4, 18, 2, p. 734a; J. DE Araujo SJ. († 1759): Cursus theologicus 4, 345, Lissabon 1734-37, t.1, p. $207 a$. 
dieser Position wegen die Scientia Media-Hypothese paradox erschien, ${ }^{109}$ hat zum Teil an dem im 17. Jahrhundert noch tastenden Umgang mit dem Unterscheidungsbegriff veritas obiectiva gelegen. Der Scholastik des 13. und 14. Jahrhunderts war er noch unbekannt. Extern ist dieses Theorieelement lange Zeit mit SuÁREz in Verbindung gebracht worden. ${ }^{110}$ Besonders Suárez' Hinweis auf das sog. veritative Sein des Aristoteles ist so interpretiert worden. ${ }^{111}$ Bezogen auf Suárez ist das jedoch eher Interpretament als positive Doktrin. Bezeichnenderweise begegnet es kaum in denjenigen kritischen Rezensionen, welche nicht mehr als seine klassische Abhandlung von 1599 vorliegen gehabt haben. ${ }^{112}$ Zwar fällt der Begriff ,objektive Wahrheit' schon beim frühen Suárez, ${ }^{113}$ aber noch der mittlere hat ihn nur zögernd aus der Erkenntnistheorie des kategorisch Zukünftigen auf die der Futuribilien übertragen. Durchgesetzt haben das Theorieelement tatsächlich Lessius und Diotallevi, ${ }^{114}$

109. Th. Barton (Pseudonym: Bonartes) ex-SJ.: Concordia scientiae cum fide e difficillimis philosophiae et theologiae scholasticae quaestionibus 3, 41, Köln 1659, p. 200; Silva y PACHeco, In Primam partem Q. 14 art. 13, 13, 118-19, t.2, pp. 443b/44a.

110. „Utrum cognoscat ea [sc. futura contingentia] in eorum veritate obiectiva antecedenter ad sua libera decreta? Conclusio est negativa.... Opposita sententia nostrae conclusioni tribui potest Suarez..."P. Cornejo OC. ( † 1618): Theologia scholastica et moralis, (11628-29) Bamberg 1671, t.1, pp. 93a/94a. Vgl. Lemos, Panoplia Gratiae 1, 5, 17, t.1, p. 243a; Collegium Salmanticense OCD., Curs. theol. 3, 7, 96. 100, t.1, pp. 502b/o4b; Magalhaes, De scientia Dei 2, 4, 2, p. 275f.; Gabriele DI SAN VINCENZO, In Primam partem 14, 191, p. 250a. Sogar den authentischen Wortlaut „fere non esse maiorem difficultatem in hac scientia conditionatorum quam absolutorum contingentium" (SUÁrez, Varia opusc. theol. 2, 2, 7, 16, t.11, p. 37oa) ersetzt ein thomistischer Autor (G. VIVEs OP.: De primatu divinae libertatis ad sciendum et decernendum de contingentibus 10, 19, Valencia 1654, p. 285a) in seinem Zitat durch ,etiam in his futuris conditionatis recurrendum esse ad veritatem obiectivam, quemadmodum in futuris absolutis". Das Interpretament ist fallengelassen bei Godoy und durch ein anderes ersetzt bei Gonet, Clypeus theol. thom. 3, 6, 4, t.1, p. 284 b.

111. SuÁreZ, Varia opusc. theol. 2, 1, 8, 8, t.11, p. 329a/b; 2, 1, 9, 22, t.11, p. 341b. Vgl. ZumeL, Utrum Deus habeat praescientiam (Opuscula t.2), p. 16oaA.

112. Gar nicht bei Navarrete, Controversiae 56, 4, t.1, fol. 353ra/55ra; Twisse, De scientia media, pp. 423-87. Nur bei Ledesma, De auxiliis, pp. 573bD. 602bA.

113. „... ens verum obiective, et significabile per veram enuntiationem..." SUÁREZ, Tratado inédito $\$ 53$, p. 119.

114. „Futurum ex hypothesi est obiective verum, cui videlicet, si iudicium conformetur, formaliter verum erit.“ Lessius, De praescientia Dei condit. 19, 16, p. 226. - „Clarissimum enim est, nulla alia ratione satis probari posse huiusmodi scientiam, si veritas illa obiectiva minime probetur." Diotallevi, De scientia quam Deus habet de contingentibus, pp. 161. 195-96. Vgl. Zumel, Utrum Deus habeat praescientiam (Opuscula t.2), pp. 129aD/bA. 134aC. 159bD/6oaB; A. Pesanzio: Commentaria brevia ac Disputationes in universam Theologiam D. Thomae Q. 14 art. 13, 5, Venedig 1606, p. 103aC; J. A. CuRIEL († 1609): Controversiae 1, 7, 168, Salamanca 1611, p. 284 b. 
und Suárez hat sich ihnen ganz zuletzt angeschlossen. ${ }^{115}$ Die Systematisierung des Begriffs der objektiven Wahrheit fällt erst in die Zeit nach Suárez (IzQuiERdo). ${ }^{116}$

\section{$\$ 8$. [Ontologie]}

Gottes Vorherwissen aus der objektiven Wahrheit des Zukünftigen herzuleiten, ist logisch der stärkstmögliche Beweis. ${ }^{117}$ Wenn das bedingt Zukünftige, genau wie das kategorisch Zukünftige, objektive Wahrheit hat, dann ist es erkenntnistheoretisch nicht minderwertig, ${ }^{118} \mathrm{~d}$.h. nicht notwendig nur der Gegenstand von Mutmaßung $(\$ 3)$, sondern möglicherweise von Wissen. ${ }^{119}$ Der Suarezismus ${ }^{120}$ vertieft die abstrakte Wahrheitsdefinitheit des göttlichen Mentalsatzes (veritas formalis determinata propositionis), wie sie VÁzQUEZ vorschwebt, ${ }^{121}$ in Bezug auf die es jedoch Gründe gibt, um daran zu zweifeln, daß sie den ihr zugedachten Zweck erfüllt, ${ }^{122}$ zur Geltung des durch den Satz bezeichneten Sachverhalts (veritas obiectiva determinata rei significatae per propositionem). ${ }^{123}$ Diese These war in der Jesuitenscholastik selber ontologisch umstritten. Der Frontverlauf dieser Kontroverse deckt

115. SuÁrez, De gratia Prol. 2, 7, 22, t.7, p. 95a. Erst aus dem Nachlaß publiziert.

116. „Quid sit et quotuplex veritas obiectiva contingens“ IzQUIERdo, De Deo uno 27, 2-4, t.2, pp. 67a-68a.

117. „Qui... probat Deum habere praescientiam futurorum ex eorum obiectiva veritate, procedit quasi a priori." Durelle, Dialecticothaea 2, 8, p. 483.

118. L. Torres (turrianus) SJ. ( $†$ 1635): Diversa opuscula theologiae 4, 2, 5, Lyon 1625, p. 169a; Recupito, Theologia 2, 1, 27, 6, t.2, pp. 141b/42a; J. MonsChein SJ. († 1769): Theologia dogmatico-speculativa: De Deo $\$ 330$, Augsburg-Freiburg 1763, p. 215.

119. „Si iam convincitur futura conditionata habere veritatem obiectivam in se, convincitur etiam esse intelligibilia ab aliquo intellectu in se, et non solum in coniecturis." Recupito, Theologia 2, $1,25,13$, t.2, p. 134 b.

120. Auch im protestantischen Suarezismus: J. W. Jäger: Disputatio philosophica de scientia futurorum conditionatorum seu, ut vocatur, media, Tübingen 1691, p. 29.

121. VÁzQuez, In Primam partem 65, 22, t.1, p. 539a.

122. Ledesma, De auxiliis, pp. 587bB-88aA; M. DE Alviz OSA. († 1633): De altissima scientia etc. tractatus 1, 6, 3, 6, Alcalá 1632, p. 134b.

123. „Ex parte obiecti, ratio cognoscendi effectus contingentes conditionaliter futuros... est... determinata veritas obiectiva, seu determinata entitas, quam conditionaliter habent praedicti effectus in se ipsis considerati. “FASulo, In Primam partem Q. 14 Art. 13, 466. 468, t.2, pp. 269b/7ob. Vgl. Ruiz de Montoya, De scientia Dei 73, 1, 13-15, p. 760; Th. Raynaud SJ. († 1663): Theologia naturalis 8, 27, Lyon 1622, p. 803a/b; RAMIREZ, De scientia Dei 21, 1-2, t.2, pp. 323a/24a. 
sich mit dem in der zugrundeliegenden Querelle des possibles, wie Jacob Schmutz sie analysiert hat. ${ }^{124}$

a. Der Realismus geht davon aus, daß die Scientia Media ihren Gegenstand so vorfindet. ${ }^{125}$ Daher (IzQuIERDo) besteht die von ihr erkannte objektive Wahrheit unabhängig von ihr. ${ }^{126}$ Die objektive Wahrheit der Futuribilien ist ontologisch deren Surplus über die bloße Möglichkeit. ${ }^{127}$ Sie gehört in die Geltungsordnung. Die Futuribilien sind ,Meinongsche Gegenstände’. Eine Äternisierung kann, ${ }^{128}$ muß aber nicht, ${ }^{129}$ damit verbunden sein. Jedenfalls bezeichnet ,objektive Wahrheit’ eine Gegeninstanz zu Gott. ${ }^{130}$ „Les partisans d' Izquierdo... font de Dieu un spectateur passif de vérités objectives qu'il ne pense et ne forme pas

Zirkelverdacht bei Godoy, In Primam partem 35, 47-48, t.2, p. 3ob; Babenstuber, Deus unus 7, 3, 29, pp. 319a/b.

124. J. Schmutz: „Les innovations conceptuelles de la métaphysique espagnole post-suarézienne: les status rerum selon Antonio Pérez et Sebastián Izquierdo“, Quaestio. Annuario di storia della metafisica 9 (2009) pp. 61-99, besonders pp. 87-89.

125. „Scientia... media non facit suum obiectum, sed supponit illud futurum sub conditione, cum omnibus causalitatibus futuris in illo statu conditionato." GABRIELE DI SAN VINCENZO, In Primam partem 14, 299, p. 275a. Ein Einwand gegen die Scientia Media-Hypothese.

126. Izquierdo, De Deo uno 28, 354, t.2, p. 169a (Definition: ebd. 28, 241, t.2, p. 144b); Junius, De provid. 12, 1, 14, p. 344a. Daher noch J. B. Franzelin SJ. († 1886): Tractatus de Deo uno secundum naturam $\$ 46$, Rom-Turin 1870, pp. 458-60.

127. „Ut autem actus sit praecise futuribilis..., sufficit veritas obiectiva, vi cuius de actu aliquo vere dici potest: Futurus esset, si futura esset aliqua conditio... Futuribilitas... superaddit tantum veritatem obiectivam, quatenus de re futuribili vere enuntiari potest non solum, quod posset esse, sed etiam, quod esset..." Antoine, De Deo uno 5, 5, 8, pp. 267b-68b. Vgl. S. Izquierdo: Pharus Scientiarum 10, 214, Lyon 1659, t.1, p. 256b.

128. „Futura conditionata libera ab aeterno habent determinatam veritatem obiectivam. “ G. M. Perrimezzi O.Minim. († 1740): In sacram de Deo scientiam dissertationes selectae 85, 3, 3, Neapel 1730, t.1, p. 389a. - „Haec propositio ,Si Iudas haberet auxilium A, converteretur', quam supponimus veram, non redditur formaliter vera $a b$ aliquo existente nunc connexo cum conversione Iudae sub eo auxilio..., sed ab aliquo aeterno et physice coexistente scientiae (sc. mediae), quodcumque illud sit." I. F. Peynado SJ. († 1696): Disputationes in III libros Aristotelis de anima 2, 6, 53-55 Alcalá 1698, pp. 420a/21a. Peynados Wahrheitstheorie, allerdings unter Absehung von den Futuribilien, behandelt BRIAN EMBRY: Truth and Truthmaking in 17th-Century Scholasticism, unv. Diss. phil. University of Toronto 2015.

129. IzQuierdo, De Deo uno 28, 349. 354, t.2, pp. 167b. 169a.

130. Ruiz de Montoya, De scientia Dei 76, 5, 4, p. 806b; ebd. 90, 7, 9, p. 917b; IzQuierdo, Pharus Scient. 10, 39, t.1, p. 227b; De Deo uno 28, 15, t.2, p. 95a; ebd. 28, 228, t.2, p. 142a/b; ebd. 28, 340-41, t.2, pp. $165 \mathrm{~b} / 66 \mathrm{a}$. 
lui-même. ${ }^{\text {"131 }}$ Es reicht, daß Gott die Kontrolle über die kreatürlichen Wahrheiten in kategorischer Form hat, über die in hypothetischer Form braucht Er sie nicht zu haben. ${ }^{132}$ Noch andere Facetten hat der von der suarezischen Fraktion innerhalb der Karmeliterschule mitgetragene Realismus. ${ }^{133}$

b. Der Relativismus relativiert genau diesen Geltungsanspruch der objektiven Wahrheit, bis hin zu krassen Zugeständnissen an die Dekretlösung. ${ }^{134}$ Daraus, daß Gottes Vorherwissen von ewigkeither wahr ist, folgt nicht, sagt AldRETE, daß auch das Gewußte von jeher wahr ist, ${ }^{135}$ auch und gerade nicht im Fall der Futuribilien. ${ }^{136}$ Molinas Ablehnung der objektiven Wahrheit sei das Produkt eines Mißverständnisses, sie verwechsele sozusagen Suárez' Position mit der von Izquierdo. Suárez habe mit der Wahl dieses Ausdrucks nur zum Ausdruck bringen wollen, daß Gottes intuitive Erkenntnis sich intentional an Nichtexistentem erfüllt. ${ }^{137}$ Bei Aldrete ist das kategorisch Zukünftige reduktionistisch der truthmaker des bedingt Zukünftigen. ${ }^{138}$ Sein Existenzialismus $(\$ 16)$ ignoriert den Impuls, welchen die realistische Semantik der objektiven Wahrheit dem

131. Schmutz, „Les innovations conceptuelles de la métaphysique espagnole post-suarézienne“, p. 96 .

132. „Licet Deus... debeat posse impedire omnem veritatem creatam, ne existat absolute, non ideo debet posse impedire, ne existat conditionate..." Monschein, De Deo $\$ 338$, p. 221.

133. R. Lumbier OC. († 1684): Tractatus de scientia Dei \$\$390-91, Saragossa 1680, p. 49b.

134. „... futura... conditionalia... supponunt (sc. decretum) conditionatum, a quo pendent in sua... veritate obiectiva." Amico, De Incarnat. 7, 64, t.6, p. 95b. Zu Amicos Praktizismus LaleMANDET, De Deo uno 8, 80, t.1, p. 275b.

135. „... sufficit veritas obiectiva non praesens, sed existens eo modo, quo per actum enunciatur, ut sit Deus omnino determinatus ad cognoscendum illud obiectum... Ut obiectum cognoscatur a divino intellectu, non requiritur ex parte obiecti veritas obiectiva nisi eo modo, quo per actum divinum enunciatur; sed actus divinus existens ab aeterno non enunciat obiectum illud habere veritatem obiectivam ab aeterno, sed pro illa differentia temporis... “Aldrete, In Primam partem 26, 4, 6. 21, t.1, pp. 366a. 369b. Vgl. Martínez, Deus Sciens 4, 4, 1, p. 661.

136. Aldrete, In Primam partem 31, 6, 1, t.1, p. 627b. Vgl. Henao, Scientia media theologice $\$ 5854$, t.2, p. 709b; González de Santalla, In Primam partem 36, 5, 5, t.1, p. 515a.

137. „Molina... aliter, quam par erat, concipit opinionem asserentium, futura libera absoluta, aut conditionata cognosci... in ipsorum obiectiva veritate: nam hoc non ita intelligi debet, ut ipsa obiectiva veritas secundum statum sibi intrinsecum praecedere debeat cognitionem, sed ita, ut ipsum obiectum immediate, hoc est, absque medio aliquo, dicatur cognosci, quamvis in se non existat." Aldrete, In Primam partem 33, 1, 5, t.1, p. 644a. Gedacht ist wohl an SuÁrez, Disp. Met. $30,15,18$, t.26, p. 175 b.

138. „... propositio... de futuro conditionato debet esse vera, quia regulatur per propositionem de futuro absoluto, posita conditione.“ Aldrete, In Tertiam partem 21, 4, 7, t.1, p. 232 b. 
Futuribilienthema überhaupt erst verdankt. Von HeriCE und GonzÁLEz DE SANTALlA, dem späteren Jesuitengeneral, wird der Begriff, objektive Wahrheit' eingeklammert. ${ }^{139}$ Um die Hypostasierung der Futuribilien zu verhüten, wird sich hier gegen Suárez auf Molina berufen. ${ }^{140}$ Esparza trägt der Besonderheit der Futuribilien dadurch Rechnung, daß er die objektive Wahrheit in diesem Fall in einen negativen Satz im Indikativ analysiert. ${ }^{141}$ OviEDo und andere betonen, die Futuribilien haben nicht objektive Wahrheit, sie würden diese nur haben. Von ihnen wird der Irrealis in die objektive Wahrheit hinein verlängert. ${ }^{142}$ Das wird vom Realismus als logischer Fehler kritisiert. ${ }^{143}$

c. Ein Zweig des Relativismus ist der Idealismus. „Diese Autoren“, sagt der Realismus, „verwechseln die objektive Wahrheit der Sachverhalte mit der formalen Wahrheit des Erkenntnisakts. " ${ }^{444}$ Die objektive Wahrheit der Futuribilien ist

139. Herice, In Primam partem 7, 90, p. 173b; González de Santalla, In Primam partem 12, 2, t.1, p. 192a; ebd. 36, 6, 29, t.1, p. 522a/b.

140. GonzÁlez de Santalla, In Primam partem 14, 46-54, t.1, p. 228b/30a.

141. „Effectus contingens, tam ut futurus conditionate, quam ut non futurus conditionate, coincidit reipsa cum veritate obiectiva contingenti pure negativa... Nulla autem veritas obiectiva pure negativa... est talis per se ipsam intrinsece, sed per solam denominationem extrinsecam ab alio intrinsece incompossibili cum eo, quod negatur." Esparza, Curs. theol. 1, 18 ad 1, t.1, p. 64 b. Dagegen Martínez, Deus Sciens 4, 7, 1, pp. 749-53; P. Di Conti (Comitibus) OSA. († 1696): Tractatus de intellectu et scientia Dei 8, 14, Padua 1684, pp. 449-52; ArANDA, Schola Scientiae Mediae 5, 211-12, pp. 369b/70a.

142. „Negandum... (sc. futura conditionata) habere veritatem obiectivam, quae sit, et dicendum tantum habere veritatem obiectivam, quae esset..." Oviedo, De anima 7, 6, 26, t.2, p. 115b. Vgl. Annat, Scientia media def. 4, 48. 52, pp. 496. 499; J. Ferrier SJ. (†1674): De Deo uno: Ad obiectiones Vincentianas 1,67-68, Toulouse 1668, pp. 363b/64a; HenaO, Scientia media theologice $\$ \$ 5799$. 5804 , t.2, pp. 697b/98b (vgl. ebd. $\$ \$ 6017-18$, t.2, p. 745a/b; ebd. $\$ 6149$, t.2, p. 776b); GoNZÁLEZ DE Santalla, In Primam partem 14, 41. 50, t.1, pp. 227b. 229a; ebd. 18, 2, t.1, p. 341b; Aranda, Schola Scientiae Mediae 4, 59, p. 269a; J. DE AgulLAR SJ. († 1708): Tractationes posthumae in Primam partem D. Thomae: De scientia Dei 1, 13, 249, Córdoba (Arg.) 1731, t.3, p. 252b. Weniger deutlich J. Banholzer SJ.: Disputatio theologica de scientia Dei $\$ 116$, Ingolstadt 1692, p. 186.

143. C. De Ortega SJ. († 1686): De Deo uno 2, 7, 6, 3, 5, Lyon 1671, t.1, p. 366a. Vgl. ebd. 2, 5, 5, 3, 7, t.1, p. 261a; ebd. 2, 7, 6, 5, t.1, pp. 368-69; RAmirez, De scientia Dei 22, 86, t.2, p. 363a; A. Erber SJ. († 1746): Theologia speculativa: De Deo uno et trino $\$ 436$, Wien 1747 , p. 431 . Daher die Distinktion bei Aranda, Schola Scientiae Mediae 5, 58. 6o, p. 336a/b.

144. „... hi autores (sc. González de Santalla etc.) absque dubio confundunt veritatem obiectivam rerum cum veritate formali cognitionis... Veritas obiectiva est extra intellectum et convenit rebus independenter, saltem formaliter, ab intellectu." J. BERnIQUe OFMObs. († vor 1705): Tractatus theologicus de divina scientia ad creaturas terminata 3, 2, 94, Alcalá 1705, p. 393a. Ein Gegner der Scientia Media-Hypothese. 
hier nichts an sich, ${ }^{145}$ sondern Projektion, nämlich eine Funktion (,extrinsische Denomination') von Gottes Scientia Media. ${ }^{146}$ Oviedo definiert die objektive Wahrheit von etwas generell als die für es extrinsische Erkennbarkeit. ${ }^{147}$ In dem letzteren Fall symbolisiert ,objektive Wahrheit' eine Konstitutionsleistung. ${ }^{148}$ Bei Perez steht die ganze Unterscheidung zwischen dem Wissen und dem Gegenstand des Wissens auf dem Spiel. ${ }^{149}$ Pallavicino und Mauro erweitern den transzendentalen (mit dem Seienden konvertiblen) Begriff der objektiven

145. „... falso supponi, determinatam veritatem obiectivam intrinsecam futuri conditionati dari de facto.“ Henao, Scientia media theologice $\$ 5800$, t.2, p. $697 \mathrm{~b} .-$ „Haec (sc. veritas obiectiva conditionata) est prorsus nihil intrinsece." W. Ayleworth SJ. († 1679): Metaphysica scholastica 5, 13, 87, Köln 1675, p. 398a.

146. „... veritas obiectiva... supponens pro obiecto ut denominato extrinsece a cognitione...“ Henao, Scientia media theologice $\$ 5798$, t.2, p. 697 b. - „... veritas obiectiva extrinseca: cuius quasi forma denominans est aeterna, et subiectum denominatum est temporale. " Ebd. $\$ 5910$, t.2, p. 721b. Dagegen IzQuierdo, De Deo uno 28, 340, t.2, p. 165 b: „Quo sane semel supposito, quidquid addatur pro retinenda scientia media non potest non esse inintelligibile, imo et prorsus chymaericum.“

147. Oviedo, Metaphysica 3, 3, 5. 21-22, t.2, pp. 247b. 249a. Daher der Distinktionsversuch von J. Platel SJ. († 1681): Synopsis cursus theologici 1, 120, Douai 1706, p. 41a; D. VIVA SJ. († 1726): Cursus theologicus 1, 3, 6, 4, Padua 1719, t.1, p. 85 b.

148. „Respondeo eo solum... (sc. futura conditionata) habere actu veritatem obiectivam, quia cognitio Dei actu ad illa terminatur..., verumtamen hoc non probat ex parte obiecti cognitionis terminatae ad eventum conditionatum dari aliquid, quod actu et absolute sit."Oviedo, De anima 7, 6, 26-27, t.2, p. 115a/b. - „Scientia Media est de se... verissima, quin quoad... veritatem suam formalem reguletur mensureturque a futuro contingenti..., sed tantum praesupponat veritatem obiectivam, quae in ipso foret..."Henao, Scientia media theologice $\$ 6087$, t.2, p. 761 . - „Scientia media veritatem, quam enuntiat, suo tendendi modo... facit." M. Drattenberger SJ. ( $† 1711)$ : Disputatio theologica de scientia Dei \$95, Dillingen 1688, p. 77. - Deswegen auch die Scheinwerfermetaphorik bei Esparza, Curs. theol. 1, 18, 15, t.1, 63a: „Deus potest ex se refundere lumen in ea, quae extra Deum, secundum se praecise, sunt purae ac merae tenebrae, id est, nihil habentia cognoscibilitatis intrinsece in se actualiter et absolute." Dagegen IzQuierdo, Pharus Scient. 10, 7, t.1, p. 221b; De Deo uno 28, 340, t.2, p. 165b.

149. „Melius ergo videtur asseri, statum conditionatum esse ipsam scientiam mediam.“ A. Perez, Opus posth.: De voluntate Dei 6, 80, p. 304a. - „Assero... futuritionem conditionatam nostrorum actuum liberorum formaliter sumptam consistere in ipsa scientia media. " GoNZÁLEZ De Santalla, In Primam partem 18, 23, t.1, p. 345b. Anders z.B. Arriaga, In Primam partem 21, 30, t.1, p. 22ob; A. De Herrera: Tractatus de scientia Dei 14, 8, Alcalá 1672, p. 366; HenaO, Scientia media theologice $\$ \$ 5985-89$, t.2, pp. 737a/38a; P. DE BugIs SJ. († 1680): Tractatus de Deo uno 8, 2, 6, Bordeaux 1676, p. 112a. 
Wahrheit ${ }^{150}$ zum Leitbegriff einer Ontologie des Supertranszendentalen. Diese verzeichnet diejenigen Prädikate, welche, vermöge seiner ,extrinsischen' Erkennbarkeit, auch Nichtseiendes hat. ${ }^{151}$ Der Bekämpfung des Idealismus gilt Izquierdos Systemanstrengung. ${ }^{152}$

d. Wo die objektive Wahrheit der Futuribilien als von der Scientia Media zu unterscheidender truthmaker (obiectum verificativum) festgehalten und wo auf der Unmöglichkeit bestanden wird, daß der truthmaker und das Wissen zusammenfallen, ${ }^{153}$ kann das immer noch auf eine bestimmte Seinsweise eingeschränkt und damit bezweckt sein, die Hypostasierung zu unterbinden. ${ }^{154}$ Empiristisch will ULLOA den truthmaker hier nicht verstanden wissen. ${ }^{155}$ Indessen: „Dieses Ja-Atom, welches empirisch nichts ist, jedoch etwas wäre und in Wirklichkeit existierte, wenn dieser Fall einer freien Willensbetätigung gegeben wäre, das ist der truthmaker. ${ }^{156}$

150. So z.B. IzQuierdo, Pharus Scient. 10, 215, t.1, p. 256b; G. Polizzi SJ. († 1691): Philosophicae disputationes: De anima 29, 8, Palermo 1675, t.3, p. 405a.

151. „... purae veritates obiectivae sunt ens supertranscendentale.“ Mauro, Opus theol. 1, 58, 19. 48-49, t.1, pp. 185a/87b. Vgl. S. Pallavicino SJ. († 1667): Assertiones theologicae 8, 307, Rom 1649-52, pp. 503-07. Zur ,cognoscibilitas extrinseca' vgl. Henao, Scientia media theologice $\$ 6083$, t.2, p. 760 ob; J. P. Doyle: „Extrinsic Cognoscibility: A Seventeenth-Century Supertranscendental Notion“, The Modern Schoolman 68 (1990/91) pp. 57-80; Ders.: „Silvester Mauro, S.J. (1619-1687) on Four Degrees of Abstraction“, International Philosophical Quarterly 36 (1996) pp. 461-74.

152. IzQuierdo, Pharus Scient. 10, 45, t.1, p. 229 a.

153. „Repugnat..., verificativum cognitionis esse ipsam cognitionem.“ M. DE AvENDAÑO Y EZtenaga SJ. († 1686): De divina scientia et praedestinatione 3, 6, 21, 6, San Sebastián 1674, t.1, p. 279a. Die Paginierung des ersten Bandes ist durchweg korrupt.

154. „Veritas obiectiva media praesupposita ad scientiam mediam... non est ens simpliciter affirmabile de praesenti, sed tantum ens verificativum. "Avendaño y Eztenaga, De divina scientia 3, 6, 21, 9, t.1, p. 28oa/b; ebd. 4, 1, 8, 16, t.2, pp. 21b/22a. Vgl. Recupito, Theologia 2, 1, 25, 22, t.2, p. 138b; Veken, De Deo uno 19, 5, p. 327b. Zur Ontologie des truthmaker vgl. Avendaño y Eztenaga, De divina scientia 3, 3, 20, t.1, pp. 123-26; ebd. 5, 2, 9, 6-15, t.2, pp. 88a-92a.

155. „... si terminis istis , determinare', ,verificare' intelligas quid crassum et physicum de praesenti existens..., omnino tibi dabo, quod in hoc sensu non determinat, non verificat scientiam mediam, exercitium illud libertatis, quod foret." UlloA, De anima 3, 2, 20, p. 316; Theol. 1, 3, 99, t.1, p. 132a. - „... veritates obiectivas de futuro conditionato non consistere pro formali in aliquo de praesenti pertinente ad divinum intellectum. "RAmirez, De scientia Dei 17, 126, t.2, p. 156a.

156. „Ille... individuus et singularis consensus, qui nunc nihil est, esset tamen aliquid et existeret in rebus, si daretur libertas..., est verificativum... huius actus scientiae mediae: ,Si existat libertas A, eliciet consensum praeventa et excitata per gratiam Dei, cui resisti potest'. 'UlloA, De anima 3, 2, 16, pp. 313-14; Theol. 1, 3, 95, t.1, p. 130a/b. 


\section{§9. [Kondizionalität]}

Die Scientia Media ist, auch in Gottes Wissenshaushalt, nur ein Typ des Wissens in kondizionaler Form, ${ }^{157}$ daher gibt das Wesen des status conditionatus sowohl im allgemeinen als auch im besonderen Stoff zu Erörterungen. ${ }^{158}$

Je nach dem bezogenen Standpunkt $(\$ 6)$ ist die Scientia Media ein kondizionales Wissen ${ }^{159}$ oder ein kategorisches Wissen mit kondizionalem Gegenstand. ${ }^{160}$ In beiden Fällen wandert $p$ logisch aus dem Focus. ${ }^{161}$ Nur $q$ ist ein Gegenstand des Urteilens, $p$ ist ein Gegenstand bloß der Vorstellung, ${ }^{162}$ umschreibbar durch die Wendung ,Gesetzt den Fall, daß.... ${ }^{163}$ Unter dieser Voraussetzung kritisiert IzQUIERDO, auf dem realistischen Standpunkt, die Identifikation des bedingt Zukünftigen mit dem Urteil ,Wenn $p$, dann $q$ ':

Das bedingt Zukünftige ist nicht durch den Akt der Prognose konstituiert. Genausowenig ist die einfache Vorstellung (apprehensio simplex), welche $p$ konstituiert oder die Bedingung angibt, unter der $q$ prognostiziert wird, ein Bestandteil von $p / q$.

157. „Omnis scientia media est conditionata, non tamen omnis conditionata est media.“ Muniesa, De provid. 2, 5, p. 20a. Vgl. Martínez, Deus Sciens 2, 5, 4, p. 195.

158. IzQuierdo, Pharus Scient. 10, 93-95. 253-57, t.1, pp. 236a/b. 263a/64a.

159. „... infero..., scientiam mediam, simplicis intelligentiae, et visionis nullo modo inter se differre ex parte obiecti..., differentiam autem solum esse in modo cognoscendi eumdem actum." Arriaga, In Primam partem 22, 9, t.1, p. 226a. Vgl. Aldrete, In Primam partem 30, 19, 8, t.1, p. 605a/b; A. Perez, Opus posth.: De intelligentia Dei 6, 113, p. 205a; Bernaldo de Quirós, De Deo 45, 25-26, p. 323a; Henao, Scientia media theologice $\$ 1498$, t.1, p. 343b; Ayleworth, Metaphysica 5, 13, 122, p. 404a; ArAndA, Schola Scientiae Mediae 1, 329, p. 79a („assertio inter nostros Modernos iam communis").

160. „Scientia de futuro conditionato... est absoluta ex parte actus, et solum conditionata ex parte obiecti." Platel, Synopsis curs. theol. 1, 128, p. 44a. Vgl. Oviedo, De anima 7, 6, 1, t.2, p. 111a; IZQuierdo, De Deo uno 28, 355, t.2, p. 169a.

161. SuÁrez, De gratia Prol. 2, 7, 21, t.7, p. 94a/b; Granado, In Primam partem 2, 5, 3, 30, t.1, p. 26oa/b; Bernaldo de Quirós, De praedest. 7, 39, p. 49a.

162. „Scientia media hypothesin ad actum liberum non affirmat nec negat, sed solummodo apprehendit; ipsum vero actum liberum, futurum sub illa hypothesi, non solum apprehendit, sed etiam affirmat vel negat... “F. X. SterzINGER SJ. († 1741): Scientia Media plene conciliata cum sacra doctrina S. Thomae $\$ 65$, Innsbruck 1728, p. 66. Vgl. Diotallevi, De scientia quam Deus habet de contingentibus, p. 243; Alarcón, Theol. schol. 2, 4, 11, 5-6, p. 152a/b; IzQUIERdo, De Deo uno 23,83 , t.2, pp. $17 \mathrm{~b} / 18 \mathrm{a}$.

163. „Dum enim ,ponimus' aliquid esse, mente constituimus illud in rerum natura, ut de illo agamus, ac si vere esset a parte rei nullo cogitante..." Diotallevi, De scientia quam Deus habet de contingentibus, p. 242. 
Das bedingt Zukünftige, $q$, ist weder zukünftig noch bedingungsweise wahr, sofern die Bedingung, unter der es das ist, nur vorgestellt oder vorgestellterweise in Form von $p$ gesetzt ist. Vielmehr ist $q$ das dann, wenn es sich wirklich so verhält, daß die Bedingung die Bedingung von $q$ ist. Also geht auch nicht von bedingungswegen die Vorstellung in $p / q$ mit ein. Auf seiten des Verstandes ist sie nur dazu erforderlich, damit er, unter der sich so vorgestellten Bedingung, $q$ prognostiziert. Wenn der Verstand prognostiziert,Wenn Judas die Gnadenhilfe A hätte, würde er sich bekehren', ist Judas' Bekehrung unter der Bedingung prognostiziert, daß die betreffende Gnadenhilfe ihm tatsächlich zuteilwürde, und daß es sie also gäbe, - nicht unter der Bedingung, daß von dieser Gnadenhilfe durch die Vorstellung von ihr unterstellt ist, daß es sie gibt und daß sie ihm zuteilwird. Denn dann würde Judas' Bekehrung nicht unter der Bedingung der betreffenden Gnadenhilfe prognostiziert, sondern unter der Bedingung der Vorstellung von dieser Gnadenhilfe, d.h. unter der Bedingung nicht ihrer extramentalen Existenz, sondern ihrer intramentalen Existenz. Das sind unterschiedliche Bedingungen. ${ }^{164}$

Wenn es eine Tendenz zur Angleichung von $p$ an $q$ gibt, dann nicht epistemisch, sondern handlungsmetaphysisch. ${ }^{165}$

Die ontologische Interpretation des status conditionatus ist zwischen Realisten und Nominalisten kontrovers, ${ }^{166}$ noch schwieriger wird es, wo, statt von den neutralen Sachverhalten, von Tatsachen die Rede ist. ${ }^{167}$ Kondizionale Tatsachen existieren nicht, behauptet UlloA. ${ }^{168}$ Der Gegenstand der Scientia Media schillert zwischen Ding und Sachverhalt. ${ }^{169}$ Der Begriff des ,kontradiktorischen Gegenteils'

164. Izquierdo, Pharus Scient. 10, 71, t.1, p. 233 a.

165. „... manifestum est, quod libertas praerequisita ad actum sit universim sub eadem conditione conditionate futura, sub qua ipse actus est conditionate futurus." Erber, De Deo uno $\$ 443$, p. 440.

166. Die realistische Position bei Avendaño, Recogn. tomi I Probl. Theol. $\$ 569$, p. 208b; HeRRera, De praedest. 2, 45-48, pp. 52-53; Araujo, Curs. theol. 4, 349-50, t.1, p. 208a. Die nominalistische Position bei A. Perez, Opus posth.: De intelligentia Dei 6, 113-14, p. 205a; Martínez, Deus Sciens 4, 1, 1, pp. 561-62; González de Santalla, In Primam partem 19, 4, t.1, p. 352a; UlloA, Theol. 1, 3, 63-65. 107, t.1, pp. 117a/18a. 135a.

167. „... futurum conditionatum (est)... ens reale, non vero aeternum, sed in tempore existens conditionate, veritas vero eius propositionis... non solum realis est, sed etiam aeterna, quippe quae in mente divina existit." Herice, In Primam partem 7, 90, p. 173b.

168. „Non... existit... aliquid, quod in se ipso sit ex parte rerum, extiturum consensum, si existat libertas A. "UlloA, Theol. 1, 3, 187, t.1, p. 173a.

169. „... patet, scientiae mediae obiectum esse tum omnes actus liberos... futuribiles..., tum etiam propositiones omnes, quibus enunciatur vel enunciari potest haec futuribilitas. ... Haec... futuribilitas ac connexio libera actuum liberorum futuribilium immediatius pertinet ad scientiam 
kann sich daher im Scientia Media-Kontext sowohl auf $p / q^{170}$ als auch auf $q^{171}$ beziehen. Das Bedingte, die Futuribilien, sind Dinge oder, besser, Ereignisse, ${ }^{172}$ die existieren bzw. nicht existieren würden, wenn die Bedingung realisiert würde. ${ }^{173}$ Die Termini ,existieren würde', ,wenn' und ,realisiert würde' bleiben in der Regel unanalysiert. ${ }^{174}$ Im Übrigen gehört eine Rekapitulation des summulistischen Lehrstücks von den Kondizionalsätzen regelmäßig fest zum Pensum. ${ }^{175}$ Die Logik des Scientia Media-Kondizionals beschäftigt den Theologen aus der Humanperspektive $(\$ 10)$, seine praktische Handhabung aus Gottes Perspektive ( $\$ 11)$.

\section{\$10. [Logik]}

Die Scientia Media-Hypothese ist nur da zuständig, wo kondizionale Aussagen, konsequenzlogisch beurteilt, immer falsch wären. ${ }^{176}$ Der Kondizional ist nicht

mediam quam veritas propositionum illarum. “ Antorne, De Deo uno 5, 5, 1, p. 249 b. Vgl. Martínez, Deus Sciens 4, 1, 1, p. 559; Junius, De provid. 12, 1, 3, p. $342 a$.

170. Albertini, Corollaria 4, 2, 15, p. 274aC; Alarcón, Theol. schol. 2, 4, 10, 4, p. 148b.

171. Alarcón, Theol. schol. 3, 5, 8, 20, p. 233a; Izquierdo, Pharus Scient. 10, 50, t.1, p. 229b. „... propositiones de contingente futuro sub conditione... vel sunt contradictoriae omnino, si apponatur negatio toti conditionali, vel ex parte, si apponatur eventui." Durelle, Dialecticothaea 2,8, p. 489 .

172. „... observandum,... hunc statum conditionatum proprium magis esse actionum quam rerum. “F. MACEdo ex-SJ. († 1681): Collationes doctrinae S. Thomae et Scoti 10, 4, 1, Padua 1671, t.1, p. 368 b.

173. „Futuribilitas formalis... est ipsa entitas rei seu actus, quae non est, sed esset, si poneretur aliqua conditio." Antoine, De Deo uno 5, 5, 1, p. 249 a. Vgl. Martínez, Deus Sciens 4, 1, 3, p. 573.

174. „Quid autem importent hae tres voces ,existeret', ,si' et ,poneretur'? Respondent communiter auctores, hoc esse per se notum... atque adeo importare conceptum irresolubilem. "Polizzi, De anima 29, 41, t.3, p. 412b.

175. „Theologo dedignandum non est Summularum interdum meminisse..." Junius, De provid. 11, 7, 1, p. 329b. Gemeint sind die Summulae logicales des Petrus Hispanus (13. Jh.), in deren Kommentierung bis ins 16. Jahrhundert die Literatur zur formalen Logik bestanden hat.

176. „Futura conditionata contingentia sunt illa,... quorum consequens potest esse, et non esse, etiam dato antecedenti seu conditione.“ Alarcón, Theol. schol. 2, 4, 4, 1, p. 135b. - „... ratio difficultatis consistit solum in hoc, quomodo propositio illa, quae enunciat effectum contingentem ut futurum ex aliquo antecedenti contingenti, possit esse bona consequentia, cum non sit necessaria.“ Albertini, Corollaria 4, 2, 7, p. 272aE. - „Si... habitudo conditionis ad conditionatum non est necessaria, sed contingens..., tunc propositio... spectat ... ad scientiam mediam. “ MAYR, Theol. 1, 380, p. 296. 
modalisiert, ${ }^{177}$ weder durch ,wahrscheinlich' noch durch ,immer' oder sonst auf eine Weise, auf die $p / q$ mit der Formel für eine Gesetzmäßigkeit verwechselbar würde. Die Gewißheit von Gottes kondizionalem Wissen beruht auf anderem als in der humanen Erkenntnistheorie. ${ }^{178} \mathrm{Da}$ es neben der Scientia Media auch ein gesetzförmiges Wissen um kontingente Wahrheiten gibt, wie RUIZ DE MoNTOYA behauptet, ist ein Sondervotum. ${ }^{179}$ Extern, in der Franziskanertheologie, ${ }^{180}$ hat es mehr Zuspruch gefunden als intern. Die Veranlassung zu dieser Spekulation war, daß SUÁREZ sich gegen VázQUEZ ${ }^{181}$ mit seiner Weigerung durchgesetzt hat, den Scientia Media-Kondizional kausal zu interpretieren. ${ }^{182}$ Die Kontingenz des Zusammenhangs $p / q$ ist rein erfolgsqualifiziert. ${ }^{183}$ Es reicht, wenn das Kondizionalgefüge Simultaneität denotiert. ${ }^{184}$ Der feste Wahrheitswert des Scientia Media-Kondizionals hängt an dem Zeitindex. ${ }^{185}$ Nur der Form nach ist er eine

177. Ruiz de Montoya, De scientia Dei 68, 2, 2-5, p. 678a/b. Vgl. Ledesma, De auxiliis, p. $623 a C$. 178. Molina, Concordia Q. 14 art. 13, 52, 37, p. 355.

179. Ruiz de Montoya, De scientia Dei 8o, 3, 7, p. 828b. Vgl. Ders.: Commentaria ac Disputationes ad Quaestionem XXII et bonam partem Quaestionis XXIII ex prima parte S. Thomae: De providentia 10, 1, 1-3, Lyon 1631, p. 157a/b. Dagegen Alarcón, Theol. schol. 2, 4, 4, 26-33, p. 139a/b; IzQuierdo, De Deo uno 28, 49-52, t.2, pp. 608b/o9a. Die von anderer Seite (BonAe Spei, Theol. schol. 11, 63-64, t.1, p. 12ob) in derselben Absicht ins Spiel gebrachte „scientia media late sumpta“ wird zurückgewiesen: Henricus a S. Ignatio, Theol. fund. 8, 756, p. 550a/b; Avendaño, Recogn. tomi I Probl. Theol. $\$ \$ 576-77$, p. 210a/b; Araujo, Curs. theol. 4, 346-48, t.1, p. 207a/b.

180. L. De Caspe OFMCap. († 1647): Cursus theologicus 3, 6, 12-26, Lyon 1641-43, t.1, pp. 106b-o9a; J. Sendin Calderón OFMObs. († 1676): Opus posthumum 5, 4, hg. von J. Bernique, Alcalá 1699, pp. 317-35.

181. Vázquez, In Primam partem 67, 17. 25, t.1, pp. 555a/56a. 561b; Ders.: Commentaria ac Disputationes in Primam Secundae S. Thomae 189, 115-16, Lyon 1620, t.2, p. 308a/b. - „Vasques autem..., quem sequitur ibi Arrubal..., requirunt ad fundamentum huius scientiae, moralem saltem connexionem in obiecto futuro ad conditionem, cum qua efficitur. Unde negant, pure disparata sciri posse a Deo." Magalhaes, De scientia Dei 2, 11, 3, p. 376.

182. „... hic modus Suarii praevalet magis hac tempestate apud Authores Societatis..." Magalhaes, De scientia Dei 2, 11, 3, p. 376.

183. „Veritas harum propositionum regulanda... est... ex ipso eventu posita connexione contingenti consequentis cum antecedenti.“ HerICE, In Primam partem 7, 59, p. $161 \mathrm{~b}$.

184. Fonseca, In Metaph. 6, 2, 4, 10, t.3, p. 126a/b; SuÁrez, Varia opusc. theol. 2, 2, 6, 4, t.11, p. 362b; HerICE, In Primam partem 7, 62, p. 162. Auch mit dem Sprachgebrauch gerechtfertigt: Ruiz de Montoya, De scientia Dei 68, 5, 17-23, p. 685.

185. „... propositiones de futuro contingenti conditionato habere aliquam determinatam veritatem, quia significant determinatum aliquod tempus... “ N. Ysambert († 1642): Disputationes in Primam partem S. Thomae Q. 14, 8, 2, Paris 1643, p. 209a. - „Scientia media repraesentat 
hypothetische Aussage, dem Sinn nach eine kategorische. ${ }^{186}$ Auch die Logikliteratur beglaubigt ${ }^{187}$ diese von der Fraktion Vázquez verspottete, Arkanlogik. ${ }^{188}$ Mit dieser These hat Suárez theologisch bis ins gegnerische Lager Zustimmung gefunden. ${ }^{189}$ Während eine starke Minderheit an dem kausalen Sinn des Kondizionals festhält, ${ }^{190}$ wird aus dem von ihr bekämpften Ansatz seit FonsecA die Folgerung gezogen, daß $q$ nicht einmal einen Bezug zu $p$ haben ${ }^{191}$ bzw. $p$ nicht einmal für $q$ relevant sein muß (sub conditione conducente / sub conditione disparata). ${ }^{192}$ Irrelevanz ist zulässig: „Wenn der Papst in Rom schläft, tanzt Mustafa in Konstantinopel. “193 Über die

conditionate illa futura immediate... ut existentia pro tali temporis differentia sub conditione.“ Aldrete, In Primam partem 28, 14, 5, t.1, p. 497a. Vgl. Martínez, Deus Sciens 4, 3, 2, p. 624.

186. SuÁrez, Tratado inédito $\$ 68$, p. 127; Varia opusc. theol. 2, 2, 5, 10, t.11, p. 358a; De gratia, Prol. 2, 7, 24, t.7, p. 95b; Becanus, Summa Theol. schol. 1, 1, 10, 6, 6, p. 65a; Ruiz de Montoya, De scientia Dei 68, 9, 5-7, p. 690.

187. D. Soto OP. († 1560): Summulae 1, 16, 3, 1, Burgos 1529, fol. 76ra/b. Vgl. Mendoza, Quodl. 7, 13, pp. 549-50; Fonseca, In Metaph. 6, 2, 4, 10, t.3, p. 125b; SuÁrez, De gratia Prol. 2, 1, 9, t.7, p. 50a; Aldrete, In Primam partem 27, 8, 14, t.1, pp. 414b/15a; ebd. 28, 9, 36, t.1, p. 466b.

188. „Scientia coexistentium inconnexorum non est scientia conditionalium: quia conditio connexionem importat per modum sequelae unius ad aliud." Recupito, Theologia 2, 1, 26, 3, t.2, p. 139b. Vgl. Ledesma, De auxiliis, pp. 604bB-05aA; Twisse, De scientia media, p. 458a; PrIDEAux, De scientia media $\$ 9$, p. 24; Voet \& Nethen, De scientia media $\$ \$ 20,24$, pp. 311-13. 318-19 („arcana quaedam Dei Logica").

189. ZumeL, Utrum Deus habeat praescientiam (Opuscula t.2), pp. 124aC. 177bB/C. 179bB-8obC; Lemos, Panoplia Gratiae 1, 5, 20, t.1, p. 251a; Felix, Primum Princ. Complut. 1, 6, 1, 13, p. 143 a/b.

190. „Quicquid in contrarium dicant Fonseca..., Suarez..., tamen conditionalis particula ,si' praeter hanc concomitantiam et coniunctionem, proprie importat aliquam causalitatis... connexionem... Particula ,si' ita videtur accipienda, ut significet idem quod significat particula ,quia', non autem quod significat particula ,ergo', hoc est veram, licet liberam, dependentiam effectus a causa..., non autem consequentiam, quae est quidem dependentia consequentis ab antecedente, tamen dependentia necessaria, non libera. "FASUlO, In Primam partem Q. 14, art. 13, 252-53, t.2, pp. 176b/177b. - „Ille enim sensus conditionalis, quem intendit Suarez, ut particula , si’ significet idem quod, quando', valde improprius est et a communi omnium conceptione alienus, qui in conditionalibus non comitantiam fortuitam, sed aliquam connexionem apprehendunt." AlARCón, Theol. schol. 2, 4, 2, 8, p. 131b. Vgl. VázQuez, In Primam Secundae 189, 119, t.2, p. 309a; Hurtado De Mendoza, De anima 9, 144-46, p. 593b; Raynaud, Theologia naturalis 8, 25, p. 802 .

191. „... in consequenti ponitur aliquis effectus relatus ad talem causam..."Agostini, In Primam partem Q. 14 art. 13, \$135, t.2, p. 113a.

192. MartíneZ, Deus Sciens 4, 3, 1, p. 616.

193. „... Deum cognoscere per scientiam mediam veritatem conditionalis disparatae." RIVADENEYRA, De scientia Dei 23, 29, p. 509b. - „Propositiones conditionales disparatae, quatenus disparatae, habent determinatam veritatem, aut falsitatem. "Peralta, De scientia media 4, 4, p. 399. 
Frage, wie etwas, das handlungsmetaphysisch nicht nach dem Schema von Erstakt und Zweitakt konfiguriert ist $(\$ 13)$, in den Scientia Media-Kondizional paßt, hat die Scientia Media-Theologie sich gespalten. ${ }^{194}$ Ruiz de Montoya verteidigt Fonsecas Position damit, daß davon die Möglichkeit auch der Kausalerkenntnis abhängt, denn die pragmatische Analyse der Bedingungsseite führt wiederum auf unendlich viele, voneinander unabhängige und sich nur zufällig überschneidende Kausalreihen. ${ }^{195}$ MaUno bemerkt, daß es aus Gottes Perspektive gar nichts Disparates gibt. ${ }^{196}$ Weil auch Fliegen in einem Scientia Media-Szenario eine Rolle spielen können, muß vor Erschaffung jeder Fliege die Scientia Media konsultiert sein. ${ }^{197}$ Diese Antizipation des Leibnizuniversums, in dem alles mit allem zusammenhängt, führt zu Skurrilitäten. ${ }^{198}$ Das ist die Veranlassung für die im 18. Jahrhundert so beliebte und von Tolstoi dann verspottete Geschichtsbetrachtung „les grands evénements par les petites causes“. 199 Auch Arriaga sondiert die Grenzen, indem er den Scientia Media-Kondizional den Wahrheitsbedingungen der materialen Implikation unterstellt. ${ }^{200} \mathrm{Da}$ er gleichzeitig bezweifelt, daß ein Satz vom Typ „Wenn die Chimäre ein freies Wesen wäre und dieses Gnadenangebot erhielte, würde sie annehmen“ (auch: „Wenn die Chimäre - das Irreale - als Weib realisiert würde, wäre sie Nonne") ${ }^{201}$ tatsächlich zu Gottes Wissenshaushalt gehört,

194. „... dubitatur..., an illa propositio vera sit, necne? Affirmat Suarez, negat Vasquez: utrumque patronum plures sequuntur.“ Oviedo, De anima 7, 6, 12, t.2, p. 113a. - „Iuxta veram et communem Iesuitarum sententiam non salvatur scientia media circa conditionata disparata." AvENDAÑo y Eztenaga, De divina scientia 4, 2, 4-5, t.2, pp. 34-36.

195. „... earum (sc. circumstantiarum) omnium coexistentia pendet ex plurimis causis valde disparatis inter se invicem et libere operantibus ac mere fortuito concurrentibus eodem tempore." Ruiz de Montoya, De scientia Dei 73, 5, 3, p. 768b. Ausführlich ebd. 78, 2, 6-8, p. 822a/b. Zum Erfolg dieser Argumentation Izquierdo, De Deo uno 28, 417, t.2, p. 18 oa („P. Didacus Ruiz..., quem Recentiores imitantur...").

196. Mauro, Opus theol. 1, 46, 22, t.1, p. 154a.

197. Mauro, Opus theol. 1, 68, 4, t.1, p. 214a/b; Pallavicino, Assertiones theol. 8, 319, p. 525. Vgl. Aldrete, In Primam partem 30, 11, 1, t.1, p. 579a: „Wenn diese Fliege in Spanien herumschwirrt, wird Johannes in Italien Mönch“.

198. „Scientiam mediam non vocamus illam, quae scurrilitates exprimit..." UlLOA, Theol. 1, 3, 69, t.1, p. 119b.

199. L. Tolstor: Krieg und Frieden II, 2, 28.

200. Arriaga, In Primam partem 21, 42-45, t.1, pp. 223-24. Vgl. Veken, De Deo uno 19, 30-31, pp. 343a-44a; Polizzi, De anima 29, 15, t.3, p. 406a/b; MAnuel de la Concepción, De scientia Dei 5, 286-9o, pp. 550-54; Ramirez, De scientia Dei 16, 201, t.2, pp. 115/16; Peralta, De scientia media 4, 5, pp. 409-18.

201. Araujo, Curs. theol. 4, 513, t.1, p. 235 b. 
hat das die Fraktion Vázquez in ihrer Vermutung bestärkt, daß auf diese Weise der Vernunftbeweis für die Existenz der Scientia Media ad absurdum geführt wird. ${ }^{202}$

\section{$\$$ 11. [Praxis]}

Die Scientia Media ist nicht nur ein kontemplatives, sondern auch ein praktisches Wissen. ${ }^{203}$ Der Kondizionalsatz repräsentiert eine Tatsache. Unter dieser Voraussetzung sind zwei Fälle zu unterscheiden. Entweder ist die Bedingung $p$ nur gesetzt, oder sie ist erfüllt, d.h. realisiert. Durch die Realisierung der Bedingung wechselt das hypothetisch Zukünftige in das kategorisch Zukünftige. ${ }^{204}$ Aus der möglichen Welt wird die wirkliche Welt. ${ }^{205}$ Bis dahin (sub conditione) ,schwebt' die Bedingung. ${ }^{206}$ Informationslücken ${ }^{207}$ hat Gottes Wissenshaushalt deswegen nicht, denn für Feststellungen darüber, was ist und nicht ist, ist die Scientia Media nicht zuständig. ${ }^{208} \mathrm{Ihr}$ Gegenstandsbereich schließt den Realisierungsfall mit ein, ${ }^{209}$ aber sie abstrahiert von ihm (praecisio a purificatione conditionis). ${ }^{210}$

202. J. Strang († 1654): De voluntate et actionibus Dei circa peccatum 3, 13, Amsterdam 1657, pp. 677-78. Über den Disput zwischen Fonseca und Vázquez: ebd. 3, 11, pp. 653-55.

203. Alarcón, Theol. schol. 2, 5, 4, 5, p. 158 b.

204. Izquierdo, Pharus Scient. 10, 278-79, t.1, p. 266a; Amico, De Incarnat. 7, 77, t.6, p. 97 a.

205. „... His sub conditione praevisis, in posteriori signo rationis (sc. Deus) efficaciter decrevit hunc Mundum condere sub his circumstantiis, sub quibus illum praeviderat scientia conditonata.“ Амico, De Incarnat. 7, 76, t.6, p. 97 a.

206. „Propositio conditionata in nullo differt ab absoluta nisi sola conditione, quae adhuc pendet, aut pendere intelligitur.“ Der-Kennis, De Deo uno 8, 59, p. 178.

207. „... non potest dari suspensio sine ignorantia.“ Silva y Pacheco, In Primam partem Q. 14 art. $13,13,230$, t.2, p. 474 a.

208. G. De Rivadeneyra: Tractatus de voluntate Dei 8, 47, Alcalá 1655, pp. 189b/90a; UlloA, Theol. 1, 3, 74, t.1, p. 121b; Mayr, Theol. 1, 389, p. 306; G. Hermann SJ. († 1766): De Deo sciente $\$$ 222, Ingolstadt 1737, p. 234. - „Deus... in ratione scientiae mediae solum attingit, quidquid in eo signo cognoscibile est per talem scientiam.“ Araujo, Curs. theol. 4, 473, t.1, p. 228b.

209. „Scientia media pendet a futuritione conditionata; sed haec, posita conditione, est absoluta: ergo, posita conditione, pendet ab absoluta. “BERnALDo DE Quirós, Opus philos. 88, 38, p. 586b. „Obiectum scientiae mediae, si existat in rebus, identificatur omnino cum consensu absoluto.“ UlloA, Theol. 1, 3, 111, t.1, p. 137a.

210. Manuel de la Concepción, De scientia Dei 5, 8, p. 299; Aguilar, De scientia Dei 1, 13, 72, t.3, p. 186a. - Zu dem Jargon vgl. Hurtado De Mendoza, De Deo Homine 13, 319, t.1, p. 174b: „... conditio impleta, vel (ut frequenter aiunt) ,purificata..." 
Gleichwohl hängt an dem Fall die praktische Bedeutung, die sie hat, denn auf ihn reduziert sich der Machteffekt. Die beiden Fälle sind mögliche Schalterstellungen. Es steht bei Gott, ob $p$ realisiert wird oder nicht. ${ }^{211}$ Die Scientia Media setzt Gott in den Stand, diese Entscheidung zu treffen. ${ }^{212}$ Der Machteffekt ist auf $p$ beschränkt, ${ }^{213}$ er bezieht sich nicht auf $p / q,{ }^{214}$ trotzdem folgt aus der Realisierung von $p$ notwendig $q,{ }^{215}$ und ist $q$ in diesem Fall auch nicht bedingungsweise, sondern: kategorisch gewollt. ${ }^{216}$ Auf die Realisierung von $p$ reduziert sich das Kapitel von dem kategorischen Vorherwissen ${ }^{217}$ und, zumindest nach Ansicht der Kritiker, auch das Kapitel Prädestination. ${ }^{218}$ Für nonA gibt es zwei mögliche Ursachen: entweder, daß $p$ realisiert und mit nonA verknüpft ist, oder, daß $p$ mit A verknüpft

211. „... Deus nequit in statu conditionato impedire hanc veritatem contingentem ,Si existat auxilium A, existet consensus'... Potest tamen impedire in statu absoluto, quia potest non purificare hypothesin. "Peralta, De scientia media 4, 5, p. 421. Vgl. Granado, In Primam partem 2, 5, 4, 9, t.1, p. 262b; Martínez, Deus Sciens 2, 5, 4, p. 198 („... casu, quo ponatur conditio...“); Ramirez, De scientia Dei 20, 117, t.2, p. 307b; UlloA, Theol. 1, 3, 116, t.1, p. 139a; Saguens, De perfectionibus divinis 2, 1, 6, 49, t.2, p. 134 .

212. "Scientia conditionata contingens de aliquo eventu sub conditione contingente potest dirigere ad ponendam, et non ponendam eam conditionem. "Herrera, De praedest. 2, 24, p. 45.

213. Zum Streitpunkt im Streit mit den Dominikanern: „Controversia... tota est de decreto cadente non supra conditionem, sed supra rem conditionatam. " Recupito, Theologia 2, 1, 28, 6, t.2, p. 145 a.

214. „... Deum ponendo hypothesim nec ponere... connexionem illius cum conditionato." RAMIrez, De scientia Dei 24, 67, t.2, p. 466a. Das wird von den Thomisten beanstandet: „Deus non solum est causa, quod purificetur conditio..., verum etiam, quod detur consensus, si dicta conditio ponatur. Sed iuxta scientiam mediam Deus... solum causaret, quod conditio purificaretur." Piccinardi, De approb. doctrinae S. Thomae 6, 2, 2, t.3, p. 180.

215. "Scientia media cum purificatione conditionis infert necessario conditionatum. “ JUNIUS, De provid. 13, 4, 10, p. 395b. Vgl. UlloA, Theol. 1, 3, 146, t.1, p. 152a; Ramirez, De scientia Dei 24, 41, t.2, p. $458 \mathrm{a}$.

216. „Necesse est, ut is, qui praescit effectum secuturum, si talis conditio ponatur, et vult conditionem ponere, iam non velit effectum sequi, si conditio ponatur, sed absolute velit effectum sequi." BASTIDA, [De scientia media] p. 515b.

217. Arriaga, In Primam partem 20, 33, t.1, p. 208b/o9a; Aldrete, In Primam partem 33, 3, 12, t.1, p. $650 a$. - „Fieri enim potest, ut non ponatur... conditio: quo in casu stabit scientia conditionata talis obiecti, sine scientia absoluta eiusdem. “J. MARTINON SJ. ( $†$ 1662): Disputationes theologicae: De Incarnatione 3, 4, Bordeaux 1644-45, t.4, p. 73 a.

218. Cabrera, In Tertiam partem Q. 1 art. $3, \$ 360$, t.1, p. 298b; Ioannes A S. Thoma, In Primam partem 20, 4, 27-28, t.2, pp. 490a/91a; Felix, Primum Princ. Complut. 1, 6, 2, 30, p. 167a/b. Das sei aber historisch unzutreffend: Martínez, Deus Sciens 4, 4, 8, pp. 712-13. 
ist, aber unrealisiert bleibt. ${ }^{219}$ Diese Alternative besteht jedoch nur, solange non A keine leere Klasse ist. Deswegen wäre die Existenz einer leeren Teilklasse $(\$ 4)$ in Gottes Wissenshaushalt der kritische Fall ${ }^{220}$ für eine Herrschaftsausübung mit den in der Scientia Media-Hypothese dafür vorgesehenen Mitteln ( $\$ 23)$. Unter der Annahme, daß dieses Risiko (,creatura rebellis') nur tatsächlich, durch den Individuenbestand der existenten Welt, ausgeschlossen ist, ${ }^{221}$ ist die Funktionstüchtigkeit der Scientia Media-Hypothese sogar ein Schöpfungsregulativ.

\section{$\$$ 12. [Situation]}

Die Scientia Media-Hypothese ersetzt den Kausalnexus durch den Zusammenhang von Bedingung und Bedingtem. Die Bedingung muß nicht kausalen Sinn haben. ${ }^{222}$ Sofern sie ihn hat, kommen die ,Umstände' ins Spiel. Die klassische Handlungsmetaphysik unterscheidet zwischen der Substanz einer Handlung und deren Umständen. ${ }^{223}$ Für die Gruppe der kausal an ihr beteiligten Umstände hat sich erst später der Kollektivbegriff, Situation' eingebürgert. Das sind die in der Scientia Media berücksichtigten ${ }^{224}$ Umstände: ,agendi, aut non agendi occasiones ${ }^{\text {“ }}{ }^{225} \mathrm{Ob}$ Hindernisse entfernt sind oder nicht, ${ }^{226}$ davon hängen $(\$ 23)$ Erfolg

219. „Ut ergo non sit actus absolutus, exigitur alterum e duobus: vel ne sit actus conditionatus, quando videtur conditio; vel ne videatur conditio, quando est actus conditionatus. "HURTADO DE Mendoza, De Deo Homine 13, 318, t.1, p. 174a. Vgl. Martínez, Deus Sciens 4, 7, 2, p. 754; UlloA, Theol. 1, 3, 93, t.1, p. 129 b.

220. Aldrete, In Primam partem 27, 8, 7-9, t.1, p. 413a/b. - „Nullus est homo, cuius Deus non praevideat opera bona et mala futuribilia sub aliqua conditione." Antorne, De Deo uno 5, 5, 7 , p. 266 .

221. Bernaldo de Quirós, De praedest. 11, 31, p. 94b; Gormaz, Curs. theol. 1, 724, t.1, p. 154b.

222. „Propositio conditionata... dicitur... ,causalis', quando conditio influit in conditionatum.“ IzQuierdo, Pharus Scient. 10, 255, t.1, p. 263b. - „Causa efficiens habet semper physicam et realem influxum in effectum, conditio vero non..., sed tantum connexionem..." P. WAdDing, De Incarnat. 3, 20, pp. 91-92. Vgl. Alarcón, Theol. schol. 2, 4, 10, 2, p. 148a. Zur philosophischen Literatur: R. SPECHT: „Über, occasio’ und verwandte Begriffe vor Descartes“, Archiv für Begriffsgeschichte 15 (1971) S. 215-55.

223. Thomas von Aquin: Summa theologica $\mathrm{I}^{\mathrm{a}} / \mathrm{II}^{\mathrm{ae}} \mathrm{Q}$. 7 .

224. „Non potest scientia media praescindere in hypothesi ab aliquibus circumstantiis..." J. DE Campoverde SJ. (†1737): Tractatus de Incarnatione Verbi Divini 10, 44, Alcalá 1711-12, t.2, p. $262 a$.

225. FonsecA, In Metaph. 6, 2, 4, 8, t.3, p. 119bC.

226. Alarcón, Theol. schol. 2, 4, 6, 17, p. 144b („remotio impedimentorum connotato consensu humanae voluntatis sub conditione futuro"). 
und Mißerfolg einer Gnadenhilfe ab. Von den Umständen hängt auch ab, was am Ende aus dem einzelnen wird. Aus jedem kann an sich alles werden. ${ }^{227}$ In einem anderen Szenario hätte auch dem größten Sünder Erlösung gewunken. ${ }^{228}$ An der Scientia Media-Hypothese wird sowohl die Bequemlichkeit dieser Auskunft ${ }^{229}$ als auch kritisiert, daß, sobald es konkret wird, ${ }^{230}$ die Konfiguration der Umstände Theodizeeprobleme verursacht: ,Gelegenheit macht Diebe.. ${ }^{231}$

Die Scientia Media-Hypothese hat sich darüber verständigen müssen, was bei der kausalen Interpretation in $p$ eingeht. ${ }^{232}$

Obwohl sich bei ihm das Ensemble der Umstände auf die jeweils aktuellen Handlungsumstände beschränkt, geht bei Molina die gesamte Vorgeschichte der Situation in $p$ mit ein. ${ }^{233}$ Die Scientia Media ist das Wissen um einen

227. „Nonne de uno eodemque homine praescivit merita, et demerita sub conditione ex hypothesi diversae constitutionis eiusdem?“ HerICE, In Primam partem 7, 74, p. 166b. - „... videt Deus, unumquemque hominem conditionate et bene, et male operaturum: bene sub infinitis auxiliis, si illi conferantur; male sub infinitis aliis auxiliis, seu combinationibus auxiliorum... "MARTínez, Deus Sciens 4, 4, 4, p. 684. - „... ex ipsius (sc. scientiae mediae) fabrica constat, authores ipsius adeo mutabilem... constituere voluntatem huimanam, ut ex conditionum quarumlibet, quas mens aliqua cogitare valeat, additione, nata sit actum suum variare,... etsi conditio in alio mundo implenda foret." White, Sonus Buccinae: De Gratia et Lib. Arb. \$ 7, p. 258.

228. Zu Judas / Petrus: R. Bellarmin SJ. († 1621): De novis controversiis inter Patres quosdam ex ordine Praedicatorum, et P. Ludovicum Molinam ex SJ. (1597) § 2, hg. von X.-M. LE BACHELET: Auctarium Bellarminianum. Supplément aux Euvres du Cardinal Bellarmin, Paris 1913, pp. 101-13, hier p. 106a; FASUlo, In Primam partem Q. 14, art. 13, 441, t.2, p. 261a; ArRIAGA, In Primam partem 21, 35, t.1, p. 221b; Agostini, In Primam partem Q. 14 art. 13, $\$ 142$, t.2, p. 115 b.

229. Caramuel y Lobkowitz, Leptotatos $\$ \$ 532-33$, p. 275a/b.

230. „Deus non cognoscit contingentia conditionate futura sub conditione vaga et indeterminata quoad circumstantias..." Platel, Synopsis curs. theol. 1, 129, p. 44b.

231. „... iuxta illud commune Gallorum proloquuium, ,L'occasion fait le larron'. Unde, cum in sententia Adversariorum (sc. Jesuitarum) Deus interdum ponat homines in illis circumstantiis et occasionibus, in quibus per scientiam mediam praescivit illos peccaturos, potius quam in aliis, in quibus praevidit eos bene operaturos, videtur esse causa, saltem moralis, cur homines peccent... “ Gonet, Clypeus theol. thom. 4, 8, 264, t.1, p. 538a.

232. "Quae se teneant ex parte hypothesis Scientiae Mediae?" Peralta, De scientia media 4, 1, p. 345. - „Dicendum, illud solum, et nil aliud, tenere se debet ex parte hypothesis, quod necessarium vel conducens est ad deliberationem et liberam electionem ipsius creaturae." STERzINGER, Scientia Media $\$ 67$, p. 69.

233. „... omnia quae necessaria erant, quousque Petrus ad instans locutionis esset deventurus cum circumstantiis omnibus tunc praesentibus..."Molina, Concordia Q. 14 art. 13, 53, 3, 7, p. 386. 
Schicksalszusammenhang, ${ }^{234}$ in dem agiert wird, in welchen der Akteur durch die Umstände als in ein mögliches Schöpfungsszenario versetzt ist, und der die Weltmitgliedschaften desselben Akteurs diversifiziert. Die Situation erweitert sich um die jeweils gewährten übernatürlichen Gnadenhilfen, ${ }^{235} \mathrm{im}$ Zuschnitt der Situation dominiert aber die Weltmitgliedschaft. Das eine ist die Providenz-, das andere die Prädestinationsvariable. ${ }^{236}$ Molina unterscheidet beide, ${ }^{237}$ ohne zu erörtern, ob sein Kalkül die Unterscheidung zwischen der Variation eines einzelnen Umstan$\operatorname{des}^{238}$ und der Wahl einer anderen Welt nicht hinfällig macht. Auf der Aufhebung dieser Unterscheidung beruht indessen seine Lösung, wieso, im Unterschied zur Wirksamkeit der Gnade, die Prädestination ausschließlich von Gottes Willen abhängt: weil sie, unabhängig vom Verhalten des Akteurs, der, wie Gott voraussieht, in diesem Szenario mitspielen würde, in einem anderen nicht, mit der Wahl eines geschlossenen und „en bloc “239 verwirklichten Systems (Natur/Gnade/Inkarnation) zusammenfällt. ${ }^{240}$

234. „... ex hypothesi, quod hunc vel illum ordinem rerum et causarum velit creare..." MoLINA, Concordia Q. 14 art. 13, 50, 16, p. 325 et passim. Diese Formel war in der zeitgenössischen Literatur (G. Sirenio [† 1593]: De fato 3, 6, Venedig 1563, fol. 22rA; SuÁrez, Disp. Met. 19, 11, 10, t.25, p. 74ob) als der antike Begriff des ,fatum' geläufig. Vgl. Cicero: De divinatione 1, 125; Augustin: De civitate Dei $5,9 .-$, ... futura ex hypothesi... pendent... ex ipsa rerum connexione et sequela unius ex altero, quae esset, si hypothesis poneretur." Lessius, De praescientia Dei cond. 19, 18, p. 229.

235. Molina, Concordia Q. 14 art. 13, 53, 2, 17, p. 375; ebd. 53, 3, 16, pp. 391/92; ebd. 53, 4, 12, p. 397.

236. Molina, Concordia Q. 14 art. 13, 49, 13, p. 312.

237. „... ex hypothesi, si ipse (sc. Deus) hunc aut illum ordinem rerum cum his aut illis circumstantiis statueret creare..." MolinA, Concordia Q. 14 art. 13, 49, 11, p. 311. - „... quae futura essent tum in eo ipso (sc. ordine rerum, quem condere decrevit), si eum quoad circumstantias et auxilia aliquo ex infinitis modis sua omnipotentia possibilibus variasset, tum etiam in quovis ex infinitis aliis ordinibus rerum quos condere potuit.“ Ebd. Q. 23 art. 4-5, 1, 8, 14, p. 515.

238. „... Molina... affirmat Deum videre... omnia, quae futura essent, si hoc aut illo modo variarentur conditiones..." Bellarmin, De novis controv. $\$ 2$, p. 106 a.

239. Le Bachelet, Prédestination, t.1, p. 27.

240. Molina, Concordia Q. 23 art. 4-5, 1, 11, 30-31, pp. 556-57; ebd. 1, 13, 1-4, pp. 575-77; SuÁREZ, Tratado inédito $\$ 60$, p. 122; Granado, In Primam partem: De praedestinatione 11, 1, 6, t.2, p. 193a/b; ebd. 11, 2, 15, t.2, p. 197b. Dieses molinistische Lehrstück wird referiert und diskutiert von Bastida, [De scientia media] pp. 518b/19a; Hurtado de Mendoza, De Deo Homine 13, 108-37, t.1, pp. 147-52; R. DE Arriaga: Disputationes theologicae in Tertiam partem D. Thomae 15, 8-25, Lyon 1654, t.6, pp. 163-67; F. DE Fourmestraux SJ. († 1683): Iusta defensio adv. convicia et imposturas Pseudophilalethis vanum Thomistarum triumphum de scientia media temere nuper iactantis $\$ 249$, Douai 1673 , pp. 144-45. Scharf von Molina distanziert sich Lessius: De praedestinatione et reprobatione angelorum et hominum $\$ 61$, Antwerpen 1610, p. 345. 
Im Vergleich dazu ist der Situationsbegriff sonst gestrafft. Die Elternhäuser ${ }^{241}$ würden die Weltmitgliedschaft konkretisieren, deswegen wird aus der Scientia Media-Hypothese aber keine Milieutheorie. Gedacht ist an zufällige, vorübergehende Umstände: Begegnungen, Wunder, ${ }^{242}$ die Kassenlage. ${ }^{243}$ Lessius und ULLOA blenden alles aus, was sich nicht in eine Dynamik der Motive umsetzt und im Seelenleben aktuell auswirkt. ${ }^{244}$ Vorwärts definiert die Resultante („cogitatio“) der so internalisierten Umstände immer nur die notwendige Bedingung für $q,{ }^{245}$ rückwärts einen dem Kausalregreß entzogenen Haltepunkt. ${ }^{246}$

Bei VÁzquez, auf den diese Psychologisierung der Situation zurückgeht, ${ }^{247}$ und dem mittleren SuÁREZ steht $p$ für eine durch Anruf, Frage, Bitte, Vorschlag, vorzugsweise also: durch Sprechakte, konstituierte Situation. Die Weltmitgliedschaft ist bei beiden durch die Reflexion auf die an jedem innerweltlichen Kausalvorgang notwendig beteiligte Mitwirkung (concursus) der Erstursache marginalisiert. ${ }^{248}$

241. „... eo quod nati simus in his rerum circumstantiis parentum, loci, temporis etc. ..." Bernaldo de Quirós, De praedest. 8, 27, p. 55a. Vgl. Hurtado de Mendoza, De Deo Homine 13, 95, t.1, p. 145a.

242. Ruiz de Montoya, De scientia Dei 62, 6, 9, p. 585 a.

243. Oviedo, De anima 7, 6, 2, t.2, p. 111a.

244. „... omnes istae occasiones ac circumstantiae reducuntur ad cogitationes vel propensiones allicientes, aut retrahentes." UlloA, Theol. 1, 3, 40, t.1, p. 107a. Vgl. Lessius, De praescientia Dei cond. 19, 3, p. 216 („quaevis hypothesis aliquo modo excitans“, „cogitatio“).

245. „... talis cogitatio non influit in peccatum Petri, est tamen conditio necessario requisita, quia praerequiritur propositio obiecti.“ Albertini, Corollaria 4, 2, 5, p. 271a/b.

246. „... ex parte hypothesis huius veritatis ,Si Petrus praeveniretur cognitione A, consentiret' nec causae cogitationis adhuc essentiales nec alius quilibet terminus connexionis eius supponi debet." IzQuierdo, De Deo uno 28, 84, t.2, p. 108 b.

247. „... Deum... non modo intelligere omnia futura libera, quae absolute futura sunt, verum etiam omnia, quae libere futura essent, si talis aut talis cogitatio nostrae voluntati applicaretur... Quocirca recte et sigillatim novit Deus, si hac cogitatione sine hac aut illa contraria praeveniretur Petrus..., liberum eius arbitrium operaretur hoc aut illo modo, consentiret aut non consentiret..." VÁzquez, In Primam Secundae 189, 115, t.2, p. 308a.

248. „... necesse est, ut in obiecto illius (sc. conditionatae) praescientiae includatur divinus concursus..."SuÁrez, Varia opusc. theol. 2, 1, 6, 12, t.11, p. 316b; Disp. Met. 22, 4, 38, t.25, p. 838a. „Dicendum est, ita Deum certo cognoscere futura sub conditione, ut etiam sub conditione subintelligatur Dei decretum de concurrendo cum arbitrio. "VÁzQUEZ, In Primam partem 67, 22, t.1, p. 557b. - „Quaelibet... scientia Dei conditionata, antecedenter ad effectum, debet sub particula conditionali ,si' obiective terminari non solum ad conditionem ipsam creatam, verum etiam ad increatam, ac liberum decretum suum. "FASulo, In Primam partem Q. 14, art. 13, 267, t.2, p. $183 \mathrm{a} /$ b. - „Hypothesis obiectiva scientiae mediae directae includit Omnipotentiam. “ UlLOA, Theol. 1, 3, 49, t.1, p. 111a. 
Molina seinerseits erwähnt diese nur beiläufig. Bezeichnenderweise ist für ihn auch der Zeitindex der Futuribilien ein Nebenumstand. ${ }^{249}$ Bei Suárez sind sie hingegen auf die Zeitachse projiziert, sie stehen in einer Art Terminkalender. ${ }^{250}$ Indem er ein hypothetisches Konkursdekret postuliert, integriert Suárez nämlich Gottes Simultankonkurs in die Scientia Media-Hypothese.

Damit in der Beteiligung zweier Akteure, Gott und Mensch, an demselben Effekt $^{251}$ die Zweitursache den Vortritt hat, überläßt die Erstursache, von deren Konkurs metaphysisch die Effektindividuierung abhängt, die Spezifikation ihrer Mitwirkungsbereitschaft der Zweitursache. ${ }^{252}$ Die Indifferenz der aufschiebenden Wirkung dieser Überlassung (,expectando, ut sic dicam, influxum creatae voluntatis") ${ }^{253}$ ist hochproblematisch. ${ }^{254}$ Kann es ein moralisch indifferentes Konkursdekret geben? ${ }^{255}$ Läßt sich die Effektindividuierung aufschieben? ${ }^{256}$ Liegt das Dekret

249. „... ex tali vel tali hypothesi in tali parte temporis et spatii... Neque in scientia ipsa in re est ullum discrimen uno et alio tempore, sed solum in obiecto, quod uno tempore existit, non item alio." Molina an Lessius, Cuenca 4.7.1594, ed. Le Bachelet, Prédestination doc. 6, t.1, p. 39.

250. „(Iudicium Dei attingit) quidquid futurum esset in quacumque differentia temporis possibilis, si Deus voluisset creare illud.“ SuÁrez, Varia opusc. theol. 2, 2, 7, 15, t.11, p. 370a. - „Dicimus... eodem modo futura ex hypothesi non certo cognosci, nisi cognosca[n]tur tali tempore et loco, ... sicut futura absolute... “ T. DE ITUREN (PIUs) SJ. († 1630): Commentaria in Primam partem D. Thomae Q. 14 art. 13, 4, 7, Madrid 1619, p. 211a. - „Scientiae conditionatae obiectum... supponitur tanquam existens in seipso et extra suas causas in ea temporis differentia, quae foret sub talibus circumstantiis." Ruiz de Montoya, De scientia Dei 68, 8, 8, p. 689b. Dazu Lalemandet, De Deo uno 8, 59, t.1, p. 254a.

251. „... essentialiter omnis actio productiva alicuius rei petit procedere indivisibiliter a causa prima et secunda, ut contra Durandum docent communiter omnes Philosophi et Theologi.“ Alarcón, Theol. schol. 2, 5, 8, 16, p. 163 a.

252. SuÁrez, Varia opusc. theol. 1, 1, 15, 3, t.11, p. 77a/b. Dazu Oviedo, Physica 10, 4, 20, t.1, p. 266a. - „... ego et Deus... mutuo determinamus nos ad eandem actionem...“ Morawski, In Primam partem, p. 78. Ich nämlich Gott auf der Typebene („quoad speciem“) und Gott mich auf der Tokenebene („quoad individuationem“): Herrera, De praedest. 6, 156-57, pp. 169-70; Manuel de la Concepción, De scientia Dei 5, 159, p. 442. - „Per ,speciem’ hic intelligimus ,plura individua sub disiunctione', hoc scilicet, vel illud, vel istud..., non vero..., rationem specificam.... P. Aler SJ. († 1727): Philosophia tripartita: Physica $\$ 598$ A, Köln 1710-24, t.2, p. 656b.

253. SuÁrez, Varia opusc. theol. 1, 1, 14, 5, t.11, p. 70 .

254. Ioannes a S. Thoma, In Primam partem 20, 4, 34-42, t.2, pp. 493-97; Mastri da Meldola, In I Sent. 3, 109-29, pp. 120b-26a; GABRIELE Di SAN VinCEnZO, In Primam partem 14, 298-300, pp. $274 \mathrm{~b} / 75 \mathrm{~b}$.

255. Oviedo, Physica 10, 4, 33-44, t.1, pp. 267b-68b.

256. Herice, In Primam partem 7, 84, p. 17ob. Zweifel bei Oviedo, Physica 10, 4, 45-50, t.1, pp. 268b-69b. 
sozusagen schon auf Lager, oder - Gott würde seinen Simultankonkurs immerhin auch versagen können ${ }^{257}$ - müßte es seinerseits jeweils ad hoc erst gefaßt sein?258 Das sind alles Probleme, die Molina nicht hat. Molina disjungiert zwischen Scientia Media und Gottes Konkurs. ${ }^{259}$ Das liegt nicht nur daran, daß in der Konkurs- und Gnadenlehre seine Terminologie, verglichen mit der von Suárez, weniger differenziert ist, ${ }^{260}$ sondern auch daran, daß für ihn gerade die profanen und die von Gott nicht intendierten Handlungen (Sünden) die Domäne der Scientia Media sind. Wie diese zu managen sind, davon wird auf alle Handlungen extrapoliert. ${ }^{261}$ Suárez' systematisches Interesse an der Scientia Media beschränkt sich hingegen auf die Erklärung der übernatürlichen Effekte.

In der Zeit nach Suárez wurde unter dem Eindruck seiner Darlegungen darüber diskutiert, ob die Gnadenstreitigkeiten nicht womöglich nur eine Folgelast der theozentrischen Theorie der Kausalität sind, in welcher beide Streitparteien übereinstimmten, auf deren Basis es jedoch keine Lösung für sie gibt. ${ }^{262}$ Suárez' Integration des Konkursdekrets in die Scientia Media-Hypothese hat nicht nur externe Sympathisanten irritiert. ${ }^{263}$ Für die Zeit nach Suárez ist der Versuch zu beobachten, die durch die Abwendung von Molina sowohl reduzierte als auch erhöhte Komplexität rückgängig zu machen:

a. Jetzt erst wird behauptet, die Vollständigkeit der Bedingung erfordere, wenigstens implizit, die Einbeziehung sämtlicher Umstände. ${ }^{264}$ Der Bedingungssingular

257. VÁzQuez, In Primam partem 67, 22, t.1, pp. 557b/58a; ebd. 99, 43, Lyon 1620, t.1, p. $491 \mathrm{a}$.

258. „... non requiritur ex parte Dei decretum aliquod praeexistens..., sed decretum sub conditione inclusum in ipsa hypothesi, quod Deus nunc haberet actu..., si ea hypothesis ponenda fuisset, et quod non haberet nec habuisset ab aeterno, si hypothesis non fuisset ponenda." L. DE Ribas SJ. († 1647): Summa theologiae 4, 6, 44, Lyon 1643, p. 237b. Vgl. Diotallevi, De scientia quam Deus habet de contingentibus, pp. 254-55.

259. Molina, Concordia Q. 14 art. 13, 53, 2, 12-13, pp. 372-73.

260. Daraus erklärt sich Suárez' Erfolg auch innerhalb der Molinisten. Vgl. z.B. BECANus, Summa Theol. schol. 1, 1, 10, 9, 8, p. 66b.

261. Molina, Concordia Q. 14 art. 13, 53, 2, 23, p. 378 („etiam comparatione omnium“).

262. „Assertores Scientiae Mediae... omnes existimaverunt concursum Dei a concursu creaturae realiter esse indistinctum; quod etiam universi fere Praedeterminantes censuerunt. "BEREUR DE Dôle, De modo coniunct. concursuum 2, 11, 2, p. 172. Sein Lob für die Klarheit von Suárez’ diesbezüglichen Darlegungen: ebd. 1, 1, 6, p. 9. Gegen Bereur: Oviedo, Physica 10, 1, 18, t.1, p. 243 b.

263. J. Punch (Poncius) OFMObs. ( $† 1660)$ : Integer Theologiae cursus ad mentem Scoti 5, 37, Paris 1652, p. 82a/b.

264. „Dico... nullam propositionem conditionatam esse veram, in cuius antecedenti non exprimuntur, saltem virtualiter, omnes conditiones et circumstantiae, sine quibus re ipsa effectus, 
wäre dann nur eine façon de parler. ${ }^{265}$ Molinas Einbeziehung der gesamten Vorgeschichte kann allerdings auch unter dieser Voraussetzung mißbilligt sein. ${ }^{266}$ Die Fraktion Suárez will von den indirekten Handlungsvoraussetzungen nichts wissen. ${ }^{267}$ Die Bedingung faßt sie betont lax. Sie kann z.B. auch disjunktive Form haben. ${ }^{268}$ Das hypothetische Konkursdekret vertritt eventuell auch ganz allein die Bedingung. ${ }^{269}$

b. Wegen der systematischen Konsequenzen, die sie hat, ${ }^{270}$ wird Suárez' Lösung von der Fraktion Vázquez als Verrat an der Scientia Media-Hypothese gewertet. ${ }^{271}$ Vázquez' eigene Lösung für die Unterbringung des Konkursdekrets ist allerdings auch umstritten, und zwar im Hinblick auf den Indeterminismus $(\$ 13)$ : Wenn es möglich wäre, daß Gott seinen Konkurs zu nonA versagt, dann würde eine notwendige Bedingung für den Eintritt von nonA fehlen, und die Freiheit der Unterlassung gäbe es nicht. ${ }^{272}$

seu consequens, non est ponendum.“Alarcón, Theol. schol. 2, 4, 10, 4, p. 148a. Vgl. Ruiz DE Montoya, De scientia Dei 78, 3, 3-4, p. 823b; Oviedo, De anima 7, 6, 5, t.2, p. 111 b.

265. „Hypothesis integra est aggregatum seu collectio ex omnibus causis antecedentibus praerequisitis, et conditionibus constituentibus potentiam proxime et complete electivam... Plerumque nostri authores pro hypothesi ponunt ,vocationem', aut ,cogitationem'...; sed tunc per synecdochen sumitur ,cogitatio', quae est pars totius hypothesis, pro tota hypothesi.“ A. Perez, Opus posth.: De scientia Dei 3, 100, p. 8ob. Vgl. González de Santalla, In Primam partem 12, 4, t.1, p. 193a; UlloA, Theol. 1, 3, 39, t.1, p. 106a/b; Ders.: Prodromus seu prolegomena ad scholasticas disciplinas 5, 207, Rom 1711, pp. 548/49. Anders Herrera, De scientia Dei 16, 30, pp. 422: „Respondeo, ex parte hypothesis nihil debere se tenere nisi id, quod exprimitur."

266. „... non est necessarium, quod singuli actus scientiae mediae repetant ab origine mundi seriem principiorum remotorum, ex quibus descendit consensus." UlLOA, Theol. 1, 3, 66, t.1, p. 118a. 267. „Actus primus remotus per hypothesin scientiae mediae saltem directe non attingitur, sed duntaxat actus primus proximus." Monschein, De Deo $\$ 256$, p. 165. Vgl. Bernaldo de Quirós, De praedest. 8, 5, p. 51b; Opus philos. 89, 19, p. 593a/b; Martínez, Deus Sciens 4, 3, 3, p. 629.

268. Ramirez, De scientia Dei 23, 49-59, t.2, pp. 398b-402a. Dagegen Aranda, Schola Scientiae Mediae 5, 219, p. 371a.

269. „... decretum applicativum indifferens, quo Deus applicat suam omnipotentiam absolute ad concurrendum cum creatura..., potest esse hypothesis adaequata scientiae stricte mediae." Ramirez, De scientia Dei 23, 40, t.2, p. 395b. Vgl. Izquierdo, De Deo uno 28, 65, t.2, p. 105 a.

270. „Deus cognoscit evidenter futura conditionata creata; sed non potest evidenter cognoscere futura conditionata creata, nisi cognoscat etiam evidenter decreta sua conditionata." L. DE Peñafiel SJ. († 1657): De Deo uno et trino 8, 27, 113, Lyon 1663-66, t.1, p. 575a.

271. Alarcón, Theol. schol. 2, 4, 6, 7, p. 143a; ebd. 2, 5, 8, 9, p. $162 \mathrm{a}$.

272. Alarcón, Theol. schol. 2, 5, 8, 51. 55, pp. 167b/68b; Oviedo, Physica 10, 4, 11, t.1, p. 265a; Arriaga, Physica 10, 57, (1669) pp. 458b/59a. Anders Martínez, Deus Sciens 4, 4, 2, pp. 671-72. 
c. Von Suárez' indifferentem Konkursdekret wird bezweifelt, daß es ein integraler Bestandteil der Bedingung ist. ${ }^{273}$ Es wird für möglich gehalten, den Simultankonkurs, je nachdem, sowohl in $p$ als auch in $q$ unterzubringen. ${ }^{274}$ Wo er aus $p$ nach $q$ nur verschoben wird, kann das Gottes Mitwirkungsvorbehalt sogar unterstreichen. ${ }^{275}$ Es gibt aber auch die Position, daß von dem Simultankonkurs systematisch ganz abzusehen ist. ${ }^{276}$ RAYNAUd zieht aus Molinas Anknüpfung an Durandus ${ }^{277}$ diese Konsequenz. ${ }^{278}$ Im Unterschied zu dem mit ihm befreundeten Kapuziner BEREur DE Dôle reicht es ihm allerdings, mit dem sog. Durandismus nicht dogmatisch, sondern fiktionalistisch zu argumentieren: Die Erstursache stimmt ihren Konkurs auf eine Scientia Media ab, die mit der unmöglichen Hypothese operiert, die Zweitursache könnte auf sich gestellt und sich selbst überlassen handeln. ${ }^{279}$ Die Reaktion auf diesen Vorschlag ist

273. „Respondeo... enunciationes istas conditionales... esse verissimas, etiamsi nullum includant conditionale decretum divinae voluntatis statuentis exhibere concursum... simultaneum." Bereur de Dôle, De modo coniunct. concursuum 2, 3, 3, p. 123. Vgl. (L. Bereur de Dôle): Thesis theologica, unde profecta sit dissensio inter Praedeterminantes ex una parte, et modernos Assertores Scientiae Mediae seu Conditionatae ex altera, et quod ea finiri possit ac debeat (1632), in Th. Raynaud: Nova libertatis explicatio 2, 4, Paris 1632, pp. 432-41.

274. Referat: Oviedo, De anima 7, 6, 6, t.2, p. 112a. - „... veritas... conditionata non antecedit decretum subiective conditionate sumptum, sed potius illud involvit ex parte hypothesis et ex parte conditionati.“ Ramirez, De scientia Dei 17, 125, t.2, p. 155 b.

275. „(Concursus simultaneus) videri debet in consequente propositionis hypotheticae, non autem in antecedente." AnNat, Scientia media def. 4, 60, p. 508.

276. Bereur de Dôle, De modo coniunct. concursuum 2, 2, 3, pp. 113-14; ebd. 4, 20, pp. 452. 454-55. Zustimmend Punch (Poncius), Theol. cursus 5, 37, p. 82b („mihi valde probabilis“); ERATH, Conciliatio $\$ 413$, pp. 150-62.

277. Molina, Concordia Q. 14 art. 13, 50, 16, pp. 324-25.

278. „Theophil. Raynaudus putat, Deum per scientiam mediam videre voluntatem humanam in se ipsa, nude ac solitarie sumpta, si sibi ipsi relinqueretur in his vel illis circumstantiis sine divino concursu. “ E. Amort CR. († 1775): Theologia eclectica 1, 5, 4, Bologna-Venedig 1753, t.1, p. 73b. Wohl aus Benedictus a S. Iасово OSA. († 169o): S. Augustini Axiomata theologica, Ferrara 1673, p. 5oob.

279. Raynaud, Theol. naturalis 8, 349, pp. 1047b/48a. Vgl. Diotallevi, De scientia quam Deus habet de contingentibus, pp. 222. 254. - Dagegen BEREur DE Dôle, De modo coniunct. concursuum 2, 10, 3, p. 168: „Impossibile est, ut decernat (sc. Deus) se proxime et identifice concursurum cum creatura ad eam ipsam actionem, quam creatura fecisset sola, si, per impossibile, ita operari potuisset." So auch Bereurs Anhänger M. DE Torrecilla OFMCap. († 1709): Quaestiones in VIII libros Aristotelis Physicorum 2, 4, 1, 7, Madrid 1669, fol. 126ra. 
gereizt, auch endox, ${ }^{280}$ denn er revidiert die an Molina ${ }^{281}$ eben vorgenommene Verbesserung. Der Suarezismus gestattet sich die Durandismus-Fiktion ${ }^{282}$ nicht auf Gottes Standpunkt, sondern nur auf dem Standpunkt des Theologen, der die Scientia Media-Hypothese darlegt.

\section{$\$ 13$. [Indeterminismus]}

Die Scientia Media verzeichnet das Ergebnis eines Handelns unter der Bedingung der Indifferenz gegen den Eintritt von A und nonA, ${ }^{283}$ d.h. unter der Voraussetzung, daß immer auch das jeweils weniger wahrscheinliche Ereignis eintreten kann. ${ }^{284}$ Die Lotterie ist ein passendes Beispiel. ${ }^{285}$ In der Scientia Media ist „alles determiniert" ${ }^{\text {"286 }}$ aber nur logisch, d.h. ereignisabhängig $(\$ 15),{ }^{287}$ nicht kausal. Von

280. „... obiectum Scientiae Mediae nequit esse quale Raynaudus somniat.“Aranda, Schola Scientiae Mediae 5, 217, p. 37ob. Vgl. Oviedo, De anima 7, 6, 6, t.2, p. 112a; Gonet, Clypeus theol. thom. 3, 4, 76-8o, t.1, pp. 232b-33b; HenaO, Scientia media theologice $\$ \$ 305-12$, t.1, pp. 99-100; Piccinardi, De approb. doctrinae S. Thomae 6, 2, 2, t.3, p. 187; Babenstuber, Deus unus 7, 3, 31, pp. 324a-25a; Aguilar, De scientia Dei 1, 13, 341, t.3, p. 283a/b. Abweichend Mastri DA Meldola, In I Sent. 3, 138. 195, pp. 128b. 143a (Ad 4); VARGAS, De Deo sciente 4, 2, 36, t.2, p. 533.

281. Auf den römischen Gnadenkongregationen: „(Dominicani) negant... scientiam mediam... Dicunt enim, per eam cognosci quid homo se solo facturus esset, sine Deo faciente, ut faceret.“ BAstidA, [De scientia media] p. 521 .

282. Bernaldo De Quirós, De praedest. 8, 35-36, p. 56b; Opus philos. 89, 42-43. 48, p. 597b. 598 b.

283. „Scientia media est illa, per quam solum affirmamus, quid eveniret libere et contingenter sub conditione indifferenti ad utrumque contradictorium. "Martínez, Deus Sciens 4, 3, 1, p. 617. Vgl. Ruiz de Montoya, De scientia Dei 73, 4, pp. 765-68; Izquierdo, De Deo uno 28, 249, t.2, p. 146 b.

284. „Non potest Deus per scientiam mediam videre hominem in omnibus casibus dissensurum gratiae remissiori, et in omnibus consensurum intensiori, sed in multis consensurum utrilibet, et utrilibet dissensurum. "Junius, De provid. 13, 4, 22, p. 397b. Vgl. SuÁrez, Varia opusc. theol. 2, 2, 7, 5, t.11, p. 366a; Ruiz de Montoya, De scientia Dei 78, 2, 10, pp. 822b/23a.

285. Aldrete, In Primam partem 26, 9, 5, t.1, p. 386b (in Kritik an Bellarmin). Pejorativ Voet \& Nethen, De scientia media $\$ 21$, p. 314 („Casus novus quidam Deus“).

286. „... hoc sensu omnia esse determinata ad unum in illa scientia.“ SuÁrez, Tratado inédito $\$ 72$, p. 130. - „... sublato omni decreto Dei absolute existente, in obiecto illo scientiae mediae invenitur sufficiens determinatio, ratione cuius possit a Deo determinate cognosci..." MARTínEZ, Deus Sciens 4, 3, 6, pp. 658-59.

287. „Determinatio logica, licet physice prior, est obiective posterior actu, ideoque simpliciter consequens et impedibilis a libertate creata." CAMpoverde, De Incarnat. 11, 35, t.2, p. $332 \mathrm{a}$. 
dem kausalen Aspekt wird abstrahiert. ${ }^{288}$ Der These, die Wahrheit von Existenzaussagen über die Zukunft könnte unter Umgehung des kausalen Aspekts determiniert ${ }^{289}$ und kausal indeterminiert ein Wissensgegenstand sein, ${ }^{290}$ wird extern regelmäßig, ${ }^{291}$ endox hingegen nur vereinzelt widersprochen, ${ }^{292}$ namentlich von dem Leibnizianer WolfF. ${ }^{293}$ Crusius' Einwand, noch stehe der Beweis dafür aus, daß die Scientia Media auf „der Erkenntnis der determinirenden Ursachen“ beruhen müsse, ${ }^{294}$ und STATTLERs Gegenthese zu Wolff, daß sie vielmehr die unzureichenden Gründe zum Gegenstand hat, ${ }^{295}$ rekapitulieren SUÁREz’ Indeterminismus:

288. „Quamvis Deus praedefinivisset omnia futura conditionata, non ideo tolleretur scientia media, sed ad summum fieret, quod Deus duplici scientia cognosceret illa futura: alia in decreto praesenti, tanquam in medio, alia absque ullo medio in se ipsis, et haec esset scientia media, et non illa." Martínez, Deus Sciens 4, 3, 5, p. 650.

289. Deswegen die Distinktion futuritio formalis / causalis: Arriaga, Logica 14, 119, (1669) p. 244a; MartíneZ, Deus Sciens 3, 1, 2-3, pp. 258-69; ebd. 4, 1, 3, pp. 574-75.

290. "De effectu indeterminato et indifferenti non datur nisi scientia indeterminata." Lalemandet, De Deo uno 8, 58, t.1, p. 251b. Vgl. Silva y Pacheco, In Primam partem Q. 14 art. $13,13,121$, t.2, p. 444 b.

291. „Implicat scientia media. ... repugnat evidenter in rebus creatis et creabilibus aliquid esse in seipso formaliter futurum sine futuro causali." (J. A. Morasch [† 1734]:) Atomismus ab iniustis Peripateticorum censuris vindicatus $\$ 393$, (Ingolstadt) 1733, p. 420. Vgl. Ledesma, De auxiliis, pp. 596bD-97aB; GufL, Metaph. $\$ \$ 1096-98.1126$, t.2, pp. 664. 684. - „Implicat, eundem actum esse futurum ,determinate' in se et ,indeterminate', hoc est, sine determinatione, in causa: nego. “ Herice, In Primam partem 7, 88, p. 172 b.

292. „Dico... in mea sententia... Deum cognoscere infallibiliter haec futura (sc. conditionata) in suis causis completis." Agostini, In Primam partem Q. 14 art. 13, \$154, t.2, p. 118b. Vgl. F. FAbBRI OFMConv. (†1630): Theologicae disputationes in Primo libro Sententiarum: De praedestinatione Dei 55, 46, Venedig 1623, p. 9a/b (vgl. jedoch ebd. 55, 73, p. 14a).

293. Сн. Wolff (†1754): Vernünfftige Gedancken von Gott, der Welt und der Seele des Menschen, auch allen Dingen überhaupt $\$ \$ 967-68$ (nebst den Zusätzen $\$ \$ 359-60$ ), Bd. 1, Halle 1743, S. 596-97; Bd. 2, Frankfurt a.M. 1740, S. 581-85.

294. „... hypothesis, quod scientia Dei, quam ,mediam’ appellant, in causarum determinantium cognitione fundata esse debeat, nondum demonstrata est. “ $\mathrm{CH}$. A. CRUsius ( $\dagger$ 1775): Dissertatio philosophica de usu et limitibus Principii Rationis Determinantis, vulgo Sufficientis $\$ 43$, Leipzig 1743, p. 40 (= Ausführliche Abhandlung von dem rechten Gebrauche und der Einschränkung des sogenannten Satzes vom Zureichenden oder besser Determinirenden Grunde, Übers. Ch.F. Krause, Leipzig 1744, S. 118).

295. B. Stattler SJ. († 1797): Philosophia methodo scientiis propria explanata 5, 325. 333, Augsburg 1769-72, t.5, pp. 275. 291. 
Kausalanalytisch wären die Futuribilien unerkennbar. ${ }^{296}$ Daß nicht, wie MolinA andeutet, ${ }^{297}$ die Indifferenz des freien Willens den Erkenntnisgrund von $p / q$ liefert, wird den Kritikern eingeräumt. ${ }^{298}$ Doch auch nicht die Bedingung $p$, die den Erstakt ${ }^{299}$ konstituiert: denn $p$ ist der zureichende Grund für alternative Zweitakte. ${ }^{300}$ Epistemologisch ist die Scientia Media ereignisreguliert, ${ }^{301}$ handlungsmetaphysisch: durch den Zweitakt, ${ }^{302}$ denn aus ihrer Perspektive liegt dieser nicht erst noch in

296. „... quantumvis penetretur voluntas nostra in actu primo, discutiatur, lustretur, comprehendatur et supercomprehendatur, non potest in ea inveniri aliquid, quod dicat, Determinate hoc faciet'.“'Arriaga, In Primam partem 21, 20, t.1, p. 218b. Vgl. SuÁrez, Varia opusc. theol. 2, 2, 7, 4, t.11, pp. 365b/66a; De praedest. 1, 7, 8, t.1, p. 255b; Lessius, De praescientia Dei cond. 20, 7, p. 234; RuIz de Montoya, De scientia Dei 73, 4, 1, p. 765a; Alarcón, Theol. schol. 2, 4, 2, 18-19, pp. 132b/33a.

297. „Deus... ita illud (sc. liberum arbitrium) penetraret, ut in eo inspiceret, in quam partem pro sua innata libertate se esset inflexurum..." Molina, Concordia Q. 14 art. 13, 50, 15, p. 324. Suárez nennt (SuÁrez, Varia opusc. theol. 2, 2, 8, 3, t.11, pp. 37ob/71a) diese von Durandus inspirierte Position (vgl. Felix, Primum Princ. Complut. 1, 6, 2, 35, p. 171a: „fere idem docet Lessius“) ,supercomprehensio'.

298. „... libertas seu indifferentia nostri arbitrii praecise sumpta, indifferenter se habet ad omnes effectus, qui ab illa possunt emanare: Ergo non potest per se esse sufficiens ratio cognoscendi determinate hunc potius effectum futurum quam illum." Becanus, Summa Theol. schol. 1, 1, 10, 7, 3, p. 65b; Herice, In Primam partem 6, 36, p. 100a. Vgl. Zumel, Informe sobre las doctrinas del P. Molina (1595), p. 548; Cabrera, In Tertiam partem Q. 1 art. 3, \$ 350, t.1, p. 297a; Voet \& Nethen, De scientia media $\$ 17$, p. 300.

299. Die Jansenisten ([F. Gesures OSB. † 1705:] Defensio Arnaldina, Antwerpen 1700, p. 572) denunzieren diesen Begriff des , actus primus' als das „Posse Molinisticum“. Daß der ,Valencianismus' (W. Hentrich SJ.: Gregor von Valencia und der Molinismus, Innsbruck 1928, S. 38-39. 139-48) in der Theorie des hypothetischen Wissens auf die Unterscheidung zwischen Erstakt und Zweitakt verzichtet, veranlaßt endox zur Distanzierung von ihm: SoAREs, De anima 5, 3, 287 , t.3, p. 282 b.

30o. „... existere actum, qui pendeat quidem ab illa hypothesi et ab influxu omnium circumstantiarum: sed tamen ita pendeat, ut, aliis omnibus positis, ipse solus potuerit non esse." DioTALlevi, De scientia quam Deus habet de contingentibus, p. 246. - „... electio libera creata sub qualibet hypothesi seu actu primo immediato ultimo completo in ratione sufficientis ad utramque partem contradictionis aut contrarietatis..."Esparza, Curs. theol. 1, 18, 3, t.1, p. 6ob.

301. „... dicamus... veritatem enuntiationum de iis futuris, quae ex libero arbitrio pendent, non ex causis, sed ex ipsis futuris eventibus iudicandam esse. "FonsecA, In Metaph. 6, 2, 2, 7, t.3, p. 91aA. Dazu Voet \& Nethen, De scientia media $\$ 17$, pp. 302/o3.

302. „... cum explicatur obiectum scientiae mediae, ex parte conditionis debent poni illa omnia et sola, quae constituunt actum primum proximum indifferentem, ex parte conditionati poni debet actus secundus liber..." Mauro, Opus theol. 1, 45, 37, t.1, p. 150a. Vgl. Diotallevi, De scientia quam Deus habet de contingentibus, pp. 239-40. 
der Zukunft. ${ }^{303}$ Auf der Basis von $p$ determiniert ist nur die Entschiedenheit des Zweitakts, A oder nonA. Darum hat $p / q$ einen festen Wahrheitswert. ${ }^{304}$

Weil in einer Situation notwendig entweder gehandelt oder nicht gehandelt wird, ist der Satz vom ausgeschlossenen Dritten auch für die hypothetische Betrachtungsweise unhintergehbar. ${ }^{305}$ Cäsar am Rubikon exemplifiziert ${ }^{306}$ den durch die Unterscheidung von Erst- und Zweitakt aufgebauten Entscheidungsdruck. ${ }^{307}$ Platz für den konträren Gegensatz von Ja und Nein gibt es in dem binären Code hingegen nicht. ${ }^{308}$ Wie stellt sich die Scientia Media-Hypothese zu möglichen Defiziten in der Konstitution des Erstakts? ${ }^{309}$ Die Fraktion Suárez hält sie auch dann

303. „... obiecta... non posse habere esse determinatum et necessarium in causa, habere vero esse determinatum in se et in actu secundo. "Herice, In Primam partem 7, 8o, p. 169b. Vgl. Suárez, De gratia Prol. 2, 7, 14, t.7, p. 91a; ebd. Prol. 2, 9, 6, t.7, p. 110 .

304. Lessius, De praescientia Dei cond. 19, 16, p. 228; Diotallevi, De scientia quam Deus habet de contingentibus, pp. 223-24; Pennotto, Propugnaculum humanae libertatis 3, 29, 12, pp. 166b/67a; Agostini, In Primam partem Q. 14 art. 13, \$139, t.2, p. 114a/b; Aldrete, In Primam partem 30, 12, 1, t.1, p. 582a; Avendaño, Probl. theol. 1, 862, t.1, p. 242b; Perrimezzi, Dissertationes 86,1, t.1, p. 394a.

305. „Id solum attingitur ex parte hypothesis a praedicta scientia (sc. media), quod est indifferens ad utrumvis, id est ad conditionatum, et carentiam illius. "RAMirez, De scientia Dei 20, 128, t.2, p. 311a. Vgl. Lessius, De praescientia Dei cond. 19, 3, p. 216; A. SEmery SJ. († 1717): Triennium Philosophicum: Logica 5, 4, 1-2, ( $\left.{ }^{1} 1674\right)$ Rom 1682, t.1, pp. 673-75. 683.

306. MaCedo, Collationes 10, 4, 1, t.1, pp. 368b/69a.

307. „Ex vi igitur illius hypothesis sequitur ex natura rei, ut causa libera in secundo instanti rationis debeat esse extra statum indeterminationis per actualem determinationem in actu secundo, ita ut pro illo instanti vere debeat habere aliquem actum secundum... "Diotallevi, De scientia quam Deus habet de contingentibus, p. 239. - „... sicuti... voluntas non potest manere suspensa ab operari, et non operari absolute, ita neque sub conditione posita praescindere potest ab operari, et non operari conditionate." Polizzi, De anima 29, 5, t.3, p. 404a/b. Vgl. Maderni, Curs. theol. 1, 4, 16, 21, t.1, p. 197a.

308. „Nomine... , dissensus' semper intelligam carentiam sive omissionem consensus.“ Izquierdo, De Deo uno 38, 35, t.2, p. 642b; G. De Rivadeneyra: Tractatus de praedestinatione sanctorum et reprobatione impiorum 3, 38, Alcalá 1652, p. 48b. Vgl. F. Alfonso SJ. († 1649): Disputationes in tres libros Aristotelis de anima 15, 101, Alcalá 1640, pp. 389b-9ob. - Die Unterlassung als dritte Option: Diotallevi, De scientia quam Deus habet de contingentibus, pp. 239. 245; Moncé, Disputationes theol. 3, 15, p. 206.

309. „Scientia... media ad hoc tantum servit, ut sciat (sc. Deus) quid voluntas creata sit factura in quibuslibet circumstantiis, si habeat omnia necessaria ad actum, non autem facit, ut sciat Deus illam habere omnia necessaria ad libertatem actus." P. WAdDing, De Incarnat. 9, 27, p. 393. Eine Aufzählung der notwendigen Bedingungen bei Monschein, De Deo §254, pp. 163-64. 
für zuständig. ${ }^{310}$ Dagegen trifft die Fraktion Vázquez Vorkehrungen gegen ihre Trivialisierung. Daß eine in der Situation mögliche Handlung aus Zerstreutheit oder Unentschiedenheit unterbleibt, sind Ausschließungsgründe. ${ }^{311}$ Am Rubikon wird nicht geangelt.

\section{\$14. [Zureichender Grund]}

Die Scientia Media ist ein koäternes Tatsachenwissen. ${ }^{312}$ Gottes Verstand ist von ewigkeither auf A festgelegt. ${ }^{313}$ Damit er das ist, dazu „reicht es“ (Henao, MartíNEZ, UlLOA), daß A zu dem betreffenden Zeitpunkt der Fall sein würde. Außer A gibt es nicht noch eigens einen Grund dafür, daß A vorhergewußt ist. ${ }^{314}$ Die Futuribilien sind dadurch definiert, daß A eher der Fall wäre als nonA. ${ }^{315}$ Warum wäre A, und nicht nonA, der Fall? ${ }^{316}$ Im Indeterminismus ist die Frage verboten. ${ }^{317}$ In der Scientia Media-Hypothese hat von Anfang an die Neigung bestanden, sie auch

310. „Si... aliquod ex his requisitis (sc. in actu primo ad agendum) desit, necesse erit, Deum cognoscere hanc causam in istis circumstantiis positam non fore acturam. "BASTIDA, [De scientia media] p. 490 o.

311. Alarcón, Theol. schol. 2, 4, 10, 5, p. 148b; Agostini, In Primam partem Q. 14 art. 13, $\$ 135$, t.2, p. 113a; González de Santalla, In Primam partem 36, 7, 39, t.1, p. 527 b.

312. „Etsi nihil de facto voluisset producere, eadem mansisset omnino scientia media." ArRIAGA, In Primam partem 22, 3, t.1, p. 224b. Vgl. Molina, Concordia Q. 14 art. 13, 53, 4, 3, p. 393; SuÁreZ, De praedest. 1, 7, 3, t.1, p. 254a.

313. „... scientia media affirmativa consensus... est ab intellectu divino ut coniuncto cum veritate obiectiva consensus; atqui divinus intellectus ut coniunctus cum hac veritate obiectiva non est potens ad actum oppositum scientiae negativae: alias esset potens ad actum falsum. "Peralta, De scientia media 3, 3, p. 333.

314. Henao, Scientia media theologice $\$ 6049$, t.2, p. $751 \mathrm{~b}$ („satis est“); Martínez, Deus Sciens $4,4,2$, p. 667 (,... obiectum terminativum... simul eiusdem scientiae determinativum sufficiens..."); UlloA, Theol. 1, 3, 100, t.1, p. 132b („hoc sufficit“).

315. „... futurum conditionate, in quantum tale formaliter, nihil aliud dicere ex suo conceptu formali, quam quod res illa, quae, futura' dicitur, esset potius, quam oppositum illius, si poneretur conditio." Martínez, Deus Sciens 4, 3, 5, p. 646.

316. „... quare existat illud extremum contingens potius quam oppositum?"HerrerA, De scientia Dei 14, 16, p. 369 .

317. Ruiz de Montoya, De scientia Dei 71, 6, 30, p. 743a; Martínez, Deus Sciens 4, 4, 1, pp. 65962; UlloA, Theol. 1, 3, 86. 104. 179, t.1, pp. 126b/27a. 134a („hic sistititur“). 169a. 
bezogen auf die Allwissenheit und aus deren Perspektive abzuweisen. ${ }^{318}$ Gott hätte auf sie, schließt nicht nur LeIBNIz aus der Suárezlektüre, keine Antwort. Wo sich nicht der Sprachregelung angeschlossen wird, daß auf Gott das Prädikat, scientia' nicht in dessen scholastischer (,cognitio per causas'), sondern in dessen alltäglicher Bedeutung Anwendung findet, ${ }^{319}$ gerät die Scientia Media-Hypothese deswegen unter Empirismusverdacht. ${ }^{320}$ Die Einforderung des zureichenden Grundes ist der Trumpf der Dominikaner. ${ }^{321}$ Zuerst Ledesma hat Suárez vorgeworfen, er verdränge einen Erklärungsbedarf. ${ }^{22}$ Damit ist sowohl für ihn als auch später für Leibniz die Scientia Media-Hypothese in ihrer suarezischen Variante erledigt; Vázquez wird, wegen seiner Deutung des Kondizionals $(\$ 10)$, von beiden günstiger beurteilt. ${ }^{323}$ $\mathrm{Da} ß$ sie in diesem Punkt noch liefern müsse, ist der Scientia Media-Hypothese auf die Dauer selber so vorgekommen. ${ }^{324}$

Gottes Verstand bestimmt generell sich nicht selbst. ${ }^{325}$ Insbesondere die Scientia Media tut das nicht. ${ }^{326}$ Sie ist passiv und kontingent, also muß es dafür, wie sie

318. „... ex parte Dei non esse quaerendam rationem..." SuÁrez, Varia opusc. theol. 2, 2, 6, 3, t.11, p. 361b; Ruiz de Montoya, De scientia Dei 75, 4, 13-14, p. 794a; Gormaz, Curs. theol. 1, 705, t.1, p. 15ob; Ulloa, De anima 3, 2, 25, p. 319; Araujo, Curs. theol. 4, 379, t.1, p. 213 a.

319. Eine Sprachregelung auch außerhalb der katholischen Theologie. Vgl. z.B. P. Molinaeus († 1658): „Theses Theologicae de omniscientia Dei“ $\$ 2$, in: (Auctores Diversi:) Thesaurus Disputationum Theologicarum in Alma Sedanensi Academia variis temporibus habitarum, Genf 1661, t.1, p. 95.

320. „... neque enim rogatus Deus, unde sciat eam futuritionem? aliquod divinum vel creatum a futuritione ipsa distinctum pro ratione reddet.“ BERNALDo DE Quirós, De Deo 37, 6, p. 295a. „Secundum autores scientiae mediae non posset Deus rationem reddere sui pronuntiati... Quae scientia pure empirica est... “ G. W. Leibniz: Opuscules et fragments inédits, hg. von L. Couturat, Paris 1903, pp. 25-27; Ders.: Textes inédits, hg. von G. Grua, Paris 1948, p. 358. Vgl. Lalemandet, De Deo uno 8, 57, t.1, p. 251 b („notitia experimentalis“). - „Die Scientia media giebt auch nie einen Erklärungsgrund an, denn Gott weiß nach derselben die zufälligen Begebenheiten nur, weil er sie weiß.“ W. L.G. Freiherr von Eberstein: Natürliche Theologie der Scholastiker, Leipzig 1803, S. 155.

321. Ledesma, De auxiliis, p. 589bD; Alvarez, Responsiones 1, 4, 5-6, pp. 133-37; IoAnnes a S. Tнома, In Primam partem 20, 4, 7-8, t.2, pp. 479b/8ob.

322. Ledesma, De auxiliis, p. $597 \mathrm{bA}$ („evasio“). Vgl. Bereur de Dôle, De modo coniunct. concursuum $4,13,5$, p. 375 .

323. Ledesma, De auxiliis, p. 6o1bA/B.

324. Aranda, Schola Scientiae Mediae 5, 146, p. 356b; Peynado, De anima 2, 6, 31, p. 405b.

325. SuÁrez, Disp. Met. 19, 5, 13, t.25, p. 715b; ebd. 30, 16, 49, t.26, p. 200a/b; De gratia Prol. 2, 6, 8, t.7, p. 81b; Aldrete, In Primam partem 26, 7, 6, t.1, p. 379a/b; Izquierdo, De Deo uno 28, 342, t.2, p. 166 a.

326. „Scientia media, licet procedat a principio indifferenti intrinsece, adhuc non est libera, quia determinatur ab extrinseco.“ Bernaldo De Quirós, De Deo 53, 38. 45, pp. 359b. 36ob. 
ausfällt, außerhalb von ihr und trotzdem gottimmanent ${ }^{327}$ einen Bestimmungsgrund geben. ${ }^{328}$ Seit Aldrete ist das sog. determinativum scientiae mediae ein großes Thema. ${ }^{329}$ Den „Gordischen Knoten“"330 zu durchhauen, bleibt trotzdem der thomistischen Dekretlösung überlassen, d.h. den decreta subiective (d.h. bezogen auf den Willen, der sie faßt) absoluta, et obiective (inhaltlich) conditionata. Diese Lösung ${ }^{331}$ scheidet aus. ${ }^{332}$ Sie schiede selbst dann aus, wenn die Futuribilien metaphysisch von dem Dekret abhängig wären.333 Der Werbung für diese Lösung verdankt dagegen Leibniz seine metaphysische Hauptthese, den Prinzipiendualismus von Widerspruchsprinzip und zureichendem Grund. ${ }^{334}$ Auch Aldrete hat die

327. „... omnis (sc. solutio) recurrens ad determinativum extrinsecum a Deo distinctum reiicitur..."Bernaldo de Quirós, De Deo 53, 31, p. 358b.

328. „Assignanda est aliqua ratio a priori, a qua determinetur divinus intellectus ab aeterno ad habendam potius notitiam istam quam oppositam. “Aldrete, In Primam partem 31, 3, 18, t.1, p. 622a. - „... cur haec scientia media de facto existat in Deo.“Ebd. 31, 2, 8, t.1, p. 617a. - „... dari in Deo ab aeterno aliquid positivum, ratione cuius determinetur intellectus divinus ad scientiam mediam..."Bernaldo DE Quirós, De Deo 50, 23, p. 344a; ebd. 53, 23-45, pp. 357b-6ob. - „Scientia... media est aliquod contingens, prout tale: ergo indiget aliquo determinativo extra se, ut existat." Ramirez, De scientia Dei 22, 135, t.2, p. 379a.

329. Rivadeneyra, De scientia Dei 21, 26-34, pp. 463-68; Herrera, De scientia Dei 14, pp. 36491; González de Santalla, In Primam partem 19, t.1, pp. 351-57 („difficultas celebris inter nostros recentiores"); Aranda, Schola Scientiae Mediae 5, 146-70, pp. 356-61; UlloA, De anima 3, 2, pp. 312-23. Historisch: HenaO, Scientia media theologice $\$ \$ 6029-30$, t.2, pp. 748b/49a.

330. Ramirez, De scientia Dei 22, 117, t.2, p. 373 a.

331. Zumel, Utrum Deus habeat praescientiam (Opuscula t.2), pp. 155aB/D. 178aC/D; IoAnnes A S. Thома, In Primam partem 20, 4, 5. 36, t.2, p. 479a. 494b. Kritisch zu Zumel Suárez, Varia opusc. theol. 2, 2, 7, 8, t.11, pp. 367a/68b (vgl. das feed back bei ZumeL, Utrum Deus habeat praescientiam [Opuscula t.2], p. 135bB/D); RuIz De Montoya, De scientia Dei 71, 9-11, pp. 747-53.

332. „Futurum conditionatum non consistit pro formali in decreto divino subiective absoluto et obiective conditionato: ita omnes ex nostris." Ramirez, De scientia Dei 17, 3, t.2, p. 117b. Vgl. Aldrete, In Primam partem 30, 9, 3, t.1, p. 573a; Martínez, Deus Sciens 4, 3, 3, pp. 632-35; ebd. 4, 3, 6, pp. 652-53.

333. UlloA, Theol. 1, 3, 100, t.1, p. 132b.

334. „Si inquirerer, quare potius sciatur actus futuritio, seu quod Petrus sit acturus, quam sit actus non futurus, sub tali auxilio: numquid ab his (sc. Molinistis) respondetur, quod hoc ideo habetur, quia est contradictio, cur actus sit extiturus potius quam non futurus, sufficiens ratio? Sed quod hoc determinate debeat in veritate prae alio existere, id ex Contradictione nulla prorsus ratione potest quis colligere... Ergo nisi decernatur, quod actus ille ponatur, non est maior ratio, quod actus sit extiturus, quam sit actus non futurus, sub tali auxilio." A. PINY OP. († 1709): Quaestiones agitatae inter Thomistas et Molinistas modo resolutae scholastico, rhythmicis versibus decantatae, Lyon 1666, pp. 59-60. 
thomistische Lösung im Blick. ${ }^{335}$ Er spekuliert über Gottes Empfänglichkeit für und über sein Determiniertsein durch eine Asymmetrie zwischen A und nonA. ${ }^{336}$

Die Jesuiten der Provinz Toledo opponieren. 337 Oviedo führt Aldretes Fragestellung auf die Skepsis gegenüber der objektiven Wahrheit zurück; ${ }^{338}$ dafür anfällig ist er freilich $(\$ 8)$ auch selber. RAmirez gibt $\mathrm{zu}$, daß in der Konkurrenz von A und nonA das eine dem anderen gegenüber irgendwie im Vorteil sein muß,339 er nimmt aber von Aldretes Thesen nicht weiter Notiz. Seine Rezension der um 1700 innerhalb der Scientia Media-Hypothese kurrenten Positionen wertet jede Abweichung von Suárez als einen Rückfall in den Prädeterminismus. ${ }^{340}$ Den gesuchten Bestimmungsgrund gibt es. ${ }^{341}$ Er fällt aber mit dem Erkenntnisgrund zusammen. Die objektive Wahrheit ist das determinativum sowohl quod als auch quo. ${ }^{342} \mathrm{Neu}$ ist nur, daß so, wie die objektive Wahrheit zu Gottes Wissen um sie in Beziehung gesetzt wird, die Scientia Media jetzt als Effekt konstruiert wird, wogegen es sonst Vorbehalte gegeben hat. ${ }^{343}$ Ihre Rekonstruktion wendet das Kondizionalverhältnis, in umgekehrter Richtung sozusagen, auf sie selber an: Die Futuribilien sind die Bedingung, das Wissen um sie ist das Bedingte. ${ }^{344}$ In der Darlegung der einschlägigen Fundierungsbeziehungen, die auf einer metasprachlichen Ebene liegen, wird sich streng, aber irreführend, im Rahmen der von Suárez objektsprachlich zur Verfügung gestellten gedanklichen Mittel gehalten. ${ }^{345}$ ULLOA unterscheidet im Begriff des

335. Aldrete, In Primam partem 33, 1, 13, t.1, p. 645 a.

336. Aldrete, In Primam partem 31, 2, 1-9, t.1, p. 616a/17b; ebd. 31, 6, 19-21, t.1, p. 631a/b.

337. „... mihi sat est asserere, nullum determinativum condistinctum a consensu condicionato posse apte designari ..." Oviedo, De anima 7, 6, 15-20, t.2, pp. 113b/14b.

338. Oviedo, De anima 7, 6, 21, t.2, p. 114b („potissimum, imo, ut suspicor, unicum fundamentum“).

339. Ramirez, De scientia Dei 22, 78-8o, pp. 359b-61a.

340. Ramirez, De scientia Dei 22, 12-17, t.2, pp. 335a/37b.

341. Ramirez, De scientia Dei 22, 138-39, p. 380a/b.

342. Ramirez, De scientia Dei 22, 33. 47, t.2, pp. 343a. 348b. Vgl. Oviedo, De anima 7, 6, 17, t.2, p. 114a; Izquierdo, Pharus Scient. 10, 45, t.1, p. 229a; Platel, Synopsis curs. theol. 1, 127, p. 43b; Peralta, De scientia media 3, 2, pp. 267-69; VArgas, De Deo sciente 4, 1, 5, t.2, p. 483.

343. Bernaldo de Quirós, De Deo 53, 41, p. 36oa; González de Santalla, In Primam partem 19, 14, t.1, p. 354a.

344. Ramirez, De scientia Dei 22, 34-35. 102, t.2, pp. 343a/b. 367b/68a. Vgl. IzQuierdo, De Deo uno 28, 355-58, t.2, pp. 169b/70a (,tanquam per conditionem quandam completivam“); HeNAO, Scientia media theologice $\$ 6082$, t.2, p. $760 a$.

345. Eng angelehnt an das suarezische Lehrstück von Gottes interner Scientia Media $(\$ 17)$ bei RAmireZ, De scientia Dei 22, 38, t.2, pp. 344b/45a. 
determinativum scientiae mediae systematisch zwischen dem Bestimmungsgrund und dem Verifikationsaspekt (in genere efficiente / in genere verificante). ${ }^{346}$ Auch bei ihm liegt die Betonung unverändert auf diesem letzteren $(\$ 8)$, denn es ist nicht notwendig, daß der truthmaker der Scientia Media aktuell existiert. ${ }^{347}$ Im Relativismus der Perezschule, der von dem Gegenteil ausgeht, wird (Cienfuegos) nach dem Bestimmungsgrund in genau diesem Sinn geforscht. Das Ergebnis ist eine krude Mischung aus Idealismus ${ }^{348}(\$ 8)$, Esoterik ${ }^{349}$ und fideistischer Skepsis. ${ }^{350}$

\section{\$15. [Impedibilität]}

Die Frage nach dem zureichenden Grund von Gottes Wissen erledigt sich dadurch, daß nicht Gottes Wille die Scientia Media bestimmt, sondern der kreatürliche Wille. ${ }^{351}$ Ihre Bestimmbarkeit ist eine rein ,gegenständliche’ ( $\left.\$ 3\right)$, d.h. Informationseffekt. Um diesen von Effekten anderer Art zu unterscheiden, hat die Jesuitentheologie den technischen Begriff Impedibilität. Er bezieht sich auf die Schnittstelle zwischen Gottes Vorherwissen und dem kreatürlichen Handeln und besagt, daß auch das Gegenteil des Gewußten den Inhalt des Wissens bilden könnte. ${ }^{352}$ Der Akteur, der zu einem Gnadenangebot (bzw. zu einer Versuchung) jetzt neinsagt, bewirkt dadurch, daß ein Ja von ewigkeither nicht der Inhalt des

346. UlloA, Theol. 1, 3, 67, t.1, pp. 118a/19a. Vgl. auch CH. Meindl SJ. (†1690): Theses theologicae de Deo $\$ \$ 95-97$, Dillingen 1673, pp. 69-71.

347. „... ut scientia media sit vera et consequenter actu de praesenti existens in Deo, necesse non est, quod suum determinativum obiectivum actu de praesenti existat." UlloA, Theol. 1, 3, 102, t.1, p. 133b. Vgl. CH. Haunold SJ. († 1689): Theologia speculativa 1, 312, Ingolstadt ${ }^{2} 1678$, p. 52a/b; Peralta, De scientia media 3, 3, pp. 281-83.

348. Cienfuegos, Aenigma Theol. 12, 2, 3, t.2, pp. 413b/14a.

349. Gottes Verstand hat die Indifferenz eines Fühlers: A. Perez, Opus posth.: De providentia 3, 45, p. 325b; Aranda, Schola Scientiae Mediae 5, 166, p. 360a; Ders.: De Divini Verbi Incarnatione 3, 1, 148, Saragossa 1691, p. 291a. Cienfuegos nennt das die „vis sympathica praesagiendi futura“.

350. Daher der Selbsteinwand Cienfuegos, Aenigma Theol. 12, 3, 12-14, t.2, pp. 444a/45a.

351. „Non Deus, sed creata voluntas, per suam indifferentiam ad utrumlibet, libere determinavit, ut esset et sciretur hoc potius scibile quam oppositum. “FASUlo, In Primam partem Q. 14, art. 13, 488, t.2, p. 277b. Vgl. Molina, Concordia Q. 14 art. 13, 52, 10, p. 340; SuÁREZ, Varia opusc. theol. 2, 2, 6, 3, t.11, p. $361 \mathrm{~b}$ („ratio ex parte obiecti“).

352. L. WAdDing SJ. († 1652): Concordia Divinorum et Humanarum 4, 93. In diesem Band S. 241. 
Vorherwissens gewesen ist. ${ }^{353}$ Er hat es also selber in der Hand, daß das Gegenteil vorhergewußt wäre. ${ }^{354}$ Zwischen dem kategorisch und dem bedingt Zukünftigen wird in dieser Beziehung kein Unterschied gemacht. Die Tendenz dazu, beides zu parallelisieren („parificatio“), 355 logisch (\$ 6), erkenntnistheoretisch ${ }^{356}$ und handlungsmetaphysisch, ${ }^{357}$ kulminiert vielmehr in der Übertragung auch dieses Merkmals, der Impedibilität, auf die Scientia Media. ${ }^{358}$ Die Scientia Media-Hypothese adoptiert das Junktim von Wahrheit und Freiheit:359 daß die Instanz, welche die betreffenden Sachverhalte wahr macht, die Freiheit hat, das auch nicht zu tun. Die These von der Impedibilität der Scientia Media ${ }^{360}$ ist dieses Junktim..$^{361}$ Deswegen

353. „... negari non potest, iuxta principia scholae nostrae (sc. Scientiae Mediae), in homine posito in libertate consentiendi, et dissentiendi, dari potentiam temporalem inducendi aliquid aeternum in Deo, medio consensu, vel dissensu." ARANDA, De Incarnat. 3, 1, 141, p. $290 a$.

354. „... in potestate hominis, de quo Deus praescivit non consensurum vocationi, est facere, ut Deus praesciverit, ipsum consensurum vocationi, nam in potestate eius revera est consentire; quod si consensurus esset, id Deus praescivisset." SuÁrez, Varia opusc. theol. 1, 3, 14, 14, t.11, p. 228a. Vgl. Molina, Concordia Q. 14 art. 13, 52, 38, p. 355; VÁzQuez, In Primam partem 68, 47, t.1, p. 581a; Rivadeneyra, De scientia Dei 17, 8, p. 367a/b.

355. „... parificatio inter futura conditionata et absoluta... “NAvArrete, Controversiae 56, 4, t.1, fol. 355ra (zu Suárez, Varia opusc. theol. 2, 2, 7, 16, t.11, p. 37oa).

356. Molina, Concordia Q. 14 art. 13, 50, 19, p. 325 („simili modo“); SuÁrez, De gratia Prol. 2, 7, 21, t.7, p. 94a/b.

357. „Non habet maiorem connexionem effectus de facto futurus cum voluntate de facto constituta in tali occasione volendi, quam effectus similis conditionaliter futurus cum voluntate etiam conditionaliter futura." SuÁReZ, Tratado inédito $\$ 52$, p. 118. Vgl. Diotallevi, De scientia quam Deus habet de contingentibus, pp. 250-51; Aldrete, In Primam partem 30, 12, 9, t.1, p. $587 a$.

358. „... scientiam visionis impedibilem esse a voluntate creata. Et similiter discurri debet de Scientia Media." Henao, Scientia media theologice $\$ 6073$, t.2, p. 757 b. Vgl. Muniesa, De provid. 9, 64, p. 220 .

359. Explizit Felix, Primum Princ. Complut. 1, 6, 2, 19, p. 158a.

360. „... fixum esse debet iuxta principia Societatis, ad libertatem requiri, ut possimus impedire... scientiam mediam nostrorum operum. “ González de SAntalla, In Primam partem: De praedest. 6, 43, t.2, p. 151b. - „... homo habet... potestatem impediendi Scientiam Mediam sive faciendi ne existat." Herrera, De scientia Dei 14, 46, p. 38o; ebd. 17, 18, pp. 475f. Vgl. ArRIAGA, In Primam partem 21, 34, t.1, p. 221b; Aldrete, In Primam partem 30, 17, 6, t.1, p. 599a; In Tertiam partem 21, 2, 13, t.1, p. 229b; IzQuierdo, De Deo uno 38, 9, t.2, p. 636b; Junius, De provid. 5, 6, 16, p. 113b; Aranda, Schola Scientiae Mediae 5, 230, p. 373b. Oviedos Sondervotum (Herrera, De scientia Dei 17, 17, p. 475; RAmirez, De scientia Dei 22, 55, t.2, p. 351a/b) ist leider verschollen.

361. „Cui liberum est ponere, aut non ponere conditionatum sub hypothesi, liberum est impedire, et determinare veritatem conditionalem et scientiam divinam ei correspondentem. ... Impedire veritatem conditionalem oppositam est formaliter determinare istam, quae cum illa 
konserviert die Scientia Media-Hypothese den klassisch-scholastischen Apparat der Argumentation, warum Gottes Vorherwissen der menschlichen Freiheit nicht widerstreitet. Auch sie argumentiert mit der von Anselm von Canterbury eingeführten Distinktion zwischen einer (kausal-)vorgängigen und einer (logisch-)nachfolgenden Notwendigkeit (necessitas consequens). ${ }^{362}$ Der Eindruck ${ }^{363}$ sei falsch, auf der Basis der Scientia Media wäre alles schon Teil eines fertigen Programms: „Wir selber legen durch unser Verhalten unmittelbar die Scientia Media fest.“" 364 Die Scientia Media ist die „Folge“365 unseres Verhaltens, etwas Nachträgliches. ${ }^{366}$ Aber wie soll sie das sein? Vor Gottes Entscheidung, Adam unter den bekannten Umständen zu erschaffen, ist es schon wahr gewesen, daß, wenn Adam unter diesen Umständen erschaffen würde, es zum Sündenfall käme. ${ }^{367}$ Molina und Suárez

opponitur.“ Ramirez, De scientia Dei 23, 109-10, t.2, p. 418a/b. - „Sciendum..., quamcumque scientiam Dei a creatura non posse aliter impediri quam per hoc, quod creatura impediat veritatem illius obiectivam. “ Monschein, De Deo $\$ 359$, p. 235.

362. „Ideo... saepe et semper inclamamus, necessitatem provenientem ex scientia media non tollere libertatem, quia est essentialiter consequens id, quod a nobis faciendum esset libere." Martínez, Deus Sciens 4, 5, 3, p. 725. Vgl. SuÁrez, Varia opusc. theol. 1, 3, 14, 14, t.11, p. 228a; VÁzQuez, In Primam partem 68, 21. 27, t.1, pp. 57ob. 572b; Ders., In Primam Secundae 189, 121, t.2, p. 309b; Diotallevi, De scientia quam Deus habet de contingentibus, p. 266; Alarcón, Theol. schol. 2, 5, 8, 57, p. 168b; Oviedo, De anima 7, 6, 13, t.2, p. 113b; Mauro, Opus theol. 1, 85, 9, t.1, p. $252 \mathrm{a}$.

363. „Sit... proprium argumentum contra scientiam mediam: Posita ea scientia de peccato Petri futuro sub tali vocatione, et posita vocatione - quae duo... antecedunt futuritionem absolutam non potest non esse absolute peccatum: ergo tollitur libertas ad illud, ergo scientia media tollit libertatem.“ Arriaga, In Primam partem 21, 29, t.1, 220b. - „... illud ipsum... Stoicorum Fatum... per hanc scientiam... introducitur." Voet \& Nethen, De scientia media $\$ 29$, p. 331. Vgl. Leibniz, Textes inédits ed. Grua, p. 359.

364. „... vel debemus posse evitare scientiam mediam, vel funditus ruit nostra libertas. “ HeRRERA, De scientia Dei 17, 20, p. 476. - „Scientia media de futuritione consensus... nullo... modo libertatem nostram laedit. ... nos determinamus Deum mediate, quatenus per consensum inducimus seu determinamus immediate scientiam mediam. "Bernaldo DE Quirós, Opus philos. 89, 31. 57, pp. 595b. 600a. - „Deus determinatur a nostro actu, qui foret, ad Scientiam Mediam de illo." Henao, Scientia media theologice $\$ 454$, t.1, p. 134a.

365. „... scientia media non antecedit, sed subsequitur ordine rationis ad dissensum. “GonZÁLEZ De Santalla, In Primam partem 38, 12, 67, t.1, p. 621a.

366. „Intrinseca scientiae posteritas denominat prius obiectum libere extiturum conditionate, respectu cuius ipsa dicitur posterior." Henao, Scientia media theologice $\$ 458$, t.1, p. 135a/b.

367. „... antequam Deus decerneret creare Adamum, et illum constituere in talibus circumstantiis, erat verum, quod, si eum crearet et constitueret in illis, peccaturus erat.“ SoAREs, De anima 5, 3, 174, t.3, p. 266b. - „Deus de primo ad ultimum... cognoscebat per scientiam mediam, primum hominem, nempe Adamum et eius posteros, lapsuros in peccatum, si Deus complaceret in existentia huius universi." Aldrete, In Tertiam partem 21, 1, 12, t.1, p. 226b. 
zufolge ${ }^{368}$ wäre das heilsökonomisch auch schon so eingeplant gewesen. Damit der Nexus zwischen dem Vorhergewußtsein und dem Eintritt des Vorhergewußten ein Anwendungsfall der harmlosen nachfolgenden Notwendigkeit ist, genügt es angeblich, daß die Welteinrichtung ein bestimmtes Scientia Media-Szenario pünktlich umsetzt. ${ }^{369}$ Aber Adam hat für das Szenario nichts gekonnt. Akut wird das Problem ${ }^{370}$ in Gestalt eines Themas, das die Scientia Media-Hypothese fast von Anfang an beschäftigt und in einen Grundlagenstreit verwickelt hat: der Frage, ob es mit der Hypothese vereinbar ist, die guten Werke auf der Basis der Scientia Media in derselben Bestimmtheit und mit der gleichen Wirkung für prädefiniert zu halten, um deretwillen von der theologischen Konkurrenz die physische Prädetermination für nötig gehalten wird. SuÁrEZ und seine Fraktion haben das bejaht (,praedefinitio Suaristica, seu simpliciter dependens a Scientia Media'), ${ }^{371}$ VÁzQuez und seine Fraktion es ebenso entschieden verneint. Wie eng ist das Junktim von Wahrheit und Freiheit? Wie „unabhängig "372 ist die kondizionale Wahrheit von der kategorischen? Für die Fraktion Vázquez muß für die Impedibilität der Scientia Media eine Bedingung erfüllt sein, welche nun gerade nicht immer erfüllt ist.

368. Molina, Concordia Q. 23 art. 4-5, 1, 8, 15, pp. 516-17; SUÁrez: Commentaria et disputationes in Tertiam partem D. Thomae Q. 1 art. 3, \$9, t.17, p. 190 .

369. „... iuxta communem sententiam... ad salvandam libertatem in creatura sufficit, ut Deus praevideat actum libere sub conditione futurum, et postea conferat ea principia, ex quibus praevidit eundem libere sub conditione futurum. “Амico, De Incarnat. 7, 91, t.6, p. 99a.

370. „Adamus in paradiso creatus sub illis circunstantiis, non potuisset non peccare, quia nec potuit impedire, ne crearetur sub illis circunstantiis, nec potuit efficere, ut Deus non praescivisset, eum fuisse peccaturum, si crearetur sub illis circunstantiis, nec potuit falsam reddere praescientiam Dei." Ruiz de Montoya, De scientia Dei 76, 5, 9, p. 8o7b. Erst recht so die Kritik aus dem konfessionell anderen Lager: Strang, De volunt. Dei 3, 13, pp. 670-74; Quenstedt, Theol. didactico-polem. 1, 8, 7, p. 317 b.

371. Die griffige Formel bei Ortega, De Deo uno 6, 2, 1, 4, 1, t.2, p. 26oa, und im Inhaltsverzeichnis von Aranda, Schola Scientiae Mediae disp. 34, p. 523. - „... maior pars nostrorum Theologorum, qui scientiam mediam defendunt, illas (sc. praedefinitiones actuum liberorum etiam antecedentes) admittant..." Martínez, Deus Sciens 4, 4, 6, p. 701.

372. „Veritas consensus conditionati est independens a veritate consensus absoluti, sine qua veritas conditionata esse potest. “ J. MARTÍnEZ DE RIPALDA SJ. ( $\dagger$ 1648): De ente supernaturali disputationes 113, 24 [25], Lyon 1634-45, t.2, p. 517b. 


\section{$\$ 16$. [Existenzialismus]}

Wenn die Scientia Media sich intentional an den Zweitakten erfüllt ( $\$ 13)$, ist bei der Willensfreiheit von Existenzannahmen abstrahiert. Nicht nur davon ist zu abstrahieren, ob die Bedingung, unter der ein Akteur soundso handeln würde, faktisch eintritt, die Existenz des Akteurs ist selber ein Teil der Bedingung. ${ }^{373}$ Gott weiß, wie hypothetische Akteure in hypothetischen Situationen ${ }^{374}$ aus freien Stücken („pro sua innata libertate") ${ }^{375}$ agieren würden. Im Hinblick darauf kann ihnen, sei es die Existenz ganz versagt bleiben, sei es die Lebensspanne verkürzt sein. ${ }^{376}$

Für die Fraktion SuÁrez wurzelt ${ }^{377}$ die Impedibilität der Scientia Media in dem status conditionatus. ${ }^{378}$ Nach derselben Logik, nach der es im Kausalsinn ein sicheres Wissen um bedingt freizukünftige Handlungen nicht gibt $(\$ 13)$, gibt es ein

373. „Sumatur homo aliquis possibilis numquam futurus: quaestio est, an de illo homine cognoscat Deus certo et infallibiliter, si illum creasset..., an peccaret necne. "SuÁrez, Tratado inédito $\$ 1$, p. 81. - „... per ,futurum conditionatum liberum' intelligimus illum (sc. effectum), qui poneretur a causa libera in his, vel illis circumstantiis libere..., et tamen de facto non poneretur, quia non ponetur talis causa, vel talia requisita ad illum.“ Agostini, In Primam partem Q. 14 art. 13, $\$ 134$, t.2, p. 112b. - „Deus est essentialiter necessitatus, ut de quacumque voluntate creata vel creabili cognoscat, quid esset factura sub quacumque hypothesi possibili, in qua relinquatur indifferens ad utrumque." González de Santalla, In Primam partem 14, 22, t.1, p. 223 a. Vgl. Molina, Concordia Q. 14 art. 13, 53, 3, 11, p. 39o; MaUro, Opus theol. 1, 45, 11, t.1, p. 147 b.

374. „... respectu personarum possibilium, quae numquam futurae sunt... in personis aliquando futuris, respectu earum occasionum, in quibus de facto nunquam invenientur... "SUÁrez, Varia opusc. theol. 2, 2, t.11, p. 343 a.

375. Molina, Concordia Q. 14 art. 13, 52, 9, p. 340; Diotallevi, De scientia quam Deus habet de contingentibus, p. 252; Aмico, De Incarnat. 7, 76, t.6, p. 97 a.

376. Fonseca, In Metaph. 6, 2, 4, 9, t.3, pp. 124b/25a; Aldrete, In Primam partem 32, 2, 7, t.1, p. 635b. Im Calvinismus ist die Theologie des Todeszeitpunkts gegen die Scientia Media-Hypothese ausgespielt worden: G. Voet: Dissertatio epistolica de termino vitae, Utrecht 1641, pp. 102-10.

377. „... determinatio scientiae mediae ab existentia conditionata est a priori..." JuniUs, De provid. 12, 2, 8, p. $345 \mathrm{~b}$.

378. „... dicimus, libertatem nunquam existentem posse actu determinare, et actu impedire scientiam mediam...“ UlloA, Theol. 1, 3, 63, t.1, p. 117a. - „... independenter ab statu tali absoluto intelligitur determinata Scientia, quae de facto existit, potens impediri..." Ramirez, De scientia Dei 22, 110, t.2, p. 37ob. Vgl. ebd. 22, 112, t.2, p. 371a; ebd. 23, 120, t.2, p. 422a. - „Scientia Media... est impedibilis in statu conditionato per dissensum, non qui est, sed qui esset, quem nimirum, si vellet, poneret voluntas, si conditio poneretur." J. B. GENER SJ. († 1781): Theologia dogmatico-scholastica 1, 293, Rom 1766-77, t.2, p. 191. Vgl. H. DE CERF: Controversia inter Angelici Doctoris sectatores de mente eius circa praedeterminationem physicam $\$ 346$, Douai 1669, p. 235; Platel, Synopsis curs. theol. 1, 129, p. 44b; Mauro, Opus theol. 1, 46, 13, t.1, p. 152a; Erber, De Deo uno $\$ \$ 444-45$, pp. 441-43. 
solches nur in einer Form, die sie auch zurechenbar macht. Die von Gott an unser Eventualverhalten geknüpften Folgen stehen „gewissermaßen“ in unserer Macht. 379 Damit gerät die Scientia Media-Hypothese, sosehr sie das ableugnet, ${ }^{380}$ in die Nähe der semipelagianisch auf Eventualverdienste gesetzten Prämien.

Dieser Schritt ist bei VÁzQUEZ verboten. Wenn es möglich ist, daß das Ergebnis des Wissens um mein Eventualverhalten von Gott vorweggenommen wird, dann hebt das die Voraussetzung auf. „Daraus, daß Gott im Besitz des hypothetischen Wissens war, daß ich die Gnadenhilfe $y$ annehmen würde, folgt nicht, daß sein entsprechendes Prädefinitionsdekret mit meiner Freiheit vereinbar ist. “ ${ }^{381}$ Dieses Wissen stand nicht in meiner Macht. ${ }^{382}$ Ein darauf gestütztes Prädefinitionsdekret hätte die Situation verändert. ${ }^{383}$ Zwischen dem status conditionatus und dem status

379. „... respondeo, illud decretum Dei (sc. praefinitionis) aliquomodo fuisse in nostra potestate, quatenus scilicet Deus non haberet illud, nisi praevidisset nostram liberam cooperationem sub conditione futuram. “ Granado, In Primam partem: De praedestinatione 11, 2, 19, t.2, p. $198 \mathrm{~b}$ (in Zurückweisung von Vázquez’ Kritik an Suárez).

380. „Sequitur ex ista positione scientiae mediae, dari meritum quoddam occultum in eo statu conditionato, in quo sit ratio aliqua motiva apud Deum eligendi unum prae alio..." MACEDo, Collationes 11, 1, 13, p. 440b; GonzÁlez De Rosende, Disputationes theol. 4, 1, 18, p. 507b. Dagegen z.B.: SuÁrez, De praedest. 1, 7, 20, t.1, p. 259a; Diotallevi, De scientia quam Deus habet de contingentibus, p. 275-78; MARTínez, Deus Sciens 4, 4, 3, pp. 678-79. - „Merita... in statu conditionato non sunt proprie merita; nam sicut Deus tunc me videt in una occasione bene merentem, ita me videt in altera occasione non merentem, sed peccantem etiam per eadem auxilia: ergo sub ea conditione non possum ego dici movisse Deum meis meritis ad eam volitionem efficacem (sc. praemiandi).“ Arriaga, In Tertiam partem 15, 24, t.6, p. $167 \mathrm{a}$.

381. „Ex eo quod Deus noverit sub conditione, me libere consensurum tali vocationi, non sequitur, in mea fuisse libertate decretum ipsius absolutum, quo praefinivit, me tale opus facturum.“ VÁzQuez, In Primam partem 99, 13, Lyon 1620, t.1, p. 485b.

382. „... licet scientia sub conditione, prior' esset voluntate illa efficaci..., ob id tamen electio illa facta ante praescientiam absolutam consensus nostri,... propter priorem illam scientiam sub conditione, nullo modo fuisset in nostra potestate." VÁzQuEZ: Commentaria ac Disputationes in Tertiam partem S. Thomae 23, 126, Lyon 1620, t.1, p. 198b. - „Haec (sc. praescientia conditionata, qua Deus praescit, quae gratia, si hic et nunc collata fuerit, sit habitura effectum, quae minime) enim ut sit in Deo vel non sit, non est in nostra potestate, quia praevenit omnem nostram actualem libertatem, etiam in esse obiectivo consideratam. "Lessius bei LE BACHELET, Prédestination doc. 96, t.2, p. 221.

383. VÁzQUez, In Primam partem 99, 14, Lyon 1620, t.1, p. 485b; ebd. 89, 96, t.1, p. 398a; Lessius, De praedest. $\$ 62$, p. 347 („... obiectum quodammodo mutatur...“); HeRICE, In Primam partem 23, 99-102, pp. 443b-45a („... non aliter... quam... physica praedeterminatio“); Moncé, Disputationes theol. 4, 5, pp. 273-76; P. WAdDING, De Incarn. 9, 25-27, pp. 392-93; RHodes, Theol. schol. $1,5,2,4,3$, t.1, pp. 139b-4ob. 
absolutus fehlt dann der Zusammenhang. ${ }^{384}$ Funktional von der Scientia Media abhängig zu sein, rettet nicht die Freiheit. ${ }^{385}$ Das bedingt Freizukünftige rangiert gar nicht in dem Sinn ,vor. ${ }^{3}{ }^{86}$ In dem status conditionatus, bezogen auf hypothetische Akteure in hypothetischen Situationen, ${ }^{387}$ gibt es keine Freiheit. ${ }^{388}$ Nicht unter Bedingungen, die unverwirklicht bleiben, sondern nur indirekt, über die freie Willensbetätigung zum Jetztzeitpunkt, entspringt der status conditionatus aus Freiheit. ${ }^{389}$ Das zu bestreiten, meint AldreTE, hätte unmittelbar deterministische Konsequenzen. ${ }^{390}$ Die faktische Existenz ist der einzige status capax libertatis, ${ }^{391} \mathrm{erst}$ mit der Existenz ist die Freiheit gesetzt. Dagegen ist es ein Mißbrauch der Sprache, „Existenz’ von hypothetischen Handlungen zu prädizieren. ${ }^{392}$ Die Impedibilität

384. González de Rosende, Disputationes theol. 4, 1, 19, p. 508a („incohaerentia status conditionati cum absoluto“). Der Jansenist argumentiert mit Vázquez gegen Suárez.

385. VÁzquez, In Primam partem 89, 96, Lyon 1620, t. 1, p. 398 b. - „(Vázquez) passim docet volitionem praedefinitivam Dei, tametsi nihil reale et physicum in creata voluntate poneret, erepturam ei, non obstante praescientia conditionalium, usum libertatis quoad id, quod praedefinitum esset." Moncé, Disputationes theol. 3, 9, pp. 167-68.

386. „... futuritio ipsa quasi obiectiva sub conditione non praecedit natura realiter futuritionem absolutam: quia haec eadem est cum illa... Status enim conditionatus prioritate quadam logica et secundum rationem dicitur ,praecedere’...“AlArcón, Theol. schol. 4, 1, 6, 17, p. 28oa. Anders z.B. IzQuierdo, Pharus Scient. 10, 57, t.1, p. 230 b.

387. „... semperque perurgendi sunt adversarii in futuritione conditionata operis hominis pure possibilis, qui nunquam extiturus est..."Aldrete, In Primam partem 26, 6, 19, t.1, pp. 377b/78a.

388. „... exercitium libertatis sub conditione non est vera libertas, sed erit vera libertas posita conditione.“ Aldrete, In Primam partem 26, 7, 12, t.1, p. 38ob. - „... operari... sub conditione, aut ita non operari, non est simpliciter operari, vel non operari: quamobrem in statu conditionato nulla libertas simpliciter... visitur." R. LYNCH (LyNCAEus) SJ. († 1676): Universa philosophia scholastica: Logica 10, 4, 29, Lyon 1654, t.1, p. 396a.

389. „... si re vera existit illa conditio, sub qua operatio illa videbatur futura, pendet ille status (sc. conditionatus) a nostro opere libero. Si autem decernat Deus, ut illa conditio non existat, minime pendet status ille a nostra operatione." Aldrete, In Primam partem 26, 6, 14, t.1, p. 377 a.

390. „... nullatenus negari potest dependentia status conditionati ab exercitio absoluto nostrae libertatis: quoniam, si non penderet status conditionatus ab hoc exercitio absoluto, nusquam esset in nobis potestas impediendi statum absolutum... "Aldrete, In Primam partem 26, 6, 15, t.1, p. 377a. - „... talis status conditionatus humanam everteret libertatem, quoniam posita conditione haberet connexionem infallibilem cum nostra operatione, et aliunde non posset impediri a nobis. "Ebd. 30, 19, 5, t.1, p. 605 a.

391. Arriaga, In Primam partem 21, 34, t.1, p. 221 b.

392. „... alioquin... nostri actus liberi futuri sub conditione, qui non sunt futuri absolute, dicerentur ,existentes'. Quod est abuti terminis et absurdissime loqui.“ AldRete, In Primam partem $30,19,7$, t.1, 605a. 
der Scientia Media ist also relativierungsbedürftig. ${ }^{393}$ Solange $p$ nicht realisiert ist $(\$ 11)$, ist sie nicht impedibel. Das interessiert den Akteur aber auch nicht. Wenn $p$ realisiert ist, ist sie impedibel. ${ }^{394}$ Hat der Akteur es dann in seiner Hand, die Scientia Media zu korrigieren? Diese Vorstellung wird mißbilligt. ${ }^{395}$ Besser spricht man von einer, dann ausgefüllten, Leerantizipation. ${ }^{396}$ Die Impedibilität hängt also an dem status absolutus, ${ }^{397}$ an dem Überschneidungsbereich mit dem kategorisch Zukünftigen. Der kontrafaktische status conditionatus verblaßt zu einem sterilen Schattenreich, ${ }^{398}$ auf das bezogen es sich erübrigt, die Zurechenbarkeit

393. „Scientia media non est absolute in nostra potestate ratione usus conditionati praecise, sed ratione usus absoluti, qui est in nostra potestate absoluta... Itaque eatenus solum potest voluntas absolute impedire eam scientiam, quatenus potest absolute impedire coniunctionem usus arbitrii cum conditionibus, sub quibus praevidetur futurus, quae coniunctio est obiectum talis scientiae. Id autem non potest voluntas potestate absoluta, nisi conditiones absolute existant." MARTínEZ DE RIPALDA, De ente supernat. 72, 8, t.2, p. 8 a.

394. „... dico, in primo statu non esse in potestate Petri efficere, ne in Deo fuerit scientia media, at hoc nec in minimo laedit eius libertatem: quod enim ego non existens aut non positus in occasione, non habuerim potestatem impediendi eam scientiam, non obest mihi, si postea, quando existo et sum in occasione, possum illam impedire... Ideo dico secundo, in eo secundo statu me posse efficere, ut non esset in Deo ea scientia media: si enim, ut possum, posito eo auxilio, non respondeo, efficio eo ipso ne Deus habuerit ab aeterno eam scientiam." Arriaga, In Primam partem 21, 33, t.1, p. 221a. - „Licet ego, dum non habeo conditionem, non possim tollere scientiam mediam, possum tamen, si illam habeam. “Bernaldo de Quirós, De praedest. 9, 61, p. 68a; Opus philos. 88, 48, p. 589a. - „... homo purificata hypothesi potest impedire, et non impedire scientiae mediae determinativum." Peralta, De scientia media 3, 3, p. 336. - Vgl. Raynaud, Nova libertatis explic. 2, 4, 31, p. 496; Aldrete, In Primam partem 26, 8, 16, t.1, pp. 384b/85a; Polizzi, De anima 29, 11, t.3, p. 405b; González de Santalla, In Primam partem: De praedest. $12,13-15$, t.2, p. $270 a / b$.

395. „Nullo modo nobis libera est, scientiam Dei, quam semel supponimus esse, impedire aut mutare." VÁzquez, In Primam partem 68, 51, t.1, p. 583b. - „Dixi (sc. scientiam mediam esse) ,impedibilem', non autem ,falsificabilem'..." UlloA, Theol. 1, 3, 54, t.1, p. 113a. Vgl. Mayr, Theol. 1, 386, p. 303; Araujo, Curs. theol. 4, 541, t.1, p. 24 ob.

396. „... scientia media pro primo signo suae existentiae non pendet ab opere, sed praescindit ab eo, quod pro signo alio sequenti pendeat, vel non pendeat. “Aldrete, In Tertiam partem 21, 1, 14, t.1, p. 229b. Vgl. Rivadeneyra, De praedest. 3, 35. 42, pp. 47a. 5ob; ebd. 4, 35. 37, pp. 70a-71a; González de Santalla, In Primam partem 19, 19-20, t.1, p. 355a; ebd. 38, 12, 69, t.1, p. $622 a$.

397. „... solum in statu absoluto et purificata conditione est liberum voluntati creatae impedire scientiam mediam, quatenus potest impedire actum liberum affirmatum per scientiam mediam. “ González de Santalla, In Primam partem 38, 8, 35, t.1, p. 6o8a.

398. „Ubinam possimus causare vel impedire nostram umbram?" VeKeN, De Deo uno 19, 36-37, pp. $346 \mathrm{~b} / 47 \mathrm{~b}$. 
aufrechtzuerhalten. ${ }^{399}$ Diese Lösung, die, vermutlich seit Hurtado de Mendoza, herrschende Lehre in der Jesuitenscholastik, ${ }^{400}$ wird auch auf das Sündenfallparadox angewandt. ${ }^{401}$

Die Fraktion Suárez (Young, Ramirez) protestiert, ${ }^{402}$ hat aber kaum mehr als Redensarten zu bieten. ${ }^{403}$ Eine zur Rettung der Zurechenbarkeit am COLLEGIO Romano vorgeschlagene äterne, intentionale' Präexistenz der freien Willensakte ${ }^{404}$ wird von beiden Fraktionen verworfen, ${ }^{405}$ in der Folge wechselt Perez zur Fraktion Vázquez. ${ }^{406}$ Meistens wird zwischen Suárez und Vázquez dialektisch laviert. ${ }^{407}$ Auf beiden Seiten sieht man die Unvermeidlichkeit einer „Quadratur des

399. „Facta ex scientia media nobis imputari nequeunt. Etenim facta, quae sunt obiectum scientiae mediae, sunt actualia alius mundi. Facta autem actualia alius mundi nobis minime imputari possunt.“ J. E. GunNER: Meditationes philosophico-theologicae de imputatione peccati adamitici ex scientia media $\$ 5$, Jena 1749, p. 10.

40o. Martínez, Deus Sciens 4, 5, 4, p. 729 („multi ex nostris Doctoribus“). Die Vermutung zur Urheberschaft bezieht sich auf das Selbstzeugnis bei Hurtado de Mendoza, De Deo Homine 13, 310, t.1, p. 173a.

401. „Voluntas Adam potest efficere, ne ipsa processerit ex tali scientia media.“ BERnALDo DE Quirós, Opus philos. 88, 35. 40, pp. 585b. 587a. Vgl. CAMpoverde, De Incarnat. 11, 19, t.2, p. 321 b.

402. „Arbitror..., non debere... distingui duo signa scientiae mediae, unum anterius, in quo sit independens a consensu libero, alterum posterius, in quo ab ipso pendeat, posita libertate..." Junius, De provid. 12, 3, 22-23, p. 35ob. Vgl. Ramirez, De scientia Dei 22, 133, t.2, p. 378b. Zweideutig Herrera, De scientia Dei 17, 18, p. 475; De praedest. 2, 37, p. 50.

403. „... dum consensus existit conditionate,... libertas moraliter existens moraliter determinat scientiam mediam. “ Marín, Theol. 1, 11, 47, t.1, p. 99b. Statt ,moraliter' kann die abschwächende Umstandsbestimmung auch (Junius, De provid. 12, 2, 3, p. 345a) lauten: ,obiective' oder ,intentionaliter'.

404. „Scientia media procedit a libero arbitrio creato, prout existente et operante intentionaliter prius, quam existat in se intrinsece et operetur physice." Esparza, Curs. theol. 1, 34, t.1, p. 124b; ebd. 1, 18, 14, t.1, p. 62b. Vgl. A. Perez, Opus posth.: De providentia 3, 72, p. 329a; Haunold, Theol. 1, 311, p. 52a; Drattenberger, De scientia Dei \$ 92, pp. 73-74.

405. Aldrete, In Primam partem 26, 7, 12, t.1, p. 38ob („,ego vehementissime dissentio“); ebd. De praedest. 2, 10, 7, t.2, p. 266a („prorsus inintelligibile“); IzQuierdo, De Deo uno 28, 340-49, t.2, pp. 165b-67b; Avendaño, Recogn. tomi I Probl. Theol. \$\$623-24, p. 221a/b. Auch der Thomist PicCINARdi, De approb. doctrinae S. Thomae 6, 2, 2, t.3, pp. 182-83.

406. „Scientia media dependet ab existentia absolutae meae operationis.“ A. Perez, Opus posth.: De intelligentia Dei 6, 40-41, p. 190a. Der Positionswechsel wird notiert von Aldrete, In Primam partem 31, 4, 1, t.1, p. 622a.

407. „... apud Iesuitas... futuritio conditionata et ipsa scientia media ponitur impedibilis a nobis, non tamen nobis libera libertate exercita." Avendaño y Eztenaga, De divina scientia 4, 1, 9, 7, t.2, p. 25b. Vgl. z.B. Manuel de la Concepción, De scientia Dei 5, 167, p. 451. 
Zirkels “, ${ }^{408}$ d.h. der spekulativen Kombination verschiedener Kausalreihen. Auf der Grundlage wird sich sogar auf die Integration des kontroversen Prädefinitionstyps verständigt. ${ }^{409}$ Selbst RuIz DE MonToya, der das Junktim von Wahrheit und Freiheit nachdrücklich verteidigt, ${ }^{410}$ tut das unter Verzicht darauf, die vazquezianische Argumentation zu widerlegen. ${ }^{411}$ Sein Versuch, zwischen Freiheit und Kontingenz mit dem Ziel zu unterscheiden, der Scientia Media, auch ohne daß die Freiheitsbedingung realisiert sein muß, die Kontingenz zu sichern, ${ }^{412}$ provoziert den Einwand, daß dadurch der Zufall metaphysisch akut wird. ${ }^{413}$ Dafür sägt die Demontage des status conditionatus, die bei Aldrete philosophisch diverse Motive hat, ${ }^{414}$ an der Scientia Media-Hypothese selbst. ${ }^{415}$

\section{$\$ 17$. [Umfang]}

Nur Gott ist das Subjekt der Scientia Media, ${ }^{416}$ also kein Laplacescher Dämon. An dieser Exklusivität gibt es ernstlich keinen Zweifel. ${ }^{417}$ Von größter systematischer

408. „Quadratura circuli, quem trahit scientia media." Junius, De provid. 12, 2, pp. 344-46.

409. Während die Fraktion Vázquez (Bernaldo DE Quirós, De praedest. 9, 32, p. 63b) die Quadratur mit zwei Kausalreihen bewerkstelligt, benötigt die Fraktion Suárez (Young) dazu deren drei. Vgl. auch TolomeI, Theol. nat. 6, 4, 19-20, pp. 734b/35a.

410. „Num libertas iam de facto conveniat scientiae conditionatae, vel solummodo conveniret libertas, si talis conditio poneretur... Nihilominus sit conclusio: Libertas iam de facto et absolute convenit scientiae conditionali, iamque ab aeterno fuit libera, diligenter quoque cavendum est, ne concedatur solummodo tunc futuram fuisse liberam, si talis suppositio poneretur... Nam illa scientia Deo est iam actu libera, cuius obiectiva veritas est iam actu libera et contingens, nec solum foret in alio casu libera et contingens; talis autem est veritas, quae est obiectum scientiae conditionalis." Ruiz De Montoya, De scientia Dei 76, 5, 1-4, p. 806b.

411. Ruiz de Montoya, De scientia Dei 76, 4, 15-16, pp. 8o5b/o6a; ebd. 76, 5, 1. 11, pp. 8o6b. 8o8a.

412. Ruiz de Montoya, De scientia Dei 76, 5, 5, p. 807 a.

413. Aldrete, In Primam partem 30, 19, 5, t.1, p. 605a. Vgl. den Angriff auf Ruiz de Montoya ebd. 31, 1, 14, t.1, p. 615b („responsio... omnino insufficiens“).

414. Aldrete, In Primam partem 26, 6, 10, t.1, p. 376a; ebd. 26, 6, 18, t.1, p. 377 b.

415. Daß in einem Rundschreiben der Ordensleitung vom 12.1.1664 (LE BACHELET, Prédestination doc. 150, t.2, pp. 378-81) von einer Krise der Scientia Media-Theologie in Spanien („et quidem in Hispania“) die Rede ist, ist vielleicht eine Reaktion auf das Erscheinen (1662) von Aldretes Disputationen zur Prima pars.

416. „Scientia media nulli creato intellectui convenit.“ RuIz De Montoya, De scientia Dei 79, 3, p. 824 b.

417. Höchstens polemisch: CABRERA, In Tertiam partem Q. 1 art. 3, §363, t.1, p. 299a. 
Tragweite ist hingegen der Streit darüber, ob ausschließlich die Geschöpfe ihr Objekt sind. Molina und seine Fraktion am Collegio Romano behaupten das. ${ }^{418}$ SuÁREz hat sich jedoch damit durchgesetzt, diese Beschränkung als inkonsequent abzuschütteln. ${ }^{419}$

Aus Molinas Konzeption der Weltenwahl folgt, daß Gott wissen muß, ob Er sich auch auf der Basis eines anderen Scientia Media-Szenarios für die Wahl dieser Welt entschieden hätte. Während die Fraktion Molina dafür auf Gottes Wissen um seine faktischen Willensakte verweist, ${ }^{420}$ spaltet die Fraktion Suárez die Scientia Media auf in eine, die vom kreatürlichen Akteur bestimmt ist, und in eine, die von Gottes Willen bestimmt ist. ${ }^{421}$ Wo Gottes hypothetisches Konkursdekret ein integraler Bestandteil der Futuribilien ist, fallen auch Gottes Willensakte unter die Scientia Media. ${ }^{422}$ Gott muß von sich wissen, daß Er entweder der Schöpfer der Welt $W_{1}$ oder $W_{2}$ wäre; daß Er, wenn Er nicht $W_{1}$ erschaffen hätte, $W_{2}$ erschaffen hätte. ${ }^{423}$ Auch das hat in Gottes Wissenshaushalt objektive Wahrheit. ${ }^{424}$ Der

418. Molina, Concordia Q. 14 art. 13, 52, 11, p. 341. - „Negata... scientia media Dei circa suos actus, concedenda est circa nostros.“ EsParza, Curs. theol. 1, 18 ad 7, 1, t.1, p. 66a. - „Pater Molina... negat... Deum habere posse respectu suorum decretorum scientiam mediam... In hac parte nostri discesserunt a Patre Molina..." Herice, In Primam partem 7, 44. 78, pp. 156a. 168a. - Auch extern registriert: Voet \& Nethen, De scientia media $\$ 3$, p. 268.

419. „... dicendum ab omni Jesuita tenore consequentiae necessario..." AguILAR, De scientia Dei 1, 14, 3, t.3, p. 304b. Vgl. Alarcón, Theol. schol. 2, 4, 8, p. 146a/b; Arriaga, In Primam partem 21, 25, t.1, p. 219b; RAmirez, De scientia Dei 23, 77, t.2, p. 407b; ebd. 17, 129-30, t.2, pp. 156b/57a; ebd. 24,35 , t.2, p. 456 a.

420. Molina, Concordia Q. 14 art. 13, 52, 13, pp. 342-43; Mauro, Opus theol. 1, 46, 6. 10, t.1, p. 151a/b. Dagegen: MartíneZ, Deus Sciens 4, 5, 5, pp. 733-39.

421. „Supponimus... Deum per scientiam mediam cognoscere decreta sua, quae existerent, si tales aut tales ponerentur conditiones.“ Ald REte, In Tertiam partem 21, 1, 10, t.1, p. 226b. - „Deus per scientiam mediam cognoscit suos actus conditionatos liberos, quos haberet, si haec, aut illa conditio poneretur.“ MADERnI, Curs. theol. 1, 4, 17, 3, t.1, p. 198b. - „Communis... sententia Doctorum in Deo adstruentium scientiam mediam respectu actuum liberorum voluntatis creatae, similem scientiam mediam adstruit in illo respectu actuum liberorum voluntatis ipsius prout futurorum sub conditione." IzQuierdo, De Deo uno 28, 435, t.2, p. 184 a.

422. Martínez, Deus Sciens 4, 4, 2, p. 672 („... fere omnes defensores scientiae mediae, paucis exceptis...").

423. Martinon, De Deo et de Angelis 9, 81, t.1, p. 181b; Aldrete, In Tertiam partem 21, 4, 3, t.1, p. 232a; In Primam partem 33, 3, 16, t.1, p. 651a. Vorsichtiger: TAnner, Univ. theol. schol. 2, 8, $5,32-33$, t.1, col. 463 .

424. „Dico..., Deum... cognoscere sua decreta conditionata... secundum veritatem obiectivam, quam habent independenter ab existentia actuali... Respondeo..., non esse verum quod ait Molina, futura illa non habere determinatam veritatem obiectivam, quam Deus in seipsa immediate attingere possit..." Martinon, De Deo 9, 83. 88, t.1, pp. 182a/83a. Vgl. Diotallevi, De scientia 
Vorschlag, dieses Wissen auf die nachgeordneten Willensakte zu beschränken und den Initialakt („Volo mundum creare“) von ihm auszunehmen, findet kaum Resonanz. ${ }^{425}$ Gott kennt nicht nur die Antwort auf die berühmte Frage, ob Er auch dann Mensch geworden wäre, wenn Adam nicht gesündigt hätte. Unabhängig von der theologischen Entscheidung dieser Frage ist es eben auch die Scientia Media, durch die Gott im Besitz der Antwort ist, nicht das Inkarnationsdekret. ${ }^{426}$ Bejahendenfalls wüßte Gott aus der Scientia Media, auf welche Art und Weise die Menschwerdung sich in diesem Fall vollzogen hätte; denn wenn sie nicht das Reparaturprogramm gewesen wäre, hätte sie sich anders vollzogen. ${ }^{427}$ Die Gott als Akteur betreffenden Alternativen sind in der Scientia Media nicht minder tief gestaffelt ausbuchstabiert als diejenigen, die die kreatürlichen Akteure betreffen. Die Scientia Media wird mit der Allmacht koextensiv. ${ }^{428}$ Für die Logik der Scientia Media entfällt jeder Unterschied zwischen Gott und Mensch. ${ }^{429}$

Molinas Einwand, ${ }^{430}$ der damit postulierte Überschuß von Gottes Wissen von sich über sein Handeln ${ }^{431}$ würde deterministisch wirken, ist grundlos ${ }^{432}$ und mit der Scientia Media-Hypothese unvereinbar. ${ }^{433}$ Die Getrenntheit von Subjekt und Objekt ist kein Strukturmerkmal der Scientia Media, beides kann auch zusammenfallen

quam Deus habet de contingentibus, p. 248; Aldrete, In Primam partem 26, 4, 8, t.1, p. 366b; Ramirez, De scientia Dei 24, 4, t.2, p. 446a; Miranda, De scientia media 5, 3, 19-21, p. 492b/93a.

425. Becanus, Summa Theol. schol. 1, 1, 10, 3, 5, p. 62a. Vgl. Junius, De provid. 5, 6, 8, p. 112 a.

426. Diotallevi, De scientia quam Deus habet de contingentibus, pp. 190-95 (auf thomistischer Basis).

427. Hurtado de Mendoza, De Deo Homine 13, 14, p. 132a (auf skotistischer Basis).

428. Mendoza, Quodl. 7, 8, p. 539 („alter modus cognoscendi futura conditionata“); Granado, In Primam partem 2, 5, 4, 4, t.1, p. 261a/b; Ruiz de Montoya, De scientia Dei 77, 3, 1, p. 812b.

429. Ruiz de Montoya, De scientia Dei 77, 2, 3-7, p. 811a/b; Ramirez, De scientia Dei 23, 71-72, t.2, pp. $405 \mathrm{~b} / 06 \mathrm{a}$.

430. Molina, Concordia Q. 14 art. 13, 52, 11-12, pp. 341-42. Molina stehe mit seiner Ansicht allein: Ruiz de Montoya, De scientia Dei 77, 6, 2, p. 817a. Vgl. aber Pallavicino, Assert. theol. 8, 321, p. 526; Esparza, Curs. theol., t.1, p. 66a; Henao, Scientia media theologice $\$ \$ 1578-1600$, t.1, pp. 36ob-65a.

431. „Sphaera intellectus divini in cognoscendo amplior debet esse quam sphaera divinae voluntatis in intendendo et volendo." González de Santalla, In Primam partem 38, 8, 33, t.1, p. 6o6b.

432. Ruiz de Montoya, De scientia Dei 77, 6, 14, p. 818 b.

433. Martínez, Deus Sciens 4, 5, 4, pp. 727-28; Bernique, De divina scientia 3, 3, 22, pp. 477b/78a. 
(„unum et idem suppositum“). ${ }^{434}$ Gott weiß alles überhaupt Wißbare. ${ }^{435}$ Dazu wird sich von ARrIAGA auf den Bewußtseinsstandpunkt gestellt: Mein handlungsbegleitendes Bewußtsein („Wenn es hell ist, stehe ich auf“) nimmt meinem Handeln auch nicht die Freiheit. ${ }^{436}$ In Umkehrung eines gegen Molina gerichteten Arguments von CABRERA ${ }^{437}$ wird aus Gottes Kenntnis seiner eigenen hypothetischen Willensakte auf die Möglichkeit seiner Kenntnis von denen anderer Personen förmlich geschlossen. ${ }^{438}$ Die kognitive Leistung der Scientia Media wird eine Funktion von Gottes Übersicht über die eigene hypothetische Willensaktivität. ${ }^{439}$ Molinas Ansatz wird so im thomistischen Sinn interpretierbar: Jedes einzelne Scientia Media-Szenario ist solch eine hypothetische Veranstaltung. ${ }^{440}$

434. „Sive in proprio, sive in alieno subiecto, semper ea scientia futurorum est posterior natura, quam ipsum exercitium libertatis, et consequenter non tollit libertatem ipsius." ArRIAGA, In Primam partem 21, 21, t.1, p. 219a. Vgl. SuÁreZ, Varia opusc. theol. 2, 2, 8, 11, t.11, pp. 374b/75a; Tratado inédito $\$ 71$, p. 130; Alarcón, Theol. schol. 2, 4, 8, 3, p. 146b; G. Hurtado SJ. († 1646): Tractatus de Deo, Madrid 1641, fol. 92r; Martinon, De Deo 9, 89, t.1, p. 183b; Aldrete, In Primam partem 32, 2, 3, t.1, p. 634b.

435. „Omne scibile scitur a Deo; sed quidquid voluntas, et maxime divina, faceret sub quibuslibet circumstantiis, est scibile: ergo..." Aldrete, In Primam partem 32, 1, 9, t.1, p. 633b.

436. Arriaga, In Primam partem 21, 22-24, t.1, p. 219a/b; Martínez, Deus Sciens 4, 5, 3, p. 724; ebd. 4, 5, 4, p. 727; Maderni, Curs. theol. 1, 4, 17, 6, t.1, p. 199a. Das Beispiel bei Junius, De provid. $5,6,10$, p. 112 b.

437. „Deus non cognoscit, quos actus haberet, si haec, vel illa conditio poneretur: ergo neque actus nostros pendentes a talibus conditionibus." CABrerA, In Tertiam partem Q. 1 art. 3, \$356, t.1, p. 298a.

438. „Deus scit suos actus liberos futuros sub conditione... Ergo... scibiles erunt nostri actus futuri.“ Bernaldo de Quirós, De Deo 52, 26, p. 352. Vgl. Aldrete, In Primam partem 30, 8, 1, t.1, p. $569 \mathrm{a} / \mathrm{b}$.

439. „Nisi Deus... cognosceret decreta quae haberet, sequeretur, ipsum non posse certo ac definite scire quidquam sub conditione eventurum. "MoncÉ, Disputationes theol. 3, 17, p. 223 (wiederholt von L. Maeratius SJ. († 1664): Disputationes in Summam Theologicam S. Thomae 1, 28, 6, Paris 1633, t.1, p. 127 bA). Vgl. Aldrete, In Primam partem 32, 1, 7, t.1, p. 633a; ebd. 33, 3, 4, t.1, p. 648 b.

440. „... eo ipso, quod dico Deum cognoscere quid facturus esset Petrus, si poneretur in talibus circumstantiis, dico: si Deus decerneret ponere Petrum in talibus circumstantiis... Itaque hoc decretum conditionatum imbibitur in illa conditionali, et nihil aliud requiritur ad cognitionem talis futuri conditionati... Cum dicimus, Si Petrus poneretur in his circumstantiis etc., converteretur', illud antecedens est dependens a decreto conditionali Dei, deponendo illum in illis circumstantiis...“ Agostini, In Primam partem Q. 14 art. 13, $\$ \$ 148,163$, t.2, pp. 117a. 122b. - Vgl. ZuMEL, Informe sobre las doctrinas del P. Molina (1595), p. 552: „Haec scientia est scientia ex hypothesi et suppositione conditionali, quod Deus hunc vel illum ordinem rerum creare velit, et 
In der integrierten Scientia Media bilden die Futuribilien eine Gott und Kreatur übergreifende Gegenstandsklasse. ${ }^{411}$ Endet das im Chaos? ${ }^{442}$ Externe Beobachter haben den Eindruck gehabt, daß der Triumph der Scientia Media-Hypothese sich erst diesem Schritt verdankt hat. ${ }^{443}$ Auch endox hat sich ihr systematischer Schwerpunkt dadurch so weit verschoben, ${ }^{444}$ daß MARTínEz Molina durch Suárez geradezu für überwunden hält. ${ }^{445}$ Bestätigt hat sich die Befürchtung, daß die Scientia Media-Hypothese darauf hinausläuft, mit zwei Registern ${ }^{446}$ arbeiten zu müssen ( $\left.\$ 22\right)$.

\section{$\$ 18$. [Atomismus]}

Sowohl dieser Vorgang als auch die Diskussion über den zureichenden Grund ( $\$ 14)$ zeigt, daß die Scientia Media-Hypothese metatheoretisch überformt worden ist. Die Scientia Media wird zu einem kontingenten Effekt, ${ }^{447}$ und der bespiegelt sich selbst. Bezeichnenderweise verwendet die einflußreiche Schule des Hurtado DE Mendoza den Ausdruck grammatisch nicht nur im Singular. ${ }^{448}$ Der Plural

ex hypothesi, quod liberum arbitrium collocetur in hoc vel illo, cum his aut illis conditionibus, ex quo praevidetur, quid esset facturum (corr.: -rus), si ita crearetur et collocaretur in hoc vel illo ordine. Sed totum hoc dicit habitudinem ad praedefinitionem et liberam Dei voluntatem. Ergo..."

441. „Vi scientiae conditionatae habet Deus 1. repraesentatos sibi comprehensive ab aeterno omnes actus liberos tum suae, tum angelicae, tum humanae voluntatis; 2 . omnes conditiones tum intellectus, tum voluntatis, quae poni antecedenter ad actus liberos possunt, et quibus positis existere possunt liberi singuli actus. Denique comprehendit, quis actus, quacumque posita ex illis omnibus conditionibus, extiturus sit in omnibus circumstantiis possibilibus, quive non sit extiturus. Unde patet amplitudo huius scientiae." Channevelle, Metaphysica t.2, p. 358.

442. Voet \& Nethen, De scientia media $\$ 29$, pp. 334-35.

443. „An Deus cognoscat sua decreta prius ratione, quam actu sint?... Multum (ni fallor) conducit ad introductionem scientiae mediae, partem tituli affirmantem defendere... "LALEMANDET, De Deo uno 8, 59, t.1, p. 259 a.

444. Henao, Scientia media theologice $\$ 335$, t.1, p. 106a.

445. Martínez, Deus Sciens 4, 2, 3, p. 604.

446. M. DE RISPOLIS OP. ( $† 1628)$ : Status controversiae praedefinitionum et praedeterminationum cum libero arbitrio, Paris 1609, pp. 92/93 (in Reaktion auf FonsecA, In Metaph. 6, 2, 4, 10, t.3, p. $126 \mathrm{bC/E}$ ). Vgl. auch (C. TiphaIne SJ.:) De ordine deque priori et posteriori 26, 6, pp. 164-65.

447. „(Scientia media) sane est quid contingens actu existens.“ UlloA, Theol. 1, 3, 96, t.1, p. 131a.

448. „... possunt considerari omnes scientiae mediae, quia possumus considerare omnes conditiones potentiae absolutae Dei ad vocandum libere Petrum. “ P. Hurtado de Mendoza SJ.: Tractatus de scientia divina. Ms. BU Salamanca 62 (ca. 1635) fol. 313r. 
bezieht sich sowohl darauf, was wir heute die konträren ,Szenarien' nennen, ${ }^{449}$ als auch auf die Konsequenzen daraus, daß die Totale und das praktische Interesse am Hier und Jetzt perspektivisch auseinandertreten. ${ }^{450}$ In mehrfacher Hinsicht ist der Atomismus das metatheoretisch zentrale Problem:

a. Auf was für Entitäten ist mit den Futuribilien Bezug genommen? Reicht es $(\$ 4)$, daß q für ein bestimmtes Ereignis auf der Typebene ${ }^{451}$ steht? Ungeachtet der Komplikation, die die suarezische Konkurslehre für die Effektindividuierung $(\$ 12)$ darstellt, dringt der Nominalismus auf den Aktatomismus. ${ }^{452}$ Die Semantik des ,einzelnen' Falls ${ }^{453}$ ist, wegen des Dualismus Ereignis / Sachverhalt $(\$ 9)$, davon noch zu unterscheiden. Erfolgt die Fallspezifikation $(\$ 4)$ auf der Typebene? Bei SuÁrez bleibt das in der Schwebe. Daß eine rein numerische Fallverschiedenheit im status conditionatus handlungsmetaphysisch gleichgültig und darum aus der Scientia Media-Hypothese auszuschließen sei, behauptet Bernaldo de Quirós und antizipiert damit das von LeIbniz sog. Principium identitatis indiscernibilium. ${ }^{454}$ Die Mehrheit (Izquierdo, Rivadeneyra, Her-

449. „... Deus loco huius scientiae mediae potuit habere oppositam scientiam mediam, qua videret, quod Angeli, et Adam non essent peccaturi: ergo Deus per diversas et innumerabiles scientias medias potuit constitui in diversis atque innumerabilibus actibus primis proximis ad electionem creandi mundum..." Mauro, Opus theol. 1, 46, 6, t.1, p. $151 \mathrm{a}$.

450. „... debet Deus ... habere totam scientia mediam de omnibus conditionate futuris... Libertas creata... salvaretur sufficienter per partialem, ut ita dicam, scientiam mediam, de eo, quod hic et nunc concernit libertatem creatam." Mayr, Theol. 1, 558, pp. 504-05. Vgl. M. Perez de UnÁnoA SJ. († 1660): De mirabili Divini Verbi incarnatione 13, 2, 9, Lyon 1642, p. 163b; Pallavicino, Assertiones theol. 8,322, p. 527.

451. „... ipse Deus per scientiam mediam directam non possit ex parte actus liberi conditionati... praescire vel affirmare potius unum individuum a creatura sub hypothesi eligendum prae alio individuo prorsus simili, sed tantum unam speciem prae alia specie eligendam, aut individuum aliquod unius speciei prae individuo aliquo alterius speciei... "STERzInger, Scientia Media $\$$ 68, p. 71. Vgl. Banholzer, De scientia Dei $\$ 106$, pp. 167-68; MaYr, Theol. 1, 411, p. 327; Monschein, De Deo $\$ 269$, p. 173.

452. „Deus illos (sc. actus futuribiles) cognoscit... secundum entitatem individualem, quam haberent, si existerent.“ Antoine, De Deo uno 5, 5, 8, p. 271b. Ausführlicher: UlloA, Theol. 1, 3, 70. 76 , t.1, pp. 120a. 123a.

453. „... casus, sub quo enunciatur exercitium libertatis,... penitus singularis..." UlloA, Theol. $1,3,169$, t.1, p. 164a.

454. „... respondeo, moraliter loquendo et in ordine ad libertatem nostram non esse ibi duo exercitia libertatis, sed unicum, licet physice duo sint. “Bernaldo De Quirós, De Deo 54, 23, p. 364b. Vgl. Ders.: De praedest. 14, 8-9, p. 114b; S. Pallavicino: Disputationes in Primam Secundae D. Thomae 4, 2, 15, 5, Lyon 1653, t.1, p. 131b. 
RERA) unterscheidet hingegen, im Interesse des Indeterminismus, auch zwischen nichtunterscheidbaren kontrafaktischen Fällen. ${ }^{455}$

b. In Izquierdos System der objektiven Wahrheit $(\$ 8)$ ist bis in alle Einzelheiten die von Bertrand Russell entworfene Philosophie des Logischen Atomismus (Wahrheitsfunktionalität, negative und disjunktive Tatsachen usw.) ausgeführt.

c. Wie hängen in der Scientia Media die elementaren kondizionalen Tatsachen untereinander zusammen? Akut wird das Problem durch die integrierte Scientia Media $(\$ 17) \cdot{ }^{456}$ Sind es isolierte Tatsachen? Die eine Schule hält sie für durch keinerlei Ordnungsbeziehungen im Verhältnis zueinander strukturiert. Sie bilden ein Simultanaggregat. 457 Es ist nicht einmal sicher, daß das formallogische Gesetz der Transitivität auf sie Anwendung findet. ${ }^{458}$ Die andere Schule nimmt Abhängigkeitsbeziehungen zwischen ihnen an: ${ }^{459}$ Sie bilden eine Totalität. Dann impliziert die Koexistenz dieser Tatsachen die Annahme von Scientiae Mediae unterschiedlicher Ordnungen. ${ }^{460}$ Verändert jede Informationseingabe

455. G. De Rivadeneyra: Tractatus de actibus humanis 16, 27-28, Alcalá 1655, pp. 448-49; IzQUIERDo, De Deo uno 30, 734-51, t.2, pp. 340a-43b.

456. „Nullus actus scientiae mediae directae connectitur cum actu ullo scientiae mediae reflexae, aut vice versa." UlloA, Theol. 1, 3, 89, t.1, p. $127 \mathrm{~b}$.

457. „... eventus contingentes conditionati se habent pure concomitanter quoad veritatem contingentem conditionatam: igitur eodem intuitu indiviso virtualiter attinguntur a Deo... Unde nequit intellectus divinus per unam illarum (sc. scientiarum conditionatarum) praescindere ac suspendi circa existentiam alterius.“ Rivadeneyra, De volunt. Dei 8, 39. 45, pp. 185a. 188b. „... duo actus scientiae mediae per se solitarie considerati non praestant, ut positio unius sit praecisio ab altero.“ Aldrete, In Primam partem 32, 3, 9, t.1, p. 638a. - „... omnes futuritiones conditionatas liberas esse simul obiective, seu simul veras, eoque simul cognoscibiles, cum sint vicissim inconnexae independentesque." Junius, De provid. 5, 6, 2, p. 11ob; ebd. 11, 8, 10, p. 333 b.

458. Izquierdo, De Deo uno 38, 56, t.2, p. 646 b (nein); Junius, De provid. 11, 9, 4-5, p. 336 a (ja).

459. „... ex actibus scientiae conditionatae, illi sunt priores, qui versantur circa obiecta magis independentia, et a quibus alias pendent, et illi posteriores, qui tendunt circa obiecta quae ab illis pendent...“ Perez de UnÁnOA, De incarnat. 13, 1, 4, p. 162b. - „... bene potest una veritas conditionata esse ratio impulsiva, ut sit altera veritas conditionata contingens, ergo... potest... una ab alterius existentia praescindere. “L. TAPolcsanyi SJ. († 1729): Theses theologicae de Deo uno et trino, Tyrnau 1727, pp. 195-96.

460. „Hinc est difficultas, an praeter illam universalissimam scientiam mediam, et hanc alteram singularissimam et maxime restrictam ad unum obiectum, habeat Deus alias scientias medias, et quot sint istae? Respondeo, habere, et esse innumerabiles... “A. Perez, Opus posth.: De scientia Dei 3, 187, pp. 96b/97a. Vgl. Aldrete, In Primam partem 32, 4, 11-12, t.1, p. 641b; ebd. 33, 3, 15, t.1, p. $650 b$. 
immer gleich alles? ${ }^{261}$ Wie strikt ist es zu vermeiden, daß das Wissen um kondizionale Tatsachen in diese miteinfließt und sie dadurch verändert? ${ }^{462}$ Impliziert die Scientia Media Reflexion, und, wenn ja, ${ }^{463}$ ist die Serie der Reflexionen ihrerseits transfinit? ${ }^{464}$ Der Scientia Media-Diskurs reorganisiert sich mengentheoretisch.

\section{\$19. [Terminus]}

Da es nicht selbstverständlich ist, daß es das Bedürfnis gibt, die Futuribilien vom kategorisch Zukünftigen epistemologisch abzusondern, ${ }^{465}$ fragt es sich, welchen Anteil daran die Benennung für diesen eigentümlichen Wissenstyp gehabt hat.

Den Kunstausdruck ,Scientia Media' hat Molina, nach eigenem Zeugnis, ${ }^{466}$ 1588 in der Erstauflage seines Buches Liberi arbitrii cum gratiae donis, divina praescientia, providentia, praedestinatione et reprobatione Concordia eingeführt, also eine beträchtliche Zeit nach der, von ihm und nachher von FonsECA, seinem

461. „... duplicem in Societatis Schola esse sententiam circa scientiam mediam directam... Una tenet omnem scientiam mediam directam, quae de facto existit, identificari non modo realiter, verum et virtualiter, in ordine ad non suscipienda praedicata contradictoria, taliter, ut quidquid convenit uni, alteri conveniat; et Petrus, qui per dissensum potest impedire scientiam mediam de suo consensu, potest similiter impedire omnem scientiam mediam, quae de facto existit respectu omnium... Altera per oppositum tuetur, quod... scientiae mediae sunt ita independentes, ut una impedita altera possit permanere, et e contra." V. RAmIREZ: Tractatus de divina praedestinatione 3, 36, Alcalá 1702, t.1, pp. 77b/78a. Ein Vertreter der ersten Position: Rivadeneyra, De volunt. Dei 8, 48-50, pp. 190a/91a.

462. „Obiectum scientiae mediae, seu integra hypothesis, sub qua videtur effectus futurus, non debet involvere ipsam scientiam mediam, sed potius debet omnino ab illa praescindere, cum sit fundamentum ipsius scientiae mediae.“ Aldrete, De praedest. 2, 11, 8, t.2, p. 267b. - „Scientia Media non involvitur sub hypothesi ipsius Scientiae Mediae.“"MuniesA, De provid. 9, 24, p. 209 b. Vgl. Arriaga, In Primam partem 32, 32, t.1, p. 367a; Bernaldo De Quirós, Opus philos. 88, 39, p. 587 a.

463. A. Perez, Opus posth.: De providentia 3, 23, p. 322b („reflexio quaedam scientiae mediae in se ipsam“); Junius, De provid. 5, 7, 6, p. 115a.

464. Rivadeneyra, De volunt. Dei 8, 40, p. 185a/b (nein); Ramirez, De scientia Dei 23, 78-79, t.2, pp. 407b/o8a (ja). Vgl. Aldrete, In Primam partem 32, 4, 4, t.1, p. 640 ob.

465. „Cur quaeso futura conditionata... non locum inveniunt in classe futurorum, sed peculiarem cellulam, videlicet scientiam mediam, postulant?" C. L. Stromeyer († 1704): Disputatio metaphysica de scientia Dei $\$ 14$, Ulm 1692, fol. B4v.

466. Molina, Concordia Q. 14 art. 13, 53, 2, 22, p. 378 (ed. 1594). 
älteren Kollegen in Evora, übereinstimmend auf spätestens 1566 datierten, ${ }^{467}$ ,Erfindung ${ }^{3} 68$ des Systems. Während dieser Umstand einer interessierten Nachwelt Anlaß zu einem unentschiedenen Prioritätsstreit geboten hat, ${ }^{469}$ gibt es an dem Urheberrecht an dem Ausdruck keinen Zweifel. ${ }^{470}$ Sein verspätetes Auftreten führte zu der Sprachregelung, ihn mit den bereits üblichen Termini ,scientia conditionata' oder ,conditionalium' gleichzusetzen. ${ }^{471}$ Aus taktischen, aber auch sachlichen, ${ }^{472}$ Gründen wurde er zu Zwecken der Selbstbezeichnung lange sogar gemieden. Bis auf wenige Ausnahmen (Mascarenhas, Becanus) erfolgte die Aneignung entweder distanziert ${ }^{473}$ oder mit der Bemerkung, daß an dem Ausdruck nichts gelegen

467. Annat, Scientia Media def. 3, 132, p. 437; Avendaño y Eztenaga, De divina scientia 7, 1, 1, 8, t.2, p. 184a; Henao, Scientia media theologice $\$ 2074$, t.2, p. 38 b.

468. „Molina recte dicitur Inventor et Dux scientiae mediae.“ H. KILbER SJ. († 1783): Theologia 1, 161, Würzburg 1767, t.1, p. 200. Vgl. Arriaga, In Primam partem 21, 6, t.1, p. 216a; A. Perez, Opus posth.: De scientia Dei 3, 100, p. 8ob; G. DE HenaO: Scientia media historice propugnata $\$ 1259$, ( $\left.{ }^{1} 1665\right)$ Dillingen ${ }^{2} 1687$, p. 328a. Anders Ferrier, De Deo uno 2, 5, 302-03, p. 342a/b.

469. Molinas Priorität: HenaO, Scientia media historice $\$ \$ 1236-41, \mathrm{pp} .32 \mathrm{ob}-22 \mathrm{~b}$; einschränkend Henao, Scientia media theologice $\$ 2072$, t.2, p. 38a. - „Fonsecam fuisse primum inventorem omnibus constet." Rispolis, Status controversiae, p. 33. Vgl. Amico, De Deo uno et trino 12, 161, t.1, p. 156a; Voet \& Nethen, De scientia media \$1, p. 265; Macedo, Collationes 10, 4, 1, t.1, p. 367a/b; J. H. Serry OP. (†1738): Historia Congregationum de auxiliis divinae gratiae sub summis Pontificibus Clemente VIII. et Paulo V., 1, 13, Antwerpen 1709, col. 70C/D; J. F. Budde († 1729): Institutiones theologiae dogmaticae 2, 2, 1, 22, Frankfurt-Leipzig 1741, p. 216b. Unentschieden: GonZÁLEZ DE Santalla, In Primam partem 13, 6-8, t.1, p. 203a; K. Reinhardt, Pedro Luis SJ (1538-1602), S. 5. Über den Prioritätsstreit wird sich in Oxford amüsiert: PrIdeaux, De scientia media $\$ 3$, p. 16; W. Charleton († 1707): The Darkness of Atheism Dispelled by the Light of Nature 10, 4, London 1652, pp. 343-44. Zugunsten ihres eigenen Ordenslehrers, des hl. Bonaventura, entscheiden den Streit die Kapuziner Buontempi, Pallad. theol. 1, 13, 341, t.1, p. 229b; B. DE Barberis OFMCap. (†1697): Cursus theologicus 1, 216, Lyon 1687, t.1, p. 118a.

470. Lessius, De praescientia Dei cond. 19, 1, p. 215; Henao, Scientia media historice $\$ 1261$, p. 328b/29a; Scientia media theologice $\$ \$ 1549-50$, t.1, p. 354a.

471. „Haec... scientia (quam P. Molina p. 329 vocat, mediam inter mere naturalem et mere liberam', alii ,conditionatam' aut ,conditionalium liberarum' praescientiam)... “ J. Deckers SJ. († 1619): [La Grace efficace et l'élection à la gloire] (1591), ed. LE BACHELET, Prédestination doc. 10, t.1, p. 79.

472. Albertini, Corollaria 4, Coroll. 4, 15, pp. 295b/96a. - „Huiusmodi scientia nulla ratione erit media, sed sub alterutro membro continebitur." Diotallevi, De scientia quam Deus habet de contingentibus, pp. 107/o8.

473. So bei P. Luis 1591 (Reinhardt, Pedro Luis, S. 131-32) und Suárez, Varia opusc. theol. 1, 1, 15, 2, t.11, p. 76b; 2, 2, 3, 4, t.11, p. 353a. - „Doctores Nostri, licet non reprobent nomen ,scientiae mediae', divisi tamen sunt.“ L. Peñafiel, De Deo uno 8, 27, 86, t.1, p. $570 a$. 
sei. Es geht nicht darum, erklärt BASTIDA vor dem Papst, ob es in Gott ein Wissen gibt, das mit diesem Ausdruck zu belegen ist, sondern darum, ob es in Gott die Sache gibt, welche Molina mit diesem Ausdruck belegt hat. ${ }^{474}$ Wo dagegen die Ausmerzung 475 der Scientia Media betrieben wurde, wurden dem in seiner Tragweite anders eingeschätzten Ausdruck gründliche Analysen gewidmet, ${ }^{476}$ zuerst nur, um den, allerdings zweischneidigen, ${ }^{477}$ Innovationstopos anzubringen, dann jedoch, um die, anfangs gar nicht beanstandete, Gleichsetzung mit dem Wissen um das bedingt Freizukünftige zu beenden. ${ }^{478}$ Die Jesuiten haben am Ende eingesehen, daß ,scientia conditionata' unbrauchbar geworden ist, seit die Gegner („post Alvarez") ${ }^{479}$ durch eine Hypothese, ${ }^{480}$ die Gott die Kontrolle über den festen Wahrheitswert der Futuribilien verschafft, ${ }^{481}$ satisfaktionsfähig geworden sind. Erst nach Suárez begannen sie, die ihnen aufgedrungene terminologische Unterscheidung zu übernehmen und ,Scientia Media' zu Abgrenzungszwecken und, bei entsprechend gelockerter Bindung an Molina, ${ }^{482}$ zum Zeichen einer Binnendifferenzen

474. BAstida, [De scientia media] p. 49ob. - „... fit, ut tota quaestio, an scientia conditionalium sit ,media', reducatur ad voces." Recupito, Theologia 2, 1, 29, 2, t.2, p. 152 b.

475. „... quaestio ista gravissima, quae de hac media scientia, seu potius contra illam, ventilatur, in hoc consistit, quod... nullo modo nullaque ratione... in Deo reperiatur." Lemos, Panoplia Gratiae 1, 5, 19, t.1, p. 247 b.

476. Besonders Zumel, Sobre las doctrinas del P. Luis Molina SJ., ed. Muñoz Delgado, pp. 54653; Ders., In Primam partem Q. 14 art. 13, 1, ${ }^{2} 1597$, t.1, pp. 280-84.

477. Ruiz de Montoya, De scientia Dei 76, 6, 4, p. 808b; Sherlog (Leonardus), Responsiones 3, 12, p. 251; Henao, Scientia media historice $\$ 1354$, p. $350 a$.

478. „Nos vero nomen et rem, scientiae mediae’ negamus: admittimus vero rem et nomen, scientiae conditionatae' valde diversae a ,conditionata' Recentiorum. "VIVEs, De primatu divinae libertatis 1, 14, p. 5a. - In dieser Absicht wird auch häufig terminologisch zwischen ,scientia media' und ,scientia conditionatorum' unterschieden: MAcedo, Collationes 10, 4, 3, 5, t.1, p. 377b. Vgl. Alvarez, De auxiliis divinae gratiae 7, 30, p. 74a; G. Ram: Tractatus de divinis praemotionibus, seu efficacia divinae causalitatis, Huesca 1611, fol. 61v; IoAnnes A S. Thома, In Primam partem 20, 1, 1, t.2, p. 433a; F. STÜMEL OFM. († 1681): Opus de essentia et natura divina $\$$ 481, Köln 168o, p. $213 a$.

479. Avendaño y Eztenaga, De divina scientia 4, 1, 2, 17, t.2, p. 5 a; González de Santalla, In Primam partem 13, 3, t.1, p. 202a; Meyer, Hist. Controv. de auxiliis 5, 45, p. $497 \mathrm{a}$.

480. Kritisch: Silva y Pacheco, In Primam partem Q. 14 art. 13, 13, 115, t.2, p. 443a („machina“).

481. Ram, De divinis praemotionibus, fol. 61v-63v; Alvarez, Responsiones 1, 4, 9, pp. $141 \mathrm{f}$.

482. „Et ,Molinistarum’ appellatio aliena valde a scriptoribus et scholis Societatis est... Nullus enim Molinae se discipulum profitetur, licet in puncto illo praecipuo specialius ille praeiverit..." Avendaño, Recogn. tomi I Probl. Theol. \$609, p. 217b. Vgl. Aldrete, In Primam partem 29, 1, 21, t.1, p. 507a; Martínez, Deus Sciens 4, 4, 8, p. 712; Daniel, Recueil t.3, p. 438; Antoine, De Deo uno 5, 5, 1, p. 25ob. Selbst Henao betont: „Velim tamen, ut si Scientia Media vocanda sit 
marginalisierenden Grundposition zu verwenden. ${ }^{483}$ Seither symbolisiert sie die eine Position ${ }^{48}$ in der übereinstimmend für entscheidend angesehenen ${ }^{485}$ Frage, ob Gottes hypothetisches Wissen prä- oder postvolitional ist. Von satirischen Auslegungen ${ }^{486}$ des Ausdrucks, Scientia Media' abgesehen wird nicht verhehlt, daß er zweideutig ist. ${ }^{487}$ Mithilfe des Begriffspaars ex parte subiecti $(\$ 20)$ und ex parte obiecti ( $\$ 21$ ) wird diese Zweideutigkeit auseinandergesetzt, ${ }^{488}$ dem Prinzipiendualismus $(\$ 6)$ adaptiert und spekulativ integriert. ${ }^{489}$

,Moliniana', Iesuitae non dicantur discipuli ,Scientiae Molinianae'..., sed discipuli Molinae in doctrina ex eius scriptis haurienda de Scientia Media." Henao, Scientia media theologice $\$ 6228$, t.2, pp. $807 \mathrm{~b} / 08 \mathrm{a}$.

483. TAnner, Univ. theol. schol. 2, 8, 5, 34, t.1, col. 464; FAsulo, In Primam partem Q. 14, art. 13, 506, t.2, p. 287 a.

484. „... scientia conditionalium... nobis et Molinae communis, cum hac differentia, quod ipse eam constituat ante decretum, nos post decretum. “P. FASSEAU OP. († 1693): Authoritas Germani Philalethis Eupistini contra Praemotiones Physicas pro Scientia Media exauthorata $\$ 483$, Douai 1670, p. 486. Vgl. Erath, Conciliatio $\$ 13$, p. 30. - „... scientiam mediam Molinae nolumus, eo quod ponat futura conditionata ante Dei liberam ordinationem. “ S. KNIPPENBERG OP. ( $† 1733)$ : Opusculum de providentia Dei gubernante per motum 8, 4, Köln 1700, p. 268. Den Gegensatz der beiden Positionen deswegen für einen nur oberflächlichen hält Silva y PACHeco, In Primam partem Q. 14 art. 13, 13, 78. 90. 122-23, t.2, pp. 433b. 436b. 444b/45b. Zu den Argumenten vgl. ebd. $12,82-85$, t.2, pp. 410a/11a.

485. „... totius controversiae de auxiliis radix et cardo..." Ionnnes a S. Thoma, In Primam partem 20, 3, 6, t.2, p. 464b. - „... arx quaestionis... “ SHerlog (LeOnARdus), Responsiones 3, 51, p. 310. - „... cardo controversiarum huius saeculi in hac materia...“ MASTRI DA Meldola, In I Sent. 3, 282, p. $163 \mathrm{a}$.

486. Beispiel: N. L'Herminier († 1735): Summa theologiae, Paris 1719, t.1, p. 535.

487. „... communi usu receptum est in Scholis, vocare ,Scientiam Mediam’ eam de futuris contingentibus conditionatis notitiam divinam, quam adstruunt Nostri, sive sic appelletur, quia mediet inter scientiam divinam necessariam, et liberam, sive inter simplicis intelligentiae, et visionis. “ Henao, Scientia media historice $\$ 1300$, p. 339a.

488. „Sicut scientia Dei dividitur ex parte obiecti in scientiam simplicis intelligentiae, et in scientiam visionis, sic ex parte subiecti dividi solet in scientiam necessariam, et liberam. "KNIPPENBerg, De provid. 8, 10, p. 297. Früher: Izquierdo, De Deo uno 23, 112, t.2, p. 23b; Henao, Scientia media theologice $\$ \$ 1552.1559$, t.1, pp. 354b. 356a.

489. Aldrete, In Primam partem 32, 3, 17, t.1, p. 639 b. 


\section{§ 20. [Trägerbezogen]}

Die Scientia Media ist das notwendige Wissen um kontingente Wahrheiten. In dieser Bedeutung ist der Begriff von Molina und Fonseca eingeführt. ${ }^{4{ }^{\circ}}$ Es ist ein notwendiges, kein freies Wissen, weil Gott das Gewußte nicht nicht wissen kann; weil es erstens jedem freien Willensakt Gottes voraufgeht, weil es zweitens nicht in Gottes Macht steht, durch dieses sein Wissen etwas anderes als das, was Er faktisch weiß, oder A eher als nonA zu wissen. ${ }^{491}$ Entweder A oder nonA ist gewußt, eine dritte Möglichkeit hat Gott nicht. ${ }^{492}$ Trotzdem ist es ein Wissen nicht um notwendige, sondern um kontingente Wahrheiten, denn es ist Gott nicht so natürlich, als daß er nicht ebensogut das Gegenteil von dem, was Er faktisch weiß, wissen könnte. Das Freiheitsprädikat bezieht sich also auf uns, nicht auf Gott. ${ }^{493}$ Diese Interpretationslinie verlängert sich

a. in der technischen Unterscheidung zwischen dem „Subjekt“ (Deus sciens) und dem „Objekt“ dieses Wissens; ${ }^{494}$

b. in dem Schluß, daß, weil die Prädikate ,notwendig' und ,frei' auf das Subjekt zu beziehen sind, die Scientia Media in bezug auf das Subjekt aber Notwendigkeitscharakter hat, das Freiheitsprädikat für sie nur extrinsisch ist; 495

490. Molina, Concordia Q. 14 art. 13, 52, 10, p. 340; FonseCA, In Metaph. 6, 2, 4, 8, p. 12obF/21aA.

491. „... ut non sit in libera potestate ipsiusmet scientis Dei, scire hunc determinatum effectum liberum, potius quam eius oppositum. “FASUlo, In Primam partem Q. 14, art. 13, 485, t.2, p. 276 b.

492. H. FABRi SJ. († 1688): Summula theologica 1, 3, 19, Lyon 1669, p. 3ob; UlloA, Theol. 1, 3, 28, t.1, p. 101 b.

493. „Scientia media inter liberam et naturalem, hoc est, quae sit libera ex parte creaturae, et naturalis ex parte Dei... “ RAM, De divinis praemotionibus, fol. 61r. - „Ea (sc. cognitio Dei) autem, quae est nobis tantum libera..., appellatur a nostris Theologis communiter ,scientia media." Esparza, Curs. theol. 1, 18, 18/20, t.1, p. 63b. Dagegen deklamiert Lemos, Panoplia Gratiae 1, 5, 12, t.1, p. 231b. - „... licet liberum sit ipsi (sc. Deo), quod existat absolute operatio libera affirmata per scientiam mediam, quatenus ipsi liberum est purificare conditionem..., non tamen est ipsi libera illa scientia... Quare haec solum est libera arbitrio creato.“ GonzÁlez dE SAnTAlla, In Primam partem 38, 8, 41, t.1, p. 610a/b.

494. „Ex parte enim obiecti est libera; ex parte subiecti necessaria, utpote libertatem Dei praeveniens. Unde vocatur ab ipso (sc. Molina) media." Lessius, De praescientia Dei cond. 19, 1, p. 215; Fasulo, In Primam partem Q. 14, art. 13, 492, t.2, p. 28oa; Mastri da Meldola, In I Sent. 3, 286, p. 164a. - „Deus per modum subiecti suae scientiae determinatus est, ut non habeat nisi cognitionem veram. “BERNALdo DE Quirós, De Deo: Index rerum s.v. ,Dei scientia et intellectus' ad p. 356.

495. „Scientia media inter naturalem et liberam, videtur magis participare de ratione scientiae naturalis quam de ratione scientiae liberae..., quia ,liberum' et ,necessarium' sunt proprietates 
c. terminologisch in der Einrichtung der Kategorie ,Kontingenz' als spekulativer Mitte. ${ }^{496}$ Kontingenz, nicht Freiheit, ist das Merkmal jedes empirischen Wissens. ${ }^{497}$ Daraus, daß dieses Wissen mit seinem Gegenstand strukturell identisch ist, ${ }^{498}$ folgt jedoch nicht, daß es ein kontingentes Merkmal Gottes ist, ${ }^{499}$ geschweige denn, daß es für Gott Zufallscharakter hat. ${ }^{500}$

Nach beiden Seiten gibt es Abweichungen. ${ }^{501}$ Die Fraktion Vázquez relativiert das Freiheitsprädikat der Scientia Media. ${ }^{502}$ In der Fraktion Suárez wird sich dagegen den Thomisten ${ }^{503}$ angeschlossen und das Freiheitsprädikat auf Gott ausgedehnt.

tenentes se magis ex parte subiecti, quam ex parte obiecti...; sunt enim proprietates intrinsecae subiecto et potentiae, non obiecto et effectui." FAsulo, In Primam partem Q. 14, art. 13, 488, t.2, p. 277b. Eine Konzession an die thomistischen Kritiker. Vgl. Piccinard, De approb. doctrinae S. Thomae 7, 1, 6, t.3, pp. 317-20.

496. „... scientiam conditionatam... ideo mediam nuncupari, quia neque Deo libera est, neque metaphysice necessaria, sed contingens.“ Junius, De provid. 9, 6, 5, p. 255 a. - „Authores Scientiae Mediae... asserunt Scientiam Mediam esse quidem contingentem, non autem liberam Deo.“ A. De Herrera: Tractatus de voluntate Dei, Alcalá 1673, p. 347. Vgl. SoAres, De anima 5, 3, 176, t.3, p. 267a; Esparza, Curs. theol. 1, 18, 2, t.1, p. 6oa; GonzÁlez de Santalla, In Primam partem 14, 86, t.1, p. 237a; Peynado, De anima 2, 6, 34, p. 407a/b; Manuel de la Concepción, De scientia Dei 5, 54, p. 336; RAmireZ, De scientia Dei 20, 100, t.2, p. $301 \mathrm{~b}$.

497. Muniesa, De provid. 2, 7, p. 2ob; Miranda, De scientia media 1, 4, 17, p. 415 a.

498. „Haec scientia totam suam contingentiam habet ab obiecto suo." HenaO, Scientia media theologice $\$ 1557$, t.1, p. 355b. Vgl. Perez de UnánoA, De incarnat. 13, 1, 4, p. 162 b.

499. „Scientia media non est formalitas contingens producta intra Deum.“ GonzÁLEZ DE SANTALLA, In Primam partem 19, 14. 27, t.1, pp. 354a. 356a/b. Über das hier gestreifte Problem für den monotheistischen Gottesbegriff ausführlicher: HeNAO, Scientia media theologice $\$ 6056$, t.2, p. 753 b.

500. Gegen einen thomistischen Gemeinplatz (CABrera, In Tertiam partem Q. 1 art. 3, \$358, t.1, p. 298a): „Ex eo autem, quod scientia conditionata sit pure contingens, non sequitur, esse Deo casualem et fortuitam. “Henao, Scientia media theologice $\$ 1556$, t.1, p. 355b; GonzÁLEZ DE Santalla, In Primam partem 19, 30, t.1, pp. 356b/57a; ebd. 38, 8, 32, t.1, p. 6o6a/b; Wietrowski, Conclus. theol. 1,388 , t.2, p. 81.

501. Einen Sonderweg in der Deutung der Kombination von ,notwendig' und ,frei' geht CH.F. D’Abra de Raconis († 1646): Summa totius philosophiae: Metaphysica 5, 4, 4, 3, Köln 1629, p. 136a.

502. „... non dicitur... simpliciter contingens..., quia est ante actualem usum libertatis divinae, et humanae.“Alarcón, Theol. schol. 2, 5, 3, 2, p. 157a; ebd. 3, 5, 8, 19, p. 233a. - „Ipsa autem scientia media dicitur , libera' creaturae, non quidem absolute, sed conditionate: nam ab aeterno cum voluntas creata non existat, ei libera esse non potest scientia media." GonZÁLEz de SANTALla, In Primam partem 38, 12, 69, t.1, p. 622a.

503. „Concedimus sane, Deum praescire conditionata, sed non scientia media inter liberam et naturalem, neque scientia media inter visionis et simplicis intelligentiae, sed scientia visionis 
Granado gibt Gott die Kontrolle über die Scientia Media mit der Begründung zurück, es gebe keine kontingente Wahrheit, die nicht von Gottes hypothetischem Dekret abhinge. Wenn Gott es würde verhindern wollen, hätte das bedingt Zukünftige daher nicht diesen Status. ${ }^{504}$ Dieselbe Erwägung veranlaßt ARrúbal zur Relativierung von Molinas Interpretationslinie und MoNCÉ zum offenen Bruch mit ihr. ${ }^{505}$

\section{$\$ 21$. [Gegenstandsbezogen]}

Die Scientia Media ist das Wissen, welches eine bestimmte mittlere Gegenstandsklasse zum Gegenstand hat. Molina ist sich bewußt, daß an der Scientia Media-Hypothese die Annahme eines "medium inter futurum simpliciter et mere possibile" Anstoß erregt, ${ }^{506}$ trotzdem ist der Ausdruck ,Scientia Media' bei ihm nicht die Kurzformel für diese Provokation. ${ }^{507}$ Es ist eine Legende, Molina hätte die Dichotomie ${ }^{508}$ Möglichkeitswissen (scientia simplicis intelligentiae) / Wirklichkeitswissen (scientia visionis) infragegestellt. ${ }^{509}$ Tatsächlich ordnet Molina Gottes

libera, qua intuetur Deus suae divinae voluntatis aeternum decretum de omnibus conditionaliter futuris..." RAm, De divinis praemotionibus, fol. 68v. Vgl. VIVEs, De primatu divinae libertatis 1, 11, p. 4b. So auch die Skotisten, z.B. A. Volpi (A Monte Piloso) OFM. († 1645): Sacrae Theologiae Summa 1, 31, 3, 5, Neapel 1622, t.2, p. 76 b.

504. „... nulla veritas cognoscitur mediante ista scientia (sc. conditionata), quae non dependeat ab aliquo actu libero divino futuro sub conditione." Granado, In Primam partem 2, 5, 3, 26, t.1, p. 259b; ebd. 2, 5, 5, 4, t.1, pp. 263b/64a. Dagegen Alarcón, Theol. schol. 3, 5, 8, 19, p. 233 a.

505. P. De Arrúbal SJ. († 1608): Commentaria ac Disputationes in Primam partem D. Thomae 39, 4, Madrid 1619-22, t.1, p. 254a. - „... nec illa sub conditione futura esse possent, nisi idem Deus nunc haberet, aut ea saltem conditione posita habiturus fuisset decretum liberum de ipsorum futuritione seu futura existentia. Quapropter nunquam probare potui quod Ludov. Molina... ait, mediam scientiam, quam inter mere naturalem et mere liberam in Deo ponit..., censendam potius esse sub naturali quam sub libera; imo neque probo medium illud scientiae quod facit membrum inter scientiam mere naturalem et mere liberam." Moncé, Disputationes theol. 3, 16, pp. 215f. Vgl. Recupito, Theologia 2, 1, 29, 14, t.2, p. 156b.

506. Molina, Concordia Q. 14 art. 13, 53, 1, 6, p. 360. - „Thomistae volunt..., inter simpliciter futurum, et possibile merum, nullum dari medium. "RIsPolis, Status controversiae, pp. 72-73. Vgl. Cabrera, In Tertiam partem Q. 1 art. 3, \$341, t.1, p. 296 a.

507. „Datur medium inter absolute futurum et possibiliter futurum, nempe conditionaliter futurum, ergo etiam debet dari scientia media." CABrera, In Tertiam partem Q. 1 art. 3, $\$ 286$, t.1, p. 287b. Eine überspitzte Interpretation von Molina, Concordia Q. 14 art. 13, 53, 4, 4, p. 394.

508. Thomas von Aquin: Summa theologica I ${ }^{\mathrm{a}}$ Q. 14 art. 9.

509. F. Zumel: Opuscula 5, 1, Salamanca 1608, t.1, p. 218a; Hurtado de Mendoza, De anima 9, 143, p. 593b; Granado, In Primam partem 2, 5, 5, 5, t.1, p. 264a; Th. Smising OFMObs. († 1626): 
hypothetisches Wissen, wie auch sonst üblich, ${ }^{510}$ dem ersten Pol zu. ${ }^{511}$ Obwohl das häufig richtiggestellt worden ist, ${ }^{512}$ hat das wenig gefruchtet. Auf der anderen Seite ist es nicht so, daß eine Scientia Media zwischen dem Möglichkeits- und dem Wirklichkeitswissen gar nicht ${ }^{513}$ vertreten worden wäre.

Aus der Legende spricht die suarezische Molinaaneignung. Die Harmonisierung dieser Deutung ${ }^{514}$ mit Molinas authentischer Position ist auch nicht immer versucht worden. ${ }^{515}$ Suárez interpretiert den Terminus im Licht einer Konzeption des hypothetischen Wissens, welche dieses theozentrisch in der Aufnahme auch der göttlichen Willensakte in diesen Wissenshaushalt fundiert $(\$ 17)$. Weil es sich

Disputationes theologicae 3, 2, 131, Antwerpen 1627, t.1, p. 382a; Recupito, Theologia 2, 1, 29, 2, t.2, p. 152b; Haunold, Theol. 1, 301, p. 5ob; Leibniz, Théodicée 1, 40, Die philos. Schriften ed. Gerhardt, Bd. 6, S. 125; J. A. Schwane († 1892): „Über die scientia media und ihre Verwendung für die Lehre von der Gnade und Freiheit“, Theologische Quartalschrift 32, Tübingen 1850, S. 394-459, hier S. 400.

510. Eine Liste bei Fasulo, In Primam partem Q. 14, art. 8, 25-26, t.2, p. 40. Suárez selber ist später zu dieser, die auch seine Ausgangsposition gewesen ist (Tratado inédito $\$ 67$, p. 126), zurückgekehrt: Suárez, De gratia Prol. 2, 6, 7, t.7, p. 81a. Das bemerkt Lemos, Panoplia gratiae 1, 5, 11, t.1, p. 229a.

511. L. Molina: Commentaria in Primam D. Thomae partem Q. 14 art. 9, Cuenca 1592, col. 464A/B; Molina an Lessius, Cuenca 4.7.1594, ed. Le BACHelet, Prédestination doc. 6, t.1, pp. 38-39.

512. „Molina... docet... praeter scientiam Dei naturalem et liberam esse aliam ..., quam ille saepius appellat ,scientiam mediam'; quod autem ea ,media' sit inter scientiam visionis et simplicis intelligentiae, nec leviter insinuavit.“'Arrúbal, In Primam partem 38, 14, t.1, p. 249 a. Vgl. Bastida, [De scientia media] p. 511b; Herice, In Primam partem 1, 9, 4, p. 18ob; Alarcón, Theol. schol. 2, 5, 3, 2, p. 157a; Godoy, In Primam partem 37, 2, t.2, p. 57a; IzQuierdo, De Deo uno 23, 111, t.2, p. 23b; Avendaño y Eztenaga, De divina scientia 4, 1, 2, 1, t.2, p. 4a; Henao, Scientia media historice $\$ 1291$, p. 337 b; J.W. JÄGER $(\dagger 1720)$ : Theologia naturalis 5, 5, Tübingen 1684, p. 162.

513. „... minus dabilis ist Scientia media inter scientiam visionis et scientiam simplicis intelligentiae, quam Scientia media inter scientiam liberam et naturalem; illa namque a nemine admissa est.“ M. Perez De Quiroga OFMObs.: Disputationes theologicae in Primum librum Sententiarum 37,6 , Segovia 1704-08, t.2, p. 55 b.

514. J. Micraelius (†1658): Lexicon philosophicum s.v. ,scientia', Jena 1653, col. 987; P. GodART: Lexicon philosophicum s.v. ,Deus', Paris 1675, p. 163. Bis dahin: VÁzQuez, In Primam partem 67, 27, t.1, p. 562a; SuÁrez, Varia opusc. theol. 1, 1, 15, 2, t.11, p. 76b; CABrera, In Tertiam partem Q. 1 art. $3, \S 283$, t.1, p. 287a; F. M. MASCARENHAS ( $\dagger 1628)$ : Tractatus de auxiliis divinae gratiae ad actus supernaturales, Lyon 1605, p. 177; Albertini, Corollaria 4, Coroll. 4, 15, p. 295b; P. DE LorCA O. Cist. († 1612): Commentaria ac Disputationes in Tertiam partem D. Thomae 10, 27, Alcalá 1616, t.1, p. 74a/b; Lemos, Panoplia Gratiae 1, 5, 36, t.1, p. 290a; Arriaga, In Primam partem 21, 3, t.1, p. 215b; B. Tellez SJ. († 1675): Summa universae philosophiae: Logica 1, 15, 3, 5, Lissabon 1641, p. 125 a.

515. Moncé, Disputationes theol. 3, 16, pp. 213-16. 
bei diesen hypothetischen Dekreten nicht einseitig um materiell solche handelt, sondern um solche, die selber nur bedingungsweise gefaßt sein würden, die also optionale Form haben (decreta subiective et obiective conditionata), scheut Suárez theologisch nicht vor der Zumutung zurück, für den Allwissenden in Gestalt der Futuribilien so etwas wie („virtuell“) Zukunft ${ }^{516}$ entstehen zu lassen. Ob bei Gott von einem in die Zukunft verlegten Wollen die Rede sein kann, war natürlich kontrovers. ${ }^{517}$

Die Scientia Media ist hier ein dynamisch dadurch definiertes Wissen, daß es real derselben Existenzschwelle voraufliegt, deren Überschreitung es in hypothetischer Form antizipiert. ${ }^{118}$ Das fördert eine Metaphysik des status medius ${ }^{19}$ und seiner Existenzweise, ${ }^{520}$ es zielt auf Weisen der spekulativen Verschränkung von

516. Die Suárezinterpretation: SoAres, De anima 5, 3, 221, t.3, p. 274a; Henao, Scientia media theologice $\$ 317$, t.1, p. 101b; Araujo, Curs. theol. 4, 18o-88, t.1, pp. 18o-81. Vgl. Diotallevi, De scientia quam Deus habet de contingentibus, p. 249; Aldrete, In Primam partem 33, 4, t.1, pp. 651-54; Avendaño, Probl. theol. 1, 822, t.1, p. 233a/b.

517. „Advertendum est, falsum esse in ipso Deo esse futuritionem aliquam in suis actibus ad intra." Zumel, Utrum Deus habeat praescientiam (Opuscula t.2), pp. 141aB/C. 145bC/D. - Den Thomisten war bewußt (PICCINARDI, De approb. doctrinae S. Thomae 7, 2, 5, t.3, p. 338), daß auch endox diese Zumutung auf viel Widerspruch gestoßen ist: VÁzQuez, In Primam partem 65, 25, t.1, pp. 540a/41a; Moncé, Disputationes theol. 3, 17, pp. 219-22; Granado, In Primam partem 2, 5, 4, 8, t.1, p. 262b; Herice, In Primam partem 7, 57, p. 16oa/b; Alarcón, Theol. schol. 2, 3, 1, 8, p. 115b; Arriaga, In Primam partem 20, 46-48, t.1, p. 213a/b; G. Hurtado, De Deo, fol. 92v/93v; Ribas, Summa theol. 4, 6, 58, p. 240a; Recupito, Theologia 2, 1, 30, 6-9, t.2, pp. 160a-62a; VeKen, De Deo uno 18, 23-24, p. 322a/b; González de Santalla, In Primam partem 36, 6, 26, t.1, p. 521b; T. Muniesa: Disputationes scholasticae de essentia et attributis Dei 13, 93, Barcelona 1687, p. 267 a.

518. „Quoniam... ipsamet determinatio voluntatis divinae prius ratione considerari potest ut futura, quam ut actu posita in re..., divina scientia... considerari potest ut praecedens determinationem liberam ut in re positam, subsequens vero illam ut futuram; et ut sic... terminatur... etiam ad... futura contingentia, vel conditionata, vel prout futura ex vi talis voluntatis divinae, et sub hac ratione talis scientia pertinet ad scientiam visionis, quamvis, ut praecedit determinationem liberam divinae voluntatis ut in re positam, aliquid participet de simplici intelligentia.“ SuÁrez, Varia opusc. theol. 2, 2, 3, 6, t.11, pp. 353b/54a. - „Futurum conditionatum dependet a divino decreto ut futuro..." FAsulo, In Primam partem Q. 14, art. 13, 474, t.2, p. 272 b.

519. „... scientia media’: quia... est... de obiectis in tertio quodam statu, sive medio. “Hurtado De Mendoza, De anima 9, 143, p. 593b; Arriaga, In Primam partem 21, 5, t.1, p. 216a; LynCH, Logica 10, 4, 28, t.1, p. 395b; Veken, De Deo uno 19, 16, p. 333b; Avendaño, Probl. theol. 1, 864, t.1, p. 243a; Ortega, De Deo uno 2, 5, 1, t.1, p. 220a. Kritisch dazu Henao, Scientia media theologice $\$ \$ 5972-84$, t.2, p. 734 b-37a.

520. „Status conditionatorum contingentium... modus quidam essendi eorum est.“ IzQUIERDO, Pharus Scient. 10, 62, t.1, p. 232a. Nämlich das „esse existentiale conditionatum“: IzQUIERDo, De Deo 28, 349, t.2, p. 167b. 
Möglichkeit und Wirklichkeit, ${ }^{521}$ auf Parameter, welche intensional ein Plus gegenüber dem Möglichen und ein Minus gegenüber dem Wirklichen ergeben, ${ }^{522}$ auf den „Übergang “523 vom bloß Möglichen zum Zukünftigen oder auf den jeweils „unendlichen" Abstand der betreffenden drei Klassenumfänge voneinander. ${ }^{524}$ Nur Wirkliches, nicht Mögliches, ist das ,bedingterweise. ${ }^{525}$ Insofern das ,bedingt' Zukünftige dem Zukünftigen das Plus, welches dieses über das bloß Mögliche hat, entzieht, unterscheidet es sich vom Zukünftigen jedoch stärker als dieses vom Möglichen. ${ }^{526}$ Das Scientia Media-Universum vermittelt zwischen Quiddität und Existenz. ${ }^{527}$ So gesehen gibt es Objekte, welche „in der Welt eine reale und vollkommene Möglichkeit haben und also zwischen dem, was wircklich geschieht, und denen bloß idealen Möglichkeiten gleichsam die Mitten ausmachen“. 528

Diese Auslegung des Ausdrucks, Scientia Media' war auch als Angebot an die Thomisten gedacht. ${ }^{529}$ Auf das Angebot eingegangen sind aber andere, vor allem die Skotisten, in der Vorstellung von einer gradualisierbaren Möglichkeit, und LEIBNIZ.530

521. „... quia futurum conditionatum et est in potentia, in quantum non est, sed potest esse absolute futurum..., et simul est ens in actu, in quantum actualiter habet futuritionem conditionatam." FASUlo, In Primam partem Q. 14, art. 13, 470, t.2, p. 275 b.

522. „... conditionaliter futurum plus aliquid actualitatis habet quam mere possibile, et minus actualitatis habet quam absolute futurum. "Ruiz de Montoya, De scientia Dei 76, 3, 3, p. 8orb. Relativiert von Arrúbal, In Primam partem 38, 25, t.1, p. 252a; Haunold, Theol. 1, 302, p. 50 ob.

523. Amico, De Deo uno 12, 234, t.1, p. 168a; Channevelle, Metaphysica t.2, p. 360. - „(Scientia) conditionata est de extractis a possibilitate et nondum pervenientibus ad existentiam. "Lumbier, De scientia Dei $\$ 333$, p. 41 b.

524. Ruiz de Montoya, De scientia Dei 76, 1, 15, p. 8oob; ebd. 76, 3, 3, p. 8o2b. Dagegen Twisse, De scientia media, p. 447a: „Nullum est intervallum... inter possibilitatem rei creatae et futuritionem eius."

525. Benjumea, Opera theol.: De scientia Dei $\$ \$ 1092-93$, t.3, p. 149b. Ein Anhänger der Scientia Media-Hypothese.

526. Perrimezzi, Dissertationes 86, 2, t.1, p. 396 a.

527. Peralta, De scientia media 3, 3, pp. 343-44.

528. С . A. CRusius: Entwurf der nothwendigen Vernunft-Wahrheiten, wiefern sie den zufälligen entgegen gesetzet werden $\$ 270,\left({ }^{1} 1745\right)$ Leipzig ${ }^{3} 1766$, S. 500.

529. Recupito, Theologia 2, 1, 29, 6. 9, t.2, pp. 154b/55b; Silva y Pacheco, In Primam partem Q. 14 art. 13, 12, 43. 79, t.2, pp. 399b. 409a.

530. Fabbri, In I Sent. 55, 27, p. 5b; Mastri da Meldola, In I Sent. 3, 286, p. 164b; Del Bene, Summa theol. 4, 13, t.1, p. 172a/b; LeIBNIZ: Causa Dei asserta $₫ 17$, Die philos. Schriften ed. Gerhardt, Bd. 6, S. 441. 
Für die Thomisten konzentrierte sich in ihr der Scientia Media-Schwindel. ${ }^{531}$ Wo auf der Dichotomie Möglichkeit / Wirklichkeit bestanden wurde, ${ }^{532}$ wurde aus der Annahme von etwas Mittlerem das Sakrileg gefolgert, daß kreatürliche Möglichkeiten sich selber verwirklichen: ein von dem Calvinisten TwISsE entwickelter und im Katholizismus rezipierter Topos. ${ }^{533}$

Für den nominalistischen Flügel der Jesuitenscholastik war die Systematisierung von Gottes Wissen nach koordinierten Gegenstandsbereichen ${ }^{534}$ obsolet. Auch wo die Scientia Media eine bestimmte Abstraktionsleistung war, ${ }^{535}$ behauptete sich die suarezische Deutung, dann in dem veränderten Kontext eines göttlichen Erkenntnisprozesses und der ihm unterlegten Abfolgemomente. Auf den Boden dieser Deutung stellte sich auch ein Vorschlag des Barnabiten MAderni, um die Scientia Media-Hypothese mit der Aufrechterhaltung der Dichotomie des göttlichen Wissens auszugleichen. ${ }^{536}$

531. „... scientia ,conditionata' Thomistica... est in Deo post decretum conditionatum formaliter existens in divina voluntate... Scientia vero, conditionata' recentiorum, post signum possibilitatis, non incipit a decreto absoluto ex parte actus, sed ante decretum Dei, fingit primo veritatem obiectivam, et secundo scientiam mediam. “Vives, De primatu divinae libertatis 1, 11, p. 4b. - „... obiectum medium... est fictum et impostura..., ex cuius falsitatis concessione nascitur... scientia media." Silva y Pacheco, In Primam partem Q. 14 art. 13, 13, 124, t.2, p. 445b. Vgl. Caramuel y Loвкоwiтz, Leptotatos $\$ 527$, p. 272b/73a.

532. „Distributio scientiae divinae in simplicis intelligentiae et visionis scientiam exhaurit totam naturam obiecti scibilis. Ergo non datur media quaedam. “VoEt \& NeTHEN, De scientia media $\$ 19$, p. 309. Vgl. Ledesma, De auxiliis, p. 588bC-89aB.

533. „At ex conditione rei mere possibilis transire non potest in conditionem rei futurae sine causa. Huius autem transitus causam nullam fingunt Jesuitae, sed nec ulla fingi potest extra Deum. “ Twisse, De scientia media, pp. 462b/63a. 486b. Vgl. Voet \& Nethen, De scientia media $\$$ 30, p. 336; GonZÁLEZ DE Rosende, Disputationes theol. 3, 5, 48-59, pp. 374b/79b. - „Cum Twissio, in quantum scientiam mediam insequitur, omnes nos copias iungimus. " Ebd. 3, 5, 6o, p. 380a. Vgl. V. Baron OP. (†1674): SS. Augustini et Thomae vera et una mens 2, 1, 2, 4, Paris 1666, t.3, p. 164; Godoy, In Primam partem 35, 69, t.2, p. 32a. Für berechtigt hält Twisses Kritik sogar Aldrete, In Primam partem 31, 3, t.1, pp. 618-22. Anders Ferrier, De Deo uno: Ad obiectiones Vincentianas 1, 35-42, pp. 355a-57a; SCHERTZER, Vae tibi Chorazin \$\$ 90-91.

534. Emphatisch Avendaño y Eztenaga, De divina scientia 3, 6, 20, t.1, pp. 276-78.

535. „opinio hac tempestate plausibilis et forte vera"Rivadeneyra, De scientia Dei 3, 36, p. 105 a. Vgl. Veken, De Deo uno 19, 9-10, p. 330a/b; Mauro, Opus theol. 1, 45, 17, t.1, p. $148 \mathrm{a}$.

536. Maderni, Curs. theol. 1, 4, 16, 24, t.1, pp. 197b/98a. 


\section{$\$ 22$. [Scientia Media reflexa]}

Molinas Definition $(\$ 20)$ ist die der Scientia Media in dem engeren Sinn (stricte). ${ }^{537}$ Sie ist insofern überholt, als sie nur auf diejenige Scientia Media paßt, welche die kreatürlichen Willensakte zum Gegenstand hat (scientia media directa), nicht auf die integrierte $(\$ 17) .5^{538}$ Okkurrenzen des Ausdrucks, scientia media reflexa' begegnen vereinzelt schon früher, ${ }^{539}$ erst ALDRETE hat das Thema jedoch durchgesetzt. ${ }^{540}$ Damit ist nicht ${ }^{541}$ Gottes kognitive Bezugnahme auf die Scientia Media gemeint, sondern eine Scientia Media in zweiter Potenz, wo die in erster Potenz einen Teil der Bedingung vertritt. ${ }^{542}$ Gott reflektiert sein eigenes Verhalten. ${ }^{543}$ Gott weiß, wie Er sich unter der Voraussetzung verhalten würde, daß darauf so und so reagiert würde. ${ }^{544}$ Je nachdem, ob Gott bzw. der kreatürliche Akteur in $p$ oder in $q$ agiert, ordnet TolomeI das kondizionale Tatsachenuniversum auf diese Weise in zwei Sparten. ${ }^{545}$

537. Ramirez, De scientia Dei 20, 14-16, t.2, pp. 272a/73a.

538. „... scientia..., media’ paulo aliter quam illa... “ MANUEL DE LA ConCEPCión, De scientia Dei 5, 277, p. 544. - „... scientia late ,media'..."VARgas, De Deo sciente 4, 2, 9, t.2, pp. 504-05. „... sola directa, sine reflexa, nondum est ,media' proprie et stricte loquendo." STERzInger, Scientia Media $\$ 56$, p. 57.

539. Fasulo, In Primam partem Q. 14, art. 13, 516. 521, t.2, pp. 291a/92b.

540. „Neque solum petit Deus, antequam quidquam libere statuat, scire, quid sequeretur in creatura, si haec aut illa poneretur conditio, verum et scire, quid sequeretur in Deo ipso, si existat hoc vel illud decretum divinum.“ Aldrete, In Primam partem 30, 18, 9, t.1, p. 603a. - „... scientia illa media reflexa... paucis abhinc annis inter nostros circumferri coepta est." LYNCH, Metaph. 7, 9, 42, t.3, p. 716a. Auch historisch dazu: Henao, Scientia media theologice $\$ \$ 1616-30$, t.1, pp. 367b-70a; Chossat, Notae in Gabrielis Vazquez Opera omnia, t.1, pp. 558-61. 581-82.

541. Martínez, Deus Sciens 4, 6, 1, p. 740; Ulloa, Prodromus 5, 208, p. 549; Araujo, Curs. theol. 4, 515, t.1, p. 236a. Anders Peralta, De scientia media 4, 2, p. 362.

542. „Vocant Recentiores nostrae ,Scientiam mediam reflexam' illam, qua Deus videt conditionate, quid ipsemet esset facturus, importando ex parte hypothesis alium actum scientiae mediae directum, hoc est, tendentem circa nostros actus liberos. “Martínez, Deus Sciens 4, 6, 1, p. 739. Vgl. M. Borrull SJ. († 1689): Divina scientia futurorum contingentium, praecipue Media, contra novissimos impugnatores defensa $\$ 821$, Lyon 1656, p. $227 \mathrm{~b}$.

543. „... per eam [sc. scientiam mediam reflexam] Deus... se reflectit in se ipsum, seu in suas proprias actiones liberas..."STERzInger, Scientia Media $\$$ 53, p. 53.

544. „Modus cognoscendi...est iste: ,Si ego, qui video inefficax esse auxilium A, vidissem esse efficax, illud decernerem.' Deinde: ,Si ego, qui video, quod in tali casu decernerem auxilium A, vidissem, quod in tali casu non decernerem, in tali casu exercerem decretum B.' Deinde: ,Si vidissem oppositum, exercerem decretum C', et sic deinceps... “ Rivadeneyra, De volunt. Dei 8,45 , p. 188 b.

545. Tolomei, Theol. nat. $6,4,18,3$, p. 734 a. 
Im Molinismus ersetzt das Lehrstück von der scientia media reflexa den thomistischen Typ des hypothetischen Dekrets $(\$ 14),{ }^{546} \mathrm{im}$ Suarezismus fungiert es als die Theorie der flexibel gehaltenen decreta subiective et obiective conditionata, ${ }^{547}$ durch deren Annahme sich die Scientia Media-Hypothese dem Skotismus empfiehlt. ${ }^{548}$ Sonst wird die Scientia Media in zweiter Potenz, sowohl in der molinistischen als auch der suarezischen Variante, extern gern als für die Scientia Media-Hypothese selbstzerstörerisch beurteilt. ${ }^{549}$ Die philosophischen Probleme, vor welche dieses Lehrstück führt, sind allerdings beträchtlich. Erst auf dieser Ebene, auf der verschiedene Scientia Media-Szenarien miteinander verglichen werden und die zu Szenarien unterschiedlichen Typs einnehmbare Position diskutiert wird, sind die modaltheoretischen Subtilitäten der möglichen Welten-Semantik aufs Tapet gekommen. Wie unterscheidet sich die scientia media de facto existens ${ }^{550}$ von fiktiven Szenarien? Es stellt sich nämlich die Frage, ob mit der Scientia Media in zweiter Potenz die Realisierung ihrer Bedingung überhaupt vereinbar ist. ${ }^{551}$ Außerhalb des Suarezismus wird das Lehrstück auch endox abgelehnt. ${ }^{552}$ Die Parität zur direkten Scientia Media besteht nicht, ${ }^{553}$ der angebliche Wissenstyp läßt sich systematisch

546. SterZInger, Scientia Media $\$ \$ 71,77,109-10$, pp. 75-76. 86. 133-34.

547. G. Hermann, De Deo sciente $\$ 275$, pp. 306/o7. Anders Junius, De provid. 5, 6, 14-15, p. $113 \mathrm{a} / \mathrm{b}$.

548. J. Merinero OFM. (†1663): Cursus theologicus iuxta Doctoris Subtilis Ioannis Duns Scoti mentem: De scientia Dei 4, 2, 7. 11, Madrid 1668, t.1, pp. 61a. 62a. Zu den beiden Dekrettypen vgl. Alarcón, Theol. schol. 2, 4, 6, 12, pp. 143b/44a; Silva y Pacheco, In Primam partem Q. 14 art. $13,12,1$, t.2, p. 388 b.

549. Sedlmayr, Deus unus 4, 5, 55-6o, pp. 450-52.

550. Junius, De provid. 5, 6, 3, p. 111a. - „... duplex sensus, in quo dicatur ,scientia media reflexa'. Primus est, quando haec scientia media reflectit supra aliam scientiam mediam, quam habuisset, sed non habuit. Secundus est, quando reflectit supra scientiam mediam, quam in hoc signo non habet, sed habebit in sequenti... Tota dubitatio devolvitur ad ultimum sensum quaestionis... An detur fundamentum, ut in scientia media distinguamus unam virtualitatem reflexam, quae cadat supra directam non existentem determinate in eo signo, sed virtualiter futuram?" Araujo, Curs. theol. 4, 517-18, t.1, p. 236b. Ein Beispiel (Mauro, Opus theol. 1, 46, 34, t.1, p. 155b) für den ersten Fall: „Si Deus habuisset hanc scientiam mediam, dedisset Iudae vocationem, qua fuisset conversus.“

551. Zu dieser Debatte auf der einen Seite Junius, De provid. 5, 6, 5. 18, pp. 111b. 113b; Mauro, Opus theol. 1, 46, 15, t.1, p. 152a/b; A. GutierreZ DE LA SAL SJ. († 1715): Tractatus scholasticus de Incarnatione Verbi Divini 8, 11, Madrid 1729, p. 233b/34a. Auf der anderen: Ramirez, De scientia Dei 23, 134, p. 427a; G. Hermann, De Deo sciente $\$ 264$, p. 295.

552. „Negandum... est, Deum habere scientiam mediam reflexam de collatione, aut negatione auxilii, seu libertatis futurae, sub conditione, quod Deus habeat hanc scientiam mediam directam, aut oppositam.“'A. Perez, Opus posth.: De intelligentia Dei 6, 50, p. 192 b.

553. Mauro, Opus theol. 1, 46, 18-19, t.1, p. 153a/b. 
nicht unterbringen. Gott muß sich zwar zu jedem möglichen Szenario verhalten, 554 aber Szenarien lassen sich nicht zusammenführen. ${ }^{555}$ Selbst unter den Förderern des Lehrstücks hat der Abbau der Skrupel Zeit gebraucht. Auch Aldrete, bei dem Gottes Souveränität wie eingeklemmt in einem Scientia Media-Mahlwerk erscheint, 556 wirkte auf die Jüngeren hesitant. ${ }^{557}$

Das Lehrstück hat den letzten Innovationsschub gebracht, jene fürchterlichen ${ }^{55}$ Interaktionskalküle, wie sie unter den entgegengesetzten Annahmen, daß die Scientia Media reflexa vom kreatürlichen Akteur impedibel, 559 bzw. daß sie es nicht sei, ${ }^{560}$ in der Folgezeit dialektisch durchgespielt worden sind. Materiell handelt es sich bei diesen in Alcalá (Young, Herrera, Ramirez, UlloA) kultivierten Subtilitäten um ein Analogon zur diplomatischen Kunst, ${ }^{561}$ technisch um die Sorte Denksportaufgaben, die akademisch früher (Ars obligatoria) in der Artistenfakultät zu Hause gewesen war, in Gestalt dieses Lehrstücks nun aber in die theologische Fakultät gewandert ist. An diesem Sport sich zu beteiligen, hat sich die thomistische Konkurrenz in Alcalá geweigert. ${ }^{562}$

554. „Deus non potest dicere... ,Ego nihil volo decernere circa ea, quae facturus essem, si haberem alias scientias medias'." MaUro, Opus theol. 1, 46, 35, t.1, p. $156 \mathrm{~b}$.

555. „Scientia, cuius nullum est excogitabile signum, nulla est; sed Scientiae (sc. Mediae) reflexae nullum est signum excogitabile: ergo..." Aranda, Schola Scientiae Mediae 5, 221, p. 371b. Vgl. González de Santalla, In Primam partem 21, 17, t.1, p. 369a; Mauro, Opus theol. 1, 46, 31, t.1, p. 155b. Dagegen: Bernique, De divina scientia 3, 3, 44, p. 490a/b; Ramirez, De scientia Dei 23, 88-106, pp. 411-17; G. Hermann, De Deo sciente $\$ \$ 276-82$, pp. 307-15.

556. „... in illo quasi complexo utriusque scientiae mediae praevidetur divinus actus liber ut absolute existens..." Aldrete, In Primam partem 32, 3, 11, t.1, p. 638 b.

557. Aldrete, De praedest. 2, 10, 8, t.2, p. 266a/b. Zur Stelle Junius, De provid. 11, 8, 6, p. 333 a („licet... fere neget scientiam mediam reflexam“).

558. „Sunt haec florida ingeniorum exercitamenta, seu lusus, et in quibus aliqui maius temporis spatium, quam aliis operaepretium videtur, insumunt. Cumque ea immisceant tractationi de Scientia Media, quasi ad hanc essent necessaria, nihil aliud efficiunt, quam reddere disputationem salebrosam, et pene horridam..." Henao, Scientia media theologice $\$ 1630$, t.1, p. $369 \mathrm{~b}$.

559. Aldrete, In Primam partem 32, 3, 5, t.1, p. 637b; Bernaldo De Quirós, Opus philos. 88, 48, p. 589a; Henao, Scientia media theologice $\$ 1732$, t.1, p. 393a; Peralta, De scientia media 4, 2, pp. 366-75; Mayr, Theol. 1, 509-15, pp. 438-49; G. Hermann, De Deo sciente \$\$306-10. 319-21, pp. 339-45. 356-59; VARGAS, De Deo sciente 4, 2, 14-20, t.2, pp. 511-20.

560. „Libertas creata nullam habet libertatem ad impediendum aut determinandum scientiam mediam reflexam." UlloA, Prodromus 5, 191, p. 532. Vgl. Martínez, Deus Sciens 4, 6, 2, p. 744; Junius, De provid. 5, 6, 17, p. 113 b.

561. Bernaldo de Quirós, De praedest. 9, 59, p. 67b.

562. D. Perez, De scientia Dei, p. 388a/b (unter Bezug auf Ramirez). 


\section{\$23. [Zweck]}

Hauptzweck der Scientia Media-Hypothese ist die Sicherung des Trienter Dogmas von der Freiheit des Menschen gegen innerchristliche Gefahrenquellen. Die Gewährung der Freiheit, d.h. daß es keine Situation gibt, in welcher nicht neingesagt werden kann, ${ }^{563}$ impliziert Scientia Media. ${ }^{564}$ Das darauf errichtete Gnadensystem verhütet den Rückfall des christlichen Vorsehungsglaubens in den stoischen Fatalismus. ${ }^{565}$ Nicht durch die Unwiderstehlichkeit der Gnade, sondern durch ablehnbare, steigerungsfähige Gnadenangebote soll das Verhalten hinlänglich steuerbar sein. ${ }^{566}$ Die Scientia Media-Hypothese ist dasjenige Gnadensystem, ${ }^{567}$ welches die Gnadenwirksamkeit als eine Funktion des Zweitakts auffaßt. Die Wirksamkeit ist kein Ausstattungsmerkmal der Gnade, sondern besteht in dem Wissen darum, wie

563. Molina, Concordia Q. 14 art. 13, 53, 2, 30-31, pp. 382-83. Eine Analyse des ,posse dissentire' in der Trienter Konzilsdefinition bei BERnALdo DE Quirós, De praedest. 10, 84-114, pp. 84b-9ob.

564. „... si determinatio Dei non dependet a scientia media nostrae operationis, iam est inevitabilis a voluntate.“ BERnAldo DE Quirós, De praedest. 10, 13, p. 72b. - „Scientia media est necessaria ad salvandam libertatem creatam, ita ut illa salvetur optime haec libertas, et sine illa salvari non possit.“ Morawski, In Primam partem, p. 55. - „... mirabilis harmonia Scientiae Mediae cum humana nostra libertate..." Henao, Scientia media theologice $\$ 453$, t.1, p. 134a.

565. „Negatio Calviniana huius scientiae (sc. mediae) Stoica est.“ Schertzer, Vae tibi Chorazin $\$ 81$. Die Gegenthese („Stoicorum Fatum introductum in Christianismum per Scientiam Mediam“) bei Leydecker, Hist. Eccl. Afric.: Diss. de Stoicorum fato, t.2, pp. 644-66. Offensichtlich sympathisiert der Molinismus mit der Gegenthese: A. Pinto Ramirez SJ. († 1654): Commentarius in Epistolas Christi Domini ad septem episcopos Asiae, quae in Apocalypsi continentur $\$ 1601$, Lyon 1652, pp. 417b-18a.

566. Molina, Concordia Q. 14 art. 13, 53, 2, 25, p. 381. - „... scientia Dei... media defenditur praecipue ad explicandum quomodo Deus salva et illaesa libertate creaturae, possit eam inflectere quo voluerit, adhibendo media quae per scientiam mediam praevidet habitura effectum, et obtentura consensum liberum.“ MARTinon, De Deo 9, 39, t.1, p. 168a. - „Communis semper fuit autorum Societatis mens, posse Deum dirigi ex praescientia conditionata ad decernendum auxilia de se indifferentia ad consensum, ac dissensum, imo stare in hoc unam ex praecipuis scientiae mediae utilitatibus.“ Rivadeneyra, De praedest. 3,16 , p. 37b. - „... licet nequeat Deus consensum extorquere, potest illum intendere addendo vires, immutando circumstantias, sub quibus simul praevisus fuit consensurus homo."Aguilar, De scientia Dei 1, 13, 335, t.3, p. 28 ob.

567. „Scientia Media essentialiter habet ostendere efficaciam, vel inefficaciam auxilii." HerrerA, De praedest. 2, 10, p. 40. - „... efficacia auxiliorum ipsissimum est obiectum scientiae mediae.“ Izquierdo, De Deo uno 38, 120, t.2, p. 66oa. Vgl. Ledesma, De auxiliis, pp. 580aD. 605aA; SuÁreZ, De gratia 5, 24, 15, t.8, p. 514b. 
der Zweitakt ausfällt. ${ }^{568}$ Es ist möglich, daß eine in diesem Sinn unwirksame Gnade nicht erteilt, ${ }^{569}$ oder daß das Angebot verbessert wird. ${ }^{570}$ Notwendig ist das nicht. ${ }^{571}$

Für die Kritiker hat die Scientia Media-Hypothese oft nur den einzigen Zweck, die Idolatrie der kreatürlichen Willensfreiheit. ${ }^{572}$ Ihnen ist der Humanitarismus unheimlich, mit dem Gott zugemutet wird, erst zu erforschen, wie die Reaktion seines Gegenübers ausfallen würde. ${ }^{573}$ Gottes Machtwirkung werde gescheut, ${ }^{574}$ diese anthropologisch aber nur gegen eine Prädetermination durch Charakter und

568. González de Santalla, In Primam partem 38, 10, 55, t.1, p. 616a („efficacia gratiae consistens in scientia media“). - „Verum est, hac sententia gratiae efficaci tantum extrinsecam congruitatem tribui, sed petitam a praescientia Dei infallibili, non a circumstantiis tantum, aut etiam ab ipsa cooperatione liberi arbitrii." H. LAMPARTER SJ. († 1670): Disputatio theologica de auxiliis gratiae Dei \$95, Dillingen 1631, p. 51.

569. „Scientia media... repraesentans inefficaciam auxilii, quantum est ex se, retrahit a collatione auxilii..." González de SAntalla, In Primam partem 36, 7, 37, t.1, p. 526b. Vgl. IzQuierdo, De Deo uno 39, 86, t.2, p. 68 ob.

570. González de Santalla, In Primam partem 38, 12, 61, t.1, p. 618a/b; Tapolcsanyi, De Deo uno, p. 183. Anders SuÁrez, De praedest. 1, 7, 15-16, t.1, pp. 257b/58a.

571. SuÁrez, De praedest. 5, 4, 8, t.1, p. 509a; Aldrete, In Tertiam partem 20, 9, 10, t.1, p. 223a; Junius, De provid. 11, 1, 7, p. 310 .

572. „Scopus Jesuitarum fuit haeresim Semipelagianam... tueri, et Idolum Liberi Arbitrii asserere.“ F. Turretini ( $†$ 1687): Institutio Theologiae Elencticae 3, 13, 3, Genf 1688, t.1, p. 235. - „... ex obiecto Scientiae mediae videtur colligi, non tantum initium fidei esse ex nobis, ut Semipelagiani asserebant, verum etiam initium cuiuscumque operis." GonzÁLEZ DE Rosende, Disputationes theol. 3, 5, 90, p. 391b. So schon der Tenor der Zensur der 14. These Molinas in dem 1601 diskutierten römischen Gutachten bei G. NuÑEz Cononel OSA. ( $† 1620)$ : Brevis enarratio actorum omnium quae circa Controversiam de Auxiliis Divinae Gratiae sub Clemente PP. VIII. et coram ipso celebrata sunt, Frankfurt 1687, pp. 43-45. Seitdem ein Gemeinplatz. Dazu aus Sicht der Jesuiten Meyer, Hist. Controv. de auxiliis 4, 18-19, pp. 291a-93a. Ausführlich auch G. Filorami O.Minim. († 1689): Lapis Lydius circa materiam de praescientia, praedestinatione, et reprobatione, Messina 1687.

573. GonzÁlez de Rosende, Disputationes theol. 3, 5, 81, p. $387 \mathrm{a} / \mathrm{b}$ („scientia exploratrix“); ebd. 4, 1, 21-22, p. 509a/b; G. Huygens († 1702): Theologia: De Deo 14, 20-22, Löwen 1695, t.3, pp. 249-50; L'Herminier, Summa theol. t.1, pp. 530. 539-45 („scientia exploratrix“). - „Quid mirum, si Deus debeat explorare, quid factura sit voluntas... ?"BANHOLzer, De scientia Dei $\$ 104$, pp. 165-66. Vgl. GonzÁlez de Santalla, In Primam partem 36, 7, 35, t.1, p. 524b; Antoine, De Deo uno 5, 5, 8, p. 271 b.

574. „Ex eo, quod Deo negetur potestas certa et infallibilis movendi causas secundas ad determinatos actus, inde originem trahit scientia media." KNIPPEnBerg, De provid. 8, 1, p. 247. 
Umwelt eingetauscht. ${ }^{575}$ Es werde der Effekt ohne die Ursache, das Geschöpf ohne den Schöpfer gewollt. ${ }^{576}$ Der Schöpfer habe sich nach dem Geschöpf zu richten. 577 Die Scientia Media sei die satanische Einflüsterung, ${ }^{578}$ sie frevele an Gottes Freiheit und an der kreatürlichen zugleich. ${ }^{579}$ Der Jansenismus, der an ihr anthropologisch zusätzlich die Nivellierung von Unschuldsstand und Sündenstand kritisiert, legt ihr die Laxheiten der sog. Jesuitenmoral zur Last. ${ }^{580}$

Bei dieser Stoßrichtung, die der Gesellschaft Jesu später den Vorwurf zuzieht, sie sei „der Vater der Aufklärung ", 581 konzentriert sich der Angriff auf das Konzept der Indifferenzfreiheit (libertas indifferentiae)..$^{582}$ Eine von den Dominikanern in Umlauf gebrachte zweckdienliche Geschichtslegende besagt, deren von Molina und

575. „Per hanc mediam scientiam, quae certitudinem habet ex arbitrio posito sub loco et tempore, ac temperamento naturali, tollitur nostri arbitrii potentissima libertas ita efficaciter, sicut tollitur per alios, qui fatalem introducebant necessitatem. "Lemos, Panoplia Gratiae 1, 5, 18, t.1, p. 246 a. Vgl. Alvarez, De auxiliis divinae gratiae 7, 16, pp. 64b/65a; Prideaux, De scientia media $\$ 10$, p. 25 (Arg. 7); W. Ames ( $\dagger$ 1634): Bellarminus enervatus, sive Disputationes Anti-Bellarminianae, Amsterdam 1658, t.4, p. 53; Twisse, De scientia media, p. 483a; Voet \& Nethen, De scientia media $\$$ 30, p. 337. - Dagegen: Suárez, De gratia Prol. 2, 9, 10, t.7, p. 112a/b; Herice, In Primam partem 7, 77, pp. 167b/68a; RuIz DE Montoya, De scientia Dei 69, 7, 3, p. 704b.

576. „... Ergo ponitur effectus sine causa, creatura sine creatore, et per consequens talis scientia est penitus explodenda." Prideaux, De scientia media $\$ 10$, p. 24. Vgl. GonzÁlez de Rosende, Disputationes theol. 4, 1, 17, p. 507a.

577. „... ergo causa determinationis causae primae est causa secunda.“ GonZÁLEZ DE RosENDE, Disputationes theol. 3, 5, 76, p. 386a. - „... Deus... esset pedissequus creaturae..., ut adversarii nobis opponunt." Perrimezzi, Dissertationes 86, 3, 2, t.1, p. 398b. - Vgl. Gabriele di SAN Vincenzo, In Primam partem 14, 290-96, pp. 273a/74b; CaCherano, Theol. 1, 3, 4, 36, t.1, p. $290 a$.

578. Piccinardi, De approb. doctrinae S. Thomae 6, 2, 1, t.3, pp. 16o-61.

579. Gabriele di san Vincenzo, In Primam partem 14, 274, p. 269b; Gufl, Metaph. \$1089, t.2, p. 659 .

580. V. Contenson OP. († 1674): Theologia mentis et cordis 2, 2, 2, 3, Köln 1687, t.1, pp. 76b-77a. Kritisch dazu Fourmestraux, Vanus Thomistarum triumphus de scientia media $\$ 367$, p. 211; Manuel de la Concepción, De scientia Dei 5, 204-12, pp. 481-89.

581. B. BAUER (†1882): Freimaurer, Jesuiten und Illuminaten, in ihrem geschichtlichen Zusammenhange, Berlin 1863, S. 5. Vgl. das jansenistische Lehrgedicht von L. Racine († 1763): La Grace 3, 131-40, Poésies, Paris 186o, p. 335.

582. „... hinc (sc. a definitione liberi arbitrii) profluxere... Dei scientia media... et plura id genus impia Jesuitarum et sequacium philosophemata.“ A. HeEreboord († 1659): Meletemata philosophica: Collegium Ethicum 11, 5, Leiden 1654, p. 51b. 
Suárez zugrundegelegte Definition sei scholastisch ein Symptom der Dekadenz. ${ }^{583}$ Diese Legende war indessen bis 1630 wirksam widerlegt. ${ }^{584}$

Wo die Scientia Media-Hypothese nicht auf den einen Zweck verkürzt wird denn zumindest einen anderen hat sie: die Vertiefung eines klassischen Gottesattributs $^{585}$-, ist es die Bequemlichkeit dieser Lösung für eine Reihe klassischer Probleme der christlichen Theologie, ${ }^{586}$ welche die Lösung suspekt macht. Entweder wird dagegen eingewandt, daß sie ein untaugliches Mittel ist, ${ }^{587}$ oder es werden die unterschiedlichen Zwecke dialektisch gegeneinander ausgespielt. ${ }^{58}$ Die Existenz einer Pluralität von Zwecken bezieht sich (\$24) auf die Einsatzschwerpunkte der Hypothese und (\$25) auf die Einschätzung ihrer Tragweite.

\section{\$24. [Einsatzschwerpunkte]}

1. Die Scientia Media ist das hyperbiographische Wissen um die Einzelperson. Jedes einzelne Ich ist ein transfiniter Wissensgegenstand. ${ }^{80}$ Die Scientia Media

583. D. Nuño Cabezudo OP. (†1614): Commentarii et Disputationes in Tertiam partem D. Thomae Aquinatis Q. 62 art. 5, Valladolid 1601, p. 174b; Alvarez, De auxiliis divinae gratiae 115, 1, p. 756a; Ledesma, De auxiliis, p. 205bC; Lemos, Panoplia Gratiae 3, 2, 29, t.3, pp. 98b/99a; Twisse, De scientia media 2, 1, 3, p. 265a; STRAng, De volunt. Dei 3, 15, p. 694; M. Sснооск († 1669): Diatriba academica explicans naturam et conditionem liberi arbitrii $\$ 15$, Groningen 1659, p. 21; J. Opstraet († 1720): Institutiones theologicae in Primam Secundae D. Thomae 4, 4, 6, Lüttich 1710, t.1, pp. 182-83; Henricus a S. Ignatio: Ethica Amoris 2, 59, Venedig 1771, t.1, p. 107b; G. W. LeIBnIZ: Philosophische Schriften, Akademie-Ausgabe VI/4, Berlin 1999, S. 1380.

584. In diesem Buch S. $13 \mathrm{ff}$.

585. „Non enim ideo est in Deo scientia media de nostris actionibus liberis, quia illa conducit ad providentiam, sed quia est perfectio simpliciter simplex." Martínez, Deus Sciens 4, 5, 4, p. 731. Vgl. Maderni, Curs. theol. 1, 4, 16, 9, t.1, p. 193a; Manuel de la Concepción, De scientia Dei 5,162, p. 444 .

586. Eine Liste bei Granado, In Primam partem 2, 5, 7, t.1, pp. 266/67. - „Ipsa quoque facilitas... non immerito hanc rem suspectam reddit.“W. HerInCKx OFMObs. († 1677): Summa theologica scholastica 1, 6, 61, Antwerpen 1660, t.1, p. 10ob. - „Quis autem non magis eligat cum Augustino ignorare, quam cum Molina intelligere?" IoAnnes A S. Thома, In Primam partem 20, 6, 4, t.2, p. 519b. Vgl. Ledesma, De auxiliis, p. 637bA/B.

587. „Inutilis est scientia media ad eos ipsos fines et usus, ob quos inventa et celebrata est.“ Strang, De volunt. Dei 3, 13, p. 667.

588. Macedo, Collationes 11, 1, 13, t.1, pp. 437-41.

589. „... quia infinitae sunt circumstantiae, infinitae hominum rerumque combinationes, quae singulae in me possunt cadere, manifestum est, infinitam esse, quam de me solo habet, scientiam conditionatam." A. A. DE SARASA SJ. († 1667): Ars semper gaudendi 1, 16, 24, hg. von J.Ch. Fischer, 
antizipiert Leibnizens Begriff der notio completa..$^{50}$ Aus der Humanperspektive regt sie zu Gedankenspielen an, wie einer sich in einer bestimmten historischen Vergangenheit verhalten haben würde. ${ }^{591}$ Wo gemeint wird, man hätte auch die Antwort darauf, stellt sich die Verwendung des Irrealis der Vergangenheit allerdings außerhalb der Scientia Media.

2. Die Scientia Media modifiziert den Gottesbegriff. Wann immer sie aus der Perspektive der ersten Person Singular erläutert wird, bildet bei MoLINA ${ }^{592}$ der Mensch den Gegenstand der Ichfiktion, bei Vázquez und SuÁrez hingegen Gott. ${ }^{593}$ Die Jesuiten haben zwar vorgeworfen bekommen, bei ihnen sei aus Jehova ein ohnmächtiger Jupiter geworden. ${ }^{594}$ Die Dominikaner haben auf den römischen Kongregationen aber eingesehen, daß auf dem Standpunkt ihres suarezischen Gegners BAstida den Gottesbegriff der Scientia Media-Hypothese von dem der physischen Prädetermination nur das trennt, daß dieser Gott sich

Frankfurt-Leipzig ${ }^{4} 1750$, t.1, p. 299. Vgl. Lessius, De praescientia Dei cond. 20, 3. 9, pp. 231. 235; Bugis, De Deo uno 8, 6, 4, p. 119a; UlloA, Theol. 1, 3, 29, t.1, p. 102 .

590. „Mente Molinae... causa libera... non potest perfectissimo modo obiective cognosci, nisi simul cognoscantur et omnia, quae sunt in causa, et praeterea omnia, quae ex causa vel esse possunt, vel erunt, vel sunt, vel fuerunt, vel essent.“ FAsulo, In Primam partem Q. 14, art. 13, 464, t.2, p. 269a. Vgl. das Referat bei Zumel, Utrum Deus habeat praescientiam (Opuscula t.2), p. $166 \mathrm{aD} / \mathrm{bA}$, und die beifällige Molinainterpretation von Bellarmin, De novis controv. $\$ 2$, p. 107a. Von Fasulo angeregt: G. BRÜNTrup SJ. / R. SCHneIder: „Complete Concept Molinism Der Molinismus vollständiger Begriffe“, in Th. MArschler / TH. SchärTl (Hgg.): Ein Gespräch zwischen systematischer Theologie und analytischer Philosophie, Münster 2015, S. 363-78, hier 371-72. Zu den Schwierigkeiten mit Molina: Becanus, Summa Theol. schol. 1, 1, 10, 7, p. 65a/b; Rivadeneyra, De scientia Dei 13, 5, pp. 294b/95a; Aldrete, In Primam partem 31,1, 7-12, t.1, p. 614a/15a; Herrera, De scientia Dei 15, 1-3, p. 392.

591. SARASA, Ars semper gaudendi 1, 4, 49, t.1, p. 69; J. A.H. UlRICH († 1813): Institutiones Logicae et Metaphysicae: Theologia naturalis $\$ 68$, Jena ${ }^{2} 1792$, pp. 96-97.

592. „... quid ego pro libertate mei arbitrii essem facturus, si me constituisset in alio ordine rerum, vel si in hoc ipso in quo me constituit, statuisset conferre mihi maiora aut minora auxilia, quam re ipsa donare statuit, vel si concessisset mihi longiorem vitam aut graviores tentationes permisisset.“ Molina, Concordia Q. 14 art. 13, 49, 11, p. 311.

593. „Si Petrus tali mea vocatione excitaretur, neque illi deesset concursus meus, quem vocatio tali arbitrio contemperata postulat, et qui sine vi et miraculo negari ei non potest, absque dubio consentiret." VÁzquez, In Primam partem 67, 22, t.1, p. 557b. Vgl. SuÁrez, De gratia Prol. 2, 5, 17 , t.7, pp. $77 \mathrm{~b} / 78 \mathrm{a}$.

594. Voet \& Nethen, De scientia media $\$ 29$, p. 332. Vgl. ZumeL, Utrum Deus habeat praescientiam (Opuscula t.2), p. 141aD-bB; B. VERDu OP. (†1626): Relectio contra scientiam mediam, Barcelona 1610, fol. 14r/15r; IoAnnes A S. ThомA, In Primam partem 20, 4, 29-33. 42, t.2, pp. 491-93. 497b; Godoy, In Primam partem 37, 21, t.2, p. 58 b. 
anderer Machtmittel bedient. 595 Dieser Gott hat ein bürokratisches Image. 596 An dem von der Gegenseite verteidigten Gottesbegriff läßt das Züge hervortreten, durch welche sich der Theodizeedruck merklich erhöht. ${ }^{597}$ Gerade auch das Theodizeebedürfnis wird durch die Scientia Media-Hypothese befriedigt, ${ }^{598}$ bis hin zur Stabilisierung einer neustoischen Zufriedenheitstechnik. 599

3. Die Scientia Media ist für die Vorsehung unentbehrlich, ${ }^{600}$ in ihr spiegelt sich, mehr noch als die merkantile Rationalität, ${ }^{601}$ utopischerweise die des absolutistischen Verwaltungsstaats. ${ }^{602}$ Indem sie die Wirkung der Erstursache auf die ,Exigenzen' der Zweitursachen abstimmt, stellt die Scientia Media die Beteiligung der Erstursache an allen kosmischen Kausalbeziehungen sicher. ${ }^{603}$ Die Scientia Media erstellt Weltszenarien zum Zwecke der Schöpfungsfolgenanalyse. Was aus jeder möglichen Welt wird, muß dem Schöpfer vorher bekannt

595. Aus Bastidas großem Vortrag über die Scientia Media von 1604 protokollierten die Dominikaner (SErry, Hist. Congreg. de auxiliis 3, 39, col. 421) eine Stelle, die sich sinngemäß auch in Bastidas Manuskript (Meyer, Hist. Controv. de auxiliis 5, 49, p. 515b) findet: „Itaque cognoscit Deus per Scientiam Mediam hoc obiectum: ,Si ego voluero, ut voluntas faciat hunc actum, potero facere ut faciat, decernendo ponere illam sub istis circumstantiis, in quibus, si ego illam ponere decrevero, ipsa faciet'.“

596. Hübsch die Karikatur bei Voet \& Nethen, De scientia media $\$ 26$, p. 327: Gott als Archivar mit Brille, der in Registern wühlt, um den Obersatz für seinen Syllogismus zu finden.

597. „Et quis, obsecro, non fateatur esse maximam huius autoris (sc. Molinae) audaciam in illo de feritate et crudelitate quae poneretur in Deo secundum sententiam Augustini et D. Thomae eo modo quo communiter intelligitur... Si Deus ex mera electione voluntaria hunc assumit, et alium relinquit, estne iniquus? est crudelis?... Si de suo facit quod vult, est crudelis? Cesset murmur..." Navarrete OP., Controversiae 32, 4, t.2, pp. 69ob/91a.

598. Ruiz de Montoya, De scientia Dei 69, 10, pp. 707-10. Dagegen: Macedo, Collationes 11, 1,13, t.1, pp. 438a/39a.

599. SARASA, Ars semper gaudendi 1, 5, 4-5, t.1, pp. 80-81. - „Scientia media nobis deest, quo minus intelligamus, quae mala evenissent nobis, nisi Deus nostras intentiones turbasset.“ F. Neumayr SJ. († 1765): Via compendii ad perfectionem, Augsburg-Ingolstadt ${ }^{3} 1769$, p. 170.

6oo. Molina, Concordia Q. 14 art. 13, 53, 3, 11, p. 390.

601. FABBRI, In I Sent. 55, 45, p. 9 a.

602. „... sicuti si aliquis rex posset praenoscere omnes effectus futuros conditionatos suorum subditorum, et ex hac perfectissima praescientia illos gubernaret, non esset in hoc dependere a suis subditis, sed suos subditos perfectissime dependere ex ipso.“ Agostini, In Primam partem Q. 14 art. 13, $\$ 163$, t.2, p. 122b. - Über dieses Modell der Calvinist: „Nimirum anthropología basis est theologías Pelagianae." Leydecker, Hist. Eccl. Afric.: Diss. de Stoicorum fato, t.2, p. 646.

603. Agostini, In Primam partem Q. 14 art. 13, $\$ 164$, t.2, pp. 122b/23a. 
gewesen sein. ${ }^{604}$ Auch das von Gott Unbeabsichtigte, die Sünde, hat bis in die fernste Zukunft seine Auswirkungen. Die These, die Auswirkungen auf die Demographie wären vernachlässigbar, ist zumindest gewagt. ${ }^{605}$ Die Scientia Media hätte Gott von der Schöpfung abhalten können. ${ }^{606}$ Sie ermöglicht die Veranstaltung der Weltgeschichte, sei es, daß darunter ein schöpfungsergänzendes Timing ${ }^{607}$ verstanden wird, z.B. auch des technischen Fortschritts, ${ }^{608}$ sei es der Bereich des zwischenstaatlichen Verkehrs, ${ }^{609}$ sei es die providenzielle Heterogonie der Zwecke. ${ }^{610}$ Sie regt zur Rekonstruktion vergangener Möglichkeitshorizonte an. ${ }^{611}$

4. An der Scientia Media-Hypothese hängt theologisch die Hoffnung, die Interdependenz der verschiedenen Providenzebenen in einem Weltplan zu bewältigen. So stark wie bei keinem anderen christlichen Glaubensartikel schwanken die endox vertretenen Ansichten darüber, ob die Scientia Media-Hypothese das Inkarnationsdekret erklärt. ${ }^{612}$ Die größte Erklärungskraft wird ihr auf Positionen (Molina, Suárez) beigemessen, auf welchen es darauf angelegt ist, den an

604. „... in omnibus cognovisse quid eventurum esset, si hoc vel illo modo res crearentur et disponerentur... “SUÁREZ, In Tertiam partem 5, 1, 6, t.17, p. 200a. - „Deus omnino independenter a creatione huius universi praescit futura conditionata huius universi. Igitur idem erit dicendum respectu cuiuscumque universi: nam pro illo primo signo aeque erat Deus indifferens ad producendum aliud universum, et consequenter non erat, cur supponeretur praescisse potius futura huius universi quam alterius.“ Aldrete, In Primam partem 30, 9, 8, t.1, p. 573b.

605. „Nullus posterorum existit de facto, qui non existeret Adamo non peccante. “CAMPOVERDE, De Incarnat. 10, 38, t.2, p. 257a. Anders MolinA, Concordia Q. 14 art. 13, 53, 2, 14-15, pp. 373-74; Ruiz de Montoya, De scientia Dei 77, 3, 13, p. 814a (zustimmend Aldrete, In Primam partem 32, 1, 8, t.1, p. 633b); Veken, De Deo uno 19, 24, p. 339b; Der-Kennis, De Deo uno 8, 66, p. 181; González de Santalla, In Primam partem 36, 5, 36, t.1, p. 525 b.

606. „... noluit Deus impedire creationem mundi, quam praevidebat per scientiam mediam daturam occasionem peccato..." J. DE Lugo, De Incarnat. 7, 21, t.2, p. 396b. Vgl. Aldrete, In Tertiam partem 20, 9, 3, t.1, p. 222a/b; Herrera, De praedest. 2, 24, p. 45.

607. Saguens, De perfectionibus divinis 2, 1, 5, 63-64, t.2, p. 103.

6o8. Fonseca, In Metaph. 6, 2, 4, 9, t.3, p. 123b; zitiert von Voet \& Nethen, De scientia media $\$ 11$, p. 283 .

609. Saguens, De perfectionibus divinis 2, 1, 5, 4, t.2, p. 81 (bella, foedera, commercia, matrimonia).

610. Ruiz de Montoya, De scientia Dei 69, 10, 18, pp. 709b/10a.

611. „... fertur naturale desiderium intellectus in indaganda etiam haec conditionata. Quare disputatur apud Livium Hist. 1. 9, quid facturi fuissent Romani, si Alexander, victo Dario, in Italiam venisset." Recupito, Theologia 2, 1, 25, 13, t.2, p. 134b.

612. Völlig ablehnend z.B. J. Prévost (Praepositus) SJ. († 1634): Commentaria in Tertiam partem S. Thomae 1, 86, Douai 1629, p. 21a. 
dem Schema Natur/Gnade/Inkarnation orientierten konventionellen Aufbau der Heilsveranstaltung durch die Scientia Media zu verwirren, ${ }^{613}$ und wo sie für das geeignete Mittel gehalten wird, um heilsökonomisch alles zu vernetzen. ${ }^{614}$ Sonst hängt das Ausmaß, in dem sie hier zum Zuge kommt, davon ab, daß durch sie nicht Tatsachen vorweggenommen sind, deren Vorwegnahme (Funktionalisierung des Sündenfalls) zu Konflikten mit der Theodizee führt. ${ }^{615}$ Dann kommt sie nur intermittierend ${ }^{616}$ in einem mehraktigen Drama zum Einsatz, durch welches sichergestellt sein soll, daß die Einplanung der Sünde von der Scientia Media abstrahiert. ${ }^{617}$

5. Der Hauptzweck der Scientia Media-Hypothese ist eine Theorie der zweckrationalen Praxis. ${ }^{618}$ Die hier in Betracht kommenden Optionen dürfen nicht auf die, häufig falsch verallgemeinerte, Alternative ,Kongruismus' / ,Molinismus' reduziert werden. Dem Prohairesisschema gemäß unter der Prämisse, daß das Ziel vorher feststeht, dient die Scientia Media der Zielsicherheit in der Wahl der Mittel. ${ }^{619}$ Von Suárez wird die Scientia Media deshalb mit technischem Wissen

613. SuÁrez, In Tertiam partem 5, 1, 2-4, t.17, pp. 198a-99b; MARTinon, De Incarnat. 3, 5, t.4, p. 73 b.

614. „Dico... Deum omnia contingentia in eodem signo decrevisse in posteriori ad scientiam mediam, atque adeo eodem simplicissimo decreto simul permisit peccatum, et praedefinivit Incarnationem in remedium peccati, ac totum negotium Redemptionis decrevit." VIVA, Curs. theol. 6, 3, 2, 5, t.6, p. 82b. - „... sat fuerit praevidisse illius (sc. Adae) peccatum sub conditione tantum futurum, dependenter a quo potuit velle Christum ut Redemptorem; nam tantum sequitur, Deum anticipasse remedium ruinae mox permittendae in posteriori signo rationis in decreto de ponendo Adam sub circumstantiis, sub quibus praevisus fuerat sub conditione peccaturus." Amico, De Incarnat. 7, 105, t.6, p. 10ob. Vgl. MolinA, Concordia Q. 23 art. 4-5, 1, 8, 15, pp. 516-17; Granado, In Primam partem: De praedestinatione 5, 4, 19-22, t.2, p. 108a/b.

615. Den Einsatz der Scientia Media-Hypothese bei Suárez kritisieren Cabrera, In Tertiam partem Q. 1 art. 3, \$\$ 365-66, t.1, pp. 299-300; MARTinon, De Incarnat. 3, 66, t.4, p. 96b; L. PeÑAfiel: Tractatus de Incarnatione Verbi Divini 3, 69, Lyon 1678, p. 57a/b; C. DE OrTEgA: Tractatus de Incarnatione 3, 2, 1, 5, Lyon 1664, pp. 401b-02b.

616. Gutierrez de LA SAL, De Incarnat. 8, 8, p. 231b/32a (kritisch zu Aldrete).

617. Aldrete, In Tertiam partem 20, 9, 6, t.1, p. 223a.

618. Exemplifiziert bei Miranda, De scientia media 2, 4, 19-22, pp. 440b/41b. Vgl. SuÁrez, Varia opusc. theol. 2, 2, 4, 2, t.11, p. 354a; RuIz De Montoya, De scientia Dei 69, 1, pp. 691b/92b; Recupito, Theologia 2, 1, 25, 13, t.2, p. 135a. Dagegen Lemos, Panoplia Gratiae 1, 5, 37, t.1, p. 292b; Voet \& Nethen, De scientia media $\$ 14$, pp. 295-96.

619. „... per hanc praescientiam conditionatam solum ponitur in Deo conditionata cognitio efficacitatis mediorum... Praescientia conditionata efficacitatis mediorum est praescientia utilitatis et bonitatis mediorum ad finis consecutionem... Haec praescientia non solum non impedit, sed 
nahezu gleichgesetzt. ${ }^{620}$ Umstritten bleibt, ob sie die Wirksamkeit der Mittel eigentlich konstituiert, oder nicht. ${ }^{621}$

Unter der Prämisse, daß die Zielintention dem Erfolg der Mittel nicht vorgreift, wird die Unentbehrlichkeit der Scientia Media verschieden begründet:

a. damit, daß pädagogisch die Mittel auf den Empfänger abgestimmt sein müssen (praescientia congruitatis); ${ }^{622}$

b. gerade entgegengesetzt mit der Indifferenz szs. nach dem Gießkannenprinzip verteilter Mittel, ${ }^{623}$ indem die sichere Einplanung von Erfolg und Mißerfolg dann lediglich den Zufall zu eliminieren hat (praescientia efficacitatis/ frustrationis); ${ }^{624}$

c. mit der Integration von Mittel und Zweck in einem, auch virtuell unteilbaren, Totaldekret. Für Molina erübrigt sich dadurch die Unterscheidung dem göttlichen Wollen supponierter logischer Abfolgemomente. ${ }^{625}$ So gesehen wäre

valde iuvat, ut intentio finis absoluta sit."BASTIDA, [De scientia media] p. 515a/b. Vgl. SuÁREZ, Varia opusc. theol. 2, 2, 4, 4, t.11, p. 354b; De gratia Prol. 2, 5, 17, t.7, p. 77 b.

620. SuÁReZ, In Tertiam partem 5, 1, 7-8, t.17, pp. 200a-202a. Vgl. RuIZ de Montoya, De scientia Dei 69, 11, 7 p. 711b; L. PeÑAfiel, De Incarnat. 3, 31. 35, pp. 47b. 48b.

621. „Scientia media necessario praerequiritur dirigens seu praecedens ad volitionem collativam auxilii... Quando volitio collativa dirigitur ex scientia media, eo quod dicat,Volo auxilium, quia est efficax', tunc... per se et essentialiter pendebit a scientia media."BERnALDo DE Quirós, De praedest. 8, 18. 22, pp. 53b/54b. Anders Aldrete, In Tertiam partem 22, 9, 9-10, t.1, p. 25ob; Rivadeneyra, De praedest. 4, 1, p. 51b. - „Non me latet, aliquos ex nostris directionem scientiae mediae negare." LYNCH, Metaph. 7, 9, 38, t.3, p. 415a.

622. Vázquez, In Primam partem 93, 4-5; ebd. 99, 42-43. 48-49, Lyon 1620, t.1, pp. 490/92. Dagegen Herice, In Primam partem 7, 76, p. 167a.

623. Lessius ed. Le Bachelet, Prédestination doc. 34. 39, t.1, pp. 182-84. 279; ebd. doc. 45, t.2, p. 19; HeRICE, In Primam partem 22, 24, p. 392 b.

624. „... talis praescientia... est necessaria ad rationem perfectae providentiae, quae postulat, ut Deus, quavis hypothesi facta, praesciat quid sit eventurum.“ Lessius, De praescientia Dei cond. 4, 16, p. 42. - „Deus ad collationem auxilii ne caeco modo procedat, dirigitur per scientiam mediam de efficacia, aut inefficacia illius.“ Peralta, De scientia media 4, 2, p. 359. - „Qui certo scit medium fore inefficax, non solum habet antecedentem potentiam intendendi efficaciter finem per illud, sed etiam potest scientiam frustrationis praeviam componere cum tali efficaci intentione." Junius, De provid. 11, 3, 6, p. 316b. - Vgl. Herice, In Primam partem 22, 25, p. 392b; Oviedo, Physica 10, 4, 43, t.1, p. 268b; Haunold, Theol. 1, 298, p. 49b/50a; Gutierrez De LA SAL, De Incarnat. 8, 12, p. 234a.

625. Molina, Concordia Q. 23 art. 4-5, 1, 8, 15, p. 516. Näheres dazu bei Molina an Lessius, Lissabon 9.10.1590, ed. LE BACHelet, Prédestination doc. 5, t.1, pp. 31-32. - „Nervos... contendit 
die Scientia Media überhaupt nicht mit einzelnem, sondern nur mit Zusammenhängen befaßt. ${ }^{626}$ Von der Fraktion Suárez wird diese, als nominalistisch gekennzeichnete, Position fast perhorresziert. ${ }^{627}$

\section{\$25. [Tragweite]}

In Gottes Wissens- und Willenshaushalt hat die Scientia Media Prinzipienrang. ${ }^{628}$ Trotzdem ist den Vertretern dieser Hypothese bewußt gewesen, daß von ihr möglicherweise auch unkritisch Gebrauch gemacht wird. Über Sinn und Grenzen (usus / abusus) mußte sich verständigt werden. ${ }^{629}$ Wie erklärungskräftig sie ist, wie hoch endox ihre Leistungsfähigkeit veranschlagt worden ist, bemißt sich nach drei Parametern, die die Scientia Media-Hypothese zu vereinbaren hat: ${ }^{630}$
a. die Unfehlbarkeit des göttlichen Vorherwissens
b. die Unfrustrierbarkeit des göttlichen Prädestinationswillens
c. die Unantastbarkeit des freien Willens

Definitionsgemäß ist dabei nur $a$ gesichert: Die Scientia Media ist dessen Gewißheitsfundament. ${ }^{631}$ MoLinA verläßt sich für $b$ und $c$ auf den Kalkül mit den unendlich

hic Doctor (sc. Molina) ad probandum, non distingui ratione intentionem finis et electionem mediorum." Hurtado de Mendoza, De Deo Homine 13, 115, t.1, p. 148b. Vgl. Granado, In Primam partem: De praedestinatione 5, 8, 8, t.2, p. 115b; ebd. 7, 4, 16, t.2, p. 152a/b; ebd. 7, 5, 6, t.2, p. 157b; Amico, De Incarnat. 7, 128, t.6, p. 103a; Recupito, Theologia 2, 1, 25, 13, t.2, p. 135a/b; Mauro, Opus theol. 1, 69, 12-13, t.1, p. 216a; Aranda, De Incarnat. 3, 1, 152, p. 292a/b; Viva, Curs. theol. 6, 3, 2, 10, t.6, pp. 85b/86a.

626. Esparza, Curs. theol. 1, 18, 4-6, t.1, p. 6ob/61a; Conti, De scientia Dei 8, 1, 1, pp. 366-67; Mauro, Opus theol. 1, 69, 18-19, t.1, p. 216b; F. Rehlinger SJ.: Disputatio theologica de scientia Dei $\$ \$ 131-32$, Dillingen 1701, pp. 226-30. Vgl. MuniesA, De essentia Dei 8, 58, p. 165 b.

627. J. PerLÍn SJ. († 1638): Apologia scholastica sive controversia theologica pro Magnae Matris $a b$ originali debito immunitate 4, 14, 3, Lyon 1630, p. 216bA/B (gegen Granado); Aldrete, In Tertiam partem 22, 5, 9, t.1, pp. 241b/42a (gegen Granado); Junius, De provid. 2, 6, 3, p. 39b (gegen Esparza); Gutierrez de LA SAL, De Incarnat. 8, 5, p. 230 (gegen Esparza).

628. RuIZ de Montoya: Commentarii ac Disputationes ad quaestiones XXIII et XXIV ex Prima parte S. Thomae 59, 1, 6, Lyon 1629, p. 642 b.

629. Aranda, Schola Scientiae Mediae 5, 234-35, p. 374b.

630. „... dixi, non controverti quaestionem de media scientia, nisi propter conciliandam infallibilitatem divinae cognitionis, et indefectibilitatem divinae providentiae et praedestinationis cum contingentia et libertate causarum contingentium. " RAM, De divinis praemotionibus, fol. $74 \mathrm{r}$.

631. Molina, Concordia Q. 14 art. 13, 53, 3, 10, p. 389. 
vielen möglichen Welten, d.h. er hebt es in seinem Scientia Media-Konzept einfach auf. VÁzQUEZ ${ }^{632}$ hält die Scientia Media-Hypothese damit für überfordert. Unmittelbar gewährleiste ihre Einführung weder den Schutz der Willensfreiheit noch den Prädestinationserfolg. ${ }^{63}$ Das ganze 17. Jahrhundert über laviert der Scientia Media-Diskurs daher zwischen zwei sogenannten Risiken, ${ }^{634}$ dem für $b$ und dem für $c$. SuÁrez' einflußreiche Synthese, derzufolge Prädestination und Freiheit nur auf der Basis eines Wissens vereinbar wären, welches den Prädestinationswillen lenkt, macht gerade daraus, daß Gott seinen Willen auch durchsetzt, das Hauptmotiv für die Einführung der Scientia Media. ${ }^{635}$ Genau diese prädestinationstechnische Instrumentalisierung, durch die sie ihr Erklärungsmonopol verteidigt, wertet Vázquez' Fraktion als Rückfall in die physische Prädetermination. Der Konflikt zwischen Suárez und Vázquez ist der zwischen dem Standpunkt der Systemimmanenz und dem Standpunkt, daß die Scientia Media-Hypothese von einer systemtranszendenten Voraussetzung abhängt.

Weil die Scientia Media-Hypothese für sich genommen nicht garantieren kann, daß es die Mittel, welche den Prädestinationswillen zum Erfolg führen, faktisch auch gibt, hält eine andere Fraktion sie durch das System der moralischen Notwendigkeit für ergänzungsbedürftig. ${ }^{636}$ In der Ablehnung dieser Hilfshypothese sind sich wieder die Fraktionen Vázquez und Suárez mehrheitlich einig, aus Rücksicht auf $a$ und auf $c$. Gleichwohl überschattet der früher absolut ausgeschlossene $e^{637}$ Zweifel an der Garantieleistung für $b$ die zweite Jahrhunderthälfte: Ist das Risiko, daß - auf der Basis der transworld identity - ein freier Wille in keinem Scientia

632. VÁzQuez, In Primam partem 67, 27, t.1, p. 562 b.

633. „Hac scientia conditionali, quam Deus habet, ad mille difficultates explicandas nonnulli Theologi abutuntur, quae si recte expendatur,... perinde est ad salvandam nostram libertatem, ac si nihil Deus sub conditione cognovisset." VázQuez, In Primam partem 89, 95, Lyon 1620, t.1, p. 398a; ebd. 99, 14, t.1, p. 485b.

634. Bastida, [De scientia media] p. 5oob; Ruiz de Montoya, De scientia Dei 69, 13, 11, p. 716b; Oviedo, Physica 10, 1, 23, t.1, p. 244b; L. Peñafiel, De Deo uno 10, 19, 97, t.2, p. 157 b.

635. Suárez, De praedest. 1, 7, 6, t.1, p. 254b/55a. Vgl. Ruiz de Montoya, De scientia Dei 69, 13, 11, p. $716 \mathrm{~b}$ („ne patiatur periculum frustrationis“); BERNALDO DE Quirós, De praedest. 7, 5, p. 43b.

636. „Si non esset necessitas saltem moralis in toto collectivo mediorum, posset contingere, ut nullum medium praesciretur infallibile ad bonum usum praecise ex vi praescientiae et collectivi..., et ex alia parte, si esset necessitas moralis in toto collectivo mediorum, et non esset praescientia conditionata, non posset Deus praecise ex vi talis necessitatis moralis in toto collectivo ferre iudicium certum de eventu futuro..." Albertini, Corollaria, p. 30o; ebd. p. 328aD/bA. Vgl. S. K. Knebel: Wille, Würfel und Wahrscheinlichkeit. Das System der moralischen Notwendigkeit in der Jesuitenscholastik 1550-1700, Hamburg 2000.

637. Ruiz de Montoya, De scientia Dei 69, 8, 15-16, p. 706a/b. 
Media-Szenario mitspielt (,creatura rebellis'), mit der Scientia Media-Hypothese notwendig verknüpft oder nicht? ${ }^{638}$ Nicht dieser Zweifel, nur der Zweifel ${ }^{639}$ daran, daß $b$ und $c$ die Scientia Media-Hypothese implizieren, wird durch eine Beschränkung der Lehrfreiheit in der Gesellschaft Jesu offiziell unterdrückt. ${ }^{640}$

\section{$\$ 26$. [Popularisierung]}

Die mediale Präsenz der Scientia Media-Hypothese wäre als scholastisches Kontroversthema unvollständig beschrieben. Sie war auch ein Politikum, zunächst für eine akademische, später auch für eine breitere Öffentlichkeit.

Sie war das „Dogma“, vielleicht besser: das Totem, der Jesuitenscholastik. ${ }^{641}$ Kirchengeschichtlich sprach aus ihr ein starkes Sendungsbewußtsein. ${ }^{642}$ Auch darum ${ }^{643}$ hat sie polarisierend gewirkt. Im Verhältnis zu ihr gab es nur Ja oder Nein, ${ }^{644}$ die

638. Ein doxographischer Überblick bei Marín, Theol. 8, 3, 6, t.1, p. 517 a.

639. „... non potest ullo modo concedi, scientiam mediam ex parte Dei praerequiri ad operandum... Uno verbo dico, in conceptu providentiae divinae... per se non includi eam scientiam mediam.“ Arriaga, In Primam partem 32, 35. 42, t.1, pp. 368a. 370a. - „Deus non indiget scientia media ad libertatem nostram servandam.“ P. WADDING, De Incarnatione 9, 26, p. 393. - „... dari posse auxilium efficax praescindendo a scientia media..."Aldnete, De praedest. 2, 11, 7, t.2, p. $267 \mathrm{~b}$.

640. Vgl. das Gutachten der römischen Generalrevisoren vom 31.3.1645, ed. Le Bachelet, Prédestination doc. 148, pp. 369-73. Daher die feierliche Erklärung bei MuniesA, De provid. 2, 98, p. $47 \mathrm{~b}$.

641. „... nostrae scholae princeps dogma, qualis est Scientia Media..." Henao, Scientia media historice: Lectori Benevolo, Lyon ${ }^{1} 1655$, fol. $3 \mathrm{~V}$. - „Societati universae axis est haec sententia (sc. scientiae mediae), quo volvitur tota machina praedestinationis conciliationisque libertatis cum divinae gratiae efficacia." Hurtado De MendozA, De anima 9, 150, p. 594b. Zustimmend zitiert von dem Lutheraner H. Kromayer (†1670): Theologia positivo-polemica 5, 7, Frankfurt-Leipzig 1687, p. 264a. - „Scientia Media, Regina et Arbitra Scholae Nostrae“ Aranda, Schola Scientiae Mediae, Vorwort. Vgl. L. Peñafiel, De Deo uno 8, 27, 6, t.1, p. 551a; Henao, Scientia media historice $\$ \$ 1274-79$, Dillingen ${ }^{3} 1687$, pp. 332b/34a; MACEDo, Collationes 11, 1, 1, t.1, p. $387 \mathrm{~b}$.

642. Herice, In Primam partem 7, 8, p. 13ob; Fasulo, In Primam partem Q. 14, art. 13, 262. 526, t.2, pp. 181b/182a. 294a/b.

643. „... istud cerebri Iesuitici delirium, scientia, inquam, media..."Voet \& NeTHEn, De scientia media $\$ 18$, p. 308 .

644. „... media ista scientia vel in totum admittenda vel in totum abiicenda... “Voet \& Nethen, De scientia media $\$ 6$, p. 273. - „Scientia media non est ponenda." CABrerA, In Tertiam partem Q. 18, art. 4, 2, 297, t.2, p. 35ob. - „... huiusmodi scientia media... est impossibilis.“ZumeL, Utrum Deus habeat praescientiam (Opuscula t.2) p. 185aD. - „Contra rationem est constituere istam scientiam mediam in ipso Deo.“ Ledesma, De auxiliis, p. 612aC. - „Nulla datur scientia media.“ 
beiden rivalisierenden Gnadensysteme negierten einander, ${ }^{645}$ ohne einander jedoch widerlegen zu können, ${ }^{646}$ die Hoffnung, einen Mittelweg zu finden, erschien naiv. ${ }^{647}$ Auf der einen Seite hat sie „die halbe Welt gegen sich in Harnisch gebracht", ${ }^{4} 48$ auf der anderen hat ihr das Prestige der Institution, die hinter ihr stand, auch geholfen. ${ }^{649}$ Das journalistische Interesse an ihr war schon durch das Aufsehen geweckt, das die römischen Congregationes de auxiliis in ganz Europa erregt hatten. PRIDEAUX' Oxforder Vortrag von 1617 beleuchtet sowohl die kontroverstheologische Manier der daraus resultierenden Befassung mit der Scientia Media-Hypothese als auch die Chancen, die sich bei diesem Thema aus den interkonfessionell neuen Allianzen $(\$ 28)$ ergaben. ${ }^{650}$

Obwohl sie sich mit ihr identifizierte, hat die Gesellschaft Jesu die Scientia Media-Hypothese aus dem Schulbetrieb in die Öffentlichkeitsarbeit nur zögernd übernommen, erst nach der Hundertjahrfeier 1640, ${ }^{651}$ auch dann in der Homiletik

Rispolis, Status controversiae, p. 72. - „Scientia media in Deo nulla omnino est et absque legitimo fundamento fuit excogitata." G. P. NAZZARI OP. († 1646): Commentaria et controversiae in Primam partem Summae D. Thomae Aquinatis Q. 14 art. 13, 1, Venedig ${ }^{1} 1610$, p. 471bA. - „Scientia media expungitur." IoAnnes a S. Thoma, In Primam partem 20, 3, t.2, p. 463. Genauso, bei anderen Prämissen, Silva y Pacheco, In Primam partem Q. 14 art. 13, 13, 97, t.2, p. 438a/b.

645. „Scientia media ac absoluta Dei praedeterminatio ad invicem opponuntur." Lemos, Panoplia Gratiae 1, 5, 1, t.1, p. 204b. - „Decretum physice praedeterminans destruit obiectum scientiae mediae." Channevelle, Metaphysica t.2, p. 369.

646. Erath, Conciliatio $\$ 362$, p. 125.

647. BASTIDA, [De scientia media] p. 516b.

648. „... nobilis illa scientia media... orbem paene medium adversum se armavit.“ Ay LEWORTH, Metaphysica 5, 13, 1, p. 388a.

649. Ein Thüringer Franziskaner: „Me quod attinet, mihi omnino sufficit auctoritas Societatis Iesu, ut omnino probabile aestimem, admittendam esse in Deo scientiam mediam... "STÜMEL, De nat. div. $\$ 485$, p. 216b. Ähnlich, nur gedämpfter, A. Gibbon DE Burgo OSA. († 1676): Theologia scholastica in D. Thomam 27, 3, 5, 1, Mainz 1669-75, t.1, p. 572a/b.

650. „... descendamus... ad oppositas sententias... Pontificii (qui inter se hic dissentiunt) sunt vel Dominicani vel Jesuitae. Reformati vero sunt Remonstrantes et Orthodoxi." Prideaux, De scientia media $\$ 9$, p. 22. Ähnlich S. Desmarets (MAREsIUs, $\dagger 1675$ ): Sylloge disputationum aliquot selectorum: De termino vitae $\$ 18$, Groningen 1660, pp. 564-77, hier p. 569: „Quod... somniant Jesuitae... de scientia media..., ... cordate ac solide a Thomistis, Dominicanis et Jansenistis, in ipsa communione Pontificia refutatum."

651. In dem Molina gewidmeten Eintrag in den Ordensbibliographien wird der Scientia Media-Hypothese Erwähnung getan erst von N. Southwell (Sotwellus) SJ. († 1676): Bibliotheca scriptorum Societatis Iesu, Rom 1676, p. 569 b. 
äußerst behutsam. ${ }^{62}$ Jansenistische Rancüne sprach von einer „Geheimlehre“653 der Jesuiten. Die Werbung für sie, die auf französisch wie die auf deutsch, ${ }^{654}$ setzte zunächst mehr auf durch Privatlektüre vermittelte erbauliche Wirkungen. Wegen der zahlreichen Neuausgaben und Übersetzungen des Klassikers von SARASA ${ }^{655}$ ist die Ratgeberliteratur auch in der Folgezeit ein wichtiger Multiplikator geblieben.

$\mathrm{Daß}$ im Französischen die Scientia Media kein Fremdwort ist, ist wohl ein Ertrag der jansenistischen Polemik. ${ }^{656}$ In der klassischen Literatur war, etwa seit der Meinungsänderung von Mersenne, ${ }^{657}$ Distanziertheit Mode, aber nicht nur der französische Episkopat wußte gründlich Bescheid, ${ }^{658}$ auch die Enzyklopädisten haben zwischen der science des conditionnels und der science moyenne sicher unterschieden. ${ }^{659} \mathrm{Daß}$ es den Pariser Journalisten der Gesellschaft Jesu gelang, den aus der Astronomie geläufigen Ausdruck ,System' auf die Scientia Media-Hypothese zu übertragen, ${ }^{660}$ war auch ein Beitrag zur Versachlichung der Diskussion. Namentlich

652. B. Neuhauser SJ. ( $\uparrow 1673)$ : Theologia ecclesiastica, Das ist Gottes-Lehr predig-weiß abgehandelt. Erster Theil: Von dem Einigen Gott $\$ 592$, Salzburg 1672, S. 253b. Es scheint, daß in seinen stilbildenden Predigten Bourdaloue († 1704) die Scientia Media-Hypothese ganz vermieden hat.

653. González de Rosende, Disputationes theol. 3, 5, 60, p. 380a.

654. L. De Marandé: Le Theologien françois 3, 3, 1, 12, (1641) Paris ${ }^{3} 1652$, t.1, pp. 95-100; E. WeIGEL († 1699): „Der Grund aller Tugenden, nämlich eine mathematische Demonstration wider alle Atheisten", in Ders.: Wienerischer Tugend-Spiegel, Nürnberg 1687, Bd. 2, S. 42-45.

655. C. Sommervogel SJ.: Bibliothèque de la Compagnie de Jésus, Bruxelles-Paris 189off., t.7, col. $622-27$.

656. Vgl. z.B. A. Arnauld († 1694): Nouvelle défense de la traduction du Nouveau Testament imprimée à Mons ( ${ }^{1} 1680$ ), Euvres, Paris-Lausanne 1776, t.7, p. 454.

657. Affirmativ: M. Mersenne O.Minim. ( $\dagger 1648$ ): Quaestiones in Genesim, Paris 1623, coll. 355-56. Negativ: Ders.: Correspondance, hg. von C. de Waard, t.3, Paris 1969, pp. 454-56; t.8, Paris 1963, pp. 597-99.

658. J. B. Bossuet ( $\dagger$ 1704): Défense de la tradition et des saints Pères 2, 13, 2-3, CEuvres complètes, hg. von F. Lachat, Paris 1862, t.4, pp. 493-502; FÉNelon († 1715): Réfutation du système du Père Malebranche sur la nature et la grace chap. 30, Euvres, Paris 1852, t.2, p. 139b.

659. Encyclopédie, Neufchastel 1765, t.14, p. 791.

66o. Daniel, Lettres au R.P. Alexandre (1698), p. 108 („une supposition... imaginaire, qui nous aide... à l'explication de plusieurs veritez", wie der Kopernikanismus). Rezipiert von P. BAYLE († 1706): Reponse aux questions d’un Provincial, $2^{\text {ème }}$ partie, in: CEuvres diverses, Den Haag 1727 / Repr. 1966, t.3, col. 775b. Mit Newtons Gravitationsgesetzen auf einer Stufe rangiert die Scientia Media bei F. Para du Phanjas ex-SJ. († 1797): Théorie des Etrres insensibles, ou Cours complèt de Métaphysique sacrée et profane $\$ \$ 1027-28$, Paris 1779, t.2, pp. 647-48. 
LeIBNIZ hat dann durch die Hinweise in seiner Théodicée (1710) dafür gesorgt, daß die europäische Öffentlichkeit des 18. Jahrhunderts anständig informiert blieb. ${ }^{661}$

Von der Popularisierung profitiert hat die Scientia Media-Hypothese eigentlich nicht. Weil der aufgeklärte Dogmatikunterricht sie nur noch in Form solchen Handbuchwissens über sie duldete, ${ }^{662}$ hat ihre Popularisierung die aggressive Abwendung von der Scholastik im katholischen Europa sogar gefördert.

\section{$\$ 27$. [Historisierung]}

Innerscholastisch hat die Scientia Media-Hypothese Epoche gemacht, ${ }^{663}$ schon darum, weil sich die Jesuiten erst mit Molinas Buch in die dogmatische Theologie eingeschaltet haben. ${ }^{664}$ Der historische Index der Scientia Media-Hypothese war von Anfang an immer mit umstritten. Nicht nur systematisch wurde über ihr Verhältnis zum Kirchenlehrer Augustin gestritten, sondern auch darüber, wie Molina selber sich dieses Verhältnis gedacht hat. ${ }^{665}$ Bei Henao, einem der ersten, der sie nicht zweckgebunden, sondern monographisch behandelt, erregt es 1663 Befremden, daß sie immer noch in pejorativer Absicht als „neu“ bezeichnet werde. ${ }^{666} \mathrm{Um}$ die Zeit war die Klärung so weit gediehen, daß lagerübergreifend eine seriöse Verständigung über die Kontroverspunkte erzielt war. ${ }^{667}$ Entgegen den Befürchtungen

661. Ruiz de Montoya ist bibliographisch noch erwähnt bei J. E. KapP: Fortgesetzte Sammlung von Alten und Neuen Theologischen Sachen, Leipzig 1751, S. 203.

662. Daß „die scholastischen Fragen, z.E. de scientia Dei media, nicht dogmatisch, sondern nur historisch behandelt worden sind“, ist in dem katholischen Rezensionswesen der Aufklärungszeit (I. SCHWARZ OSB. [† 1794]: Anleitung zur Kenntnis derjenigen Bücher, welche den Candidaten der Theologie wesentlich nothwendig und nützlich sind, Koburg 1804, S. 304) für ein Dogmatiklehrbuch eine Empfehlung.

663. SuÁrez, Varia opusc. theol. 2, 2, 3, 1, t.11, p. 352a; VÁzquez, In Primam partem 67, 27, t.1, 562a; Lemos, Panoplia Gratiae 1, 5, 34, t.1, p. 284b; Ruiz de Montoya, De scientia Dei 76, 6, 6, p. 8o8b; Alviz, De scientia 1, 7, 1, 1, p. 176a; Ionnnes A S. Thомa, In Primam partem 20, 6, 10, t.2, p. 524b (vgl. ebd. 20, 6, 4, t.2, p. 520a); Mastri da Meldola, In I Sent. 3, 207, p. 145b; VeKen, De Deo uno 19, 1, p. 325a; Aldrete, In Primam partem 29, 1, 19, t.1, p. 506 b.

664. G. Gengell SJ. (†1727): Admiranda Jansenismi 1, 2, 1, Braunsberg 1715, p. 105.

665. Alarcón, Theol. schol. 2, 4, 5, 20, p. 142a; ebd. 2, 4, 11, 9, p. 152 b.

666. „Scientiae Mediae Opinio iam non est nova, cum sit plusquam centenaria." Henao, Scientia media historice $\$ 1316,{ }^{3} 1687$, p. 342 b (Imprimatur: 1663 ).

667. Vgl. z.B. die Darlegung des Skotisten Mastri da Meldola, In I Sent. 3, 279-86, pp. $162 \mathrm{~b}-64 \mathrm{~b}$. 
in der Selbstzensur mancher Autoren ${ }^{668}$ hat das päpstliche Publikationsverbot über das schwebende Verfahren in der Gnadensache die Entstehung einer Literatur zu diesem Thema nämlich kaum behindert.

Aus der Defensive heraus, unter anhaltendem Konkurrenzdruck und dank der dadurch auch erhöhten kritischen Maßstäbe ist die akademische Erfolgsgeschichte der Scientia Media-Hypothese in der katholischen Welt bis gegen 1700 noch von den Zeitgenossen gut erforscht. Ab etwa 1630 erschien, als Nebenzweig der Literatur zum Verlauf der Gnadenstreitigkeiten, der fortgesetzte Literaturbericht speziell über diesen Streit (origo progressusque Scientiae Mediae bzw. litis contra Scientiam Mediam). ${ }^{669}$ Eine sich darauf spezialisierende Zeitgeschichtsschreibung schlug eine Brücke zum Journalismus. ${ }^{670}$ Die Veranlassung dazu war die Unklarheit über den kirchenrechtlichen Status der Scientia Media-Hypothese. ${ }^{671}$ Soweit sie von Jesuiten herrührt, trägt diese Literatur daher apologetischen Charakter. Das Argument, sich „nur historisch“ mit der Scientia Media zu befassen, wehrte den Verdacht ab, es werde sich über das Publikationsverbot hinweggesetzt, ${ }^{672}$ aber gerade die Historisierung hat den Streit auch neu angefacht. ${ }^{673}$ Erleichtert wurde sie erstens dadurch, daß sich die Gesellschaft Jesu zu der Zeit schon bewußt war, daß sie die Gefangene der einmal getroffenen Systementscheidung war (der Fall Tiphaine 1640), ${ }^{674}$ zweitens dadurch, daß sich ihr interner theologischer Disput („bellum

668. Beispiele: Raynaud, Nova libertatis explic. 2, 7, 4, p. 552; Prévost (Praepositus): Commentaria in Primam partem S. Thomae, Douai 1632, p. 167b; R. Aversa CRM. († 1657): Sacra theologia 1, 14, 27, Rom 1640, t.1, p. 302b. Anders: IzQuiERdo, De Deo uno 30, 438, t.2, pp. 28ob/81a; Henricus a S. Ignatio, Theol. fund. 8, 46o, p. 483a/b.

669. Ioannes a S. Thoma, In Primam partem 2o, 1, 14, t.2, p. 438b; Sherlog (Leonardus), Responsiones P.I, p. 1.

670. Sherlog (Leonardus), Responsiones 1, 1, p. 1; Henao, Scientia media theologice $\$ 1805$, t.1, p. 409a. Ein Jansenist (GonZÁLez De Rosende, Disputationes theol. 3, 5, 63, p. 381a) über Henao: „... quasi arcanarum rerum scrutator magis quam scriptor".

671. Serry, Hist. Congreg. de auxiliis Praef. \$3, p. iv.

672. „... Adde nec de ipso Scientiae Mediae articulo scholasticam suscipi controversiam, sed historialem congressum..." SHerlog (LeONARdus), Responsiones 3, 58, p. 320. - „... mere Historice..." Henao, Scientia media historice Lectori Benevolo, ${ }^{1} 1655$, fol. $3 \mathrm{v}$.

673. „Gran persecucion se comienza á levantar contra la Apologia del P. Sherloque en defensa de la ciencia media... "Francisco Isidro Monzon SJ. an R. Pereyra SJ., Salamanca 8.1.1645, in: Cartas de algunos PP. de la compañía de Jesús sobre los sucesos de la monarquía entre los años de 1634 y 1648, t.6 (= Memorial histórico español t.18), Madrid 1864, p. 5.

674. Dazu die römischen Aktenstücke 148-50 (aus den Jahren 1645 bis 1664) ed. LE BACHELET, Prédestination, t.2, pp. 365-81. 
domesticum “ $)^{675}$ inzwischen auf eine andere Ebene verlagert hatte $(\$ 22)$. Henao betonte die Einheitlichkeit der Doktrin, ${ }^{676}$ die inzwischen aufgetretenen Differenzen wurden verschleiert, nicht verschwiegen.

\section{$\$ 28$. [Peripherie]}

Außerhalb der katholischen Welt fehlt es bis heute an den nötigen Vorarbeiten für eine Rezeptionsgeschichte der Scientia Media-Hypothese.

Im Calvinismus ist das, trotz der Agitation gegen die Arminianer, anfänglich vorhandene Interesse an $\mathrm{ihr}^{677}$ nach Twisses Intervention in eine an Alvarez orientierte schroffe Ablehnung umgeschlagen. ${ }^{678}$ In Reaktion darauf hat sie umgekehrt im Luthertum die philosophischen und theologischen Fakulktäten erobert (Zentrum: Jena). ${ }^{679}$

Je nach dem konfessionellen Hintergrund variieren auch die, an sich wenig interessanten, Stellungnahmen der frühneuzeitlichen Philosophie. ReID, im calvinistischen Schottland, äußert sich ablehnend. ${ }^{680}$ In der Schulmetaphysik des protestantischen Deutschland ist die Scientia Media-Hypothese hingegen auch im 18. Jahrhundert ein stehender Artikel, ${ }^{681}$ übrigens untrennbar von SARASAS („ein

675. Martínez, Deus Sciens 4, 5, p. 714; Araujo, Curs. theol. 4, 518, t.1, p. 236b.

676. „Societatis Authores... conveniunt omnino in existentia et essentia Scientiae Mediae.“ Henao, Scientia media theologice $\$ 1502$, t.1, p. 344b.

677. „... praescientia haec... a decreto definiente minime dependet, sed illud necessario... antecedit." F. Gomarus ( $†$ 1641): Disputationes theologicae 10, 32, in Opera theologica omnia, Amsterdam 1664, t.2, p. 27b. Vgl. A. van WALE (†1639): Loci communes S. Theologiae, in Opera omnia, Leiden 1643, t.1, pp. 174b-75b.

678. Vgl. z.B. S. Rutherford: Exercitationes apologeticae pro divina gratia 1, 5, Franeker 1651, pp. 187-213; J. SCHULER: Exercitationes philosophicae 2, 13, in: Philosophia nova methodo explicata, Den Haag 1663, t.1, pp. 156-61.

679. Historische Hinweise bei S. J. Baumgarten ( $†$ 1757): Untersuchung theologischer Streitigkeiten, hg. von J. S. Semler, 1, 1, 4, 44, Halle 1762, Bd. 1, S. 445-48. Nach dem Dreißigjährigen Krieg ist auf den Universitäten Jena, Wittenberg und Tübingen die Scientia Media gerade auch als philosophisches Disputationsthema gut vertreten gewesen. Vgl. H. Marti: Philosophische Dissertationen deutscher Universitäten 1660-1750. Eine Auswahlbibliographie, Berlin 1982, Nr. 1867, $7643,9556,8563,9574,3610,3611,3357$.

680. Th. ReId (†1796): Essays on the Active Powers of Man 4, 11, The Works, hg. von W. Hamilton, Edinburgh ${ }^{8} 1895$, pp. 632a-33a.

681. Historisch: Eberstein, Natürliche Theologie, S. 155 (Crusius, Darjes). Ergänzend: J. P. Reusch († 1758): Systema Metaphysicum $\$$ 922, Jena 1735, pp. 660-61; F.CH. BaumeIster († 1785): 
Leibniz seiner Zeiten“) $)^{682}$ eminenter Wirkung im deutschen Sprachraum. Nachdem schon WeIgeL 1687 den der Scientia Media-Hypothese gewidmeten Abschnitt seiner eigenen natürlichen Theologie einverleibt hat, ${ }^{683}$ stammt von dem Wolffianer Reusch die Anregung zu der, theologisch auch sachkundig kommentierten, ${ }^{684}$ Sarasaübersetzung von 1748. In Reaktion auf die Kritik ${ }^{685}$ an der Verwendung der Scientia Media in seiner deutschen Metaphysik ( $\$ 13)$ erwähnt Wolff persönlich diese in seinen lateinischen Werken zwar nicht mehr, aber nur, um von der Orthodoxie unbehelligt darzulegen, „was es mit der Scientia Media eigentlich zu sagen hat" ${ }^{686}$ Mit dem einschlägigen Paragraphen macht erst der transzendentale Idealismus kurzen Prozeß ${ }^{687}$ Danach ist von einer,Wiederentdeckung' erst wieder seit 1974 in der angloamerikanischen Szene die Rede. ${ }^{688}$

Elementa philosophiae recentioris $\$ 288$, Leipzig 1747, pp. 326-27; I. G. CANZ: Philosophia fundamentalis $\$ 1036$, Tübingen 1744, p. 147; W. F. WeISE: Dissertatio de scientia Dei media $\$ \$ 40-42$, Jena 1762, pp. 34-36; M.Сн. Hanov: Potiores philosophiae recentioris controversiae $\$ 108$, Leipzig 1765, pp. 110-11; J. A. EBerHard ( $† 1809$ ): Kurzer Abriß der Metaphysik $\$ 370$, Halle 1794, S. 187-88.

682. A. A. von SARASA: Die Kunst, stets frölich zu seyn, ( $\left.{ }^{1} 1746\right)$, hg. u. bearb. von Ch.E. von Windheim, Helmstedt 1761, S. b3v.

683. E. WeIGEL: Philosophia mathematica, Jena 1693, t.2, pp. 94-97.

684. J.СH. FIsCHER: „Einleitung in die vierte Abhandlung des ersten Hauptstücks des ersten Theils des Sarasae, in welcher die dreyfache Erkäntniß Gottes, die Sarasa weitläuftig erkläret, erläutert wird", in: A. A. von SARASA: Sittenlehre, oder die Kunst sich immer zu freuen und stets vergnügt zu seyn, Magdeburg ${ }^{2} 1764$, Bd. 1, S. 157-63.

685. Jenenser Theologisch-philosophisches Fakultätsgutachten (6.12.1725), zitiert in J. H. ZEDLER (Hg.): Großes vollständiges Universallexicon s.v. ,Welt (die beste)', Leipzig-Halle 1732-52, Bd. 54, Sp. 1714-47, hier 1719 .

686. Сн. WolfF: Ausführliche Nachricht von seinen eigenen Schriften, die er in deutscher Sprache herausgegeben, Frankfurt a.M. ${ }^{3} 1757$, S. 335.

687. J.Сн. Lossius: Neues philosophisches allgemeines Real-Lexikon s.v. ,scientia media', Erfurt 1803-07, Bd. 4, S. 52-54 („durch... die neuere Philosophie... außer Umlauf gesetzt“); W. T. KRUG: System der theoretischen Philosophie: Metaphysik $\$ 188$, Wien 1818, S. 418.

688. „Most recently Alvin Plantinga's rediscovery of Luis Molina’s doctrine of middle knowledge has fanned the fires of that old controversy... "W. L. Craig: The Problem of Divine Foreknowledge and Future Contingents from Aristotle to Suarez, Leiden 1988, p. xii. 


\section{Konklusion}

1. Anfangs ist alles Neue verworren, ausbuchstabiert worden ist es erst im Lauf der Zeit, auch Molinas Hypothese. Wenn es intellektuell Kollektiverzeugnisse gibt, dann ist die Scientia Media-Hypothese ein solches. Suárez' überragende Bedeutung als Systematiker, in der sich die Generationen nach ihm einig waren, ${ }^{689}$ hat sich bestätigt. Das Feld allein beherrscht hat trotzdem auch er nicht. Vorhandene Spezialstudien zur Theologie einzelner Autoren ersetzen daher nicht das Studium dieses Prozesses. Vollends witzlos ist es, wenn über Middle Knowledge geschichtsvergessen drauflosphilosophiert wird. Zeit wäre es für problemgeschichtliche Spezialstudien. Das Studium müßte von der Einsicht geleitet sein: Daß alles auf Lateinisch ist, und daß alles irgendwie ähnlich klingt, ist kein Zeichen dafür, daß über Generationen ein fertiges System gepaukt worden ist. Es ist der scholastische Jargon des Scientia Media-Diskurses. Das ist hermeneutisch nicht Ballast, sondern Chance.

2. Die katholische Kirche hat das lange Zeit so gesehen. Nachdem die römischen Congregationes de auxiliis 1607 unentschieden geschlossen worden waren, definierte 1748 der Hl. Stuhl den Status quo durch einen Pluralismus, der drei katholische Gnadensysteme unterschied und vor gegenseitiger Verketzerung schützte: das der „Thomisten“, das der „Augustiner“ und das der „Anhänger von Molina und Suárez". ${ }^{60}$ Das war eine betont vorsichtige Umschreibung für ein drittes System, dasjenige eben, welches mit der Scientia Media-Hypothese operiert. Die sprachlich von ihr abgeleiteten Lagerbezeichnungen ,Medistae' oder ,Mediscientiantes', ${ }^{691}$ die sie hergab, haben sich nicht eingebürgert, sind aber weniger mißverständlich als andere in der Literatur gebräuchliche Bezeichnungen, namentlich als das bis heute kurrente ,Molinisten'. Allerdings ist auch so noch nicht zu erkennen, daß nicht nur die auf der Basis der Scientia Media-Hypothese historisch entstandenen Gnadensysteme deswegen untereinander keineswegs

689. „Molinam subsequatur Suarez sectatorum scientiae mediae lumen clarissimum, quem a doctrinae amplitudine et sublimitate, iure magnum appellavero." Fourmestraux, Vanus Thomistarum triumphus de scientia media $\$ 136$, p. 77. - „Pater Franciscus Suarez... quae breviter Molina proposuerat, late et profunde discursit et validissime propugnavit contra omnes adversarios, qui contra scientiam mediam usque ad sua tempora scripsere." GonzÁlez de SAntalla, In Primam partem 13, 4, t.1, p. 202 b.

690. Enchiridion symbolorum, definitionum et declarationum de rebus fidei et morum $\$ 2564$ (Ep. „Dum praeterito“ 31.7.1748), hgg. von H. Denzinger / A. Schönmetzer, Freiburg i. Br. ${ }^{32} 1963$, pp. 510-11.

691. Cacherano, Theol. 1, 3, 4, 7, t.1, p. 282a; Conti, De scientia Dei 8, 12, p. 439; G. Da Vita OP. ( $\dagger 1677)$ : Tractatus de proprio et per se principio, unde provenit peccatum in actionibus voluntariis $\S 1735$, Palermo 1665, p. $450 b$. 
übereinstimmen, sondern daß die Vielstimmigkeit bis in die Explikation der Scientia Media-Hypothese selbst reicht. Von den Dominikanern sind diese internen Differenzen aber schon damals in Rom bemerkt worden. ${ }^{692}$ Es blieb bei den Gegnern ein Gemeinplatz, daß Molina, Vázquez und Suárez, die Architekten der Hypothese und Schulhäupter der Jesuitenscholastik, einander widersprechen. ${ }^{693}$ Weit entfernt, daß sie den Scientia Media-Pluralismus abgeleugnet hätten, wurde sich von manchen Jesuiten sogar frech dazu bekannt: Die Forschung mache nun einmal Fortschritte. ${ }^{64}$ Selbst die sonst nur aus der Kontroverstheologie geläufigen Unhöflichkeiten sind in den Fraktionskämpfen nicht immer vermieden worden. „Degeneres Assertores Scientiae Mediae!“, „Entartete Anhänger des Systems!“695 haben sich Jesuiten an den Kopf geworfen. Doxographisch ist das im Jahrhundert der Gnadenstreitigkeiten übliche Niveau der Differenzierungsbereitschaft nicht gehalten worden. In dem Maß, wie das Interesse an dem dogmatischen Streitpunkt nachließ, ist es nur immer gesunken. Keine historische Disziplin hat diesen Verlust aufgefangen.

3. Völlig versagt hat die Philosophiegeschichtsschreibung. Gerade von ihr wäre zu erwarten, daß sie einen geschärften Sinn für Systemansprüche hat. Der Grad an Aufmerksamkeit, der den Systembildungen der Vergangenheit entgegengebracht wird, steht jedoch in der dafür zuständigen Geschichtsschreibung bis heute in dem genau umgekehrten Verhältnis zu der Zahl der Autoren, die sie Gründe hat, für daran beteiligt gewesen zu halten. Der ungebrochene Geniekult (Descartes! Kant!)

692. Serry, Hist. Congreg. de auxiliis, 3, 39, col. 420B (Sitzung vom 27.7.1604).

693. „Iesuitae diversimode explicant hanc scientiam mediam.“ Felix, Primum Princ. Complut. 1, 6, 2, 3, p. 146a. - „Praecor advertas, quale erit aedificium scientiae mediae, quod in suis primis fundatoribus tantam habuit contradictionem. “V. FERRE OP. († 1682): Tractatus theologici in Primam partem D. Thomae 1, 1278, Salamanca 1675-76, t.1, p. 855b. - „Discordant... principaliter tres Authores, nempe Molina, Vasques et Suarius, et se mutuo destruunt, in assignando fundamento principali talis scientiae mediae." Magalhaes, De scientia Dei 2, 11, 3, p. 375; ebd. 2, 3, 1, p. 262; Lemos, Panoplia Gratiae 1, 5, 11, t.1, p. 230a; ebd. 1, 5, 17, t.1, p. 243b; PrideAux, De scientia media $\$ 10$, p. 26; Baron, SS. Augustini et Thomae mens 2, 1, 2, 4, t.3, pp. 161-62; Macedo, Collationes 11, 1, 3, t.1, p. 391b; Caramuel y Lobkowitz, Leptotatos $\$ 533$, p. 276a/b; EbersteIn, Natürliche Theologie, S. 153 .

694. „Neque vero Scientiae Mediae ab suis authoribus propterea male consulitur, quod inter se non modo verbis, sed rebus etiam interdum dissentiant... ... concors illa Doctorum discordia... Laborem potius Thomistis ingeminat haec responsionum varietas: nihil enim evincunt, dum unam impugnant, cum adhuc supersint plures ac forte validiores, quibus Scientiae Mediae patroni ipsorum impetus frangant." FERrIER, De Deo uno: Ad obiectiones Vincentianas 1, 74, p. 365a/b. Vorsichtiger HeNAO, Scientia media theologice $\$ \$ 1501-17$, t.1, pp. 344-48.

695. Muniesa, De provid. 9, 36, p. 213 a. 
hat zur Folge, daß gigantische Diskursformationen im historischen Bewußtsein veröden. Der Scientia Media-Diskurs ist dafür ein Paradefall. Seine Autoren sind aus der Nomenklatur der Philosophiegeschichtsschreibung verbannt. Ob man dabei eine intellektuelle Anstrengung an der Radikalität der Fragestellung, an dem Geist der Gründlichkeit, an dem Konkurrenzdruck - externem wie internem -, an der Überwindung der Provinzialität oder auch an dem Lektürepensum und, bei der verarbeiteten Literatur, an der Quote zeitgenössischer Autoren mißt: unter jedem dieser Gesichtspunkte erweist sich die Systematisierung der Scientia Media-Hypothese als die große dialektische Baustelle der Frühen Neuzeit. Wenn Aristoteles recht hat und die gesuchte, erste Philosophie' sich auch durch ihren Schwierigkeitsgrad ausweist, ist sie ihre heimliche, um den Begriff des kontingenten Seins zentrierte, Metaphysik.

4. In der Scholastik waren ihre wunden Punkte immer die Hauptsehenswürdigkeit der Scientia Media-Hypothese. Ihretwegen lohnt die Besichtigung dieses Lehrgebäudes auch heute. Die hier vorgeschlagene, nach oben offen ausdifferenzierbare Topik gibt einen Leitfaden durch die Literatur an die Hand.

Der Führer durch die Literatur zu einem Thema unterliegt gesteigert der Dokumentationspflicht jeder historischen Darstellung. Nur im ständigen Quellenbezug kann dieser Pflicht genügt sein und läßt sich, ob ihr genügt ist, auch kontrollieren. Dazu dient die Verzahnung von Text und Fußnoten. Wo jedes Aktenstück eine dogmatische Abhandlung ist, kann das Ergebnis des Aktenstudiums nicht seinerseits der dogmatische Abriß sein. Der Extrakt ähnelt eher einem Album: dem der in diesem Diskurs benutzten Prämissen. Alben ordnen irreduzible Vielheit. Alben streben nach Vollständigkeit und bleiben unvollständig. Alben verzichten auf den autoritären Gestus, sie schieben sich nicht vor die Sache, sie laden zur Besichtigung ein.

Dem Selbststudium steht in diesem Fall auch nichts im Weg. Für das hier ausgewertete Material ist die Digitalisierung der Bibliotheken inzwischen abgeschlossen. Die Technik hat uns von den historischen Zufällen der Anschaffungspolitik der Bibliotheken und ihrer Verluste befreit. Zivilisationsgeschichtlich zum erstenmal sind heute die Quellentexte komplett überall konsultierbar. Die Exaktheit des Apparats ist darum nicht eitel Pedanterie, sondern ein Gebot der Stunde.

Die Scientia Media-Hypothese muß in der intellektuellen Landschaft der Frühen Neuzeit nicht länger daliegen wie ein verwunschener Palast, den niemand betritt. 


\section{Anhang zu $\$ \$ 6-8$}

Der Thomismus opponierte einer den Futuribilien beigelegten dekretunabhängigen ,objektiven Wahrheit'. Wie er dabei argumentiert hat, zeigt eine Stelle in einem Manuskript, welches eine in Salamanca im Schuljahr 1683/84 zu dem Thema gehaltene Vorlesung dokumentiert. Es stammt von dem, nicht weiter bekannten, Theatiner Juan de Cardenas y Mendieta. ${ }^{696}$ Begriffsgeschichtlich relevant ist die an der betreffenden Stelle vorgenommene Unterscheidung zweier bekämpfter Positionen, einer, die dem Jesuiten Vázquez, und einer anderen, welche dem Jesuiten Herrera zugeschrieben wird. Der Begriff veritas obiectiva, mit dem das Referat dieser zweiten Position operiert, reduziert sich nicht auf die Wahrheitsdefinitheit, sondern hat noch ein zusätzliches Merkmal.

Juan de Cardenas y Mendieta CR.: Tractatus de scientia Dei disp. 4, 73-132

(73) Quinta sententia et communior his temporibus, seu quintus dicendi modus, asserit Deum cognoscere futura contingentia conditionata ,in se ipsis'. Verum authores huius modi dicendi discriminantur adhuc, dum alii asserunt talia futura conditionata esse in se cognoscibilia ratione suae veritatis obiectivae, quam habent pro signo priori ad decretum et independenter a decreto, ex vi et lege contradictoriarum. Ita P. VAzQuez tract. de scientia Dei disp. 67 cap. 2. 3, quem sequitur Alarcon tract. 2 disp. 4 cap. 6, et alii communiter. (74) Alii autem asserunt talia futura conditionata habere ex se cognoscibilitatem obiectivam ex se, ex suppositione nempe eventus futuri, ex eo scilicet, quia aliquando et pro aliqua differentia temporis erit determinate vera vel determinate falsa. Ita P. Augustinus de Herrera Complutensis tract. de scientia Dei q. 13 sect. 2, et alii Doctores ex eadem Societate. [...]

Reiicitur primus modus dicendi quintae sententiae

(114) Sit quinta conclusio. Deus non cognoscit futura contingentia conditionata in eorum veritate obiectiva, quam ex vi et lege contradictoriarum sortiuntur. [...]

Reiicitur secundus modus tuendi quintam sententiam

(129) Sit conclusio sexta. Implicat Deum cognoscere futura contingentia conditionata in eorum veritate obiectiva, quam ipsa futura sortiantur ex eo, quod in tempore est necessario una de inesse vera, et altera determinate falsa. (130) Probatur conclusio, quia veritas obiectiva ex terminis consistit in connexione praedicati cum subiecto; sed pro signo anteriori ad decretum in futuris contingentibus conditionatis non potest stare aliqua vera et determinata connexio inter praedicatum et subiectum, inter consensum sub auxilio $A$ cum Petro: ergo futura contingentia conditionata nullam habent veritatem obiectivam pro signo anteriori ad decretum. Maior constat. Nam veritas obiectiva talis conditionis est, ut penes ipsam mensuretur veritas formalis; sed veritas formalis consistit in eo, quod actus intellectus affirmet connexionem, quae est in obiecto;

696. Tractatus de scientia Dei expositus a P. Ioanne de Cardenas et Mendieta in D. Caroli Borromaei PP. C.R.M. Salmantino Collegio Vespertino Lectore pro cursu ab Anno Domini 1682 usque ad 1683. MS. BU Sevilla Fondo Antiguo A 331/o85, fols. 1-111. Neben weiteren Manuskripten desselben Autors beschrieben bei E. Moore SJ.: „Manuscritos teológicos postridentinos de la Biblioteca de la Universidad de Sevilla“, Archivo Teológico Granadino 20 (1957) 287. Dort fehlt die Information, daß der zweite Teil des Traktats, der die „Disputatio quarta de scientia futurorum contingentium conditionatorum, ubi de scientia media disquiritur" enthält, auf 1683/84 datiert ist. Die folgenden Exzerpte aus fols. $74 \mathrm{~V}-82 \mathrm{v}$ geben in Klammern die Paragraphenzählung dieser vierten Disputation. 
unde communiter dicitur, quod ab eo, quod res est, vel non est, propositio dicitur vera vel falsa: ergo veritas obiectiva ex terminis consistit in connexione praedicati cum subiecto. Probatur ergo principalis minor, quia pro signo anteriori ad decretum liberum Dei solum considerantur praedicata essentialia, consensus Petri v.g. secundum se sumpti, et auxilia indifferentia tam ad consensum, tam ad dissensum. Sed nullum horum est causa determinate inferens et causans connexionem inter consensum Petri cum Petro sub tali, vel tali auxilio. Ergo pro signo anteriori ad decretum non potest stare in futuris contingentibus conditionatis aliqua vera et determinata connexio inter praedicatum et subiectum. (131) Rursus, si ob aliquam rationem hoc futurum contingens conditionatum , si Petro in tali occasione confertur auxilium $A$, consensus existit' esset determinate vera pro signo anteriori ad decretum, maxime, quia in tempore sua de inesse ea est determinate vera, scilicet ista ,Petrus consentit sub auxilio A'. Sed esto in tempore una de inesse sit determinate vera, non exinde licet colligere, quod propositio conditionalis de futuro contingenti sit determinate vera pro signo anteriori ad decretum: ergo nulla est ratio suadens propositionem conditionalem de futuro contingenti esse determinate veram pro signo anteriori ad decretum. Maior continet Adversariorum doctrinam. Probatur minor, quia, licet propositio de inesse sit in tempore determinate vera, non licet inferre, quod pro signo possibilitatis sit sua conditionalis determinate vera - alias, ut saepe diximus, esset necessaria, et eius contraria vel contradictoria impossibilis -, ergo similiter, esto una de inesse sit in tempore determinate vera, non licet inferre, quod propositio conditionalis de futuro contingenti sit determinate vera pro signo anteriori ad decretum. Et ratio utriusque: quia propositio conditionalis de futuro contingenti non mensuratur per suam de inesse formaliter, sed solum terminative, et ab ordine ad illam mensuratur formaliter. Sed pro signo possibilitatis rerum et pro signo anteriori ad decretum, vel pro signo scientiae mediae, quod fingunt Adversarii, nulla est causa determinate causans hunc ordinem ad signum de inesse, cum pro illis signis solum considerentur praedicata essentialia rerum et decretum omnino indifferens ad utrumque. Ergo, esto in tempore una de inesse sit determinate vera, non exinde debet colligi, quod conditionalis de futuro contingenti correspondens illi propositioni debet esse determinate vera vel falsa. (132) Rursus, ut propositio de inesse sit vera in tempore, necessario exigit supponere decretum absolutum de eius existentia: ergo similiter, ut sua conditionalis de futuro contingenti sit determinate vera vel falsa, debet supponere decretum subiective absolutum et obiective conditionatum. 



\section{Luke Wadding SJ. (1593-1651/52) und sein Traktat über Gottes Wissen vom kontingent Zukünftigen}

Aus dem Fundus der Universitätsbibliothek von Salamanca stammt das hier vorzustellende Stück. Das Manuskript Concordia Divinorum et Humanarum ${ }^{1}$ ist laut Titelblatt ein Nachlaßwerk des Jesuiten Luke Wadding. Unter dem Titel Tractatus de scientia Deifuturorum contingentium wird daraus das vierte Buch gesondert ediert.

Zuwenig wissen wir von dem posttridentinischen Tractatus de scientia Dei, als daß nicht jede Ausgrabung archäologisch ein Gewinn wäre. Von Kleinigkeiten abgesehen liegt nur das im Druck vor, was schon seinerzeit veröffentlicht worden ist. Das ist an sich nicht wenig. Manches davon wurde im 19. und 20. Jh. wiederaufgelegt, wenn auch nur ausnahmsweise kritisch ediert. Sich an eine Erweiterung der Quellenbasis zu machen, hat man sich bisher nicht getraut. Zu erdrückend wirkt, da es nach der von der Aufklärung erreichten Abschaffung der scholastischen Theologie nicht mehr studiert und daher unverdaut geblieben ist, bereits die Fülle des Gedruckten. Man kann das Zögern verstehen. Was auch immer aus der noch größeren Fülle des Ungedruckten hervorgeholt wird, vorläufig ist es mit dem Stigma der Beliebigkeit behaftet, zumal dann, wenn es nicht schon eingeführten Autorennamen zuzuordnen ist. Während wir über die theologischen Lehrstühle in Paris und Oxford während des 13. und 14. Jhs. inzwischen chronologisch bestens Bescheid wissen, ist die Theologie der frühen Neuzeit selbst in den akademischen Zentren terra incognita. Uns fehlen die Maßstäbe für das Vorhandene und daher erst recht für das, was uns alles fehlt.

Nach Erfindung der Scientia Media-Hypothese, gegen 1566, ist ein Jahrhundert lang an ihr gefeilt worden. Für manche Einzelheit verlieren sich die Quellen ihrer Systematisierung im Ungewissen, denn nur ein Bruchteil der Literatur ist auch gedruckt. So verhältnismäßig groß und, bei der wohlüberlegten Publikationspolitik der Gesellschaft Jesu, auch qualitativ hervorragend dieser Bruchteil ist, ein Studium ihrer Geschichte kommt um die Einbeziehung handschriftlicher Archivalien nicht umhin. Der absoluten Zahl nach haben sich deren nicht wenige erhalten.

1. BU Salamanca Ms. 156, 914 fols. Beschrieben in O. Lilao Franca / C. Castrillo Gonzalez: Catálogo de manuscritos de la Biblioteca universitaria de Salamanca, t.I, Salamanca 1997. 
Allerdings darf man sich für die Quellenforschung davon nicht zuviel versprechen, denn einem unüberschaubaren, zersplitterten Fundus steht der Totalverlust allererster Provenienzen gegenüber. Bei den Archiven der Provinz Toledo, in bezug also auf die Hinterlassenschaft des Jesuitenkollegs Alcalá de Henares, müssen wir inzwischen davon ausgehen, daß sie verschollen sind. ${ }^{2}$ Das macht aus dem Rest ein Riesenfragment und relativiert sogar den tröstlichen Umstand, daß die Quellen in bezug auf Kastilien reichlich fließen. ${ }^{3}$

\section{Das Dokument}

Durch das Titelwort Concordia ist klar, in welchen Disput sich der sonst kaum bekannte Autor mit dem Text seinerzeit eingeschaltet hat.

Die Geschichte der christlichen Spekulation ist, auf verschiedenen Gebieten, eine Suche nach dem goldenen Mittelweg. Die Denkanstrengung der als Concordia bezeichneten Literaturgattung ist darauf gerichtet, Einseitigkeiten zu vermeiden und zwischen Skylla und Charybdis hindurchzusteuern. Seit Anselm von Canterbury wird sie vor allem mit einem Thema verbunden: einer Hypothesenbildung, die dazu bestimmt war, die menschliche Willensfreiheit mit der Unfehlbarkeit von Gottes Vorherwissen und der Übermacht seines Prädestinationswillens auszugleichen. Das wohl berühmteste so betitelte Buch ist Molinas Liberi arbitrii cum gratiae donis, divina praescientia, providentia, praedestinatione et reprobatione Concordia von 1588. Ihr antwortete 1610 die Humani arbitrii legitima cum efficacia auxiliorum divinae gratiae Concordia des physischen Prädeterministen Diego Alvarez. Waddings Manuskript ist ein Dokument der Blütezeit der Literatur, welche durch Molina angestoßen war. Anselm ist unvergessen $\left(\$_{360}\right)$, aber für Waddings Concordia ist die zeitnahe Vorgeschichte wichtiger: Ihr Autor führt einen Zweifrontenkrieg, sowohl gegen die physische Prädetermination der Dominikanerschule als auch gegen Übertreibungen im eigenen Lager. Er muß zusehen, wie er die eigene

2. Jacob Schmutz, der Archivstudien zum gegenwärtigen Manuskriptbestand der spanischen Jesuitenscholastik getrieben hat, erwähnt ein vor dem Bürgerkrieg nachweislich noch vorhanden gewesenes diesbezügliches Verzeichnis des Kollegs von Murcia; es sei jedoch (J. Schmutz: La Querelle des possibles. Recherches philosophiques et textuelles sur la métaphysique jésuite espagnole, 1540-1767. Thèse de doctorat Bruxelles / Paris 2003, 1192) unauffindbar. Für das Jesuitenkolleg von Alcalá de Henares sei praktisch mit Totalverlust zu rechnen: „[...] étudier la tradition complutense reste une véritable chasse aux fantômes." Ibid., 579.

3. Die Nachlässe der von den Jesuiten zu besetzenden zwei theologischen Lehrstühle an der Universität Salamanca während des Jahrhunderts 1668/1767 bei A. MoRÁn SJ.: „El primer catedrático Jesuita de Prima de Teología en la antigua universidad de Salamanca“. Miscelanea Comillas 14 (1950) 85-143, hier 128-42. 
„Kohärenz“ ( $\$ 428$ ) und seine Lösung gegen den Eindruck verteidigt, sie berechtige zu Zweifeln an seiner Linientreue ( $\$ 468)$.

Bei den Jesuiten war die Concordia mit der Scientia Media-Hypothese zu bewerkstelligen, das Programm also durch Hypothesenbildung zu Gottes Wissen abzuarbeiten. Das ist es auch für den vorliegenden Text $(\$ \$ 323,325)$. Leider ist er Fragment. Von den geplanten zehn Büchern liegen nur die ersten vier vor. Dieses Fragment ist aber Bauruine, nicht Überbleibsel. Der Autor hat sich seinerzeit mit der Vorstellung, die Ausführung seines Plans auf unbestimmte Zeit verschieben zu müssen, schon abgefunden und das Manuskript durch einen Anhang so weit abgerundet, daß es seiner Meinung nach publikationsreif war $(\$ 445)$. Die ersten drei Bücher befassen sich mit anderen Materien. Nach einer großen handlungsmetaphysischen Vorbereitung, vor allem der ausführlichen Kritik an dem System der physischen Prädetermination in dem umfangreichen zweiten Buch, wendet sich der Autor in dem vierten Buch Gottes Vorherwissen zu. Bei der Scientia Media sind wir damit immer noch nicht. Sie wäre das Thema des fünften Buchs gewesen $(\$ \$ 146,415)$. Das vierte ist ein freier Kommentar zu den Artikeln 8 und 13 der Q. 14 des ersten Teils der Summa theologica. Überschrieben sind sie Utrum scientia Dei sit causa rerum, Ist Gottes Wissen kausal strukturiert?, und Utrum scientia Dei sit futurorum contingentium, Hat Gott ein Wissen von dem Freizukünftigen?

Wir betreten also die Werkstatt des jesuitenscholastischen Thomismus. Dieser Traditionshintergrund darf nicht verkleinert werden. An der thomistischen Inspiration des Texts gibt es keinen Zweifel. Wenn in Franceschis Schublade, Thomismus' die Jesuiten aussortiert sind, dann zeigt schon allein die Existenz dieses Texts, wie wenig berechtigt das ist. Der Jesuitenspott über die „Thomistissimi“4 galt nur dem von der Dominikanerschule gelehrten Theorem der physischen Prädetermination. Eifrig wird sich zum Indeterminismus und zu Gottes Respekt vor der menschlichen Willensfreiheit bekannt ( $\$ \$ 119,142,301,305)$. Die kritische Auseinandersetzung mit der Thomasexegese der Dominikanerschule, welche der Jesuit führt, ist dem Tenor nach nicht originell, aber solide. Unüberhörbar mischt sich Ärger darein. „Was der hl. Thomas gemeint hat", heißt es einmal (\$ 32$)$ auf Alvarez gemünzt, „ist nicht autoritär von oben herab zu verkünden und als die richtige Interpretation den Gelehrten aufzudrängen, sondern durch den Stellenvergleich plausibel zu machen."

Um das schulmäßige Fortleben des Thomismus außerhalb des von den Dominikanern gelehrten Systems zu dokumentieren, wäre der Text gleichwohl nur einer unter zahllosen, die das tun. Zu diesem Zweck wäre eine Edition überflüssig. Zwar reduzieren sich die aus der älteren Scholastik verarbeiteten Bildungseinflüsse auch nicht auf Thomas, und der Karmeliter John Baconthorp, den Wadding im

4. P. Sherlog (Pseudonym: Leonardus) SJ.: Responsiones ad expostulationes recentium quorundam Theologorum contra Scientiam Mediam 2, 57, Lyon 1644, 170. 
Manuskript studiert haben will, ${ }^{5}$ war unter den Jesuiten des 17. Jahrhunderts sonst kein Name, der sich besonderer Wertschätzung erfreut hätte. Eine Edition würde sich aber auch nicht im Hinblick auf die hier ausgebreitete scholastische Gelehrsamkeit lohnen. Bei Lichte besehen ist sie doch mehr eine aus zweiter Hand. Unter diesem Aspekt dokumentiert der Text eher den Erfolg, den der Jesuit Diego Ruiz de Montoya (1562-1632) mit der Leistung gehabt hat, zu bestimmten systematischen Knotenpunkten wirklich die gesamte intellektuelle christliche Vergangenheit noch einmal, ein letztes Mal, scholastisch aufbereitet zu haben. Von dem Scharfsinn und dem Fleiß dieses Gelehrten haben - bis in die Gegenwart - Generationen profitiert.

Der dokumentarische Wert des vorliegenden Thomaskommentars liegt ganz nach der systematischen Seite hin. Bezogen auf die Theorie des göttlichen Vorherwissens ist er ein Zeugnis für die Ausgestaltung dessen, was wir den Suarezismus nennen. In der Hypothesenbildung beider Schulen, der Dominikaner wie der Jesuiten, gewahrt er Einseitigkeiten $(\$ 401)$, um die in einer spekulativen Anstrengung zu überwinden der Faden da aufgenommen wird, wo Suárez ihn liegengelassen hat.

Zum Zweck der Grobsortierung hat diese Feststellung ihr Gewicht, ihre Aussagekraft ist dennoch begrenzt. Von den Jesuiten dieser Generation war virtuell ein jeder ,Suarezianer, denn Suárez hatte Maßstäbe dafür gesetzt, was man die gründliche, die scholastische Behandlung des Themas nennen kann. Wie häufig in solchen Fällen, sind, je mehr man die Einzelheiten studiert, desto mehr Unterschiede zu bemerken. Hier schon äußerlich. Ohne daß er außergewöhnlich lang wäre, ist unser Traktat immerhin mehr als doppelt so lang wie, ein halbes Jahrhundert früher, Suárez' Dissertation De scientia Dei futurorum contingentium absolutorum. Dabei befaßt sich Waddings Text, legt man ihn daneben, eigentlich nur mit dem Stoff der Schlußkapitel 7 bis 9. Die veränderte Disposition liegt nicht an stärkerer Spezialisierung. Wadding holt nicht weniger weit aus als Suárez. Die Akzente sind anders gesetzt. Besser als im Spiegel von Suárez zeigt sich das, wenn man Waddings Disposition neben die von Vázquez' Kommentar zur Q. 14 art. 13 hält.

Vázquez hatte 1598 den Stoff in fünf Kapitel eingeteilt:

\section{Disp. 64 An Deus certo sciat futura contingentia ex ipsorum praesentia reali in aeternitate}

Disp. 65 An aliqua ratio certitudinis scientiae, qua Deus novit futura, assignari possit Disp. 66 An propositio singularis de futuro contingenti sit vera

Disp. 67 An futura sub conditione a Deo certo cognoscantur

Disp. 68 An praescientia Dei tollat arbitrii nostri libertatem

5. „[...] cuius scripta, quibus maximopere delector, saepe doleo a sodaliti sui alumnis Patribus Carmelitanis [...] praelo donata non esse [...]“ Concordia fol. 239v. Da Baconthorps Sentenzenkommentar gedruckt vorlag, ist es nicht klar, worauf sich diese Bemerkung bezieht. 
Davon behandelt Wadding nun, wie gesagt, nicht nur das vierte Kapitel nicht, die Scientia Media-Hypothese, sondern auch nicht das dritte, die sowohl Vázquez als auch Suárez im Hinblick auf diese Hypothese systematisch so wichtige Wahrheitsdefinitheit der Aussagen über kontingent Zukünftiges.

Aus einer Fehlanzeige folgt nicht viel, immerhin aber doch so viel, daß selbst im Zeichen der Scientia Media-Hypothese der Traktat über Gottes Vorherwissen keineswegs stereotypisiert war. Darum sagt ,Suarezianer' erst einmal nicht viel.

\section{Ein Ire in Kastilien}

Über die Person des Verfassers unterrichten zwei biographische Dokumente, die in einem Dossier zusammengestellt sind:

1. Der ordensoffizielle Nachruf des Jesuiten Juan de Piña (1580-1657), ein typisches Stück Hagiographie. Geplant war gewesen, die lateinische Übersetzung desselben der posthumen Publikation von Waddings Opus beizugeben.

2. Die Skizze seines Landsmannes und Ordensgenossen Edmund Hogan (18311917). Sie ist einer Galerie kostbarer Miniaturen zu Angehörigen dieser Sippe entnommen, welche ebenfalls eifrige Katholiken und namhafte Gelehrte gewesen sind. In manchen Punkten ist sie allerdings überholt.

„I have never read of any one family in Ireland or out of it", bemerkt Hogan an anderer Stelle dieser Artikelfolge, ,that could equal that of the Waddings for the highest gifts of the intellect; nor do I know of any city of its size at that time that produced such a number of men of great talents as did the City of Waterford. “6 Unseren Autor, den Jesuiten Luke Wadding (1593-1651/52), Theologieprofessor in Salamanca, darf man nämlich nicht mit dem gleichnamigen Franziskaner (1588-1657) verwechseln, seines Zeichens Theologieprofessor in Rom. Der war sein Cousin. Ihm ist in Waterford das Denkmal errichtet, gegen dessen Entfernung von seinem angestammten Platz im Stadtzentrum vor einigen Jahren die Einwohner auf die Straße gegangen sind. Außerdem erwähnenswert sind noch: der Augustinereremit Richard Wadding, Theologieprofessor in Coimbra, der Jesuit Peter Wadding (1583-1644), Theologieprofessor in Löwen, Prag und Graz, der Jesuit Ambrose Wadding (1583-1619), der sich als Philosophieprofessor im schwäbischen Dillingen Gaudin nannte, ${ }^{7}$ sowie der Jesuit Michael Wadding (1586-1644), der sich als

6. E. Hogan SJ.: „Worthies of Waterford and Tipperary“, Journal of the Waterford and South East of Ireland Antiquarian Society 3 (1897) 183/84.

7. U.G. LeInsle: Dilinganae Disputationes. Der Lehrinhalt der gedruckten Disputationen an der Philosophischen Fakultät der Universität Dillingen 1555-1648, Regensburg 2006, 562. 
Theologieprofessor in Mexico Godinez nannte. ${ }^{8}$ Das Phänomen multipliziert sich, wenn man die verwandten Familien - die Whites, die Walshs, die Sherlogs - miteinbezieht. In der noch ungeschriebenen Geschichte des Migrationshintergrundes der akademischen Kulturen der Frühen Neuzeit nähmen die Waddings trotz ihrer vielleicht etwas einseitigen Interessenrichtung jedenfalls einen Ehrenplatz ein. Sie gehörten zu der großen Schar katholischer Iren, Schotten und Engländer, die in der ersten Hälfte des 17. Jahrhunderts - sei es in den Spanischen Niederlanden, sei es auf der iberischen Halbinsel - zum Studium nach Spanien gezogen sind und dort oder von dort aus akademisch Karriere gemacht haben. ${ }^{9}$

Die Gesellschaft Jesu war für die Söhne dieser Sippe offenbar besonders attraktiv. Das wird erstens daran gelegen haben, daß die Jesuiten im Europa der frühen Neuzeit über das dichteste Netz von Lehranstalten verfügt haben. Die Intensität eines geistigen Klimas läßt sich überhaupt daran messen, wie hoch die Wahrscheinlichkeit dafür ist, daß leibliche Geschwister ähnliche Lebensläufe aufweisen. Phasenweise tritt dieses an sich unwahrscheinliche Phänomen gehäuft auf, man denke z.B. an die Generation der Schlegels, Humboldts, Grimms, Brentanos und Reichenspergers. Auch in der Jesuitenscholastik war das Brüderpaar Peter und Luke Wadding kein Einzelfall. Die Gebrüder Lugo, Peñafiel und Mangold figurieren mit jeweils mehr oder weniger großen literarischen Leistungen bis zum Verwechseln ähnlichen Zuschnitts.

Zweitens brauchte man als Ire in diesem erst 1540 gegründeten Orden keine Minderwertigkeitskomplexe zu haben. In den älteren katholischen Orden führte der irische Patriotismus leicht zu Verstimmungen. Englische Franziskaner ärgerten sich darüber, daß ihr Ordensbruder Luke Wadding Irlands Ruf, akademisch finstere Provinz gewesen zu sein, aufbesserte, indem er Beute-Iren machte, namentlich aus

8. L.M. Mendizabal: „Godinez“, in: Dictionnaire de Spiritualité t.6, Paris 1967, 565-70. Zusätzliche Literatur in: Dictionnaire d'Histoire et de géographie ecclésiastiques t.21, Paris 1986, 425.

9. Vgl. die Kurzbiographien bei E. Hogan: „Chronological Catalogue of the Irish Members of the Society of Jesus, from the year 1550 to 1814", in H. FoLEY SJ.: Records of the English Province of the Society of Jesus vol. VII/2, London 1883 . Über die franziskanische Irish connection: T. O'CoNNOR (Hg.): The Irish in Europe, 1580-1815, Dublin 2001; DeRs./M.A. Lyons (Hgg.): Irish Communities in Early Modern Europe, Dublin 2006; T. O'ConNor: „La solidarité contre-réformée: les réseaux de collèges irlandais dans l'Europe catholique, 1578-1793", in Étudiants de l'exil. Migrations internationales et universités refuges (XVI $-\mathrm{XX}$ siècles), hgg. von P. Ferté/C. Barrera, Toulouse 2009, 71-80; J. SchмuтZ: „Was Duns Scotus a Voluntarist? Juan Caramuel Lobkowitz against the Bratislava Franciscans", in Explorations in Late Scholasticism, hgg. von P. Dvoř́k/T. Machula, Prag 2016, 147-84, hier 148-50. 
dem Ordenslehrer Johannes Duns Scotus. ${ }^{10}$ In Oxford brauche nur einer Woodford geheißen zu haben, schon sei er für Waterford reklamiert. ${ }^{11}$

Nicht nur dem Ordenshistoriker der Franziskaner, der sich an dem von ihm errichteten römischen Irish College (Collegium Hibernicum) als Waffenschmuggler großen Stils betätigte, auch seinen unter die Jesuiten gegangenen Cousins Peter und Luke Wadding, wird von Hogan ihr vielleicht weniger militanter, aber doch tatkräftiger, Patriotismus hoch angerechnet. Sehr schön beleuchtet Hogan durch das, was mit Waddings irischer Herkunft zusammenhängt, die praktische Seite an einem Autor, die über die weniger aufregende Seite, die des spekulativen Theologen, nicht zu kurz kommen darf. Die Bemerkung ist daher nicht überflüssig, daß, an welchem Ort der damaligen katholischen Welt man auch immer Theologie trieb, ob in Mexiko, Salamanca oder Prag, sich in der Theologie von diesen uns heute so prägend erscheinenden Zeitumständen nichts wiederfindet. So glühend ihr Patriotismus war, waren die Waddings dagegen immun, sich einen irischen Nationalgott zu erdichten, etwas in der Art des gnädigen, des deutschen Gottes, wie er im national beschwingten 19. Jahrhundert die Vorstellungswelt des liberalen Protestantismus vergiftet hat.

Unser Wadding hat sein Erwachsenenleben in der Ordensprovinz Kastilien verbracht. Sein Werdegang zeigt ihn in die dortige Szene völlig integriert. Philosophie studierte er an demselben Irish College von Salamanca, dessen Präsident zeitweilig (1617-18), bevor er nach Rom ging, sein gleichnamiger Cousin war. Theologie studierte er an dem Jesuitenkolleg von Valladolid. Danach gab er als junger Dozent den dreijährigen Philosophiekurs an dem Kolleg von Santiago de Compostela. Von dort an das Kolleg von Valladolid zurückgekehrt, lehrte er fünfzehn Jahre lang, ${ }^{12}$ vermutlich von 1623 bis 1638, Dogmatik, zuletzt auf dem ersten theologischen

10. Vgl. das 10. Kapitel „Disputatio de Scoti patria“ in Christopher Davenport (Franciscus A S. Clara) OFM. (†1680): Fragmenta seu Historia minor Provinciae Angliae Fratrum Minorum, Douai 1665, 19b-26b. Diese Dissertation, mit Sonderpaginierung, findet sich in den Opera omnia scholastica et historica, Douai 1665-67, t.1. Ein englischer Nationalist, der die schottischen und irischen Ansprüche auf scholastische Ruhmestitel so bescheidet: „Imo, quod notatu dignum est, nec in Hibernia, nec in Scotia ullum tunc temporis erat gymnasium scholasticum. Anno scilicet 1411 incepit studium Sancti Andreae, anno 1480 Aberdonensis et Glasconensis Academiae in Scotia institutae leguntur..., quod est duobus pene saeculis post Scoti aetatem; sed de Hibernia in monumentis nostris hactenus ne gry." (Ebd. 23a/b)

11. Davenport, Fragmenta seu Historia minor Provinciae Angliae Fratrum Minorum, 33a/b.

12. „... per quindecim annos, quibus Vallisoleti legi Theologiam..." L. Wadding, Brief an Gabriel de Henao, 11.12.1649, zitiert in G. DE Henao SJ.: Scientia Media historice propugnata $\$ 33$, Lyon $1655,22 \mathrm{a}$. 
Lehrstuhl. In dieser Eigenschaft verfolgte er 1627 argwöhnisch die Spanienreise des Löwener Professors Jansenius. Die Gebrüder Wadding waren Antijansenisten der ersten Stunde, Jahre bevor der Löwener Augustinismus sich zu dieser cause celèbre auswuchs, die die katholische Kirche an den Rand eines Schismas gebracht hat. Peter Wadding, damals Jansenius' Kontrahent in Löwen, bildete auch in Person eine Zielscheibe für dessen Angriffe. Im übrigen, informierte Peter seinen Bruder, lästere der Löwener Universitätstheologe mit Vorliebe über die spanischen Jesuiten. ${ }^{13}$ Luke seinerseits wird ein - anonym überlieferter - Brief an Peter zugeschrieben. ${ }^{14}$ Datiert aus Valladolid vom 10. März 1627, berichtet darin ein über die Löwener Verhältnisse in der Tat wohlinformierter Jesuit sehr gereizt über die Rundreise, die Jansenius als Abgesandter der Universität Löwen damals durch Spanien in der Absicht unternahm, die führenden Universitäten zur Bildung eines Kartells gegen die hochschulpolitischen Ambitionen der Jesuiten zu bewegen und vor allem die theologischen Fakultäten gegen den Löwener Gnadenmolinismus aufzustacheln. ${ }^{15}$ „Wir hier“, schreibt er, „haben seiner Kampagne eifrig (acriter) entgegengearbeitet. Wir haben erklärt, daß er Holländer und in seinen Prätensionen einer wenig katholischen Gesinnung verdächtig ist. Hätte er sich daher hier so unvorsichtig geäußert wie in Salamanca, wäre er ohne Zweifel der Inquisition übergeben worden. Deren Hand ist übrigens immer noch ausgestreckt. Denn just heute abend ist eine Anweisung nach Salamanca abgegangen, Ermittlungen anzustellen, ob er etwas gegen die Gesellschaft Jesu oder ihre Lehre vorgebracht hat, woraus sich, wenn man seine verdächtige Abstammung, seine Person und sein Geschäft mit in Anschlag bringt, auch nur die geringsten Zweifel daran ergäben, daß er gut katholisch ist. Dazu bedarf es bei seiner Person und unter den obwaltenden Umständen nur sehr wenig. Wenn ihm also ein paar Worte vorgehalten werden könnten, landet er vermutlich im Kerker und wird von der Inquisition bestraft." Wenn es nach ihm gegangen wäre, hätte sich die Inquisition also schon zu diesem Zeitpunkt mit Jansenius befaßt. Daß sich Luke Wadding in dieser Angelegenheit als Denunziant betätigt hat, ist gut möglich, wenn auch nicht schon durch die Tatsache bewiesen,

13. „Doctrinam Patrum nostrorum in Hispania Iansenius parvi facit; dicit enim nostros quoad doctrinam nihil fieri in Hispania." Peter Wadding SJ. an Luke Wadding SJ. in Valladolid, zitiert nach A. Perez Goyena SJ.: „Jansenio en España“, Razón y Fe 56 (1920) 172-88; 451-65; 57 (1920) 181-97; 318-33. Hier Razón y Fe 56 (1920) 462.

14. J. Orcibal (Hg.): Correspondance de Jansénius, Louvain-Paris 1947, 369-72. Nach Jansenius' Rückkehr schickte Peter Wadding eine Kopie des Briefs mit dem Ausdruck des Bedauerns, daß nicht alle so viel Initiative bewiesen hätten wie sein Bruder, am 24.4.1627 an den Provinzial der Flandro-Belgischen Provinz (ebd. 382).

15. J.A. Martinez Bara: „Jansenio, las Universidades españolas, los jesuitas, la Inquisición y el Consejo de Castilla“, Revista de archivos, bibliotecas y museos 73 (1966) 555-603. 
daß er zum Gutachterbeirat der Inquisition gehört hat - „apud Supremum Sanctae Fidei Senatum censor", heißt es auf dem Titelblatt der Concordia. Diese Nebentätigkeit war bei jemandem, der als scholastischer Theologe Karriere machte, in Spanien der Regelfall. Wie dem auch sei, in dieser Affäre hatten die Jesuiten vorläufig das Nachsehen, denn Jansenius konnte verrichteter Dinge und ungeschoren wieder abreisen. ${ }^{16}$ In Salamanca blieben die Jesuiten ab 1628 für Jahrzehnte von der Möglichkeit ausgeschlossen, an die Universität berufen zu werden. „Ausgestreckte Hand“ hin, „ausgestreckte Hand“ her - quis avertet eam? (Is. 14, 27) -, Jansenius' Gastgeber in Salamanca, der Universitätsrektor Basile Ponce de León OSA., hatte offenbar doch den besseren Draht zur Inquisition.

$\mathrm{Zu}$ Waddings Schülern in Valladolid hat Gabriel de Henao (1612-1704) gehört. Von dessen Hand ist das Manuskript, durch das aus dem akademischen Jahr 1635/36 Waddings Prädestinationstraktat überliefert ist. ${ }^{17}$ Als jüngeren Kollegen hatte Wadding in Valladolid den genialischen Antonio Perez (1599-1649), ${ }^{18}$ zuerst (1625-28) als Philosophiedozenten, später (1631-34) auf einer der beiden anderen Theologieprofessuren an dem Kolleg. Niemand, der die Texte der beiden miteinander vergleicht, wird die große Zahl von Berührungspunkten verkennen. Perez war schon an dem Kolleg von Salamanca, als auch Wadding dann dorthin auf den ersten theologischen Lehrstuhl berufen wurde. Von 1638/39 bis 1644 lehrte er dort weiter Dogmatik, anschließend Exegetik. 1646 bis 1649 übernahm er das Rektorat am Kolleg von Burgos. In Salamanca war er der Nachfolger für Martínez de Ripalda ${ }^{19}$ gewesen, der 1637 an das Colegio Imperial in Madrid gewechselt war,

16. Über die Umstände der Abreise aus Spanien, ob Jansenius habe die Flucht ergreifen müssen oder nicht, kam es 1686 zu einer Kontroverse zwischen dem Jesuiten Cornelius Hazart und dem Benediktiner Gerberon. Gerberons Gegendarstellung in A. Arnauld: Euvres t.3o, Paris-Lausanne 1779, 481-95.

17. Tractatus de praedestinatione et reprobatione, BU Salamanca Ms. 756.

18. Die Perezliteratur bis 2000 bei S.K. Knebel: „Salamanca und sein Ambiente. Ein Repertorium zur Jesuitenscholastik des 17. Jhs.“, in Die Ordnung der Praxis, hgg. von F. Grunert $/$ K. Seelmann, Tübingen 2001, 429-58, hier 453f. Seitdem: J. Schmutz: „Dieu est l'idée. La métaphysique d'Antonio Perez (1599-1649) entre néo-Augustinisme et crypto-Spinozisme“, Revue thomiste 2003, 495-526; Ders.: „Les innovations conceptuelles de la métaphysique espagnole post-suarézienne: les status rerum selon Antonio Pérez et Sebastián Izquierdo“, Quaestio. Annuario di storia della metafisica 9 (2009) 61-99; A. PÉreZ: Presciencia y posibilidad. La inteligencia de Dios [Comentario a Suma Teológica, I, disp. V-VI], hg. u. übers. von J. Cruz Cruz, Pamplona 2006; G.P. Soliani: Dio e mondo. Trascendenza e creazione in Antonio Pérez S.J., Diss. phil. (unv.) Venedig 2016; S.K. KNEBEL: „Das Cogito und die Krise des Schulbegriffs der Reflexion“, Freiburger Zeitschrift für Philosophie und Theologie 63 (2016) 57-88, hier 69f. 74. 83f.

19. P. Dumont: „Ripalda (Jean Martinez de)“, DThC 13 (1936) 2712-37; L. Ceyssens: „Juan Martinez de Ripalda et le troisième volume de son De ente supernaturali (1648)“, De gulden passer 33 (1955) 1-26. 
und vermutlich hat er nach dessen Tod ihn dann auch 1649 auf dieser politisch einflußreichen Stelle in Madrid beerbt. Ripalda war ein besonders engagierter Antijansenist. Von Wadding besorgte er sich eines der nötigen Gutachten (1645) für sein großes polemisches Werk Adversus Baium et Baianos. Die Genugtuung, die Jesuiten an die Universität Salamanca zurückkehren zu sehen, hatte Wadding nicht mehr. Seine Schüler Juan de Barbiano (1614-76), auf der cátedra de Prima de teología, und Richard Lynch (1610-76), auf der cátedra de Visperas, schafften das erst 1668, als die Universität von der Königin zwei den Jesuiten gewidmete Stiftungsprofessuren aufoktroyiert bekam. ${ }^{20}$ Hogans Angabe, Wadding sei Universitätsprofessor gewesen, ist daher korrekturbedürftig. Der Anachronismus geht vielleicht auf ein durch einen Druckfehler entstandenes Mißverständnis zurück. ${ }^{21}$ Am 30 . Dezember 1651 soll Wadding gestorben sein, die Angaben schwanken, vielleicht nicht von ungefähr. Wieso ein auf Juli 1652 datiertes Inquisitionsgutachten von ihm noch mitunterzeichnet ist, ${ }^{22}$ ist vorläufig unklar. Waddings theologischer Nachlaß ist zuerst 1950 bibliographiert, im Rahmen der universitätsgeschichtlichen Studie des Jesuiten Apolinar Morán. ${ }^{23}$

20. Sowohl Barbiano als auch Lynch hatten allerdings 1652 an der Universität promoviert (MoRÁn, „El primer catedrático Jesuita“, 95f.) und waren daher schon inkorporiert. Daß sie seiner Licentiatenpromotion am 8.7.1666 beigewohnt hätten, bezeugt J. SAÉNZ DE AGUIRRE OSB.: Ludi Salmanticenses, Salamanca 1668, t.1, 21-22.

21. „P. Lucas Wadingus Primarius olim Professor Theologiae [tum in Collegio Vallisoletano S. Ambrosii,] tum in Universitate Salmanticensi pro Regali S. Spiritus Collegio, demumque in Scholis Regiis Madritensibus Interpres disciplinae moralis Aristotelicae atque Christianae [...] Ita observantissimus mihi Magister [Proh dolor!] fato iam functus anno 1651. "Henao, Scientia Media historice propugnata $\$ 33$, Lyon ${ }^{1} 1655$, 22a. In dem verbreiteten Dillinger Nachdruck der erweiterten Ausgabe von 1665 ist der in eckige Klammern gesetzte Text ausgelassen. Nur durch den authentischen Wortlaut wird klar, daß ,in Universitate Salmanticensi“ in dem weiteren Sinn, dem des Aggregats von Kollegien, und das Pronomen „pro“ spezifikatorisch und daher einschränkend $\mathrm{zu}$ verstehen ist.

22. C. De Ortega SJ.: Tractatus duo, de Trinitate, necnon, De Incarnatione, Lyon 1664, e2v.

23. MoRÁN, „El primer catedrático Jesuita“, 126. Waddings handschriftlicher Nachlaß in der BU Salamanca umfaßt (Lilao Franca / Castrillo Gonzalez, Catálogo de manuscritos de la Biblioteca universitaria de Salamanca, t.1, Salamanca 1997) die folgenden Stücke:

Ms. 156 Lucas Wading: Concordia divinorum et humanarum, 914 fols.

Ms. 155 Concordia divinorum et humanorum, 840 fols. (am Ende - Appendix - defekt; fol. 2r: „Petrus [sic!] Wadingus concordia divinarum perfectionum“).

Ms. 767, 1 Guading de Auxiliis, fols. 1r-82r.

Ms. 756 Tractatus de praedestinatione et reprobatione. Esta de letra de el P. Gabriel Henao. Author suyo es el P. Lucas Guadin, fols. 1r-65v (fol. 1r: „anno 1635“; fol. 65V „Finis anno 1636, authore P. Luca Guadin in Collegio Vallisoletana S. Ambrosii Societatis Iesu“). 


\section{Datierung des Manuskripts}

Das Manuskript Concordia Divinorum et Humanarum repräsentiert das reife Stadium von Waddings Denken. An dem Text ist die vierziger Jahre über gearbeitet worden, darüber gestorben ist der Autor aber nicht. Es sei, merkt der Herausgeber Lynch an, „schon vor Jahren“ entstanden (iam olim ab eo elaboratum). Der notdürftige Abschluß wird (\$445) mit lästigen Geschäften motiviert. Wahrscheinlich ist das eine Anspielung auf die Übernahme der Verwaltungsaufgaben in Burgos, denn auf eine Neuerscheinung des Jahres 1646 ist so bezuggenommen, daß damit nachträglich die Notwendigkeit eines Einschubs begründet wird. ${ }^{24}$ In Madrid hat Wadding die Arbeit an dem Manuskript anscheinend nicht wieder aufgenommen, sondern die Drucklegung des fertigen Teils betrieben. Bis auf den Anhang zum vierten Buch gehört der Text daher der Periode von Waddings Lehrtätigkeit in Salamanca an. Diese Zeit war für die Jesuiten von der Notwendigkeit bestimmt, auf den großen Angriff des Johannes a S. Thoma (Poinsot) zu antworten. Mindestens zweimal - es sind noch mehrere undatierte Tractatus de scientia Dei von ihm überliefert, vermutlich jedoch aus früherer Zeit - hat Wadding während dieser Zeit über den Gegenstand des hier edierten vierten Buchs gelesen, in den akademischen Jahren $1639 / 4 \mathrm{O}^{25}$ und $1643 / 44 .{ }^{26}$ Die Pflicht zu dieser Vorlesung ging unter den Kollegen anscheinend reihum. 1640/41, wissen wir, hat sie Bernardo Aldrete (1594-1657) gehalten. ${ }^{27}$ Er wurde Waddings Nachfolger auf dem Lehrstuhl in Salamanca.

Ms. 766 Vvading De Scientia Divina, fols. 1r-66v.

Ms. 782, 1 Disputationes de scientia Dei, ad q. 14 D. Thomae Partis primae, per R. Patrem Lucam Guadin Sacrae Theologiae Professorem dignissimum Primariaeque Cathedrae Moderatorem in hac Salmantina Academia hoc anno 1639, fols. 1r-94v (fol. 94v: „Finis 1. Augusti anno 1640 ").

Ms. 818, 1 Tractatus de scientia Dei, ad quaestionem decimam quartam Prima partis Sancti Thomae, fols. 1r-72v (fol. 1r: „Padre Lucas de Guadin de la Compa de Jesús, año de 1643 y $44^{\text {“) }) . ~}$ Ms. 1233, 3 Tractatus de scientia Dei, fols. 68r-84v (marg.: „Guadin“).

Ms. 781, 1 De visione Dei, fols. 1r-46v.

24. Concordia fol. 590v: „Post haec scripta pervenit ad nos tomus secundus in $\mathrm{I}^{\mathrm{am}} \mathrm{II}^{\mathrm{ae}}$ Magistri Francisci de Araujo [...] “ Über die Zusammenhänge unterrichtet G. DE HenAo: Scientia Media theologice defensata $\$ \$ 1878-99$, Lyon 1674-76, t.1, 426-32.

25. BU Salamanca, Ms. 782, 1, fols. 1r-94v.

26. BU Salamanca, Ms. 818 , 1 , fols. 1r-72v.

27. „De divina scientia nostrorum actuum liberorum ut absolute futurorum, nec non de scientia conditionata eorumdem, quae Media appellari solet: ubi e re nata de auxiliis divinae gratiae, deque usu scientiae mediae“ (138 S.). 


\section{Dogmatischer Standpunkt}

Den dogmatischen Standpunkt unseres Traktats zeigt die von ihm eingenommene Stellung in der Prädefinitionslehre $(\$ 403)$. Es ist der suarezische Kongruismus. Bezogen auf eine Teilklasse der freien Handlungen soll die Scientia Media-Hypothese es ermöglichen, sie so ähnlich von Gott vorherbestimmt („prädefiniert“) zu denken, wie die Dominikaner das mit dem Instrument physische Prädetermination bewerkstelligen. Darin ist der Autor mit Suárez einverstanden. Anstatt jedoch, wie Suárez, nur eine bestimmte Lösung für das Problem zu sehen, wie das unter Schonung der menschlichen Willensfreiheit bewerkstelligbar ist, besteht für Wadding hier noch eine Alternative ( $\$ 449$ ), und es ist nicht Suárez' Lösung, welche er vorzieht. Damit eine bestimmte Handlung in Zukunft unfehlbar und in allen Einzelheiten so eintritt, wie Gott das will, läßt Suárez vor dem Akt der Prädefinition Gott durch die Scientia Media über das geeignete Mittel dazu unterrichtet sein. Das geeignete Mittel: das heißt, eine Situation, in welcher der freie Wille auch mitspielt. Wadding dagegen findet die Scientia Media für den Akt der Prädefinition entbehrlich. Es reicht, wenn die Scientia Media erst anschließend, bei der Umsetzung, zum Zug kommt. Prädefiniert sein müssen die betreffenden Handlungen nämlich gar nicht in allen Einzelheiten. Derselbe Zweck läßt sich auf diese oder jene Weise, durch diesen oder jenen Akt, erreichen. Die Umsetzung der Prädefinition läßt also einen Spielraum. Das, was durch die Scientia Media vorab garantiert sein muß, ist lediglich die Existenz geeigneter Mittel zur Umsetzung überhaupt. Ist es möglich, daß es deren nicht gibt? Nein, meint Wadding. Daraus folgt aber, daß der von ihm bevorzugte Prädefinitionstyp deterministisch umkippt. Dieser Einwand gegen das Spielraummodell wird von Wadding bemerkenswert auf die leichte Schulter genommen. So schlimm sei das nicht, ist buchstäblich sein letztes Wort ( $\$ 476)$.

Daraus, daß der Autor dem suarezischen Prädefinitionstyp den anderen vorzieht, folgt nicht wenig. In dem ganzen Text ist des festen Wahrheitswerts von Sätzen über das Freizukünftige nur sehr beiläufig ( $\$ 175)$ gedacht. Hingegen ist es ihm wichtig ( $\$ 390)$, in Gottes Wissen ein Stadium zu unterscheiden, in dem es nicht im Besitz der Kenntnis desselben ist. Der disjunkten Referenz werden die erheblichsten Zugeständnisse gemacht ( $\$ \$ 432,451-61$ ). Die Scientia Media ist zu einer Hilfshypothese degradiert, die Zweifel daran abzuwehren hat, daß auf dieses Paradigma die Prädefinition der freien Handlungen gegründet sein kann.

Waddings Theorie gehört in den größeren Zusammenhang des im 17. Jahrhundert ausgetragenen Systemwettbewerbs zwischen der Scientia Media-Hypothese und dem statistischen Paradigma der moralischen Notwendigkeit. ${ }^{28}$ Als einer der

28. S.K. KnebeL: Wille, Würfel und Wahrscheinlichkeit. Das System der moralischen Notwendigkeit in der Jesuitenscholastik (1550-1700), Hamburg 2000, 275-485. 
ersten hat er die These vertreten, daß dieses zweite Modell theologisch hinter der Scientia Media-Hypothese nicht zurücksteht.

Es sei keineswegs ein Anthropomorphismus, versichert der Autor, sich von Gott zu denken, daß in seinem Wissens- und Willenshaushalt auch das Oder eine Rolle spielt. Aufgrund eines disjunktiven Dekrets will Gott, daß entweder das Individuum A oder das Individuum B zur Existenz bestimmt ist. Nicht, welches von beiden, sondern nur, daß nicht keines von beiden existieren wird, ist damit entschieden. Gott hat bestimmte Zwecke und kann es doch vorläufig unentschieden lassen wollen, durch welche Mittel genau sie erreicht werden. Er kann einen Effekt vorherbestimmen, ohne deswegen bereits (a) dessen Ursachen, (b) dessen individuierende Umstände festzulegen. Gott wird die Möglichkeit vorbehalten, effektindividuierende Festlegungen aufzuschieben. Erfunden hat Wadding diesen Ansatz nicht - er war die Spezialität und ein Exportartikel des Milieus, das unten als ,Salamanca und sein Ambiente' charakterisiert werden wird ${ }^{29}$-, aber dieser Autor einer Concordia ist überzeugt, theologisch daran den Stein der Weisen zu haben. Die disjunktiven Dekrete ermöglichen es Gott auf der einen Seite, den eigenen Willen souverän zur Geltung zu bringen, auf der anderen Seite aber auch, dem Menschen den unerläßlichen Entscheidungsspielraum zu lassen. Zur Wahrung der menschlichen Willensfreiheit reicht die Existenz marginaler Differenzen, etwa die Wahl der Umstände für eine Handlungsweise, welche ihrem Typ nach feststeht. Die disjunktive Notwendigkeit soll es prinzipiell ausschließen, mit der Willensfreiheit in Konflikt kommen zu können (\$\$398, 462). Zugleich soll Gott unter keinen Umständen befürchten müssen, daß immer nur neingesagt werden würde. Die impossibilitas metaphysica resistendi toti collectioni mediorum, die Wadding lehrt ( $\$ 454)$, bezieht sich auf den größten anzunehmenden Unfall. In der Scientia-Media-Hypothese wurde er unter dem etwas irreführenden Problemtitel creatura rebellis diskutiert. Damit gemeint gewesen ist, was heute der Angsttraum der Werbeagenturen wäre, die Möglichkeit des absolut renitenten Konsumenten. Natürlich kann der Allmächtige nie sein Pulver verschossen haben. Trotzdem scheint es unter indeterministischen Prämissen kein Widerspruch in sich zu sein, daß ein freier Wille quer durch die Unendlichkeit möglicher Welten zu einem in bestimmter Weise ausgestatteten Gnadenangebot immer neinsagen würde. An diesem freien Willen würde die Scientia Media-Hypothese auflaufen, er wäre nicht

29. Knebel, Wille, Würfel und Wahrscheinlichkeit, 335-40; W. Redmond: „The Three-Stranded Cord: Calling a Truce in the War over God and Human Freedom“, in: Proceedings of the Society for Medieval Logic and Metaphysics 3 (2003) 51-81. Redmond analysiert das System von MATiAS BLANCO SJ. (1660-1734), Tractatus de libertate creata sub divina scientia, voluntate et omnipotentia, Mexico 1746, der an den disjunktiven Dekreten die Basis für eine Einigung mit den Protagonisten der physischen Prädetermination zu besitzen glaubte. 
prädestinierbar. Von diesem Fall hatten die Jesuitentheologen seit Suárez die Möglichkeit, daß er eintritt, durchweg eingeräumt. ${ }^{30}$ Auch aus Sicht des Allmächtigen sei dieser größte anzunehmende Unfall nicht an sich unmöglich, sondern nur relativ unmöglich, bezogen auf gewisse Erfahrungsregeln. Man nannte das damals ,moralisch unmöglich', wir heute sagen dafür ,extrem unwahrscheinlich'. Das nun ist Wadding zuwenig. Die Betonung bei ihm liegt auf ,impossibilitas metaphysica“: Unmöglichkeit in dem strengen Wortsinn, so daß die Annahme des Gegenteils einen Widerspruch in sich schließt. Wadding ist der erste Jesuitentheologe, der rundweg leugnet, daß es ein Restrisiko gibt. Die creatura rebellis ist nicht nur faktisch ausgeschlossen. Die creatura rebellis ist eine Chimäre. Mit dieser These geht Wadding namentlich auch über seinen Lehrer Lugo hinaus. ${ }^{31}$ Innerhalb der Gesellschaft Jesu ist Wadding damit zwar wohl in der Minderheit, aber nicht isoliert geblieben. Ein Enkelschüler von ihm wird diese These in das Zentrum der eigenen Dogmatik stellen. ${ }^{32}$ Das hat diesen Mann, González de Santalla (1624-1705), nicht daran gehindert, von den Jesuiten am Ende an die Spitze ihrer Gesellschaft berufen zu werden; wenn sie seine Wahl zum General hinterher bereut haben, hat das andere Gründe gehabt.

Das kongruistische Lehrstück von den Prädefinitionen wird von Wadding zwar unter der Voraussetzung verteidigt, daß an irgendeinem Punkt die Scientia Media-Hypothese interveniert. Für das Thema dieses Traktats, die Theorie von Gottes kategorischem Vorherwissen generell, folgt daraus aber nichts. Im Rahmen der Scientia Media-Hypothese reduziert sich Gottes kategorisches Vorherwissen üblicherweise (\$\$ 402, 405) auf das Paket aus Scientia Media-Szenario und Realisierungsdekret. Für unseren Text ist das $(\$ 407)$ nicht an sich so (in re), sondern

30. KNeBEL, Wille, Würfel und Wahrscheinlichkeit, $186 \mathrm{f}$.

31. „Impossibile enim est moraliter loquendo aliquem hominem reperiri de quo non sciat Deus, quod, si in tali seu tali occasione taliter moveretur, consentiret, et rursus, quod, si in tali occasione poneretur, peccaret. Quam impossibilitatem explicuit S. Augustinus lib. $1^{\circ}$ Ad Simpl. quaest. 2 his verbis: "Cum eadem res saepe alio modo dicto moveat, alio modo dicta non moveat [...] etc." [...] Videt ergo Deus respectu cuiuslibet hominis multa auxilia efficacia et multa inefficacia, et licet possit homo etiam moraliter facere, quod haec auxilia in particulari non fuerint visa efficacia aut inefficacia, non tamen potest moraliter facere, quod Deus non videret aliqua auxilia efficacia, aliqua inefficacia. Hoc enim est moraliter necessarium, et per consequens certissime scit homo, aliqua esse auxilia quae ex suppositione iam praevisa a Deo non potuerunt esse ipsi utilia in potentia consequenti, ut praedixi, et pro his debetur orare, ne dentur." IOANNES DE LUGo SJ.: Tractatus de gratia Dei in quaestionem 109 et sequentes ex Prima Secundae Sti. Thomae (ca. 1624), Ms. BU Salamanca 956, fol. 257v.

32. S.K. KNEBEL: Suarezismus. Erkenntnistheoretisches aus dem Nachlass des Jesuitengenerals Tirso González de Santalla (1624-1705). Abhandlung und Edition (= Bochumer Studien zur Philosophie 51), Amsterdam / Philadelphia 2011, 157ff. 
lediglich aus der Perspektive unserer Hypothesenbildung (in ratione nostra), d.h. aus Suárez' Perspektive. Darin liegt eine erhebliche Relativierung. Weil das Lehrstück von der Prädefinition nicht für Gottes Vorherwissen seinem Gesamtumfang nach aufkommt - es ist ausdrücklich $(\$ 403)$ nicht verallgemeinerungsfähig, die ,Sünden' genannte Teilmenge der Ereignisse fällt nicht unter die Prädefinition -, impliziert das Vorherwissen gar nicht die Scientia Media-Hypothese. Wenn Waddings Verteidigung seines alternativen Prädefinitionsmodus darauf hinausläuft, die Scientia Media elegant auszumanövrieren ( $\$ 475$ ), dann ist also zu vermuten, daß dahinter mehr steckt.

Seine Abhandlung über die Scientia Media, wie gesagt, besitzen wir nicht, das Studium seiner Theorie des kategorischen Vorwissens begründet aber Zweifel an dem Enthusiasmus dieses Jesuiten für das Totem der Jesuitenscholastik. Das Eingeständnis, daß es ohne sie nicht geht, wird lange vor sich hergeschoben. Fast wirkt sie wie ein Deus ex machina, nur dazu da, um auf dem Höhepunkt der Verwicklung ein Ende zu machen. In den betreffenden Abschnitten des Schlußteils ( $\$ \$ 413-15$ ) geht es bemerkenswert hastig zu. Hingegen wird Gottes Kontingenzwissen sehr nachdrücklich auf den Sockel der göttlichen Willensbetätigung gestellt. Durch sie ist das Kontingenzwissen konstituiert, nicht durch den Primat des Erkenntnisobjekts ( $\$ 394)$, und wenn diese These dann doch relativiert wird $(\$ 415)$, bleibt diese Konzession an die Scientia Media-Hypothese obskur. Soweit das Kontingenzwissen logisch auf eine Seite festgelegt ist, ist es das aus Dezisionismus $(\$ 386)$ in Kombination mit der klassischen und dennoch ermüdend breit vorgetragenen Denkfigur der ,nachfolgenden' Notwendigkeit des faktisch Existenten. Der Primat der Scientia Media ist nur eine humane Fiktion $(\$ 423)$.

Wo hätte der Autor in der anstehenden Abhandlung über die Scientia Media für diesen Wissenstyp die metaphysische Basis hergenommen? Die voluntaristische Lösung scheidet hier aus ( $\$ 375)$. Bricht das Manuskript also nicht von ungefähr ausgerechnet da ab, wo es zum Schwur hätte kommen müssen? Die Frage muß gestellt sein, schlüssig beantworten läßt sie sich nicht.

Nach der Seite hin, in der er eine interne Kontroverse führt, liegt der dokumentarische Wert dieses Texts. In der Jesuitentheologie, bei der wir uns einbilden, wir wüßten Bescheid, wenn wir ,Suarezismus' und ,Molinismus' assoziieren, dürfen die Risse und Sprünge, die sie kreuz und quer durchziehen, nicht übersehen werden. Die interne Kritik, gesteht der Autor selber $(\$ 73)$, mache ihm mehr zu schaffen als die von außen. Der Disput betraf ja nicht ein untergeordnetes Detail, sondern eine Prinzipienfrage. Es ging darum, ob die Scientia Media-Hypothese in der Theologie der Jesuiten ein Erklärungsmonopol behauptet oder nicht: ob es neben ihr auch noch andere Hypothesen gibt, die ihr in der einen oder anderen Hinsicht das Wasser reichen können. In diesem Sinn ist unser Autor Pluralist. 


\section{Suarezismus}

Weswegen also, wenn er weder thematisch noch seiner Tendenz nach etwas zur Scientia Media beizusteuern hat, dieser Text deren Akten hinzugefügt? Weil er trotzdem etwas zur Aufhellung ihrer inneren Voraussetzungen beiträgt. Der Text dokumentiert, daß an der Verbreitung dieser Hypothese noch andere Gedankenreihen beteiligt waren als die, welche sonst in die Werbung für sie einfließen.

In der zweiten Generation der Suarezianer, welcher der Autor angehört, gab es zu der Stellung, die man als Jesuit zur Gnadenlehre einzunehmen hatte, nicht mehr viel zu sagen. Durch Aquavivas Dekret von 1613, das die Ordenslehre auf den suarezischen Kongruismus festgelegt hatte, stand das zu lehrende Gnadensystem im Großen und Ganzen fest. Einen Jesuiten um die Mitte des Jahrhunderts einen Suarezianer zu nennen, ist überhaupt wenig informativ. In der Regel erfährt man dadurch nur, daß er auf den, der ihn so nennt, den Eindruck macht, immer noch hingebungsvoll ein Scholastiker gewesen zu sein. Häufig ist das kein Lob. Die Schwammigkeit der Positionsbezeichnung, Suarezismus' hat auch einen Grund in der Sache. An Suárez hatte man als Jesuit ja weit mehr als, fast durch das gesamte philosophische und theologische Kurrikulum, eine bestimmte Doktrin. Eine scholastisch so wohlorganisierte, so wohlausgewogene, von Idiosynkrasie freie Textmasse hatte die Gutenberggalaxie noch nicht gesehen, und es hat sie aus der Feder eines einzigen Autors auch nie wieder gegeben. Doch selbst die staunenswerte Übersichtlichkeit, die Suárez mit seiner Produktivität zu verbinden verstanden hatte, und die wirkungsgeschichtlich schwer ins Gewicht fällt, ist nicht der größte unter seinen Ruhmestiteln. Nie wird man versucht sein, Suárez neben einen Christian Wolff zu stellen, sosehr ihm der an Produktivität und Ordnungsliebe auch gleichkommt. Es ist die betätigte Kraft zur Synthese, für die Suárez bei allem, was er angefaßt hat, zu Recht so berühmt ist. Diese Kraft hat ihm im 17. Jahrhundert diese ja nicht nur unter den Jesuiten, sondern im europäischen Geistesleben, singuläre Stellung verschafft. Die Kehrseite davon ist freilich, bei der Unzahl von Themen, die er in diesem Geist abgehandelt hat, ein dermaßen diffuses Image, daß ,Suarezismus' als Positionsbezeichnung fast nichtssagend ist. Davon macht nur eine Handvoll Sonderlehren eine Ausnahme, in der Theologie also z.B. die praedefinitio Suaristica. Sonst hat die Dynamik der Jesuitenscholastik dafür gesorgt, daß sich die Doktrin selbst eines solchen Mannes den Köpfen nicht eigentlich auferlegte. Schnell waren für einzelne Traktate, nicht selten aber auch über die ganze Bandbreite des philosophischen und theologischen Kurrikulums, Korreferate anderer Jesuiten verfügbar, die Suárez' Antworten kritisch diskutierten und relativierten. Seit den 166oer Jahren waren zwar Bestrebungen im Gange, ihn zum Ordenslehrer aufzubauen. Gegen 1700 entstanden an manchen Universitäten sogar richtige Suárezprofessuren. Der mallorquinische Historiker Ramis-Barceló, der das Phänomen untersucht hat, zeigt 
jedoch, daß für die Errichtung solcher Lehrstühle der politische Wille maßgeblich war, die Gleichberechtigung der Jesuiten mit den Dominikanern durchzusetzen. ${ }^{33}$ In einem paritätischen System sollten auch sie das Recht haben, über die Besetzung ihnen gewidmeter Professuren selbständig zu entscheiden.

Den Suarezismus auch unseres Autors sucht man besser in der Neigung zur spekulativen Synthese als in einem spezifizierbaren doktrinellen Anschluß an seinen großen Vorgänger.

Zwei einander scheinbar widerstreitende Argumentationsziele hat der Text, sie will er harmonisieren. Von Gottes Kontingenzwissen will er sowohl zeigen, daß Gott auch in dieser Beziehung Herr im Haus ist, als auch, daß Gott in dieser Beziehung nicht autark ist. Durch die Scientia Media-Hypothese ist die Nichtautarkie das große Thema geworden: Es gibt ein göttliches Wissen, bei welchem der Schlüssel zu der Gesamtheit der Affirmationen und Negationen nicht bei Gott liegt, sondern bei der Kreatur. Auf diesen Standpunkt stellt sich auch der Autor des Manuskripts: „Wenn man unterstellt, es wäre für den Allmächtigen eine Zumutung, das Verhalten der Kreatur abzuwarten, gleitet der Allmachtskult in Servilität ab... Gottes Souveränität verlangt nicht, daß Gott imstande ist, rücksichtslos zu dekretieren, daß von diesem freien Willen in dieser Situation dieser freie Willensakt erbracht wird. “"34 Die Nichtautarkie nicht wieder zu eliminieren, aber sie zu einem dialektischen Moment von Gottes Souveränität herabzusetzen, das ist die selbstgesetzte Aufgabe des Texts. Die Lösung, die er vorschlägt, besteht in der Minimalisierung des kreatürlichen Anteils. Das erreicht er durch die systematische Distinktion verschiedener Bedeutungen, in denen etwas als ,Objekt' fungiert, sowohl für ein Erkenntnisvermögen im allgemeinen als auch für Gottes Verstand im besonderen.

In der scholastischen Erkenntnistheorie bezeichnet der Unterscheidungsbegriff ,objektiv' die eine der beiden Weisen, auf die etwas ,im' Verstand sein kann, nämlich so, daß es auf die intentionale Aktivität bezogen ist. Vermöge seiner, intentionalen Präsenz, heißt es in dem Text, ist das Objekt im Verstand (\$224). Im übrigen

33. „A nuestro entender, el suarismo se empezó a afianzar como opinión preeminente cuando, en la década de 1660, los jesuitas, gracias al apoyo regio, recibieron cátedras pro religione en algunas universidades hispánicas.” RAFAEL RAMIS-BARCELó: „La configuración y el desarrollo universitario del suarismo en el siglo XVII“, in Entre el Renacimiento y la Modernidad: Francisco Suárez (1548-1617), hgg. von J.L. Fuertes / M. Lázaro Pulido / Á. Poncela González / M.I. Zorroza, Madrid-Porto 2018, 267-291, hier 290.

34. „[... [ respondeo, religionem omnipotentiae in superstitionem vanae observantiae declinaturam, si omnis expectatio creaturae omnipotentem dedecere credatur." Concordia fol. 673v („creaturae“ ist ein genitivus obiectivus). - „Concludo ergo, Dei dominium non petere essentialiter, quod proxime potens sit Deus nullo expectato decernere efficaciter existentiam liberi actus ut efficiendi per hoc determinate principium completum. " fol. $678 \mathrm{v}$. 
kann alles mögliche ein ,objektives' Sein haben, auch reine Phantasiegebilde. ${ }^{35}$ An dem Begriff des Objekts sind verschiedene Aspekte zu unterscheiden. Von denen bleibt nur einer übrig, unter welchem Gottes Wissen auf ein Objekt so angewiesen ist, daß es Gottes Autarkie übersteigt. In der scholastischen Terminologie ist dies das obiectum terminativum, im Unterschied zum obiectum motivum. Daß sich ein Erkenntnisakt an etwas gegenständlich oder intentional erfüllt (,terminiert'), erklärt in der Scholastik überhaupt nicht das Zustandekommen des betreffenden Akts. Nur im Bereich der präsenzgebundenen, intuitiven' Erkenntnis deckt sich die Ursache von dessen Zustandekommen mit dem Aktinhalt, sonst hat es andere Ursachen. Daraus, daß Gott Informationen verarbeitet, folgt daher nicht, daß der freie Wille auch die Ursache für die Veränderungen in Gottes Wissenshaushalt ist. Entsprechend unterscheidet unser Text zwischen zwei Ordnungen, der ,intentionalen' und der ,physischen' oder , realen ' $(\$ \$ 70,188,232)$. Auf die letztere - wir würden sie den genetischen Aspekt nennen - bezieht sich das Theorem, daß es für Gott kein obiectum motivum gibt, das nicht mit Ihm identisch wäre $(\$ \$ 159,280)$ : Was Gott auch immer erkennt, ausschließlich durch sein eigenes Wesen wird es Ihm vorstellig. Auf diese - klassische - Lehre legt unser Text allen Nachdruck. Gerade dadurch wird die „intentionale“ Ordnung für andere Konnotationen frei. Das obiectum terminativum ist in der scholastischen Terminologie das, Objekt' in des Wortes eigentlichster Bedeutung: ${ }^{36}$ die für intentionale Akte essentielle Möglichkeit, daß sie sich an etwas erfüllen. Auch Gott hat eine Pluralität solcher Objekte. Die in der Erkenntnistheorie üblichen Beispiele für solche intentionalen Erfüllungen, ,Baum’ etwa, orientieren das Gemeinte an möglichst einfachen Vorstellungen. Gottes Kontingenzwissen erfüllt sich aber an Sachverhalten. Wie tut es das? Der Text behauptet: in disjunktiver Form, in Form von kontradiktorischen Gegensatzpaaren, ,A oder nonA'. Wer behauptet, auf der Basis der Autarkie dieses Wissens verfügte Gott über mehr als das, hätte anzunehmen, daß die Kontingenz von Gott entschieden ist. Nur so könnte Gott im voraus mit Bestimmtheit auf A bezugnehmen. Der Jesuit lehnt das ab. Der Verzicht ist der Preis dafür, daß Gottes Kontingenzwissen der Dichotomie unterworfen wird: willensbasierte Autarkie einerseits, ein Bereich der intentionalen Erfülltheit andererseits.

35. Historisches Wörterbuch der Philosophie s.v. ,Subjekt/Objekt; subjektiv/objektiv', hgg. von J. Ritter / K. Gründer / G. Gabriel, Basel 1971-2004, Bd. 10, 401.

36. „Obiectum ut obiectum habet rationem terminandi, non movendi: cui alludit nomen ,obiecti': nam ,obiectum' videtur significare illud quod obiicitur potentiae et circa quod terminatur actus alicuius." Antonius Andreas OFM. († ca. 1340): Quaestiones super XII libros Metaphysicae 4, 2, Venedig 1523, 17ra. - „Respondeo, communem sententiam nomine ,obiecti intellectus' nihil aliud significare quam id, quod cognoscitur." R. DE ARRIAGA SJ.: Disputationes theologicae in Primam partem D. Thomae 18, 23, Antwerpen 1643, t.1, 188a. 
Aber natürlich nimmt Gott doch mit Bestimmtheit auf A oder mit Bestimmtheit auf nonA bezug. Nur reicht es dazu nicht, daß Gottes kognitiven Akten intentionale Erfüllungen zugeordnet sind, dazu muß das obiectum terminativum zu einem höheren Typ von Objekt fortbestimmt sein. Der Autor nennt es das „obiectum determinativum“. Die Frage nach dem zureichenden Grund $(\$ \$ 57,191)$ dafür, daß Gott A vorherweiß statt nonA, wird dahin beantwortet, daß der menschliche freie Wille dieser zureichende Grund ist (\$302). Durch das Verhalten des Menschen ist Gottes Vorherwissen auf A festgelegt. Das Leitmotiv und der Grundbegriff der Darlegungen dieses Texts lautet determinatio obiectiva $(\$ \$ 76,80,92,137-38,148$, $164,167,191,194,243,284)$. Die Minimalisierung des kreatürlichen Anteils läuft darauf hinaus, daß dieser nur auf eine bestimmte Weise vorrangiert. Es ist die Theoriebildung präzise zu dieser Weise, der prioritas a quo determinationis obiectivae, auf welche sich der Autor etwas einbildet (\$92). In der Struktur des obiectum determinativum liegt für ihn das ganze Geheimnis.

\section{Extrinsische Prädetermination}

Durch sein obiectum determinativum ist Gottes Kontingenzwissen „prädeterminiert“ ( $\$ 305)$. Gott, wie ihn dieser Traktat konzipiert, ist ein Deus praedeterminandus in tempore $(\$ 140)$. Aus drei Gründen ist das eine herausfordernde These.

Erstens, der in den Gnadenstreitigkeiten vielverhandelte und von den Jesuiten sonst immer nur als freiheitsfeindlich bekämpfte Begriff der Prädetermination wird umfunktioniert und einfach umgedreht. Nicht Gott prädeterminiert die Kreatur, die Kreatur „prädeterminiert“ Gott ( $\$ \$ 275-89$ ). Das grenzt schon an Blasphemie. Der Nachweis, daß und wieso sein Vorherwissen Gott nicht freisteht, gestaltet sich ähnlich aufwendig (Kap. 21-23) wie sonst, in bezug auf den menschlichen Willen, die Absicherung von dessen Freiheit; in beiden Fällen müssen viele Hintertürchen identifiziert und geschlossen werden.

Zweitens, die Rede von Gottes „Prädetermination“ impliziert für das Kontingenzwissen, um das es geht, ein physikalisches Modell. Der Autor orientiert sich an dem scholastischen Musterbeispiel für den Zusammenhang von Ursache und Wirkung. Gott in seiner Eigenschaft als Träger und Produzent des Kontingenzwissens wird $(\$ 289)$ dem Feuer, das freie Handeln der Kreatur wird dem Brennstoff und das Kontingenzwissen selber wird dem Brennen analogisiert. Ein Wissen will mit Informationen gefüttert sein, sonst gibt es nichts zu wissen. An dem Verhältnis von Feuer und Brennstoff hat die scholastische Naturphilosophie immer die Wichtigkeit der Randbedingungen demonstriert. Das Eintreten der Wirkung hängt davon ab, daß das Feuer, die Ursache, dem Brennstoff auch gehörig angenähert ist. Daran, daß die Randbedingungen erfüllt sind, hat die Kausalwirkung ihre notwendige und 
hinreichende Bedingung, erst dadurch ist sie determiniert. Das setzt auch unser Autor auseinander. Er artikuliert den folgenden Strukturzusammenhang:

- Aus dem Eintreten der Wirkung folgt, daß Feuer und Brennstoff einander gehörig angenähert sind.

- Damit das Feuer, als die Ursache, seine Wirkung tun kann, müssen sie gehörig angenähert sein.

- Das Feuer tut seine Wirkung, wenn sie gehörig angenähert sind.

- Wenn sie gehörig angenähert sind, dann tritt die Wirkung notwendig ein.

Unter den durch die Koexistenz von Zeit und Ewigkeit gewährleisteten Bedingungen ist Gottes Kontingenzwissen ein in diesem Sinn determinierter Effekt.

Drittens, die Prädetermination ist deswegen aber nicht etwa kausal zu denken. Die Ordnungsstrukturen, deren Analyse den Traktat beschäftigt, sind durchweg anderen Typs als die Kausalordnung, in der die Ursache das Erste und die Wirkung das Zweite ist. Zum einen geht die Prädetermination, umgepolt, nicht vom ,Feuer', sondern vom ,Brennstoff' aus. Damit ist das ganze Verhältnis von Gott und Kreatur neujustiert. Zum andern steht, von dem Sonderfall Prädefinition abgesehen, der zu erklärende Effekt, das Kontingenzwissen, überhaupt nicht im freien Belieben eines der beiden Pole $(\$ \$ 282,299)$, weder in dem des göttlichen noch in dem des menschlichen Willens. Weder erklärt er sich aus einer auf das Handeln der Kreatur gerichteten kausalen Einflußnahme noch aus etwas Derartigem in der Gegenrichtung. In beiden Richtungen scheidet das Modell des physischen Influxes $(\$ 151)$ aus. Es soll ein symmetrisches Verhältnis sein $(\$ 307)$, bei dem beide Seiten des Verhältnisses einander implizieren ( $\$ 293$ ). Das wird auf anderer Grundlage erreicht als auf der von so oder so deklinierten Kausalwirkungen, nämlich nicht auf die Weise, daß das Implikationsverhältnis irgendwie der Effekt intrinsischer Denomination wäre. Es ist der Effekt, extrinsischer' Denomination.

Der Text bestätigt einmal mehr, wie grundlegend wichtig für die Jesuitenscholastik der aus dem Schularistotelismus stammende Konzept des ,Denominierens' gewesen ist, Von dem Text ist nichts zu verstehen, wenn nicht verstanden wird, daß es darin unablässig um das ontologische Fundament bestimmter Gegenstandsprädikate geht. ,Denominationen' stehen auf dem Prüfstand; mit Hilfe der Kursivierung der betreffenden Adjektive versucht die vorliegende Edition, das zu verdeutlichen. Der Begriff, Denomination' ist dabei nur das Sprungbrett, um zwischen ,intrinsischen' und, extrinsischen' Denominationen zu unterscheiden. Diese Distinktion liegt auf der höchsten Einteilungsebene der Prädikate, welche einem Gegenstand beigelegt sein können. „Der Uhu ist gesehen.“ Grammatisch und logisch ist das genauso ein Prädikat wie gefiedert. Im Unterschied zu dieser 
Eigenschaft ,inhäriert' es dem Gegenstand aber nicht, ontologisch hat es sein Fundament außerhalb des Gegenstands, in der Aktivität eines Beobachters. Dem Uhu ist das Prädikat gleichgültig; im nächsten Augenblick ist er schon weg, und ein wahrer Satz hat sich in einen falschen verwandelt. Die Erlangung vollständiger Klarheit über diesen Unterschied und über die Tragweite, die er hat, ist eine der größten Errungenschaften der Scholastik des 14. Jahrhunderts. Den kategorialen Eigenschaften, den ,Substanzbegriffen', traten die ,Funktionsbegriffe' gegenüber. In der Jesuitenscholastik wird routinemäßig mit der Distinktion operiert, quer durch alle Stoffgebiete. Es ist hier nicht der Ort, das auszuführen. ${ }^{37}$ In unserem Text ist der Unterscheidungsbegriff, extrinsische Denomination' gang und gäbe $(\$ \$ 2,124$, 142, 151, 159, 187, 210, 212-13, 218, 246). Affirmativ, wie er den Begriff ,Prädetermination' verwendet, kommt es ihm darauf an, daß auch der sich als eine extrinsische Denomination konstruieren läßt ( $\$ \$ 281-84)$. Auf dieser Basis die blasphemisch klingende Umpolung in dem Verhältnis von Gott und Kreatur vorzunehmen, ist die idée directrice seiner spekulativ dichtesten Passagen.

Auf Gottes privilegiertem Erkenntnisstandpunkt ist es natürlich keine Kunst, die Zukunft vorherzuwissen. Die Erklärung dafür liegt, wie seit eh und je, in der Unterscheidung zwischen Zeit und Ewigkeit. Gott erkennt, erläutert ein angesehener katholischer Dogmatiker des 19. Jhs. die zu lösende Aufgabe, erstens die freien Handlungen der Kreatur schon zeitlich vor dem Eintreten derselben und weiß folglich zeitlich früher um dieselben, als der Handelnde selbst um dieselben weiß, und als die Handlungen durch ihre eigene Wirklichkeit sich erkennbar machen können. Zugleich aber erkennt Gott zweitens dieselben vor ihrem Eintreten ebenso in ihrer eigenen Wirklichkeit wie im Augenblicke ihres Eintretens und schaut sie folglich in steter Gegenwart, so daß er sie nicht als ihm selbst zukünftig, sondern bloß in der Reihenfolge der Zeit zukünftig erkennt. „Wenn daher sein Wissen in der ersten Beziehung als ein früher vorhandenes, Vorherwissen (praescientia) genannt werden kann und muß: so darf dies doch nicht in dem Sinne geschehen, als ob damit, wie bei uns, eine von dem Gegenwärtigschauen verschiedene Erkenntnisweise ausgedrückt werden solle. “38

Ob unser Autor den zweiten Punkt so unterschreiben würde, sei dahingestellt. Es finden sich in unserem Traktat dazu lange Ausführungen mit einem Exkurs zur

37. J.P. Doyle: „Prolegomena to a Study of Extrinsic Denominationin the Work of Francis Suarez, S.J.“, Vivarium 22 (1984) 121-60; S.K. KNEBEL: „Intrinsic and Extrinsic Denomination. The 14th Century Connection of 17th Century Aristotelianism“, in Der Aristotelismus in der Frühen Neuzeit: Kontinuität oder Wiederaneignung?, hgg. von G. Frank / A. Speer, Wiesbaden 2007, 97-115.

38. M.J. Scheeben: Handbuch der katholischen Dogmatik II. Buch: Gotteslehre $\left({ }^{1} 1875\right) \$ 452$, Freiburg i.Br. ${ }^{3} 1948,192$. 
tense logic $(\$ 252) .39$ Den ersten Punkt würde er jedenfalls nicht unterschreiben, darum kommt er mit dem Begriff ,Prädetermination'. Zur Erklärung stellt er die Frage: Was heißt es für A, daß A von Gott vorhergewußt ist? Antwort: Gottes Vorherwissen läßt den Gegenstand in dem Verhältnis zu sich vorrangieren. Auf Gottes Erkenntnisstandpunkt hat A von dem Vorherwissen das Prädikat, daß A dem Vorherwissen vorrangiert. Der Text erläutert das (\$132) durch die Unterscheidung zweier Hinsichten, in deren jeder das gilt. Erstens so, daß der gemeinte Sachverhalt grammatisch im Futur steht: Erst wird A der Fall sein, ehe von A gewußt werden wird, daß A der Fall sein wird. Erst unter der Voraussetzung, daß A der Fall ist, ist das auch vorhergewußt. So gesehen liegt das Vorrangieren von A an A selber, nämlich zu dem Zeitpunkt, zu welchem der freie Wille machen kann, daß A oder nonA der Fall ist: das Vorrangieren von A als eine intrinsische Denomination für A. Zweitens unter Abstraktion von dem grammatischen Futur; denn auf Gottes Standpunkt, der Ewigkeit, gibt es weder Vergangenheit noch Zukunft. Dann besteht das Vorrangieren von A darin, daß das Vorherwissen funktional von A abhängig ist, d.h. von etwas, das auch nicht der Fall sein könnte. Während in der ersten Hinsicht das Vorherwissen erst noch der Effekt von A sein wird, ist es in der zweiten Hinsicht dieser Effekt bereits und das von jeher. In dieser Hinsicht ist das Vorrangieren von A für A eine extrinsische Denomination. Es ist daher das Resultat eines doppelten Vorgangs: sowohl der Selbstbestimmung des freien Willens als auch einer Ermöglichung, daß der freie Wille auf diese Weise dem Vorherwissen vorrangiert. Deswegen reduziert sich das Vorhergewußtsein von A nicht darauf, eine extrinsische Denomination davon zu sein, daß Gott A vorherweiß. Gottes Kontingenzwissen wird vielmehr als die Wirkung davon aufgefaßt, daß sein Träger und Produzent in der Position ist, die für die Prädikate aus Erkenntnisbeziehungen sonst charakteristische Äußerlichkeit im Verhältnis von Subjekt und Prädikat zu überwinden: „Das chemische Element Radium ist eine Entdeckung von 1898“, „Kuckucksnester sind Fiktion“, „Pluto ist kein Planet“. Dadurch zu überwinden, daß Gott das eigene Wissen von dem Handeln der Kreatur abhängig macht. Präzise zur Bezeichnung für die Folge aus diesem Schritt wird $(\$ 281)$ die Formel, extrinsische Prädetermination’ eingeführt: „Durch diese gegenständliche extrinsische Prädetermination von seiten desjenigen Prinzips, welches durch seine Freiheit das Prinzip der Impedibilität dieses Wissens ist, ist Gott extrinsisch dazu prädeterminiert, eben dieses Wissen auch hervorzubringen, denn in bezug auf das Wissen besteht diese extrinsische Prädetermination genau darin, daß sie den vorgängigen Anspruch darauf darstellt, daß es von Gott gesetzt wird.“

39. Weiteres dazu bei S.K. KNEBEL: „Sebastián Izquierdo (1601-1681) und die Zeitlichkeit des Bewußtseins", Freiburger Zeitschrift für Philosophie und Theologie 65 (2018) 401-42, hier 406 (Fußnote 28) und 418 (Fußnote 94). 


\section{Impedibilität}

Die „Prädetermination“ Gottes durch das obiectum determinativum umschreibt die Nichtautarkie von Gottes Kontingenzwissen. Wieso ist durch diese Art und Weise, etwas zu wissen, die Äußerlichkeit im Verhältnis des Wissensgegenstandes zu seinem Gewußtsein überwunden? Der Grund ist in dem letzten Zitat genannt: die ,Impedibilität' des Kontingenzwissens. Der freie Wille ist das principium impeditivum et extrinsece praedeterminativum $(\$ 283)$ des Vorherwissens.

Der Kontingenz des Effekts mißt eine indeterministische Handlungsmetaphysik einen unendlichen Wert bei, allem anderen nur relativ in bezug darauf. ,Impedibilität' nennt die Bedingung, von welcher ihre Aufrechterhaltung abhängt: daß nämlich etwas so ist, daß es auf den freien Willen als die Aufhebungsbedingung für es bezogen ist. Diese Seinsweise haben die futura contingentia. Wenn es in der Vergangenheit liegt, hat Kontingentes ja aufgehört, kontingent zu sein. Nur das in die Zukunft Projizierbare ist, impedibel'. Darum ist auch das Wissen um die futura contingentia ,impedibel'. Zukunftsbezogen, wie der Begriff der Impedibilität ist, bezeichnet er bei Wadding ein Merkmal, das sich zugleich auf die Struktur des Vorherwissens ( $\$ \$ 93,129,150-55,282)$ und auf die Struktur seines Gegenstandes ( $\$ 193)$ bezieht. Der Ausdruck symbolisiert das ontologische Fundament dafür, daß die Tatsache, daß A dem Vorherwissen vorrangiert, für A eine intrinsische Denomination ist. Insofern dafür das Symbol, steht er zugleich für die Nichtautarkie von Gottes Kontingenzwissen. Unter diesem Begriff wird sie verhandelt. ,Impedibilität' ist ein Grundwort, wenn nicht das Grundwort unseres Traktats.

Die Zusammenhänge deuten sich schon bei der ersten Erwähnung an, in der Einleitung zu dem Kapitel über „Das Prinzip, auf welchem die Tatsache beruht, daß A dem göttlichen Vorherwissen vorrangiert“. Dieses zehnte Kapitel beginnt ( $\$$ 93) so: „Ich führe dieses Vorrangieren auf ein sehr einleuchtendes Prinzip zurück: darauf, daß das göttliche Vorherwissen von unserer freien Entscheidung nicht kausalerweise abhängt, sondern impediblerweise. Es liegt bei uns, wie wir uns entscheiden, daß Gott von ewigkeither etwa unseren Haß vorhergewußt hat, nicht unsere Liebe. Ob wir hassen oder lieben, ist ja die Sache unserer freien Entscheidung. Wenn es der Haß ist, der gezeitigt wird, dann ist notwendig auch von ewigkeither Haß, und nicht Liebe, der Gegenstand des Vorherwissens gewesen. Daß Gott nicht dieses, sondern jenes, von ewigkeither vorhergewußt hat, liegt nicht in dem Sinn an unserem freien Willen, daß wir auf dieses Wissen direkt Einfluß nähmen, sondern indirekt: insofern wir nämlich dessen Gegenstand setzen können oder auch nicht setzen. Indem A gesetzt wird, wird auch das betreffende Wissen gesetzt, indem nonA, wird das betreffende Wissen verhindert (impeditur).“

Der Unterschied zu einer Kausalwirkung wird an einer späteren Stelle ( $\$ 147)$ deutlicher: „Es ist seinem zeitlichen Sein nach, daß der freie Willensakt dem 
Vorherwissen Gottes vorrangiert, indem nämlich aus seiner Existenz von ewigkeither die Existenz seines Vorhergewußtseins folgt und zwar in dem Sinn folgt, daß die kreatürliche Ursache dieses freien Willensakts es würde verhindern können, daß er es ist, der von ewigkeither vorhergewußt ist. Deswegen rangieren der kreatürliche freie Wille und dessen Akt dem Wissen vor: nicht physisch oder von ursprungswegen. Denn nach keinem Typ Kausalität wirken sie auf das Vorherwissen: weder, indem sie dieses erzeugen, noch, indem sie den Träger des Vorherwissens dazu in den Stand setzen. Während der Träger des Vorherwissens dazu schon in dem Stand ist, brauchen sie ja noch nicht einmal zu existieren. Um eine Kausalwirkung zu sein, bedürfte es indessen gerade einer solchen Koexistenz und des In-den-Stand-Setzens, und nicht nur dazu bedürfte es dessen, auch dazu, um auch nur als die Bedingung von etwas physisch oder von ursprungswegen diesem vorzurangieren. Also nicht in dem Sinn, physisch und von ursprungswegen, rangieren der freie Wille und sein Akt Gottes Vorherwissen vor, sondern setzender- und aufhebenderweise. Durch den eigenen Akt der Liebe zu Gott macht nämlich der freie Wille, daß dieser Akt von ewigkeither vorhergewußt ist: nicht, indem er kausal eine Wirkung auf das Vorherwissen übt, sondern, indem dieses die Folge von jenem ist, und indem er selber das Hindernis dafür ausräumt. Das Hindernis läge in dem Eintritt des entgegengesetzten Akts. Sowie dieses Hindernis ausgeräumt ist, ist Gott kraft seiner Vollkommenheit kausal auf das Vorherwissen festgelegt. Der kreatürliche Wille hingegen, wie gesagt, wirkt durch seinen Akt nicht kausal bestimmend, sondern durch das Ausräumen des Hindernisses: insofern er die Macht hat, es auch nicht auszuräumen. Durch die Setzung des Gegenteils würde er es dann vielmehr verhindern, daß der Akt der Gottesliebe vorhergewußt ist. Der kreatürliche Wille ist also nicht die Ursache dafür, daß Gottes Wissen besteht, sondern dafür, daß A oder nonA gewußt ist. Das reicht aber auch dafür, daß er dem Wissen wirklich vorrangiert: nicht physisch oder von ursprungswegen, sondern rein bestimmenderweise, von entscheidungswegen."

Wie ist es möglich, daß etwas präzise auf diese Weise - setzender- bzw. aufhebenderweise - als Gegenstand des Wissens diesem vorrangiert? Diese Frage treibt unseren Traktat um. Die Vorstellung von einer Prädetermination Gottes grenzt vielleicht an Blasphemie, ist aber jedenfalls nicht irgendeine geistreiche Pointe, sondern ein eher grüblerischer Versuch, die Schnittstelle zwischen dem freien Handeln und der betreffenden ,Nachricht' handlungsmetaphysisch auf den Begriff zu bringen. Ohne Handlungen keine wahren Aussagen über die Handlungen, aber wie entstehen diese aus jenen?

Gottes Vorherwissen muß man sich als das Display für eine Klasse von Informationen vorstellen, deren Urheber nicht Gott ist. Als Apparat hat es aber seine technischen Voraussetzungen. Deren Alleinurheber ist Gott. Gottes Kontingenzwissen resultiert aus dem geregelten Zusammenwirken zweier Faktoren, ohne daß 
das Resultat von dem einen oder von dem anderen der beteiligten Faktoren so intendiert wäre ( $\$ \$ 280-82$ ): „Jeder der beiden Faktoren rangiert auf seine Weise dem Wissen vor: der eine als das, wodurch das Wissen als solches existiert, der andere als das, wovon das Wissen beliebig aufgehoben oder gesetzt sein kann... Zur Indifferenz seiner beiden Faktoren ist das Wissen daher nicht gleichursprünglich in Beziehung zu setzen, d.h. nicht so, daß es unmittelbar die Leistung der Indifferenz des einen wie des anderen wäre. Unmittelbar ist es die Leistung des aktiven Faktors, denn der produziert das Wissen, ohne daß produktiv direkt oder indirekt noch irgendetwas anderes intervenierte. Hingegen ist es nicht unmittelbar die Leistung des geschaffenen freien Willens, insofern es bei diesem liegt, dieses Wissen zu bestimmen bzw. aufzuheben. Denn das tut er vermittelst seines eigenen Verhaltens, nach welchem sich das Wissen dann richtet... Was den aktiven Faktor von A und nonA betrifft, ist der nur dann frei, wenn bei ihm auch die Impedibilität liegt. Der in diesem Sinn freie Faktor ist in bezug auf A und nonA aber nur dann unmittelbar frei, wenn er es auch unmittelbar verursacht. Daraus folgt, daß weder der eine noch der andere Faktor über Gottes Kontingenzwissen die Freiheit hat: Gottes Wissen nicht, weil es nicht nach Belieben auch das Gegenteil weiß; der geschaffene freie Wille unmittelbar aber auch nicht, denn der kann zwar machen, daß das Gegenteil gewußt wird, aber nicht unmittelbar dadurch, daß er dieses verursacht, sondern nur vermittelst seines eigenen Verhaltens. In meiner Hypothese ist die Wirkung aber, welche er durch sein Verhalten ausübt, keine kausale, sondern die nach Art von Impedibilität und Determination."

Weder dem einen noch dem anderen Faktor läßt sich der Effekt der Impedibilität auf Gottes Display also eindeutig zuordnen. Der kritische Punkt ist, was daraus für den Träger und Produzenten des Kontingenzwissens folgt. Worin besteht für Gott die „Prädetermination“, welcher Er unterliegt? Gott spielt in diesem Verhältnis nicht geradezu die passive Rolle. Bestimmbarkeit war im aristotelischen Hylemorphismus ja das Merkmal der Materie. ${ }^{40}$ Analogie zur Materie scheidet theologisch aus. Dennoch verhütet nur der Dualismus der zwei Register, auf den der Autor in dem letzten Satz anspielt, daß man sich von Gottes Vorherwissen vorstellen muß, es funktionierte nach Art einer Billardkugel. Der Stoß, von dem die Billardkugel ihre Richtung empfängt, ist das Musterbeispiel einer mechanischen Wirkung. Diese Art Wirkung, von der die jesuitischen Kritiker der physischen Prädetermination stets geargwöhnt haben, daß sie dieser Hypothese über das Verhältnis Gottes zum

40. Mit , aristotelischem Hylemorphismus' ist die Traditionslinie Averroes / Thomas von Aquin gemeint, nicht Avicenna / Duns Scotus. Die Semantik von ,Zufall' differenziert die beiden Traditionen. Vgl. S.K. Knebel: „'Volo magis stare cum Avicenna...' Der Zufall zwischen Averroisten und Avicennisten“, in Wissen über Grenzen, hgg. von A. Speer / L. Wegener (= Miscellanea Mediaevalia Bd. 33), Berlin-New York 2006, 662-76. 
freien Willen zugrundeliegt, ist in der umgekehrten Richtung zwar ausgeschlossen. ${ }^{41}$ Nur ist, was mit dem Wechsel in das andere Register gewonnen sein soll, darum keineswegs klar.

Von Teilen der Scholastik wird der, passiven' Indifferenz systematisch die ,aktive' Indifferenz entgegengesetzt, d.h. die Freiheit der Selbstbestimmung. Auch unser Traktat legt Gott „aktive Indifferenz“ bei $(\$ \$ 302,429)$, allein damit ist nicht die Willensfreiheit gemeint. Das wäre handlungsbezogen. Um das praktische Verhältnis eines Handlungssubjekts zu seinen Handlungen geht es aber nicht, sondern um das kognitive Verhältnis zu Handlungen fremder Subjekte. Nicht nur zwischen Handlungen und den Informationen über Handlungen muß differenziert werden, auch zwischen dem Verhältnis zu dem einen und zu dem anderen. Offenkundig dringt hier eine Unentschiedenheit, eine kognitive Unentschiedenheit, in den Begriff der , aktiven' Indifferenz ein. Das ist die radikalste Folgerung, die unser Traktat theologisch zieht $(\$ 318)$ : „Gottes Indifferenz ist einzigartig und ausschließlich Ihm vorbehalten. Kraft derselben ist Er die adäquate Ursache einander jeweils entgegengesetzter Akte, ohne daß diese als Handlungen zu klassifizieren wären. Im kreatürlichen Bereich ist es ja so: Wo immer eine aktive Indifferenz bereit ist, zwei Akte zu zeitigen, ist jeder derselben seinem Wesen nach eine Handlung. Von keiner selbständigen kreatürlichen Wirkursache findet man, daß sie sich in ihrer Wirkungsweise nach der Handlungsweise einer anderen Ursache richtet. Eine kreatürliche Ursache, welche in ihrer Wirkung vom Handeln einer anderen abhängt, hat diese andere nötig, um dadurch selber erst noch Ursache zu werden. Ohne jene ist sie nicht zur Wirkung bereit. Daher ist im kreatürlichen Bereich eine zur Wirkung bereite und dabei in bezug auf zwei Akte indifferente Ursache das handlungsbezogen. Hingegen wird man feststellen, daß ohne diese Handlungsbezogenheit eine zur Wirkung bereite Ursache stets auf eine Seite festgelegt ist. Als Ursache zur Wirkung bereit und aktiv indifferent in bezug auf zwei Akte zu sein, ohne daß das handlungsbezogen wäre, ist folglich eine Vollkommenheit, welche wir den Kreaturen nicht mitgeteilt finden. Sie hat ihren Grund in Gottes kognitiver Vollkommenheit. Um das kontingent Zukünftige zu erkennen, bedarf diese nichts weiter als dessen Existenz. Sie bedarf deren aber nicht kausalerweise, sondern ausschließlich, um sich daran intentional zu erfüllen. Das geschieht so, daß sie kraft desselben göttlichen Erkenntnisvermögens, durch das sie von A erkennt, daß A eintreten wird, sich genauso an nonA würde intentional erfüllen können: wenn nonA eben das wäre, was der kreatürliche Wille Gott darbietet. Beides zusammen, die dem kreatürlichen Willen gewährte Freiheit im Hinblick auf den Gegenstand des Wissens und Gottes kognitives Vermögen, alles Künftige allein gestützt auf die

41. „[... [ non est per modum potentiae passivae.“ F. SuÁrez: Varia opuscula theologica 2, 1, 5, 4, Opera omnia, Paris 1856-78, t.11, 309b. 
Existenzbedingungen dieses Gegenstandes zu wissen, macht, daß Gottes Wissen der Effekt einer adäquaten Ursache ist, welche bezogen auf das Wissen A und das Wissen nonA kausal gesehen absolut indifferent ist, und daß das Wissen, das Gott hat, gleichwohl nicht eine Handlung ist, sondern daß alles, was an diesem Wissen Handlung ist und was insofern zu diesem Wissen prädeterminiert, auf die Seite des kreatürlichen Willens fällt.“

Die Besonderheit von Gottes Indifferenz besteht also in der Bezogenheit auf den binären Code impediri / non impediri. Der Autor des Texts läßt sich darüber nicht näher aus, aber jeder Zögling des Suarezismus wurde bei der Ontologie, die er im Kopf hatte, hier hellwach. Er hatte das traditionelle Universum aus Substanzen und Akzidenzen durch eine neue Klasse von Entitäten zu erweitern gelernt, die sog. Modi. In der suarezischen Ontologie hat sich, erläutert der beste Kenner der Materie den Schulhintergrund, so gut wie unbeachtet eine „Revolution“ zugetragen: die „Überlagerung der traditionellen Substanz-Akzidens-Ontologie durch eine neue res-modus-Ontologie“. Das habe „Auswirkungen auf alle Teile der theoretischen Philosophie“ gehabt, ${ }^{42}$ die Theologie gewiß nicht ausgenommen. Für die Modistae bestand die ontologische Funktion des Modus darin, „ein seinem Wesen nach etwas Anderes informierendes Seiendes zu sein, das formal die Indifferenz

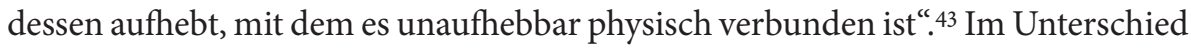
zur „informatio“ durch die substantiellen oder akzidentellen Formen ist der Modus die „aktuale Information“44 Schon wegen der Flüchtigkeit, die ein Modus in vielen Fällen hat, ist im Verhältnis zu ihm der Träger so eindeutig nicht mehr nur Substrat und Materie. Darum bilden die Modi die Brücke von dem alten Begriff der ,Information', der sich auf die Seinsweise des Akzidens bezieht, zu dem uns heute geläufigen. Wenn sich in unserem Traktat alles darauf zuspitzt, daß es etwas gibt,

42. U.G. LeINSLE: „Rodrigo de Arriaga im Streit um modale Entitäten“, in Bene scripsisti ... (Festschrift Sousedík), hgg. von J. Beneš u.a., Prag 2002, 161-89, hier 161. Gegen seinen Prager Kollegen Arriaga („Recentiores [...], qui magnam partem suae Philosophiae et Theologiae speculativae consumunt in explicandis modis [...]") disputierte der Bruder unseres Autors, Peter WAdDing (WAdingus) SJ.: Tractatus de Incarnatione, Antwerpen 1636, 1-33 („Disputatio prooemialis de natura Entium modalium“). Er wußte: „Sententia statuentium modos est inter recentiores praesertim in Hispania communis."

43. Leinsle, Dilinganae Disputationes, 130 (unter Bezug auf $\mathrm{CH}_{\mathrm{H}}$. Haunold SJ.: Modi physici $\$ 14$, Dillingen 1644, 5; vgl. auch P. Hurtado De Mendoza SJ.: Disputationes in universam philosophiam: Metaphysica 2, 60. 62, Lyon 1624, 738a/b). Ein scharfer Kritiker des Modismus ist C. Tiphaine (Tiphanus) SJ.: Declaratio ac defensio scholastica doctrinae Sanctorum Patrum Doctorisque Angelici de hypostasi et persona, Pont-à-Mousson 1634, 207-371. Darin vor allem das Kapitel „Proponitur et solvitur Argumentum pro Modis a rerum indifferentia ductum“(308-19).

44. LeINSLE, „Rodrigo de Arriaga“, 170. Leinsle arbeitet Arriagas Bedeutung für die Verknüpfung von ,modus' und ,informatio in der Diskussion mit Hurtado de Mendoza und Oviedo heraus. 
worin die ultimative Indifferenz - die Indifferenz des göttlichen Vorherwissens kontingenterweise aufgehoben ist, unterhielt man als Modista also das innigste Verhältnis zu diesem Etwas.

Wie schon angedeutet, ist die Unentschiedenheit von Gottes Wissen für unseren Traktat, ein weites Feld. Es wird Ernst damit gemacht, Gott offen für entgegengesetzte Informationen zu denken. Die Impedibilität hat auf Gottes Seite ihr Gegenstück. In das Vorherwissen wird förmlich ein Stadium zumindest relativer Unbestimmtheit eingebaut $(\$ \$ 165,379)$, ein Stadium des Abwartens (expectatio, $\$ 68)$. In Gottes Wissen klafft damit unverhohlen eine Lücke. Nicht um sie zu verhehlen, wohl aber, um sie zu beschönigen, wird zu wechselnden Ausdrücken gegriffen. Von praeoccupatio ( $\$ 115)$ ist die Rede, von einem göttlichen praevenire ( $\$ 151)$, von Abschlag und Vorschuß ( $\$ 155)$. Die Prädetermination zum Vorherwissen von A gibt es von ewigkeither, es ist ( $\$ 276$ ) eine ,hypothetische': eine, die ihrerseits unter Vorbehalt steht. Es geht darum, Gott der Art von Effekt auch gewachsen zu denken, um welche diese Erkenntnistheorie der indeterministischen Handlungsmetaphysik kreist, indem sie gebetsmühlenartig ihre Disjunktion von Setzen und Aufheben wiederholt. Was da in immer neuen Versuchen, es zu umschreiben, und in immer neuen Erklärungsanläufen umkreist wird, ist die Figur der Leerantizipation. Es stellt sich die Frage, ob hier nicht doch vielmehr die passive Indifferenz, also ein Begriff der ,Indifferenz', welcher ganz andere Grundlagen hat als derjenige der scholastischen Handlungsmetaphysik, auf Gott projiziert ist. Dem Jesuiten wäre dieser andere Begriff aus der ignatianischen Spiritualität ${ }^{45}$ immerhin intim vertraut gewesen.

\section{Auch ein Beitrag zur Scientia Media-Hypothese}

Wir hatten Anhaltspunkte für die Vermutung, daß dem Autor unseres Texts die Scientia Media-Hypothese mehr Notbehelf gewesen ist, sogar ein wenig lästig, kurz, daß sie ihm Verlegenheit bereitet hat. Der Eindruck, sie werde in dem Traktat marginalisiert, bedarf gleichwohl einer Berichtigung. Bezogen auf die Ebene, auf der von dem Kontingenzwissen generell gehandelt wird - und diese Ebene, die oberhalb der Einteilung in kategorisch und hypothetisch, ist das Thema der ersten siebenundzwanzig Kapitel des vierten Buchs -, ist der Eindruck unzutreffend. Der

45. „[...] para hacer sana y buena elección [...] segundo: es menester [...] hallarme indiferente sin affección alguna dessordenada, de manera que no esté más inclinado ni affectado a tomar la cosa propuesta que a dexarla, ni más a dexarla que a tomarla; mas que me halle como en medio de un peso [...] Tercero: pedir a Dios nuestro Señor quiera mover mi voluntad y poner en mi ánima lo que yo debo hacer acerca de la cosa propósita."I IgNACio DE Loyola SJ.: Ejercicios espirituales $\$ \$ 179-80$, Obras completas ed. I. Iparraguirre / C. de Dalmases, Madrid 41982, 247. Genauso z.B. M. Godinez (= Wadding) SJ.: Practica de la Theologia Mystica 1, 15, Sevilla 1682, 37. 
Hauptteil des Traktats ist eine durch die Impedibilität initialisierte Theorie des Kontingenzwissens, man könnte von einer Metaphysik der Impedibilität sprechen.

Dem schon erwähnten González de Santalla, nachmaligem Jesuitengeneral, hat festgestanden, daß nach den Grundsätzen der Gesellschaft Jesu der Indeterminismus handlungsmetaphysisch davon abhängt, daß „wir die Scientia Media unserer Handlungen würden verhindern können “. ${ }^{46}$ Damit war nicht gemeint, daß wir uns der Scientia Media etwa auch müßten entziehen können. Eine ,informationelle Selbstbestimmung' hat im Verhältnis zu Gott theologisch nie zur Diskussion gestanden. In anderen Kontexten hat der Datenschutzgedanke die spanische Scholastik schon beschäftigt, seit dem 16. Jahrhundert, nicht nur in lebenspraktischen Belangen, sondern bis in die Hypothesenbildung über die Kommunikation der Engel. Mit der unverzichtbaren ,Impedibilität' der Scientia Media war jedoch nur gemeint, daß der Mensch es sein muß, der durch sein Handeln den Inhalt dieses Wissens festlegt.

Was das kategorische Vorherwissen betrifft, ist es die Grundüberzeugung aller Anhänger der Scientia Media-Hypothese, daß der Mensch jederzeit machen kann, daß A, der Inhalt des jeweiligen Vorherwissens, niemals vorhergewußt gewesen wäre. Wir haben, sagt Vázquez, Gottes Vorherwissen „,in unserer Macht“.47 Die Frage ist nur, ob daraus folgt, daß das auf die Scientia Media übertragbar ist. Hat der Mensch auch darüber, was Gott über sein Verhalten in der Unendlichkeit möglicher Welten weiß, die Kontrolle? Molina nimmt das an, an der in der Scientia Media-Literatur vermutlich meistzitierten Stelle der Concordia, in der Definition aus der zweiten Auflage von 1595: „Die Scientia Media ist Gott nicht in dem Sinn wesentlich, daß Er nicht auch das Gegenteil davon wissen könnte, was Er durch sie erkennt. Gesetzt den Fall, der kreatürliche freie Wille würde in Zukunft anders als so handeln - und die Möglichkeit hat er -, dann würde Gott vermöge desselben Wissens eben das gewußt haben, nicht das, was Er tatsächlich weiß." ${ }^{48}$ Auch wenn die Impedibilität der Scientia Media, unter diesem Begriff, kaum vor

46. T. González de Santalla SJ.: Selectae disputationes ex universa Theologia Scholastica: De praedestinatione 6,43 , Salamanca $1680-86$, t.2, 151 b (s.o. S. 78 ).

47. „[...] cum praescientia Dei supponat, rem esse futuram, et quaelibet res libere a nobis futura sit in nostra potestate, efficitur, praescientiam etiam Dei, quatenus praescientia est, in nostra etiam potestate esse, hoc est, quod Deus praesciat, aliquid esse futurum vel non futurum, nobis liberum esse." G. VÁzQuez SJ.: Commentaria ac Disputationes in Primam partem S. Thomae 68, 47, Paris 1905, t.1, 581a.

48. „[...] dicendum neque etiam in eo sensu esse naturalem, quasi ita innata sit Deo, ut non potuerit scire oppositum eius quod per eam cognoscit. Si namque liberum arbitrium creatum acturum esset oppositum, ut revera potest, idipsum scivisset per eandem scientiam, non autem quod reipsa scit.“ L. Molina SJ.: Liberi arbitrii cum gratiae donis, divina praescientia, providentia, praedestinatione et reprobatione Concordia Q. 14 art. 13, 52, 10, Oña-Madrid 1953, 340. 
der Entstehungszeit unseres Traktats diskutiert wird, in der Sache geht der Gedanke auf Molina - und Fonseca - zurück. So gesehen wäre der Nachweis, daß Gottes Vorherwissen mit der menschlichen Willensfreiheit vereinbar ist, bezogen auf das hypothetische Vorherwissen „mit derselben Leichtigkeit“49 $\mathrm{zu}$ bewerkstelligen wie in bezug auf das kategorische.

Allein, das blieb Annahme. Sobald dieser Annahme Gründe geliehen wurden, sobald sie durchdacht wurde, hat sie, haben wir gesehen, die Scientia Media-Hypothese in eine Grundlagenkrise gestürzt. Unter den Merkmalen der Scientia Media ist die Impedibilität das systematisch brisanteste.

Auch unser Text weicht den mit dieser Annahme verbundenen Schwierigkeiten aus. Für seine Metaphysik der Impedibilität wählt er systematisch eine fundamentalere Ebene als die, auf der die Unterschiedlichkeit des kategorischen und des hypothetischen Vorherwissens zu berücksichtigen wäre. Das vierte Buch definiert für die darin stark in Anlehnung an Thomas von Aquin entwickelte Theorie des Vorherwissens diese Ebene $(\$ 319)$. Auf die bezogen ergibt sich das Merkmal Impedibilität einfach daraus, daß das Vorherwissen erkenntnistheoretisch als Widerspiegelung konzipiert wird..$^{\circ}$ Wie sich der Autor die Impedibilität speziell der Scientia Media denkt, bleibt hingegen unklar. Es gibt Gründe, um daran zu zweifeln, daß er das kohärent hinbekommen hätte. Nichtsdestoweniger schließt der in diesem Traktat ausbuchstabierte Zusammenhang von extrinsischer Prädetermination, Impedibilität und Gottes Indifferenz die Scientia Media mit ein. Auch wenn er zur ,Hauptsache' nicht kommt, ist der Text wegen der Hinordnung auf diese Hauptsache, durch die Anstrengung, der er sich unterzieht, sie systematisch herzuleiten, ein Aktenstück zur Geschichte der Systematisierung der Scientia Media-Hypothese. Er ist förmlich gesättigt von ihr, nur thematisiert wird sie nicht. Seine Metaphysik der Impedibilität ordnet ihn in dasjenige Diskursstadium ein, in dem die Scientia Media-Hypothese so weit war, ihre eigene Metatheorie hervorzutreiben. Man konnte reden, worüber man wollte, dabei heraus kam immer Scientia Media.

Daß sie hier präsent ist, unterliegt keinem Zweifel ( $\$ \$ 247,303 / 04,316$ u.ö.). Der Ausdruck „scientia media“ wird zwar gemieden, aber er fällt $(\$ \$ 452,474 / 75)$. Auch an äußeren Zeugnissen fehlt es nicht. Der Jesuit Bernaldo de Quirós (1613-68) verzeichnet in seiner Liste von Jesuitentheologen, welche sich zwar nicht eigens mit der Scientia Media-Hypothese befaßt hätten, aber deswegen „nicht weniger engagiert“

49. „Dico [...], eadem facilitate conciliari libertatem cum hac scientia conditionata, ac conciliatur cum scientia absoluta." A. Perez SJ.: In Primam partem D. Thomae tractatus V Opus posthumum: De Deo uno 3, 100, Rom 1656, 80a.

50. Die Spiegelanalogie ist in unserem Text allerdings nicht explizit. Im Scientia Media-Kontext findet sie sich z.B. bei N. Martínez SJ.: Deus Sciens, sive de scientia Dei 4, 5, 3, München 1678, 724. 
für sie eingetreten seien, auch einen „Wading“ ${ }^{51}$ Mit größter Wahrscheinlichkeit handelt es sich dabei um unseren Wadding. Quirós, ein Nachfolger von Wadding in Valladolid, kannte den zwanzig Jahre Älteren mindestens aus seiner Studienzeit. Ein Kommilitone von ihm, Henao, ${ }^{52}$ war damals direkt Schüler von Wadding. Der bekannte Historiker der Scientia Media, zitiert eine ihm, Henao, gegenüber abgegebene eidesstattliche Erklärung seines alten Lehrers, die wenigstens indirekt auch auf dessen Position Licht wirft. Es ging um die Frage, ob ein einstiger Vorkämpfer der Scientia Media-Hypothese nach seinem Ausschluß aus der Gesellschaft Jesu bei dieser Position geblieben war; die Dominikaner hatten das bezweifelt. Er habe sie nach wie vor vertreten, widersprach Henao, gestützt auf Waddings Zeugnis von $1649 .{ }^{53}$ Also just um die Entstehungszeit des Traktats hat Henaos Gewährsmann nach Kräften den Eindruck zerstreut, die affirmative Einstellung zur Scientia Media-Hypothese wäre eine Sache der Coterie.

Wie weit Waddings Engagement für sie ging, ist der Information natürlich nicht zu entnehmen. Auch innerhalb der Gesellschaft Jesu ist die Scientia Media-Hypothese auf Widerstand gestoßen, teils auf offenen, mehr noch auf versteckten. Der bekannteste Fall offener - und darum nur anonym oder pseudonym publik gewordener - Opposition damals war der Fall Tiphaine. Interessanter, weil die Motive dafür hier nicht auch anderswoher bekannt sind, sind die Fälle versteckter Opposition. Wenn es richtig ist, in Bernardo Aldrete (1594-1657), der an dem Kolleg von Salamanca gelehrt hat, den Führer der versteckten Opposition zu sehen, dann entbehrt es nicht einer gewissen Wahrscheinlichkeit, daß unser Autor, ein Kollege von Aldrete, zu dieser Gruppe gehört hat. Aldrete ist allerdings auch der beste Beweis, daß aus dieser Einstellung trotzdem profunde Abhandlungen über die Scientia Media entstanden sind. Das ungeschriebene fünfte Buch des Manuskripts hätte geschrieben sein können.

51. „[...] alii vero sunt, qui licet in transcursu et per occasionem, non tamen minus vivide et ex animo eandem sententiam [sc. Deum habere scientiam conditionatam ante omne decretum liberum sua voluntatis] exprimunt: Hurtado de Mendoca, Coninck, Cardinalis de Lugo, Raynaudus [...], Hemelman, Oviedo, Zuniga, Wadingus, Perlines [...]“ A. Bernaldo de Quirós SJ.: Selectae Disputationes theologicae de Deo, Lyon 1654, 605b.

52. A. Bernaldo De Quirós: Selectae Disputationes theologicae de praedestinatione, Trinitate, et Angelis 2, 1, Lyon 1658, 5b; Henao, Scientia Media historice propugnata $\$ 1270$, Salamanca ${ }^{2} 1665$, $343 a$.

53. Henao, Scientia Media historice propugnata $\$ 33$, Lyon 11655, 22a. Zitiert bei L. Meyer (Pseudonym: Theodorus Eleutherius) SJ.: Historiae Controversiarum de Divinae Gratiae auxiliis 6, 29, Antwerpen 1705, 727b. Dem Privatbrief eines Molinisten hat die Gegenseite freilich keine Beweiskraft zugestehen mögen: J.H. SERRY OP.: Historia Congregationum de auxiliis divinae gratiae 5, 7, 5, Antwerpen 1709, 920D. 


\section{Idealismus}

Wie ernst ist durch die Annahme eines Kontingenzwissens, das Gott ausdrücklich nicht freisteht, Gottes Autarkie eingeschränkt? Die Dominikaner sagen: Gottes Kontingenzwissen ist davon die Wirkung, daß das Handeln der Kreatur prädeterminiert ist. Das Kontingenzwissen beruht auf der Prädetermination der Zukunft. Nein, sagt unser Autor, es ist der Effekt des Bestimmtseins durch den Gegenstand, an welchem es sich intentional erfüllt, des Bestimmtseins durch sein obiectum determinativum und folglich, genau umgekehrt, davon die Wirkung, daß es durch das Handeln der Kreatur prädeterminiert ist. Damit hat sich die Fragestellung insgesamt verschoben. Die Hauptsorge dieses Autors einer Concordia Divinorum et Humanarum gilt nicht mehr der Sicherung eines Wissenstyps, welches dem menschlichen Akteur seine Freiheit garantiert. Sie gilt der Frage, was für das göttliche Subjekt dieses Wissens daraus folgt, daß sein Kontingenzwissen von der Art ist, daß es das tut. Was folgt für Gott aus der durch Molina ein für allemal veränderten Situation? Es ist nicht nötig, in allen Einzelheiten zu referieren, wie der Traktat es anstellt, die von ihm angestrebte Synthese zuwegezubringen. Es genügt, sich die genannten systematischen Motive zu vergegenwärtigen, um die Spurrille und die Windungen vor sich zu haben, in denen diese spekulative Anstrengung sich vollzieht.

Gottes Wissen ist von dem Gegenstand nicht dadurch,,prädeterminiert“, daß es auf ihn trifft, daß es ihn so außer sich vorfindet, wie das erkenntnistheoretisch die Position endlicher Geister ist. Nur die Erkenntnisimmanenz des Gegenstandes sichert diesem den Primat, der um seiner Kontingenz willen postuliert wird. Die Frage, was vorrangiert, der Gegenstand dem Wissen oder das Wissen dem Gegenstand, wird mit einem Sowohl-als-auch beantwortet, bei dem die eine Seite, der Primat des Gegenstandes, aber funktional von der anderen Seite abhängig ist. Obwohl nicht Gott, sondern der freie Wille darüber bestimmt, was Gott vorherweiß, ist die Entscheidung des freien Willens nicht das Erste oder jedenfalls nicht so unbedingt das Erste, wie in jeder Kausalbeziehung die Ursache das Erste und die Wirkung das Zweite ist. Nur in einer bestimmten Beziehung ist in dem Verhältnis zwischen dem Vorherwissen und dem Vorhergewußten die Entscheidung des freien Willens das Erste, in anderer Beziehung nicht. Diese Beziehungen werden subtil unterschieden, unter verschiedenen Gesichtspunkten geordnet, und es wird dargelegt, wie es mit dem behaupteten Anspruch auf den Primat in der einen Beziehung zusammenhängt, daß die Beziehung, in welcher dieser Primat nicht besteht, dem Vorherwissen seinerseits so nachdrücklich den Primat sichert, daß der Primat in der ersten Beziehung, der des Vorhergewußten, in einer dritten Beziehung zuletzt doch zum Effekt des Primats des Vorherwissens wird. Das liest sich (\$150) so: „Wie es sich im Vorherwissen darstellt, daß der Gegenstand vorrangiert, besteht das darin, daß das Vorherwissen ihm von ewigkeither nachrangiert, so jedoch, daß 
die Tatsache, daß es ihn voraussetzt, selber eine Leistung des Wissens ist, denn von intentionalitätswegen setzt es an und für sich den Gegenstand voraus. Darauf hat der Gegenstand, sobald er existiert, einerseits auch Anspruch, und andererseits ist genau das durch die Freiheit, in der der Gegenstand seinerzeit zu setzen ist, auch impedibel.“ Gottes Wissen setzt sich seinen Gegenstand voraus (\$\$180, 285). Der Erkenntnisgegenstand wird ,in der Sphäre der göttlichen Erkenntnisaktivität erst konstituiert“ (\$ 284). Das Wissen „konstituiert“ den Gegenstand in seiner Vorgängigkeit und damit ( $\$ 185)$ die zukünftige Existenz des freien Akts. Es setzt von ewigkeither die Zukünftigkeit des Gegenstandes als durch es, das Vorherwissen, konstituiert voraus $(\$ 180)$. Gottes Vorherwissen ist dessen futuritio intentionalis $(\$ \$ 176,188,234)$, d.h. es kennt nicht die Zukunft, es ist die Zukunft. Das Vorherwissen konstituiert den Gegenstand in seiner Erkennbarkeit. Nicht, daß er erkannt ist, ist für ihn das Prädikat, das er aufgrund ,extrinsischer Denomination' von dem Vorherwissen hat, sondern, daß er im voraus erkennbar ist $(\$ \$ 159,246)$. So etwas zu behaupten, hätte Suárez ferngelegen, obwohl er über die Terminologie dazu verfügt hat. 54

Was hier los ist, kann uns ein Experte für diese Dinge erklären. Johann Gottlieb Fichte (1762-1814) definiert in seiner Wissenschaftslehre die „wahre Streitfrage des Realismus und des Idealismus“. Sie besteht in dem Zweifel, „welchen Weg man in Erklärung der Vorstellung nehmen“ soll: den, daß „das Nicht-Ich als Ursache der Vorstellung, sie als sein Effect gesetzt wird“, oder den, daß „das Ich die Substanz derselben, sie aber sein Accidens sey"? ${ }^{55}$ Diese Frage müsse in aller Abstraktheit gestellt sein, unter Abstraktion „von aller Zeitbedingung“. ${ }^{56}$ Man setze für Fichtes Explanandum, die „Vorstellung“, Waddings „Vorherwissen“. Dann ist klar, der Ort, um Fichtes Frage in dieser Form zu stellen, war der scholastische Tractatus de scientia Dei. Auf die Frage gibt Waddings Traktat auch kategorisch Antwort. Der

54. Suárez benutzt den Begriff, extrinsische Denomination' nicht, um damit die Erkennbarkeit des Zukünftigen zu bestimmen, sondern das Erkanntsein: „[... ] possunt futura contingentia terminare divinam scientiam, etiamsi ab aeterno non habeant existentiam aeternam ad Deum, sed tantum pro suis temporibus; quia hoc terminare non est aliquid reale intrinsecum in obiecto determinante scientiam, sed est denominatio extrinseca proveniens ab ipsa scientia. "SuÁrEZ, Varia opuscula theologica 2, 1, 8, 6, t.11, 329a. - Die Erkennbarkeit war für Suárez etwas gewesen, das dieser extrinsischen Denomination von seiten des Gegenstandes zugrundeliegt: „[...] est [...] ipsum esse, quod res est suo tempore habitura [...] Illud ergo esse, quatenus est sufficiens fundamentum ex parte obiecti terminativi, ut videri possit a Deo [...], est sufficiens ratio ex parte eiusdem obiecti, ut possit esse praesens actui intuitivae scientiae. Haec igitur aptitudo ex parte rei cognoscendae dici potest, ex parte eius, praesentia obiectiva [...] “ Ibid. 2, 1, 8, 9, t.11, 329b.

55. J.G. Fichte: Grundlage der gesammten Wissenschaftslehre (11794), Sämmtliche Werke, hg. von I.H. Fichte, Berlin 1845/46 / Repr. 1971, Bd. 1, 155/56.

56. Ebd. 179. 
handlungsmetaphysische Indeterminismus impliziert erkenntnistheoretisch den Idealismus. Das ist die in dem 13. Kapitel vorgetragene These, und das ist das Originelle an diesem Traktat. Er dokumentiert die in Salamanca starke Stellung derjenigen Fraktion, die sich durch die sublimste aller metaphysischen Versuchungen, die Futuribilien, sehr prinzipiell zu einer Kritik an der Hypostasierung von etwas bewogen gefunden hat, dem denkunabhängig Realität beizulegen dieser Auffassung nach ein Sakrileg wäre. Die Erkennbarkeit der freien Willensakte der Kreatur ist nicht irgendwie intrinsisch von ewigkeither Gottes Wissen vorgegeben, weder positiverweise noch negativerweise $(\$ \$ 122-25)$. Denn daß sie das disjunktiverweise ist, „A oder nonA“ $(\$ \$ 3,19,168)$, ist ein Hohn auf den Anspruch, damit wäre etwas dem Wissen vorgegeben. Wadding ist ein Molinist, der die Binnensphäre des Allwissenden, die Ewigkeit, von all dem wieder freischaufelt, was sich dort inzwischen, namentlich durch Ruiz de Montoya (\$\$ 126-27, 168, 193), an Erkennbarkeiten abgesetzt hat.

Innerhalb der Scientia Media-Hypothese hat sich damals der Konflikt der realistischen und der idealistischen Schulrichtung an dem Streit um die Verwendung des Begriffs ,objektive Wahrheit' entzündet. Die realistische Schule setzt ein robustes Zutrauen in den Bestand objektiver Wahrheiten, in Tatsachen, auch, wenn keiner sie kennt, denn zumindest der Allwissende kennt sie. Aus der Ecke kommen, um das aus der Philosophiegeschichte bekannteste Beispiel zu zitieren, die theologischen Bemerkungen in einer anderen Wissenschaftslehre, der von Bernard Bolzano, zur Absicherung der ,Sätze an sich'. ${ }^{57}$ Dagegen hat die idealistische Schule unüberwindlich Skrupel, der Allwissenheit ein Tatsachenuniversum vorzuknallen. In unserem Text beteiligt sich Wadding an dem Streit zwar nicht $(\$ 171)$, der Konflikt hat sich aber auch nicht in dem Streit um den Begriff, objektive Wahrheit' erschöpft. So nicht seinesgleichen hat dieser Streit nur auf der symbolischen Ebene, aus begriffsgeschichtlicher Sicht.

Was daraus folgt, wenn von dem idealistischen Ansatz die Anwendung auf die Scientia Media gemacht wird, bei dem Schritt also, der bei Wadding selber unterbleibt, erfährt man bei dessen mehrfach erwähntem Enkelschüler González de Santalla:

Bevor Er die betreffende Gnadenhilfe erteilt, hat Gott, in seiner Eigenschaft als dessen rein physisches Prinzip, dasjenige Scientia Media-Szenario festgelegt, das in Übereinstimmung mit der freien Entscheidung der Kreatur ist. Daß Gottes Verstand vor Erteilung der Gnadenhilfe das Scientia Media-Szenario festlegt, nicht

57. Historisches Wörterbuch der Philosophie s.v. ,Wahrheit, objektive', hgg. von J. Ritter / K. Gründer / G. Gabriel, Basel 1971-2004, Bd. 12, 154-63; J. SchmutZ: „Sebastián Izquierdo“, in: Sur la Science divine, hgg. von J.Ch. Bardout / O. Boulnois, Paris 2002, 412-35; Ders.: „Der Einfluß der böhmischen Jesuitenphilosophie auf Bernard Bolzanos Wissenschaftslehre“, in Bohemia Jesuitica 1556-2006, hgg. von P. \& R. Cemus, Prag 2010, 603-15. 
frei, sondern notwendig und so, daß Gott sich dabei nach der freien Entscheidung des kreatürlichen Willens richtet, scheint evident: Die Scientia Media liegt jedem freien Dekret Gottes voraus und existiert in Gott, auch wenn der kreatürliche Wille, über dessen freie Handlung dieses Wissen bedingungsweise eine Aussage trifft, niemals existieren sollte. Auch wenn Gott von ewigkeither entschieden hätte, gar nichts zu erschaffen, wüßte Er ja nichtsdestoweniger, wie Peter sich verhalten würde, wenn er erschaffen würde und, auf der Basis der Indifferenz gegenüber A und nonA, diese indifferente Gnadenhilfe bekäme. In diesem Fall wäre es nun nicht der kreatürliche Wille, der das Scientia Media-Szenario festlegt, denn etwas, das nicht existiert, hat auch keine Eigenschaften, und der kreatürliche Wille wäre in diesem Fall nichtexistent. Außerdem liegt es nur insofern bei dem kreatürlichen Willen, Gottes Wissen festzulegen, als es bei ihm liegt, sich handelnderweise selber festzulegen. Über Gottes Wissen hat die Kreatur nämlich nicht unmittelbar die freie Verfügung, sondern nur insofern, als ihr die Handlung freisteht, welche von dem Wissen vorausgesetzt wird. Ein kreatürlicher Wille jedoch, der niemals und nirgendwo existiert, ist nicht in der Lage, sich handelnderweise festzulegen: also auch nicht, Gottes Wissen festzulegen. Wenn der kreatürliche Wille in diesem Fall also nicht das Prinzip ist, welches das Scientia Media-Szenario festlegt, dann ist folglich ganz allein Gottes Verstand dieses Prinzip, nicht zwar, indem er das Szenario frei wählt, sondern so, daß er mit Notwendigkeit dahin tendiert (non quidem libere eligendo scientiam, sed necessario erumpendo in illam). Einmal da, wird dieses Szenario in Übereinstimmung mit der freien Entscheidung sein, die der kreatürliche Wille treffen würde, wenn ihm die Gnadenhilfe zuteilwürde... Eigentlich ist es nicht der kreatürliche Wille, der das Scientia Media-Szenario festlegt. Das wird von ihm nur gesagt, weil er die objektive Bedingung stellt, unter der Gott aus sich heraus das Szenario festlegt. Einzig und allein Gottes Verstand ist es, der das Scientia Media-Szenario festlegt, allerdings eben so, daß Er sich dabei nach unserer freien Entscheidung richtet... ${ }^{8}$

Also selbst die Scientia Media-Hypothese hat mit der Autarkie von Gottes Wissen nicht endgültig gebrochen. Der Idealismus legt es darauf an, die Autarkie zu restaurieren. In dieser Absicht Gottes Verstand eine Art Instinkt beizulegen („necessario erumpendo"), ist eine Verlegenheitsformel, aber doch aufschlußreich. Auf das Problem der eigentümlich passiv gefärbten , aktiven' Indifferenz, das uns an Waddings Gott beschäftigt hat, fällt dadurch zusätzlich Licht.

Waddings Flucht in den Idealismus hat noch einen weiteren Aspekt. Im Zuge der Eliminierung des creatura rebellis-Risikos lehnt er das von ihm zu einer, metaphysischen' Notwendigkeit bzw. Unmöglichkeit verschärfte statistische Paradigma der moralischen Notwendigkeit an diejenige Notwendigkeit an, mit welcher ein Dreieck die Winkelsumme von $180^{\circ}$ hat. Zwischen dem höchsten Grad, in dem ein Risiko eliminierbar ist, und den ewigen Wahrheiten liegt für ihn keine Kluft. Das

58. González de Santalla, Theologia Scholastica: De praedestinatione 12, 13-14, t.2, 269b/70a. 
schließt es aus, daß die ewigen Wahrheiten in einen platonischen Geltungshimmel projiziert sind. Durch den Monotheismus sind sie für Kontingenz aufgeschlossen. So brutal wie bei Descartes, für den die ewigen Wahrheiten den Gesetzen gleichen, die ein König gibt, spreizt sich der Monotheismus hier allerdings nicht auf. Wadding ist ein Pionier jenes seltsamen Glasperlenspiels mit den existenzial interpretierten Modalitäten ,notwendig', ,möglich', ,unmöglich', das es fertiggebracht hat, die ewigen Wahrheiten dem Monotheismus nicht nur zu unterwerfen, sondern auf diese Weise Gott und Kreatur zu solidarisieren. Diese Modalontologie kündigt die traditionelle Alternative von Essentialismus und Nominalismus auf. Wadding unterschreibt den ontotheologischen Konnexionismus $(\$ \$ 71,254)$. In dem über Jahrhunderte geführten metaphysischen Disput um die Wurzel der Wesensmöglichkeiten der Dinge, in der sog. Querelle des possibles, hat ein Gelehrter unserer Tage unlängst den Konnexionismus als eine der großen Antwortoptionen identifiziert und zuerst beschrieben. Weder präzise über seinen Verstand noch über seine Allmacht wäre Gott danach zu dem Reich der ewigen Wahrheiten in Beziehung zu setzen, sondern über seine eigene Wesenheit. Dadurch sind sie „konstituiert".59 "La métaphysique de Pérez“, schreibt Jacob Schmutz, „puisée selon ses propres dires au plus profond de l'esprit d'Augustin, visait à restaurer la souveraineté de Dieu sur les possibles, par un processus de quasi-identification entre la toute-puissance et les possibles: c'est la toute-puissance divine qui est possibilitas possibilium, impossibilitas impossibilium et necessitas necessariorum. Tout ce que l'essence de Dieu peut répresenter est possible, ce qu' elle ne peut représenter est impossible, et tout énoncé vrai et nécessaire consiste à faire un énoncé sur la vérité première et immuable qu'est Dieu lui-même. Dieu est ainsi conçu comme un parfait miroir ou représentation des possibles..."60 Anstatt die Notwendigkeit der logischen Implikationsverhältnisse zwischen den Wesensmöglichkeiten und deren Negaten im Interesse des „nominalistischen Willkürgottes“ (Blumenberg) zu zersetzen, wird sie vom Konnexionismus so strikt als ein Reflex der Notwendigkeit aufgefaßt, mit der Gott existiert, daß in dem hypothetischen Fall, daß das verächtlichste Geschöpf, die Fliege, existenzunfähig wäre, diese Unmöglichkeit unmittelbar auf den Schöpfer durchschlägt. Gott selber wäre dann aufgehoben. ${ }^{61}$

59. Schmutz, „Dieu est l'idée“, 517-23.

6o. Ders., „Les innovations conceptuelles de la métaphysique espagnole post-suarézienne“, 67. Eine von Schmutz' Forschungen angeregte vortreffliche Dissertation schlägt dafür die Bezeichnung „Truthmaker Theism“ vor: BRIAN EMBry: Truth and Truthmaking in 17th-Century Scholasticism 7, 3, unv. Diss. phil. University of Toronto 2015, 259-75.

61. J. Schmutz: „Bartolomeo Mastri et la mouche“, in Rem in seipsa cernere. Saggi sul pensiero filosofico di Bartolomeo Mastri (1602-1673), hg. von M. Forlivesi, Padua 2006, 469-520, hier besonders 472-97. 
Die Unterwerfung des paganen Essentialismus unter das Dependenzdenken des christlichen Monotheismus riskiert hier in voller Bewußtheit den hypothetischen Atheismus. Anhand eines anderen Nachlaßwerks, desjenigen von Waddings jüngerem Kollegen Antonio Perez, und unter Zuziehung weiterer handschriftlicher Quellen hat Schmutz von dem System des Konnexionismus gezeigt, eine wie verbreitete metaphysische Option es im 17. Jahrhundert gewesen ist. ${ }^{62}$ Den Refrain von deren populärer Version hat man aus der frechen Mystik des Cherubinischen Wandersmanns im Ohr: ${ }^{63}$

Ich weiß, daß ohne mich Gott nicht ein Nu kann leben;

Werd ich zunicht, er muß von Not den Geist aufgeben.

\section{Diskursarchäologie}

Ob diese Concordia zwischen Skylla und Charybdis nicht doch Schiffbruch erleidet, steht auf einem anderen Blatt. Indessen wird man den Jesuiten des 17. Jhs. zubilligen, daß sie sich auf schwindelerregende Wirkungen nicht nur bei der Ausmalung kirchlicher Innenräume verstanden haben.

Aus dem Gesagten, mehr noch aus den Hinweisen im Apparat, ist klar, daß es hermeneutisch hoffnungslos verfehlt wäre, immanent zu einem Verständnis dieses Texts gelangen zu wollen. Waddings Gedankengang zu referieren, ohne dabei fortlaufend auf den Schulhintergrund Bezug zu nehmen, wäre nur dilettantisch. Das ist bei scholastischen Texten fast immer so. Hier kommt erschwerend hinzu, daß der Schulhintergrund seinerseits auf dem derzeitigen Forschungsstand reichlich verworren ist, denn wir wissen immer noch viel zuwenig über den Lehrbetrieb an den Jesuitenkollegien. Es fehlt für die Jesuitenscholastik generell und speziell für eine so wichtige Ordensprovinz wie Kastilien synchron und diachron an der nötigen tabellarischen Übersicht. Für einzelne Anstalten gibt es zwar die Chronologie des Lehrpersonals. Wegen der, besonders in den unteren Rängen, starken Fluktuation geben die Informationen in der Zusammenstellung jedoch wenig her. Mit der Orientierung an der Institution muß sich die an den Personen verbinden. Die Lehre verknüpft Personen miteinander. Im Auge zu behalten sind erstens, synchron, die Kollegenschaften über diverse Anstalten, zweitens, diachron, über mehrere Generationen, die Schülerschaften. Letzteres ist nicht so sehr über ein Studium der Archive

62. Schmutz, La Querelle des possibles, 347-458.

63. Angelus Silesius: Cherubinischer Wandersmann 1, 8, Sämtliche poetische Werke, hg. von H.L. Held, München 1924, Bd. 3, 12. Schefflers Verbindungen zu den Jesuiten sind bekannt. Sie feierten seine Konversion zum katholischen Glauben 1653 als Triumph. 
als über das Studium der Texte zu ermitteln. Erst so, in der Filiation, werden die Schulzusammenhänge deutlich werden. Ohne deren Kenntnis bleibt das Studium der Jesuitenscholastik ein Stochern im Nebel.

Das Quellenstudium kann punktuell solche Zusammenhänge erhellen. Aus dem vorliegenden Manuskript geht insbesondere hervor, wessen theologischer Schüler der Autor war: der des Juan de Lugo (1583-1660), ${ }^{64}$ des späteren Kardinals, gnadentheologisch eines Kongruisten. ${ }^{65}$ Bevor er ans Collegio Romano berufen wurde, lehrte Lugo, von 1616 bis 1621, Dogmatik an dem Jesuitenkolleg von Valladolid. ${ }^{66}$ Damals haben, ebenfalls jeweils nach eigenem Zeugnis, eine Reihe der später berühmtesten Jesuitenscholastiker bei ihm studiert: Rodrigo de Arriaga (1592-1667), Juan Martínez de Ripalda (1594-1648) und Bernardo Aldrete (1594-1657). Lugo und Arriaga („le subtil Arriaga“) sind zwei Namen, die Pierre Bayle der Aufnahme in die Nomenklatur seines Dictionnaire historique et critique gewürdigt hat. Ripalda ist Gegenstand des längsten Artikels, der im Dictionnaire de Théologie Catholique einem Jesuitenscholastiker des 17. Jahrhunderts überhaupt gewidmet ist. Was Aldrete betrifft, haben wir gesehen, daß dieser - sonst weniger prominente - Name aufs engste, enger als die anderen, auch als Arriaga, ${ }^{67}$ in die Geschichte der Scientia Media-Hypothese verflochten ist. Das waren also Waddings Kommilitonen, mit dieser Bande ist er zeitlebens geistig im Austausch gewesen, die Ähnlichkeit zwischen ihnen ist entsprechend groß. Teils haben ihn die weiteren Karrierestationen mit ihnen wieder zusammengeführt, wie bei Aldrete, teils auf Dauer auseinandergebracht, wie bei Arriaga, aber das ist nebensächlich. Die Hauptsache ist das durch den vorliegenden Text dokumentierte Schulmilieu. In seiner personellen Zusammensetzung überschneidet es sich natürlich mit anderen

64. Selbstzeugnis Concordia fol. 277v: „[...] eminentissimo Joanne Cardinali de Lugo Magistro meo et Domino colendissimo $[\ldots]^{\text {“ }}$

65. Die Wirksamkeit der Gnadenhilfe sei dieser als Prädikat in actu primo beizulegen, also von ausstattungswegen: J. DE Lugo SJ.: Tractatus de gratia Dei disp. 7 sect. 2, Ms. BU Salamanca 956, fols. 241V-247v. Vgl. auch, aus späterer Zeit, J. DE LuGO: „De efficacia gratiae“ (Rom, 1.5.1631), in X.-M. Le BACHelet SJ.: Prédestination et grâce efficace. Controverses dans la Compagnie de Jésus au temps d'Aquaviva (1610-1613), Louvain 1931, t.2, 347-49, besonders 349 (vor „subsistendi consequentia“ ist das „non“ zu tilgen).

66. „Durante su permanencia en Valladolid, además del tratado De Sacramento Eucharistiae, explicó Lugo los tratados De Fide en 1617-18 y De Incarnatione en 1618-19. “ C. BACIERo SJ.: „Juan de Lugo y su autógrafo inédito de filosofía“, Miscelanea Comillas 47-48 (1967) 169-212, hier 211. Vgl. E. Olivares SJ.: „Juan de Lugo (1583-166o. Datos biográficos, sus escritos, estudios sobre su doctrina, bibliografía“, Archivo Teológico Granadino 47 (1984) 5-129.

67. Zu Arriaga sehr gut U.G. LeInsLE: Einführung in die scholastische Theologie, Paderborn 1995, 317ff.. 
solchen Milieus, namentlich dem des Pedro Hurtado de Mendoza, und außerdem muß man es sich generationenübergreifend vorstellen: Salamanca und sein Ambiente. ${ }^{68}$ Dieses Milieu ist nicht nur die Ursache der Ähnlichkeit, die man zwischen den Beteiligten findet. Es ist auch die Ursache dafür, daß bevorzugt untereinander disputiert wurde. Mit der Anzahl der Prämissen, die man teilte, stieg in der Scholastik - und sank nicht etwa - die Bereitschaft zum Disput. Einstige Kommilitonen disputierten nicht nur gegeneinander, sondern bemerkenswert häufig gegen ihren einstigen Professor, auch noch, als Lugo zum Kardinal erhoben war. Waddings Schulmilieu war in dieser Beziehung quicklebendig.

\section{Ein Unfall in der Gutenberggalaxie}

Wadding hat Pech gehabt. Da war einer Theologieprofessor an den wichtigsten Lehranstalten der Ordensprovinz Kastilien, hat bei seinem Tod ein veröffentlichungsreifes Manuskript zu demselben Thema wie Molinas Buch hinterlassen, aber dieses Manuskript bricht auf der Schwelle zur Scientia Media-Hypothese ab. Obwohl es trotzdem sogar schon die Ordenszensur passiert gehabt hat, obwohl auf dem Titelblatt des druckfertigen Tomus primus complectens quattuor libros schon Opus posthumum, quod nunc primum prodit steht, ist die Drucklegung dann doch unterblieben ${ }^{69}$ - warum, wissen wir nicht. Vermutlich ist es das Fehlen der ,Hauptsache', das den Autor, selbst bei den üppigen Budgets, die für Publikationen dieser Art damals zur Verfügung standen, nicht weniger als die Existenz in der Gutenberggalaxie gekostet hat. Vereinzelte Erwähnungen in der Literatur dienen dazu, der Möglichkeit einer Verwechslung mit seinem Cousin und Namensvetter vorzubeugen, dem Herausgeber der Werke des Johannes Duns Scotus. ${ }^{70}$ Daß Zedlers Großes Universal-Lexicon 1747 zu unserem Luke Wadding notiert, „ein Jesuite, der sich zu Madrid durch seine theologische Gelehrsamkeit und politische Klugheit

68. Dazu Knebel, „Salamanca und sein Ambiente“. Der bibliographische Teil dieser Studie ist durch die Verfügbarkeit der Texte über Google Books und der biographische durch die von Jacob Schmutz initiierte Online-Biobibliographie Scholasticon überholt.

69. „No obstante, creemos que permanece inédito, pues hemos tratado en vano de identificarlo en varias bibliotecas, y no se halla registrado en ningún indice bibliográfico entre las obras publicadas.“ MoráN, „El primer catedrático Jesuita“, 126.

70. Daß sich z.B. das „Lucae Wadingo“ in der Liste der Theologieprofessoren, denen der eitle Caramuel eines seiner Werke gewidmet hat (J. CARAmuel y Lobkowitz O.Cist.: Cursus moralis philosophicus theologicus, sive Theologia fundamentalis moralis, Frankfurt a.M. 1652, 27), tatsächlich (Schmutz, „Was Duns Scotus a Voluntarist? Juan Caramuel Lobkowitz against the Bratislava Franciscans“, 150) auf den Franziskaner bezieht, ist nicht sicher. 
in großes Ansehen gesetzet"71 - dem Verfasser muß Piñas Nachruf vorgelegen haben -, spricht mehr für die Qualität dieses Lexikons als dafür, daß von irgendeiner Seite noch Bedarf an der Information bestanden hätte. In Jöchers Gelehrtenlexikon, vier Jahre später, ist auf sie verzichtet. Um die Mitte des 19. Jahrhunderts war Wadding so gründlich vergessen, daß er nicht einmal mehr in der Nomenklatur (8-9000 Namen) der siebenbändigen Bibliothèque des écrivains de la Compagnie de Jésus figurierte.

Aus Hogans biographischer Skizze wissen wir, daß unser Wadding es dabei gewissermaßen doch in die Gutenberggalaxie geschafft hat, nur leider so, daß sein Anteil an der betreffenden Publikation nicht mehr zu ermitteln ist. Er kann sich auf Redaktionelles beschränken, aber auch beträchtlich sein. Um die Zeit seiner Exegetikprofessur in Salamanca muß Wadding sich bereiterklärt haben, ein gelehrtes Werk der wüstesten Art in die Gutenberggalaxie zu befördern. Ein Ordensgenosse, Freund und Verwandter, Paul Sherlog oder Sherlock (1595-1646), hatte den Einfall gehabt, die Urgeschichte der Welt zu schreiben, darüber war er verstorben. Der Verleger war erleichtert, als Wadding tatsächlich die ersten zwei Bücher des Monstrums lieferte. Das pompöse Dankschreiben steht im Vorspann zu dem 1651 glücklich erschienenen Folianten. Hogan zitiert daraus. Die Idee dieser Antiquitatum Hebraicarum Dioptra war damals an sich nicht so bizarr. Von den esoterischen Kreisen abgesehen, in denen man sich vielfach solchen Spekulationen hingab, besitzen wir auch aus dem kirchlichen Establishment großangelegte Versuche dieser Art, etwa die Origines sacrae des anglikanischen Bischofs Edward Stillingfleet (1635-99). In der Gesellschaft Jesu war Athanasius Kircher (1602-80) für die Produktion solcher Folianten zuständig, die mit den scholastischen Folianten aber auch nicht die leiseste Ähnlichkeit haben. Bei der Dioptra war der Gedanke ein anderer, nämlich im Gegenteil, es müsse möglich sein, das Genre der Genesiskommentare mit dem scholastischen Traktat De creatione zu verbinden. Scholastik und Geschichte sollten nicht zwei getrennte Welten bleiben. Sherlog hatte bewiesen, daß er der Mann dafür war. Er hat den Impuls zur Geschichtsschreibung der Scientia Media-Hypothese gegeben, in der Beziehung war er der Wegbereiter für Waddings Schüler Henao. Nur war im Fall der Dioptra das Ergebnis ein kruder Mischmasch. Selbst die Art von Superstition wird bedient, welche das Spanien der Inquisition so kühl abgeschüttelt hat: Hexenritt, Hexensabbat, Teufelsbuhlschaft. Amerika und Fernrohr kommen natürlich auch vor. Hogans vorsichtig geäußerte Vermutung, das zweite Buch stamme aus Waddings Feder, ist mit Sicherheit unzutreffend. ${ }^{72}$

71. Zedlers Großes Universal-Lexicon Bd. 52, Leipzig 1747, 390.

72. Nicht nur, daß nur aus der noch zu Sherlogs Lebzeiten erschienenen Literatur zitiert wird, gerade in dem zweiten Buch zitiert Sherlog sich auch mehrfach (24ob, 331a, 338a) selbst. 
Nur die Exkurse zur scholastischen Gotteslehre im ersten Buch stechen von dem Stil, in dem beide Bücher sonst abgefaßt sind, hinreichend stark ab, um es zumindest möglich erscheinen zu lassen, daß hier von außen eingegriffen ist. Doch auch das ist unsicher, denn Sherlog war zwar Exegetiker, aber scholastisch bestens versiert. Hurtado de Mendoza hat ihn seinen Lieblingsschüler genannt. ${ }^{73}$ Weder der heterogene Eindruck, welchen das erste Buch macht, noch der Umstand gewisser dogmatischer Übereinstimmungen mit Waddings hier ediertem Text, auf die im Apparat hingewiesen ist, würde es rechtfertigen, die scholastisch interessanten Partien Sherlog abzusprechen. Um das theologische Profil eines ansonsten bisher unbekannten Autors kennenzulernen, ist der Eifer, den Wadding auf das Einzige verwandt hat, was von ihm je im Druck erschienen ist, auch so aber natürlich nicht gering zu veranschlagen.

Hier interessieren die Umstände, unter denen Wadding mit seinem eigenen Werk in der Gutenberggalaxie verunglückt ist. Das gebrachte Zeitopfer ist nicht der einzig erwähnenswerte.

Wie erschien ein Buch? Der Schlüssel zu dem institutionellen Kontext der vorgesehenen Veröffentlichung ist das zum Abschluß eines Begutachtungsverfahrens vorgeschriebene formelle Ordensimprimatur durch den Provinzial. In dem vorliegenden Fall ist die Kopie desselben zusammen mit dem Manuskript überliefert. Ausgefertigt ist es von Pedro Pimentel (1594-1658), von 1650 bis 1653 Provinzial von Kastilien. Das Imprimatur, sonst nicht weiter mitteilsam, datiert aus Salamanca vom 14. Mai $1653 .^{74}$

Es liegt auf der Hand, daß in einer Provinz mit zwei so hervorragenden Anstalten wie Salamanca und Valladolid diese unmittelbar Rom untergebene amtliche Stellung, weit über ihre satzungsgemäßen Befugnisse hinaus, einflußreich war. Funktionär ja, aber auf die Person kam es an. Pimentel, ein Mann aristokratischer Herkunft, war als Theologe Insider des gekennzeichneten erweiterten Milieus. Bei der internationalen Arbeitsteilung, die auf dem Höhepunkt des europäischen

73. Knebel, „Salamanca und sein Ambiente“, 456. Vgl. P. Sherlog SJ.: Antiquitatum Hebraicarum Dioptra, in duos libros tributa. Opus posthumum, Lyon 1651, 51a („, [...] noster olim Praeceptor Petrus Hurtado de Mendoca [... $]^{\prime \prime)}$.

74. „Facultas Patris Provincialis Societatis Iesu in Provincia Castellana. - Petrus Pimentel, Provincialis Societatis Iesu in Provincia Castellana, potestate ad id mihi facta a R. admodum P. Goswino Nickel eiusdem Societatis Praeposito Generali, facultatem do, ut opus inscriptum Concordia divinorum, et humanorum a Patre Luca Wadingo nostrae Societatis Theologo, Sacraeque Theologiae professore, compositum et eiusdem Societatis gravium doctorumque hominum iudicio approbatum, typis mandaretur. In quorum fidem has litteras manu nostra subscriptas, et sigillo nostro munitas dedimus Salmanticae die 14. Maii an. 1653. - [gez.] Petrus Pimentel.“ fol. 4r. - In ihrer Beschreibung des Ms. 156 lesen Lilao Franca und Castrillo Gonzalez irrtümlich: „1643“. Korrekt Morán, „El primer catedrático Jesuita“, 126. 
Barock innerhalb der Gesellschaft Jesu zu beobachten war, war ein Provinzial damals kulturpolitisch eine Schlüsselfigur. Nicht von ungefähr gab Pascal seiner Denunziation der Jesuitenmoral die Form von Briefen ,an einen Provinzial“.

Das Wirken eines Provinzials ist bibliographisch nachverfolgbar. Wenn man das Imprimatur für Waddings Text in die Reihe gleichartiger Vorgänge einordnet, ergibt die zeitliche Abfolge der Akten eine pipeline. In seiner Amtszeit ${ }^{75}$ für veröffentlichungswürdig hielt Pimentel:

Salamanca, 4.7.1651: Bernardo Aldrete SJ.: De Mysterio Incarnationis, 2 Bde. Valladolid, 18.2.1653: Gabriel de Henao SJ.: Scientia Media historice propugnata. Salamanca, 14.5.1653: Richard Lynch SJ.: Cursus philosophicus, 3 Bde.

Valladolid, 27.9.1653: Antonio Bernaldo de Quirós SJ.: Disputationes theologicae in Primam partem D. Thomae.

Valladolid, 30.9.1653: Gabriel de Henao SJ.: Tractatio theologica scholastica et moralis de Eucharistiae Sacramento.

Valladolid, 1.10.1653: Antonio de Escobar y Mendoza SJ.: Theologia moralis, Bde. $4-7 .^{76}$

Der Tenor der Liste ist klar: alles großformatige Werke von Professoren aus Salamanca und Valladolid, überwiegend Scholastik, darunter auch Scientia Media-Literatur (Aldrete, Henao, Quirós). Diese Werke sind zügig, meist binnen Jahresfrist, erschienen, allesamt in demselben Verlag, bei Borde, Arnaud \& Rigaud in Lyon. ${ }^{77}$ Sie gehören zum Fundus der Hochschul- und Klosterbibliotheken quer durch Europa. So gut, wie seine Schüler in der Liste vertreten sind (Lynch, Henao), hätte Wadding perfekt ins Bild gepaßt. An der Ernsthaftigkeit der Veröffentlichungsabsicht gibt es so gesehen keinen Zweifel. Nachdenklich macht nur der Umstand, daß das Imprimatur für Wadding und das für Lynch unter demselben Datum ausgestellt sind.

75. Die Lücke 1652 erklärt sich daraus, daß Pimentel in dem Jahr eine Zeitlang seinen Amtsgeschäften nicht hat nachgehen können: Er war auf Reisen, zeitweilig auch in französischer Gefangenschaft. Vgl. A. Astrain SJ.: Historia de la compañía de Jesús en la asistencia de España, Madrid 1920, t.6, 2.

76. Zu diesem Imprimatur für Bände, die damals noch gar nicht vorlagen, vgl. K. WEIss: P. Antonio de Escobar y Mendoza als Moraltheologe in Pascals Beleuchtung und im Lichte der Wahrheit, Freiburg i. Br. 1911, 35f. Pimentel hat auch die Edition des teils kastilianischen, teils römischen Nachlasses von Antonio Perez in die Wege geleitet: (P. Bermudez SJ.:) „Ratio operis“, in A. Perez, In Primam partem D. Thomae, Rom 1656, A4r.

77. Dazu, wie in Lyon die Foliantenproduktion durch joint venture bewältigt wurde, vgl. C. PÉLIGRY: „Les Editeurs lyonnais et le marché espagnol au XVI ${ }^{\mathrm{e}}$ et XVII ${ }^{\mathrm{e}}$ siècles“, in: Livre et lecture en Espagne et en France sous l'Ancien Régime. Colloque de la Casa de Velázquez, Paris 1981, 85-95. 
Lynch, ein Ire aus Galway, war der Herausgeber des Manuskripts. Den Spaniern imponierte sein humanistischer touch.$^{78}$ Piñas Nachruf, die Übersetzung rührt von ihm her, hat er allerdings leider nicht dadurch abgerundet, daß er etwas aus der Schule plauderte, sondern mit irischem Patriotismus. Wechselseitig war man über den Stand seiner literarischen Pläne im Bilde gewesen. Aus dem Manuskript erfahren wir, daß der damals kaum Vierzigjährige sich bereits mit der Absicht trug, seinem dreibändigen Philosophiekurs, der 1654 erschien, auch noch einen Theologiekurs folgen zu lassen. ${ }^{79}$ Für ein so ehrgeiziges Projekt gab es zu der Zeit nur das Vorbild Arriaga. Obwohl Lynch in Salamanca Karriere gemacht hat, ist daraus nur zum kleineren Teil etwas geworden. ${ }^{80}$

Die Koinzidenz des Imprimatur läßt vermuten, daß von Lynch ein Paket geschnürt war. Was seine Herausgeberschaft anbelangt, konnte er dem Provinzial gegenüber mit der Pflege der eingespielten und für die Jesuiten in Kastilien so enorm wichtigen Geschäftsbeziehung zu dem Lyoner Verlagshaus argumentieren. Die zum Dank dafür, daß er es übernommen hatte, Sherlogs Buchprojekt zu retten, an Wadding noch eben (1651) öffentlich ergangene Einladung, seine eigenen Madrider rechtsphilosophischen Vorlesungen zu verlegen, ${ }^{81}$ war nicht alltäglich.

Der Provinzial ist auf Lynchs Vorschlag eingegangen. Das diesem für seinen Philosophiekurs erteilte Imprimatur war mehr als eine Routineangelegenheit. An diesem Philosophiekurs ${ }^{82}$ scheint Pimentel persönlich interessiert gewesen zu sein. Genau die Kurskorrektur, die er markiert, die vorsichtige Abkehr von dem "corrente nominalista", 83 dem bis dahin die Philosophiefolianten der spanischen Jesuitenschule ausnahmslos zugearbeitet hatten, ${ }^{84}$ muß Pimentel befürwortet haben. Denn in demselben Jahr hat er sich noch für einen anderen, weniger umfangreichen, Philosophiekurs mit ähnlicher Tendenz eingesetzt. In dem Fall war der Verfasser, Juan Juaniz y Echalaz - ein langjähriger (1632-45) Logikprofessor

78. E. Esperabé Arteaga: Historia pragmática é interna de la Universidad de Salamanca, Salamanca 1917, t.2, 577; MoRÁN, „El primer catedrático Jesuita“, 103-05.

79. „P. Ricardus Lynceus [...] in Theologia, quam totam praelo dare cogitat [...]“ Concordia fol. 225r.

8o. Sein theologischer Nachlaß in der BU Salamanca bei Morán, „El primer catedrático Jesuita“, 140-41.

81. Sherlog, Antiquitatum Hebraicarum Dioptra, a2r/v.

82. $\mathrm{Zu}$ verschiedenen Aspekten die Arbeiten von Piero Di Vona, John P. Doyle und Stefan Meier-Oeser bei Knebel, „Salamanca und sein Ambiente“, 451.

83. E. Caruso: Pedro Hurtado de Mendoza e la rinascita del nominalismo nella Scolastica del Seicento, Florenz 1979.

84. Vgl. Knebel, Suarezismus, 74. 
in Salamanca, inzwischen aber schon Prälat, Bischof in Navarra -, kein Jesuit und hatte folglich kein Ordensimprimatur nötig. Pimentels Unterstützung für ihn war keine in direkt amtlicher Eigenschaft, sondern bestand in einem blumigen Grußwort (Valladolid, 25.7.1653), das im Vorspann zu dem Werk abgedruckt ist. Auch dieses Werk ist dann in demselben Verlag erschienen.

So günstig, wie institutionell die Verhältnisse lagen, wundert es also, daß Waddings Manuskript liegengeblieben ist. Das Fehlen der ,Hauptsache’ wäre für sich genommen nicht Grund genug. Beispielsweise war die Gotteslehre des Francisco de Lugo, der das Mißgeschick gehabt hatte, auf dem Atlantik durch einen Piratenüberfall sein Manuskript zur Scientia Media-Hypothese zu verlieren, trotzdem 1647 bei dem Verlag in Lyon herausgekommen. Aber Waddings Manuskript hat, verglichen damit, was bei den spanischen Jesuiten damals sonst für veröffentlichungswürdig galt, unleugbar Schwächen. Das hat dem Provinzial auch bei oberflächlichem Blättern unmöglich verborgen bleiben können.

Von den gebotenen Textproben sei dem Leser versichert, daß sie durch die Übersetzung nicht gewonnen haben. Man liest scholastische Texte wirklich besser auf Lateinisch. Dennoch ist auch an dem Original eine gewisse Schwerfälligkeit nicht zu verkennen. Das liegt nicht an dem logischen Jargon, dessen Metasprachlichkeit an dem disputativen Habitus scholastischer Texte von jemandem, der daran nicht gewöhnt ist, verwirrend und manchmal abstoßend gefunden wird. Dieser Jargon ist hier keineswegs penetrant. Was dem Text fehlt, ist der Schwung, die muntere Diskursivität, die bei den literarischen Erzeugnissen der Jesuitenscholastik in der Regel die Lektüre erquickend macht und vor allem auch die Merkfähigkeit des Lesers nicht überanstrengt. Von der Elastizität von Suárez' Stil, von der ruhigen Klarheit des Ruiz de Montoya hat Wadding nichts. Der Autor bohrt sich förmlich in seinen Gegenstand hinein. Der Typ Strenge des Denkens, welchen der Text repräsentiert, zeichnet sich weniger durch die logische Schärfe der Gedankenführung aus als durch die Konstruktion von Strukturzusammenhängen und Fundierungsverhältnissen. Alles wird sozusagen nur immer fester gezurrt. Den Zusammenhang der fortlaufend unterschiedenen und aufeinander bezogenen dialektischen Momente artikuliert der geübte Thomist vornehmlich mit den Mitteln der Akt-Potenz-Ontologie. An den fälligen Distinktionen wird schon schwer geschleppt. Daß der Autor freigiebig an Beispielen wäre, um seine Distinktionen zu erläutern, wird man nicht sagen. Selten wird das clair obscur der Abstraktion auch nur von einer Analogie erhellt. Der parenthesenreiche, ungewöhnlich verschachtelte Satzbau verstärkt den Eindruck, es mit Spinnweb zu tun zu haben. Die Sätze sind vollgestopft mit Infinitivkonstruktionen und Umstandsbestimmungen. Waddings Stil, möchte man fast sagen, bestätigt die übelsten Vorurteile gegen das scholastische Latein. 
$\mathrm{Zu}$ konstatieren ist ein Abbau der disputativen Struktur. Diese verleiht den scholastischen Texten im allgemeinen ihre große Übersichtlichkeit. Zwar ist schon die Quästionenform des 14. Jhs. um einiges komplexer als das klassische Vorbild der Summa theologica, und die Disputation der posttridentinischen Scholastik kann sehr ausladend sein. Trotzdem vertritt in den Cursus philosophici und Cursus theologici die disputatio regelmäßig die Hauptebene der inneren Gliederung. An diesem Standard gemessen verzichten die Texte der späteren Jesuitentheologie häufig auf Übersichtlichtlichkeit. Das Denken bricht aus einer Fortbewegung aus, deren Gang zwischen Behauptung und Widerlegung abwechselt. Das kann ein Vorteil sein, muß es aber nicht. Breite und Weitschweifigkeit werden so begünstigt.

In Waddings Fall wird zwar fleißig von These zu These fortgeschritten, das Argument kommt trotzdem nicht recht vom Fleck. Der Opponent ist stets präsent, er erhebt Einwände, doch es sind überwiegend Selbsteinwände. Wo zu ihrer Lösung einmal der geschulte Logiker gefragt wäre, wird der Ton leicht gereizt (\$271). Wadding macht sich überhaupt wenig aus den - könnte man sagen - scholastischen Tugenden. Nur ausnahmsweise wird das, was ihn von diesem oder jenem Ordensgenossen trennt, deutlich herausgestellt. Lieber gibt er sich, womit man naturgemäß wenig Anstoß erregt, als patristisch und in Thomas von Aquin versierter Kontroverstheologe. Kompositorisch wirkt das Ganze ungleichmäßig. Das Niveau des hier edierten Texts schwankt beträchtlich. Auf anspruchsvolle Kapitel folgen in derselben Breite scholastische Trivialitäten. Anscheinend hat der Autor $\mathrm{zu}$ verschiedenen Zeiten seiner Lehrtätigkeit und zu unterschiedlichen Zwecken entstandene Papiere kompiliert.

Den Publikationsgepflogenheiten des Ordens hat Waddings Text also nur unvollkommen entsprochen. Die naheliegende Vermutung, daß für einen Kulturpolitiker ein Text der zäheren Art doch eher zweite Wahl war, steht unter einem doppelten Vorbehalt. Es bedürfte der Archivstudien, um sicherzugehen, daß normalerweise ein erteiltes Imprimatur zur Drucklegung geführt hat, und um zu klären, ob es überhaupt bei dem Provinzial gelegen hätte, die Verhandlungen mit dem Verlag zu führen. Unter der Annahme jedoch, daß die Initiative für den nächsten Schritt bei ihm gelegen hätte, ist es plausibel, daß er die Sache auf die lange Bank geschoben hat. Aus Sicht des Provinzials mag das erteilte Imprimatur sehr wohl eben nur Teil eines Handels gewesen sein, eine sowohl Lynch als auch Lyon erwiesene Höflichkeit. Denn ein Motiv, sich vor den Karren der Irish connection spannen zu lassen, hatte der Kastilianer nicht. 


\section{Zur Edition}

Es folgt die Teiledition des Manuskripts Concordia divinorum et humanarum, BU Salamanca 156. Die vier Bücher, die es enthält, sind überschrieben: I. De Divinarum perfectionum, quae inter se repugnare videntur, concordia (37 Kapitel). II. De divinarum determinationum ad unum, si omnino antecedentes sint, falsa concordia cum humana libertate (73 Kapitel). - III. De concordia libertatis cum divina determinatione ad unum, ineunda per suppositionem consequentem (37 Kapitel). - IV. De suppositionis consequentis quidditate, de scientiae futurorum contingentium, praesertim absolutorum, natura et concordia cum humana libertate (34 Kapitel). Gegenstand der Teiledition ist das vierte Buch (fols. 797-914).

Den allemal schwierigen Entschluß zu einer Teiledition hat der Umstand, daß es die Edition des Teils eines Torsos ist, eher erleichtert. Übrigens ist Fertiges darum nicht weniger fertig, weil weitere Systemteile noch hätten folgen sollen. Der für die Teiledition gewählte Titel Tractatus de scientia Dei futurorum contingentium stammt von dem Herausgeber. Die Gründe dafür sind einleitend dargelegt.

Philologisch ist zu bemerken, daß zur Textkonstitution ausschließlich dasjenige Manuskript herangezogen worden ist, das der Herausgeber Lynch seinerzeit für die Drucklegung vorgesehen hatte. Es ist eine von anderer Hand durchkorrigierte Reinschrift, die vermutlich erst der Herausgeber hat anfertigen lassen. Stellenweise hat er sie durch längere Marginalien, über deren Status er nichts mitteilt, ergänzt. Eine andere, unvollständige Version (BU Salamanca 155) ist nicht benutzt worden. Damit ist nicht gesagt, daß sie im Hinblick auf die erforderlichen Konjekturen nicht von Interesse wäre. Der hier edierte Text beruht also nicht auf der Version, welche dem Begutachtungsverfahren zugrundegelegen hatte. Flüchtigkeitsfehler haben sich, auch von dem Herausgeber unbemerkt, eingeschlichen.

Die Herausforderung für die Textkonstitution lag jedoch weniger in den hin und wieder erforderlichen Konjekturen als darin, daß die Textmasse in Kapitel und unterhalb dieser Ebene nur grob in Paragraphen eingeteilt ist. Die erwähnten stilistischen Eigenheiten des Verfassers erhöhen die Schwierigkeit, welche sich daraus ergibt. Die Paragrapheneinteilung ist nach Möglichkeit beibehalten. Bis auf die Kennzeichnung der wörtlichen Zitate stammt die gesamte übrige Textartikulation, von der Interpunktion und allen Arten der Auszeichnung über die Absätze bis zur Paragraphenzählung, vom Herausgeber. Bei Aufzählungen sowie bei Literaturangaben sind die Ordinalzahlen im Ablativ nie ausgeschrieben, sondern als Ziffern mit Exponent gegeben. Runde Klammern markieren Parenthesen, eckige Klammern sind Zusätze des Herausgebers. In Anbetracht der nur geringen Anzahl von Konjekturen ist auf die in historisch-kritischen Ausgaben sonst übliche Trennung der Apparate verzichtet. Zitate aus der Antike und aus Thomas von Aquin sind nicht eigens nachgewiesen. Sonst ist dort, wo die Stellenangabe nicht schon aus dem Text 
hervorgeht, außer der Seite der benutzten Ausgabe auch die innere Gliederung angegeben. Der Index scholasticus gibt über die vom Verfasser, nicht über die vom Herausgeber, zitierte Literatur Auskunft.

Interpunktion und Kursivierung verstehen sich als Vorschlag, als Lesehilfe, und unterliegen durchgängig der Kritik. Der philosophische Mediävist weiß, daß auch noch so vieles Kollationieren dem Herausgeber eine Entscheidung nicht abnimmt: die Zeichensetzung. Die sorgfältig vermerkte Konjektur, die Abweichung von dem überlieferten Wortlaut, ist harmlos verglichen mit der dem Herausgeber unablässig abverlangten Entscheidung über Punkt und Komma. In der fertigen Edition gibt über das So-und-nicht-anders der Interpunktion kein kritischer Apparat Rechenschaft, und vernünftigerweise kann dergleichen auch nicht verlangt werden. Jede Edition ist ein Konstrukt, in dem ältesten technischen Sinn von constructio, aber je philosophischer der zu edierende Text ist, desto größer ist auch das Risiko, daß falsch gesetzte Zäsuren Schaden anrichten. Davon, wie sie den Text abteilt und akzentuiert, hängt es ab, ob eine Edition gelungen ist. Das ist auch eine Frage des Mehr und Weniger. Während ein Zuviel schlimmstenfalls Unsinn produziert, bleibt ein Zuwenig dem Text den Schlüssel zu seinem Verständnis schuldig.

Die vorliegende Edition ist sich bewußt, daß sie in dieser Beziehung eher etwas zuviel des Guten tut. Die filigrane Architektur dieser spätscholastischen Gebrauchsliteratur ist auch im Schriftbild artikulationsbedürftig. Die dieser Textsorte eigene Reflektiertheit, ihr Rhythmus, der daraus resultiert, sind dem heutigen Leser nicht durch dauernde Übung in Fleisch und Blut übergegangen. Sie vermitteln sich ihm daher nicht leicht ohne typographische Hilfen. Mit der Einschaltung von Absätzen allein ist es nicht getan. Bezogen auf den einzelnen Satz wird, um die logischen Abhängigkeiten zu klären, von Kommata reichlicher Gebrauch gemacht als sonst üblich. ${ }^{85}$ Damit nicht genug, wird der durch und durch distinktive Stil durch Kursivierung verdeutlicht. Natürlich kann sich der Herausgeber von Fall zu Fall irren. Er zieht es jedoch vor, dieses Risiko in Kauf zu nehmen, als dem Text ein hermetisches Äußeres zu belassen, von dem er überzeugt ist, daß der es nicht zu haben braucht.

85. Das dictum propositionis durch ein Komma abzuteilen, ist in der spanischen Scholastik des 17. Jhs. übrigens nicht unüblich gewesen. 



\section{Dossier: Luke Wadding, SJ}

\section{By Edmund Hogan SJ. (1831-1917)}

Father Luke Wadding, the son of Thomas Wadding and his wife, Mary Walsh, was first cousin of Father Ambrose Wadding, S.J., and Luke, the glory of the Franciscan Order. His father was Mayor of Waterford in 1596, and was a devoted Catholic. Hence an English official reports of him: „Thomas Wadding holds a chief office under the Crown, in the County of Waterford, and dwells in that city; a busy fellow, inclined to breed dissension, and allied in these parts. ${ }^{\text {2 }}$ Another, Bishop Lyon, writes: „the Mayor of Waterford, which is a great lawyer, carrieth the sword and rod, as I think he should do, for her Majesty; but he nor his sheriffs never came to church sithence he was Mayor nor sithence this reign, nor none of the citizens, men nor women, nor in any town or city throughout this Province" of Munster. Thomas was the father of three Jesuits, and, I think, even of four, as Thomas Wadding, alias Guadin, was born in Waterford, in 1594, entered the Society at Villagarcia, in Spain, in 1610, at the same time as Luke, ${ }^{3}$ was studying in the College of Valladolid in 1614, and died there on the 25th of November, 1615.

The mother of Luke and Thomas was aunt of Dr. Thomas Walsh, Archbishop of Cashel, and Father Richard Walsh, S.J., ${ }^{4}$ both sons of Robert Walsh; and I think, was aunt of three other Jesuits, namely, Richard (son of James), James, and Edward Walsh.

Luke Wadding was born in Waterford, in 1593; his early training was, no doubt, such as has been already described in the sketch of his cousin, Ambrose. About the year 1605, he was sent to the Irish College of Lisbon, where his brother Michael, and three other Waddings were studying about that time. ${ }^{5}$ From Lisbon he went to the

1. Der fünfte Artikel der Artikelfolge von E. Hogan SJ.: „Worthies of Waterford and Tipperary“, in: Journal of the Waterford and South East of Ireland Antiquarian Society 3 (1897) 55-71 (Stephen White SJ.), 119-34 (Paul Sherlog SJ.), 183-201 (Peter Wadding SJ.); 4 (1898) 3-8 (Ambrose Wadding SJ.), 9-13, 71-72 (Luke Wadding SJ.), 73-82 (Michael Wadding SJ.).

2. Cal. Of Carew MSS. Year 1596, p. 608.

3. Villagarcia Catalogus of 1611, in Archiv. Gen. S.J. Father Uriarte, a Spanish Jesuit, says that Thomas was Luke's brother, and entered the Society about the same time as Luke.

4. Cf. Spicilegium Ossoriense, vol. ii, p. 137.

5. Excerpts from the „Matricula“ of the Irish College of Lisbon, made in 1615, which were appended to the Catalogue of that year. 
Irish College of Salamanca, and his name is on its „List of Students who became Jesuits from 1600 to 1640 “, which the Rev. Dr. William McDonald, its Rector in 1876 , kindly copied for me.

In the year 1610 Luke Wadding entered the Jesuit Noviciate of Villagarcia, joining his brother Michael, who had entered the year before, and to be followed by his brother Thomas the year after. So there were four brothers, young Jesuits, and their cousin Ambrose all abroad in spite of the Penal Law: „No one henceforth shall send his children or relations beyond the seas for education. Those who are abroad must return within a year, under penalty of the confiscation of their property. No Papist shall dare to exercise the office of schoolmaster in the kingdom. "6

In 1611 Luke was teaching Latin in the Jesuit College of Montforte de Lemos. ${ }^{7}$ In 1617 he was in the Province of Castile, as we learn from an Irish catalogue of that year, in which figure 18 Jesuits, natives from Waterford, and 10 of Clonmel, 4 of Fethard, and 3 of Cashel.

In 1625, according to the catalogue of Valladolid College, Luke was on its staff, „was 32 years of age, and 15 years a Jesuit, had taught Humanities and Philosophy, had talents of a high order, and had distinguished himself in his studies; he had a great aptitude for teaching (optimum talentum ad docendum) and was fit to govern as superior." The Irish Catalogue of the same year merely says that he was in Spain. On the 18th of October, 1626, he took his degree of Professed Father of the Four Vows.

In 1633 he occupies a chair of Theology at Salamanca, „is 39 years old, and 22 years a Jesuit, and had been previously Professor of Philosophy."

In 1636 and 1639 he is at the College of Valladolid, and, I think, occupies the responsible post of „Prefect of Studies“; he is praised much for his success in his studies, his judgment, and talent for teaching and governing. ${ }^{9}$

In 1642 and 1645 he is fourth on the staff of the University of Salamanca, the celebrated Father Martin de Esparza being seventh. In the catalogues of that place in those years he is praised for his genius, prudence, judgment, varied learning, solid virtues, great capacity for teaching Theology, for transacting business matters and, the writer adds, „as I believe, for governing “.10

The Irish Jesuits were naturally anxious to secure such a man for his native land. On the 24 th of April, 1642, the Superior, Father Robert Nugent, wrote to Father General Vitelleschi: „Father John Lombard of Waterford is dead, Father Richard

6. Father D. Murphy's „Our Martyrs“, pp. 17, 18.

7. Spanish Catalogue of that year and place.

8. [Ibid.]

9. [Ibid.]

10. [Ibid.] [Wadding hat nicht an der Universität, sondern am Jesuitenkolleg gelehrt. SKK.] 
Walsh (Luke Wadding's first cousin) is dangerously ill; if he dies, only two remain in Waterford, of whom one is rather deaf, and the other deaf and blind. Wherefore it seems necessary to send us for the work in Waterford two Waterford men, either Father Peter Wadding, from Bohemia, or his brother, Luke, from Salamanca, and Father Paul Sherlog.“ On the 28th of February, 1643, he again writes: „I hope your Paternity will send to us from Spain Father Paul Sherlog and Father Luke Wadding, who are absolutely necessary in this Mission. "11

In 1643 , on the 28 th of June, the Supreme Council of Ireland wrote from Kilkenny „To Father Luke Wadding, of the Society of Jesus in Spain: Reverend Father, wee have sent back Father Talbot into Spaine, to render humble and hearty thanks to his Catholicke Majesty for the great affection he bears to our cause and Nacion; and we have authorized you, as by our severall commissions you shall finde, to agitate our affairs, as well at Courte as with the Prelates and Clergie of Spaine. We know your zeal to the cause and the care you have to your country"... ${ }^{12}$ According to Sir Richard Bellings, ${ }^{13}$ Father James Talbot, O.S.A., and Father Luke Wadding, Professor of Divinity at Salamanca, procured 20,000 crowns for the Irish cause.

In 1648, in addition to his other duties, he held the responsible post of „Prefect of the Irish Mission", whose duty it was to look to the interests and discipline of the Irish Jesuit Colleges in Spain and Portugal, ${ }^{14}$ and to transact matters for the Jesuits of Ireland.

In 1649 he was on the staff of the Imperial College of Madrid, and Professor of Ethics or Jurisprudence. ${ }^{15}$ In 1651 he edited and supplemented Father Paul Sherlog's Hebraica Dioptra, which he got published at Lyons, in France. He continued to live at Madrid as Professor, and as "Prefect of the Irish Mission“, and several letters of his are preserved in the Irish College of Salamanca, the last of which is dated Madrid, October 25 th, 1651.

Father Wadding died at Madrid on the 3oth of December, 1651, according to the Annual Letters of the Province of Toledo, and a document in the Archives of the Irish College of Salamanca. ${ }^{16}$ According to the latter document, he died at the

11. Vol. B in the Archives of the Irish Province under the years 1642 and 1643.

12. See this letter and various instructions from the Supreme Council in vol. ii, pp. 279-284 of Sir J. Gilbert's „Hist. of the Confederation“.

13. Ibidem vol. i, p. 150

14. Dr. McDonald, p. 566 of „The Irish Ecclesiastical Record“, year 1874, on the Irish Colleges abroad.

15. „Maestro de Moral en los Estudios Reales“, Madrid Catalogue, S.J., of that year.

16. Quoted in Irish Eccles. Record of 1874, p. 566; the General Necrology of the Society dates his death 30 th Dec., 1652. 
age of 58 years; „he was gifted with extraordinary talents, and his superiors employed him in teaching various classes at Salamanca and Valladolid. In the course of time he became Rector of the College of Burgos, and gave great satisfaction by his government thereof. So great was his fame that the most learned consulted him in their difficulties; and his virtue and piety were so well known, that the leading people of the different towns in which he resided sought him as director of their consciences. " ${ }^{17}$

The „Annual Letters of the Province of Toledo“ for the year 1651 give his obit at the III of the Kalends of January, 1651, and adds, „He was a man of extraordinary talent and culture, who rendered service to his hearers and won fame for himself in professorial chairs. All his lectures were charged with the learning and delivered with the authority of one filled with multifarious erudition. Nor did he excel more by his learning than by the conspicuous light of his good example. For his virtue and science he was held in esteem by most illustrious men, and was employed as Theologian of the Inquisition, and was consulted in their doubts by judges of the Temporal and Spiritual Courts. His learning and counsels were always up to the level of the high estimation in which he was held, and he was a man whom you might compare with the highest." 18

This is high praise given by Spaniards at a time when flourished most eminent men, such as De Esparza (Wadding's fellow professor), and others too numerous to mention.

Father Wadding, and the other Waddings, the Whites, Walshes, Sherlog, Murty, and other men of Waterford, raised to a great height the estimation in which Irishmen were held in Spain, an echo of which is found eben in Gil Blas. He says: "I was so fond of disputation that I used to stop the passers-by, whether known to me or not, in order to argue with them. Sometimes I addressed Irishmen, ${ }^{19}$ who were eager for a fray; and it was a sight to behold how we disputed - what gestures, what grimaces, what contorsions. Our eyes were full of fury, our mouths foaming; one would take us possessed by the devil rather than for Philosophers."

Gil Blas is a little grotesque, indeed, and reminds one of Lewis Carroll's -

„In my youth“, said his father, „I took to the law,

And argued each case with my wife;

And the muscular strength, which it gave to my jaw,

Has lasted the rest of my life."

17. [Ibid.]

18. Quem summis aequiparare possis.

19. Des Figures Hibernoises. 
But it shows that the Irish in recent times were ardent and subtle disputers, or, as they were styled in the Continental Universities, „ratione furentes“, and that they inherited the „perfervidum ingenium Scotorum“ of their ancestors.

Father Wadding did not, as far as I know, publish any book, but there are nine volumes of his theological and philosophical MSS. in the Library of Salamanca, ${ }^{20}$ and his correspondence from 1642 to 1651 is in the Irish College of that city. ${ }^{21}$ After his death, the Irish Jesuits asked Father General to have (if not his MSS.) his library to be sent to them. I am not aware that their request was granted fully; but in the College of Waterford there is a Commentary on Scripture, by Tirinus, in which is written in Spanish: „It belongs to the Mission of Ireland; Father Luke Guadin gave it to it with the permission of our Father General.“

Though Wadding published nothing of his own, he prepared for the Press and supplemented and, in 1651, edited the Hebraica Dioptra of his fellow-townsman, Father Sherlock, S.J., who died in 1646. It was published at Lyons in a folio of $710 \mathrm{col}-$ umns, and is prefaced by a long Latin address of the publisher to the Very Reverend Father Luke Wadding, S.J., from which we gather a few details.

Of the three books De Hebraeorum Republica, which Father Sherlog intended to write, only one was completed, and Wadding put it in order for the Press. The publishers, Borde, Arnaud, and Rigaud, urge him to give to the world his own lectures on „Artes Politicae“, delivered in the Imperial Academy of Madrid, though they know he is busily occupied, not only as „Praeceptor Politicorum“, a position which he holds with so much competence and dignity, but as „Sancti Officii Qualificator“, and as one who is constantly consulted on all sides as an oracle. They are sorry he has so many and so exacting admirers; but they hope that as soon as possible he will send them his „eximium illud opus“, which he promised them, and they will gladly print any work of his erudite and cultured mind.

The first Book of the Hebraica Dioptra is De Orbe Condito, the second De Opere Sex Dierum. When it was within my reach I wrote a note to the effect that „Father Wadding was the author of the Second Book"; this I cannot now verify.

Father Meehan little knew how he was exalting the glory of Padre Luca Wadding, O.S.F., when he said Luke inherited a larger amount of talent than fell to the lot of any of his kinsmen; they were all outshone by his fame, and seem like so many stars set in the aureole with which religion and science have encircled his head. ${ }^{22}$

20. Foley's Record of the English Province S.J., Part II-IV. Addenda in Chronolog Catalogue of the Irish Province, p. 21; also P. Sommervogel's Bibl. des Ecrivains de la Compagnie de Jésus, under Luke Guadin.

21. Letter by its Rector, Dr. McDonald, to me, Jan. 23, 1876.

22. „Franciscan Monasteries“, 5th Ed., p. 208. 
He informs the reader that the others were professors of theology at Coimbra, Prague, Louvain, Dilingen, and Madrid. From our sketches of them it is clear that they were a great deal more than that. To speak here only of Luke, S.J., he was not only Professor of Theology at Madrid, as Father Meehan says, but also at Valladolid and Salamanca, „Qualificator S. Officii“", and was consulted as an oracle, on account of his learning and prudence - „quemque summis aequiparare possis“. Father De la Reguera, a Spanish Jesuit, in his sketch of Luke's brother Michael, prefixed to a translation of and commentary on Michael's Mystical Theology, a folio book in two volumes, dedicated to Pope Benedict the Fourteenth; he says, with more accuracy than Father Meehan, that Luke, at Salamanca, Valladolid, and Madrid, occupied the first chairs of Theology - „primas sacrae Theologiae cathedras rexit“.

The last we hear of Father Wadding is in a letter of Father Christopher Mendoza (perhaps Hurtado de Mendoza, who was Father Sherlog's professor), ${ }^{23}$ who, in 1675, alludes to Father Luke's death as occurring at the College of St. George, Madrid. ${ }^{24}$

23. [Ein Irrtum. Pedro Hurtado de Mendoza starb schon 1641. SKK.]

24. Cardwell's transcripts of MSS. in the Archives de l'État, Brussels, Stonyhurst MSS., quoted in Foley's „Records“, Part ii, p. 799. 


\section{Luke Wadding SJ.}

Tractatus de scientia Dei futurorum contingentium

(Concordia Divinorum et Humanarum t.1, Ms. BU Salamanca 156, fols. 797-914) 

[fol. 2r]

\section{P. Richardus Lynceus, Sacrae Theologiae Doctor, et Magister Salmanticensis, ad Lectorem}

Animus erat Reverendo Patri Lucae Wadingo, Societatis nostrae Theologo, universam fere Theologiam in lucem edere, nova quidem, et singulari, sed tamen apositissima methodo, nempe in concordiam redigendo discordias, quae primo aspectu apparent in mysteriis nostrae Fidei. Magni viri magnis ac se plane dignis conatibus obfuit mors, immortalisque ingenii plurima et praeclarissima monumenta, proh dolor, posteritati invidit. Hoc unum (quippe iam olim ab eo elaboratum, numerisque suis absolutum) ea eripere nobis non potuit. At certe voluit insignis eius modestia, qua ad extremum usque spiritum de se rebusque suis humiliter sentiebat. Ignoscant mihi tamen pii manes defuncti, ignoscat illa animi demissio, quae vivo maxima fuit, et nunc eadem sequitur tellure repostum. Ego praestantiam et celsitudinem operis demiratus ac de ingenti ex eo utilitate secutura certus, et multorum etiam votis ac paene convitio lacessitus feci, ut Superiorum permissu typis mandaretur. ${ }^{1}$

De Authoris mira eruditione, admirabili iudicio, subtilissimo ingenio, deque eius multis et magnis virtutibus (quos ille, ut verus Societatis alumnus, pluris semper fecit quam doctrinam aliasve ullas dotes naturales et humanas) non quae possem omnia, ne prologum vertam in historiam, sed tamen aliqua dicerem impraesentiarum, nisi mihi laborem hunc qualem qualem praeripuisset R.P. Ioannes Piña Imperialis Collegii nostri Matritensis Rector, virque doctissimus, si quis alius, ut testantur quatuor tomi Commentariorum eius in Ecclesiasticum, ${ }^{2}$ nec magis doctrina quam vitae probitate et absoluta morum gravitate inter nostros externosque valde spectabilis. In Epistola, ergo, funebri, quam ad Patres ac Fratres Provinciae Toletanae de Patris Wadingi morte solitisque pro eo suffragiis Deo offerendis Hispano idiomate scripsit, haec quidem habet a me fideliter ac totidem fere verbis latine reddita:

1. Der letzte Satz ist zitiert bei A. MoRán SJ.: „El primer catedrático Jesuita de Prima de Teología en la antigua universidad de Salamanca“. Miscelanea Comillas 14 (1950) 85-143, hier 126. Er liest statt „mandaretur“: „ederetur“.

2. IoAnnes de Piña: Commentaria in Ecclesiasticum, 5 Bände, Lyon 1634-57. 
„Vigesimo die mensis huius ereptus e vivis est (sic Deo visum) P. Lucas Wadingus, in cuius morte id nobis solatio est, adeo pie ac religiose eum semper vixisse, ut mori admodum non timeret. [2v] Honestis et catholicis parentibus natus est Waterfordiae, quae una ex primariis Hiberniae civitatibus est, indeque puer adhuc in Hispaniam traiecit. Quadraginta duo anni nunc sunt, quum Societati nomen dedit, viginti tres, cum in ea ad professionem quatuor votorum admissus. Philosophiam Compostellae docuit, Theologiae Primarius Professor prius Pinciae, postea Salmanticae fuit, utrobique Studiorum Praefectus, in Salmantino etiam Collegio Sacrarum Litterarum, et in hac demum Philippi IV. Hispaniarum Regis Curia Ethicorum Aristotelis interpres. Facile dictu non est, quanto ubique discipulorum concursu ac fructu, quanta nominis sui celebritate, qua Societatis gloria. Verum enim vero, etsi tanta fuerit eius doctrina, non minores fuere virtutes, harumque et illius mutua ad se accessione et pulcherrima veluti mixtura ambas fecerat illustriores. Adeo deditus orationi fuit, sic divinis rebus intentus, ut haec eius non solum praecipua, verum etiam unica videretur occupatio. Mira fuit eius pietas in venerabile Sacramentum Altaris, cuius videndi saepiusque adorandi studio id sibi in Collegiis deligebat cubiculum, quod propinquius esset Ecclesiae, nec contentus sacrum, etsi morbis debilitatus, quotidie celebrare, longa ad id meditatione se praeparare, eoque peracto in gratiarum actione diu persistere, haud paucas insuper missas devotissime audiebat. In Beatissimam Virginem (a qua quidquid oraverat, sic ipse dicebat, exoraverat) tenerrimo fuit affectu: praesertim vero eius purissimam conceptionem eximie colebat, quotiesque exigeret occasio, omni ope et opera insudabat ei defendendae et illustrandae. Iam Societatem tamquam matrem unice diligebat, et si quae adversus eius doctrinam aut institutum scriptave aut ministeria tempestas, ille vel primus vel praecipuus sedare, ille solum reducere, collectasque a calumniatoribus nubes fugare. Quam autem in ea defendenda strenuus, tam certe diligens fuit in eius regulis vel minimis observandis, adeo paupertatis amans, ut nihil particulare in victu aut vestitu, sive sanus esset, sive valetudinarius, admitteret. Tantaque erat spiritualis laetitia, quam vir Dei ex rigida hac sui tractatione percipiebat, ut pro nihilo haberet damnum salutis, si quod forte immineret. Superiorum placitis addictissimus erat, et quae praecipiebant vel etiam leviter insinuabant quantumvis difficilia, tamen magna animi alacritate et promptitudine parique iudicii conformitate exequabatur. Qua erat humilitate praeditus, ab omni praelatura etiam atque etiam abhorrebat, auditusque est aliquando dicere, se quodcunque in Societate officium et vel Coadiutoris temporalis officium libenter suscepturum, dum ne aliis praeesset, [3r] sed enim magna, qua pollebat in rebus agendis prudentia, et egregium gubernandi talentum obstitere piis eius votis, admotusque est a Superioribus regimini Burgensis Collegii, cui toto triennio praefuit, non sine maximo subditorum solatio et commodo spirituali ac temporali. Provinciae etiam Castellanae Consultor fuit, et, nisi ipse solus, nemo alius non dignum iudicabat, qui Provincialis renunciaretur. Par fuit 
eius apud externos authoritas, par iudicii, prudentiae et religionis opinio. Itaque, quoties cuperent sive civitatum magistratus publicis peccatis et malis obviam ire, sive supremi totius Regni Ministri et Regis Senatores ne vel minimum ab aequo in gravissimis causis aberrare, sive Episcopi passim et Archiepiscopi subditorum saluti spirituali consulere dioecesesque suas reformare, sive Quaesitores sacri (et qui in inferioribus, et qui in supremo sedent Sanctae Inquisitionis senatu, anteque omnes ipse omnium generalis Praeses) in rebus difficilioribus exitum invenire, ab eius consilio et sententia omnes pendebant. Magnatum certe favore ubique claruit et valuit ut quis maxime, sed eo (quae fuit illius erga Deum et proximos charitas, fuit autem ardentissima) ad solatium utebatur miserorum, ad incarceratos xenodochiorumque aegros eleemosinis sublevandos, ad pacem inter discordes componendam, et ad omnis generis scandala tollenda. Ubicunque degeret, multos utriusque sexus aut ad bonam frugem revocare aut ad studium perfectionis accendere. Certe haud pauca sanctimonialium monasteria ei vel reformationem debent vel fervoris incrementum. Nunc sponsae Christi, cum se concionibus, quas ad eas habebat frequentes, spiritualibusque instructionibus destitutas vident, itemque memores religiosae illius gravitatis, modestiae et circumspectionis, quibus sibi omnium conciliabat animos, nobiscum deflent viri obitum. Catholicissimi Hiberni, cum pro Fide vel bellarent vel exularent, largiter ab eo adiuti, Patrem Patriae appellare. Nullius ordinis aut nationis homo, nulla communitas religiosa aut saecularis eius opem poposcit, cui non opitularetur. Pietatis, ergo, officiis supra quam corporis vires ferebant totus incumbens, et, quamquam quinquaginta octo annos natus, magis tamen laboribus quam annis fractus, in malignam febrem incidit, naturamque et medicinam, licet meliores huius Curiae medici accederent, superante malo, desperatum tandem est de eius salute. Hunc religiosissimus Pater nuncium laetanter accepit. Inter angustias mortis ac morbi nihil eo patientius. Nulli eius questus audiebantur, non nisi verba conformitatem cum divina voluntate significantia et frequentissima [3v] cum Christo et Sanctissima eius Matre, Sanctisque suis tutelaribus colloquia, peccatis sacra confessione crebro expiatis, Eucharistia, et bis in Viaticum et saepius etiam antea, prae devotionis ardore, recepta, sacroque oleo munitus animam Deo reddidit. Corpus eius terrae mandatum est assistentibus praecipuis Curiae Proceribus dolentibusque et nos et se tali viro orbatos. Iidem postridie cum lecta miserorum manu charissimo sibi Patri persolvenda convenerunt. ${ }^{3}$ Id nunc reliquum est, ut illum Vestra Reverentia in eo sancto Collegio solitis curet suffragiis iuvari. Vale etc."

Hactenus R.P. Piña, testis quidem omni exceptione maior, de Patre Luca Wadingo.

Dedit eum Hibernia Hispaniae, Hispania Societati, Societas caelo.

3. Dieser Satz ist kaum lesbar. 
Hibernia nostra Hispaniae: velut olim Angliae Scotum, Italiae Petrum Hibernicum magni Aquinatis Thomae in Philosophia magistrum, Galliae Clementem et Albinum Parisiensis Universitatis fundatores, Germaniae Academiarum etiam Fuldensis, Sangallensis et Herbipolensis primos praeceptores, aliosque aliis regionibus viros litteris et sanctitate praestantissimos.

Hispania Societati: ut magna illa lumina Soarium, Vasquium, Molinam, Valentiam, Toletum, Lugum etc.

Societas caelo: ut nobis pollicentur inprimis eximiae hominis virtutes, neque non etiam nota sanctitatis fanima, qua quodam die, inter orandum, videre sibi visa est eius animam post tridui purgatorium in caelos evolantem.

$\mathrm{O}$ te felicem, Waterfordia, tali cive. Etsi non esses tot clara ingeniis, nec genuisses Sherlogos, Murtios, Lombardos, Wadingos alios, tamen, vel solo nostro Luca, Sole clarior luceres. Haec siccavere lacrimas meas in obitu conterranei, amici, commilitonisque optimi, et simul effecere, ne sinerem, quod in me fuit, eius memoriam apud posteros interire. Accipe igitur, Amice Lector, hoc eius opus posthumum, ex quo fortasse coniicere poteris, quantus vir fuerit, tanquam ille staturam Herculis ex planta, et vale ac fruere. 


\title{
Liber quartus
}

\author{
De scientia futurorum contingentium \\ secundum rationem communem ad absolutam \\ et conditionatam, eiusque concordia cum \\ creata libertate, ubi etiam in particulari agitur \\ de scientia absolutorum ${ }^{1}$
}

Libro praecedenti ostendimus, concordiam omnis determinationis ad unum cum libertate eius, ad quod determinat, ineundam necessario esse per consequentiam determinationis ad id, respectu cuius est determinatio. Nunc eius suppositionis quidditatem explicabimus, et quia, ut capite $4^{\circ}$ libri praecedentis ostensum manet, radix contentionis in divinis determinationibus est praescientia futurorum, huius obiectum - tam motivum quam terminativum - et modum tendendi explicabimus, et a capite $9^{\circ}$ quidditatem prioritatis obiecti liberi ad divinam praescientiam explicare incipiemus, et denique capite $24^{\circ}$ tribusque sequentibus, et capite $34^{\circ}$, praescientiae concordiam cum creati obiecti libertate elucidabimus.

\section{Caput 1. An futura contingentia praesciantur a Deo in causis}

2. $1^{\circ}$ Supponendum est, futurorum contingentium, quae a sola libertate Dei dependent, praescientiam, tam absolutam quam conditionatam, esse in ipsorum causis, quia eiusmodi futura determinanda praevie sunt per liberum decretum Dei, sine quo inferiores causae naturales non sunt sufficienter applicatae nec proxime potentes operari, quia solum ex se habent posse, si praevia determinatione applicentur, et ad id, quod prima causa fieri determinaverit. Eorum ergo effectus in hac determinatione ut absolute affirmata cognoscuntur absolute, et sub eadem conditionate futuri iudicandi sunt.

Idemque dicendum est de futuris contingentibus a creata libertate pendentibus, quae libera sunt $\mathrm{ab}$ extrinseco tantum seu per denominationem extrinsecam ab actu

1. [In margine corr.]: Liber 4 De suppositionis consequentis quidditate, de scientiae futurorum contingentium, praesertim absolutorum, natura, et concordia cum humana libertate. 
creato libero, ad illum tamen necessario consequuntur. Nam haec contingentia in suis causis proximis cognosci possunt, cum sint ad unum determinatae.

Solum ergo controvertitur de futuro contingente, quod tale est ab intrinseco et immediate per se ipsum, quod est tantummodo actus liber creatae voluntatis, an cognoscatur in causa.

3. $2^{\circ}$ Supponendum est, futuri contingentis immediate et per se contingentis et liberi creatae [797v] voluntatis aliam esse in Deo praescientiam disiunctivam, qua cognoscitur, a causa libera ut instructa omnibus praerequisitis oriturum hunc vel illum actum - inter quos habet liberam eligendi facultatem -, aliam, qua determinate cognoscitur, quisnam illorum orietur.

Primam ergo scientiam - sive absoluta sit, sive conditionata - haberi in causa, certum est.

Ut expresse docet S. Thomas q. 16 De Malo art. 7 his verbis: „Quae sunt ad utrumlibet, non possunt praecognosci in suis causis determinate, sed sub disiunctione, utpote quia erunt, vel non erunt: sic enim habent veritatem. "Nam causa libera, quae, scilicet, se habet ad opposita, quatenus proxime et expedite potens ad illa, est necessitata ad unum vel alterum exercendum (ut libro $2^{\circ}$ capite $54^{\circ}$ ostendi, et iterum ostendetur libro $6^{\circ}$ ), cum non possent omnia extrema libertatis a tali causa omitti libere - nam hoc esset extra sphaeram integram libertatis liberam causam ut liberam operari - nec etiam possunt omnia extrema libertatis omitti per determinationem alterius causae, ex suppositione, quod liberae causae concessa sit proxima et expedita facultas ad electionem inter duo: quia haec expeditio essentialiter requirit, determinatam esse primam causam ad non impediendam utriusque extremi existentiam, sed potius ad conservandam potestatem secundae, ut inter illa eligat. Huic ergo, ut proxime et expedite potenti operari libere unum e duobus, necesse est aliquod illorum disiunctive operari. Ergo in ipsa, ut sic potente, agnoscet Deus disiunctive, unum vel alterum extremum libertatis secuturum esse. Id, inquam, cognoscet in causa, vel absolute affirmando divinum decretum, vi cuius causa creata constituenda est maxime potens ad operandum, vel conditionate, quatenus, vi essentiae divinae, cognoscit Deus, quod, si habeat decretum constituendi causam creatam libere potentem ad operationem, operabitur hoc vel illud extremum disiunctive. Haec enim conditionalis est omnino necessaria, et ideo per conditionatam scientiam necessariam disiunctive cognosci debet a Deo (ut in particulari agentes de absoluta et conditionata scientia futurorum explicatius trademus). Ex quo patet, controversiam praesentem solum institui de praescientia determinata unius extremi ut futuri prae alio.

4. $3^{\circ}$ Supponendum est, quod, quando quaeritur, an futura contingentia per determinatam scientiam unius prae alio cognoscantur ,in causis“, non esse sensum, an praecise cognoscantur in illis tanquam in obiecto pure motivo cognitionis nam capite sequenti ostendemus, hoc sensu futura in causa sua increata necessario 
cognoscenda esse a Deo, cum aliud esse implicet divinae [798r] cognitionis motivum -, sed, an cognoscantur in causis tanquam in obiecto determinativo. Sumimus "determinativum“ pro eo, quod tale est in actu secundo et sua essentia, ita, ut implicet illud perfecte cognosci, et non determinare intellectum, ut cognoscat illud. ${ }^{2}$ Controversia ergo praesens est, an futura cognoscantur ,in causis“ ut in obiecto determinativo seu necessario determinante divinum intellectum ad eius, quod futurum est, cognitionem.

Et quamvis, ad controversiam hanc dirimendam, sufficere videantur quae libro $2^{\circ}$ discussimus ad probandum, quod effectus liber non possit esse in sua causa determinatus - quia inde sequitur, nullam contingentis causam posse esse determinativum ad unius extremi libertatis prae alio cognitionem -, attamen, quia res est tanta contentione hoc saeculo agitata, expedit, sub propriis terminis cognoscendi futurum contingens in causis ostendere, quantum a veritate et antiquitate aberrent Novorum ThOmistarum cogitationes.

5. Prima ergo sententia est, futura contingentia cognosci in causis ut determinatis ad unum a prima et universali rerum omnium causa, quamvis particulares causae, in se consideratae, indifferentes sint et proinde insufficientes ad determinandum, vi sua, ad unius potius quam alterius cognitionem.

Sic Bañez Prima parte q. 14 art. $13 \$ 1$ conclus. 2 , 3 et $4 ;^{3}$ Alvarez lib. $2^{\circ}$ De auxiliis disp. 12; ${ }^{4}$ Gonzalez Prima parte disp. 44 numero $21 ; 5$ IoAnnes a S. Thoma Prima parte disp. 19 art. 2, et alteri huius aevi Thomistae, moti

$1^{\circ}$ fundamentis adductis lib. $2^{\circ}$ ad probandum, quod prima causa omnium inferiorum causarum, etiam liberarum, effectus praevie determinare debeat. Ii ergo effectus in causis ut determinati a prima cognosci debent.

$2^{\circ}$ Quia alio modo non sunt determinate cognoscibiles effectus contingentes. Ad quod probandum, externorum probationibus domesticas addemus a cap. $8^{\circ}$, paulo - ni fallor - validiores.

$3^{\circ}$ Quia Patres et antiqui Scholastici docent, effectus contingentes, etsi particularibus causis contingant, non tamen universali: apud quam ab aeterno determinati sint, et respectu cuius necessarii sint et indefectibiles.

2. aliud corr.

3. Dominicus BañeZ: Scholastica commentaria in Primam partem Angelici Doctoris, ed. L. Urbano, T.1, Madrid-Valencia 1934, 351b/52b.

4. Didacus Alvarez: De auxiliis divinae gratiae et humani arbitrii viribus et libertate, ac legitima eius cum efficacia eorundem auxiliorum Concordia, Rom 1610, 95a-96b.

5. IoAnnes GonzÁlez de Albelda: Commentaria et Disputationes in Primam partem Angelici Doctoris D. Thomae 43, 29, Alcalá 1621, t.1, 471b. 
6. Sed quia his obiectionibus (utpote alibi discussis) nunc immorandum non est, ipsis breviter de medio sublatis, planam secundae sententiae viam sternemus. Quae primo opponuntur, libro citato repulsa sunt. Secundi ordinis obiectiones capitibus sequentibus solventur.

Ultima vero parvi momenti est. Nam ideo eventus rerum sunt secundis causis contingentes, non primae, quia in secundis nulla [798v] est determinatio praeveniens eiusmodi eventus, nec praecedens ad illos tempore aut natura: non quidem natura, quia contingentes et liberi eventus sunt, neque etiam tempore, quia in secundis causis eventuum ignaris et undequaque indeterminatis nulla est - nec intentionalis, nec physica - exigentia determinata eius quod erit, ideoque omnino contingenter illis eveniunt contingentia, Deo autem non ita: quia, licet nullam habeat in se determinationem natura praecedentem ad effectus liberos, at habet determinationem aeterna duratione praecedentem. Quod est praescientia et providentia. Ideoque in Deo omnia determinata dicuntur, antequam eveniant, illique nihil evenire contingenter: quia non contingit alicui, quod praevia quasi expectatione ${ }^{6}$ exigit, ut eveniat. Excipe ipsum eligentem libere id quod evenit, quia, licet praescientiam aliquando habeat futuri actus sui, oportet hunc dici illi contingentem, quia est illi formaliter 7 liber, Deo autem nullus actus noster est liber formaliter. Unde, omnem esse illi prius - prioritate aeternae durationis - notum, sufficit, ne aliquis illi contingens sit.

7. Ne autem aliquid praesidii pro hac opinione quaeratur a nonnullis male intellectis Doctorum locutionibus, advertere necesse est, plures - inter quos est VALENTIA Prima parte [disp. 1] q. 14 puncto $5 \$ 2$ assertione 3 - asserere, quod in causae secundae determinatione cognoscitur eius effectus. ${ }^{8}$ Haec autem determinatio non est in actu primo, sed in actu secundo, qua se determinat causa secunda, per suam actionem, ad effectum productum.

Deinde, nec favent huic sententiae Doctores asserentes, contingentia cognosci in supercomprehensa causa, ut loquitur Molina Prima parte q. 14 disp. $14,{ }^{9}$ quia solum intendunt, supercomprehensionem causae, quae est infinita perfectio, qua divina essentia omnia repraesentat, esse rationem motivam cognoscendi omnia quae erunt, et quae essent, si poneretur aliqua conditio. Quod verum esse, probabimus capitibus sequentibus, non tamen, quod sit ratio determinativa ad unum cognitionis futuri contingentis.

6. Wadding definiert: „Expectatio est exigentia alicuius aliena libertate impedibilis.“ fol. 673v. 7. „Formaliter est adverbium, et per consequens dicit modum; unde dicit modum compositionis alicuius praedicamenti praedicati cum subiecto [...] Per ly formaliter nihil intelligo nisi, per se' primo modo. Ista convertuntur." Petrus Thomae OFM.: De modis distinctionum q. 7, fol. 53vb, zitiert nach G.G. BRIDges: Identity and Distinction in Petrus Thomae, St. Bonaventure 1959, 103.

8. Gregorius de Valentia: Commentaria theologica in Summam Theologicam D. Thomae, Lyon 1609, t.1, 269B.

9. Ludovicus Molina: Commentaria in Primam D. Thomae partem, Cuenca 1592, 577-78. 
8. Praeterea, nec iuvat, plures dicere, rationem cognoscendi futura esse divinam essentiam ut determinatam divina voluntate. Quod videtur indicare, divinam voluntatem determinantem ad futurum esse rationem cognoscendi illud. - Etenim, sensus horum Doctorum est (quem libro sequenti trademus), ad futura absoluta cognoscenda motivum cognitionis esse divinam essentiam ut determinatam volitione non determinante ad unum, sed constituente creatam voluntatem indifferentem ad duo. Hac voluntate determinatur divina essentia de se indifferens ad volendum dare arbitrio creato proximam potestatem liberam [799r] ad duo, vel illam nolendam. Non est autem divina essentia sufficiens motivum ad cognoscendum id quod libere futurum est, nisi ut determinata per volitionem dandi creaturae liberam facultatem: quia, si oppositam haberet, nihil libere futurum cognoscere valeret, quia nihil libere futurum esse posset.

9. Denique, nec iuvat, multos dicere, futura contingentia cognosci in divina voluntate, permissione, ${ }^{10}$ providentia, praedestinatione, quae sunt futurorum causae. Nam haec verissima sunt (ut sequentibus libris ostendemus), sed tamen non probant, in causa, ut omnino antecedit effectum liberum, hunc cognosci tanquam in obiecto determinativo. Nam voluntas Dei, in qua necesse est cognosci futura contingentia, est indifferens causa ad illorum esse, et non-esse, ideoque, in illa cognosci oportere futura, intelligendum est: tanquam in obiecto motivo, non vero determinativo. Permissio autem, providentia et praedestinatio, etsi causae sunt et connexae, non tamen sunt causae nec natura antecedentes, quatenus connexae sunt: quia rationem causae habent per actum voluntatis divinae - qui indifferens est ad contingentium esse et non-esse -, connexionem vero per conditionatam praescientiam simul cum illa voluntate existentem in Deo. Haec autem non est praerequisita ordine naturae aut causalitatis ad effectum, cuius praedestinationem constituit.

Et licet ad aliquos effectus liberos detur singularis affectus praedeterminativus, qui illos natura antecedat, quatenus est infallibiliter cum illis connexus - eo quod ex sua natura praescientiam effectus futuri sub medio indifferenti, quod decrevit, supponat -, attamen hic affectus non est causa omnino antecedens: quia subsequitur conditionatam praescientiam effectus in se ipso; ac proinde scientia absoluta effectus in illo non est in causa ut omnino antecedente et ut primo determinante: quia ad praescientiam, quam affectus ille praedestinativus supponit, determinat ipsum obiectum liberum (ut in sequentibus ostendemus).

Quomodo autem doctrina huius et praecedentis numeri applicari possit ad scientiam conditionatam, libro $7^{\circ}$ dicendum est. ${ }^{11}$

10. promissione corr.

11. „[... ] libro $7^{\circ}$, ubi de efficacium praefinitionum circa obiecta libera possibilitate et quidditate agemus." fol. 682r. 


\section{Caput 2. Secunda sententia proponitur et probatur esse Sancti Thomae}

10. Secunda sententia est, futura contingentia non posse in suis causis omnino antecedentibus tanquam in obiecto determinativo cognosci. Sic omnes Patres et Doctores, quos libro $2^{\circ}$ capitibus $17^{\circ}[799 v]$ et $19^{\circ}$ citavimus pro neganda praevia determinatione causali omnino antecedenti operationem liberam, et similiter, quos citavimus libro praecedenti a capite $5^{\circ}$ pro concordia determinationis ad operationem liberam cum libertate illius, ineunda per suppositionem consequentem, ${ }^{12}$ et quos hoc libro ad idem citabimus a capite $24^{\circ}$. Nam eo ipso, quod negent, contingentia posse esse in suis causis determinata, negant cognitionem illorum in causa tanquam in obiecto determinativo cognitionis, cum determinare nequeant ad unius extremi libertatis prae alio futuri cognitionem nisi ad unius prae alio existentiam futuram determinando.

In terminis autem praesentis controversiae secundam hanc sententiam adeo expresse docent $\mathrm{S}$. Thomas et antiqui eius discipuli, ut mirum sit, apud ReCENTIORES invaluisse oppositam. Ego sane nullam invenio in S. Tнома sententiam nec saepius repetitam nec verbis expressioribus traditam, quam, contingentia non posse certo cognosci in causis ob indifferentiam, quam in illis habere debent, et ideo, divinum intuitum ferri debere super illa prout sunt in sua praesentialitate: quia in illa sola habent determinationem ad unum et impossibilitatem aliter essendi, ipsis convenientem ex suppositione, quod sunt. Hoc ostendunt imprimis loca S. ThомaE, quae adduximus libro $2^{\circ}$ capite $11^{\circ}$ ad probandam repugnantiam praeviae determinationis causalis ad actionem liberam. Deinde, idem clare ostendetur locis citandis hoc libro capite $25^{\circ}$ ad probandum modum, quo certitudo divinae praescientiae cum libertate sui obiecti concilianda est.

11. Praeterea, hanc sententiam manifeste docet Thomas Prima parte q. 14 art. 13: „...] contingens [...] dupliciter potest considerari. Uno modo, in se ipso, secundum quod iam actu est. Et sic non consideratur ut futurum, sed ut praesens; neque ut ad utrumlibet contingens, sed ut determinatum ad unum. Et propter hoc sic infallibiliter subdi potest certae cognitioni, utpote sensui visus, sicut cum video Socratem sedere. Alio modo potest considerari contingens, ut est in sua causa. Et sic consideratur ut futurum et ut contingens nondum determinatum ad unum: quia causa contingens se habet ad opposita. Et sic contingens non subditur per certitudinem alicui cognitioni. Unde quicumque cognoscit effectum contingentem in causa sua tantum, non habet de eo nisi coniecturalem cognitionem. Deus autem

12. Zur Distinktion ,suppositio antecedens / consequens' vgl. Franciscus Suarez: Varia opucula theologica 1, 1, 3, 7, Opera omnia, Paris 1856-78, t.11, 16a/b; Didacus Ruiz DE Montoya: Commentarii ac Disputationes de scientia Dei 33, 2, 6, Paris 1629, 264a. 
cognoscit omnia contingentia, non solum prout sunt in suis causis, sed etiam prout unumquodque eorum est actu in se ipso.“

Recentiores Thomistae citati pro prima sententia volunt, haec verba intelligenda esse de causis contingentium, secundum quod in se sunt indeterminatae, non vero, secundum quod a Deo determinatae sunt ad agendum.

Sed eorum interpretatio et verbis et menti et honori S. THomaE [8oor] contraria est:

Verbis, quia expresse asserit, contingentia non posse habere determinationem in causa.

Menti, quia contraponit esse, quod contingentia habent in causis, cum esse, quod habent ut actu sunt extra causas in sua praesentialitate. In hac autem sola, ait, futura contingentia habere determinationem ad unum. Ergo nullam habent antecedenter ad hanc praesentialitatem. Ait praeterea, futurum nullam habere determinationem, secundum quod futurum est, id est, secundum esse, quo antecedit praescientiam (ut infra videbimus). Esse autem, quod habent in decreto determinante causas secundas, non est esse praesens in se, sed esse ab aeterno futurum. Ergo, contra mentem S. Doctoris dicatur, quod eiusmodi decreto determinentur causae contingentes.

12. Denique, honori S. Doctoris opponitur interpretatio, quia eius discursum futilem prorsus et inanem reddit. Etenim S. Doctoris discursus eo tendit, ut divinae scientiae certitudo respiciat obiectum determinatum ad unum et non indifferens ad se aliter habendum, quin hoc obstet contingentiae obiecti. Id explicat duplici consideratione contingentis: $1^{\circ}$ ut est iam actu in se ipso praesens et non futurum; $2^{\circ}$ ut est in causis. Primo modo, inquit, determinationem habet, et secundo modo contingentiam. Haec statuum distinctio solide concludit intentum, si futurum „in causis“ significet futurum secundum omnem rationem essendi quam habet in causis omnibus et praerequisitis prius natura, quam sit in se ipso.

Nullius autem ponderis est, an futurum in causis de solis creatis secundum se sumptis sumatur, vel de solis indifferentibus supponendo, eas ab alia causa determinandas esse ad unum, priusquam effectum contingentem in se ipso producant: tum, quia contingentia effectus non salvatur, nec secundum rem nec secundum S. Thомам, per hoc, quod eius causae creatae in se semper contingentes sint (ut libro $2^{\circ}$ late ostensum est), tum, quia esset manca et ad intentum indifferens divisio status rei in se, et in causis, si „esse in causa“ non includeret omne virtuale esse: quod excludit esse formale, quo contingens est in se. Nam si contingentiam effectus ex eo salvari docet, quod determinatio, quam habet, est tantum ob praesentiam et ex suppositione, quod existit, et eius ratio redditur ex eo, quod in causis nulla sit contingentis determinatio, manifeste apparet, particulam „in causis“ de omni esse virtuale effectum contingentem antecedente sumi oportere. Nam de aliquo tantum 
sumi, non probat, quod contingens solum habet [8oov] determinationem ut est in se ipso praesens, cum ante hanc praesentiam determinatum esse habeat eo ipso, quod una tantum causa ad illud determinata sit et reliquas determinet, quamvis ex se indifferentes sint.

Tum etiam, quia inutiliter insisteret D. Thомаs in formali determinatione, quam futura habent per actualem praesentiam, si ante illam agnovisset causalem aliquam determinationem non repugnantem contingentiae effectus. Etenim si hanc agnovisset Tномаs, eam assignare deberet ut rationem infallibilem cognoscendi, et non ipsam actualem praesentiam. Nam determinatio illa causalis per divinum decretum, si daretur, esset, ut ADVERSARII docent, et causa conservativa libertatis effectus et obiectum determinativum Dei ad infallibilem cognitionem illius. Qua ergo ratione posset, ad divinae scientiae certitudinem explicandam, recurrere ad determinationem obiecti in se ipso, quae nec esset determinativum obiectum divinae cognitionis, nec ad contingentiam explicandam iuvaret, si haec per indeterminationem causarum in se ipsis divino decreto protectam salva consistit? Ad quid futurorum contingentium in se ipsis praesentiam ad aeternitatem, ut certo cognoscibilia sint, tanquam fundamentum unicum et necessarium hoc articulo - et tot aliis in locis - ponderavit, si sufficiens determinativum cum libertate compossibile in aliqua futurorum contingentium causa daretur? Sane inutilis esset $\mathrm{S}$. Doctoris et eius INTERPRETUM labor in hac praesentia (de qua capite 18) explicanda. Quis enim illorum non iudicaretur inutili labore consumi, si, ad explicandam cognitionem effectuum naturalium, qui suas causas necessarias consequantur, multum insisteret in explicanda illorum effectuum praesentia in aeternitate? Nonne effectus plane et distincte docuit Angelicus Doctor in suis causis cognosci? Quod patet ex hoc ipso articulo, cuius verba retulimus, et ex q. 57 Primae partis art. 3, et q. 86 art. 4, et ex q. 2 De Veritate art. 12, et q. 16 De Malo art. 7, et ex lect. 13 libri 1 Perihermeneias $\$$ „Ponit secundam rationem“. Quibus locis, praesertim tribus ultimis, et etiam cap. 66 et 67 Primi Contra Gentiles, conferens causas necessarias cum liberis, in illis determinate cognosci, dixit, effectus ipsarum, non vero in his. Loquitur autem de causis necessariis non ut impeditis, sed expeditis et proxime applicatis ad agendum. ${ }^{13} \mathrm{Nam}$ alias non possunt determinate ostendere, effectum suum esse extiturum. Quod S. Doctor passim repetit plurimis aliis in locis. In causis ergo liberis eodem modo sumptis - id est, secundum omne, quod praerequirunt ad effectum -, asserit, non esse determinate cognoscibilem eorum effectum. Alias frigidet et frivola esset earum contrapositio [801r] ad causas necessarias. Nam nec in his, secundum se consideratis et non ultimo applicatis cum omni praerequisito ad agendum, cognoscibile est determinate, quid acturae sunt.

13. Zu ,applicatio ad agendum' vgl. Franciscus SuAreZ: Varia opucula theologica 1, 1, 6, 5, Opera omnia, Paris 1856-78, t.11, 26b/27a. 
13. Denique, S. Doctori parum obsequiosa censenda est ea interpretatio, quia cum aliis eius dictis non cohaeret.

Nam imprimis, eodem art. 13 ad 3 ait: „contingentia, [...] quae sunt scita a Deo, oportet esse necessaria secundum modum quo subsunt divinae scientiae“, id est, secundum quod exigunt determinate scita esse a Deo. At non admittunt Novi Thomistae, quod in causis ut determinatis a Deo, habeant contingentia necessitatem essendi; suam enim determinationem volunt esse infallibilitatis, non necessitatis. Ergo S. ThomaE repugnat, scibilem determinate esse effectum contingentem in aliqua praevia determinatione causarum.

14. Deinde, nihil est apud S. Tномам frequentius quam excludere omne determinativum seu obiectum determinate exigens cognitionem divinam antecedens ipsam actualem praesentiam. Sed illa determinatio causarum antecedit eius actualem praesentiam in se ipso. Ergo sibi contradiceret S. THомAs, si in aliqua eiusmodi determinatione cognoscibilem agnosceret effectum contingentem.

Minor, et consequentia evidentes sunt.

Maior autem patet ex Secunda Secundae q. 171 art. 6 ad 2: „[...] quamvis contingentia futura, prout sunt in se ipsis, sint determinata ad unum, tamen prout sunt in suis causis, non sunt determinata, quin aliter possint evenire." Determinationem ergo a causis excludit, secundum quod distinguuntur ab esse, quod effectus habet in sua praesentialitate.

Ideo in $1^{\circ}$ [Sententiarum] distinctione 38 q. 1 art. 5 (ad medium corporis): „[...] quaedam causae sunt, quae se habent ad utrumque: et in istis causis effectus de futuro nullam habent certitudinem vel determinationem; et ideo contingentia ad utrumlibet in causis suis nullo modo cognosci possunt. Sed quando iam efficiuntur in rerum natura, tunc habent in se ipsis esse determinatum; et ideo quando sunt in actu, certitudinaliter cognoscuntur [...]" En exclusam omnem determinationem a causis contingentium, et inde deductum, quod non in causis, sed in se ipsis solum sunt certo cognoscibilia. Deductio autem nulla esset, si posset ante actualem praesentiam dari in causis alia determinatio.

Quare omnem determinatam veritatem contingentis, antequam actu sit, inficiatur manifeste ibidem ad 2: „[...] futurum contingens non est determinate verum antequam fiat, quia non habet determinatam causam [...] [801v] Sed dum est in actu, determinate verum est." Omnis ergo determinata veritas contingentis antecedens actuale esse a S. THома manifeste adversatur.

Et ad 3: Futurum contingens „relatum ad Dei cognitionem est necessarium, quia ad ipsam non refertur nisi secundum quod est in esse actuali“. En iterum repetitam exclusionem relationis determinatae ad scientiam unius - exclusam ab omni quo praecedit actuale esse futuri in se -, et hac exclusione probatum a Doctore Angelico, quod non sit inconveniens, futurum contingens, ut refertur ad divinam 
cognitionem, necessarium esse: cum necessitas essendi proveniens ab actuali esse eius contingentiae non obsit.

Quod eadem claritate repetit ad 5, ubi, postquam dixisset „(res futura) subiacet divinae scientiae [...] secundum quod habet esse determinatum in actu“, conferens hoc esse determinatum cum indeterminatione causarum, explicat, has debere sumi secundum omne id quo praecedunt ad ipsum esse actuale futuri. Subdit: „[...] ista res [...], ut est in causis [...], antequam sit in actu“ - nota explicationem essendi „in causis“ per „antequam sit in actu“, ut pateat, causas ab ipso sumi secundum omne id quo antecedunt actualem effectus contingentis existentiam - „non habet necessitatem, nec ibi est scita a Deo futura esse; non enim scit Deus effectum contingentem esse determinatum in causa sua: quia esset falsa scientia, cum in causa sua determinatum non sit."

15. Tandem (ut alia plura omittam), contradictio eius interpretationis [ $\$ 11]$ cum aliis $S$. Thomae dictis constat ex quadam frequentissima eius doctrina superius indicata, quod, scilicet, futura contingentia non possunt a Deo determinate cognosci ut futura, sed ut praesentia. Futuritionem (ut capite $16^{\circ}$ explicabo) vocat rationem essendi, quae praesentiam antecedat, sitque causa, cur ipsa postea sequetur. Unde Prima parte q. 16 art. 7 ad 3 ait: „[...] quod nunc est, ex eo futurum fuit antequam esset, quia in causa sua erat ut fieret“. Non posse autem contingentia certo cognosci ut futura sunt, docet tum locis indicandis capite illo, tum Prima parte q. 14 art. 13 verbis supra citatis, sed clarius et fusius q. 2 De Veritate art. 12 in corpore, ubi - postquam docuisset, effectus necessarios, v.g. eclipsim et ortum solis, posse per cognitionem, cui nequeat subesse falsitas, cognosci ut futuras, quia „necessarium“, inquit, „non potest impediri quin sit, antequam fiat, eo quod causae eius sunt immutabiliter ordinatae ad eius productionem“ - [802r] subdit: „Sed contingens impediri potest antequam sit in esse productum, quia tunc“ - id est, pro omni signo antecedente ad eius esse productum - „non est nisi in causis suis, quibus potest accidere impedimentum ne perveniant ad effectum“ - quia potest libere produci oppositus -, ,sed postquam iam contingens in esse productum est, iam non potest impediri. Et ideo de contingenti, secundum quod est in praesenti, potest esse iudicium illius potentiae vel habitus in quo nunquam falsitas invenitur [...] Ex quo patet, contingens, ut futurum est, per nullam cognitionem sciri, cui falsitas subesse non possit. Unde, cum divinae scientiae non subsit falsitas nec subesse possit, impossibile esset, quod de contingentibus futuris scientiam haberet Deus, si cognosceret ea ut futura sunt." Idem eadem expressione repetit in responsione ad 1, et eadem claritate q. 16 De Malo art. 7.

Ex quibus sic contra Novos Illos InTERPRETES argumentor: Contingentis ut futuri non potest esse certa cognitio, ut $\mathrm{S}$. Tномаs citatis verbis ait. Sed contingens, dum est in causis secundum omnem rationem qua praecedunt natura actualem 
praesentiam effectus, in se ipso consideratur ut futurum, ut q. 14 Primae partis art. 13 in corpore docet idem Doctor: „[...] contingens [...] dupliciter considerari potest. Uno modo in se ipso, secundum quod iam in actu est: et sic non consideratur ut futurum, sed ut praesens [...] Alio modo [...] ut est in sua causa: et sic consideratur ut futurum. " Unde futurum est, iuxta D. Tномам, secundum omnem considerationem eius in causa ut haec est distincta et antecedens ad esse effectus in actu.

Ex his duabus praemissis sequitur evidenter: Ergo contingentium nulla potest esse certa cognitio in aliquo signo causali actualem praesentiam contingentis antecedenti: cum omne eiusmodi signum sit futuritionis, non praesentiae rei in se. Sancto ergo Thomae contradicunt citati InTERPRETES eumque sibi contradicentem inducunt, dum volunt, ab ipso concedi certam futurorum cognitionem in signo aliquo natura antecedente actualem contingentis praesentiam; ac proinde, praedeterminationem causarum contingentium - quam certum est natura praecedere ad actualem illorum praesentiam et sufficiens motivum et determinativum certae praescientiae esse - manifestum est cum Angelici Doctoris sententiis pugnare.

16. Totum hunc discursum de incertitudine contingentis ut futurum est, seu secundum rationem essendi, quam habet in causis ante praesentiam, et de certitudine fundanda in sola eius praesentia, aureis his verbis complectitur Angelicus Doctor lib. $1^{\circ}$ Contra [802v] Gentiles cap. 67: „Ex his autem iam aliqualiter patere potest, quod contingentium singularium ab aeterno Deus infallibilem scientiam habuit, nec tamen contingentia esse desistunt. Contingens enim certitudini cognitionis non repugnat, nisi secundum quod futurum est, non autem secundum quod praesens est. Contingens enim, cum futurum est, potest non esse, et sic cognitio aestimantis, ipsum futurum esse, falli potest. Falleretur enim, si non erit, quod futurum esse aestimavit. Ex quo autem praesens est, pro illo tempore, non potest non esse, potest autem in futurum non esse. Sed hoc iam non pertinet ad contingens, prout praesens est. Unde nil certitudini sensus deperit, cum quis videt currere hominem, quamvis hoc dictum sit contingens. Omnis igitur cognitio, quae supra contingens fertur, prout praesens est, certa esse potest. Divini autem intellectus intuitus ab aeterno fertur in unumquodque eorum, quae temporis cursu peraguntur, prout praesens est, ut supra ostensum est. Relinquitur igitur, quod de contingentibus nihil prohibet, ab aeterno Deum infallibilem scientiam habere." 


\section{Caput 3. Obiectiones contra mentem S. Thomae}

\section{Opponi posset,}

$1^{\circ} \mathrm{S}$. Тномам solum videri negasse contingentibus determinationem et certam cognoscibilitatem in causis propriis et particularibus, $1^{\circ}$ Contra Gentiles cap. 67: „Ordo [...] contingentium ad suas causas proximas est, ut contingenter ex eis proveniant." Et alibi non semel utitur nomine „propriarum causarum“, ut explicet, cui causae contingens debeat esse effectus.

$2^{\circ}$ quae supra $[\$ 6]$ ex Patribus adduximus, scilicet, primae causae nihil advenire contingenter. Nam S. Thомаs id non videtur dixisse in sensu a nobis tradito, nempe, quia non adveniunt Deo creati eventus ut non exigenti determinate, quod eveniant prius duratione quam actu; nam S. Thomas, q. 9 cap. 9 Primae partis ${ }^{14}$ et alibi, divinae voluntati ut causae tribuit, quod effectus certo eveniant, et quod contingenter eveniant, quia utrumque vult. Ergo in illa determinationem agnoscit.

Tertioque saepe ait, effectus etiam contingentes in causis cognosci a Deo. Quod specialiter de causa increata defendere tenetur, cum doceat, illam - nempe divinam essentiam ut divina voluntate determinatam - esse rerum omnium causam. Generaliter autem futura in causis cognosci, docet, ait Alvarez disp. 10 De auxiliis n. $4,{ }^{15} 1^{\circ}$ Contra Gentiles cap. 66 et cap. 67 , ubi ait S. Thomas, in causa, et completa et non impedita, futura cognosci, et cap. 68 , ubi ait, omnia cognosci in causis, et Prima parte q. 14 art. 13, ubi docet, non solum [803r] „in se ipsis“, sed etiam „in causis“ cognosci futura, subintelligendo, ut vult Alvarez, „determinatis“.

18. Respondeo ad primum, proximas causas non esse solas creatas, sed etiam includere increatam, quae immediatissima causa est et non solum proxima, sed etiam approximans et applicans caeteras omnes ad operandum. Unde contingenter - si pro eodem sumatur ac "indifferenter“ - a prima etiam, quatenus rationem causae habet, provenire effectus contingens debet. Loquor de „contingentia“ cum hac limitatione, quia "contingenter" operans sumi potest pro causa, in qua antecedenter ad effectum non solum causalitate, sed nec duratione, detur aliqua determinatio ad effectum. Et hoc sensu non operatur „contingenter“ causa prima, quia omnia, quae facienda sunt, priusquam fiant, determinata habet in sua praescientia. Unde, quando contingentia effectuum specialiter explicatur in ordine ad causas proprias et particulares, non innui, quod in his solis determinationem causalem habeant, et non in causa proxima, sed, quod in hac non sit omnimoda

14. Gemeint ist vielleicht: Summa theologica I q. 19 art. 4.

15. Didacus Alvarez: De auxiliis divinae gratiae et humani arbitrii viribus et libertate, ac legitima eius cum efficacia eorundem auxiliorum Concordia, Rom 1610, 9ob/91a. 
indeterminatio contingentiae antecedens - tam causalitate quam duratione -, ut est in causis propriis. ${ }^{16}$

19. Ad secundum sufficiant, quae diximus libro praecedenti capite $4^{\circ}$, ubi ostendimus, nullam Dei voluntatem posse dare certitudinem de effectu libero creato, nisi accipiat conditionem vel suppositionem creatae libertatis; ac proinde in nulla voluntate, quae sit causa simpliciter antecedens et praerequisita ad effectum contingentem, hunc posse determinate cognosci certitudinaliter. Dico „determinate“; nam indeterminatam et disiunctivam scientiam liberam, qua Deus cognoscat hunc vel illum actum libere oriturum hic et nunc ab arbitrio creato, potest Deus in sua voluntate efficaci et omnino antecedente habere, quia ipsa decernit efficaciter, quod fiat $\mathrm{ab}$ arbitrio creato hic vel ille actus, et quod fiat libere, ut ipse S. Doctor manifeste docet q. 16 De Malo art. 7. Divina ergo voluntas, ut antecedens est, vult et ostendit cum disiunctione unum vel alterum ex oppositis extremis libere futurum. Ut autem ostendit unum determinate futurum, non potest omnino antecedens esse, sed aliquam consequentem suppositionem involvere, ut citato loco citatis et collatis $\mathrm{S}$. Thomae testimoniis contra Ioannem a S. Thoma ostendi.

20. Ad tertium respondeo, nos non negare, quod S. Thomas asserat, futura contingentia aliquo modo cognosci in [803v] suis causis (ut capite praecedenti animadvertimus et capitibus $4^{\circ}$ et $5^{\circ}$ probabitur). Nam certum est, quod in causa increata futura contingentia cognoscantur tanquam in obiecto motivo, et etiam, quod in causa creata aliquo modo cognoscantur, quatenus videt Deus ordinem causarum ad illa, seu modum quo in causis continentur. Qui est modus continentiae indeterminatae seu continentiae non determinantis nec exigentis unum prae alio. Solum ergo negamus, quod determinate cognoscat Deus futura contingentia in aliqua causa - sive creata, sive increata - tanquam in obiecto sufficienter determinativo ad notitiam certam et determinatam illorum, seu cum quo connectatur determinata illorum praescientia. Nam de hoc tantummodo controvertimus.

21. Quae autem adducit pro se Alvarez, nec fideliter nec admodum considerate in medium producta videntur: non fideliter, quia S. Thомав textus et sensus immutatur, nec considerate, quia ex locis, quibus probari contenditur opposita sententia, manifeste ostenditur, eam improbandam esse.

Ab ultimo incipiamus. Alvarez disp. illa 10 numero 4 ait, ${ }^{17} \mathrm{~S}$. Thomam Secunda Secundae q. 171 art. 6 ad 2 docere, quod „Deus dupliciter intuetur effectus contingentes, et futuros: uno modo, ut sunt in se ipsis praesentes in aeternitate, alio modo, ut

16. proximis corr.

17. Didacus Alvarez: De auxiliis divinae gratiae et humani arbitrii viribus et libertate, ac legitima eius cum efficacia eorundem auxiliorum Concordia, Rom 1610, $91 \mathrm{a}$. 
sunt in suis causis secundis determinatis“. Ex quo infert, in causarum determinatione cognosci quid operaturae sint.

Sed textus S. Thомаe longe aliter habet. Nam nec habet particulam „secundis“ nec particulam „determinatis“, sed omnis determinationis expressam exclusionem $\mathrm{ad}^{18}$ explicationem sensus quo dicit, futura cognosci „in causis“. Verba enim S. Thомав sunt: „Ad secundum dicendum, quod divina praescientia respicit futura secundum duo: scilicet secundum quod sunt in se ipsis, inquantum scilicet illa praesentialiter intuetur, et secundum quod sunt in suis causis.“ Quid autem sit, ea cognosci „in causis“, sic explicat: „[...] inquantum scilicet videt ordinem causarum ad effectus“. Videns enim hunc ordinem causarum ad effectus contingentes videt hos, secundum quod sunt in suis causis. Sunt autem sine determinatione ulla ad unum, quia causa contingens se habet ad opposita, ut S. Doctor Prima parte q. 19 art. 3, et passim alibi, docet. „In causis“ ergo, iuxta Тномам, non nisi secundum indeterminationem et disiunctionem - ab ipso doctam q. 16 De Malo art. 7 - cognosci possunt futura contingentia vel ad summum, quod inclinatio aliqua in illis detur, ut unum potius quam aliud sequatur (ut statim dicemus). Sed quid ad alia loca divertimur, cum locus citatus ab Alvarez, [804r] in quo versamur, intentum nostrum contra ipsum convincat. Immediate enim post verba illa „videt ordinem causarum ad effectus“ subiungit: „Et quamvis contingentia futura, prout sunt in se ipsis, sint determinata ad unum, tamen prout sunt in causis, non sunt determinata, quin possint aliter evenire." En exclusam a S. ThOMA determinationem causarum, quam ipsi Alvarez adscribit. Quod confirmant sequentia usque ad finem solutionis secundi illius argumenti. Nam in illis docet, Deum aliquando prophetis revelare futura communicando illis scientiam, quam habet de contingenti eventu in se ipso: et tunc prophetiae veritatem petere, quod effectus in se ipso eveniat, cuiusmodi dicit oraculum illud „ecce virgo concipiet“; aliquando vero communicando tantum illis scientiam, quam de ordine causarum habet seu dispositionem et inclinationem, quam in illis cernit, ut sit futurus effectus: et tunc veritatem infallibilem prophetiae non petere, quod effectus in se ipso revera sequatur, sed quod iuxta causarum dispositionem sequi deberet, quamvis de facto non sequatur, quia dispositio et ordo causarum non determinat inimpedibiliter secuturum esse effectum. Sic prophetatam ait mortem Ezechiae et subversionem Ninivae. Locus ergo hic aperte probat, nullam esse certam cognitionem futuri in causis ordinatis ad eius esse.

22. Locus desumptus [\$ 17] ex Prima parte q. 14 art. 13 eosdem habet defectus.

Nam imprimis litera ordine inverso traditur: quia in illa non habetur, futura non solum in se ipsis cognosci, sed etiam in causis, ut Alvarez refert. Nam, cum id quod respicit S. Doctor tanquam discursus sui intentum sit, quod Deus futurorum

18. et corr. 
cognitionem in sua praesentialitate habeat, ut per hoc certitudinem divinae cognitionis probaret, id indicat aliter concludendo „Deus autem“, inquiens, „cognoscit contingentia non solum prout sunt in suis causis, sed etiam prout unumquodque eorum est actu in se ipso", cumque sic - ut supposuerat - subdantur certae cognitioni, sequitur, Deum illam de futuris contingentibus habere.

Deinde, glossa Alvarez textum destruit. Particulae enim „cognoscit [...] ut sunt in [suis] causis“ addit hanc „scilicet determinatis“, cum S. THomas contingentia, prout sunt, indeterminata esse velit, ut ex verbis eius initio huius capitis relatis patet. Nam, duplici praemissa consideratione futurorum - in se, et in causis -, ea in se determinata et praesentia esse docet, in causis vero futura et indeterminata; [804v] a Deo autem non solum, prout sunt in causis, scilicet, secundum esse futuritionis et indeterminationis, sed etiam, prout in se praesentia et determinata sunt, cognosci. Glossa ergo „determinationis“ non glossa, sed textus iniusta correctio, censenda est.

23. Ad trium illorum capitum 1 Contra Gentiles sententiam non minus infeliciter appellat Alvarez.

In primo, quod ${ }^{19}$ est sexagesimum sextum, ${ }^{20}$ ait, ${ }^{21} \mathrm{~S}$. Тномам pronunciare: „Ea quae sunt praesentia, praeterita vel futura [nobis], cognoscit Deus secundum quod sunt in potentia sua, et in propriis causis, et in se ipsis. Et horum cognitio dicitur notitia visionis." Ita quidem est, sed quid in hac sententia pro causali contingentium determinatione decernitur? An, quia Deus futura cognoscit prout sunt in sua potentia et in propriis causis, ideo illa cognoscere debet esse in causis illis determinata? Respondebit ALVAREZ affirmative, quia de causis illis subintelligenda est particula "determinatis“. Sed glossa haec praesentis quoque textus corruptela est. Nam in illo S. Thomas futura cognosci, ait, prout sunt in causis sine determinatione, quia sic solum in causis veritatem habent contingentia. Ideoque, ut probet, non solum indeterminationem, quam habent in causis, de illis cognosci, sed etiam determinatam et certam visionem de illis haberi, prosequitur: „Horum scientia visionis dicitur: non enim Deus rerum, quae apud nos nondum sunt, videt solum esse, quod habent in suis causis, sed etiam illud, quod habent in se ipsis, inquantum eius aeternitas est praesens [...] sua indivisibilitate omni tempori, et tamen esse cuiuscumque rei Deus cognoscit per essentiam suam etc." Quod addit, ne putaretur, rerum cognitionem in se ipsis non haberi per essentiam ut motivum - licet non ut determinativum - cognitionis.

19. qui corr.

20. sexagesimus sextus corr.

21. Didacus Alvarez: De auxiliis divinae gratiae et humani arbitrii viribus et libertate, ac legitima eius cum efficacia eorundem auxiliorum Concordia, Rom 1610, 90 . 
24. Ad caput autem 67 mirum est confugisse Magistrum Alvarez, cum in eius fronte scriptum videre potuerit: „Contingens [...] certitudini cognitionis non repugnat, nisi secundum quod futurum est, non autem secundum quod praesens est. Contingens enim secundum quod futurum est", id est, secundum esse, quo in causis antecedit praesentiam, „potest non esse. Ex quo autem praesens est, pro illo tempore non potest non esse etc. [...] Relinquitur ergo, quod de contingentibus nihil prohibet, Deum ab aeterno scientiam infallibilem habere." Sic Tномаs numero $1^{\circ}$ illius capitis.

Numerum autem 2 sic incipit: Hinc „contingens a necessario differt, secundum quod unumquodque in sua causa est. Contingens enim sic in sua causa est, ut non esse ex ea possit, et esse; necessarium [...] ex sua causa non potest non esse. Secundum [805r] id vero, quod utrumque eorum in se est, non differt quantum ad esse, supra quod fundatur verum“, scilicet supra esse determinatum, „quia in contingenti secundum id, quod in se est, non est esse, et non esse, sed solum esse, licet in futurum contingens possit non esse. Divinus autem intellectus ab aeterno cognoscit res, non solum secundum esse, quod habent in causis" - quod est esse futurum et indifferenter se habens ad opposita, quando effectus est contingens -, „, sed etiam secundum esse, quod habent in se ipsis. Nihil igitur prohibet, ipsum habere aeternam cognitionem de contingentibus infallibilem." Quid clarius pro excludenda omni determinatione a futuro contingenti in omni signo quo futurum - seu antecedens actualem praesentiam - intelligitur, et pro certitudine per ordinem ad solam determinationem praesentiae statuenda? Et tamen in hoc capite, vult Alvarez, A S. Tнома numero $3^{\circ}$ huius capitis defendi, quod contingens ut futurum - seu prius natura quam praesens sit - determinatum sit a Deo, quia affirmat, „[...] ex causa contingenti completa, si non impediatur" certo secuturum effectum; scit autem Deus, an impedienda sit, vel non. Levis haec et inanis coniectura plus valuit apud Alvarez ad suam sententiam S. Thomae adscribendam quam manifesta oppositae sententiae protestatio a S. Doctore duobus numeris praecedentibus scripta. Quam facile quod volumus ab aliis nihil tale cogitantibus dici persuademur!

\section{Dupliciter hunc locum interpretatur FERRARIENSIS:}

$1^{\circ}$ Quod intelligatur „de effectibus causarum naturalium. Quia fortassis“, inquit, „de effectibus voluntatis cognitio causarum et impedimentorum non sufficit ad certitudinem [cognitionis], nisi cognoscatur ipsa causa ut [actu] ultimate operans non impedita, quod est cognoscere effectum, ut iam est in suo esse, non autem solum, ut est in causis. ${ }^{\text {22 }}$

22. Franciscus de Sylvestris Ferrariensis: In Summam contra Gentiles I, $67 \S 7$, ed. Leon. t.13, 194a. Vgl. Didacus Ruiz de Montoya: Commentarii ac Disputationes de scientia Dei 50, 4, 10, Paris 1629, 474a. 
$2^{\circ}$, et melius, dicitur, locum intellectum de effectibus voluntatis nihil obstare, quia causam liberam intelligi „non impeditam“ est intelligi non impeditam a se ipsa per operationem oppositam. Unde, effectum in causa sic "non impedita“ videri est, illum videri ut praesentem in se ipso et non ut futurum in aliqua causae determinatione. "Aliter dici potest", ait FERRARIENSIS in commentario rationis primae, "quod tunc", scilicet, in causa ut non impedita, „non cognoscitur contingens ut futurum, sed ut praesens. Quia non potest certitudinaliter cognosci causa nullo modo impediri a productione effectus, nisi quando cognoscitur usque ad [ipsam] productionem [805v] effectus inclusive, quod non impeditur [...] Et sic cognoscitur effectus ut praesens. ${ }^{\text {23 }}$ Cognosci ergo causam liberam non esse ab effectus determinati productione impediendam, est cognitio obiecti includentis formaliter ipsam praesentiam productionis, qua libere excluditur eius impedimentum.

26. Ais: Ergo S. Thomas idem per idem probavit hac tertia ratione.

Respondeo, probasse idem per idem diversimode conceptum, scilicet cognitionem praesentiae unius extremi per liberam non-existentiam oppositi. Nam cuivis manifestum esse debet, Deum cognoscere, an causa contingens impedienda sit ab amore, v.g., praescindendo a modis, quibus impediri possit. Ex illa autem propositione simpliciter concessa evidenter sequitur, amorem futurum esse cognosci: quia causa contingens completa ad amorem amabit sine ullo dubio, nisi impediatur. Quomodo autem ut sic completa impediri possit, non explicuit hac tertia ratione S. Doctor, sed explicatum in praecedentibus supponit: per hoc, quod nulla causalis determinatio aut impeditio possit dari in causa ut se habente ad opposita, eo quod in illa, ut antecedit praesentiam, quodlibet extremum sit tantummodo futurum futuritione contingenti. Quae sit ratio inferendi necessitate disiunctiva unum vel alterum, cum indifferentia tamen, ut quodlibet extremum, quod ab eiusmodi causa futurum contingenter denominatur, impediri possit per liberam oppositi existentiam.

27. Capitis tandem 68 sinistra est interpretatio. $1^{\circ}$ expendit Alvarez, ${ }^{24}$ Thomam ratione quarta asserere, quod Deus effectus cognoscat in causis, $-2^{\circ}$, quod post rationem quintam dicat, „quod Deus se ipsum cognoscendo nostrae voluntatis motus cognoscere possit“.

Ad primum respondemus, non alia solutione opus esse nisi verbis sequentibus S. Thомаe. Probat enim, cogitationes et affectus nostros a Deo cognosci, hoc syllogismo: Deus cognoscit omnia, secundum quod sunt in suis causis. At aliqua

23. Sylvestris Ferrariensis: In Summam contra Gentiles I, $67 \$ 4$, 1, ed. Leon. t.13, 192a.

24. Didacus Alvarez: De auxiliis divinae gratiae et humani arbitrii viribus et libertate, ac legitima eius cum efficacia eorundem auxiliorum Concordia, Rom 1610, 91a. 
sunt, nempe artificialia, quorum causa est intellectus et voluntas artificis. Ergo, huius cogitationes et affectus cognoscere debet Deus. Sed quae huius discursus affinitas cum cogitationibus Alvarez? Eam enim nec maior propositio habet nec minor nec consequentia.

Non consequentia, quia in hac solum concluditur, Deum cognoscere humanos affectus, quia sunt causae artificialium.

Nec minor, quia, intellectionem et volitionem artificis esse causam operum artificialium, intantum posset induci ad probandum, quod Deus in decreto suo cognoscat opera nostra, inquantum ex paritate artificis creati probaretur, [806r] divinum artificem nostros actus, qui sunt ipsius opera, decernere efficaciter, ut creatus artifex decernit sua. At nulla est haec paritas, quia opera creati artificis sunt actus potentiae locomotivae ad nutum obedientis directioni artis, quin ei possit resistere, actus autem arbitrii nostri sunt potentiae aptae resistere directioni artificis supremi, quatenus est causa omnino antecedens eius liberam determinationem. Ideoque divinus artifex ut omnino antecedens arbitrii creati exercitium, illud movet ad artefacti executionem imperio politico, creatus vero artifex despotico. Quod non tollit, quin Dei voluntati resistere non possit arbitrium, si ipse decrevit salvare nos aut in nobis opera salutis producere: si, inquam, id decreverit modis, quibus novit ea opera, etsi libera, infallibiliter tamen esse a nobis cum Dei gratia exercenda.

28. Nec tandem in maiori S. Thомав est ulla affinitas cum doctrina novi huius interpretis, quia nos etiam illam libenter concedimus. Quis enim negare potest, contingentia cognosci secundum quod sunt in suis causis? Imo inde cum S. TномA inferimus, ea non cognosci ut determinate futura in suis causis, quia non habent in illis determinate futura esse, sed indeterminate et disiunctive, quia sic solum habent veritatem ut contenta in suis causis. Quod (ut cap. $1^{\circ}$ notavi) expresse tradit ipse Thomas q. 16 De Malo art. 7: „Quae sunt ad utrumlibet, non possunt cognosci in suis causis determinate, sed sub disiunctione, utpote quod erunt, vel non erunt. Sic enim habent veritatem. "Etenim, AdversariI negare non poterunt, quod Deus cognoscat futura secundum esse quod habent in sua omnipotentia et in voluntate creata antecedenter ad determinationem divinae voluntatis. Nam ante illam evidens est, quod habent aliquod esse in causis, et hoc esse, qualecunque sit, cognosci oportere a Deo. Unde ex eo, quod dicat S. Thomas, futura cognosci a Deo secundum quod sunt in suis causis, solum sequitur, ea cognosci debere prout sunt in causis. Quod autem in illis sint determinata pro aliquo signo antecedente actualem illorum praesentiam, S. THOMAs nunquam affirmavit, sed tanta expressione negavit ubique, quanta id Recentes Thomistae affirmant.

29. Si opponas, in causis non determinatis solum cognosci contingentia ut possibilia, SANCtum vero Тномам non asserere solum, quod contingentia possibilia cognoscantur prout sunt in causis, sed etiam, $[806 \mathrm{v}]$ cognosci in illis contingentia 
futura; at transire a possibili ad futurum non habet effectus ullus nisi per decretum Dei: ergo contingentia futura cognosci nequibunt nisi vi illius, -

Respondetur facile, contingentia cognosci prout sunt in causis, et esse in causis non solum ut possibilia, sed etiam ut futura, et ut futura in causis cognosci esseque et cognosci ut futura vi decreti divini: omnia haec ADVERSARIIs concedimus. Negamus tamen, futura ut talia esse aut cognosci in causis aut decreto Dei, ut determinate futura: quia determinate futura in illis non sunt, sed indeterminate et disiunctive, ut S. Thomas q. illa 16 De Malo expresse docuit.

30. Itaque in causis, ut seclusis a decreto Dei existente, solum cognosci possunt effectus ut possibiles vel, ad summum, ut conditionate futuri: sub conditione, quod Deus illas decreto suo applicet ad operandum: quia non potest sciri vi causarum sine decreto, secuturum esse ${ }^{25}$ absolute ad illas ullum effectum. Ad hanc ergo futuritionem opus est existere aliquod decretum Dei praedeterminans quidem ad unum effectum, si hic sit necessarius, indifferens vero ad duos, si effectus sit liber, determinans tamen, ut unus vel alter a creato arbitrio cum divino concursu fiat. Quare in causa iam completa necesse est esse et videri effectum non possibilem tantum, sed etiam futurum; si tamen liber est, videri debet ut futurus contingenter: ita scilicet, ut causa illum libere ponere debeat vel impedire, ac proinde circa illum vel ponendum vel impediendum, aliquid agere et consequenter non omnino in potentia se habere. De qua futuritione toto hoc libro saepe agemus.

31. Post conscriptam hanc S. Thomae interpretationem de futuris contingentibus cognitis quidem in sua causa per modum futurorum, sed non cognitione determinate indicante unum extremum, sed disiunctive unum vel alterum esse, vidi illam expresse traditam a Patre SuArez $1^{\circ}$ De Gratia Proleg. 2 cap. 9 n. 6 his verbis: „At vero $\mathrm{D}$. Thомаs in absolute futuris aliam determinationem [...] agnoscit, nimirum praesentialitatis in aeternitate, quae non est in causa, sed in ipso effectu in se ipso [...] Ad hanc autem [...] non oportet supponere causam ad unum determinatam in actu primo; sed satis est supponere illam completam omni modo in actu primo, non ad unum tantum effectum, sed ad plures cum indifferentia. Nam a tali causa potest prodire determinatus effectus pro eius libertate, et de necessitate aliquis prodibit considerando actum ut futurum, quamvis [807r] non hic vel ille determinate ex vi dispositionis causae in actu primo completo, sed confuse aliquis. Considerando autem actum ut praesentem [...], necessario futurus est certus et determinatus actus in specie et individuo [...] Idemque modus determinationis intelligendus est in futuris conditionatis etc. ${ }^{26}$ Quibus verbis operationem liberam ut futuram

25. esse suppl.

26. SuARez: Opera omnia t.7, 110a/b. 
futuritione antecedente praesentiam - quae est futuritio in causa - docet, iuxta $\mathrm{S}$. Thомам et veritatem, habere disiunctivam necessitatem et determinationem ad hoc, ut vel libere existat vel libere impediatur a sua causa, nullam tamen determinationem ad unum.

De hac ergo futuritione fatemur, quod contingentia in causis suis completis per decretum divinum cognoscantur ut futura, at vero, ut in causis futura, non posse per certitudinem cognosci, quodnam determinate extremum sequetur, sed quod sequetur hoc aut illud vel, ad summum, quod aliquando - inspecta causarum inclinatione - sequetur hoc potius quam illud: cognitione, quae limites coniecturae non excedat. ${ }^{27}$

32. Haec omnia a S. Thoma, eadem qua a nobis expressione, asserta et centies repetita ostendimus, ut videat lector, quo iure oppositum sentientes de S. ThомaE patrocinio gloriantur. S. ThOmAE mens non quasi e tripode decernendo obtrudenda est viris doctis, sed expensis eius dictis et sententiis persuadenda. Deberent ergo novi illi interpretes quae a nobis adducta sunt Doctoris Sancti testimonia dissolvere et cum iis, quae ipsis favent, conferre. Illis enim intactis Angelicam mentem assequi aut peritis assequutam persuadere inani labore contenditur.

33. IoAnnes a S. Thoma, qui post tot scripta Nostrorum prodiit, praesertim post Hieronymum Fasolum et Didacum Ruiz, qui gravissimo authoritatis pondere ex innumeris $\mathrm{S}$. THOMAE sententiis sententiam nostram munierunt, omnibus praetermissis suam sententiam de cognitione futurorum contingentium in causis non minus fidenter quam Alvarez, S. Thomae esse pronunciat: ${ }^{28}$

$1^{\circ}$ Quia Prima parte q. 16 art. 7 ad 3 ait, effectum habere a causa, quod futurus sit, cumque sola prima causa sit „aeterna [...], non sequitur, quod ea, quae sunt, semper futura fuerint, nisi quatenus in causa sempiterna fuit, ut essent futura; quae quidem causa solus Deus est.“

$2^{\circ}$ Quia q. 12 De Veritate art. 11 Dei „consilium“ a „sententia“ distinguens in eo, "quod consilium sit dispositio Dei, qui operatur omnia secundum consilium voluntatis suae, sententia vero id, quod causarum merita et dispositiones secuturum esse indicant“, concludit: „Ex parte sententiae, quae respicit causas inferiores, invenitur [807v] mutabilitas, sed ex parte consilii invenitur semper

27. Gott keine Konjekturalerkenntnis der Zukunft beizulegen (Summa theologica Q. 14 art. 13), ist auf seiten der Jesuiten immer eines der stärksten Argumente zugunsten der Scientia Media-Hypothese gewesen. Vgl. z.B. Gabriel Vazquez: Commentaria ac Disputationes in Primam partem S. Thomae 64, 4, Opera omnia, ed. M. Chossat, Paris 1905, t.1, 517b.

28. Ionnnes A S. Thoma: Cursus theologicus in Primam partem D. Thomae 19, 2, Alcalá 1637, t.1, $590 a / b$. 
immutabilitas." Ergo in consilio suo ut causa caeteras determinante cognoscit Deus futura contingentia.

$3^{\circ}$ Quia q. 14 Primae partis art. 9 ad 3 habet, quod „Dei scientia est causa rerum voluntate adiuncta. Unde non oportet, quod quaecumque scit Deus, sint vel fuerint vel futura sint: sed solum ea quae vult esse, vel permittit“; nec est „in scientia Dei, ut illa sint, sed quod esse possint“. Ergo in divina voluntate causante aut permittente cognosci oportet quae erunt, sicut in scientia et potentia, quod esse possunt.

Haec obiectiones fidelius quidem, sed non felicius propositae sunt quam superiores.

34. Ad primam concedimus, aeternam contingentium futuritionem in sola sempiterna causa dari et consistere in eo, quod in illa fuerit, ut essent. Sumpta autem hac „futuritione“ non intentionaliter, pro divina praescientia, sed causaliter, ut eam fere semper sumit S. Thомаs, dico, cum ipso, contingentia ut futura causaliter in sempiterna causa non esse determinata ad unum nec determinate cognoscibilia, sed indeterminate et disiunctive (ut ex ipso ostendi). Nec cum ipso ${ }^{29}$ sentire potest, qui contingens, secundum quod futurum est et antecedens natura actualem praesentiam, quam in se ipso extra causas habet, vult per certitudinem cognosci posse. Cum ergo esse, quod habet in aeterna causa, sit esse futurum seu determinatio ad postea essendum in se ipso - et non actualis et formalis praesentia illius in se -, sequitur, nomine, non re, S. Tномам in hac controversia sequi, qui effectum, ut in aeterna causa futurum determinate cognoscendum esse defendit. Verum quidem est, in aeterna causa posse futura determinate cognosci, non tamen in illa, ut est omnino antecedens praesentiam futuri, sed in illa ut coniuncta cum suppositione aliqua praesentiam involvente. Quo pacto cognoscitur in ipsa Dei praescientia et in decretis absolutis conditionatae praescientiae attemperatis.

35. Secundum minus urget. Quia consilium Dei immutabile esse, unde probat, in causa immutabili omnino antecedente natura, cognoscenda determinate a Deo esse contingentia? Dices, quia cognoscenda sunt in consilio, et consilium est immutabile et omnino antecedens. Contra: Quia immutabilitas divini consilii antecedentis et causantis non petit, determinate hoc potius quam illud extremum libertatis sequi - quia in iis, ad quorum determinationem Deus creato arbitrio concedit liberam facultatem, divinae voluntatis consilium non est eligentis, sed applicantis et cooperantis, ac proinde nec statuentis, ut hoc [808r] determinate fiat, sed, quod fiat ab arbitrio eligente, et a Deo cooperante, vel hoc vel illud extremum -, unde, quodcunque sequatur, consilium Dei stabit et voluntas eius fiet. In divino ergo consilio contingentium ut est causa omnino antecedens ad illa, non cognoscit 
Deus determinate futurum, quia hoc Deus efficaciter non statuit per aliquid, quo omnino antecedentis causae munus sortiatur, sed quod erit ab arbitrio creato et potentia Dei, hoc vel illud, quia hoc est, quod Deus antecedenter decernit, non aliud. Disiunctum ergo illud, et non determinate unum potius quam alterum, futurum esse in consilio antecedente voluntatis suae cognoscit, ut quaestione citata De Malo art. 7 ipse Thомаs testatur.

36. Tertium eiusdem ponderis est. Nam, quod Deus non cognoscat fieri nisi quae fieri vult vel permittit, non probat, quod in voluntate, qua illa vult aut permittit, tanquam in causa antecedente debeat Deus determinate cognoscere, quid erit. Probat quidem, quod in divina voluntate cognoscenda sunt futura: vel indeterminate - si, quod illa sola decernit, attendatur: quia decernit disiunctive hoc aut illud extremum fore -, vel determinate: si concursui obiecti motivi, quod divina illa voluntas et essentia exercent, adiungatur existentia et praesentia determinata unius extremi in se ipso ut obiectum determinativum. Itaque nihil ex illo testimonio contra nos iure deduci potest.

Contra arguentem tamen ex illo deduci potest, scientiam, quae est causa rerum, adiuncta voluntate, non esse scientiam visionis, sed simplicis intelligentiae: quia est scientia, in qua non est „ut sint res, sed ut possint esse“, et vi cuius non oportet ea quae sciuntur, esse, aut fuisse, aut futura esse (ut libro praecedenti capite 10 ponderavimus). Thоміsтis autem familiare est hoc loco probare, quod scientia visionis sit rerum causa. Non ergo ista, ${ }^{30}$ sed scientia, in qua solum est, ut "possint esse“ contingentia, et voluntas, in qua est, ut sint futura, cum indeterminatione tamen respectu cuiusvis determinate sumpti, causa contingentium futurorum thomistice censenda est.

\section{Caput 4. Futura contingentia in solis causis omnino antecedentibus non posse a Deo determinate cognosci}

37. Sic (ut capitibus antecedentibus ostensum est) S. Thomas, qui omnibus locis a nobis expensis, in quibus negat cognitionem [808v] futurorum contingentium in causis, cum triplici limitatione propositae conclusionis intelligendus est:

$1^{\circ} \quad$ scilicet, quod neget eiusmodi cognitionem in causis omnino antecedentibus: quia nec negat remotam aliquam futuri causam, quae, ex suppositione consequenti operationis conditionate futurae, applicet indifferentia media ad absolutam eius productionem (ut libro praecedenti a capite $18^{\circ}$ ostendi), nec in hac causa negari potest futurum contingens cognosci.

30. illa corr. 
$2^{\circ}$ Quod non neget in causis omnino antecedentibus cognitionem indeterminatam et disiunctivam futuri, sed solum determinatam unius extremi, ut ipse expresse docet q. 16 De Malo art. 7.

$3^{\circ}$ Quod non asserat, futura contingentia in causis omnino antecedentibus nullo modo cognosci determinate, sed non cognosci in solis illis: ita, ut ipsae non solum concurrant motive, sed sufficienter determinent ad determinatam futurorum cognitionem.

Hunc esse S. Thomae sensum, patet ex q. 14 Primae partis art. 13 ibi: „Unde quicumque cognoscit effectum contingentem in sua causa tantum, non habet de eo nisi coniecturalem cognitionem. " Certam ergo cognitionem solum negat haberi, si sit „tantum in causa“. Unde certa esse potest, si non tantum in causa habeatur, sed partim in obiecto ipso: ita, ut causa sit obiectum motivum cognitionis, et ipse effectus determinativum (ut capitibus sequentibus explicabitur).

38. In hac conclusione $S$. Thomam sequuntur antiqui eius discipuli. Ferrariensem $1^{\circ}$ Contra Gentiles cap. 67 nobis pro hac conclusione concedit ipse BAÑEZ supra [ $\$_{5}$ ] citatus. Nec minus manifeste eam tradit Thomistarum Princeps CAPreolus. De quo Ledesma De auxiliis (sub initio) in quaestionis propositione ait: „Capreolus etiam videtur esse huius sententiae",31 scilicet, negantis praevias determinationes causales actuum liberorum, in $2^{\circ}$ [Sententiarum] dist. 45 q. 1. Sed in dist. 38 q. 1 art. 2 conclusione 1 eam ita expresse tradit, ut non possit de eius mente dubitari. Eamque probat, quia voluntas creata potest se impedire, quantumcunque sit ad eliciendam volitionem inclinata. Ideo voluntate „cognita, et quibuscumque causis ad actum volitionis concurrentibus, non potest certitudinaliter cognosci, an ipsa producet illum actum, vel non producet, an impedietur", intellige: a se ipsa, ut supra dixerat, „vel non.“ Concluditque: „Et ideo, ad hoc, quod actus eius futurus certitudinaliter cognoscatur, oportet, quod videatur in se, et non solum secundum esse, quod habet in causa sua."32 Videatur etiam conclusio 2 ad 7. argumentum Aureoli.

39. De Caietano etiam ait Ledesma, quod „videtur favere“. Videtur sane, quia id oculis cernitur a legentibus ipsum q. 57 [809r] Primae partis art. $3 \$$ „Adverte“.33 Ubi ait, „supponi“ a S. Tнома, „ut discussum q. 14, quod futura contingentia in causis sint penitus ignota: sicut de futuris necessariis ab eodem supponitur, ut peritis notum, quod in causis cognoscantur." Quaestione autem 14 S. Thомae eam

31. Petrus de Ledesma: Tractatus de divinae gratiae auxiliis, Salamanca 1611, $7 \mathrm{bD}$.

32. Ioannes Capreolus: Defensiones theologiae D. Thomae Aquinatis, Tours 1900-07, t.2, 46ob.

33. Thomas de Vio Caietanus: Commentaria in Primam partem Summae theologiae Angelici Doctoris S. Thomae Aquinatis Q. 57 art. $3 \$ 4$, in Thomas Aquinas: Opera omnia ed. Leon., Rom 1888ff., t.5, 75b. 
sententiam CAIETANUs probat ob indeterminationem, quam necesse est contingentia in suis causis habere. Futura contingentia, ait $\$$ „Ad obiectiones autem“, 34 comparata ad causas determinatas ad productionem alicuius magis quam oppositi, „declinant a contingentia, secundum quod determinatio causarum ad alteram partem magis, vel minus, vel totaliter exigit." Et ne dubitari posset, doctrinam hanc exclusionis contingentiae per determinationem causae intelligendam quoque esse de prima causa, ac, proinde, eius determinationem praeviam, si daretur, contingentiae repugnaturam, explicans CAIETANUs, quomodo intelligendum sit, causam secundam non agere nisi ut motam a prima, ait $\$$ „Nec sustinendus“, $35 \mathrm{id}$ non debere intelligi de „motione praevia actioni propriae“, sed de „motione cooperante intrinsece ad propriam actionem“. Ergo, ex sententia CAIETANI, impossibile est, contingentem et liberum effectum, si talis remaneat, esse aut cognosci in causa omnino determinata ad ipsum, sive ex natura causae, sive ex accidentaliter adveniente praedeterminatione primae causae provenire dicatur determinatio.

40. Eandem doctrinam prius tradidit insignis Thomista Aegidius Romanus in Castigatorio art. 3 ad 4. argumentum..$^{36}$ De aliis vide Fasolum Prima parte q. 14 art. 13 dubitatione $9 .{ }^{37}$ Eiusdem sententiae sunt omnes, quos libro $2^{\circ}$ capitibus 11 , 13, et 14 citavi pro neganda determinatione praevia causae liberae. Nam in hac, non determinata ad unum, non potest determinate unum potius quam aliud cognosci. Qui autem eiusmodi praedeterminationem negant, sunt - praeter S. THомам et antiquos Thomistas, Scotumque et Scotistas (ut ostendunt Montepiloso, Faber et Hugo Cavellus) - Scholasticorum antesignati Magister Sententiarum, Alexander, D. Bonaventura, Albertus, Ockamus, Gregorius et fere omnes antiquitatis Doctores. Ex quibus triginta nobis concedunt BAÑEZ, LEDESMA, ZUMEL et alii oppositae factionis (ut loco citato ostensum est). In quo Scholastici sanctos Patres ibidem citatos imitati sunt plurimosque alios, quos libro praecedenti capite 7 atque libro $2^{\circ}$ capitibus 11,13 et 14 adduximus, ut sartum et tectum statuentes, contingentia non ideo futura esse, [809v] quia praesciuntur a Deo, sed ideo praesciri, quia futura sunt.

34. Caietanus: In Primam partem Q. 14 art. $13 \$ 14$, ed. Leon. t.4, 189b.

35. Caietanus: In Primam partem Q. 14 art. $13 \$ 23$, ed. Leon. t.4, $191 \mathrm{a}$.

36. Aegidius Romanus: Defensorium seu Correctorium librorum Doctoris Angelici S. Thomae Aquinatis in Guilhelmi Lamerensis Thomae Mastigis Corruptorium, ed. Walter Heinrich Streuesdorff OSA., Köln 1624 / Repr. Frankfurt a.M. 1968, 30-31.

37. Hieronymus Fasolus: In Primam partem Summae S. Thomae commentaria, Lyon 1623-36, t.2, 114-16. 
41. Quam doctrinam totius antiquitatis authoritate venerandam esse, docet Franciscus Romaeus Praedicatorum Ordinis Generalis Magister, qui centum ab hinc annis floruit. Cuius verba libro De libertate operum, veritate 8 , sunt haec: "Quodsi ad antiquos Doctores te convertas, reperies fere omnes in hanc unam convenisse sententiam, [...] non ex eo, quod Deus scit aliquid futurum esse, idcirco futurum est“ - loquitur de pendentibus a nostra libertate -, ,sed quia futurum est, Deus novit etc. "38 Nam hinc evidenter sequitur, ex Sanctorum Patrum et Doctorum sententia, non cognosci futura a Deo vi ullius antecedentis causae, etiam divinae determinantis decreto suo causas ${ }^{39}$ secundas. Si enim in praevio hoc decreto cognoscerentur a Deo futura, inanis esset Patrum doctrina. Ea enim utebantur Patres ad persuadendam ethnicis libertatem operationum nostrarum, quamvis a Deo praesciantur, et ad salvandum, quod Deo nequaquam tribuendum sit, quod male operemur. Id autem non salvari, si contingentia cognoscantur in Dei decreto, manifestum est. Nam si id sensissent, nullo negotio ab ethnicis et haereticis eorum responsio ut inanis et sibi nequaquam constans sic redargui posset: Respondetis, nos libere operari, quamvis Deus nos operaturos praesciat: quia non ideo operamur, quia praescit, sed Deum praescire, quia operamur. Contra: Vos dicitis, Deum praescire nostram operationem, quia illam efficaciter decernit. Ex hoc autem sequitur, imprimis, esse aliud ob quod operamur aeque infallibiliter inferens nostram operationem, ac eam infert praescientia. Inaniter ergo refugitis concedere, nos operari, quia Deus nos operaturos praescit, cum concedatis, nos operari, quia Deus decernit. Et inanius confugitis ad praescientiam non causantem tanquam ad libertatis propugnaculum, cum supponatis aliam causam non minoris determinationis, qua actus praedeterminetur. Nam si decreti infallibilis praevia causalitas non obstat libertati, ut quid negatur ea causalitas praescientiae ob effectus, quem cognoscit, libertatem? Vel quo indicio nobis persuadetur libertas operationum ob negatam praescientiae infallibilis ${ }^{40}$ causalitatem in illas, si infallibili decreto eadem causalitas conceditur? Deinde, si praevii decreti vi praescit Deus, quid operaturi sumus, necesse est - ut etiam Recentiones Thomistae fatentur -, praescientiam huius decreti esse causam nostrae operationis, cum vi illius dirigatur Deus ad exequendum id, quod ab ipso decretum est. Contradicentia ergo sunt, nos non operari, quia Deus nos praescit operaturos, et, Deum praescire, quod operabimur, vi antecedentis et inviolabilis decreti nostrae operationis. [81or]

38. Franciscus Romaeus: De libertate operum et necessitate, adversus pseudophilosophos christianos, Lyon 1558, 49. Apologetischer Gemeinplatz der Jesuitentheologie; zitiert z.B. auch von Rodericus de Arriaga: Disputationes theologicae in Primam partem D. Thomae 20, 38, Antwerpen 1643, t.1, 210a.

39. causas suppl.

4o. infallibili corr. 
42. Eodem modo redarguere possent ethnici et haeretici Patrum responsionem, qua parte defendit, peccata nostra Deo illa praescienti non tribui. Nam et illa futura esse, patet, quia praesciuntur, si praesciri dicantur in decreto. Et licet id non sequeretur, attamen nequaquam Deus vindicaretur a calumnia causantis peccata - loquor de entitatibus actuum pravorum, quia eorum causalitas sufficit ad intentum praesens. Voluerunt enim Patres Deum liberare a calumnia causantis peccata praescita, non, quia non est causa formalitatis peccati, sed, quia non ideo actus futurus est, quia Deus novit illum esse futurum. Quae ratio inanis esset, si praescientia aliud supponeret ex parte divinae providentiae, cui causalitatem, praescientiae negatam, concederent. Adde, ethnicos indiscriminatim de scientia et providentia blasphemasse, quod libertatem everterent et ad peccatum exequendum determinarent, Patresque ipsis satisfecisse per hoc, quod scientia Dei non sit causa, cur operemur, sed nos simus in causa, quod Deus de nobis praesciat, quid operaturi simus. Ex quo sequitur, Patres non agnovisse in divina providentia aliquid omnino antecedens praescientiam, quod sit determinata causa nostrae operationis, et in quo praescientia, illam futuram esse, cognosceret - si enim aliquid huiusmodi daretur, nullius momenti esset ad probandum, quod divina providentia libertati non obstat -, ideo Deum praescire nostram operationem, quia operaturi sumus, et non e contra: cum aliud, praeter eius praescientiam, determinate causans operationem, libertatem - a praescientia, quia non est causa, non laesam - laedere posset, quia determinata causa est.

43. Denique, haec omnia confirmantur ex Patrum contrapositione, qua causalem existentiae operum "quia praesciuntur" negantes, affirmant illam de praescientia comparatione operum, scilicet, ideo illa praesciri, quia extitura sunt. Hoc enim manifeste innuit, non dari aliam rationem operibus priorem, ob quam Deus opera praesciat. Si enim daretur, non recte diceretur, Deum praescire opera futura esse, quia futura sunt, sed: ideo praesciri futura, quia decreta sunt. ${ }^{41}$ „Inepte enim dixeris“, ait Lessius in Apologetico de gratia efficaci cap. 3 n. 24, „Deum [...] praescivisse futuros Angelos, quia futuri erant, cum causam, cur futuri essent, [...] apud se haberet: suum videlicet decretum. " 42 Sed de his vide, quae diximus libro praecedenti capitibus $5^{\circ}, 6^{\circ}, 7^{\circ}, 9^{\circ}$ et $10^{\circ}$, et libro $2^{\circ}$ capite $17^{\circ}$ et sequentibus.

41. „Et sane, ut recte observavit Lessius in Apolog. De gratia efficaci cap. 3, si futura libera cognoscerentur, quia decreta sunt, non dicerentur ideo cognosci, quia sunt futura, sed, quia sunt decreta." fol. 614v/15r.

42. Leonardus Lessius: De gratia efficaci, decretis divinis, libertate arbitrii et praescientia Dei conditionata Disputatio apologetica, Antwerpen 1610, 25. 
44. Quae autem hactenus dicta sunt de Patrum et antiquorum [810v] sententia circa determinatam contingentium futurorum praescientiam in causa excludendam a Deo, eodem modo procedunt de scientia absoluta et conditionata. Ideoque ad conceptum scientiae futurorum contingentium in communi, de qua liber hic instituitur, applicanda sunt. Eius autem probationes sunt omnes, quas adduximus libro $2^{\circ}$ ad impugnandas praevias actuum liberorum determinationes. Neque enim aliter impugnari potest praescientia contingentium in causis praedeterminatis nisi praedeterminationis causarum impugnatione, nec potest, his expugnatis, defendi praescientia illorum in causis. Vide ergo libro citato praedeterminationum impugnationes: ab eversa libertate operantium, a negata non-operantibus operandi sufficientia, a destructa potestate resistendi gratiae, qua vincimus, et tentationi, cui succumbimus, ab imputandis Deo hominum flagitiis, et a multis aliis absurdis eam praedeterminationem consequentibus. Vide etiam Authores Nostros ${ }^{43}$ praescientiam contingentium futurorum in praedeterminatis causis ob praedictas rationes valide expugnantes: Bellarminum libro $4^{\circ}$ De Gratia et Libero Arbitrio cap. $15,{ }^{44}$ Suarium Opusculo de Scientia Dei libro $1^{\circ}$ cap. $3,{ }^{45}$ et Prolegomeno de Scientia Conditionata cap. 8 etc., ${ }^{46}$ Molinam, Vazquez, et Valentiam capite $1^{\circ}$ citatos, SALMERONEM tomo $4{ }^{\circ}$ parte 3 tractatu $14,{ }^{47}$ LESSIUM loco proxime citato, ARRUBAL Prima parte disput. $42,{ }^{48}$ Albertinum tomo $1^{\circ}$ folio 281,49 FAsolum Prima parte q. 14 art. 13 disp. 9, ${ }^{50}$ et GranADo ad eundem articulum, ${ }^{51}$ BECANUM Prima parte

43. An einer früheren Stelle (fol. 225r) verweist das Manuskript auch auf die Ausführungen zur Kritik des Systems der physischen Prädetermination in einem damals noch unveröffentlichten Werk aus Waddings Schule: „[...] et P. Ricardus Lynceus to.2 Philop. lib. 4 tract. 8 c. 5 et 6 [...]“ Vgl. Richardus Lynceus: Universa philosophia scholastica, Lyon 1654, t.2, 195-98.

44. Robertus Bellarminus: De controversiis christianae fidei adversus huius temporis haereticos, Neapel 1858, t.4, 375-77.

45. SuAREZ: Opera omnia t.11, 300-06.

46. SuARez: Opera omnia t.7, 96-107.

47. Alfonsus Salmeron: Commentarii in Evangelicam historiam, Köln 1604-15, t.4, 498.

48. Petrus de Arrubal: Commentaria ac Disputationes in Primam partem D. Thomae, Madrid 1619-22, t.1, 270-76.

49. Franciscus Albertinus: Corollaria, seu Quaestiones Theologicae, praecipue in Primam et Tertiam partem S. Thomae, quae deducuntur ex principiis Philosophicis complexis, Lyon 1610, 281-87.

50. Hieronymus Fasolus: In Primam partem Summae S. Thomae commentaria, Lyon 1623-36, t.2, $114-25$.

51. Iacobus Granado: Commentarii in Summam Theologiae D. Thomae, Sevilla 1623, t.1, 213-44. 
tract. $1^{\circ}$ cap. 10 q. $7,5^{52}$ Didacum Ruiz De Scientia Dei a disput. $33,{ }^{53}$ TAnnerum tomo $1^{\circ}$ disput. 2 q. 8 dub. $6 \$ 8,5^{4}$ Alarcon tractatu $2^{\circ}$ disput. 2 cap. $7,5^{55}$ HericE tractatu $1^{\circ}$ disp. 6 cap. 2 et $3 .{ }^{56}$

\section{Caput 5. An, et quo sensu, futura contingentia cognoscantur a Deo in ideis et in divina essentia}

45. De ideis celebris est controversia, an in illis cognoscat Deus futura contingentia. Negant Scotus in $1^{\circ}$ dist. 39 q. unica $\$$ „Circa istas“,57 Henricus, Durandus, Ockamus, Gabriel et alii ex antiquis, quos referunt et sequuntur P. VazQuez Prima parte disp. 65 cap. 1 1 $^{58}$ Albertinus tom. $1^{\circ}$ quaestione secunda Theologica folio 283,59 Becanus Prima parte cap. 10 q. $8,{ }^{60}$ et Fasolus Prima parte q. 14 art. 13 dubit. 10. ${ }^{61}$ Affirmativam vero sententiam docet S. Thomas Prima parte q. 14 art. 13 , et q. 15 art. 3 ad 4, et $1^{\circ}$ Contra Gentiles cap. 66 et 68, et q. 2 De Veritate art. 7 ad 6, et q. 3 De Veritate art. 6 in corpore. Quem sequuntur CAPreolus in Prima parte dist. 38 q. 1 art. 3 ad 4, Caietanus Prima parte [811r] q. 14 art. $13 \$$ „His praelibatis" ${ }^{62}$ et caeteri Antiqui et Recentiores Thomistae. Eiusdem sententiae est S. Bonaventura in $1^{\circ}$ [Sententiarum] dist. 36 art. 2 q. 3, Albertus Prima parte q. 60 membro 3 quaestione incidente, Alensis Prima etiam parte q. 23 memb. 3 art. 4, aliique plures, quos referunt et sequuntur Molina Prima parte q. 14 art. 13 disp.

52. Martinus Becanus: Summa theologiae scholasticae, Rouen $1657,65$.

53. Didacus Ruiz de Montoya: Commentarii ac Disputationes de scientia Dei, Paris 1629, $261 \mathrm{ff}$.

54. Adam Tanner: Universa Theologia scholastica, Ingolstadt 1626-27, t.1, 468.

55. Didacus Alarcon: Prima pars Theologiae scholasticae, Lyon 1633, 105-08.

56. Valentinus Herice: Quatuor tractatus in Primam partem S. Thomae, Pamplona 1623, 87-106.

57. IoAnnes Duns Scotus: I Ord. dist. $39 \$ 7$, Opera omnia ed. L. Wadding, Lyon 1639 / Repr. 1968, t.5, 1294.

58. Gabriel Vazquez: Commentaria ac Disputationes in Primam partem S. Thomae, in Opera omnia, ed. M. Chossat, Paris 1905, t.1, 530-31.

59. Franciscus Albertinus: Corollaria, seu Quaestiones Theologicae, praecipue in Primam et Tertiam partem S. Thomae, quae deducuntur ex principiis Philosophicis complexis, Lyon 1610.

6o. Martinus Becanus: Summa theologiae scholasticae, Rouen 1657, 65.

61. Hieronymus Fasolus: In Primam partem Summae S. Thomae commentaria, Lyon 1623-36, t.2, $125-27$.

62. Caietanus: In Primam partem Q. 14 art. $13 \$ 17$, ed. Leon. t.4, $190 a$. 
14 et $15,{ }^{63}$ Fonseca libro $6^{\circ}$ Metaphysicae cap. 2 q. 4 sect. $7,{ }^{64}$ et RuIz disput. 24 De Scientia Dei sect. $3 .{ }^{65}$ Idem defendit Suarez in Opusculis libro $1^{\circ}$ De Scientia Dei cap. 4, sed „ideas“, contra acceptionem communem, sumens pro ipsa futurorum scientia. ${ }^{66} \mathrm{Si}$ enim haec esset legitima ,idearum“ acceptio, non posset controverti, an per ideas aliquid cognoscatur, cum extra controversiam sit, Deum cognoscere quodvis obiectum per scientiam suam. „Idea“ ergo sumitur pro divina essentia ut immutabili aut participabili a creatura per divini artificis productionem. Ipsa ergo ut cognita a Deo, ipsum, ut exemplar, dirigente ad hoc, ut eius aliquam perfectionem in creatura deliniet, idea est, ut citati Theologi docent. Ideoque peccatorum et obiectorum omnium, quae a Deo non possunt causari, negant Theologi dari proprias ideas, ac proinde illa per ideas oppositorum obiectorum cognosci dicunt.

46. Lis haec facile dirimetur, si sensus, in quo negari, et concedi, debet cognitio futurorum in ideis aperiatur.

$1^{\circ}$ Enim, in illis solis tanquam in obiecto sufficienter determinativo divini intellectus ad determinatam praescientiam futurorum contingentium, evidens est, haec non posse cognosci. Quod utriusque partis Doctores fatentur. Nam licet D. Bonaventura, Alexander et Albertus videantur ideis solis, absque alterius consortio, vim repraesentativam futurorum concedere, non contendunt, nullo alio expectato - nec per modum virtutis repraesentativae nec per modum requisiti posse ideas actu repraesentare futura, sed, quod id possint non expectato ullo alio ut virtute aut causa cognitionis. Nam aliquid amplius requiri evidens est: sive sit voluntas divina determinans ideas, ut multi loquuntur, vel praesentia ipsorum futurorum in aeternitate, ut alii, vel utraque: ut ego S. THомAм et antiquos sensisse non dubito. Nam voluntatem divinam requirunt ad futuri cognitionem, quia, nisi per hanc determinetur divina essentia, ut velit creatum arbitrium applicare et disiunctive determinare, ut hoc vel illud agat, nihil libere futurum esse aut cognosci potest. Quia tamen haec voluntas Dei non determinat ad unum, opus est, quod [811v] alterum extremum determinate praesens sit in sua differentia temporis divinae aeternitati, ad hoc, ut idea eius obiecti aeternam cognitionem determinatam actu inferat (ut in sequentibus explicabitur). Quod non solum de futuris absolutis,

63. Ludovicus Molina: Commentaria in Primam D. Thomae partem, Cuenca 1592, 573-99.

64. Petrus de Fonseca: Commentariorum in Metaphysicorum Aristotelis Stagiritae libros T.3, Köln 1615 / Repr. 1964, 116-18.

65. Didacus Ruiz de Montoya: Commentarii ac Disputationes de scientia Dei, Paris 1629, $197 \mathrm{~b}$. Ruiz ist auch die Quelle des Autorenkatalogs.

66. „[...] idea nihil aliud est quam ipsemet actus sciendi, ut repraesentans rem existentem.“ SuÁreZ: Opera omnia t.11, 307a. Vgl. Disputationes metaphysicae 25, 1, 9-10, Opera omnia t.25, $902 \mathrm{a} / \mathrm{b}$. 
sed etiam de conditionatis suo modo intelligendum esse, infra explicabimus. Itaque idea aliud requirit, ut futuri repraesentationem actualem in Deo operetur. Etenim, ut Caietanus Prima parte q. 14 art. $13 \$$, Ad secundum autem, et reliqua“ advertit, ${ }^{67}$ divina essentia et idea aliquorum est repraesentativa "mere naturaliter" - eorum, scilicet, quae non possunt aliter se habere -, aliorum vero "naturaliter" quidem, sed „ex suppositione libera“. Futurorum vero contingentium, quae aliter se habere possunt, non potest nisi hoc modo repraesentativa esse; nam aliter futura contingentia non essent, sed essentialiter necessaria.

47. $2^{\circ}$ Futura contingentia cognosci in divinis ideis non tanquam in obiectis determinativis - scilicet, quae ex sua essentia habeant determinare ad iudicium unius extremi prae alio futuri -, sed tanquam in obiecto pure motivo - quod, scilicet, vim habeat inferendi cognitionem futuri sine connexione determinata cum illo -, affirmandum omnino est. Id enim de divina essentia dicendum esse, statim ostendemus. Essentia autem divina ab ideis indistincta est. Futura ergo contingentia quorum dantur ideae, per illam ut ideam repraesentantur, ea vero quorum non dantur ideae, per has repraesentabilia non sunt tanquam per ideas proprias, sed tanquam per ideas aliorum. Nam essentia divina ut est causa permissiva peccati, est causa productiva in se ipsa cognitionis futuri peccati, divina autem essentia ut permissiva peccati formaliter, est causativa boni oppositi, quo evitari libere possit: unde, ut obiectum formale repraesentativum peccati, est idea bonitatis oppositae.

48. $3^{\circ}$ Dicendum est, in divina essentia ut obiecto formali motivo, omnia futura contingentia cognoscenda esse, tam absoluta quam conditionata.

Sic Theologi communiter, immo et Scotus, qui futurorum cognitionem in ideis negat loco supra citato. De essentia tamen divina in $1^{\circ}$ dist. 35 q. unica $\$$ „Potest dici“68 et dist. 39 q. etiam unica $\S$ „Viso de contingentia“69 expresse docet, quod sit obiectiva ratio cognoscendi futura, quamvis dependenter a divino decreto. Quare ideis solum negat vim repraesentandi independenter a decreto.

Ratio conclusionis est, quia nihil creatum potest esse formale obiectum divinae cognitionis, ${ }^{70}$ debet ergo esse aliquid divinum. Hoc autem non potest non esse essentia [812r] Dei, quia Deus nihil potest cognoscere futurum nisi dependenter a

67. Caietanus: In Primam partem Q. 14 art. $13 \$ 17$, ed. Leon. t.4, 190a/b.

68. IoAnnes Duns Scotus: I Ord. dist. $35 \$ 9$, Opera omnia ed. L. Wadding, Lyon 1639, t.5, 1251. 69. IoAnnes Duns Scotus: I Ord. dist. $39 \$ 23$, Opera omnia ed. L. Wadding, Lyon 1639, t.5, 1307-08. Dazu Gabriel Vazquez: Commentaria ac Disputationes in Primam partem S. Thomae 65, 19, Opera omnia, ed. M. Chossat, Paris 1905, t.1, 538a.

70. Ausführlich dazu Didacus Ruiz de Montoya: Commentarii ac Disputationes de scientia Dei 10, 2-3, Paris 1629, 89-92. 
praecognita essentia, cum huius essentialis cognitio supponatur ad omnem liberam. Nihil etiam potest cognoscere futurum, quin ipsa futuri cognitio sit per se ipsam cognitio divinae essentiae, cum futurum ut ab illa producendum cognoscere debeat; non autem propter aliud: ergo propter se, ut formale et specificativum obiectum (ut in sequentibus explicabitur).

49. $4^{\circ}$ Dicendum est, conclusionem praecedentem non solum de absolutis, sed etiam de conditionatis futuris contingentibus veram esse. Nam etiam conditionatorum praescientia habet pro formali obiecto motivo essentiam divinam, cum eam ut ${ }^{71}$ cognitam praesupponat et cognoscat ut cognitam propter se et ut dantem esse cognitioni.

50. $5^{\circ}$ Dico, idem dici debere de divina voluntate, licet modo diverso. Nam nihil futurum cognoscitur nisi per divinam voluntatem ut futuri principium - vel positivum vel permissivum - et ut cognitionis futuri obiectum. Nihil enim - nec absolute nec conditionate - cognoscitur esse futurum nisi per ea sine quibus non potest esse. Nihil autem esse potest, iuxta Augustinum in Enchiridio cap. 95, „nisi omnipotens fieri velit, vel sinendo, ut fiat, vel ipse faciendo ${ }^{\prime \prime}:{ }^{72}$ ut fiat, vel ipse efficiendo. Quaevis ergo futuri cognitio divinam voluntatem, a qua dependet, cognoscere debet. Cognoscit autem illam ut specificativum sui, quia illam cognoscit propter se ipsam vel tanquam principium a quo est, vel tanquam finem ob quam est. Nam, cum infinitae excellentiae sit voluntas illa, aliqua habitudo ex his duabus illi potest, ac proinde debet, competere respectu cognitionis sui.

Nec obstat, voluntatem, a qua dependere cognoscuntur futura, esse indifferentem, ne in illa cognosci possint tanquam in obiecto formali motivo: quia hoc non petit absolutam connexionem determinatam cum cognitione obiecti materialis, ut sit eius formale specificativum, sed vim illam inferendi posita aliqua conditione: sicuti videmus in essentia ut est obiectum specificativum praescientiae futurorum, et sicut causa ut sit effectiva, immo et necessario effectiva, non petit absolutam et determinatam connexionem cum effectu, sed sufficit esse connexam cum illo sub aliqua conditione.

51. $6^{\circ}$ Haec tamen est in divina voluntate diversitas obiectiva respectu scientiae conditionatae, ${ }^{73}$ et absolutae, quod ad hanc requiritur existens, immo et praeexistens, [812v] voluntas divina, quae requiritur ad esse futuri - quia praescientia absoluta hanc voluntatem ut libere existentem affirmat et supponit -, ad scientiam vero

71. et corr.

72. Augustinus: Enchiridion 95, PL 40, 276.

73. conditionis corr. 
conditionatam futuri nec praeexistens neque existens requiritur voluntas divina necessaria ad esse futuri, quia illam non affirmat esse, sed sub illa affirmat futurum. Unde praescientiae absolutae divina voluntas est obiectum formale ut principium virtualiter influens in illam, at vero respectu conditionatae scientiae non est formale obiectum ut principium, sed, ut finis propter quem existit divina essentia, et cuius est species intelligibilis. Deus enim omnes actus suos possibiles utpote infinitos et infinite amabiles, amat necessario propter se ipsos. Unde amor necessarius Dei et essentia, cum qua identificatur et quam constituit, est propter divinos actus, ut esse est propter operari (licet etiam illi respiciant divinam essentiam ut finem, et principium). Hinc est, quod actus illi possibiles possint per divinam essentiam influere in cognitionem sui ut formale obiectum: quia ad hoc sufficit, obiectum per speciem, quae propter ipsum existat, influere in cognitionem.

52. Si opponas, Deum actus suos possibiles, quos non affirmat existere, sed sub conditione illorum affirmat extitura alia obiecta, hos, inquam, actus cognoscere propter essentiam suam ut formale obiectum illorum: ergo non propter se ipsos; ac proinde non erunt obiectum formale cognitionis eorum, quae sub conditione talium actuum futura affirmantur, -

Respondetur negando primam consequentiam. Nam licet omnes divini actus sive existentes sint, sive non -, cognoscantur propter divinam essentiam, cognoscuntur etiam propter se ipsos: sicut personales perfectiones cognoscuntur propter se ipsas et etiam propter essentiam, sicut etiam essentia propter se ipsam et propter personas cognoscitur, quia, sicut personae propter se sunt et propter essentiam, sic etiam essentia et propter se et propter personas existit (sunt enim sibi invicem fines - ut S. Thomas de essentia asserit q. 22 De Veritate art. 1 ad 12, et q. 23 art. 1 ad 6, de personis vero ad 3 , et art. 1 eiusdem quaestionis in corpore, et alibi saepe -, licet soli essentiae conveniat habitudo principii virtualis respectu personarum). Et propter se cognoscuntur personae, quia utrumque hoc obiectum est specificativum cognitionis suae et alterius. Ex quo fit, neutrum esse materiale, quia quod tale est, nullatenus propter se cognoscitur. Similiter ergo actus divini, qui possibiles cognoscuntur et ad alia, sub conditione illorum, affirmanda assumuntur, tam propter se cognoscuntur - ut finis -, quam propter essentiam ut habentem rationem finis [813r] et principii cognitionis ipsorum, ideoque non materiale, sed formale obiectum sunt divinae cognitionis affirmantis aliquid, sub ipsis, futurum.

53. $7^{\circ}$ Dico: Quod de divina voluntate dicimus, dicendum est de praedestinatione, sine qua non possunt esse bona, et permissione, sine qua non possunt esse mala: quia eo ipso, quod sine illis nequeant esse bona, aut mala, utrorumque praescientia necessario respicit illas, et respicit illas ut specificativa et formalia obiecta et non ut pure materialia. 
De scientia absoluta facilius id intelligitur: quia, cum praedestinatio necessaria ad esse actus boni sit divina voluntas indifferens, qua Deus illum, quantum est ex se, esse positive intendit - ideoque tribuit omnia praerequisita ad eius esse -, et praescientia conditionata, qua novit Deus, habita a Deo hac voluntate, hominem esse bene operaturum, utrumque vero horum habet pro obiecto praescientia absoluta. Et in illo cognoscit extiturum esse actum.

De scientia vero conditionata paulo quidem difficilius, sed satis bene, intelligitur. Nam scientia illa non potest non cognoscere se ipsam. Unde cognoscens, quod, si Deus velit, quantum est ex se, actum bonum, hic erit, cognoscere necessario debet, eam voluntatem, si habeatur, fore identificandam cum praescientia conditionata actus futuri sub illa et consequenter fore praedestinativam. Praedestinationem ergo cognoscit ut formale obiectum, et conditionatum ut materiale. Quod sufficit, ut dicatur conditionatum „in“ praedestinatione cognoscere.

Idemque dicendum est de permissione, quia haec duplex est: alia in actu primo, qua constituitur per solam voluntatem illam, qua Deus ex se vult actum bonum nam, ut hic libere fiat, vult Deus non impedire, per libertatis denegationem, oppositum actum malum, in quo displicet -, alia est in actu secundo: scilicet voluntas haec ut habens adiunctam praescientiam eventus mali secuturi - per accidens et contra Dei intentionem - ad voluntatem illam non negandi, sed dandi, libertatem ad illum. Utraque autem haec permissio cognoscitur, et cognoscitur ut formale obiectum, peccatum vero futurum ut obiectum materiale. Haec omnia explicatius tradenda sunt, dum egerimus in particulari de modo, quo utraque haec scientia in essentiam, et voluntatem divinam tendit.

54. $8^{\circ}$ Tandem dicendum est, in divina essentia cognosci futura tanquam in specie intelligibili illorum et tanquam in principio intellectivo. Principii [813v] intellectivi habitudo satis nota est in divina essentia respectu actuum liberorum scientiae et voluntatis, quia est virtuale principium illorum: et intelligens et volens per illos. Habitudo autem speciei intelligibilis est ab omnibus Theologis recepta - cum D. Tнома Prima parte q. 14 art. 2, 4, et 11, 12, 14-, quia species intelligibilis est id, quo obiectum proxime intelligibile redditur. Divina autem essentia est id, quo proxime intelligibilia redduntur a Deo omnia quae intelligit. Nam licet aliud, praeter Deum, ad futura intelligenda requiratur, non requiritur ut influens, sed ut conditio extrinsece requisita ad hoc, ut influat divina essentia. Haec ergo intellectus, obiecti formalis, et intelligibilis speciei rationes habet respectu futurorum contingentium. 


\section{Caput 6. An, et quo sensu, futura contingentia cognoscuntur a Deo ,in se ipsis“}

55. $1^{\circ}$ Dicendum est, ea aliquo vero sensu in se ipsis cognosci, quia sic passim Theologi loquuntur, ${ }^{74}$ praesertim S. Тномаs locis omnibus citatis capite $2^{\circ}$ et $3^{\circ}$, ad probandum, quod futura contingentia non cognoscantur in causis. Nam fere semper addit, cognosci non in causis, sed „in se ipsis“. Videatur Prima parte q. 14 art. 6 ad 1, et art. 13 tertio quoque verbo, q. 57 art. 3 in corpore, et ad 3, et q. 20 art. 2 ad 2. Item Secunda Secundae q. 171 art. 6 ad 2, et q. 174 art. 1 in corpore, et $1^{\circ}$ Contra Gentiles cap. 66, et saepius cap. 67. Similiter q. 2 De Veritate art. 4 ad 6, et art. 12 in corpore, in $1^{\circ}$ [Sententiarum] dist. 38 q. 1 (unica est) art. 5 in corpore, ${ }^{75}$ et ad 3 , et tandem q. 16 De Malo art. 7: „Respondeo dicendum, quod dupliciter possunt futura cognosci: uno modo in se ipsis, alio modo in suis causis. In se ipsis quidem a nullo cognosci possunt, nisi a Deo.“ Et paucis interiectis: „[... impossibile est, quod aliqua cognitio subiacens ordini temporis cognoscat futura in se ipsis. Talis autem est omnis cognitio creaturae [...] Unde impossibile est, quod aliqua creatura cognoscat futura in se ipsis. Sed hoc est proprium solius Dei, cuius cognitio est elevata supra totum ordinem temporis." Postea explicat triplicem continentiam rerum in causis: aliam indifferentem omnino ad duo, aliam omnino et inimpedibiliter determinatum ad unum, aliam determinatam impedibiliter seu inclinatam. Et concludit, sola $2^{\circ}$ modo contenta in causis posse certo in illis cognosci; ac proinde contingentia ad utrumlibet non posse nisi in se ipsis certo cognosci. S. THOMAM sequuntur Capreolus, Ferrariensis, Caietanus et caeteri Doctores antiqui et moderni relati capitibus 2 et 4 .

$56.2^{\circ}$ Dicendum est, non cognosci a Deo futura [814r] in se ipsis tanquam in obiecto formali. Qui modus cognoscendi „in“ aliquo est strictissimus et summe proprius, ideoque Deus in nullo aliquid cognoscere potest hoc modo nisi in se ipso: quia ipse solus est formale obiectum ad omnia, quae cognoscit. ${ }^{76}$

Neque etiam futura cognoscit in se ipsis eo solum titulo, quo „in se“ cognosci dicitur id cuius totum esse, quod in se habet, distinctissime cognoscitur. Nam hic sensus a proprietate scholastici sermonis recedit, licet non infrequenter a Scholasticis usurpetur et iuxta illum etiam possibilia in se ipsis cognosci a Deo dicantur a S. Thoma, S. Bonaventura, Alexandro, Alberto, Ricardo, Durando, Gregorio, Molina, Suario, Vazquez aliisque antiquis et modernis, quos refert et

74. Verbreitet aber erst seit Suárez und Vázquez: Didacus Ruiz de Montoya: Commentarii ac Disputationes de scientia Dei 29, 1, 5, Paris 1629, 243 a.

75. Der Stellenkatalog bis hierher aus RuIz De Montoya, De Scientia Dei 29, 1, 3, p. 242 b.

76. Vgl. Ruiz de Montoya, De Scientia Dei 29, 1, 1, p. 242 b. 
sequitur Didacus Ruiz De Scientia Dei disp. 11 sect. $3 .{ }^{77}$ Cognoscuntur ergo futura contingentia in se ipsis speciali modo, quo non cognoscuntur in se ipsis veritates necessariae. Quod patet ex Authoribus prima conclusione citatis. Dicunt enim ut speciale contingentibus, quod non in causis, sed in se ipsis cognosci debeant: quia de necessariis concedunt scientiam illorum in suis causis; ac proinde de illis non verificatur modus cognitionis ipsorum in se ipsis, quo dicitur, contingentia cognosci in se ipsis et non in causis.

57. $3^{\circ}$ Dicendum est, hunc specialem modum, quo futura contingentia cognoscuntur a Deo in se ipsis, consistere in eo, quod futura contingentia non solum sint obiectum terminativum, sed etiam determinativum divinae cognitionis. „Determinativum“ autem obiectum cognitionis est non solum, quod determinate exigit illam, sed, quod non praesupponit aliam determinatam exigentiam obiectivam illius. Quod enim illam supponit, non determinat, sed determinatam ab alio supponit indifferentiam cognoscendi hoc vel illud. Hoc sensu certum est, Authores dixisse, futura cognosci „in se ipsis“. Ea enim „in se ipsis“ cognosci dicuntur ab Authoribus eodem sensu, quo negant, illa cognosci „in causa“. In causa autem non negant illa cognosci ut in obiecto formali motivo et specificativo cognitionis, sed solum, quod in illa cognoscantur ut determinante absolute et absque alio requisito ad cognitionem huius potius quam illius extremi futuri. Hoc ergo sensu futurum , in se ipso" cognosci a Deo dicitur: scilicet quatenus in se et ratione sui est obiectiva ratio, quae primo determinat divinam cognitionem, "determinat“, inquam, non per influxum, sed per exigentiam, ${ }^{78}$ qua petit, quod divina essentia, per modum principii et obiecti, se determinet causaliter ad futuri cognitionem (ut in sequentibus late explicabitur). [814v]

\section{Ruiz de Montoya, De Scientia Dei, pp. 99-101.}

78. Zu ,exigentia' vgl. Rodericus de Arriaga: Cursus philosophicus: Phys. 7, 92, Antwerpen 1632, 339b. Unterschieden wird zwischen ,exigentia physica’ und ,metaphysica’: „[...] exigentia physica [...] superari potest a divina omnipotentia [...] At exigentia metaphysica superari non potest, quia haec immediate et proxime oritur ex ipsa rei natura et praedicatis eius intrinsecis [...]" Bartholomaeus Mastrius de Meldula: Disputationes theologicae in tertium librum Sententiarum 3, 444, ( $\left.{ }^{1} 1661\right)$ Venedig 1731, 181a. Waddings Wörterbuch vermeidet hier eine Festlegung: „Respondetur, ,necessitatem essendi‘ non solum sumi pro ea, quae causalis est, sed etiam pro ea, quae est pura exigentia vel connexionis. Nam quae necessario exigit aliud, aut cum illo connectitur, ex necessitate illud exigit, daturque in eo necessitas, ut aliud sit, ita ut impossibile sit, eo existente non dari aliud. Hoc sensu, quae consequuntur ad aliud, v.g. intuitus, quo cerno alium sedentem, est ,necessitas' connexionis et exigentiae respectu sessionis; eodemque sensu est ,determinatio' respectu eiusdem sessionis, non quidem ,determinatio causalis, sed purae exigentiae et connexionis, quo sensu consequentes exigentias et praesuppositiones esse ,determinationes' eodem modo, quo sunt, necessitates', manifestum est, cum non minus proprie dicantur exigentiae, determinatae quam exigentiae, necessariae ob determinatam et necessariam connexionem cum eo, quod praesupponunt: determinatio ergo purae connexionis congrue et Philosophice intelligitur respectu alterius omnino praesuppositi." fol. 179r. 
58. $4^{\circ}$ Ex dictis concluditur, futurorum cognitionem habere pro obiecto formali motivo divinam essentiam et praedicata divina necessaria ad esse futuri, pro terminativo vero et materiali futura ipsa. Quia vero ad horum cognitionem non determinatur Deus praevio aliquo praedicato divino cum tali cognitione determinate connexo, futura ipsa non solum terminant, ${ }^{79}$ sed etiam determinant praescientiam sui, ideoque in se ipsis cognosci dicuntur ut in obiecto determinativo, in causa vero increata tanquam in obiecto formali motivo. ${ }^{80}$ Dicuntur autem communiter a S. Tнома et antiquis Doctoribus non cognosci „in causis“, sed „in se ipsis“: non, ut excludant cognitionem in divina causa tanquam in motivo, sed tanquam in determinativo; sensusque illorum est, vi solius causae increatae non posse determinari intellectum divinum ad cognitionem futurorum, quia haec secundum omnia ${ }^{81}$ quae praerequiruntur causaliter ad futurum contingens, existens esse potest et cognita, quin determinetur divinus intellectus ad futuri determinatam cognitionem. Non potest autem esse praesentialiter in se futurum, quin determinetur divinus intellectus ad illius cognitionem. Ideo simpliciter in se ipsis, et non in causis, cognoscuntur futura, id est, non in causis „tantum“, ut explicuit S. Thomas Prima parte q. 14 art. 13 in corpore, seu in causis ut se solis determinate exigentibus divinam futuri praescientiam.

59. Obiicies, cognosci futura contingentia in se ipsis est cognosci immediate, sicut cognosci in alio est cognosci medio illo. At non possunt futura cognosci a Deo immediate, cum necesse sit ea cognosci propter aliud, quia formale obiectum divinae cognitionis esse non possunt. Ergo non possunt cognosci in se ipsis.

Respondeo, quod sensu proprio dicitur cognosci „in se“ debere immediate. Unde, quod omnino „in se" cognoscitur, sine ullo medio cognosci debet. Quod vero in aliquo genere cognoscitur ,in se“, id est, in genere determinativi, admitto, quod in illo genere careat medio. Sic se habet futurum contingens. Cognoscitur enim sine medio praedeterminante ad eius cognitionem; ac proinde est obiectum immediatum in genere determinativi: scilicet ante quod aliud obiectum ad eius cognitionem determinans non datur. Quare S. Thomas eodem sensu, quo dixit, futurum contingens ,in se ipso“ cognosci, illud etiam immediate a Deo cognosci docuit in $1^{\circ}$ [Sententiarum] dist. 38 q. 1 art. 5 ad 6, ubi de re contingenti ait: „Non attingit eam, nisi prout est in esse actuali suo praesentialiter considerato.“ Additque:

79. „[... terminari, iuxta communem omnium acceptionem, nihil est aliud quam cognosci, et eo modo, quo res cognoscitur, eo est ,terminus' cognitionis. " Rodericus De Arriaga: Disputationes theologicae in Primam partem D. Thomae 19, 9, Antwerpen 1643, t.1, 185b.

8o. Vgl. Didacus Ruiz de Montoya: Commentarii ac Disputationes de scientia Dei 29, 1, 6, Paris $1629,243 \mathrm{a}$.

81. per del. 
„Cursus Sortis“ ut voluntarius et liber „secundum quod erat in potentia tantum, non erat subiicibilis certitudini divinae scientiae. Si enim Deus vidisset ipsam causam", ut Sortem, „et non vidisset immediate effectum in esse suo, nunquam potuisset istud [815r] scire." En cursum liberum Sortis immediate in suo esse a Deo cognitum et non aliter certo cognoscibilem.

\section{Caput 7. Probatur contingentium futurorum cognoscibilitas in se ipsis, ut obiecto terminativo, concurrente divina essentia ut obiecto motivo, sine ullo praedeterminante decreto}

6o. Ad probationes adverte:

$1^{\circ} \quad$ In futuris contingentibus rationem obiecti determinativi nihil aliud esse quam aptitudinem et exigentiam determinandi divinam scientiam, non determinatam ad esse antecedenter ad futuri existentiam; nam per hoc habet futurum esse primam exigentiam determinatam praescientiae cum aliqua prioritate (in sequentibus explicanda). Quod sufficit ad rationem obiecti determinativi. Unde eo ipso, quod probetur, ad cognitionem futuri sufficere, quod ipsum sit aptum et potens terminare sine praecedenti ullo alio determinativo, sufficienter probatum manebit, quod futurum sit obiectum determinativum divinae cognitionis.

$2^{\circ}$ Nos in huius capitis titulo non dixisse, quod divina essentia absque ullo decreto possit sufficienter concurrere ut obiectum motivum ad cognitionem divinam, sed, quod sufficiens obiectum motivum sit absque decreto praedeterminante. Etenim decretum indifferens Dei debere, simul cum essentia, formalis obiecti et motivi rationem habere ad cognoscenda futura, capite praecedenti statutum est (et libro sequenti latius probabitur).

61. Conclusio ergo nostra est, divinam futuri contingentis praescientiam nullo obiecto a se distincto egere nisi ipsa futuri existentia ut terminante, et divina essentia cum decreto indifferenti ut obiecto movente et specificante, „cum decreto“, inquam, quod praescientia absoluta futuri affirmet et praerequirat ut existens, et quod scientia conditionata respiciat ut conditionem sub qua affirmati, quin eius aut ullius - decreti existentiam requirat.

62. Huius conclusionis Authores duobus capitibus praecedentibus retulimus.

Eius vero prima probatio est impossibilitas cognoscendi futura contingentia alio modo, scilicet, vi antecedentis determinationis in divino decreto.

Nam, iuxta S. Thомам et Thomistas citatos cap. $2^{\circ}$ et $3^{\circ}$, obiectum ut certo cognoscibile debet habere statum necessitatis: [815v] Contingentia „oportet esse necessaria secundum modum, quo subsunt divinae scientiae“, ait S. THomAs Prima parte q. 14 art. 13 ad 3. Sed nulla est necessitas futuri contingentis antecedens eius 
existentiam, ut vel ipsi Thomistae fatentur: praeviam enim determinationem necessitatem afferre, negant. Ergo antecedenter ad existentiam futurum contingens non habet statum certae cognoscibilitatis.

Deinde, futura prava nequeunt vi huius determinationis divini decreti praenosci, nam hoc, ex suo formali conceptu, deberet esse essentialiter connexum cum malitia humana antecedenter ad huius positionem: nam alias non esset sufficiens determinativum cognitionis malitiae. Id autem est impossibile, quia impossibile est, Deum simpliciter et absolute velle, quod non sit homini possibile evitare peccati malitiam. Id autem necesse est Deum velle, si eiusmodi decretum habet, quia vult ne malitiam possit evitare homo: ex suppositione divini decreti - componendo negationem entitatis pravae cum suppositione illius decreti essentialiter exigentis malitiam -, et vult, quod ponatur suppositio decreti. Vult ergo absolute ne homini sit possibile evitare peccatum.

Quod confirmatur: Quia decretum ipsum est essentialis et antecedens impossibilitas evitandi malitiam, cum sit essentialis et antecedens repugnantia cum evitatione malitiae - repugnantia autem cum aliquo est impossibilitas illius -, ergo Deus, volens antecedenter suum decretum, vellet dari, antecedenter ad malitiam, essentialem impossibilitatem vitandi ipsam. Quod et conceptui malitiae et divinae bonitati omnino repugnat.

Deinde, ${ }^{82}$ Deus non potest videre contingens in decreto, cui possit resisti. Si enim illi resisti posset, non posset sufficienter certificare de eventu obiecti decreti. At implicat, contingens causari per aliquid, cui non possit resisti.

Denique, causa relinquens sufficientiam ad libere ponendam oppositum seu negationem effectus, non est sufficiens determinativum cognitionis determinatae de futuro tali effectu, quia sufficientia ad oppositum effectus est contingentia causae ad effectum; contingens autem causa se habens ad opposita non potest certo ostendere unum. At nullum potest esse decretum Dei de futuro contingenti, quod non relinquat sufficientiam ad libere ponendum oppositum. Ergo nullum est, quod certo possit ostendere unum determinate futurum esse prae alio. - Haec late prosequuta vide libro $2^{\circ}$ praeclusis omnibus evadendi viis, quas hactenus ADVERSARII aggressi sunt.

63. Secunda probatio sit: Quia divinus intellectus non eget ad futura cognoscenda ullo principio, quo ipsa non egent ad essendum. Sed futura ad essendum in tempore non egent aeterna determinatione omnino antecedente. Ergo nec Deus ea eget ad futura cognoscenda, et consequenter ea cognoscit sine medio praedeterminante ad illorum cognitionem, vi tamen suae infinitae [816r] essentiae petentis determinare ad cognoscendum omne quod revera erit.

Duplex haec consequentia legitima est.

82. Denique corr. 
Maior autem videtur evidens, quia divinus intellectus, cum sit infinitae virtutis intellectivae, et divina essentia, cum infinita sit in ratione obiecti, habent ex se determinationem essentialem ad cognoscendum omne cognoscibile ita, ut non egeant ullo obiecto a se distincto tanquam motivo, sed tanquam pure terminativo. Ex quo sic argumentor: Ad habendam rationem obiecti terminativi nihil requiritur in obiecto nisi quod requiritur ad esse, cum omne esse sit aptum ex se terminare cognitionem, si alias detur sufficiens intellectus et sufficiens obiectum motivum. Ergo implicat, plus requiri ab aeterno ad hoc, quod Deus cognoscat obiectum, quod erit in tempore, quam quod dentur ab aeterno ea quae in aeternitate necessaria sunt ad hoc, ut, quod futurum dicitur, existat in tempore.

Minor autem, scilicet ad temporalem futuri liberi existentiam non requiri determinationem, quae futurum et eius praescientiam natura antecedat (esto non repugnaret eius libertate), probatur:

$1^{\circ}$ Quia de facto Deum hac determinatione usum non esse, constat ex Ecclesiastici 15 [v. 14], in quo docetur, Deum „relinquere hominem in manu consilii sui“, ut, quod melius ipsi visum fuerit, eligat, Deumque „apponere ipsi ignem et aquam“ - vitam et mortem -, ut „manum ad quod voluerit, porrigat“. Quis autem dicat, „relictum esse in manu consilii sui“ eum, qui, etsi consilium secum habeat de obiecto eligendo, praeoccupatur ab alio eligente, ut hoc determinate faciat et non aliud? Quis etiam optionem, nisi inani ioco, datam dicat inter ignem et aquam, si extremum, ad quod manus extendenda est, praevie determinetur $\mathrm{ab}$ apponente ignem et aquam, et impediatur impedimento insuperabili extendi manus ad alterum? ${ }^{83}$

$2^{\circ}$ Quia, loquendo in genere, non est necesse, quod omne eligens praevie determinetur ad hoc determinate eligendum: cum Deus sine ulla praevia determinatione eligat. Non repugnat autem vim hanc sic eligendi communicari creaturae: quia cum illa communicata compatitur dependentia essentialis creaturae a Deo ut prima causa, primo libero et primo determinante ad aliquid operandum, quia haec omnia per essentialem Dei cooperationem et concursus indifferentis praeparationem aptissime intelliguntur (ut libro $2^{\circ}$ a capite $54^{\circ}$ vidimus).

64. Tertia probatio sit: Quia determinata veritas temporalis futuri obiecti est Deo sufficiens ad illud sine ulla ${ }^{84}$ praedeterminatione cognoscendum ab aeterno. [816v] Nam omne verum temporale est determinate $a b$ aeterno affirmabile in se ipso $a b$

83. Vgl. Didacus Ruiz de Montoya: Commentarii ac Disputationes de scientia Dei Disp. 39 (Utrum caput 15 Ecclesiastici efficaciter probet libertatis indifferentiam esse solutam quocunque vinculo praedeterminantis necessitatis?), Paris 1629, 322-37.

84. alia corr. 
infinitae virtutis intelligentia sine ulla praevia determinatione aeterna: sicut omne verum naturale - exceptis secretis cordium - intelligibile est ab intelligentia Angelica eo ipso, quod Angelo coexistat, quin alia determinatione obiectiva egeat Angelus ad eius obiecti perceptionem (iuxta sententiam omnium THOMISTARUM asserentium, Angelos percipere obiecta, quae successive existunt, per species universales ipsis ab initio creationis inditas). Divino autem intellectui, qui aeternaliter intelligit et mensuratur aeternitate, per quam coexistit omnibus extituris, idem est, rem esse extituram, ac Angelo, de praesenti coexistere: tum, quia divinus intellectus infinitae virtutis est, et ideo videt ${ }^{85}$ ea, quae non sunt, tanquam ea, quae sunt; tum, quia, quando cognoscens habet essentialiter durationem, per quam obiecto praesens erit, quando hoc extiterit, iam, quantum est de se, praesens illi est et consequenter aeque aptum ad id cognoscendum ac cognoscentia limitata, quando coexistunt obiectis. Unde sicut haec, per coexistentiam obiecti, sunt in statu apto ad habendam cognitionem incipientem cum tali coexistentia, sic Deus per aeternitatem praesens omnibus, quantum est ex parte sua, aptissimus erit ad omnia cognoscenda, antequam sint, cognitione terminata ad eorum praesentialitatem. Haec est ratio, qua S. THomas Prima parte q. 14 art. 13 probat divinam cognitionem futurorum (de qua infra latius).

65. Quarta probatio sit: Ut Deus vi divinae suae essentiae et volitionis tanquam formalis obiecti cognoscat futura, sufficit, quod petat specificare cognitionem seu illi speciem et esse communicare posita aliqua conditione, licet essentia non petat illam poni. Etenim iuxta ipsos Adversarios divina essentia et idea est obiectum formale cognitionis futurorum - ut THоміsтAE et communiter omnium Theologorum sententia docet -, etiamsi ad cognoscenda absolute futura egeat decreto aliquo suae voluntatis (sive dicatur determinatum ad unum, sive indifferens ad duo). Ergo optime intelligitur, divinam essentiam et volitionem esse obiectum formale per hoc, quod petant dare esse cognitioni obiecti futuri: supposito, quod detur tale futurum.

\section{Negabis consequentiam:}

$1^{\circ}$ Quia essentia divina comparatur ad volitionem ut inadaequatum obiectum formale cognitionis futuri voliti. Ideoque eius positionem expectare potest, ut utraque simul influat in cognitionem. Obiectum vero futurum non potest nec partialem rationem obiecti formalis habere respectu divinae cognitionis, ideoque non potest eius positio expectari. Nam adaequata ratione formali cognoscendi posita, in intellectu sequi necesse est cognitionem obiecti materialis: quia necessaria est vel illatio vel connexio cognitionis obiecti materialis cum cognitione formalis, si hoc sit adaequata [817r] et sufficiens ratio cognoscendi, ut in obiectionibus urgebitur. 
$2^{\circ}$ Quia existentia futuri non est aeterna, sed temporalis. Unde, licet essentia, ut determinet cognitionem futuri, egere possit volitione sua, quae aeterna est, at essentia et volitio non possunt futurum expectare ut conditionem ad eius cognitionem habendam, quia haec aeterna esse debet, futurum vero est temporale.

67. Sed neutra disparitas sufficiens est, quia non solum obiectum formale partiale, sed etiam totale, potest - non absolute, sed - dependenter ab aliqua conditione, quam non exigit, determinare ad cognitionem obiecti materialis:

$1^{\circ}$ Quia causa adaequata, etiamsi naturaliter et necessario agat, saepe non habet determinare ad effectum nisi dependenter ab aliqua conditione, quam non necessario exigit: ut patet in igne comparato ad applicationem. Similiter ergo poterit divina essentia et volitio esse motivum adaequatum cognitionis futurorum et per modum naturalis causae in illam influere, quamvis egeant obiecto ut conditione, et repraesentare naturaliter quidem - ut de ideis dixit Caietanus Prima parte q. 14 art. $13 \S$, Secundum autem, et reliqua ${ }^{\text {“86 }}$-, non tamen pure naturaliter, „sed naturaliter ex aliqua suppositione“.

Consequentia probatur, quia ad esse obiecti motivi sufficit, quod ab illo habeat esse cognitio. Quod enim ita obiicitur cognitioni, ut illam in intellectu producat, sufficienter movet intellectum ad cognoscendum. Sicut ergo virtus aliqua, etsi adaequate activa sit, potest egere ad agendum conditione aliqua, quae activa nullatenus sit, sic virtus motiva, etsi adaequata sit, potest ad movendum egere alio, quod motivum non sit, sed pura motionis conditio. Sic ergo se habet divinus intellectus respectu obiecti futuri. Ex se enim habet totam virtutem principii et motivi cognitionis illius, illoque eget non, ut iuvet ad cognoscendum, sed solum, ut terminet cognitionem: movente seu influente divino obiecto et principio.

Non nego, aliqua obiecta formalia adaequata eo ipso, quod cognoscantur, nullo alio expectato determinare - ut in praemissis consequentiae et in obiecto quovis absolute connexo essentialiter cum alio patet, si perfecte cognoscatur -, sed hoc non requiri ad communem rationem motivi obiecti (ut in solutione obiectionis capite sequenti proponendae explicabitur).

68. Secunda etiam disparitas reiicitur, quia ab aeterno cognoscente expectari praesentiam obiecti contingentis futuri ad illud cognoscendum, non est, cognitionis exercitium suspendendum esse, donec adveniat existentia obiecti - ita, ut cum hac incipere debeat cognitio -, [817v] sed, ad aeternum cognitionis exercitium expectari temporalem obiecti praesentiam ad aeternitatem. Per expectationem hanc intelligo indifferentiam divini esse ad cognoscere, et non cognoscere futuri,

86. CaIetanus: In Primam partem Q. 14 art. $13 \$ 17$, ed. Leon. t.4, 19 ob. 
et necessariam existentiam futuri in se existentis ad hoc, ut ab aeterno cognoscatur. Aeterno enim cognoscenti (ut capite $18^{\circ}$ ostendemus) sufficit temporalis praesentia sui obiecti ad aeternitatem, ut cognosci aeternaliter possit. Nam ad cognoscendum aliquid, sufficit, illud esse praesens cognoscenti in duratione, qua cognoscere debet: ut ad comburendum sufficit, combustibile esse approximatum combustivo in loco et tempore, quo combustio exercenda est. ${ }^{87}$ At eo ipso, quod aliquid temporaliter coexistat aeternitati, coexistit divino cognoscenti secundum durationem, in qua cognitionem exercere debet, quia duratio haec est aeternitas. Ergo coexistit illi cum sufficienti approximatione, ut aeternam exerceat cognitionem. Temporalis ergo duratio obiecti non est disparitas sufficiens ad hoc, ut negetur temporali existentiae obiecti ratio conditionis et approximationis obiecti necessaria et sufficiens ad aeternam eius praesentiam (supposita infinita sufficientia motivi et intellectivi divini).

69. Quinta tandem probatio sit, essentiam divinam sine ullo praedeterminativo decreto unius obiecti potius quam alterius, posse esse disiunctive praedeterminans absolute simul cum indifferenti decreto divino, ad hoc, ut sequatur in tempore - consequutione causalitatis realis, sive positivae, sive permissivae - unum vel alterum extremum libertatis, quod arbitrio creato libuerit. Estque determinans conditionate, ut sequatur unum vel alterum sub conditione talis decreti. Ergo absque ullo decreto praedeterminante habet divina essentia sufficientem vim motivam et intellectivam futurorum contingentium absolute, et conditionate: ita, ut ad illam cum decreto consequi debeat, pro signo virtualiter posteriori, absoluta praescientia futuri, et ad illam independenter ab existente decreto scientia conditionata unius vel alterius determinati extremi.

70. Consequentia est evidens: Quia eo ipso, quod necesse sit, absolute, aut conditionate, existere in tempore vel hoc determinatum extremum libertatis vel illud, necesse est, ab aeterno verum esse, esse determinate hoc aut illud, quod est: aeterna cognitione vera cognoscibile et cognitum esse. Ergo, si absque praedeterminante decreto necessarium esse potest, quod unum vel alterum extremum libertatis vi divinae essentiae existat, necesse erit vi illius, quod cognoscatur. Divina enim essentia ex se determinata est, per modum intellectus obiecti et speciei, ad omne cognoscibile. Unde eadem necessitate, qua habet ponere in tempore physice aliquod obiectum, habet [ $818 \mathrm{r}]$ illud intentionaliter ponere in se ipsa. Quod est ponere eius cognitionem.

71. Antecedens vero probatur, quia, etsi Deus non praedeterminet suo decreto ad unum extremum libertatis determinate, potest praedeterminare disiunctive, ut unum vel alterum fiat decreto tali: ut per essentialem veritatem dicatur, quod non

87. Dieser Vergleich wird weiter erläutert $\$ \$ 245,284,289$. 
possit cum decreto illo coniungi carentia utriusque extremi collective, sed necesse sit aliquod cum illo coniungi. Ergo cum hoc decreto existente inferet essentia Dei absolute unum vel alterum extremum determinate. Et licet non existat hoc decretum, erit essentiae divinae essentiale, quod, si detur tale decretum, secuturum sit vel unum vel alterum extremum libertatis, quia essentia divina connectitur necessario cum omni aeterna veritate essentiali, immo Ipsa est omnis essentialis veritas. ${ }^{88}$ Unde, cum essentialis veritas sit, quod decretum efficax disiunctivum, quo Deus decernit unum vel alterum extremum libertatis sub arbitrio creato determinari, non possit frustrari - ac proinde necesse, quin sequatur, quod arbitrium creatum aliquod determinet -, evidens est, de conceptu divinae essentiae - ut omne decretum antecedit - esse, quod, si habeatur eiusmodi decretum, sequatur unum vel alterum extremum libertatis. De eius ergo conceptu est, independenter a decreto existente, quod sequatur vel unius vel alterius extremi determinata cognitio, et decreto habito necessum erit, quod absoluta cognitio sequatur.

72. Si autem dicas, hoc argumento non probari, determinatam cognitionem - absolutam, aut conditionatam - futuri posse intelligi sine decreto praedeterminativo ad unum, sed solum disiunctivam, -

Contra, nam determinata cognitio manifeste sequitur: cum sequatur, eo modo necessarium esse, vi divinae essentiae poni cognitionem, quo vi illius necesse est poni obiectum liberum. Ergo, cum necesse sit, vi decreti disiunctivi efficacis sequi vel determinate unum vel determinate alterum, quin posset in suspenso manere collective disiunctum - quia necessitas non est suppositionis disiunctae, qua „aliquis equus“, v.g., „requiritur ad equitandum“, sed disiunctivae, qua dicitur veritas disiunctivae enuntiationis, v.g. „aliquis homo sedet“, aliquem determinate sedentem petere $^{89}$-, manifeste sequitur, non disiunctivum actum sciendi, qui necessarius est, sed determinatum eius quod futurum est, sequi in Deo debere ex vi necessitatis absolutae, aut conditionatae, qua necesse est unum aut alterum extremum liberum determinate futurum esse..$^{\circ 0}$

73. Tota huius capitis doctrina late explicanda est in sequentibus solvendo graves obiectiones domesticas, quae plus nobis facessent [818v] negotii quam exterae, quas libro $2^{\circ}$ dissolvimus.

Prima erit, obiectum motivum non determinans intellectum ad materialis cognitionem non posse sufficiens esse ad eius cognitionem.

88. Zu diesem „konnexionistischen“ Theorem vgl. \$2 254 .

89. Zur Distinktion ,disjunkt' (Termdisjunktion) / ,disjunktiv' (Aussagendisjunktion) vgl. Petrus de Fonseca: Institutiones dialecticae 6, 28, Köln 1616, 303.

9o. $\mathrm{Zu}$ diesem Thema vgl. $\$ \$ 174,436,441,459-60$. 
Secunda, prius esse debere obiectum futurum contingens quam cognoscatur, cum, iuxta SS. Patres, ideo cognoscatur, quia futurum est; at non potest esse prius divina cognitione ut existens in se: ergo ut existens in decreto ipsum determinate continente.

Tertia, ad cognitionem divinam futuri debere supponi aeternam eius cognoscibilitatem determinatam; nulla autem eiusmodi esse potest nisi per determinationem decreti.

Quarta: Prius est, obiectum contingens ab aeterno esse futurum, quam cognosci. Ergo debet ad cognitionem praecedere aeterna eius et determinata futuritio. Haec autem determinationem ad esse necessario includit.

Quinta: Intellectus divinus prius natura determinatus esse debet ad praescientiam futuri, quam illam habeat, quia intelligendi actus - praesertim conditionatus non est formaliter liber. Ergo debet dari aeternum aliquod determinativum divini intellectus praecedens scientiam. Hoc autem non potest esse nisi decretum Dei.

Haec obiectiones late proponendae et latius dissolvendae sunt in sequentibus, et - occasione illarum - praescientiae futurorum quidditas, subsecutio ad obiectum, libertas, et concordia cum libertate explicanda est.

\section{Caput 8. Quomodo motivum indifferens ad esse et non-esse futuri obiecti possit esse motivum sufficiens ad cognoscendum determinate, illud esse futurum}

74. Obiicies $1^{\circ}$ contra praecedentem doctrinam: Sine decreto antecedenter efficaci non datur in Deo sufficiens motivum futuri cognoscendi, quia implicat, motivum aliquod intellectui sufficere, nisi sit determinativum intellectus: vel per se ipsum, si sit motivum evidens, vel per determinationem voluntatis, si sit motivum probabile. Intellectus enim non movetur ad suum assensum libere, sed necessario; ${ }^{91}$ ac proinde proposito motivo sufficiente necessario rapitur ad assensum. At secluso decreto determinante nullum est determinativum ad cognitionem determinatam futuri. Ergo decretum illud concedendum est, ut detur sufficiens motivum cognitionis futuri.

75. Ad solutionem, dico, adnotanda sunt:

Primum (quod capite $5^{\circ}$ ostensum est, scilicet), quod, licet ad scientiam conditionatam futuri contingentis non praerequiratur existens decretum Dei, quod formaliter respicit, requiri tamen ad absolutam.

91. „[...] intellectus secundum se neque est liber quoad specificationem sui actus neque quoad exercitium: ergo nullo modo est liber. “Franciscus SuAREZ: Disputationes metaphysicae 19, 5, 13, Opera omnia t.25, 715b. Zustimmend Thomas de Lemos: Panoplia Gratiae 3, 2, 11, Lüttich 1676, t.3, $115 \mathrm{~b}$. 
Secundum (quod capite praecedenti probavi) est,

- decretum hoc esse essentialiter connexum absolute cum existentia aut libera carentia [819r] futuri,

- et essentiam divinam, independenter ab existentia talis decreti, esse conditionate connexam cum hoc quod est, ponendum esse futurum aut liberam eius carentiam sub conditione, quod tale decretum habeatur a Deo;

ac proinde

- decretum requisitum, ut esse futuri contingentis absolute existat, sicut habet inferre, simul cum essentia, quod vel existat absolute futurum vel libera eius carentia, sic etiam habet essentialiter inferre, quod Deus habeat vel absolutam scientiam contingentis futuri vel absolutam scientiam carentiae liberae illius.

Et similiter

- essentia, independenter ab existentia decreti, sicut habet conditionate essentialiter inferre, quod vel existat futurum contingens (si habeatur decretum requisitum ad eius esse), vel, sub eadem conditione, eius libera carentia: ${ }^{92}$ sic habet essentialiter inferre, quod vel praesciatur, sub conditione decreti, futurum esse determinatum extremum, vel praesciatur, quod, sub conditione decreti, erit oppositum: quia habet vim inferendi scientiam eius, quod erit. Erit autem, sub conditione decreti, unum e duobus, cum carentia alterius.

Illius ergo scientiam inferre debebit essentia.

76. Dico ergo, disiunctivam hanc connexionem esse motivum sufficiens, in ratione motivi, ad cognoscendum determinate extremum, quod erit: quia, licet praescientia Dei exigat etiam obiectum ipsum, quod erit, tamen non exigit illud ut motivum aut specificativum - dans esse divinae cognitioni -, sed ut pure terminativum; nec exigit, illud obiectum ab aeterno dari, sed in tempore. Unde adaequatum obiectum, in ratione motivi et aeternaliter existentis, est divinorum praedicatorum disiunctiva connexio cum futuro. Itaque ex temporali existentia et aeterna determinatione ad hoc, quod sequatur in tempore unum vel alterum extremum libertatis, conflatur adaequatum obiectum divinae essentiae futurorum. Ex quo patet, obiectivam determinationem Dei ad cognoscendum futurum, constitui immediate et per se tam aeterno quam temporali obiecto. Quia determinatio illa petit duo:

Primum est vis specificandi seu dandi esse et speciem divinae cognitioni. Secundum est connexio determinata cum illo.

Hoc secundum non habet obiectum motivum praecedens natura divinam cognitionem, nec primum convenire potest obiecto pure terminativo. Ergo per neutrum eorum sufficienter constituitur obiectiva determinatio; ac proinde illam utrumque per se constituere debet.

92. existentia corr. 
77. Ex his respondetur obiectioni negando primum antecedens. Ad eius probationem distinguo propositionem assumptam "motivum indifferens ad duo non potest esse sufficiens intellectui ad cognoscendum [819v] unum determinate":

Quando motivum includit adaequatam sufficientiam ad esse utriusque, et intellectus ad intelligendum non eget nisi iis quibus obiectum eget ad essendum: nego, motivum illud indifferens non esse sufficiens in ratione motivi.

Quando vero vel motivum indifferens ad duo non includit adaequatam sufficientiam ad utrumque, vel intellectui non satis est ad cognoscendum quod obiecto ad essendum: concedo, non sufficere motivum indifferens, sed opus esse, intellectum moveri per aliquod determinate connexum cum obiecto, quod affirmat.

78. Ratio prioris est, quia, quando obiectum indifferens ad duo includit adaequatam sufficientiam ad existentiam utriusque, et intellectus non eget ad cognoscendum nisi iis quibus obiectum eget, ut sit, necesse est, positis ab aeterno tali intellectu et obiecto motivo - etiamsi hoc indifferens sit -, cognosci a Deo obiectum terminativum, quod erit in tempore: quia sola praerequisita indifferentia sunt. Quae exigit, dari ab aeterno temporalis existentia liberi obiecti ad hoc, ut sit, et consequenter ad hoc, ut ab aeterno cognoscatur a Deo.

79. Ratio etiam secundi manifesta est, quia, quando intellectus talis est, ut ad intelligendum non sufficiat illi, quod obiectum sit, sed ultra petit, ab eo iuvari et moveri ad intelligendum - eo quod obiectum debeat simul concurrere ad cognitionem -, necesse est, motivum cognitionis - id est, obiectum dans illi esse - non esse indifferens: quia tunc debet habere rationem motivi ipsum obiectum determinatum quod cognoscitur (vel aliud, quod propter ipsum existat et loco illius concurrat). Divinus ergo intellectus, cum non petat hoc titulo obiecta futura, potest vi indifferentis motivi illa cognoscere, quia hoc motivum est sufficiens ad illorum esse, et Deus est ita perfecte intellectivus, ut non egeat ad aeternaliter intelligendum ullo aeterno requisito nisi illis quae obiectum requirit dari in aeternitate ad hoc, ut ipsum existat in tempore. Temporalis ergo existentia obiecti, licet requiratur etiam essentialiter a divina cognitione, requiri non potest ut motivum, sed ut pure terminativum.

80. Ex dictis sequitur:

$1^{\circ} \quad$ Motivum divinum, ut determinet ad cognitionem futuri, egere ipso futuro tanquam requisito, quod terminet in se et immediate divinam cognitionem. „Immediate“, inquam, id est, sine alio medio distincto a se, quod obiectivam determinationem cognitionis adaequate constituat, seu, quod cum futuri determinata cognitione connexum sit.

$2^{\circ}$ Sequitur, quo pacto divinus intellectus a suo motivo non libere determinetur, sed necessario: quia, licet motivum secundum se non necessitet ad unum potius quam aliud extremum libertatis cognoscendum, necessitat tamen simul cum 
obiecto terminativo [82or] determinato. Quare autem praescientia divina ob connexionem determinatam, quam habet cum obiecto terminativo creato - nequaquam influente in eius esse nec habente veram prioritatem naturae respectu illius -, non exerceatur a Deo cum formali libertate, sed cum necessitate, dicemus capite $22^{\circ}$.

\section{Caput 9. De prioritate obiecti libere futuri ad divinam eius praescientiam}

81. [Obiicies:] Prioritas haec necessaria est, cum obiectum contingens futurum esse sit ratio, cur cognosci dicatur a Sanctis Patribus. Prius ergo esse debet quam scientia ipsius. ${ }^{93}$ At non est prius in se: ergo in decreto determinante ad eius esse.

Minor probatur, quia prioritas obiecti liberi ad cognitionem divinam aeterna debet esse, cum ab aeterno sit posterior divina cognitio. Nequit autem posterius dari, quin detur, aut datum sit, prius, nec potest praescientia posterior in aeternitate esse obiecto, quin de hoc verificetur ab aeterno, quod habet aliquid posterius se ipso. Hoc autem est formalissime esse prius illa. ${ }^{94}$

82. $2^{\circ}$ Probatur minor, quia obiectum nequit in tempore exercere ullam prioritatem respectu divinae praescientiae, quia temporalis existentia obiecti supponit exercitam, respectu aeternae praescientiae sui, omnem prioritatem, quae erga eam exerceri potest. Ergo nullam exercet.

Antecedens patet, quia obiectum supponit exercitam totam posterioritatem, quam ex parte sua habere potest praescientia respectu obiecti, cum haec posterioritas indistincta sit a praescientia ipsa, et haec ab aeterno existens sit. Implicat autem exerceri posterioritatem praescientiae non exercita prioritate ab eo, respectu cuius dicitur posterior (ut vidimus). 95

$83.3^{\circ}$ Probatur eadem minor, quia prioritas obiecti liberi ad praescientiam, si quae est, debet esse a quo. At implicat exerceri munus huius prioritatis respectu aeternae cognitionis ita, ut incipiat in tempore, cum nihil aliud sit prioritas a quo exercita respectu aeternae praescientiae quam aeterna huius existentia posita dependenter ab eo, respectu cuius dicitur posterior. ${ }^{96}$

93. Diesen Obersatz eines nachher $(\$ \$ 147-51)$ beantworteten Arguments läßt Wadding vorläufig gelten. Problematisiert wird er von Didacus Ruiz De Montoya: Commentarii ac Disputationes de scientia Dei 35, 3, 9, Paris 1629, 305a.

94. illo corr.

95. Beantwortet $\$ 152$.

96. Beantwortet $\$ 153$. 
84. $4^{\circ}$ Denique probatur, quia divinum aliquod praedicatum esse posterius, pendens, determinatum ab aliquo creato ut in se existente, dedecet divinam perfectionem: quia constituit veram dependentiam a priori. Tota ergo prioritas actus liberi creati ad divinam praescientiam debet esse non actus in se, sed ut existentis in divino decreto determinante ad eius esse et cognitionem. ${ }^{97}$

85. Haec prioritas accurate discutienda est ad solutionem obiectionis propositae capite praecedenti [ $\$ 74]$. Omissis vero pluribus [820v] quae alii circa illam erudite et subtiliter cogitarunt,

Dico $1^{\circ}$ : Prioritas, quam actus noster liber habet respectu divinae praescientiae, sibi non est prioritas causae nec originis - quod omnes Theologi supponunt - nec etiam est rigorosa prioritas naturae, quae nonnullis conditionibus conceditur.

Prioritas enim naturae et originis est ordo principii aut causae vel saltem conditionis, quae causam simpliciter et proxime potentem actu constituunt. Conditiones enim, licet non denominentur producentes, attamen aliquae illarum alterius producentis potentiam complete sumptam constituunt. Nam potentia in ratione completae constituitur omnibus illis quibus formaliter excluditur ab agente actualis impotentia seu impossibilitas agendi; ac proinde omnia illa praecedere debent $n a$ tura effectum - cum potentia hanc praecedentiam habeat - debentque coexistere agenti, quando effectum producit: cum agens, quando agit, debeat esse actu complete potens ad agendum et consequenter tunc habere omnia quibus potens constituitur; nam, iuxta Philoso phum $2^{\circ}$ Physicorum textu 37, „Causae actu existentes, et ea, quorum sunt causae, simul sunt ", 98 quod de causa ut completam virtutem habente intelligi necesse est. Cum ergo creatum obiectum liberum non requiratur ut coexistens Deo tanquam complete potenti ipsum praescire - quia sic potens est ab aeterno -, sequitur, obiectum illud non esse „prius" respectu praescientiae vera prioritate naturae nec originis.

86. Nec refert, si obiicias: Divinam praescientiam essentialiter requirere temporalem existentiam sui obiecti saltem ut conditionem. Quod autem haec conditio non petatur ut coexistens Deo ab aeterno, sed ut in tempore extitura, non tollit prioritatem naturae: tum, quia non-existentia possunt natura praecedere, ut patet in rebus praeteritis; tum, quia futura, etsi duratione subsequantur, possunt natura praecedere intentionalem actum, quia taliter ad illum requiruntur, ut sine futura existentia nulla sit praesens potentia.

87. Respondeo, ea quae non existunt, quando id, ad quod requiruntur, ponitur in esse, non posse ratione sui illud praecedere natura, quia non possunt per se complere actualem potentiam ad illud. Ad summum ergo possunt natura praecedere

97. Beantwortet $\$ 154$.

98. Vgl. Thomas de Aquino: In II Phys. 6, 9. 
per aliud, quod causae et effectui producendo coexistat. Ut finis praecedit natura electionem non in se, sed in intentione sui. In se enim non praecedit, sed subsequitur natura, non, inquam, praecedit natura prioritate a quo, sed prioritate eius, ad quod fluit amor et propter quod est. Etenim, ad quem - per sui cognitionem - movet, in se habet vim movendi: tanquam id, ad quod seu ad cuius existentiam - non: a cuius existentia - fluit amor. Similiter obiectum absens potest natura praecedere cognitionem per praesentem speciem, et praeterita causa [821r] per aliquid ab ipsa causatum. Et denique, futurum, si sit finalis causa, praecedit natura per se finaliter et etiam per aliquid, quod ob ipsum, tanquam ob finem, causatum est.

88. Qua doctrina statuta dico, futurum obiectum liberum non posse requiri ad divinam praescientiam ut natura praecedens: quia nec est finalis causa nec productiva nec alterius generis, nec conditio potentiam causae cognoscendi - quae in omni genere, quo causalis est virtualiter scientia divina, est solus Deus - constituens: quia futurum obiectum nec ratione sui constituit aeternam potentiam completam, quam Deus habet ad cognoscendum futurum - quia haec existens ab aeterno est -, neque etiam ratione alterius, ad quod ipsum futurum aliquo genere causae vere influat. Et consequenter absolute nullam habet veram naturae prioritatem respectu praescientiae.

89. Ex quo patet ad obiectionem [ $\$ 86]$. Nam, licet temporalis existentia obiecti requiratur ad aeternam eius praescientiam, non tamen requiritur ut constituens completam potentiam - quam Deus ab aeterno habet ad talem praescientiam -, sed ut purus praescientiae terminus, ante cuius existentiam datur integra virtus et potentia ad praesciendum. Cuius virtutis, etiam ut completa est, nullum constitutivum dependet ulla vera dependentia ab obiecto praescientiae, et consequenter hoc non potest medio alio, in quod influat, praecedere natura praescientiam.

Quod vero in obiectione dicitur, sine futura existentia obiecti nullam esse aeternam potentiam ad illius praescientiam, verum quidem est, si propositio illa faciat sensum compositum - praesciendi sine temporali existentia -, non autem, si sensus sit, non dari potentiam completam praesciendi absque eo, quod, simul cum tali potentia, detur existentia obiecti praesciendi. Quod sufficit ad veritatem doctrinae a nobis traditae. Nam a conditionibus, ${ }^{99}$ quae non requiruntur ut coexistentes causae, non dependet effectus tanquam a coexistentibus sibi ipsi, ideoque eius dependentia ab illis non est stricta illa, quae imitatur dependentiam, quam habet effectus a causa sine qua - ut sibi coexistente - nequit existere effectus: eo quod actu accipiat ab illa esse. Conditiones ergo, quae ex parte causae cum eadem necessitate coexistentiae requiruntur, sunt, quae causalitate et natura praecedunt effectum, non aliae: quia a caeteris est minor dependentia. Quae proinde non significatur per praecedentiam causalitatis aut naturae.

99. cognitionibus corr. 
90. Ex dictis sequitur, praescientiam divinam nec priorem nec posteriorem natura esse respectu futuri obiecti. Non priorem, quia non est causa illius (ut libro $2^{\circ}$ vidimus), neque posteriorem, quia neque est causata nec producta, etiam virtualiter, [821v] ab obiecto, neque est producta a divino intellectu dependenter ab obiecto tanquam a constituente actualem virtutem, qua divinus intellectus est actu et complete potens ad illam habendam seu virtualiter producendam.

91. Dices, praescientiam, si nec sit natura praecedens nec subsequens suum obiectum, debere esse concomitantem natura respectu illius - nam aliquem naturae ordinem inter se servare debent divina praescientia et obiectum ipsius -, concomitantia autem naturae aeque videtur repugnare in aeterna praescientia respectu temporalis obiecti, ac subsecutio.

Respondeo, nullum ordinem positivae simultatis aut concomitantiae naturae dari inter praescientiam divinam et obiectum creatum, sed aliud genus ordinis (de quo statim). Etenim positiva simultas naturae petit duo coniungi ad influendum respectu alicuius tertii. Quam simultatem non est necesse dari in praescientia divina et obiecto, quamvis illam dari nequaquam repugnet, cum temporale et aeternum simul natura influant in eundem effectum. Potest tamen dici, praescientiam et obiectum habere simultatem et concomitantiam naturae quasi negativam: quatenus se invicem exigunt, et neutrum exigit alterum ut natura praecedens. Nam, ut Aristoteles in Postpraedicamentis, agens de modis simultatis, ait: „Natura simul sunt, quaecunque convertuntur quidem secundum eius, quod est esse consequentiam, sed nequaquam alteri est causa, ut sit. "100 Sic autem se habent divina praescientia et creatum obiectum liberum.

92. Dico $2^{\circ}$ : Actus liberi arbitrii est prior a quo divina praescientia sui, non prioritate a quo naturae vel influxus (ut dixi), sed prioritate a quo determinationis obiectivae.

Hanc conclusionem iudico esse omnium Doctorum, qui defendunt, Deum praescire liberos actus creatos in se ipsis et non in alio Deum praedeterminante ${ }^{101}$ ad illorum cognitionem. Hi enim negant influxum creati obiecti in divinam cognitionem - etiam per modum conditionis, cuius coexistentia requiratur ad constituendum Deum potentem cognoscere -, et etiam concedunt, obiectivam determinationem Dei ad cognoscendum debere per ipsum liberum obiectum partialiter constitui. Ergo prioritas, quam concedunt in obiecto libero respectu divinae cognitionis, est prioritas a quo non influentis, sed determinantis. In explicatione autem et probatione huius prioritatis nil apud Authores invenio quod pleniore luce non egeat.

100. Aristoteles: Cat. 13, 14b27-29.

101. Vgl. $\$ \$ 138-40,275-76$. Die Anwendung von ,praedeterminari’ auf Gott ist ungewöhnlich. 


\section{Caput 10. Principium, cui innititur prioritas obiecti creati liberi ad divinam praescientiam}

93. Ego prioritatem hanc ad clarissimum principium reduco, scilicet, divinam praescientiam a nostra libera electione pendere non dependentia [822r] causalitatis, sed impedibilitatis, ${ }^{102}$ quia in nostra potestate electiva est, quod Deus ab aeterno habuerit praescientiam nostri odii, v.g., potius quam amoris, cum in nostra electione libera constituatur odium potius quam amorem exercere. Exercito autem in tempore actu odii necesse est odii potius quam amoris praescientiam in aeternitate extitisse. Praescientiam ergo Dei huius potius quam illius obiecti fuisse ab aeterno, in nostra libera potestate constitutum est non ita, ut directam ullam potestatem exerceamus circa scientiam, sed indirectam: quatenus possumus ponere et non ponere obiectum. Quo posito, ponitur, et quo non posito, impeditur praescientia illius.

94. Quam doctrinam Doctores omnes Negantes Praevias Determinationes liberorum actuum constanter defendunt, dum docent, divinam praescientiam supponere liberam nostram operationem. Qui autem in sua potestate habet suppositionem, habet etiam in eadem potestate ea quae ad illam consequuntur.

Eandem doctrinam communiter statuunt Patres et antiqui Scholastici, quos libro $3^{\circ}$ capite 5 retulimus, et alii, quos cumulate expendit Ruiz De Scientia Dei disp. 33, 34, 49 et 50, ${ }^{103}$ dum docent, non ideo hominem operaturum esse actum liberum, quia Deus id praescivit, sed ideo Deum id praescivisse, quia homo libere operaturus est. Homo ergo operando in causa est, quod Deus praesciverit, et operando oppositum faceret, quod Deus illud praescivisset. Ergo habet in potestate sua, ut praesciat Deus quod ipsi homini libuerit: non causalitatem ullam exercendo in divinam praescientiam, sed in obiectum, cum cuius esse et non-esse connectitur esse aut non esse praescientiam illius per inevitabilem connexionem.

Sic S. Thомаs doctrinam Patrum proxime traditam explicuit Prima parte $\mathrm{q}$. 14 art 8 ad 1 his verbis: „[...] ideo praescire Deum aliqua, quia sunt futura, intelligendum est secundum causam consequentiae, non secundum causam essendi“, id est, non secundum causam influentem in esse praescientiae. „Sequitur enim, si aliqua sunt futura, quod Deus ea praescierit; non tamen res futurae sunt causa,

102. Vgl. hingegen IoAnnes Duns Scotus: Reportatio Parisiensis examinata I dist. $38 \$ 44$, ed. J.R. SöDER: Johannes Duns Scotus: Pariser Vorlesungen über Wissen und Kontingenz. Lat.-Dt., Freiburg i.Br. 2005, 54: „Sed quomodo [sc. cognoscit Deus alteram partem contradictionis futuri contingentis] infallibiliter? Dico, quod [...] ratio infallibilitatis est, quia voluntas Dei est immutabilis et non impedibilis [...]“

103. Didacus Ruiz de Montoya: Commentarii ac Disputationes de scientia Dei, Paris 1629, 261-302. 417-85. 
quod Deus sciat.“ „Sequitur" intellige de consequentia a priori, nam alias sinistra esset haec S. Thомав interpretatio, ut libro praecedenti capite 3 ostendi. Vide libri illius caput 5 , quo probatur, divinam praescientiam esse suppositionem consequentem respectu liberae operationis, quam praenoscit futuram, et speciatim verba Iustini q. 58 Ad Orthodoxos ibi relata: „Non praescientiam consequitur futurum, sed futurum consequitur praescientia. " ${ }^{104}$ Et aurea, ad nostrum institutum, verba Damasceni Dialogo contra Manichaeos: [822v] „Ac quidem vis Dei praesciens a nobis causam haudquaquam habet. At vero, ut ea quae facturi sumus, praesciat, a nobis proficiscitur." ${ }^{105}$ Vide etiam Hugonem Victorinum lib. $1^{\circ}$ De Sacramentis p. 2 cap. 22, ubi docet, possibile nobis esse, quod Deus non praesciverit operationem quam in nostra potestate habemus. ${ }^{106}$ Et IOANNEM MAIOREM in $1^{\circ}$ dist. 38 ad argumenta 8 et 10, et in quaestionis epilogo, ubi libertatem cum praescientia conciliat, quia in potestate Petri est non peccando facere, quod Deus ab aeterno non sciverit ipsum esse peccaturum, sed oppositum. ${ }^{107}$ Praeterea Marsilium in $1^{\circ}$ ad finem quaestionis 40 , ubi ait, in potestate Socratis est facere, ut nunquam fuerit verum illud antecedens „Deus scit Socratem esse peccaturum“. ${ }^{108}$ Quod apud caeteros Theologos passim reperies.

95. De praedicto ergo principio videtur mihi non posse magis dubitari quam de hominis libertate ad operandum et non-operandum, et de connexione divinae praescientiae cum obiecto quod affirmat. Nam temporalis existentia obiecti est essentialis illatio aeternae praescientiae illius, et carentia talis obiecti est impeditio aeternae praescientiae illius. Ergo, cum in tempore sit nobis liberum poni tale obiectum aut eius carentiam, erit nobis in tempore liberum, quod ab aeterno fuerit existens aut impedita praescientia talis obiecti. Implicat enim simpliciter posse aliquid quod essentialiter repugnat cum alio, nisi illud impeditum reddendo aut supponendo.

104. PS.-IUstinus: Responsiones ad Orthodoxos, PG 6, $1300 \mathrm{C}$.

105. Ioannes Damascenus: Dialogus contra Manichaeos 79, PG 94, 1577B. Zitiert bei RuIZ DE Montoya: De Scientia Dei 33, 4, 13, p. 271b.

106. Hugo de S. Victore: De sacramentis christianae Fidei I/2, 22, PL 176, 215. Zitiert bei RuIZ De Montoya: De Scientia Dei 33, 4, 28, p. 273b.

107. IoAnnes Maior: In Primum Magistri Sententiarum disputationes et decisiones nuper repositae, Paris 1530, 7ov/71r. Referiert von Ruiz de Montoya: De Scientia Dei 33, 8, 17, p. 286 b.

108. Marsilius de Inghen: Quaestiones super IV libros Sententiarum I, 40, ed. M.J.F.M. Hoenen: Marsilius van Inghen ( $†$ 1396) over het goddelijke weten. Zijn plaats in de ontwikkeling van de opvattingen over het goddelijke weten ca. 1255-1396, Nijmegen 1989, Deel II, 108-110. Zitiert bei RuIZ DE Montoya: De Scientia Dei 33, 8, 19, p. 286b. 
96. Nec obstat certitudini huius principii, Doctores aliquos, quos refert et sequitur P. Ruiz disp. 31 De Scientia Dei sect. 4, dubitasse de hac propositione, immo et illam negandam censuisse: „Deus nunc est potens non habere praescientiam de peccato Antichristi“, solumque vere dici posse, quod Deus potuit ab aeterno non habere illam praescientiam. ${ }^{109}$ At esset nunc potens non habere praescientiam, si homo in tempore esset potens illam impedire, quia, illam impediri ab homine, impossibile est nisi Deo illam non habente.

Non, inquam, hoc obstat:

$1^{\circ}$ Quia quod facit aliquibus creditu difficile, quod Deus sit nunc potens non habere praescientiam obiecti liberi, est, quia id sonare videtur, Deum nunc constitui potentem ita, ut eius potentia temporaliter aut scientia in tempore exercenda videatur. At nulla ad haec imaginanda occasio datur asserendo, hominem in tempore posse non operando facere, ne detur aeterna praescientia suae operationis. Quod ex se manifestum est; ac proinde RuIzIUs ipse, qui hanc propositionem negat „Deus nunc potest non habere praescientiam peccati futuri", eo quod significare videatur potestatem temporalem et habitae praescientiae [823r] mutabilitatem, concedit tamen, citata disputatione 31 sect. 1 n. $11,{ }^{110}$ hanc propositionem ,homo potest non peccando facere, quod Deus non praesciat suum peccatum“.

$2^{\circ}$ Quia praedictam propositionem sine fundamento negant Doctores illi et contra communem sententiam Magistri, Alexandri Alensis, Alberti, S. Bonaventurae, Scoti, Durandi, Capreoli, Maioris, omniumque Nominalium et fere omnium ANTIQUORUM, ut fatetur ipse Ruiz, ubi supra sect. 2. ${ }^{111}$

96. Ego controversiam de propositione illa existimo de solo nomine esse. Nam omnes, qui de illa disputant, fatentur tria:

Primum est, Deum non posse in tempore scire aliquid quod non praescierit $\mathrm{ab}$ aeterno.

Secundum, non posse id quod semel scivit, aliquando non scire.

Tertium est, scientiam quam Deus habet de obiecto libero, non esse simpliciter necessariam Deo, sed solum ex contingenti suppositione obiecti aut ipsiusmet praescientiae.

His statutis ab utriusque sententiae Doctoribus nullum manet de re dissidium. Nam negantes, Deum nunc posse non habere praescientiam, non negant in Deo indifferentiam ad illam simpliciter et non facta suppositione obiecti aut

109. Ruiz de Montoya: De Scientia Dei 31, 4, 2, p. 252b. Vgl. ebd. 33, 9, 8, pp. 288b/89a.

110. Ruiz de Montoya: De Scientia Dei, p. 249a.

111. Ruiz de Montoya: De Scientia Dei, pp. 250-51. 
ipsius scientiae. Nec affirmantes, quod nunc potest non habere praescientiam, affirmant, dari indifferentiam ad praescientiam non habendam in sensu composito talis suppositionis. Solum ergo controverti poterit, an ex eo, quod addatur in propositione particula „nunc“, reddatur propositio illa reduplicativa alicuius suppositionis determinantis indifferentiam aeternam Dei ad habendam et non-habendam praescientiam determinati obiecti liberi. Si enim per particulam „nunc“ redderetur propositio illa reduplicativa alicuius suppositionis determinantis divinam indifferentiam, falso diceretur, Deum nunc posse non habere praescientiam. Verissime autem id diceretur, si particula illa non reddat propositionem reduplicativam ullius suppositionis determinantis.

97. Mihi videtur, non reddi propositionem illam reduplicativam suppositionis determinantis per additionem illius adverbi, ac proinde simpliciter veram esse. Sensus enim illius absolutus est, solumque affirmat, nunc dari aeternam indifferentiam Dei ad non habendam praescientiam peccati, v.g. Quod de Fide est. Nam licet de Fide etiam sit, hanc indifferentiam esse ab aeterno determinatam ad aliquod extremum, id tamen non tollit indifferentiam prioritate naturae praecedentem. Ut patet manifeste in arbitrio creato. Quod indifferens est in instanti reali, quo se determinat, cum indifferentia illius sit causa activa determinationis [823v] actualis; ${ }^{112}$ causa autem coexistere debet effectui a se immediate producto. Patet etiam aeque manifeste in Deo iuxta oppositam sententiam, quae concedit, Deum potuisse ab aeterno non habere praescientiam peccati: et tamen ab aeterno determinatus fuit vel per illam vel per oppositam praescientiam.

98. Praeterea: Ideo opposita sententia negat propositionem illam, quia nunc necesse est, ab aeterno fuisse Deum determinatum ad aliquod extremum indifferentiae. Sed etiam $a b$ aeterno necessarium fuit, Deum determinatum esse per aliquod illorum extremorum, scilicet per praescientiam peccati aut carentiam illius. Ergo, sicut dicitur, Deum fuisse indifferentem ad habendam et non-habendam praescientiam, ita et dici debet nunc quoque indifferentem esse.

99. Deinde: Indifferentia illa antecedens natura determinationem seu determinatam praescientiam aeque invariabilis est ac ipsa praescientia. Ergo sicut eo ipso, quod praescientia fuerit $a b$ aeterno, dicitur, eam nunc quoque esse, similiter de indifferentia, quae ab aeterno fuit, ad illam habendam necessario verificandum est, quod nunc quoque detur.

112. D.h. die indifferentia activa, im Unterschied zu der indifferentia obiectiva (= Wertungsspielraum der praktischen Vernunft) und der indifferentia passiva (= Gleichgewichtszustand). Für die Jesuiten konstituiert die indifferentia activa das Wesen der Freiheit. 
10o. Denique: Idem est dicere „Deus nunc est potens potentia aeterna, ad non-habendam praescientiam peccati“ ac dicere, Deum nunc habere potentiam, qua fuit $a b$ aeterno potens ad non-habendam peccati praescientiam: cum potentia aeterna a parte ante, ut aiunt, sit idem ac potentia qua $a b$ aeterno Deus potuit. Si, ergo potuit $a b$ aeterno non habere praescientiam peccati, potest etiam et nunc: non potentia, quae $\mathrm{e}^{113}$ incipiat esse, nec quae exercitium nunc incipiens habere possit, sed quae aeterna sit et aeterno exercitio determinari debeat.

101. Si obiicias, propositionem hanc „Deus nunc potest habere praescientiam peccati“ reduplicare - vel saltem aliquo modo affirmare - coexistentiam divinae potentiae intellectivae futurorum ad temporalem durationem praesentem; at coexistentia haec repugnat exercitio determinationis divinae potentiae intellectivae, quia ante omnem temporalem durationem necesse est determinationem illam exerceri, -

Respondeo, coexistentiam divinae virtutis intellectivae ad temporalem durationem, immo et huius coexistentiae reduplicationem, nec obstare virtuti intellectivae nec illius aeternae determinationi per scientiam peccati aut per oppositum: quia cum coexistentia ad aliquam temporalem durationem quis dubitet, et virtutem intellectivam et huius determinationem per quamlibet ex illis praescientiis componibilem esse? Ergo etiam sub reduplicatione coexistentiae ad temporalem durationem Deus est potens non praescire peccatum, non quidem potentia temporali nec determinanda per temporalem [824r] actum, sed potentia aeterna aeternumque actum respiciente.

102. Aliter dicendum foret, si duratio temporalis, quae reduplicatur, non esset duratio indifferens ad esse et non-esse obiecti praescientiae, sed determinata ad eius esse aut non-esse: ut si particula "nunc" designet durationem praesentis peccati, v.g. Nam si eam designans sumatur in propositione non specificative, sed reduplicative, ${ }^{114}$ falso dicetur, Deum in illo nunc - seu: ut coexistentem peccato - posse non habere eius praescientiam: quia propositio sic reduplicans significat, posse componi coexistentiam temporalem peccati cum Deo ut habente praescientiae aeternae de tali peccato carentiam. Quod omnino impossibile est.

113. non del.

114. Scholastische Distinktion zur Verwendung des Synkategorems „inquantum“. 


\section{Caput 11. Ex superiori principio deducitur et probatur actus liberi creati prioritas et determinatio obiectiva respectu divinae praescientiae}

103. Ex supradicto principio explicatur facile prioritas determinantis ad determinatum, et electivi ad eligibile, quam habet libertas operationis et arbitrii nostri respectu divinae praescientiae.

Nam id in cuius libera electione est existentia et non-existentia alterius, praecedit illud speciali prioritate, de qua Aristoteles $5^{\circ}$ Metaphysicae cap. 11 dixit: „Prius est, cuius electionem, ut alterum sequatur, necesse est. “115 Itaque ipsa necessitas existendi aut non-existendi ad alterius liberam electionem facit, quod posterius sit ipso eligente id quod tali necessitati subiacet, et quod prius sit id quod habet liberam potestatem ponendi necessitatem - seu essentialem exigentiam - existentiae alterius et similiter necessitatem, ut non existat. Necessitas haec existentiae alterius potest dupliciter a principio electivo poni:

$1^{\circ}$ Causando existentiam ipsam alterius, sive mediate, sive immediate, sicut principium liberum causat suam electionem et ea quae ab electione causantur. Nam ipsa existentia causata causatur necessitas et exigentia existendi, quam habet sibi identificatam, necessitas, inquam, existendi ex suppositione, quod existat. $2^{\circ} \quad$ Potest ita poni, ut sola necessitas seu essentialis exigentia existentiae causetur a principio electivo, quin ullo modo causet existentiam, quae exigitur.

104. Hoc secundo modo ponit necessitatem divinae praescientiae de operatione libera arbitrium creatum. Solum enim causat liberam operationem suam, quae exigit necessario dari aeternam praescientiam ita, ut, pro libertate arbitrii, posset exigi praescientia opposita, determinante se arbitrio ad oppositum obiectum. [824v] In huiusmodi potestate electiva dari prioritatem respectu eius quod in illa constituitur, expresse docuit D. Augustinus $1^{\circ}$ Retractationum cap. 22 „In nostra potestate“, inquiens, „non est nisi quod nostram sequitur voluntatem“. ${ }^{116}$ Potestas ergo electiva praecedit ea quae in tali potestate habet, ac proinde, quod haec debent esse vel voluntarii actus eligentiae a tali potestate orti vel aliquid ad illos - et consequenter ad potestatem electivam - subsecutum.

105. Probaturque manifeste:

$1^{\circ}$ Quia est vera potentia impediendi existentiam illius. Potentia autem impeditiva alterius praecedit existentiam illius, cum nihil impediri possit postquam est, nec dum est, sed antequam sit.

115. Aristoteles: Metaphysica 5, 11, 1018b23.

116. Augustinus: Retractationum I, 22, 4, PL 32, 620. 
$2^{\circ}$ Quia indifferens potestas, ut aliud sit et non sit, non potest habere indifferentiam hanc post actum nec cum inclusione actus, ad quem est indifferens: ergo illam habet in statu antecedentiae ad actum. Hinc est, potentiam liberam non solum praecedere suum actum, quia effectiva illius est, sed etiam, quia est libera facultas et potestas ad hoc, ut sit et non sit; ac proinde non solum respectu eorum quae libera potentia nostra facere potest, sed etiam respectu eorum quae non a nobis, sed ab aliis, causanda sunt, si pro nostro arbitrio impediri et ad existentiam reduci possunt, veram prioritatem exercet: ut illam formaliter exercet circa puram omissionem operationis - in sententia, quae illam admittit ${ }^{117}$-, quamvis nullam effectivam causalitatem exerceat formaliter circa talem omissionem, sed solum interpretative. ${ }^{118}$

106. $3^{\circ}$ Probatur et explicatur haec prioritas, quia non solum praecedit, quod influit, sed etiam, quod determinat non influendo, sed removendo prohibens cum potestate illud non removendi. At sic se habet ad scientiam divinam amoris, v.g., potentia libera amandi et amor, quia libera amoris carentia est essentiale impedimentum praescientiae amoris. Hoc autem impedimentum removetur per amorem cum potestate illud non removendi, et ita removetur, ut eo amoto Deus inevitabiliter determinetur ad praescientiam amoris. Cum enim ex divinae perfectionis et voluntatis efficacia necesse sit - efficacia disiunctiva -, alterutrum e duobus extremis liberis fore et determinate a Deo cognosci, sequitur, quod, si arbitrium creatum removeat prohibens ${ }^{119}$ scientiam amoris - quod est libera amoris carentia -, necessarium omnino sit dari praescientiam amoris. Ex quo patet, arbitrium creatum per amorem determinare obiective ad divinam praescientiam, concurrentibus - ad formalem praescientiae determinationem per modum potentiae et motivi - solis praedicatis divinis et arbitrio creato ut removente prohibens: quo remoto necesse sit dari praescientiam. Ex quibus concludo, arbitrium creatum, etsi non sit principium divinae scientiae, esse tamen principium impeditivum et determinativum illius: [825r] determinativum, inquam, non per influxum, sed per remotionem impedimenti aut positionem conditionis modo iam explicato. Hoc sensu intelligitur quod capite 9 diximus: dari prioritatem a quo obiecti liberi respectu divinae praescientiae. Est enim „prius" non ut principium a quo causatur, sed a quo determinatur, et a cuius libertate impediri potest praescientia. Ex dictis patet, non solum facultatem ipsam

117. Der sog. Omissionspurismus. Der Autor lehnt ihn handlungsmetaphysisch ab. Vgl. $\$ \$ 398$, 433 .

118. Zur Distinktion, formaliter / interpretative' vgl. Roвеrт Ноцкот: Determinationes quarundam quaestionum, Lyon ${ }^{1}$ 1497, F6rb: „Dicendum, quod velle dicitur dupliciter, vere vel interpretative. Vere dicitur homo velle illud, quod est obiectum actus volendi, interpretative vero, quando vult illud, ad quod sequitur aliud. Dicitur tunc illud aliud velle interpretative."

119. per del. 
electivam creatam, sed etiam eius electionem, esse priorem respectu divinae praescientiae de illa. Nam electio nostra libera est id per cuius positionem arbitrium creatum ponit necessitatem et determinationem praescientiae, et per quod impedit praescientiam de extremo opposito. Determinatio autem praescientiae per remotionem impedimenti, quod posset non tolli, prior est quam praescientia.

107. Praeterea: Quia Aristoteles $5^{\circ}$ Metaphysicae cap. 11 sic habet: „Priora et posteriora dicuntur quaedam quidem tanquam aliquo primo et principio in singulo genere existente, quod propinquius est cuidam determinato aut simpliciter et natura, aut ad aliquid, aut ad ubi, aut ab aliquibus. "120 In quem locum S. Thomas, qui apud ipsum est textus 16, principium, inquit, ,, in unoquoque genere est id, quod est primum" in illo genere; et prius dicitur "quod est propinquius principio alicui determinato", posterius "quod est remotius“ ab illo. ${ }^{121}$ Electio autem libera propinquius et immediatius subditur libertati arbitrii nostri quam divina praescientia de tali electione. Ex duobus autem, quae subduntur arbitrio, id habet esse prius altero, iuxta S. Thomae et Aristotelis doctrinam, quod libertati arbitrii immediatius et propinquius coniungitur et ratione sui constituitur in eius potestate, id vero posterius, quod remotius est et ratione propinquioris constituitur in arbitrii potestate. Nam, cum arbitrium, respectu eorum quae in eius potestate constituuntur, probaverimus esse primum - eo quod sit principium determinativum et impeditivum illorum -, et manifestum sit, id, quod ad primum magis appropinquat, esse prius, posterius vero id, quod remotius est a primo, sequitur, divinam praescientiam esse posteriorem respectu nostrae electionis, et hanc esse priorem a quo non causaliter, sed pure determinative: ut ratio per quam arbitrium creatum exercet facultatem liberam, quam habet, ut sit, et non sit, praescientia Dei: ponendo aut non ponendo obiectum divina praescientia cognoscibile.

\section{Caput 12. Explicatur nonnullis obiectionibus praecedentis capitis doctrina [825V]}

108. Circa praecedentem doctrinam

Obiici potest $1^{\circ}$, determinans non semper habere rationem prioris respectu determinati. Nam concursus divinus ad actum liberum est determinatus a concursu creaturae, et tamen creaturae concursus non praecedit, nec re nec ratione, concursum divinum. Ergo, quamvis obiectum liberum determinet ad divinam praescientiam, non ideo dicetur illa prior.

120. Aristoteles: Metaphysica 5, 11, 1018b9-12.

121. Thomas de Aquino: In V Metaph. lect. 13 n. 936. 
Respondeo, actualem concursum Dei nequaquam determinari ab actuali concursu creaturae, quia concursus Dei actualis nullam habet indifferentiam determinabilem hoc vel illo concursu creaturae, cum habeat realem identitatem determinatam cum hoc concursu creato vel illo. Quod ergo determinatur ab actuali concursu creaturae, est concursus Dei sumptus in actu primo. Hic enim formaliter determinatur ad agendum et concurrendum, per concursum et actionem creaturae, qui simul et aeque primo est actio ac ${ }^{122}$ concursus Dei. Dicitur autem creatura determinare concursum et potentiam Dei - et non Deus creaturam -, quia, licet effective tam determinet Deus creaturam - determinatione concomitante - quam creatura Deum, cum Deus et creatura efficiant actionem qua in actu secundo determinantur ad agendum, attamen sola creata voluntas elective determinat tam se ipsam quam Deum ad agendum: quia ipsa sola est causa eligens, ut hic et nunc fiat actio.

Hinc patet, nullam esse vim obiectionis. Actio enim creaturae non est prior actione Dei, quia illam non determinat, at vero, quia actio ipsa formaliter determinat Deum et creaturam ad agendum, ideo praecedit effectum formalem agentis, quem constituit. Et quia Deus est causa effective determinans per actionem, et voluntas creata elective, ideo tam Deus quam voluntas actionem praecedunt. Unde nullum est determinans, quod in eo genere, quo determinat, non praecedat. ${ }^{123}$

109. Obiicies $2^{\circ}$ : Quamvis arbitrium creatum ponat actum, quem eo ipso, quod existat, necesse est praesciri a Deo, non ideo determinare Deum ad praescientiam. Nam potentia necessario operans producendo suum effectum ponit obiectum quod necesse est cognosci a Deo, et tamen non determinat Deum ad cognoscendum. Ergo nec potentia libera dicetur Deum determinare ad cognoscendum ex eo, quod ponat obiectum quo posito non potest Deus illud non praescire.

Respondeo, potestatem arbitrii nostri non ideo determinare ad divinam praescientiam, quia utcunque ponit aliquid cum illa connexum, sed quia id ponit ut exercitium indifferentis potestatis, cui liberum est, dari et non dari praescientiam divinam de existentia huius potius quam alterius extremi libertatis. Nam hoc modo [826r] ponere exigentiam divinae praescientiae est ponere exigentiam cum praecedentia ad id quod exigitur. Quod enim habet in sua potestate, alterum poni aut non poni, prius illo est (ut probavimus). Ponere autem exigentiam ad aliquid praecedendo ad id quod exigitur, est determinare ad eius positionem - aliquando causaliter, aliquando vero pure determinative, per remotionem impedimenti.

110. Obiicies $3^{\circ}$, non posse intelligi, quod in tempore detur potestas electiva et determinativa eius quod necesse est iam fuisse ab aeterno, et non fuisse. Nam eligibile et determinabile non potest esse determinatum et existens dependenter $a b$

122. et corr.

123. Dazu weiter Kapitel 22. 
electione duratione prius, quam existat potentia electiva et determinativa illius. Etenim supponendo, quod iam alterutrum e duobus executum aut impeditum est: quaenam potestas intelligi potest ad eius positionem aut impeditionem? cum ex terminis notum videatur, omnem potestatem ad aliquid esse ad nondum positum aut impeditum. Unde finis - de cuius quidditate est causare, antequam existat in se: quia causat ut existens in cognitione aut intentione - non potest causare, quando iam existit in se, eo quod iam causatum, aut non causatum, supponat id cuius causa esse potuit. Ergo, cum arbitrium creatum supponat, prius duratione aeterna, vel positam vel impeditam esse praescientiam Dei, implicabit, quod in tempore habeat liberam potestatem respectu talis positionis et impeditionis. Hoc enim esset habere potestatem ad praeteritum. Quae a Philosophis implicatoria iudicatur.

111. Respondeo, quod, quando vis determinativa aut impeditiva est per verum influxum in id quod impeditur aut determinatur, non potest dari respectu actus, qui nonnisi de praeterito - seu prius duratione, quam existat talis potentia - existens aut impeditus esse potest. At respectu actus, qui non determinatur ad esse per influxum talis potentiae nec impeditur per influxus suspensionem, potest dari praesens potentia, etsi actus nonnisi de praeterito esse aut impediri possit. Nam huiusmodi actus, cum sit intentionalis, potest ferri ad terminum nondum existentem et illum futurum exigere, et etiam potest, quia infinite perfectus est, illum exigere ut purum terminum nullo modo influentem aut dantem esse. Ergo, cum manifestum sit, posse respectu existentiae huius termini liberam potestatem creatam esse temporalem, non minus manifestum erit, dari posse eandem libertatem ad existentiam et impeditionem praescientiae talis termini aeterna duratione praecedentem. Etenim, licet temporalis potentia supponat, praescientiam iam fuisse [826v] ab aeterno aut non fuisse, at non supponit hoc ut prius natura aut causalitate existens, sed sola duratione. Nec supponit, duratione praecessisse vel scientiam vel eius carentiam independenter ab eo, quod talis potentia operatura est: sed dependenter. Supponit enim, id ab aeterno praecognitum esse a Deo quod ipsi potentiae liberae ponere libuerit: cum Deus nonnisi per attemperationem ${ }^{124}$ ad id quod futurum est per arbitrii libertatem, aeternam praescientiam habeat.

112. Quod explicari potest per suppositionem impossibilem, quod Deus inciperet in tempore cognoscere actum nostrum liberum, absque ullo tamen influxu liberi obiecti in divinam cognitionem. Tunc enim sine difficultate perciperetur vis determinativa et impeditiva cognitionis divinae in arbitrio creato: ob libertatem ponendi et non ponendi terminum divinae cognitionis. Ergo, cum Deus eodem prorsus modo cognoscitivus sit obiecti futuri ac praesentis, quin, ob praecedentiam

124. Dasselbe Vokabular bei Antonius Perez: In Primam partem D. Thomae opus posthumum: De providentia Dei 3, 45, Rom 1656, 325b. 
aeternam cognitionis, ullo modo laedatur indifferentia arbitrii creati ad ponendum in tempore obiectum in aeternitate praecognitum, sequitur, eadem ratione dari posse in tempore vim impeditivam aeternae cognitionis ac daretur respectu cognitionis temporalis in casu illo impossibili. Quod capite sequenti magis explicabitur.

113. Cui doctrinae non obstat reprobata a Philosophis potestas ad praeteritum. Quae enim reprobatur, est duplex:

Prima est potestas ad faciendum, quod praeteritum non praeterierit, ex suppositione, quod praeteriit. Quae potestas etiam circa futurum neganda est. Nam, ut S. Augustinus lib. $26^{\circ}$ Contra Faustum cap. 4 ait, ${ }^{125}$,tam non possunt futura non fieri, quam non fuisse facta praeterita, quoniam non est in Dei voluntate, ut eo sit aliquid falsum, quo verum", licet in hac consideratione aliquid speciale habeat praeteritum: quia ex suppositione, quod semel extiterit, non potest in ulla subsequente duratione verificari, quod non praeterierit; potest autem praesens et futurum in subsequente duratione praesens et futurum amplius non esse.

Secunda potestas reprobata ad praeteritum est potestas causativa, vel impeditiva causaliter, eius quod praeteriit. Causatio enim praesens actu ponens obiectum in duratione praeterita impossibilis est, immo etiam est impossibile poni in esse de praesent $i$ id quod aliquando praeteriit, cum impossibilis naturaliter sit reproductio eorum quae aliquando esse desierunt.

At vero libera potestas ad praesentem positionem puri termini requisiti ad praeteritam tendentiam intentionalem, quin haec per termini influxum producenda aut reproducenda sit, est potestas ad praeteritum quae nonnisi vulgari et irrationabili terminorum intelligentia reprobari potest. ${ }^{126}$

114. Causa autem errandi in illorum intelligentia est, primo, reductionem [827r] potentiae ad actum, cum sit transitus a posse ad esse, facere: $1^{\circ}$ ut potentia apprehendatur cum respectu ad id quod nondum est; $2^{\circ}$ praeteritas tendentias iam causatas et determinatas supponi in nostra apprehensione et ideo postea nec determinabiles nec impedibiles apprehendi.

Huiusmodi autem apprehensio partim corrigenda est et partim explicanda. Nam transire a potentia aliqua ut influente petit terminum aut productionem quae non erat, cum nihil possit duratione antecedere suam causam. At potestas ad aliquid non causandum a tali potestate, sed pure terminandum, potest esse ad praeteritum, si hoc sit intentionalis tendentiae. Quae ad terminum se posteriorem ferri potest.

125. Augustinus: Contra Faustum XXVI, 4, PL 42, 481. Zitiert bei Didacus Ruiz de Montoya: Commentarii ac Disputationes de scientia Dei 33, 3, 10, Paris 1629, 268a.

126. Zur Relativierung des Satzes „Ad praeteritum non datur potentiam“ vgl. Rodericus DE ARriaga: Disputationes theologicae in Primam partem D. Thomae 20, 40, Antwerpen 1643, t.1, 210-12. 
Nam si terminus hic libere ponendus sit a causa creata, haec potestatem habebit impeditivam et libere determinativam praeteritae tendentiae: per potestatem libere productivam termini ad quem tendere debet.

115. Secunda errandi causa in aequivocatione fundatur. Nam „determinatio“ et „non-impeditio“ scientiae duplici sensu sumi potest:

$1^{\circ} \quad$ obiective ex parte termini. Nam libera positio termini cognoscendi est determinatio cognitionis, id est, exigentia obiectiva. Quam ipsa cognitio aliquo modo praesupponit ut impedibile liberam non-impeditionem.

$2^{\circ} \quad$ Sumi potest ex parte cognitionis seu aeternae praescientiae. Nam huius determinatum esse positum ab aeterno, iuxta futuram exigentiam obiecti, est etiam determinatio scientiae ab obiecto (ut capite sequenti explicabimus). Quando ergo dicimus, arbitrium creatum posse nunc determinare aut impedire divinam praescientiam circa determinatum suum actum, sensus non est, determinationem aut impeditionem ut exercitam ex parte praescientiae posse nunc incipere, sed nunc poni et incipere posse determinationem aut impeditionem ut exercitam ex parte obiecti. Cuius obiecti exigentiae, per aeternam praeoccupationem, satis fit in existentia aut non-existentia praescientiae illius.

116. Lenitur autem difficultas talis potentiae $[\ldots]^{127}$ Deo fundimus orantes, ut dignetur nobis hoc vel illud bonum concedere aut malum avertere. His enim orationibus, etsi aliquid temporale ponendum aut non-ponendum petamus, petimus etiam, quod Deus illud velit aut nolit. Quod est posse petere et obtinere praeteritum. Clarius vero ipsos divinos actus petimus, quando rogamus, ut Deus nobis ignoscat, ne irascatur, ut oculos ad nos convertat, et similia. Cum ergo certum sit, nos posse Deum precibus flectere, et quod ipse nobis dedit potestatem filios Dei fieri et consequenter ad [827v] placendum Deo eiusque gratum affectum et complacentiam filiis debitam ad nos inclinandi et similiter potestatem ad promerendam et avertendam displicentiam et iram, dubitari non debet, nos petere posse praeterita et potestatem determinativam ac impeditivam habere respectu actuum aeternorum. Qui, licet humano more petantur et apprehendantur, ac si incepturi essent, attamen divino modo per anticipatam integra aeternitate solutionem existunt praeveniente Deo in aeternitate temporales creaturarum exigentias.

117. Minus obstat, quod de fine in obiectione illa tertia [ $\$ 110$ ] adducebatur, quia finis vera causa est, licet non per se, sed per sui cognitionem aut intentionem causans; ac proinde causare nequit effectum, qui tempore antecedit cognitionem aut intentionem sui, potest autem causare effectum, qui antecedat existentiam finis in se ipso,

127. Eine Zeile Textverlust. 
quia per se non causat, sed per aliud quod antecedere debuit. Unde in se existente nullam exercet causalitatem. In nostro autem casu, cum nulla sit causalitas - nec mediata nec immediata - obiecti respectu praescientiae, sed pura tantum terminatio seu positio termini praeteritae tendentiae et exigentia illius ut praeteritae, optime potest posterius duratione ad ipsam tendentiam poni et illam ut prius ponendam exigere et determinare.

118. Obiicies $4^{\circ}$, hoc modo determinare - per exigentiam sine causalitate - non sufficere ad constituendam in obiecto prioritatem a quo respectu divinae praescientiae, quia non sufficit ad habendam rationem principii respectu illius. Prioritas autem a quo non convenit nisi principiis. Et licet Aristoteles (capite praecedenti citatus) dixerit, electivum habere prioritatem respectu eorum quae eliguntur aut elective ponuntur, ideo id dixit, quia electivum est principium respectu electionis, et electio respectu obiectorum quae eliguntur.

Respondeo, prioritatem electivi principii esse respectu omnium quae in libera illius potestate constituta sunt, quia respectu omnium habet rationem principii [... $]^{128}$ Ad rationem vero prioris a quo non requiritur determinate ratio principii productivi, sed sufficit ratio principii, a quo determinari et impediri potest aliud. Quod non est, esse principium productivum eius quod determinatur, nec suspensivum influxus quo producendum erat id quod impeditur, sed solum esse productivum impeditionis et determinationis, et pure impeditivum et determinativum eius cuius determinatio aut impeditio producitur. Hoc ergo modo constituimus prioritatem a quo in libertate et obiecto creato respectu praescientiae divinae. Nam prioritas a quo principii determinativi [828r] et impeditivi extendatur ad omne determinabile et impedibile ab ipso. Cum ergo divina scientia - ut huius determinati obiecti - sit impedibilis et determinabilis libere ab arbitrio, necesse est ad illam extendi prioritatem a quo principii electivi et liberi exercitii ipsius.

119. Obiicies $5^{\circ}$ dedecere divinam perfectionem, quod in potestate creata situm sit, Deum habere aut non habere determinati actus liberi potius quam oppositi praescientiam.

Respondeo, sinistre sentire de divinae scientiae perfectione et creatae libertatis dominio qui putant dedecere Deum, quod arbitrio creato liberum sit et consequenter in eius potestate constitutum, quod Deus habeat huius determinati obiecti potius quam oppositi praescientiam. Nam hoc omnino necessarium est eo ipso, quod Deus nolit praeeligere et praedeterminare, obiectum esse cognoscendum, sed quod huius determinatio relinquatur arbitrio creato.

128. Eine Zeile Textverlust. 
Addo autem, potius exaltari mirifice divinae intelligentiae perspicaciam asserendo, quod, quamvis Deus nihil praedeterminaverit de nostri actus existentia, eum tamen cognoscere debeat eo ipso, quod nos illum in tempore elicituri sumus. Eo autem ipso, quod Deus non egeat aeterno praedeterminativo, sed illi sufficiat temporalis existentia obiecti, ad cognoscendum, necesse est, constituto obiecto in nostra potestate, in illa etiam constitui, quod Deus habeat aut non habeat talis obiecti praescientiam. Imperfectio quidem esset, si id possemus per influxum vel, si ullam eiusmodi potestatem haberemus ipso Deo illam non donante. At illam donatam et non influentem habere, nescio quo iure dici possit divinam perfectionem dedecere. Unde dici optime potest, scientiam esse sub nostra potestate et nostrae libertati subdi.

Qui vero his terminis uti nolit - eo quod ad verborum sonum, licet non ad sensum, subiectionem in Dei praescientia indicare videantur -, ab illis abstineat, dum dicat, praescientiam Dei esse in libertate aut arbitrio nostro. Adverto tamen, nomina „subiectionis“ et „subditionis“ sine ullo incommodo admitti posse in divina praescientia obiecti contingentis utendo illis non in sensu proprio, sed in translativo et metaphorice. Nam propria subiectio exercetur respectu superioris et imperantis, transfertur autem ab hoc proprio significato nomen illud ad id quod quovis modo sequitur alterius voluntatem et pro alterius libito esse aut non-esse habet.

\section{Caput 13. An prioritas obiectivae determinationis exerceatur ab obiecto creato [828v] libero respectu divinae praescientiae ab aeterno vel in tempore?}

120. Respondeo et dico $1^{\circ}$, actionem et potentiam liberam $u$ troque modo exercere prioritatem respectu divinae praescientiae ac proinde illam ab aeterno praecedere etsi non existant -, et etiam in tempore - quando existunt -, et consequenter tam temporalem quam aeternam prioritatem respectu praescientiae habere.

Aeterna satis probatur in obiectione tertia capitis praecedentis [ $\$ 110$ ], quia praescientia ab aeterno exercetur cum attemperatione et respectu posterioris ad obiectum liberum. Ergo datur aeterna comparatio obiecti cogniti cum praescientia tanquam cum posteriori. Haec autem comparatio est formalissima prioritas aeterna obiecti ad scientiam, cum sit terminare aliquid tanquam ab aeterno posterius ipso terminante. Quod est obiectum terminans respici ut prius.

Temporalis vero prioritas patet, quia arbitrium creatum ut existens in tempore habet liberam facultatem ad hoc, quod fuerit aut non fuerit ab aeterno praescientia determinata sui actus. Haec autem potestas est prioritas (ut probatum manet). Actus etiam in tempore existit tanquam id per quod potestas libera impendiendi et determinandi divinam praescientiam immediate exercetur. Ergo existit ut petens 
aeternam scientiam sibi attemperatam et se posteriorem. Hoc autem est obiectum esse prius praescientia.

Restat nunc explicare rationes formales huius aeternae et temporalis prioritatis.

121. Dico $2^{\circ}$ : Actus creatus liber non est prior ab aeterno divina praescientia sui per aliquod aeternum esse determinatum - distinctum a praescientia et illam natura praecedens -, sed per determinationem ab aeterna ipsius praescientiae posterioritate et attemperatione, quae obiectum ipsum, quod erit in tempore, denominat $\mathrm{ab}$ aeterno prius sicut illud denominat cognitum. Denominat, inquam, prius: non prius existens in aeternitate, sed prius extiturum in tempore.

122. Prima pars conclusionis patet, quia actus creatus ab aeterno non habet aliquod esse determinatum in se - quia temporalis est - nec determinatum in suis causis - quia liber est. Nullum ergo determinatum esse habet ab aeterno existens ante scientiam.

NoNNULLI ${ }^{129}$ finxerunt determinatum quoddam esse negativum connotans existentiam temporalem rei, quae erit. Quod esse, quamvis non sit divinum, dicunt posse esse $a b$ aeterno, quia est negativum, et esse determinatum ob connotationem ad esse potius quam non-esse liberi amoris, v.g. - AlII ${ }^{130}$ positivum quoddam esse obiectivum meditantur distinctum ab esse physico, cui putant minime repugnare, quod sit aeternum, quando aeterna est eius cognitio. Illudque esse tot obscuris imaginationibus comminiscunt, ${ }^{131}$ [829r] ut mihi solum videatur permittere, quod in tenebris suis delitescant, quam illos ad lucem publicam examinando evocare.

123. Sufficiat pro ipsorum fictionibus despiciendis scire, nullum negativum esse contingens dari posse ab aeterno nisi vi alicuius aeterni fundamenti positivi, ad quod consequatur. Nullum ergo dari potest esse negativum connotans et petens extiturum determinate actum ${ }^{132}$ liberum nisi vi alicuius positivi fundamenti determinantis

129. Gemeint ist Benito de Robles SJ. (1571-1616), Theologe in Salamanca. Vgl. Antonius Perez: In Primam partem D. Thomae opus posthumum: De scientia Dei 3, 129, Rom 1656, 87a: „Pater Benedictus de Robles, qui multorum iudicio subtilitate ingenii fere omnes huius saeculi superavit, et de quo dictum fuit, in rebus metaphysicis proximum fuisse Augustino, et cuius sententiis acutissimis recentiores sua scripta illustrarunt, et novum theologizandi rationem induxerunt, sententiam plane excogitavit acutissimam. Supponebat, dari negationes ab aeterno [...] Dicebat itaque, rei futurae absolute dari negationem ab aeterno essentialiter connexam cum futuro, quae perit in momento, quo res est [...] Has negationes dicebat esse futuritionem, et statum futuri, et talem futuritionem esse Deo rationem cognoscendi."

130. D.h. die Skotisten.

131. communiunt corr.

132. modum corr. 
existentiam talis amoris. Cum ergo nullum huiusmodi positivum fundamentum ab aeterno detur ante praescientiam, chimaericum erit, in negativo aliquo esse aeterno determinatam connotationem illam imaginari.

124. Obiectivum vero esse positivum aeternum - ab aeterna cognitione futurorum et a temporali illorum existentia distinctum - non minus manifeste chimaera est, cum obiectum scientiae futurorum non aliud sit quam id ipsum quod futurum in tempore est. Esse autem cognitum vel cognitioni obiectum, quod illi convenit ab aeterno, nihil aliud est quam extrinseca denominatio a divina cognitione, cui obiicitur. ${ }^{133}$ Ergo in esse cognito nullum datur esse medium inter obiectum quod erit, et aeternam eius cognitionem.

125. Praeterea: Si daretur tale esse obiectivum medium ab aeterno, non daretur necessario, sed contingenter, cum absolute contingens sit cognosci a Deo, quod creatura hunc determinate actum liberum exercebit. Ergo ad eiusmodi esse oportet supponi aliquod posse, a quo valeat esse et non esse vel tanquam productum vel tanquam resultans ex illo, sive productione per se terminata ad ipsum. Hoc autem posse non est creata aliqua virtus, cum haec ab aeterno non detur. Erit ergo virtus divina. Tunc sic: Esse hoc obiectivum vel resultat immediate per se ipsum a divino posse et virtute, vel medio aliquo actu intentionali, cuius sit obiectum. Non per se ipsum: nam alias esset formalissime actus intentionalis divinae potentiae indifferentis, quia esset immediata determinatio illius; ac proinde esset volitio aut cognitio divina, et non esset aliquod medium inter ipsas et temporale obiectum. - Si vero resultat a divina virtute illud esse obiectivum medio aliquo actu talis virtutis, rogo, an hic actus sit volitivus futuri obiecti vel cognoscitivus? Si cognoscitivus: ergo ad cognitionem divinam non praesupponitur esse obiectivum amoris, sed potius ad illam subsequatur tanquam ad fundamentum, ad quod resultat. Si vero dicatur, illum actum esse volitivum: ergo ad esse obiectivum futuri amoris liberi et consequenter ad esse physicum illius - quod essentialiter connectitur cum obiectivo - praesupponitur determinatio in causa et decreto Dei iam satis a nobis impugnata. [829v]

126. P. Didacus Ruiz De Scientia Dei disp. 28 sect. 7 in aliam incidit cogitationem, quam ALII non indocti probarunt, scilicet, ab aeterno dari ante praescientiam

133. Vgl. z.B. Gualterus Chatton OFM.: I Sent. dist. 3 q. 2 art. 1-3: „[...] idem est esse cognitum et esse in anima sicut cognitum in cognoscente. Utrobique enim est denominatio extrinseca obiecti ab ipsa cognitione, quae denominatio est introducta per auctores, qualiter dicimus, quod Homerus est in opinione, et creaturae in mente divina. [...] Non est imaginandum, quod esse cognitum sit quoddam esse distinctum ab ipsa cognitione et ipsa re extra quae cognoscitur, sed quod ipsa res extra extrinseca denominatione denominatur cognita seu esse in anima per illam cognitionem“ (ed. N.A. FitzPatrick: „Walter Chatton on the Univocity of Being: A Reaction to Peter Aureoli and William Ockham“, Franciscan Studies 31 (1971) 88-177, hier 93). 
ordinem quondam rationis obiecti, quod erit, ad divinam praescientiam. Hunc ordinem dicit esse respectum quendam cognoscibilis ad aeternum cognoscitivum, illumque necessario resultare ex eo, quod in tempore extiturum sit obiectum, et ob illum ab aeterno cognoscibile esse obiectum temporale. ${ }^{134}$

Sed in hoc mihi videntur Authores ii aut verbis ludere aut implicantia coniungere. Nam vel esse cognoscibilem ab aeterno amorem, v.g., qui erit in tempore, requirit aeternum aliquod esse verum et reale antecedens cognitionem, quod sit determinate connexum cum amore, vel non. Si requirit, inciditur in impugnata - ab ipso Ruiz et caeteris Nostrorum - praedeterminantia decreta. Si non requiritur: ergo hic ordo aeternus non potest vere, sed ficte, dari. Si autem dicat, dari ab aeterno

134. „Ultra praesentiam obiectivam, quae consistit in extrinseca denominatione cogniti, datur in rebus futuris alia formalitas, in qua consistit praesentiae quidditas, quatenus rem futuram formaliter constituit in ratione obiecti visibilis a Deo. Haec autem praesentia est realis, quantum ad entitatem rerum, quae sunt praesentes; quia nimirum esse reale proprium et intrinsecum, quod res futurae habebunt in tempore realiter existens, illud ipsum, ex eo praecise, quod realiter et actualiter existet tali tempore, iam ab aeterno fuit aptum, et habens omnia, quae requiruntur ex parte obiecti materialis, ut aeterna Dei visio possit illas res, et earum futurum esse, cognoscere eadem ipsa certitudine et evidentia, qua cognoscit illas, quando actualiter existunt in tempore. Eodem spectat illa praesentia obiectiva in actu primo, quam tradit SuAREz lib. $1^{\circ}$ De Scientia Futurorum c. 8 n. 9. - Unde sequitur $1^{\circ}$, praesentiam futurorum in aeternitate realem esse, quantum ad esse materiale, quod est praesens: caeterum non realem, sed relationem rationis esse praesentiam ipsam formaliter acceptam. Fundatur enim haec relatio in entitate reali, quae nondum est, nec fuit ab aeterno, et tamen ab aeterno fuit haec relatio, quatenus ex eo solum, quod istae res aliquando futurae realiter et actualiter erant, eo ipso veritatem habeant determinatam atque scibilitatem, ratione cuius sciri poterant a scientia aeterna, quae ambit omnia tempora. - Sequitur $2^{\circ}$, praesentiam hanc esse priorem denominatione passiva cogniti ac, proinde, non esse praesentiam obiectivam in actu secundo. Quia secundum considerationem nostram est prius, obiectum esse aptum, ut cognoscatur et contineri intra sphaeram cognoscibilium per talem cognitionem; posterius autem est actualiter cognosci. - [...] Sitque prima conclusio: Prius ratione, quam futura sciantur a Deo, datur in illis tota formalitas praesentiae in aeternitate, quae est ratio, propter quam futura sunt intelligibilia per scientiam aeternam. [...] Probatur a ratione, quia quodlibet obiectum supponitur habere rationem obiectivam, et esse intra sphaeram obiectorum prius ratione, quam actualiter cognoscatur quacumque cognitione. Atque illa ratio obiectiva constituens aliquam rem in ratione obiecti apti et contenti intra sphaeram obiectorum est ratio ex parte obiecti praesupposita, ut actualiter cognoscatur obiectum. [...] Ergo, res futuras habere rationem obiecti scibilis et determinate veri, atque eo ipso contineri intra sphaeram obiectorum scibilium a Deo, hoc ipsum praesupponitur prius ratione, quam res futurae sciantur actualiter. Haec autem erit praesentia, quae supponitur ex parte materialis obiecti, ut futura possint actualiter a Deo sciri.“ Didacus Ruiz de Montoya: Commentarii ac Disputationes de scientia Dei 28, 7, 1-6, Paris 1629, $236 \mathrm{a} / \mathrm{b}$. - „[...] concedimus [...] formalitatem praesentiae, quae est ordo rationis ad cognitionem divinam; qui ordo consistit in hoc, quod iam ab aeterno futura habent conditiones requisitas ex parte materialis obiecti, ut possint ab aeterna scientia cognosci in se ipsis secundum esse reale et proprium, quod habebunt.“ Ebd. 28, 8, 14, p. 239 b. 
fundamentum fictionis, ac proinde confictum illum ordinem dari vere ab aeterno fundamentaliter, licet non formaliter, -

Contra: quia vel fundamentum adaequatum huius aeterni ordinis - a nobis conficti aut fabricati - est aliquod verum esse determinatum antecedens praescientiam, vel non. Si est, inciditur in absurda praedeterminationum. Si non est: ergo primum esse determinatum aeternum, quod habent futura contingentia, est, quod habent in divina cognitione. Quod si huic fundamento cognitionis aeternae innixus quis velit tanquam a posteriori discurrere ad prius aliquod fingendum determinate connexum cum scientia quod, ante ipsam, ab aeterno extiterit: nihil contra ipsum habemus, cum se fingentem ipse fateatur et etiam fateatur, nullum revera dari aeternum esse determinatum praecedens cognitionem.

Quod est prima nostrae conclusionis pars.

127. De cognoscibilitate vero determinata, quae RuIzIUm decepit, agemus capite 15 [ $\$ 168$ ]. Nunc animadverto, iniuste ab illo adduci SuARIUm pro aeterno illo esse determinato futurorum. Nam licet SUARIUs doceat, dari cognoscibilitatem determinatam qua obiectum, quasi in actu primo, cognoscibile determinate sit, attamen cognoscibilitatem hanc determinatam ad unum non admittit $a b$ aeterno dari ante scientiam, sed solum in tempore dandam esse. Ut patet ex libro $1^{\circ}$ De Scientia Futurorum capite $8^{\circ}$ citato a P. RuIz, et ex capite $7^{\circ}$ eiusdem libri. Sed de hoc loco proxime citato redibit sermo [ $\$ 259]$.

Maneat ergo firma praecedentis conclusionis nostrae prima pars, scilicet, actum liberum creatum non praecedere ab aeterno praescientiam sui per aeternum aliquod esse praescientia ipsa distinctum.

128. Secundam vero partem eiusdem conclusionis probo: Quia necesse est [83or] dari aeternam prioritatem liberi obiecti determinati ad aeternam praescientiam illius (ut conclusione praecedenti ostendimus), at haec prioritas necessario includit determinationem unius potius obiecti liberi quam oppositi, ergo prioritas illa constitui non potest nisi per aliquod esse aeternum determinatum ad unum. Tunc sic: Ante scientiam nulla est determinatio aeterna unius extremi libertatis creatae potius quam alterius, determinationes vero aeternae post praescientiam existentes inutiles sunt ad constituendam aeternam prioritatem obiecti ad praescientiam. Ergo per ipsam determinationem, quam obiectum habet in divina scientia formaliter, constituitur aeterna prioritas obiecti ad illam. Ideo autem per illam constituitur, quia ipsa ${ }^{135}$ formaliter est aeterna praesuppositio obiecti estque posterioritas et subsecutio sui ad obiectum, eo quod sit aeterna quasi dependentia ab obiecto tanquam

135. Sc. praescientia. 
a libera determinatione: temporaliter exigente praescientiam, ex libertate potente illam impedire. ${ }^{136}$ Ratio autem formaliter constituens scientiam ab aeterno posteriorem obiecto - subsecutam ad illud, obiectumque praesupponens - hoc denominat prius: quia prius est id quo aliud est posterius, ad quod aliud subsequitur, et quod ab alio praesupponitur.

129. Quod sic ulterius explico et probo: Nam amorem liberum esse ab aeterno priorem praescientia sui, nihil aliud est quam ab aeterno terminare praescientiam: ut determinabilem et impedibilem in tempore a nostra libertate ad amandum. At amorem nostrum liberum ab aeterno terminare praescientiam a libertate creata in tempore impedibilem, non distinguitur ab ipsa praescientia. Ergo nec prioritas aeterna amoris liberi ab eius aeterna praescientia distinguetur.

Minor - de qua sola dubitari potest - probatur, quia obiectum futurum actu terminare ab aeterno praescientiam, idem ex parte formae denominantis est ac praescientiam terminari ab aeterno ad tale obiectum. Impedibilitas vero praescientiae ab obiecto est intrinsecus modus tendendi ipsius praescientiae. Ergo obiectum $\mathrm{ab}$ aeterno actu terminare praescientiam impedibilem non distinguitur formaliter ab ipsa scientia - ut natura sua impedibili - terminata ad tale obiectum. Haec ergo praescientia, cum denominet ab aeterno suum obiectum non solum cognitum, sed etiam tali praescientia cognitum - id est, scientia per libertatem impedibili et consequenter posteriori -, denominabit necessario obiectum ipsum cognitum tanquam aliquod, quo posterior est praescientia et a quo dependet tanquam a libero [830v] exercitio principii talis praescientiae. Quod est formaliter obiectum ab aeterno denominari prius.

130. Ex quibus patet, aeterna et denominativa hac prioritate obiectum esse prius respectu praescientiae per ipsam tanquam per actuale exercitium et actum secundum obiectivae exigentiae liberae, qua in tempore exigit dari aeternam praescientiam impedibilem a libertate ponentis tale obiectum: ad modum, quo agens est actu praecedens natura actionem formaliter per actionem ipsam. Huius enim dependentia actualis ab agente, quae est actualis posterioritas actionis ad agens, denominat ipsum id a quo actu dependet actio: quod est formaliter agens esse prius actione, sicut est actionem esse posteriorem agente. Similiter ergo per scientiae posterioritatem et subsecutionem seu quasi-dependentiam denominatur obiectum esse id a quo dependet et quo posterior est scientia. Per ipsam ergo obiectum est ab aeterno prius: ut actualiter exercens ab aeterno vim praecedendi, quam in se habebit in tempore.

136. „[...] Respondeo [...], ad subsecutionem sufficere impedibilitatem, quamvis non detur ratio determinabilis, ut ex se constat et libro sequenti [sc. $4^{\circ}$ ] cap. 9 explicabitur." fol. 681v. 


\section{Obiicies:}

$1^{\circ} \quad$ Prioritatem obiecti liberi creati ad praescientiam esse prioritatem existendi. Dicitur enim prius, quatenus verum est, ideo esse praescientiam, quia est obiectum, non econtra. At per scientiam non dicitur, obiectum esse prius existens quam ipsam scientiam. Etenim obiectum non est ab aeterno prius existens in se - cum in se non existat ab aeterno - nec prius existens in alio, cum in nullo habeat determinatam existentiam antequam illam habeat in praescientia; non existit autem in praescientia obiectum prius, quam existat praescientia, ut per se patet. Ergo obiectum a praescientia formaliter nullam habere potest denominationem prioris.

$2^{\circ} \quad$ Prioritas obiecti est prioritas libere determinantis ad praescientiam determinatione exercita saltem per remotionem prohibentis et exigentiam praescientiae. At obiectum ab aeterno non est determinans ad scientiam: tum, quia determinat per sui existentiam, quae ab aeterno non datur; tum, quia determinatio ad scientiam et libera non-impeditio illius non potest exerceri per ipsam scientiam, sed per aliquid antecedens ad ipsam. Nam eius determinatio est determinatio faciens, ne scientia exerceatur a Deo cum formali libertate; ac proinde determinatio, qua determinatur ab obiecto, antecedens esse debet: quia haec sola est, quae necessitatem inducit.

$3^{\circ}$ Quia, si obiectum per ipsam praescientiam exerceret ab aeterno prioritatem in ipsam, ab aeterno esset obiectum potens exercere illam prioritatem: per aeternam potestatem, quae datur ad exercitium scientiae. At obiectum, antequam sit, esse sic potens, inintelligibile est: ergo actualis praecedentia [831r] obiecti ad scientiam exercita formaliter per scientiam ipsam inintelligibilis et impossibilis erit.

132. Ad primam obiectionem respondeo, prioritatem obiecti ad praescientiam esse prioritatem in existendo, id est, esse prioritatem, qua existentia obiecti dicitur et est - prior. Nego autem, non denominari ab aeterno, a praescientia, obiectum prius existens quam praescientiam, non quidem existens ab aeterno, sed extiturum in tempore. Denominatur ergo extiturum prius. Quod duplicem habet sensum et utrumque verum. Primus est, denominari - a praescientia - obiectum extiturum esse prius: ita, ut habiturum sit in tempore tam existentiam quam prioritatem aliquam, qua ab aeterno carebat. Secundus est, quod denominetur extiturum tanquam prius prioritate aliqua, quam non de futuro, sed ab aeterno, habeat.

Itaque eadem existentia futura in tempore habebit quidem prioritatem exercitam ex parte sui, quae obiecto et eius libertati intrinseca est. Consistit enim in existentia actus liberi ut exigentis, quod ab aeterno fuerit praescientia sui: impedibilis tamen per liberam facultatem, qua obiectum eius in tempore ponitur. Ratione cuius prioritatis comparatur obiectum liberum ad praescientiam ut actus primus ad 
secundum, quia comparatur ut liberum determinativum ad determinabile et impedibile. - Ab aeterno vero habet temporalis existentia obiecti prioritatem extrinsecam et denominativam. Quae consistit in eo, quod praescientia existat per modum actualis dependentiae sui ab obiecto tanquam a libera determinatione potentiae potentis scientiam - per obiecti negationem - impedire. Ratione huius exercitii prioritatis obiecti ad scientiam comparatur scientia ad obiectum et eius libertatem ut actus secundus ad primum, scilicet ut actu determinatum et non impeditum, ad determinativum et impeditivum.

133. Quomodo autem actus secundus potentiae impeditivae et determinativae possit duratione praecedere suum actum primum, etsi aliqui difficile percipiant, facile intelligitur (ut supra ostendi), si consideretur, actum secundum, quem dicimus praecedere, esse intentionalem tendentiam, quae terminum, antequam sit, respicere potest; et actum primum, quem defendimus, non esse causativum, sed pure terminativum, cum potestate ipsum non ponendi. Libertas haec creata ad ponendum obiectum, et divina virtus intellectiva non egens coexistentia obiecti ad habendam praescientiam illius - sed potens et petens praevenire omnem exigentiam obiecti: habendo praescientiam, qua exigetur prius duratione quam exigatur - reddit facilem antecessionem actus secundi scientiae petitae ab obiecto, ad actum [831v] primum, qui est ipsa obiectiva exigentia divinae praescientiae.

134. Si contra solutionis praecedentis doctrinam urgeas,

$1^{\circ}$ scientiam non esse priorem se ipsa, prioritatem vero obiecti dandam esse ante scientiam: ergo scientia non potest formaliter constituere obiecti prioritatem ad ipsam;

$2^{\circ}$ obiectum liberum esse prius divina scientia per semetipsum: ergo non per scientiam; -

Ad primum facile respondemus, prioritatem obiecti aeternam et exercitam in actu secundo respectu scientiae non antecedere scientiam, sed esse scientiam ipsam: sicut prioritas actualis et exercita causae ad actionem non antecedit actionem, sed est ipsa actio. Prioritas vero haec obiecti ad scientiam nullius absurdi est, quia non est prioritas, quae denominet scientiam praecedentem ad se ipsam, sed quae denominet ipsam subsequentem ad aliud, et hoc praecedens ad ipsam.

Secundum vero non difficilius solvitur advertendo, dupliciter sumi reduplicationem obiecti „per se ipsum“, scilicet, vel reduplicando rationem subiectivam, quae immediate per se respicit denominationem praecedentis ab aeterno, vel reduplicando rationem formalem actualis exercitii praecedendi ab aeterno. Hoc notato dicimus, obiectum „per se ipsum“ praecedere ab aeterno, reduplicante ly „per se“ rationem susceptivam denominationis aeternae praecedendi: ut materia formaliter „per se ipsam“ dicitur recipere formam. Negamus vero, obiectum „per se“ 
praecedere ab aeterno, reduplicante particula illa „per se“ rationem formalem exercitii praecedendi ab aeterno: quia haec per rationem formalem aeternam, quae est ipsa scientia, constituitur, non per ipsum obiectum temporale.

135. Ad secundam obiectionem [ $\$ 131]$ respondetur, obiectum esse ab aeterno actu determinans scientiam per ipsammet formaliter, quia huius passiva determinatio seu existentia determinata - est actus secundus obiecti ut terminantis ipsam per modum prioris et exigentis. Sic autem „terminare“ est „determinare“. Ergo, cum sic terminare $\mathrm{actu} \mathrm{ab}$ aeterno obiectum sit denominatio ab aeterna scientia terminata ad obiectum tanquam ad prius, hoc per ipsam scientiam formaliter determinat in actu secundo eius existentiam ad modum, quo causa activa actu et formaliter determinatur ad agendum per actionem.

136. Dices, determinationem scientiae ab obiecto debere illam praecedere: ergo non potest constitui per ipsam scientiam.

Respondeo, duplicem esse determinationem respectu scientiae: aliam formalem et actus secundi, aliam virtualem et actus primi. Prima constituitur per scientiam ut determinate existentem ob exigentiam aliena libertate et electione ponendam. [832r] Secunda constituitur per obiectum ut exigens praescientiam et existens per libertatem impeditivam praescientiae. Prima ergo determinatio aeterna quidem est, sed non praecedit scientiam, secunda vero praecedit scientiam, non tamen est aeterna, sed temporalis: utpote indistincta ab ipsa existentia obiecti liberi. Quare, licet determinatio haec obiectiva habeat aeternam prioritatem denominative ab obiecto - sicut illam habet ipsa obiecti existentia -, at non habet determinatio illa aeternam existentiam, sicut existentia obiecti - aeternam habens prioritatem denominative a scientia - non habet ab aeterno existere. Determinatio ergo obiectiva, quae scientiam praecedit, non existit ab aeterno nec praecedit ut ab aeterno existens, sed ut extitura in tempore.

137. Hinc colliges, quod, licet scientia ab aeterno sit determinata ab obiecto - id est, terminata ab illo tanquam ab aliquo, quod respicitur ut prius -, non est determinata per determinationem obiectivam aeternam, sed per obiectivam temporalem, et per determinationem formalem aeternam.

138. Colliges etiam, determinationem ad scientiam, ut se tenet ex parte obiecti, esse praedeterminationem illius, quia est determinatio praevia, cum obiectum se habeat per modum prioris respectu scientiae (ut iam probavimus). Unde, cum haec determinatio obiectiva non sit existens ab aeterno, nulla datur ab aeterno existens praedeterminatio scientiae, et tamen verum est, Deum scire obiectum futurum ex praedeterminatione ipsius obiecti non quae existat, sed quae existet. 
139. Verumque consequenter est, Deum ab aeterno habere scientiam praedeterminatam ab obiecto non praedeterminatione existente ab aeterno, sed extitura in tempore. Sicut enim scientia potest esse ab aeterno terminata ab obiecto, quod non est ab aeterno, sed erit in tempore, sic potest esse ab aeterno praedeterminata a praedeterminatione, quae non est, sed erit, quia esse ab aeterno praedeterminatam est esse ab aeterno existentem vi praedeterminationis seu praeviae determinationis. At scientia potest ab aeterno existere dependenter a praevia determinatione futura: ergo et esse ab aeterno praedeterminata a praedeterminatione futura.

Minor patet, quia obiectum, quod non est, sed erit, habet rationem prioris respectu scientiae aeternae et etiam rationem determinationis, cum praescientiam determinate exigat. Ergo haec existit ab aeterno dependenter a praevia determinatione futuri obiecti.

140. Si autem quaeras: an, sicut dicitur, scientiam esse „ab aeterno praedeterminatam“ ab obiecto, sic etiam [832v] dici possit, Deum esse „ab aeterno praedeterminatum“ ab obiecto ad scientiam habendum? -

Respondeo, Deum esse „praedeterminatum“ ad habendam scientiam, significare, determinationem aliquam praeviam ad scientiam $a b$ aeterno existere. Cum ergo nulla ab aeterno existat, non est verum, Deum ab aeterno esse praedeterminatum ad habendum huius determinati obiecti liberi praescientiam. Nec obstat, a nobis concedi, scientiam Dei ab aeterno esse praedeterminatam, quia hoc in uno sensu verificatur: per aeternam existentiam scientiae dependenter a praedeterminatione, quamvis haec aeterna non sit. Deum autem esse "praedeterminatum“ ad scientiam, non alium sensum admittit nisi determinationem, quae antecedat scientiam, ab aeterno existere. Quod falsum est. Non est ergo Deus praevie determinatus ad scientiam ab aeterno, sed praedeterminandus in tempore. ${ }^{137}$

141. Si opponas, praeposteram esse praedeterminationem hanc temporalem ad id quod non potest nisi ante ipsam existere, -

Respondeo, praeposteram fore, si poneretur ad aliquid quod ante existere debeat antecedentia a quo, non autem ad id quod antecedit solum in quo et duratione. ${ }^{138}$ Concedo etiam, quod praepostera foret praedeterminatio, si poneretur ad aliquid duratione prius praedeterminandum per causalitatem et influxum, aut ad aliquid quod non esset intentionalis tendentia. At vero ad intentionalem

137. Vgl. \$ 157 .

138. Der Unterschied ist, daß die Priorität a quo (ein Begriff aus der Trinitätstheologie) kausalanalytisch von der Zeitordnung abstrahiert, die Priorität in quo nicht. „Prioritas [...] in quo supra prioritatem originis et a quo dicit veram causalitatem, quam non includit praecise prioritas originis [...] “Franciscus de Oviedo: Cursus integer philosophicus: Phys. 7, 3, 6, Lyon 1640, t.1, 241a. Vgl. Rodericus de Arriaga: Cursus philosophicus: Phys. 7, 93-94, Antwerpen 1632, 339b. 
tendentiam - eamque non causabilem, sed impedibilem -, non praepostere, sed debito ordine, ponitur praedeterminatio: ipsam subsequens non a quo, sed in quo subsecutione durationis, quia, quod sic subsequitur, potest ab intentionali tendentia respici et a creata libertate poni: ut exigens et praecedens a quo scientiam aeterna duratione praecedentem in quo.

142. Ad tertiam obiectionem $[\$ 131]$ respondeo, arbitrium creatum, sicut denominative a scientia est actu praecedens et determinans illam, sic per denominationem a potestate Dei ad habendam scientiam actu determinatam et subsecutam ad futurum obiectum, extrinsece denominari posse determinans et praecedens scientiam; ac proinde obiectum habere duplicem potestatem respectu scientiae: aliam exercendam in tempore per obiectum ipsum et arbitrii libertatem, aliam vero exercendam ab aeterno per divinam potestatem habendi scientiam. Etenim haec "potestas“ divina est potestas habendi et non-habendi scientiam non ex Dei ipsius electione determinante ad illam, sed ex electione arbitrii creati, ac proinde est potestas sciendi obiectum quod creaturae placuerit ponere. Potestas autem, quae in exercitio suorum actuum attemperatur et quasi subditur arbitrio alterius, [833r] dicitur attemperative potestas alterius, et per quam illud alterum agens potest, potens' dici: ${ }^{139}$ eo sensu, quo ,nostra' dicuntur, quae in nostra libera potestate habemus, et nos , posse', quae pro libito nostro poni aut impediri necesse est. Cum ergo divinam potentiam cognoscitivam futurorum actuum, quoad eius exercitium, in nostra potestate habeamus, per illam dicimur ab aeterno posse determinare et impedire eius actus. Quod nihil aliud est quam, potestatem cognoscitivam Dei circa actus nostros liberos esse potestatem attemperatam libertati creatae et ab illa obiective impedibilem et determinabilem in cognoscendo hoc potius obiecto libero quam opposito.

Haec de ratione formali aeternae prioritatis obiecti ad praescientiam divinam. Restat prioritatem, quam in tempore habemus, explicare.

143. Dico ergo $3^{\circ}$ : Ratio formalis, per quam obiectum liberum in tempore antecedit et determinat praescientiam divinam sui, in duobus consistit. Primum est libertas, qua existit ut exercitium potentiae potentis, sed tamen nolentis, praescientiam divinam - per talis obiecti suspensionem - impedire. Secundum est exigentia, qua obiectum petit aeternam sui praescientiam in Deo dari.

Probatur conclusio, quia prioritas obiecti liberi ad scientiam est prioritas principii electivi, id est: impeditivi et determinativi illius per liberam electionem obiecti, a quo determinate exigitur praescientia, vel carentiae eiusdem obiecti, per quam impeditur (ut in superioribus probavimus). Ergo ratio, per quam obiectum praecedit et determinat praescientiam sui in tempore, est libertas, qua respicit suum principium electivum, et exigentia, qua connectitur cum praescientia sui.

139. dicitur corr. 
144. Ex quo patet, principium electivum creatum praecedere divinam praescientiam sui actus liberi, per libertatem, qua potest mediis suis actibus exigere aut impedire praescientiam cuiuslibet in particulari. Praecedit autem ad praescientiam ut electivum ad eligibile: sine ulla ${ }^{10}$ determinatione ad ullius determinati extremi libertatis praescientiam. Actus autem electionis liberae praescientiam sui praecedit simul et determinat: „praecedit“ autem non ut electivum, sed ut eligens - seu ut ratio formalis, per quam principium creatum electivum, quod supponitur ad scientiam, actu eligens est -, „determinat" vero, quia non praecedit cum indifferentia ad hanc et illam scientiam, sed cum determinata exigentia praescientiae sui. Dici tamen potest (ut saepe a nobis dicta est) prioritas ipsius electionis ad praescientiam [833v] prioritas „principii electivi“: non tamen sumpti secundum se, sed prout est in actu. Dicitur enim electio electivi prioritatem habere, quatenus est ratio, per quam principium electivum determinare et impedire potest praescientiam.

145. Et licet electio creata sit actus secundus sui principii electivi, est tamen actus primus respectu scientiae tanquam termini eligibilis - seu per electionem inferibilis -, quia ad eligibile, quando non est immediatus actus sui principii electivi, praecedit non solum ipsum principium ut electivum est, sed etiam ut eligens, et consequenter praecedit ipsa electio ad eiusmodi eligibile diciturque habere - respectu illius - prioritatem electivi ut participatam per immediatam coniunctionem cum tali principio. Dicitur etiam „principium“ et „actus primus“ respectu eligibilis, quia potentia electiva constituitur, per electionem, proxime potens ad eligibile, quod, media illa, habet in sua potestate. Nam proxima potentia ad ea quae dependenter a potentia libera, sed tamen sine formali libertate immediata, exercentur, constitui debet per determinatam exigentiam illorum medio actu, qui sit immediate et per se liber. Determinatam autem praescientiae divinae - dandae, aut impediendae - exigentiam habet potentia libera per suum actum. Ideoque per illum praecedit, tanquam per constitutivum actus primi proximi potentiae impeditivae et determinativae, divinae praescientiae.

146. Hactenus dicta de prioritate et determinatione potentiae et obiecti liberi creati respectu praescientiae divinae facilius intelliguntur respectu praescientiae absolutae, quia huius obiectum est potentia, quae revera erit et operabitur. Ideoque habet obiectum, a quo intelligi possit eius dependentia. Difficile autem explicatur prioritas et determinatio obiecti ad scientiam conditionatam. Sed tamen (suo loco) ostendemus, scientiam hanc, licet ex parte sua et subiective dependeat absolute ab obiecto libero - illudque eodem modo supponat ut impedibile ${ }^{141}$ ab eius libertate -, attamen obiective conditionatam esse eius scientiae dependentiam et obiecti

140. illa corr.

141. impedibilis corr. 
praesuppositionem ad ipsam, quia non petit simpliciter dari obiectum, nec dari arbitrium creatum, quod possit ipsam impedire, sed, quod arbitrium possit ipsam impedire, si existat cum talibus requisitis ad operandum, et quod sub eisdem requisitis obiectum a scientia affirmatum ponat in esse. Ut libro $5^{\circ}$ late ostendemus.

\section{Caput 14. Solutio obiectorum capite $9^{\circ}$, et compendium [834r] doctrinae eiusdem capitis et quinque sequentium}

147. Doctrinam quinque capitibus praecedentibus fusius traditam placuit in compendium redigere, ut uno quasi intuitu tota videatur et iudicetur et ad obiectorum solutionem commodius inserviat.

Ad obiectionem ergo capitis 9 respondendum est negando primam eius minorem [ $\$ 81$ ], scilicet, actum liberum non praecedere divinam praescientiam secundum esse quod habet in tempore. Praecedit enim, quia existit exigendo praescientiam sui $\mathrm{ab}$ aeterno dari et taliter dari, ut causa creata talis actus liberi possit aeternam praescientiam de illo impedire. Hoc enim facit, ut causa creata libera et eius actus praecedant scientiam prioritate a quo, non quidem naturae aut originis - quia in nullo genere causae aut principii influunt vere in praescientiam: nec tanquam producentes illam nec tanquam constituentes principium praescientiae actu et complete potens ad illam (quia non requiruntur ut actu existentes, quando actu et complete potens est principium ad habendam praescientiam; ea autem coexistentia et constitutio completionis actualis requiritur tam ad causam et principium quam ad conditiones natura vel origine praecedentes) -, non ergo praecedunt causa libera creata et eius actus divinam praescientiam prioritate a quo naturae vel originis, sed prioritate $a$ quo principii determinativi et impeditivi. Determinat enim arbitrium creatum ad aeternam praescientiam amoris per amorem ipsum, non quidem influendo in praescientiam, sed exigendo illam et removendo prohibens, scilicet obiectum oppositum, quod est amoris carentia. Hoc enim amoto Deus causaliter a sua perfectione determinatur ad praescientiam amoris. Arbitrium vero creatum (ut dixi) determinat per suum actum non causando, sed removendo prohibens, cum potestate id non removendi, sed potius impediendi amoris praescientiam per positionem obiecti oppositi. Arbitrium ergo creatum est principium non a quo est scientia Dei, sed a quo determinari et impediri potest. Quod sufficit ad veram prioritatem a quo divinae praescientiae: non a quo naturae vel originis, sed pure determinationis et electionis.

148. Potestas enim impeditiva alterius et indifferens facultas ad hoc, ut ponatur et non ponatur pro libito et electione impedientis, constituit „prioritatem“, de qua expresse ARIstoteles agit $5^{\circ}$ Metaphysicae cap. $11,{ }^{142}$ quia potestas illa non potest intelligi

142. Aristoteles: Metaphysica 5, 11, 1018b9-12; Thomas de Aquino: In V Metaph. lect. 13 n. 936. 
respectu rei reduplicative - dum est - neque ex suppositione, quod extiterit, ac proinde illam [834v] respicit cum prioritate et praecisione indifferentiae ab eius esse et non-esse. Ea autem indifferentia determinativa et impeditiva constituit prioritatem non solum respectu eorum, quorum est potentia productiva, sed etiam respectu omnium, quae pro libito determinare potest, etiamsi illa ${ }^{143}$ nequeat producere. Nam prioritas determinativi et impeditivi se extendit ad omne quod vere determinabile et impedibile est per ipsam. Cum ergo hanc potestatem in tempore habeat arbitrium creatum, et illam exerceat per suos actus tanquam per rationes obiectivas impediendi aut determinandi praescientiam, sequitur, in tempore exerceri prioritatem respectu praescientiae divinae, et illa priorem esse causam liberam ut impeditivam et libere determinativam, - actum vero liberum ut obiectivam determinationem ac liberam non-impeditionem unius praescientiae et impeditionem oppositae.

149. Dicitur autem non solum potentia libera, sed etiam actus noster ipse prior quam divina praescientia, quia actus ille immediatius accedit ad principium electivum, in cuius potestate tam actus quam praescientia illius constituitur. Cum ergo principium hoc sit principium respectu omnium quae ab ipso dependent - eo quod sit principium determinativum et impeditivum illorum -, sequitur, actum liberum creatum esse priorem respectu praescientiae, quia inter ea, quae ab aliquo primo dependent seu illud tanquam primum respiciunt, id habet esse prius, quod propinquius accedit ad primum et ab illo ratione sui determinabile et impedibile est, id vero esse posterius, quod remotius est ab electivo principio et ratione alterius propinquioris - impedibile et determinabile est.

150. Ad primam ${ }^{144}$ ergo minoris probationem et doctrinae huius impugnationem distinguo assumptum. „Prioritas obiecti liberi ad praescientiam debet esse aeterna“ ut exercita ex parte divinae praescientiae: concedo; ut exercita ex parte ipsius obiecti: nego. Nam prioritas obiecti ut exercita ex parte praescientiae est aeterna praescientiae posterioritas et subsecutio ad obiectum, huiusque praesuppositio ad scientiam constituta per ipsam scientiam, cum ipsa, per se ipsam, sit praesuppositio obiecti, quia est respectus ad obiectum, ut exigenda in tempore ab ipso, et impedibilis per libertatem, qua in tempore obiectum ponendum est. Obiectum ergo, v.g. amor libere extiturus ut terminans ab aeterno praescientiam sui tanquam impedibilem ex libertate creati amantis, est id, a quo ab aeterno dependet praescientia amoris tanquam a libera non-impeditione et exigentia sui. Unde obiectum est ab aeterno prius quam praescientia per ipsam praescientiam tanquam per actualem [835r] dependentiam - non influxus, sed impedibilitatis et determinationis - sui a tali obiecto: ut a libera determinatione potentiae praescientiam illam impedire potentis.

143. illam corr.

144. tertiam corr. 
151. Etenim prioritas non solum constituitur per exigentiam, qua potentia exigit poni terminum a se pendentem, sed etiam per actualem dependentiam, qua terminus exigit et respicit potentiam. Prima enim prioritas est actus primi, secunda vero actus secundi: ut cernitur in activa potentia, quae per virtutem, qua exigit actionem, est prior illa in actu primo, et per actionem, quae ipsam tanquam principium sui respicit, est prior in actu secundo: ipsamet actione. Primam harum prioritatum habet obiectum creatum respectu praescientiae divinae in tempore, estque illius existentiae et libertati intrinseca. Secundam vero habet ab aeterno per extrinsecam denominationem a praescientia, quae per se ipsam est intentionalis dependentia non influxus, ut saepe dixi, sed impedibilitatis - ab obiecti libertate. Nec mirandum est, hanc dependentiam, licet sit actus secundi, praecedere duratione suum actum primum: quia est actus secundus tendentiae intentionalis. Quae ab aeterno praevenire potest exigentiam qua in tempore exigetur, et obiectum, a quo exigitur, respicere ut purum terminum nullo vero influxu concurrente ad eius esse.

152. Ad secundam probationem minoris $[\$ 82]$ respondeo, obiectum in tempore existens supponere - prioritate in quo seu durationis - exercitam respectu praescientiae sui omnem prioritatem, cuius exercitium requiritur ad esse praescientiae. Haec autem est, quae constituitur per exigentiam, qua praescientia exigit futurum obiectum, non vero, quae constituitur per exigentiam, qua obiectum exigit praescientiam. Utramque hanc exigentiam ostendimus constituere prioritatem obiecti; et eam, quae constituitur per exigentiam, quam ipsa praescientia habet, concedimus requiri et exerceri $a b$ aeterno, eam vero, quae constituitur per obiectivam exigentiam, qua praescientia exigitur, ad hanc solum requiri ut exercendam in tempore, quamvis habeat rationem actus primi impeditivi et determinativi respectu divinae praescientiae: quia (ut dixi) actus secundus determinati et impediti, quando intentionalis est - et non existens per influxum principii determinativi et impeditivi -, potest illum duratione praecedere.

153. Ad tertiam probationem [ $\$ 83$ ] respondeo, prioritatem obiecti talem respectu praescientiae divinae esse a quo, non tamen naturae aut originis, sed purae determinationis [835v] aut impedibilitatis, qua praescientia dependet ab obiecto libero non causaliter, sed impedibiliter - tanquam ab exigente illam per modum liberae remotionis impedimenti, quo impediri posset. Nego tamen, exercitium actuale huius prioritatis non posse incipere in tempore, licet exercitium prioritatis obiecti quasi passive sumptum - ex parte scientiae - aeternum esse debeat. Voco autem exercitium prioritatis ex parte obiecti actuale: non, quia non comparetur per modum actus primi liberi determinativi ad scientiam Dei ut actum secundum, sed, quia est actuale exercitium creatae potentiae liberae ad praescientiam impediendam aut determinandam. Per hoc autem exercitium potentia creata determinat - impedibiliter - praescientiam tanquam per terminum, a quo praescientia habet per se ipsam actu dependere modo explicato. 
154. Ad quartam $[\$ 84]$ respondeo, imperfectionem quidem fore, quod per influxum creati obiecti in divinam praescientiam haec esset illo posterior aut ab illo determinata aut dependens. At vero esse illo „posteriorem“ non causaliter, sed impedibiliter- esseque eodem modo „dependentem“ et „,determinatam“-, nullius est absurdi: quia hoc non facit obiectum habere prioritatem naturae respectu divinae scientiae, sed prioritatem solius termini, ad cuius liberam positionem et suspensionem necesse sit poni, aut non poni praescientiam. Unde, licet admittamus dependentiam a priori praescientiae ab obiecto libero ita, ut veram aliquam prioritatem habeat obiectum respectu illius, negamus tamen „dependentiam“ stricte dictam: quia ea, quam admittimus, non est a priori prioritate naturae, a quo scilicet scientia accipiat suum esse, sed a quo impediri et non impediri potest. Nec est stricta „determinatio“, quia haec, stricte accepta, significat determinationem actualem. Quam nequaquam exercet obiectum respectu divinae scientiae, quia solum habet „determinare" per modum removentis prohibens et exigentis, praescientiam determinari a suo principio, scilicet a divina essentia tanquam ab habente rationem intellectus, speciei intelligibilis et obiecti motivi respectu praescientiae futurorum. Quod tam longe abest ab omni imperfectione, ut potius mirifice commendet divinam intelligentiam - nullo a se distincto egentem ad intelligendum nisi tantummodo positione futura obiecti - et conservet creatam libertatem ponendi et non ponendi in tempore obiectum praescientiae. Quae libertas ad obiectum est etiam consequenter libertas ad praescientiam impediendam et exigendam ac determinandam per liberam obiecti positionem aut suspensionem.

155. Ex dictis colligitur $1^{\circ}$ sensus huius propositionis „Prius est, arbitrium creatum se determinare, quam Deum praescire, quod se determinabit". Nam de [836r] duplici prioritate vera est haec propositio, de aeterna scilicet et temporali. Ab aeterno enim prior est existentia ${ }^{145}$ determinationis creatae quam praescientia illius, et etiam est prior in tempore: $\mathrm{ab}$ aeterno quidem non, quia determinatio creata habeat ante praescientiam sui aeternam aliquam existentiam, sed, quia prius est, determinationem creatam in tempore existere, quam Deum ab aeterno praescire, quod existet: quia temporalis existentia determinationis creatae habet aeternam prioritatem denominative $\mathrm{ab}$ aeterna posterioritate praescientiae tanquam a formali ratione actualis dependentiae seu impedibilitatis a libertate obiecti. Vera etiam est propositio illa de prioritate temporali principii determinativi et impeditivi praescientiae. Unde quoad hanc prioritatem principii, sensus illius propositionis est, priorem esse determinationem voluntatis nostrae de futuro - quia, antequam existat, non est de praesenti, ${ }^{146}$ sed „erit" prior - quam scientia: illa prioritate exigentis scientiam ex libera electione potentiae illam potentis impedire. Ex quo patet, temporalem

145. praescientia corr.

146. Zum Begriff enunciatio de praesenti vgl. $\$ 252$. 
existentiam creati obiecti liberi ab aeterno denominari prius extituram in tempore quam praescientiam illius in aeternitate: non prioritate in quo, sed a quo, exercita tam ab aeterno - per dependentiam scientiae ab obiecto - quam in tempore: exercenda per obiectivam exigentiam, quam obiectum existendo in tempore habebit; huicque exigentiae, per anticipatam solutionem eius quod exigetur, satisfacit aeterna virtus intellectiva.

156. $2^{\circ}$ Colligitur sensus huius propositionis „Obiectum liberum creatum determinat ad divinam praescientiam sui“. Etenim vera est tam de aeterna quam de temporali determinatione.

Primo enim determinat obiectum liberum ut actus primus per temporalem exigentiam aeternae praescientiae. Determinat etiam haec eadem existentia obiecti in actu secundo divinam praescientiam per ipsammet aeternae scientiae ab ipso pendentis existentiam; ac proinde haec determinatio aeterna est, illa vero temporalis.

Si autem quaeras: Quomodo possit temporale determinatum esse actu determinans ab aeterno? -

Respondetur, non esse „determinans“ per hoc, quod ante scientiam detur existens ab aeterno illud determinativum voluntatis nec in se nec in alio determinate connexo cum eius praescientia, sed quia ipsa determinatio aeterna et formalis Dei ad sciendum in actu secundo, per scientiam ipsam, est etiam actus secundus obiecti liberi $[836 \mathrm{v}]$ in tempore existentis et exigentis aeternam praescientiam cum prioritate ad ipsam. Ob quam rationem ad illam determinat ab aeterno, per ipsammet scientiam, et in tempore, per se ipsum. Haec autem exigentia dicitur actus primi respectu scientiae, quia est exigentia praecedens non in quo, sed a quo, praescientiam. Quae ab aeterno ad exigentiam obiecti temporalis ponitur, praeveniente divinae perfectionis eminentia exigentiam temporalem per aeternam positionem eius quod exigitur.

$157.3^{\circ}$ Colligitur sensus huius propositionis „Deus habet praescientiam futuri praedeterminatus a creata determinatione“. Simpliciter enim vera est, quia verum est, Deum habere praescientiam futuri dependenter a praevia determinatione seu determinata exigentia obiecti creati.

Si autem quaeras, an verum sit, Deum ab aeterno praedeterminari ad scientiam futuri? -

Respondeo, in uno sensu id esse verum, in alio non. Verum enim est, si „aeternum“ appellat ${ }^{147}$ supra „scientiam“: quia sensus est, existere ab aeterno scientiam praedeterminatam, seu dependenter a praevia determinatione, seu exigentia obiecti existentem. Falsum autem, si „aeternum“ appellat supra „praedeterminationem“, quia haec non est aeterna, sed temporalis, cum praedeterminatio obiecti indistincta

147. Summulistischer Terminus; hier in derselben Bedeutung wie „cadit“. 
sit ab eius existentia. Unde sequitur, Deum non esse ab aeterno obiective „praedeterminatum“ ad sciendum futurum, sed esse „praedeterminandum“, licet ab aeterno sciat futurum „praedeterminatus“, id est, dependenter a futura praedeterminatione.

Haec prae oculis habenda sunt ad intelligendam praescientiae futurorum quidditatem et ad sequentes difficultates solvendas.

\section{Caput 15. Determinata cognoscibilitas futuri sine decreto illud praedeterminante explicatur}

158. Contra doctrinam hactenus probatam de futuro cognito in se - independenter ab omni decreto praedeterminante - obiecimus insufficientiam indifferentis motivi ad determinatam cognitionem, et ineptitudinem futuri obiecti in se ad praecedendum et determinandum divinam cognitionem. Nunc $3^{\circ}$ obiicimus, ad determinatam praescientiam aeternam unius obiecti liberi potius quam oppositi necessarium esse, quod eiusmodi obiectum sit ab aeterno determinate cognoscibile, et consequenter, quod $a b$ aeterno detur determinata cognoscibilitas illius. At haec non potest dari, nisi unum [837r] extremum libertatis sit ab aeterno praedeterminatum in divino decreto. Ergo necesse est, illud sic praedeterminari.

Minor patet, quia determinata cognoscibilitas aeterna obiecti constitui nequit nisi per aliquod esse determinatum, quod obiectum, vel in se vel in alio, ab aeterno habeat. Cum ergo nullum habeat aeternum esse determinatum in se, necesse est, quod illud ab aeterno habeat in alio: at non in alio nisi in divino decreto praescientiam antecedente. Nam esse determinatum, quod habet in ipsa praescientia, non constituitur cognoscibile, sed cognitum. Cognoscibilitas autem praecedere debet cognitionem. Ergo determinata cognoscibilitas aeterna debet divinam cognitionem praecedere per aeternum esse, quo Deus rei futurae existentiam voluntate sua praedeterminat.

159. Respondeo, duplicem esse futuri obiecti „cognoscibilitatem“ determinatam: aliam intrinsecam, indistinctam ab eius esse, - et hanc non est opus ab aeterno dari, nam, etsi praecedat prioritate a quo divinam cognitionem sui, non est necesse, quod simul duratione cum illa existat ab aeterno, cum divinus intuitus ad res, antequam existant, ferri possit. Alia est determinata cognoscibilitas extrinseca ${ }^{148}$ obiecti liberi, - et hanc concedo coexistere et praeexistere debere aeternae praescientiae talis obiecti. Consistit autem cognoscibilitas haec in virtute cognoscitiva divini intellectus et vi determinativa, quam habet divina essentia per modum speciei

148. Zu diesem Begriff vgl. John P. Doyle: „Extrinsic Cognoscibility: A Seventeenth-Century Supertranscendental Notion“, The Modern Schoolman 68 (1990/91) 57-80. 
intelligibilis et obiecti motivi. His constituitur adaequata sufficientia ad determinate cognoscendum obiectum libere futurum, et consequenter $a b$ illis sufficienter denominatur tale obiectum determinate cognoscibile. A cognoscitiva enim et determinativa virtute denominatur extrinsece obiectum determinate cognoscibile - sicut a virtute productiva denominatur producibile.

160. Ad huius impugnationem $[\$ 158]$ respondeo, determinatam cognoscibilitatem extrinsecam et aeternam obiecti liberi non constitui per esse determinatum talis obiecti, sed per esse determinabile illius: sicut esse determinate eligibile obiectum non constituitur per esse determinatum obiecti, sed per determinabile. Vis enim indifferenter electiva aut cognoscitiva cuiuslibet e duobus extremis determinatis denominat utrumque determinate cognoscibile divisive. Divisive, inquam: non, quia simul et collectim non det denominationem determinate cognoscibilis - sicut et electivum eligibilis - utrique extremo, sed, quia non dat uni simul cum alio eligi, aut cognosci. Solum enim denominat quodvis illorum eligibile et cognoscibile cognitione $[837 \mathrm{v}]$ et electione unius divisa a cognitione, et electione alterius.

161. Sed contra hoc urgebis:

$1^{\circ} \quad$ Esse determinabile obiecti non constituere illud determinate cognoscibile, saltem proxime, in ratione futuri. Nam ea determinabilitas aeque respicit et denominat duo opposita extrema libertatis, et tamen non potest cognosci, quod utrumque erit. Ergo, ut cognoscatur ab aeterno, unum illorum determinate esse futurum, non sufficit aeterna determinabilitas, sed requiritur esse determinatum illius.

$2^{\circ} \mathrm{Ab}$ aeterno necesse est unum extremum esse cognoscibile prae alio: ergo, et dari aeternam cognoscibilitatem unius prae alio, et consequenter, dari cognoscibilitatem unius, quod non sit cognoscibilitas alterius. Quae non nisi per determinationem ad unum constitui potest.

$3^{\circ}$ Cognoscibilitas aeterna futuri debet esse cognoscibilitas determinans Deum ad illud cognoscendum. Nam Deus futurum cognoscit ex suppositione aliqua necessario inferente divinam cognitionem. At determinabilitas unius extremi libertatis non determinat Deum, ut cognoscat, illud esse futurum: cum recte stet, determinabile esse, nunquam tamen, esse determinandum. Ut ergo cognoscat Deus determinate futurum unum extremum, et non aliud, necesse est, quod ad divinam cognitionem praecedat cognoscibilitas illius extremi constituta per esse determinatum illius.

162. Respondeo, esse determinabile unius extremi non sufficere ad determinatam praescientiam illius sine esse determinato, non tamen aeterno, sed temporali: quia, ut praesciatur amor, v.g., necessarium est, quod habeat in se determinatum esse in sua praesentialitate seu temporali duratione, quia hoc esse affirmatur per divinam praescientiam. Ante illam tamen non requiritur ulla determinatio aeterna amoris. 
Etenim aeterna indifferentia cognoscitiva duorum - constituta per integram sufficientiam causativam cognitionis cuiuslibet illorum - sufficit cum temporali determinatione unius, ut hoc prae alio cognoscatur ab aeterno, et consequenter ad hoc, ut ab aeterno cognoscibile sit unum prae alio. Nam licet determinata existentia obiecti requiratur ad praescientiam illius, quia tamen nec requiritur ut causa cognitionis nec ut conditio, quae existere debeat, quando exercenda est cognitio, ideo ante illam et ab aeterno datur sufficiens vis cognoscitiva obiectum temporale denominans ab aeterno cognoscibile; ac proinde datur aeterna cognoscibilitas futuri obiecti indifferens tamen ad $d u o$, ut aeterna est, et ad unum determinata per esse temporale obiecti.

163. Ad obiectionem ergo respondeo concedendo, aeternam determinabilitatem indifferentem esse ad oppositorum cognitionem, [838r] et negando eius insufficientiam ad id, quod futurum est, cognoscendum. Non enim dicimus, sufficientem esse ad determinatam unius extremi cognitionem sine obiectiva talis extremi determinatione - scientiam suo modo praecedenti -, sed, sufficientem esse sine aeterna determinatione talis extremi; temporalis autem omnino requiritur, ut cognoscibilitas aeterna obiective determinata sit de futuro. Nam ad determinatam unius extremi scientiam - praeter aeternum intellectum, obiectum motivum, et speciem intelligibilem - requiritur in tempore, ut praecedat scientiam obiectum terminativum illius et determinativum principiorum indifferentium ad scientias oppositorum, ut unum illorum determinate cognoscatur.

164. Hanc determinationem obiecti, licet ex parte temporalis sit, probavimus (in superioribus) ab aeterno supponi a praescientia illius, et ideo concedi potest, cognoscibilitatem obiecti ut determinatam ad unum aeternam esse: non quoad existentiam, sed quoad praesuppositionem ipsius. Cum enim praesupponatur a scientia, per aeternum et formalem huius conceptum, necesse est, praesuppositionem obiectivae determinationis, et hanc ut praesuppositam, aeternam esse. Ad futuri autem cognitionem determinatam non requiritur, cognoscibilitatis determinationem ab aeterno existere, sed ab aeterno praesupponi. Potest autem ex parte scientiae $a b$ aeterno praesupponi, quamvis ipsa determinatio non ab aeterno, sed temporaliter, existat.

Uno ergo verbo obiectioni respondetur: „Determinabilitas aeterna non sufficit ad determinatam cognitionem“, si haec, praeter cognoscibilitatem aeternam et indifferentiam, non supponat temporalem determinationem obiectivam talis cognoscibilitatis: concedo; si supponat: nego. Quod autem illam, etsi temporalis sit, supponere possit aeterna praescientia, iam satis probatum est.

165. Ad secundum $[\$ 161]$ respondeo, ab aeterno ante scientiam existere cognoscibilitatem unius extremi prae alio non appellante particula „prae“ supra „cognoscibilitatem“, sed supra „extremum“: quia scientiam praecedit cognoscibilitas aeterna 
cuiusque extremi divisim ab alio cognoscendi; ac proinde ante scientiam non datur aeterna cognoscibilitas unius prae alio determinata ad unum, sed indifferens ad duo, et determinata - aut determinanda - in tempore: ita tamen, ut huius determinationis detur aeterna praesuppositio ad scientiam per scientiam ipsam formaliter constituta. $[838 \mathrm{v}]$

166. Ad tertium $[\$ 161]$ responsio petenda est ex capite 8. Hinc breviter dico, Deum determinari ad cognoscendum ex suppositione aliqua necessario connexa cum eius cognitione. Haec autem suppositio non est sola aeterna cognoscibilitas, sed aeterna simul et temporalis: illa per modum causae seu virtualis principii, haec vero per modum termini a scientia praesuppositi. Ideoque concedo, Deum necessario, seu ad essentialem exigentiam alicuius praesuppositi ad eius cognitionem, cognoscere futurum. Haec autem exigentia non est aeterna, sed temporalis, divinaque cognitio $\mathrm{ab}$ aeterno existit ut attemperata futurae exigentiae sui obiecti illam praeveniens aeterna duratione, et tamen ita proprie existens, quia exigitur ab obiecto, ac si obiectum ad ipsam duratione praecessisset. Nam cognitionem existere, quia ab obiecto exigitur, est existere dependenter ab obiecto tanquam ab aliquo, quod ipsa praesupponit. Potest autem obiectum - quod non est ab aeterno, sed in tempore existit - respicere et praesupponere, ab illoque dependere non causaliter, sed impedibiliter. Ergo potest - licet aeterna sit - existere, quia exigetur ab aliquo ipsam praecedenti cum illa essentialiter connexo. Quod ad scientiae necessitatem sufficere, probabimus capite $22^{\circ}$.

167. Si instes: ergo non datur ab aeterno tota cognoscibilitas determinata futuri, nam haec (ut diximus) specialiter constituitur per obiecti temporalem existentiam, - ex quo ulterius inferes: ergo non datur ab aeterno adaequata sufficientia ad determinatam futuri cognitionem, nam sufficientia haec constituitur per determinatam cognoscibilitatem; -

Respondeo, totam cognoscibilitatem motivam determinatae praescientiae obiecti liberi existere debere ab aeterno, ut aeterna praescientia habeatur, non vero totam terminativam. Et tamen obiectum ab aeterno est sufficienter cognoscibile determinate, dummodo in tempore existat terminus, quem aeterna cognoscibilitas denominat cognoscibilem: quia, ut eiusmodi obiectum sit ab aeterno cognoscibile, sufficit integrae causae cognitionis aeterna existentia, quamvis non existat terminus cognoscendus. Hic enim, etsi requiratur essentialiter ad sui cognitionem, non requiritur ut ab aeterno existens, sed ut existens in tempore. Et ideo sufficiens datur cognoscibilitas ab aeterno, quia datur tota quam necesse est dari in aeternitate, in qua exercenda est cognitio. Est, inquam, haec sufficiens, si danda sit in tempore determinatio obiectiva aeternae cognoscibilitatis motivae per terminativi existentiam. 
168. Hinc sequitur, inutiliter fatigari Patrem RuIz De [839r] Scientia Dei disp. 28 sect. 7 in explicanda cognoscibilitate determinata futuri per aeternum quendam respectum rationis, quem ab aeterno habet ad id quod in tempore existit in ordine ad divinam cognitionem: quo respectu, inquit, constituitur „aptum“ ab aeterno cognosci. ${ }^{149}$

Etenim (ut capite $13^{\circ}[\$ 126$ ] arguebam), nulla datur ante cognitionem divinam vera cognoscibilitas aeterna futuri, quae sit determinata ad illud potius quam ad eius oppositum cognoscendum. Nam haec aeterna determinatio praevia ad divinam cognitionem praevia etiam foret ad eius obiectum, neque aliud esse posset nisi decretum divinum de obiecti existentia. Nihil enim vere datur ab aeterno respiciens determinate - seu per determinatam connexionem - obiectum praescientiae futurum nisi vel praescientia ipsa vel volitio Dei, cum non possit esse nisi divinus actus intentionalis. Si ergo est determinatio praecedens scientiam, debet esse determinata volitio obiecti scientiae eiusque praedeterminatio. Ergo, qui hanc impugnant - cum Patre RuIz -, non possunt ante praescientiam agnoscere aeternam ullam cognoscibilitatem vere determinatam ad unum, sed omnino indifferentem et a temporali obiecto determinabilem. Ergo respectus ille rationis, quo RuIz constitui dicit determinate cognoscibile ab aeterno liberum obiectum, quod erit in tempore, non est aliquid verum determinatum ad unum ab aeterno existens ante praescientiam. Illum autem respectum per rationem formare, illumque apprehendere, ac si ab aeterno existens daretur, liberum cuivis erit: fundamentum praebente temporali determinatione obiectiva et aeterna sufficientia ad illam cognoscendam.

169. Concludo ergo - totam huius capitis doctrinam breviter resumendo -, Deum ex se esse ab aeterno determinatum ad cognoscendum id quod in tempore extiturum est, et ideo esse determinatum ad amorem cognoscendum sub conditione, quod in tempore extiturus sit, et ad cognoscendum odium sub conditione, quod extiturum sit. Unde purificata hac conditione „existendi in tempore“, per illam terminative et per divinam essentiam motive constituetur integra cognoscibilitas determinata ad unum, sufficitque ad determinandam absolute aeternam praescientiam futuri. Nam cognoscibilitas terminativa, etsi debeat ab aeterno praesupponi a praescientia sui, non tamen debet existere ab aeterno ad hoc, ut aeterna eius scientia habeatur. Sufficit enim, ab aeterno existere obiectum motivum, et praesupponi a scientia, quod in tempore existet terminativum: quia, licet obiectum [839v] illud motivum non sit per se determinatum ad unum potius quam ad alterum extremum libertatis, est tamen sufficiens et integra virtus motiva ad unius et alterius

149. Didacus Ruiz de Montoya: Commentarii ac Disputationes de scientia Dei 28, 7, 1, Paris $1629,236 \mathrm{a}$. 
cognitionem, quin aliud per modum motivi - vel ab aeterno existentis - requiratur: etsi aliud requiratur per modum terminativi et existentis in tempore.

170. Ex dictis in hoc capite constat, veritatem futurorum contingentium non esse adaequate aeternam. Nam obiectiva illorum veritas est cognoscibilitas per veram cognitionem. Haec autem, ut dixi, partim constituitur per motivum aeternum et indifferens futurorum, et partim per terminativum, quod determinatum et temporale est.

Ex quo etiam patet, obiectivam veritatem contingentem formaliter, ut est determinata, temporalem esse, non aeternam, licet ab aeterno supponatur, eam esse extituram in tempore. Sic autem supponitur per ipsam aeternam eius praescientiam, quae est sui obiecti temporalis praesuppositio (ut capite 13 probatum est).

Haec de veritate obiectiva. Formalis autem veritas determinata futurorum est adaequate aeterna, quia indistincta est a determinata praescientia unius extremi essentialiter vera, quam Deus ab aeterno habet. ${ }^{150}$

171. Sequitur etiam ex dictis, Nonnullos Nostrorum, quibus adhaeret Magister Alviz, ${ }^{151}$ inaniter sibi complacuisse in explicatione quadam veritatis obiectivae, quatenus requiritur ad divinam praescientiam et ad eam supponitur. Explicatio autem est, quod ad praescientiam requiratur obiectiva veritas "non determinata, sed determinanda“, quia quod de futuro affirmatur, est determinandum esse in tempore, veritas autem obiectiva futuri ut determinanda datur ab aeterno, licet non detur ut determinata.

Explicatio haec nil speciale affert per vocem veritatis „determinandae“, quod ab omnibus eadem proprietate non explicetur per veritatem „determinatam“. Nam utentes voce veritatis „determinandae“ non agnoscunt veritatem determinandam per determinationem praeviam ad existentiam futuri actus liberi, sed ${ }^{152}$ determinandam per ipsam existentiam determinatam liberi actus. Haec ergo, ut determinata suo tempore, est futura ab aeterno et consequenter $\mathrm{ab}$ aeterno determinata est de futuro. Nullus autem Nostrorum voluit, alio sensu „determinatam“ esse ab aeterno obiectivam veritatem futurorum, nisi de futuris. Idem autem est, veritatem esse „determinandam“, ac esse de futuro determinatam, seu futurum esse quod determinetur in tempore. Nihil ergo additur praedicta explicatione.

150. Zur Unterscheidung veritas obiectiva / formalis vgl. $\$ \$ 182,253,255$.

151. Martinus de Albiz: De altissima scientia etc. tractatus 1, 6, 3, 8, Alcalá 1632, 135aE. Vgl. Gasparus de Ribadeneira: Tractatus de scientia Dei 12, 8, Alcalá 1653, 277a: .„[...] dixit optime Magister Albiz [...], iudicium hoc divinum et similia ,Petrus peccabit' non habere ab aeterno veritatem obiectivam determinatam, sed determinandam.“

152. per del. 
Si vero in illa contenderetur, veritatem ut „determinandam“ ab aeterno - id est, [840r] aeternum respectum determinatum ad unum potius quam ad aliud extremum libertatis in tempore extiturum - dari in Deo ante praescientiam, non esset explicatio, sed negatio sententiae nostrae et affirmatio oppositae adstruentis aeternam praedeterminationem ad liberi obiecti praescientiam.

\section{Caput 16. Explicatur futuritio contingentium et veritas huius causalis „Ideo scit Deus liberum actum nostrum esse futurum, quia futurus est“}

172. Futuritionem hanc explicare necesse est, ut satisfiat obiectioni, quae ex illa contra doctrinam nostram formari sic potest:

Rerum omnium quae in tempore existent, quamvis existant libere, necesse est dari aeternam futuritionem determinatam. Nam eo ipso, quod existant in tempore, necesse est posse ab aeterno determinate affirmari, quod erunt. At haec aeterna futuritio determinata obiecti liberi praecedit scientiam illius, cum ideo, iuxta S. Patres, Deus cognoscat, obiectum liberum esse futurum, quia futurum est. Ergo determinatio aliqua aeterna futuri liberi praecedit divinam scientiam. Haec autem determinatio non potest aliunde quam a divino decreto praedeterminante provenire. Ergo in hoc, et non in se, cognoscitur obiectum liberum.

173. Ad solutionem suppono, futuritionem esse rationem formalem, per quam res constituitur futura, id est, habitura esse post non-esse sui. Duplex autem est ratio habendi hoc esse post non-esse: Prima est causa ipsa rei futurae. Quae, per se ipsam, est non-esse rei in instanti naturae quo ad illam praecedit causa, et est ratio essendi post causam in posteriori instanti naturae. Secunda est ipsum esse rei in sua praesentialitate, et non-esse illius in duratione antecedente. Ideo duplex est futuritio rei: alia in causis seu per causas, alia in se seu per se ipsam ut subsecutam ad non-esse sui.

174. Futuritio rei in causis - seu constituta per causas - potest esse vel determinata ad unum: quando, scilicet, causae determinant existentiam unius ita, ut cum causis - ut proxime potentibus ad illud - non sit componibilis carentia illius. Hanc futuritionem habent in suis causis effectus necessarii.

Alia est futuritio in causis indeterminata indifferens ad $d u o$, eo quod causae petant fore unum aut alterum ipsorum, et ideo non possint componi cum carentia utriusque collective sumpta, sic tamen cum carentia utriusvis per existentiam cuiuslibet illorum. [840v] Hanc futuritionem habet in sua causa effectus liber, quia vi causae liberae complete potentis necesse est, quod existat effectus liber, vel, quod a causa libere omittatur; ac proinde necesse est, ipsum vi talis causae esse 
extiturum, nisi ab ipsa causa libere impediatur eius existentia. Et hoc est, illum esse in sua causa futurum contingenter, id est, futurum cum indeterminatione. Nam contingentia effectus in causa est indeterminatio causae ad talem effectum potius quam ad oppositum, cum determinatione tamen et necessitate disiunctiva ad alterutrum efficiendum. Quam necessitatem et indeterminationem explicuit S. Thomas q. 16 De Malo art. 7: „Quae sunt ad utrumlibet, non possunt cognosci in suis causis determinate, sed sub disiunctione, utpote quod erunt, vel non erunt. Sic enim habent veritatem. "Ob hanc rationem D. Thomas Prima parte q. 14 art. 13 docuit, futurum contingens in causa non esse determinate affirmabile per scientiam certam, sed ad summum per coniecturalem: eo quod causa possit propendere magis in unum extremum libertatis quam in alterum, non tamen ad ullum in particulari praedeterminata esse.

175. Et obiter notari potest quod aliqui defendunt - et ARISTOTELI $1^{\circ}$ Perihermeneias cap. 8 et aliis locis tribuunt - circa propositiones de futuro contingenti, eas scilicet non esse determinate veras nec falsas. Quod defendi potest secundum statum futuri contingentis, quem effectus liberi habent ante suam existentiam, scilicet in causis. Nam vi huius futuritionis contingentis nec est verum determinate, quod erunt, nec falsum, sed indifferens ad utrumque; verumque solum est per disiunctivam enunciationem, quod erit unum vel alterum, ut ait S. Doctor citata q. 16 De Malo art. 7 , licet ex vi status, quem futura habent in se ipsis, necesse sit determinatam affirmationem illorum aut esse determinate veram aut determinate falsam. Unde simpliciter necesse est eas propositiones determinatam veritatem aut falsitatem habere, quia ad hanc necessitatem sufficit ipsis aliquo ex capite repugnare, quod veritate et falsitate careant.

176. Totam huius, et etiam praecedentis, numeri doctrinam traditam habemus a S. Thомa ad citatum Aristotelis locum lect. $13 \$$ „Ponit secundam rationem“.153 Ad cuius intelligentiam adverte, $S$. Doctorem fere semper explicare futuritionem rerum per causas in quibus, prius quam sint, futurum est, ut sint: ut ex verbis citandis patebit et ex aliis pluribus citatis capitibus 2 et 3, quibus probat, res contingentes a Deo certo cognosci, quia non ut futurae, sed ut praesentes in se ipsis, cognoscuntur. Ut praesentes autem determinationem et necessitatem habent, licet non ut futurae, quia ut sic considerantur [841r] in causis, in quibus ad unum determinatae esse non possunt. Quod etiam late probat citato loco Primae partis. Quae doctrina ut aliis aeque certis non repugnet, intelligenda est de futuritione pura et physica, quae praesentiam antecedat ut ratio, cur sit, seu faciens, quod sit. Hoc enim sensu neque existentia rei dicitur eius futuritio seu ratio, per quam est futura, quia, etsi sit ratio

153. Thomas de Aquino: In I Perih. 13, 10. 
formalis per quam res erit, id tamen habet ut praesentia ipsa rei, non ut aliquid praesentiam antecedens. Et similiter neque scientia futuri, licet sit antecedens determinatio petens, quod existat, dicitur physica et realis futuritio: quia non est faciens, quod res postea sit, sed futuritio intentionalis, ut dicemus.

Futuritionem ergo puram et causalem communiter intelligit D. Тномаs, quando de „futuritione“ loquitur. Quod ipse testatur Prima parte q. 16 art. 7 [ad 3] dicens: „[...] quod nunc est, ex eo futurum fuit, antequam esset, quia in causa sua erat, ut fieret“. Ideo lectione illa [In Perih.] 13 [n. 10] sic ait: „[...] falsum est [...], quod omne, quod est verum [esse, verum] $]^{154}$ fuerit determinate dicere esse futurum", intellige: futuritione causali, quae praesentiam antecedat; nam hoc futuritionis genere non omne quod est determinate verum, fuit determinate futurum, cum non omne, quod est, habuerit esse determinatum in suis causis. „Ad cuius evidentiam“, prosequitur S. THOMAS, „considerandum est, quod, cum verum hoc significet, ut dicatur aliquid [esse] quod est, hoc modo est aliquid verum, quo habet esse. Cum autem aliquid est in praesenti, habet esse in se ipso [...]. Sed quandiu aliquid est futurum, nondum est in se ipso, est autem aliqualiter in sua causa. Quod [...] contingit tripliciter: Uno modo, ut sic sit in sua causa, ut ex necessitate ex ea proveniat. Et tunc determinate habet esse in sua causa. Unde determinate potest dici de eo, quod erit. Alio modo aliquid est in sua causa, [ut] quae habet inclinationem ad suum effectum, quae tamen impediri potest. Unde et hoc determinatum est in sua causa, sed mutabiliter. Et sic de hoc vere dici potest hoc erit, sed non per omnimodam certitudinem. Tertio aliquid est in sua causa pure in potentia, quae etiam non est magis determinata ad unum quam ad aliud. Unde relinquitur, quod nullo modo potest de aliquo eorum [determinate dici], quod sit futurum, sed quod sit, vel non sit." En explicatam a D. Tнома triplicem futuritionem rei per causam, et praecipuam et fere unicam acceptionem „futuri“ apud ipsum esse per rationem essendi quam, antecedenter ad praesentiam, habet in sua causa. Quam futuritionem respectu effectus liberi asserit indifferentem esse, quamvis inclinationem habere possit ad unum potius quam ad [841v] alterum.

Haec de futuritione indeterminata effectus liberi in causa.

177. Futuritio vero determinata effectus liberi in se est determinatio ad esse orta ex ipsa existentia et praesentia rei in duratione subsequente ad non-esse eiusdem rei vel saltem praesentiae illius. Haec enim praesentia, ut comparata ad antecedentem durationem, est futuritio sicut eadem praesentia est praeteritio, respectu durationis subsequentis, et praesentia, prout absolute sumitur, sine comparatione ad prius aut posterius.

154. So die von den früheren Drucken abweichende Lesart der Editio Leonina. 
178. Hinc sequitur $1^{\circ}$, duplicem esse futuritionem determinatam rei in se:

Alia est realis et obiectiva. Quae constituitur per existentiam et praesentiam rei subsequentem ad durationem, in qua non existit. Existere tamen potest affirmatio secuturae existentiae. Alia est rei in se futuritio intentionalis. Quae est intentionalis determinatio existentiae futurae ideo praecedens, quia sequetur existentia rei. Hanc enim dicimus esse determinationem ad esse post non-esse non aliunde quam ab ipsa existentia ortam.

Duplicem hanc rei in se futuritionem videtur mihi aperte docuisse AUGUSTINUM lib. $11^{\circ}$ Confessionum cap. 14,15 et 18 , in quibus ostendit $1^{\circ}$, quod futurum nondum est in se, sed erit, rationemque, per quam in se erit, esse eam, per quam futurum est, ac proinde esse futuritionem illius; $2^{\circ}$ futurum de praesenti esse tantum in anima rationemque futuri praesentialiter sumpti non extra, sed solum intra animam seu intellectum dari, quatenus in illo fuit per praenotionem praesentiae rei in se ipsa. Ergo futuri praenotio est intentionaliter futuritio eius seu determinatio praesens, ut postea sit.

179. Sequitur $2^{\circ}$, divinam praescientiam esse intentionalem et aeternam futuritionem obiecti in sua praesentialitate temporaliter extituri: quia est aeterna determinatio intentionalis secuturae existentiae ideo determinans illam extituram, quia illa in sua duratione existens est per antecedentem non-existentiam.

Sequelam hanc, cum praecedenti, confirmare possumus ex Divo Anselmo Dialogo de Veritate cap. 11, ubi ait: ${ }^{155},[\ldots]$ non est vera oratio, quae dicit futurum esse aliquid, nisi re ipsa sit aliquid futurum, nec aliquid est futurum, si non sit in summa veritate. "Ubi et futuritionem realem ac intentionalem probat, et hanc explicat per summam veritatem, per quam statim explicat aeternam et necessariam futurorum - eo ipso, quod futura aliquando sint - veritatem.

180. $3^{\circ}$ Sequitur, ante divinam praescientiam nullam dari ab aeterno futuritionem determinatam obiecti, [842r] quia nulla datur aeterna praedeterminatio obiecti, et consequenter nulla existens ante scientiam, quia nulla ante ipsam existens dari potest nisi decretum praedeterminativum obiecti. Hoc tamen non obstante concedendum est, ab aeterno praesupponi ad scientiam futuritionem temporalem obiecti, quia, licet haec non existat ab aeterno, existit tamen aeterna eius praesuppositio: non quidem antecedens scientiam, sed per ipsam formaliter constituta. Ipsa enim (ut saepe dixi) est futuri obiecti praesuppositio.

155. Anselmus Cantuariensis: De veritate 10, Opera omnia, ed. F.S. Schmitt, Stuttgart-Bad Cannstatt 31984, vol. 1, 190. 
181. $4^{\circ}$ Sequitur, determinatam futuritionem realem et obiectivam actus creati liberi in se non dari ab aeterno nec etiam in tempore ante eius existentiam. Futuritio enim illa est ratio, per quam actus in sua existentia subsequitur ad non-esse sui. Haec autem ratio non datur prius quam res existat, sed per ipsam eius existentiam.

Nec obstat, rem non dici „futuram“, quando existit nec postquam extitit: ergo futura solum est, antequam existat; ac proinde eius futuritio danda est ante existentiam; -

Respondeo enim, hoc argumento probari quidem - et manifeste -, aliquam rei futuritionem dari antequam sit. Hanc ego libenter concedo. Sed dico, non esse futuritionem realem et obiectivam, qua actus liber extiturus est post non-esse sui, sed intentionalem, qua affirmatur extiturus. De reali autem futuritione assero, illam dari, quando res existit.

182. Si urgeas, de re existente non esse verum, quod nunc sit futura: esset autem id verum, si ipso existente daretur eius futuritio, -

Respondeo distinguendo assumptum „non est nunc vere futurum“ veritate obiectiva: nego; veritate formali cognitionis ipsi coexistentis et illam de futuro affirmantis: concedo. Quia veritas obiectiva futura est obiectiva aptitudo rei, ut per veram cognitionem de futuro affirmetur, id est, per cognitionem, quae obiectum ut futurum respicit. Formalis autem veritas de futuro est veritas cognitionis, quae affirmet, obiectum extiturum esse post ipsam. Quando autem existit, obiectum habet suum intrinsecum praedicatum aptitudinis, ut de futuro affirmetur per cognitionem antecedentem, licet non ut affirmetur de futuro per cognitionem sibi coexistentem. Haec enim non potest asserere, obiectum non esse sibi praesens, sed post ipsam extiturum; ac proinde, [842v] si affirmet vere, futuram esse praesentiam, quae nunc datur, ipsa non debet esse nunc praesens. Ergo non ex eo, quod non possit per propositionem obiecto coexistentem vere affirmari de futuro obiecti praesentia, sequitur, non dari de praesenti obiectivam et realem futuritionem. Datur enim, cum detur ratio, ob quam ante praesentem hanc existentiam dici poterat, eam esse futuram. Est ergo futuritio obiectiva existens, quando res est praesens, et ea praesenti dici potest vero aliquo sensu „res est nunc futura“, id est: nunc habens obiectivam futuritionem, scilicet rationem, ob quam affirmari potest eius existentia de futuro per cognitionem, quae duratione praecedat talem existentiam. Quod nobis confirmat modus communis enunciandi de futuro, quem non solum explicamus per propositionem hanc "res erit“, sed etiam per hanc „res erit futura tali tempore“, id est: habebit eo tempore obiectivam futuritionem, quae est existentia in illo, quatenus est ratio vere enunciandi illam, antequam sit, enunciatione affirmante de futuro. Ex quo obiter patet, enunciationem de futuro per „erit“ et „futurum est“ aliquam in modo significandi diversitatem habere, quia „est futurum“ admittit duplicem sensum: unum, quo significet idem quod „erit“; alterum, quo significet, de praesenti 
dari futuritionem obiecti: ${ }^{156}$ vel intentionalem, antequam existat, - vel obiectivam, quando iam existens est.

183. Si autem replices, affirmabilitatem hanc obiectivam rei futurae per cognitionem duratione praecedentem debere antecedere ad futuri existentiam, quia affirmabilitas dari debet, quando affirmatio datur: ergo affirmabilitas de futuro et obiectiva futuritio non potest per futuram existentiam constitui, -

Solutio petenda est ex capite $1^{\circ}$ et $3^{\circ}$, in quibus ostendimus, cognoscibilitatem, quae coexistere debet cognitioni, esse eam, quae cognitionem causat, non, quae illam terminet: quia, existente integra cognitionis causa ex parte potentiae et obiecti motivi potest in duratione antecedente ad affirmabilitatem pure terminativam - id est, ante capacitatem intrinsecam obiecti ad terminandam cognitionem - existere cognitio ad ipsam terminata.

184. Concludo ergo, futuritionem obiectivam liberi actus creati non dari ab aeterno, sed in tempore, nec distinctam esse a temporali eius existentia, sed per illam in recto constitui et in obliquo connotare praecedentem durationem, in qua ipsa non existat realiter, sed solum intentionaliter in cognitione affirmante, quod erit, - at vero intentionalem eius obiecti futuritionem aeternam esse, sed tamen indistinctam a divina praescientia.

185. Ex quibus ad obiectionem in initio capitis propositam [843r] respondeo concedendo, dandam necessario esse ab aeterno futuritionem actus liberi existentis in tempore. Nego autem, hanc futuritionem aeternam praecedere ad actus liberi praescientiam. Constituitur enim formaliter per illam.

Ad probationem respondeo, causalem illam Patrum „Deus actum futurum cognoscit, quia futurus est" non verificari de ratione, per quam res constituitur in esse aeternaliter futuri, sed de ea, per quam futura erit in tempore. Haec enim futuritio est, per cuius esse aut non-esse potest arbitrium creatum determinare aut impedire divinam praescientiam de tali futuritione seu de existentia, ob quam dicitur ab aeterno, quod res erit in tempore. Ergo haec futuritio seu existentia est, quae praecedit divinam cognitionem (modo explicato capite $11^{\circ}$ et sequentibus), et de qua - ob hanc praecedentiam - verificatur ideo, Deum scire rem esse futuram, quia futura est. Sensus enim est, ideo cognosci ab aeterno, quia futura est temporaliter, vel - quod idem est - quia existens est in tempore post non-esse sui. Particulam vero causalem „ideo“ diximus capite $2^{\circ}$ et $3^{\circ}$, cum S. Tнома, non significare causalitatem ullam obiecti in divinam cognitionem, sed illationem, qua

156. Genauso Antonius Perez: In Primam partem D. Thomae opus posthumum: De scientia Dei 3, 127, Rom 1656, 86b. Anders Petrus Hurtado de Mendoza: Universa philosophia: De anima 9, 89-9o, Lyon 1624, 585b/86a. 
necesse sit, posito obiecto in tempore dari ab aeterno scientiam, quia, inquam, id necesse sit necessitate constituta per aliquid quod divina cognitio respicit ut prius: non prioritate causae, sed prioritate principii electivi, in cuius potestate sit divinam scientiam determinatam impediri per suspensionem obiecti, vel necessario poni posito obiecto.

186. Si contra traditam doctrinam obiicias, ab aeterno praesupponi ad scientiam obiectum ut determinate futurum: ergo praeexistere debet ab aeterno ante scientiam aliqua obiecti determinata futuritio, -

Respondeo, „praesupponi“ ad scientiam futuritionem determinatam obiecti praesuppositione constituta per ipsam scientiam - quatenus haec per se respicit obiectum suum ut prius extiturum in tempore -, non autem praesuppositione constituta per aliquid distinctum ab ipsa scientia. Et sub hac distinctione explicato antecedenti consequens neganda est. „Praesupponi“ enim ab aeterno potest non solum quod ab aeterno est, sed etiam, quod in tempore erit, quia hoc potest esse principium impeditivum et determinativum aeternae tendentiae intentionalis attemperatae futuro obiecto libero, id est ita existentis, ut per libertatem, qua ponitur obiectum, ipsa possit impediri: per obiecti suspensionem (ut saepe dictum est). Non ergo ex eo, quod ab aeterno „praesupponatur“ futuritio obiectiva seu existentia rei in tempore, sequitur, futuritionem, quae supponitur, debere ab aeterno existere.

187. Dices: Ex eo quod detur aeterna praesuppositio futuritionis [843v] temporalis, sequitur, dari ab aeterno huius futuritionis praecedentiam ad divinam futuri cognitionem: ergo, et dari aliquid aeternum determinatum praecedens scientiam.

Sed eodem modo respondendum est: concedendo sequi, quod danda sit „aeterna praecedentia“ obiectivae futuritionis temporalis ad scientiam, constituta per extrinsecam denominationem praecedentis, quam obiectum accipit ab actuali subsecutione qua scientia illud respicit, - non vero „praecedentiam aeternam“ constitutam per obiectum aut aliud, quod praecedat scientiam vel ab illa ullo modo distinguatur. Ut in superioribus late explicuimus.

188. Denique oppones, ex eo, quod res sit existens in tempore, necessarium esse, quod prius fuerit futura, et quod sic futuram esse sit ratio, cur cognoscatur: ergo ante scientiam debet dari futuritio aliqua praecedens obiecti existentiam.

Respondeo, ex eo, quod res existat in tempore, necesse est, quod „prius“ duratione „fuerit futura“ non futuritione reali seu physica distincta a cognitione, sed intentionali a cognitione indistincta. Nego autem, rationem cognoscendi esse futuritionem, quae duratione „praecedit existentiam rei“. Non enim haec, sed illa, quae constituitur per ipsam rei existentiam, est ratio obiectiva, cur existat scientia modo iam explicato. 
189. Doctrina hactenus tradita in nullo dissonat S. Thomae q. 14 Primae partis art. 13 docens, certitudinalem cognitionem futuri liberi ad illud tendere ut iam praesens est in actu, non ut futurum. Nam loquitur de praesentia temporali, quam res habet extra causas, ut ostendemus capitibus sequentibus, et, licet eam existentiam dicat non esse „futuritionem“, sed „praesentiam“, nequaquam doctrinae traditae opponitur. Nam solum negat, rei existentiam extra causas esse futuritionem puram: quae scilicet tantum sit futuritio cum exclusione - aut negativa aut saltem praecisiva praesentiae. Non autem negat, quod ullo ${ }^{157}$ modo sit futuritio.

190. Duplicem enim futuritionem nos probavimus: aliam extrinsecam - constitutam vel per futuri causas vel etiam per eius cognitionem - duratione priorem; et haec futuritio pure futuritio est, quia rei praesentiam in priori, quo ipsa existit, excludit. Aliam vero intrinsecam, quae est ratio per quam res erit in tempore, et consequenter per ipsius rei existentiam constituitur. Haec existentia, licet sit futuritio comparata ad praesens non-esse sui, cui succedit, est tamen praesentia sumpta absolute et etiam respective ad aeternitatem, cui non succedit, sed praesens est (ut capite sequenti dicemus). Et ideo non est futuritio pura, sed habens simul cum futuritione habitudinem praesentis. Quod nullatenus repugnat, quandoquidem habetur per habitudinem [844r] ad diversa.

191. Ideoque recte dici potest, rem existendo „transire“ a statu futuro ad statum praesentis: non, quia praesens nullum futuritionis conceptum habeat, sed, quia non habet illum, a quo transit, nempe futuritionis purae antecedentis et extrinsecae. Sicut etiam iam existente re dicitur non esse in statu possibilitatis, sed ab illo „transisse" ad existentiam. Sensus enim est: non esse in statu possibilitatis extrinsecae, quam habet per denominationem a potentia causarum, quae pura possibilitas est - vel puritate negativa existentiae vel saltem praecisiva -, non vero, quod nullum possibilitatis statum habeat et extra omnem sit. Hoc enim falsum est, cum ipsa rei existentia et essentia, quam reddit existentem, habeant intrinsecam possibilitatem. Quae est non-repugnantia seu consonantia praedicatorum quibus res constituitur.

Hoc ergo sensu iure dixit S. Thomas, rem contingentem ut subditur certae cognitioni, non esse in statu futurae, qui per puram futuritionem constituatur, id est, per futuritionem, quae existentiam et praesentialitatem rei antecedat. Quia omnis futuritio antecedens existentiam et cognitionem futurorum est ea, quam habent in suis causis. Haec autem futuritio est contingens, qua scilicet contentum in causis "consideratur ut futurum, et contingens nondum determinatum ad unum“, ait $\mathrm{S}$. Doctor, „quia causa contingens se habet ad opposita, et sic contingens non subditur per certitudinem alicui cognitioni“. Non autem negat, quod subdatur futurum

157. nullo corr. 
certae cognitioni per futuritionem non puram neque extrinsecam aut antecedentem ad suam praesentialitatem, sed hac ipsa constitutam: eo quod sit intrinseca ratio ob quam dici potest prius duratione, quam existat, eam esse extituram. Ob hanc enim expresse ait S. Thomas subdi futurum contingens certae cognitioni, „dupliciter“, inquiens, „considerari potest contingens: uno modo in se ipso, secundum quod iam in actu est, et sic non consideratur ut futurum “ - futuritione pura, actum existendi antecedente - „sed ut praesens, neque [ut] ad utrumlibet contingens sed ut determinatum ad unum. Et propter hoc sic infallibiliter subdi potest certae cognitioni

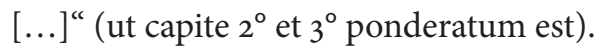

Nulla ergo ratio aut futuritio antecedens obiectum liberum et eius praescientiam est ratio sufficiens - sufficientia se sola determinante - ad determinatam cognitionem futuri contingentis; ac proinde necesse est ipsam temporalem praesentiam, qua res existet in sua duratione, includi in obiectiva determinatione divinae scientiae, $[844 \mathrm{v}]$ et ratione illius verificari „Deum cognoscere futurum liberum, quia futurum est" sumpta particula „quia“ in sensu illativo a priori non causae aut naturae praecedentis, sed connexi per modum determinativi, exigentis scientiam ex libertate potentis illam impedire. Ut late in superioribus explicui.

\section{Caput 17. Obiectio nova contra doctrinam capitum praecedentium}

192. IoAnnes A S. Thoma disp. 19 Primae partis art. 2 contendit, ${ }^{158}$ determinatam veritatem futuri contingentis a nobis incongrue proferri ut rationem, cur futurum determinate cognoscibile a Deo sit, arguitque sic: Futurum contingens, antequam sit, nullum habet esse nisi futuri. At esse futurum contingenter non potest fundare determinatam cognoscibilitatem. Ergo nec illam fundare potest esse futuri contingentis.

Consequentia legitima est, et maior ex se nota, cum ante praesentiam ${ }^{159}$ rei haec non possit esse praesens: ergo, ad summum, poterit esse futura.

Minorem vero probat

$1^{\circ}$ Ex S. Thoma $-1^{\circ}$ Perihermeneias lect. 13, et q. 2 De Veritate art. 12 ad 1, et q. 16 De Malo art. 7, et Prima parte q. 14 art. 13 - asserente, futurum contingens ut futurum est, non posse determinate cognosci certitudinaliter, sed solum ut praesens.

$2^{\circ}$ Quia futurum contingens ut futurum est in statu indeterminationis, quia esse futurum habet ut consideratur in sua causa. Ut sic autem determinatum esse nequit ad unum, quia est futurum contingenter et impedibiliter.

158. Ioannes A S. Thoma: Cursus theologicus in Primam partem D. Thomae 19, 2, Alcalá 1637, t.1, 587a-88a.

159. praescientiam corr. 
Respondet ipse pro nobis, futurum contingens impedibile esse quoad esse, non quoad futuritionem. „Haec enim est determinata ex suppositione, quod res erit. Suppositio autem illa est vera, ut eventus ipse declarat, quia de facto ponitur, quando evenit.“

Contra hanc vero solutionis larvam sic digladiatur:

„Sed contra [est]: quia futuritio ista non est aliud quam ipsum esse ut ponendum. Sed est impedibile ipsum esse ut ponendum [...] Ergo ipsa futuritio est impedibilis [...] Quod autem dicitur, esse determinatum ex suppositione, quod res erit, est idem ac dicere, quod ex suppositione, quod est futurum, est determinatum, quod sit futurum. Quod nullus negare potest. Sed haec veritas non est contingens, sed necessaria, nec pertinet ad exercitium futuritionis, sed ad essentialem rationem quidditatis [...] Facit enim hunc sensum: Futurum est futurum [...] Nec ad hoc cognoscendum est necessarium lumen infinitum [...] Cum vero dicitur, quod suppositio illa est vera, ut eventus probat, latet hic magna aequivocatio. Ille enim eventus non reddit [ $845 \mathrm{r}$ ] veram determinate ipsam futuritionem, ut futuritio est, sed transfert futuritionem in actualem praesentiam eveniendo; et ratione eventus determinatur in actu quod ratione futuritionis indeterminatum erat. Et sic urgetur ratio, quia eventus ille vel sumitur ut futurus, vel ut praesens in actu, quando iam solvit futuritionem et transfert in praesens. Eventus ut futurus non potest reddere veram illam suppositionem, quia sic est ipsamet futuritio, et illa est contingens et ad utrumque. Non ergo eventus ut futurus reddit certam illam suppositionem futuritionis. Sic [enim] idem per idem redderetur certum. Et eadem difficultas est de ipsa suppositione futuri eventus, atque de ipso eventu ut futuro. Eventus autem [ut] praesens non reddit suppositionem illam futuritionis veram determinate, quia praesens ut praesens solvit futuritionem. Ergo ex illo eventu non potest sumi verificatio determinata in statu futuritionis, sed solum verificatio determinata, prout redditur praesens. Et in hoc perpetuo laborat D. Thomas, ut futurum non dicatur determinate verum, ${ }^{160}$ nisi inquantum reducitur ad aliquem modum praesentiae. ${ }^{“ 161}$

193. Haec obiectio plura continet animadversione digna.

Et primum, responsio, quam nostro nomine tradit, nec nostra est nec vera nec tandem ${ }^{162}$ a Theologo illo satis impugnata. Quis enim Nostrorum dixit, determinatam futuritionem liberi actus non esse a nobis impedibilem? Si enim haec impedibilitas non esset, quo pacto evitabilis esset actus futurus, qui ad determinatam

160. futurum corr.

161. Ionnnes a S. Thoma: Cursus theologicus in Primam partem D. Thomae 19, 2, Alcalá 1637, t.1, 588aD-bC.

162. tamen corr. 
futuritionem sui inevitabiliter sequatur? Id ergo a nobis non dicitur nec verum est, quia nihil determinate connexum cum actu libero potest esse inevitabile a potentia ad talem actum libera.

Verum quidem est, Nostrorum AliQuos agnovisse determinatam futuritionem actus liberi ratione distinctam ab eius existentia, impedibilem a potentia libera non formaliter et per se, sed fundamentaliter per actum liberum, in cuius existentia fundatur: ut RuIz et alii (capite $13^{\circ}$ citati) philosophantur. Hi a nobis supra impugnati sunt. Eos tamen parum laedit impugnatio IoANNis a S. THOMA. Nam licet futuritio illa determinata sit ex suppositione, quod erit actus, non sequitur, solum determinari aut cognosci, futurum esse futurum, ex suppositione, quod est futurum - hoc enim est verum necessarium et a quovis limitato intellectu cognoscibile -, sed, ponendam esse suppositionem, quae inferat aeternam futuritionem actus: quod contingentis et abstrusae veritatis est.

194. Deinde, responsio vera obiectionis propositae in ipsa eius propositione invenietur, [845v] si „futuritionis“, cui innititur, legitimus intellectus ex capitibus praecedentibus statuatur. Obiectio est, rem, antequam sit, solum habere esse futurum; esse autem futurum est indeterminatum: ergo res, antequam sit, solum habet indeterminatum esse: ergo incapax ad fundandam certitudinem cognitionis.

Responsio est, rem, antequam sit, nullum habere esse quod determinatam cognitionem fundare seu exigere possit, solumque illud habere per esse determinatum quo praesens temporaliter est aeternitati, et, quia ad hanc praesentiam fertur divinus intuitus, ideo Deum invenire determinationem obiectivam sufficientem ad determinandam certitudinem suae cognitionis: ut cum S. Thом et communi antiquorum Doctorum explicuimus et toto hoc libro et capitibus sequentibus amplius explicabimus.

195. Si autem opponas: Ergo non defendimus, quod Nostris Doctoribus familiare est, scilicet, futurum cognoscibile determinate esse ut futurum ob determinatam eius futuritionem, -

Respondeo, futuritionem, quae a NosTRIs assignatur pro ratione determinatae cognitionis, non antecedere existentiam et praesentiam rei nec ab illa distingui. Unde promiscue a Nostris modo existentia rei, modo eius futuritio - sumpta pro ratione formali, per quam res existet: quae est ipsa existentia - assignatur pro ratione, cur Deus possit cognoscere futura, etsi contingentia sint ad non-esse: quia contingentia non sunt nec indifferentia ad non-essendum ex suppositione, quod extitura sint, cum omne, dum est, necesse sit esse. Ea autem esse in se extitura supponit divina illorum praescientia. Haec est ratio nostra, quam, cum S. ThомA, ex Sanctis Patribus desumpsimus (ut ex libro praecedenti et ex toto hoc libro manifeste apparet). 
196. Si autem nobis opponatur, „futuritionem“ a S. Тнома non sumi pro ipsa futura existentia, sed pro habitudine, quam in causis habet, ut sit, -

Respondeo (iuxta dicta capitibus $2^{\circ}$ et $3^{\circ}$ ), „futuritionem“ a S. Thoma sic eam describente sumi pro futuritione, quae pure futuritio est conceptum praesentiae rei in se nec includens nec supponens, sed omnino illum antecedens. Haec purae futuritionis quidditas solum constituitur per modum essendi, quem res habent in suis causis, attamen non excludit alium modum futuritionis non purae, sed admixtam habentis praesentiam. Nam futuritio est ratio per quam res erit post non-esse sui, seu, per quam eius existentia affirmabilis est de futuro, seu, antequam sit. Sic autem affirmabilis est existentia rei per se ipsam obiective et per cognitionem duratione priorem intentionaliter. Unde ipsa existentia comparata ad cognitionem priorem est futuritio physica et obiectiva, [846r] cognitio vero ipsam praecedens est futuritio formalis. Quibus fit, „futuritionem“ distingui posse in causalem, de qua praecipue agit $\mathrm{S}$. Thомаs, et in formalem, hancque in obiectivam et intentionalem (ut capite $16^{\circ}$ explicuimus ex Divis Augustino et Anselmo).

Sumpta ergo contingentis „futuritione" non pro esse quod habet in causis - licet etiam hoc esse ut est in causis completis ad operandum, futuritionis, etsi diversae, conceptum habeat -, sed pro existentia ipsa per quam formaliter erit post non-esse sui, nulla eget responsione obiectio IoAnNis a S. THома, quia solum contendit, futuritionem, quae praesentiam omnino antecedat, nullam posse habere determinationem certitudini cognitionis sufficientem. Quod libentissime fatemur et obiicienti parum salutare esse statim ostendemus. Ideoque dicimus, certitudinem hanc ad ipsam futuri existentiam ut praesentem aeternitati (modo in sequentibus explicando) terminari, et consequenter nullam esse obiectivam cognoscibilitatem aeternam determinatam ad unum, quae praescientiam antecedat, sed, totam cognoscibilitatem hanc - scilicet ad unum determinatam et praescientia divina priorem - esse temporalem, hancque infinito cognoscenti de se cognoscitivo cuiusvis extremi quod in tempore existet, sufficere ad aeternum eius intuitum (ut late capitibus praecedentibus ostensum est).

197. Si autem instet, hoc non esse futuritionem, sed temporalem praesentiam, proferre ad certam cognoscibilitatem explicandam, -

Respondeo, esse proferre futuritionem a praesentia indistinctam; de qua controverti, an „futuritionis“ nomine significari possit, est controversia de nomine. Nos posse, asserimus cum Samctis Patribus asserentibus, futura ideo cognosci a Deo, quia futura sunt, seu quia existentiam habent de futuro affirmabilem seu affirmabilem antequam sint. Quod S. quoque Thomas approbat, nam Patrum sententiam amplectatur et interpretatur Prima parte q. 14 art. 8, concedens, futura praesciri, quia futura sunt, intelligendo ly "quia“ de "causa consequentiae, non de causa essendi“. Cum ergo art. 13 ea etiam certo praesciri dicat, quia in se ipsis existentia 
sunt praesentiaque aeternitati, praesentiam hanc „futuritionem“ in aliquo sensu appellari posse supponit. Quod S. quoque Augustinus lib. $11^{\circ}$ Confessionum cap. 14,15 et 18 docet (ut capite $16^{\circ}$ ostendimus).

198. Denique animadversione dignum est, IoANnem a S. Thoma adeo impense contendere, ne futuri ut futuri - id est, ut contenti in causis -, sed solum ut praesentis, dari possit certa praescientia: cum [846v] haec verissima doctrina aperte pugnet cum praescientia certa futurorum contingentium in decretis antecedentibus efficaciter et causaliter determinantibus existentiam futurorum. Si futura contingentia solum sunt certo cognoscibilia ut praesentia - et non ut futura -, qua doctrinae cohaerentia dicuntur certo cognosci in divinis decretis? Nonne haec perfectissimae causae futurorum sunt? Nonne in illis futura determinate sunt obiecta quae decernunt? Praesentia enim non sunt in decretis formali et physica praesentia, sed solum causali et eminentiali: cum divina voluntas et potentia non formaliter, sed eminenter, suos effectus contineat.

Praeterea, S. Thомаs ubique asserit - praesertim Prima parte q. 16 art. 7 ad 3 -, quod id "quod nunc est, ex eo futurum fuit, antequam esset, quia in causa sua erat, ut fieret“. Sed in divino decreto efficaci, quod est perfectissima causa - si daretur -, „esset, ut fieret futurum contingens“. Ergo esse futurum et futuritionem in illo haberet, non praesentiam. Dari ergo decretum in quo certo cognoscatur, determinatum extremum libertatis esse futurum, aperte pugnat cum Thomistica doctrina - a Theologo illo iure statuta -, quod scilicet contingens ut futurum non possit subdi per certitudinem ulli cognitioni, sed solum ut praesens.

199. At dices - iuxta illum et alios novos Thomistas -, in divino decreto futurum esse praesens.

Video id ab ipsis dici, non tamen componi cum S. Tнома loco citato definiente, quid sit, rem esse futuram, antequam praesens sit. Id enim est „esse in causa, ut fiat“. Ergo, in decreto Dei esse, quod fiat aliquid, est, illud esse futurum, et non praesens.

Praeterea, si esse in decreto Dei determinatum effectum liberum creatum, esset habere praesentiam, et cognosci in illo decreto esset cognosci futurum ut praesens et non ut futurum -, sequeretur, eodem iure dicendum esse, quod effectus necessarii non cognoscantur ut futuri, sed ut praesentes, sicut id dicitur de contingentibus. Hoc autem Divo Thomae manifeste repugnat: ergo et dici, quod contingentia cognita in decreto efficaciter causativo cognoscantur ut praesentia, et non ut futura.

Maior patet, quia effectus necessarii non minus efficaciter decreti sunt a Deo quam contingentes: ergo aeque praesentes - et non futuri - in decreto illo erunt ac effectus contingentes, ac proinde aeque in illo cogniti non ut futuri, sed ut praesentes.

Minor vero constat vel ex ipsis locis S. Thomae, quibus Theologus Ille probat, contingentia non posse certo cognosci ut futura. 
Primus [847r] enim sic habet $1^{\circ}$ Perihermeneias lect. $13 \S$ „Ponit secundam rationem“ [n. 10]: „Falsum est, quod omne, quod est verum [esse, verum] ${ }^{163}$ fuerit determinate dicere esse futurum.“ Quod probat, quia „cum verum [hoc] significet [ut dicatur] aliquid esse quod est, hoc modo aliquid est verum, quo habet esse. Cum autem aliquid est in praesenti, habet in se ipso esse [...], sed quandiu [aliquid] est futurum, nondum habet esse in se ipso; est autem aliqualiter in sua causa." En constitutum esse futuri per esse in causa, et praesentiam per esse in se ipso seu extra causas. Subiungit autem [n. 11], tripliciter effectum esse futurum seu in causa contentum: $1^{\circ}$ per determinationem et necessitatem ad unum, $2^{\circ}$ per inclinationem sine determinatione, $3^{\circ}$ per omnimodam indifferentiam sine inclinatione ad unum potius quam ad alterum. Primum effectum ait determinate et certo cognosci ut futurum, secundum solum coniecturaliter, tertium nec coniecturaliter determinate cognosci posse ut futurum. Evidens ergo est, iuxta S. Tномам, necessarios effectus a futuris secerni in eo, quod certo cognosci possint etiam ut futuros, contingentes vero solum ut in se ipsis et ut extra causas suas praesentes sunt. Sed S. ipsum Doctorem audiamus: „Quod quidem“, scilicet, esse futurum et in causa, „,contingit tripliciter: uno modo ut sic sit in causa, ut ex necessitate ex ea proveniat, et tunc determinate habet esse in sua causa; unde determinate potest dici de eo, quod erit. Alio modo aliquid est in sua causa, [ut] quae habet inclinationem ad suum effectum, quae tamen impediri potest; unde et hoc determinatum est in sua causa, sed mutabiliter, et sic de hoc vere dici potest hoc erit, sed non per omnimodam certitudinem. Tertio est aliquid in sua causa ${ }^{164}$ pure in potentia, quae etiam non est magis determinata ad unum, quam ad aliud; unde relinquitur, quod nullo modo potest de aliquo eorum determinate dici, quod sit futurum, sed quod sit, vel non sit." Nota ergo: Est distinctio contingentis a necessario, iuxta S. Thомам, quod contingens non potest ut futurum et antecedens praesentiam certo cognosci, sic vero necessarium.

Idem repetit S. Doctor q. 2 De Veritate art. 12 (quem citat Theologus Ille) rationem reddens, cur necessaria in causis certo cognosci possint, non vero contingentia: quia „necessarium“, inquit in corpore articuli, „non potest impediri, quin sit, antequam fiat [...] Sed contingens impediri potest, antequam sit in esse productum."

Ex tertio loco, quem citat Theologus Ille, scilicet [847v] q. 16 De Malo art. 7, probatur non minus efficaciter idem intentum. Nam in corpore articuli sic incipit: „[...] dicendum, quod dupliciter possunt futura cognosci: uno modo in se ipsis, alio modo in suis causis. In se ipsis quidem a nullo cognosci possunt nisi a Deo."

163. So die von den früheren Drucken abweichende Lesart der Editio Leonina.

164. sed del. 
In causis vero explicat triplicem cognitionem: aliam eorum quae sunt contingentia ad utrumlibet et in potentia ad duo; aliam eorum quorum activa causa non potest impediri a suo effectu: quae dicuntur „ex necessitate“ contingere; aliam denique eorum quorum causa inclinata est ad unum, sed impedibiliter. Statimque subdit: „ea, quae sunt ad utrumlibet, non possunt praecognosci in suis causis determinate, sed sub disiunctione, utpote quia erunt, vel non erunt. Sic enim habent veritatem. Ea vero, quae sunt in suis causis ut ex necessitate ab eis provenientia, possunt per certitudinem cognosci in suis causis etc." Alia plura omitto, cum manifestum sit, S. Tномам id singulariter tribuere effectibus contingentibus, quod ut futura in suis causis nequeant certo cognosci, sed solum ut sunt in se ipsis praesentia, oppositumque asserere de necessariis. Ergo praesentia, vi cuius intelligit certo cognosci contingentia, non est ea, quam habent in divino decreto - nam hanc quoque necessarii effectus habent -, sed ea, quam habent formaliter per suam existentiam.

200. Ex his detegitur „magna“ illa „aequivocatio“, quam IoAnnes a S. Thoma latere ait in eo, quod „suppositio futuri est vera, ut eventus probat“. Aequivocatio consistet in eo, quod supponat ipse, nos „determinatae futuritionis“ nomine intelligere existentiam futuri contingentis in causa. Hanc existentiam contingentis in causa „futuritionem“ illius appellari concedimus, non tamen futuritionem „determinatam“, sed ,indeterminatam“ et „contingentem“, quia insufficiens est ad determinandam certitudinem cognitionis. Futuritio ergo determinata - in nostra sententia - fundatur in ipsa praesentia rei succedente post non-esse sui. Haec enim est ratio ob quam de re, antequam sit, dici potest, quod erit. Quo intellecto sine ulla aequivocatione cognoscitur, eventum ipsum existentiae rei probare determinatam eius futuritionem seu capacitatem, ut de futuro affirmetur cognitione ipsam praecedenti secundum rationem.

201. Ex dictis etiam evanescunt caetera quibus AUThor ILLE vim propositae obiectionis urgere nititur:

$1^{\circ}$ Ait, hoc ipso, quod res sit extra causas, tollitur eius contingentia.

$2^{\circ}$ Solvitur per praesentiam eius [848r] futuritio. Neque ut futurum neque ut contingens cognoscitur vi existentiae, sed ut praesens et necessarium.

$3^{\circ}$ Existentiae et determinationis ${ }^{165}$ diversae debent esse causae a causis futuritionis, quae indeterminata est.

Respondetur enim, ad primum, ex eo, quod res sit, non tolli eius contingentiam seu posse non esse - attenta exigentia causarum. Haec enim contingentia semper manet. Dicitur autem „tolli“ - id est, non manere - post determinationem actus in sensu composito illius. Quod proprie non est aliquam indifferentiam, quae

165. determinationes corr. 
debebatur, tolli, sed determinari per suum actum et impediri oppositum. Quod sufficit ad certitudinem, quae non attendit indifferentiam principii, sed determinationem actus.

Ad secundum dico, per praesentiam transiri a futuro indifferenti ad futurum determinate, cuius ratio non solvitur, sed statuitur, per praesentiam. Haec enim habet conceptum futuritionis ut comparata ad durationem, in qua non est, sed affirmatur, quod erit.

Ad tertium respondeo, causas futuritionis indifferentis et disiunctivae diversas esse a causis praesentiae: quia futuritio illa est creata ipsa causa completa libera, cuius causa est solus Deus illam complens ad indifferenter operandum et sua ipsa completione necessitans ad hoc, ut unum vel alterum extremum libere operetur; at vero futuritionis determinatae non alias esse causas nisi causas existentiae: quia haec „futuritio" secundum rectum, quod dicit, non distinguitur ab existentia. Huius autem causa est voluntas creata ut eligens et elective determinans unum prae alio, Deus autem ut adiuvans cooperando et praeparans praevie applicando voluntatem ad operandum (ut libro $2^{\circ}$ late explicatum est).

\section{Caput 18. An Deus cognoscat futura contingentia ut futura sibi, vel aliis?}

202. Communis Patrum sententia est, Deum non cognoscere aliquid ut futurum sibi vel respectu cognitionis suae, sed ut futurum respectu rerum et cognitionum creatarum. Deo enim, inquit S. Gregorius lib. $20^{\circ}$ Moralium cap. $23,{ }^{166}$ „nihil futurum est, ante cuius oculos praeterita nulla sunt, praesentia non transeunt, futura non veniunt“. Ex quo infert, proprius dici, quod Deus „sciat“, quam quod „praesciat“ . 167 Et S. Thomas q. 2 De Veritate art. 12 ait, quod, si Dei scientia significari posset a nobis, „ut est [...], magis deberet dici, quod Deus scit hoc esse, [848v] quam, quod sciat, futurum esse, quia sibi nunquam futura sunt, sed semper praesentia." Quam doctrinam expressis plurimorum Patrum testimoniis confirmatam vide in $\mathrm{P}$. Didaco Ruiz De Scientia Dei disp. 28 sect. 4 et 5, caeterisque interpretibus Primae partis ad quaestionis 14 art. 13. Eam tamen explicare opus est et cum aliis non minus certis doctrinis componere.

166. scimus quia del.

167. Gregorius Magnus: Moralium 20, 32, PL 76, 175. Zitiert bei Didacus Ruiz de Montoya: Commentarii ac Disputationes de scientia Dei 33, 4, 30, Paris 1629, 274 a. 
203. Imprimis enim nihil certius est quam Deum aeterna duratione praecedere omnia creata. Nam antequam formaretur orbis, a saeculo et usque in saeculum ipse est Deus, et antequam quicquam faceret a principio, ab aeterno ordinata est divina sapientia et per illam rerum omnium ordines statuti et electi ante mundi constitutionem praedestinati, et similiter damnati sunt reprobi. Praeterea certum est, post omnium quae finem habebunt destructionem Deum permansurum: „Ipsi peribunt, tu autem permanebis. "168

Ex quibus oppugnari potest praecedens doctrina, quia, quae posteriora sunt duratione, sunt futura respectu prius existentis, quia extiturum post aliquod est futurum post illud.

Deinde, in priori quo aliquod praecedit duratione, sunt affirmabilia quae subsequentur; at non ut in illo priori existentia: ergo ut extitura post ipsum et consequenter ut futura respectu illius.

Similiter, etiam Deo ut existenti post interitum creaturae haec praeterita videtur, quia Deus est post eius destructionem existens, et ipsa Deo sic existenti scilicet, post eius interitum - non est praesens nec futurus: ergo est praeterita. ${ }^{169}$

Denique impugnatur eadem doctrina ex capite praecedenti, in quo diximus, divinam cognitionem esse aeternam futuritionem intentionalem rerum quae existent. Ergo est cognitio affirmans illas de futuro illasque respiciens ut futuras respectu sui.

204. Ad haec et alia componenda sciendum est,

$1^{\circ}$ Deum non esse duratione sua priorem nec posteriorem creaturis: ordine successivo scilicet constituendo cum illis successionem, qua aut ipsi succedant creaturae aut creaturis Deus. Quorum utrumque repugnat Deo.

Ideo Augustinus lib. $9^{\circ}$ Confessionum cap. 10: „[...] fuisse, aut futurum [esse] non est in ea“, scilicet divina duratione, „sed esse solum, quia est aeterna. Nam fuisse, et futurum [esse] non est aeternum. ${ }^{“ 170}$ Quia aeternitas, iuxta Theologos - ex definitione BoETHII -, tota simul et indivisibiliter existere debet.

205. Hinc $2^{\circ}$ dicendum est, per divinam durationem - quae est aeternitas - Deum non praecedere creaturas modo [849r] communi, quo dicimus temporalia aliqua aliis esse „priora“. Communis enim sensus huius prioritatis est, quod quae „priora" dicuntur, existent in temporali duratione, cui nullatenus coexistat id, ad quod praecedunt. Hoc autem sensu Deus non est „prior" ulla creatura, quia non habet durationem, cui possit creatura, si existat, non coexistere: cum necesse sit omne existens esse coexistens Deo.

168. Hebr. 1, 11 (Ps. 102, 27).

169. praeteritus corr.

170. Augustinus: Conf. IX, 10, 24, PL 32, 774. 
206. Ex quo $3^{\circ}$ dicendum est, aeternitatem respectu omnium in quavis duratione existentium habere ordinem praesentis ad praesens. „Ordinem“ sumo non, ut in strictiori significatione explicatur, per dispositionem plurium secundum prius et posterius, sed significatione latiore, ut significat habitudinem unius ad aliud (quamvis et in priori quoque sensu ipsa habitudo praesentiae inter Deum et creaturam, ut sibi praesentes sunt, cum praesentiae ratio dispar in utroque extremo sit, et ea ipsa, quae aeternitatem facit temporalibus durationibus praesentem, probet in ipsa eius praesentia infinitam praecedendi eminentiam modo statim explicando). Itaque omnia quovis tempore existentia Deus respicit cum ordine praesentis ad praesens, sive ipsa in nostro $n u n c$ - eo scilicet quo existimus et loquimur - praesentia sint, sive praeterita, sive futura. Nam, ut Augustinus lib. $15^{\circ}$ De Trinitate cap. 7: „[...] praeterita et futura cum praesentibus sunt cuncta Deo praesentia “ ${ }^{171}$ Cuius ratio est, quia praesentia quoad durationem constituitur per coexistentiam; repugnat autem aliquid quovis tempore, quod tunc non coexistat Deo: ergo repugnat aliquid esse existens quod eo ipso non sit Deo eiusque aeternitati praesens.

207. $4^{\circ}$ Dicendum est, praedicta non obstare quo minus simpliciter dicendum sit, Deum aeterna duratione "praecedere“ creaturas. In divinis enim et humanis eloquiis nil hac assertione indubitantius profertur, eamque nemo inficiari ausus est nisi cum limitatione ad determinatum aliquem sensum.

208. Probatio conclusionis est explicatio legitimi sensus „praecedentiae“, quae in illa asseritur. Licet enim verificari non possit ratione praecedentiae, qua Deus ita prius duret, ut ipsi succedant creaturae, neque ita, ut existat per durationem, in qua non existant - id est, cui non coexistant creaturae in quavis duratione existentes (ut dictum est) -, attamen aliis modis vere prior est aeterna duratio rei quam ulla temporalis: quia non solum prior est dignitate, necessitate, causalitate et subsistendi consequentia, ${ }^{172}$ sed etiam amplitudine durandi, quia [849v] per ipsam Deus a parte ante aeternus est, cum tamen nulla creatura sic aeterna sit. Hoc autem sufficit, ut verissime dicatur Deus per aeternam durationem „praecedere“ creaturas et „prius“ illis existere. Nam conceptus ipse existendi sine durationis principio est excessus durandi respectu habentis existendi initium: sicut quod durat sine fine excedit duratione omnia, quae finiuntur, plusque durat quam ea, quorum existentiae finem durandi habent. Illimitatio ergo versus initium est plus durare praecedendo ad omne quod incipit: sicut illimitatio versus finem est, comparatione eorum quae finiuntur, plus durare, permanendo sine fine licet non simpliciter subsequendo.

171. Augustinus: De Trin. XV, 7, PL 42, 1066.

172. Zu dem Ausdruck „subsistendi consequentia“ vgl. Aristoteles: Cat. 12, 14a29; Gualterus Burleus: „Liber Praedicamentorum“, in: Edita in Artem veterem, Venedig 1519, fol. 41vb. 
209. Praeterea probatur, quia quod aeternum est, per exclusionem initii durationis ita comparatur ad quodcunque incipiens, ut infinitis durationibus temporalibus anterioribus, si hae producerentur - ut syncathegorematice possunt -, coexisteret formaliter per durationem ipsam qua illi repugnat incipere. Hoc autem facit divinam durationem habere in se latitudinem maiorem - non numero partium, quibus componatur, sed - excellentia perfectionis, qua partibus successivae latitudinis quantumcunque extensae aequivaleat et coexistere debeat. Haec ergo amplitudo, qua necesse est carere omnia quae incipiunt, divinam durationem illis - per aeternam durationem, qua carent - priorem constituit.

210. Dices: Non constituit posterioritatem Dei in se ipso, respectu rerum finientium, quod permaneat illis finitis: ergo nec constituit prioritatem Dei in se ipso, respectu incipientium, quod ipsis comparetur ut existens sine initio cum incipientibus existere.

Negatur consequentia, quia ad prioritatem unius in se ipso respectu alterius ut posterius incipientis sufficit habere durationem, cui coexistat negatio rei ut durantis per durationes praecedentes ad eam, qua de facto incipit existere. Ob hanc causam Deus prior est creaturis eo ipso, quod ab aeterno et sine initio existat, creaturae vero existere incipiant, quia hoc ipso verum est, quod Deo existente creaturae caruerunt aeterna duratione, immo et temporalibus sine fine, quas ante eam, per quam inceperunt, habere possent. Et etiam eo ipso verum est, quod, si existerent durationes illae priores, Deus illis coextitisset per durationem, qua essentialiter in se existens est. Quod facit Deum in se ipso esse perfectissime priorem creaturis.

Non potest autem in se posterior esse ulla creatura, quia ad hoc opus esset, creaturam fore in se priorem Deo eiusque negationi coexistens. Quod repugnat. Unde, Deum post creaturas desinentes existere, probat longiorem sine fine durationem, non tamen posteriorem in [85or] se, sed solum in aliquo extrinseco, quia solum est posterior, secundum extrinsecam denominationem coexistentis rebus posterioribus, ea quae desinit esse. V.g., post Adami existentiam coextitit Deus Abrahamo. Quod non est, Deum quoad aliquid intrinsecum, sed quoad simultatem existentiae cum Abrahamo, posteriorem esse posterioritate intrinsece afficiente solam Abrahami existentiam.

211. Si urgeas: Deus a nobis ideo dicitur „prior“ in se creaturis, quia coexistit negationi durationum praecedentium ad eas, quibus creaturae incipiunt; sed etiam coexistit negationi durationum subsequentium ad eam, qua creaturae finiuntur: ergo, vel subsequitur in se ad res quae desinunt, vel non est in se prior rebus quae incipiunt; -

Respondeo negando, Deum esse „in se“ priorem ob coexistentiam illam formaliter sumptam. Nam, esse in se priorem non est, eius coexistentiam ad negationem praecedentium durationum priorem esse, sed habere in se perfectionem durandi, quae comparatur ad creaturam ut non-incipiens ad incipientem. Ideo Deus ex parte 
sua constituitur prior, si aliud, cum quo comparari possit eius duratio non-incipiens, existat incipiendo. Unde, licet Deum esse absolute „priorem“ creatura dicat aliquid extrinsecum, nempe existentiam incipientis creaturae, cui comparetur, attamen haec existentia requiritur ut id, ad quod praecedit in se ipso et per se ipsum Deus, non ut ratio per quam praecedit. At vero coexistentia ad res posteriores est Deo ratio formalis subsequendi ad priores ita, ut denominatio subsequendi non cadat supra Deum in se et per se illam recipientem, sed solum recipientem ratione alicuius extrinsece quod denominationem coexistentis constituit. Ideo autem non recipit in se denominationem subsequentis aut posterioris existentis quam creaturae, quia non incipit in se esse - post negationem essendi - creaturis coexistentem. Quod omnino necessarium erat ad hoc, ut in se esset „posterius“ creaturis. Est autem in se illis "prior" ob rationem oppositam, quia scilicet in se habet durationem non-incipientem, qua creaturae incipiendo carent.

212. $5^{\circ}$ Ex dictis constat, Deum non ita "praecedere" creaturam incipientem ob carentiam initii nec deficientem ita „subsequi“ ob carentiam finis, ut adveniens creatura Deum, qui praecessit, respiciat tanquam praeteritum nec post ipsam permansurum respiciat ut futurum: quia Deus in se nec praeteritus esse potest nec futurus, cum ad praeteritum requiratur desinere et ad futurum [850v] incipere. Unde omne esse praeteritum et futurum Deo convenit per extrinsecam denominationem, v.g., Adamo coextitisse, coextiturum esse Antichristo.

213. Obiicies, Deum posse enunciari de praeterito et de futuro non secundum extrinsecam denominationem, sed secundum esse intrinsecum. Vere enim dicitur „Fuit ab aeterno, et in aeternum erit“. In se ergo habet aliquid praeteriti et futuri.

Respondetur, enunciationes illas Deum in se respicere non affirmando, quod in se est futurus aut praeteritus, sed affirmando, quod in se habet durationem, cui coextiterunt durationes praeteritae et futurae. Sensus enim est, Deum coextitisse aut coexistere potuisse - durationibus, quae praecesserunt cognitionem, quae de praeterito affirmat, et coextiturum esse - aut posse - durationibus, quae post transactam durationem cognitionis affirmantis de futuro existent aut existere possunt.

Praeterea respondetur, illas propositiones etiam verificari sufficienter in sensu negativo ita, ut haec „Deus fuit ab aeterno“ significet, illum ita existere, quod non habuerit initium durandi, sensus vero propositionis de futuro „Deus erit in aeternum“ sit, Deum ita existere, ut non sit habiturus finem. Positive enim (ut dixi) nihil intrinsecum Dei habet durationem, quae cognitionem antecesserit praetereundo seu non-coexistendo cognitioni, nec durationem, quae post transactam cognitionem incipiat. Primum autem requiritur ad cognitionem de praeterito, secundum ad cognitionem de futuro, ut S. Thomas citata q. 2 De Veritate art. 12 testatur.

Unde quod positive et intrinsece affirmatur de Deo, est, ipsum esse praesentem $\mathrm{ab}$ aeterno et in aeternum. Quae autem de futuro ac de praeterito dicuntur de Deo 
vel solum verificantur negative vel positive extrinsece: ratione alicuius extrinseci constituentis coexistentiam cum praeterito aut futuro.

214. $6^{\circ}$ Dicendum est, prioritatem qua Deus creaturas duratione praecedit, non facere, ut ipsi Deo creaturae proprie sint „futurae“, nec, quod per divinam cognitionem de futuro cognoscantur.

Ratio est: Quia, ut S. Thomas q. 2 De Veritate art. 12 ait: „Tunc [...] aliquid cognoscitur ut futurum [est], quando inter cognitionem cognoscentis, et rei eventum invenitur ordo praeteriti ad futurum. Hic autem ordo non potest inveniri inter cognitionem divinam, et [...] rem contingentem, sed semper ordo divinae cognitionis ad rem quancunque est sicut ordo praesentis ad praesens. "Itaque communis acceptio „futuri“ est, illud sic dici comparatione rei aut durationis, quae habeat prioritatem exclusivam praesentiae ad illud, et consequenter, quae non habeat [851r] coexistere futuro, quando hoc fuerit praesens, sed tunc debeat transire in praeteritum.

Ideoque cognitio enuntians, futurum aliquid esse, ex modo enunciandi negat coexistentiam obiecti cum duratione, quam ipsa ex parte sua consignificat, scilicet cum ea, in qua ipsa enunciatio incipit esse, eiusque sensus est: „Erit obiectum post me transactam“. Quod intelligendum est: post transactam vel cognitionis substantiam vel saltem durationem illam inceptionis, quam cognitio ex parte sua significat. Dico „ex parte sua“, ut notetur, aliam differentiam temporis consignificari ex parte obiecti. ${ }^{173}$ Cum ergo praedictus modus enunciandi futura repugnet divinae cognitioni, repugnabit, quod illa ut sibi - aut aeternae Dei durationi - proprie futura esse cognoscat.

215. $7^{\circ}$ Cognoscit tamen Deus illa ut „futura“ minus quidem proprie sibi, quatenus cognoscit ea ut posterius duratione existentia quam divina cognitio, proprie autem futura aliis creatis obiectis prioribus. Sic S. Thomas, loco proxime citato [De Veritate q. 2 art. 6] ad 6. argumentum: „[...] cognoscit“, inquiens, futura contingentia „sibi ut praesentia, aliis autem futura“. Et $1^{\circ}$ Contra Gentiles cap. 66: „Quicquid [...] in quacunque parte temporis est, coexistit aeterno, quasi praesens eidem, etsi respectu alterius partis temporis sit praeteritum, aut futurum. " Cognoscit enim Deus, quod Antichristus, v.g., post multa tempora erit et comparatione illorum $f u$ turus sit, mundumque hunc, etsi ante ipsum nihil creatum extiterit, cognoscit Deus futurum comparatione saeculorum, quibus ipse prius existere poterat quam extitit, vel quibus alius mundus prius existere poterat. Nam, licet saecula illa durationum ex se praecedentium ad eas, quibus mundus incepit - id est, quae, si darentur, deberent necessario constituere cum durationibus saeculorum, quae de facto constituta

173. Dieses Theorem auch bei Antonius Bernaldo de Quiros: Opus philosophicum 99, 19, Lyon 1666, 689a/b. 
sunt, ordinem non simultanei aut posterioris, sed prioris - licet, inquam, saecula illa non praecesserint, attamen mundi saecula existunt ut ex se posteriora illis, et ideo respectu illorum dicuntur futura.

216. Non autem sic dicuntur proprio respectu divinae cognitionis, quia haec enunciat futura ita, ut, licet non absolvat suum obiectum a tempore illud mensurante, ipsa tamen in se a tempore et successiva duratione ipsam mensurante absolvitur, quia mensuratur aeternitate, quae omnes temporis differentias ambit et cui necesse est nostrum praeteritum, praesens et futurum coexistens et praesens esse. Ideoque necessarium est, quod divina cognitio [851v] eo ipso, quod de aliquo affirmat existentiam, affirmet coexistentiam illius cum se ipsa, etsi per durationem limitatam, quae comparetur ad aliquas creaturas ut futura, ad alias ut praeterita, et comparatione illorum praeterita, et futura affirmetur a divina cognitione, sibi autem praesens: id est existens per durationem coexistentem durationi ipsius cognitionis divinae, quae affirmatur.

217. Si autem opponas, divinam cognitionem non affirmare de re futura, quod sit ab aeterno sibi, vel Deo, praesens: ergo affirmat, illam esse sibi, et Deo, futuram, -

Negatur consequentia: quia inter illa duo datur medium, nempe cognosci ab aeterno, rem esse temporaliter praesentem Deo (ut capite sequenti explicabitur). Hinc tamen non sequitur, divinam cognitionem non esse aeternam futuritionem intentionalem rerum quae existunt: quia, licet illa non respiciat ut futura sibi, respicit tamen illa ut futura aliis temporalibus durationibus res illas praecedentibus. Ideoque est intentionalis determinatio petens, res illas succedere post alias priores, et affirmans, eas respectu priorum futuras esse seu extituras post illorum existentiam. Quod sufficit, ut dicatur aeterna futuritio illarum. Ad hanc enim non requiritur cognosci, obiectum futurum esse post ipsam, nisi quando cognitio est futuritio - seu determinatio obiecti futuri - respectu sui. Non dicimus autem, divinam cognitionem esse intentionalem rerum futuritionem respectu sui, sed respectu aliorum, cum quibus affirmat res futuras ordinem successive posterioris habere.

218. Ex his patet ad rationes dubitandi.

Ad primum enim respondetur, quod, etsi Deus duratione aeterna antecedit creaturas, attamen non sunt illi proprie „futurae“, quia ipse non potest illis esse unquam praeteritus. In aeterna autem illa duratione priori concedo Deum non cognoscere creaturas ut in illo nunc aeternitatis existentes duratione aeterna, nego tamen, quod non cognoscat eas aliqua duratione coexistentes illi nunc aeternitatis, quo durat cognitio divina. Coexistentes enim illi per temporalem durationem cognoscuntur - ac proinde non illi, sed aliis creaturis - futuras esse.

Ad secundum respondeo, quod, licet Deus post creaturas pereuntes remaneat, non est "posterior" illis in se ipso, sed solum in extrinseca denominatione coexistentis, quae aliquid post creaturas desinentes incipiens includit. 
Ad tertium respondeo, divinam cognitionem (ut explicuimus) esse futuritionem, qua non Deo, sed creaturis prioribus, futurae sunt posteriores.

\section{Caput 19. [852r] Quae sit futurorum contingentium in aeternitate praesentia, et quid conferat ad divinam illorum cognitionem}

219. De hac praesentia agit S. Thomas q. 14 Primae partis art. 13 illam et eius conducentiam ad divinam cognitionem sic explicans: „[...] omnia, quae sunt in tempore, sunt Deo ab aeterno praesentia, non solum ea ratione, qua habet rationes rerum apud se praesentes, ut quidam dicunt, sed quia eius intuitus fertur ab aeterno super omnia, prout sunt in sua praesentialitate. Unde manifestum est, quod contingentia et infallibiliter a Deo cognoscuntur, inquantum subduntur divino conspectui secundum suam praesentialitatem: et tamen sunt futura contingentia suis causis proximis comparata." Quibus verbis agnoscit duplicem rerum praesentiam: Aliam, qua sunt praesentes per rationes aeternas seu ideas ut participabiles a creaturis. In quibus rationibus dubium non est, quod res habeant aliquam praesentiam, non tamen solam hanc - „ut quidam dicunt“ -, quia sola illa esset insufficiens ratio determinativa ad cognitionem determinatam et certam futurorum contingentium, cum aeternae rationes ideales rerum sint illarum causae - sive „ideas“ sumas ut antecedunt omnem divinae voluntatis determinationem, sive applicatas ad agendum per determinationem divinae voluntatis, quam respectu liberorum suppono indeterminatam esse, determinatam vero respectu eorum quae a causis secundis non libere fiunt -; at in causis solis non haberi potest certa liberorum contingentium cognitio, ut ipse Tномаs ibidem sic testatur: „[...] causa contingens se habet ad opposita; et sic contingens" ut futurum - id est ut antecedens in causis suam praesentialitatem cum determinatione ad illam habendam vi causae, nisi ab ipsa causa libere impediatur: quod contingentem futuritionem constituit - „non subditur per certitudinem alicui cognitioni. Unde quicunque cognoscit effectum contingentem in sua causa tantum, non habet de eo nisi coniecturalem cognitionem.“ „[...] Divina enim praescientia“, ait ipse Secunda Secundae q. 171 art. 6 ad 2, „respicit futura secundum duo: scilicet secundum quod sunt in se ipsis, inquantum scilicet ipsa praesentialiter intuetur, et secundum quod sunt in suis causis, inquantum scilicet videt ordinem causarum ad effectus. Et quamvis futura contingentia, prout sunt in se ipsis, sint determinata ad unum, tamen prout sunt in suis causis, non sunt determinata, quin possint aliter evenire." Quia determinatio, quam habent in causis, est disiunctiva - ut ipse S. Doctor explicuit q. 16 De Malo art. 7 -, [852v] vi cuius necesse est poni unum extremum libertatis a causa, nisi ab illa libere impediatur per positionem oppositi. Omnem ergo aditum praecludit S. Doctor ad certam futurorum cognitionem habendam in causis, omnemque determinationem 
causarum ad unum negat illam solum concedens futuro in se ipso. Ut capite $2^{\circ}$ et $3^{\circ}$ huius libri late ostensum est.

220. Ex quo concludit, praesentiam rerum in aeternitate non debere esse solum eam, qua praesentes sunt per aeternas rerum rationes. Nam alias nulla posset esse de illis certa cognitio. Ideo aliam addit praesentiam rerum in aeternitate, quatenus scilicet divinus intuitus fertur ab aeterno supra omnia prout sunt in sua praesentialitate. Quibus verbis et rerum extra causas temporalem praesentiam realem in se ipsis ad aeternitatem docet et aeternam in divino intuitu, vi cuius ab aeterno sunt formaliter praesentes Deo intentionaliter.

221. Patri Ludovico Molinae Prima parte q. 14 art. 13 disp. 14 non videtur placere praedicta nostra aeternarum rationum interpretatio, qua negamus $S$. THомам in illis agnovisse vim sufficientem ad determinandum Deum obiective ad cognitionem determinatam futuri. ${ }^{174}$ Sed cum Molina facile componimur advertendo, nec nos negare, quod aeternae rationes causativae rerum sint obiectum primarium scientiae futurorum adaequatumque obiectum motivum. Solum enim dicimus, cum S. Doctore, quod rationes illae rerum causativae non sint se solis - absolute et independenter ab omni cognitione et termino distincto - determinativae ad futuri determinatam cognitionem. Etenim, ut Caietanus eo articulo $₫$ „Ad secundum autem, et reliqua" ait, ${ }^{175}$ rationes illae aeternae non sunt repraesentativae futurorum „mere naturaliter, sed naturaliter ex suppositione libera“. Quam suppositionem ego, cum S. Thома, assero, esse ipsam temporalem existentiam rerum, qua res in sua praesentialitate coexistunt aeternitati. Molina vero contendens, aeternas et ideales rationes esse sufficientes ad repraesentanda futura, non vult esse sufficientes ad futurum hoc potius quam illud repraesentandum mere naturaliter, sed naturaliter et necessario ex suppositione libera, cum qua - in doctrina S. THомав et MolinaE - nullam possunt habere connexionem determinatam causales rationes illius nec temporales nec aeternae.

222. Duo tamen explicanda restant:

Primum: Quo sensu dixerit S. Thomas, futura quoad praesentiam, quam in se - extra rationes aeternas - habent, esse Deo ab aeterno [853r] praesentia?

Secundum: Quid conferat praesentia aut coexistentia ad aeternitatem, ut a Deo cognoscantur ab aeterno futura?

Circa utrumque dicam breviter quod sentio. Quid vero de aliorum sententiis iudicandum sit, capite sequenti indicabimus.

174. Ludovicus Molina: Commentaria in Primam D. Thomae partem, Cuenca 1592, 576-77.

175. Caietanus: In Primam partem Q. 14 art. $13 \$ 17$, ed. Leon. t.4, 19 ob. 


\section{Circa primum quatuor ab omnibus ut certa statuuntur.}

Primum est, futura, quando existunt, coexistere aeternitati, cum haec sit essentialiter existens et consequenter cuivis existenti necessario coexistens.

Secundum est, futura non habere aeternam, non-incipientem durationem, cum de Fide sit, quod creaturae omnes in se esse incipiant, et quod nullum verum esse extra Deum habuerint quod incipiens non fuerit. Quod deesse existentiae, nulli catholico dubium esse potest. Ex quo patet, res, quando incipiunt esse in se, incipere quoque esse in aeternitate, et quando desinunt, desinere in aeternitate esse, quia earum praesentia est coexistentia. Hanc autem necesse est cum existentia incipiente incipere et illa desinente desinere. Nulla autem est contradictio, quod sint et desinant in eadem aeternitate eaedem res, quia aeternitas, etsi indivisibilis duratio sit formaliter, est virtualiter et aequivalenter ${ }^{176}$ divisibilis, quia non est successiva, sed essentialiter permanens.

Tertium est, aeternitatem praeteritis, praesentibus et futuris coexistere ex parte sua per eandem indivisibilem durationem, et in ea nullum esse successivum ordinem durandi respectu creaturarum (ut capite praecedenti vidimus inde inferentes, quod Deo proprie nihil est futurum aut praeteritum).

224. Quartum denique est, futura secundum quod in suis differentiis realiter praesentia sunt, esse Deo intentionaliter praesentia ab aeterno, quia illa ab aeterno prout in se sunt, intuetur. In genere vero intentionalis praesentiae - qua scilicet obiectum formaliter est intra cognoscentem per cognitionem, quae ad ipsum tendit - futura sunt singulari modo praesentia per divinam cognitionem eo quod haec illa non respiciat ut futura sibi, sed ut praesentia: quia non affirmat Deus, illa habitura esse post transactam divinam cognitionem, qua repraesentantur, sed habere esse temporale illi coexistens ita, ut intentionalis repraesentatio divinae cognitionis petat realem coexistentiam obiecti ad ipsam et repugnet cum successivo ordine prioris aut posterioris ad ipsum. De hac praesentia intentionali futurorum - quae in nulla cognitione praeter divinam invenitur - aptissime intelliguntur loca SS. Patrum asserentium, Deo omnia [853v] praeterita et futura praesentia esse. Nam loca, in quibus praesentiam illam tradunt, expressam mentionem faciunt scientiae ut rationis ob quam futura et praeterita sunt Deo praesentia. Eorum verba videri possunt in commentationibus D. Thomae Primae partis q. 14 art. 13, et in P. Ruiz De Scientia Dei disp. 28 sect. $1,4,5,6$, et 7 .

225. Dubium ergo restat de sola praesentia reali futurorum ad aeternitatem, an aliquam ab aeterno habeant. S. Tномам communiter et sui et externi censent hanc futurorum praesentiam docuisse. Nam articulo citato futura ab aeterno praesentia

176. Zur Distinktion formaliter / virtualiter vgl. Historisches Wörterbuch der Philosophie s.v. „Virtualität I“, hgg. von J. Ritter / K. Gründer / G. Gabriel, Basel 1971-2004, Bd. 11, 1062-66. 
esse docuit, et ob hanc praesentiam cognosci a Deo. Ergo aeternam praesentiam habent. Quae a cognitione distinguatur et ad illam praecedat ut ratio cognoscendi.

226. Mihi vero - quicquid alii dicant - manifestum videtur, S. Thомам nequaquam agnovisse praesentiam futurorum ab aeterno, quae praecedat divinam scientiam et sit Deo ratio sciendi. ${ }^{177}$ Etenim praesentiam futurorum, quam ab aeterno dari affirmat distinctam ab ea, quam habent in aeternis rationibus essendi seu rerum causis, sic [\$ 219] explicat: „[...] omnia, quae sunt in tempore, sunt Deo ab aeterno praesentia, non solum ea ratione, qua habet rationes rerum apud se praesentes [...], sed quia eius intuitus fertur ab aeterno super omnia, prout sunt in sua praesentialitate." Ideo ergo praesentia sunt futura ab aeterno - praesentia distincta a rationibus causalibus -, quia divinus intuitus fertur super illa ut sunt in sua praesentialitate. Ex quo antecedente duplex infertur consequens:

Primum: Ergo non ideo cognoscit Deus futura, quia sunt ab aeterno praesentia ita, ut praesentia illorum ab aeterno habita sit ratio a priori, cur cognoscantur: cum potius dicat ideo praesentia esse ab aeterno, quia cognoscuntur.

Secundum consequens est: Ergo intuitus ipse divinus est ratio formalis, qua futura fiunt ab aeterno praesentia Deo; ac proinde eorum praesentia ab aeterno intentionalis est, non realis, in sententia S. Thomae.

227. Quod vero communiter dicitur, scilicet, S. Tномам dedisse praesentiam rerum ab aeterno pro ratione, cur Deus cognoscat futura, nullo nititur fundamento. Nam pro ratione divinae cognitionis solum dat temporalem praesentiam rerum in se ipsis, scilicet determinationem quam in actu habent, ut sunt extra causas (ut manifeste constat ex initio corporis illius articuli). Quia vero ad res ut sunt in sua praesentialitate, fertur ab aeterno divinus intuitus, asserit, illa esse Deo ab aeterno praesentia: distincta praesentia ab ea, quam habent res in causis.

228. Ratio autem, cur invaluerit communis illa persuasio circa mentem S. THомав, videtur esse, quod, statuta praesentia [854r] futurorum ab aeterno, immediate subiungit S. Doctor: „Unde manifestum est, quod contingentia et infallibiliter a Deo cognoscuntur, inquantum subduntur divino conspectui secundum suam praesentialitatem: et tamen sunt futura contingentia suis causis proximis comparata." Quibus verbis videtur infallibilem cognitionem futurorum deducere ex eo, quod sint Deo ab aeterno praesentia.

177. So auch die herrschende Lehre in der Jesuitenscholastik. Vgl. Franciscus Suarez: Varia opucula theologica 2, 1, 7, 19, Opera omnia t.11, 326b/27a; Gabriel Vazquez: Commentaria ac Disputationes in Primam partem S. Thomae 64 cap. 5, Opera omnia, ed. M. Chossat, Paris 1905, t.1, 528b-3oa. 
Hanc tamen coniecturam inanem esse, ipsa Doctoris Angelici verba satis demonstrant. In illis enim non infert ex praesentia futurorum ab aeterno, quod infallibiliter cognoscantur, sed, quod recte componatur infallibilitas cognitionis divinae cum contingentia futurorum. Ideo statuta his verbis illorum praesentia „[...] omnia, quae sunt in tempore, sunt Deo ab aeterno praesentia, [...] quia eius intuitus fertur ab aeterno super omnia" non subiunxit: unde manifestum est, quod contingentia infallibiliter a Deo cognoscantur - ut subiungi deberet, si ex praesentia inferenda esset infallibilitas -, sed illationem sic formavit: Unde manifestum est, quod contingentia et infallibiliter a Deo cognoscantur, et tamen sint futura contingentia suis causis proximis comparata. Quod ergo infert ex praesentia rerum in divino intuitu est, non obstare contingentiae rerum aeternam divinae scientiae infallibilitatem. Divina enim scientia infallibilis est, quatenus ab aeterno fertur eius intuitus ad futura - non prout futura sunt tantum in suis causis, sed - prout praesentia actu sunt in se ipsis. Ob quem etiam intuitum, inquit, sunt Deo ab aeterno praesentia. Ex quo concludit - et quidem manifeste -, aptissime componi infallibilitatem scientiae cum obiecti contingentia, cum huic obstare non possit infallibilitas, qua videtur determinatum obiectum - non in causis, quibus contingens est, sed - in se ipso.

229. Ad quid ergo, ais, S. Thомas agens eo articulo de modo cognoscendi futura et de ratione, ob quam illa cognoscit Deus, agit de praesentia futurorum in aeternitate et de perfectione, qua aeternitas tota simul est et omnibus rebus praesens? Id enim extra rem esset, nisi praesentia rerum in aeternitate - et hanc complecti omnes differentias temporis - non deserviret ad futura ab aeterno cognoscenda. Non autem potest complexus ille aeternitatis ad futurorum cognitionem deservire, nisi quia ob illam necesse est futura esse Deo ab aeterno praesentia, et ob eam praesentiam $\mathrm{ab}$ aeterno cognosci.

230. Huic obiectioni respondeo, S. Thomam non probare certam cognitionem Dei de futuris contingentibus nec ex praesentia aeterna futurorum in aeternitate (ut vidimus) nec ex praesentia [854v] aeternitatis ad futura seu amplitudine, qua aeternitas futura complectitur, quamvis ex hoc complexu et praesentia aeternitatis non inefficax argumentum desumi posset ad cognitionem futurorum. De quo infra. Tria enim eo articulo [Prima parte q. 14 art. 13] probat S. Thomas:

Primum, certe cognosci futura.

Secundum, cognosci non successive, sed ab aeterno.

Tertium, nec certitudinem nec aeternitatem cognitionis divinae impedire quominus contingenter succedant effectus post causas.

231. Primum probat ex duplici statu contingentium: altero in suis causis, in quibus docet non posse haberi certitudinalem cognitionem determinatam de illis; altero, quem habent in se ipsis ut sunt actu extra causas, in quo statu potest illorum 
cognitio haberi, quia determinata sunt. Hoc notato concludit, Deum habere certam cognitionem futurorum, quia „contingentia omnia cognoscit non solum prout sunt in suis causis, sed etiam prout unumquodque eorum est actu in se ipso“.

232. Probato hoc primo asserto immediate transit ad secundum, de futuris cognoscendis non successive, sed ab aeterno, his verbis: „Et licet contingentia fiant in actu successive, non tamen Deus successive cognoscit contingentia, prout sunt in suo esse, sicut nos, sed simul.“ Cuius rationem reddit: „Quia sua cognitio mensuratur aeternitate, sicut etiam suum esse: aeternitas autem tota simul existens ambit totum tempus. "Ex quo infert intentum, scilicet, Deum omnia simul et ab aeterno cognoscere, his verbis: „Unde omnia, quae sunt in tempore, sunt Deo ab aeterno praesentia." Quod de praesentia intentionali necesse est intelligi, non de praesentia reali: quia haec nec sequitur ex eo, quod divina cognitio mensuratur aeternitate - omnia tempora ambiente -, neque erat, quod S. THOMAS $\operatorname{ad}^{178}$ probandum assumpserat, scilicet, Deum non successive, sed ab aeterno, omnia cognoscere.

Ad quod assumptum probandum statuit duas praemissas. Prima est: Divina cognitio sicut et divinum esse mensuratur aeternitate. Secunda: Aeternitas autem non est successiva, sed tota simul. Ex quibus praemissis inepte inferretur „Ergo, quae Deus cognoscit, sunt ipsi ab aeterno realiter praesentia“, quia termini, quos haec propositio inter se connectat, non connectuntur in praemissis cum termino aliquo medio, immo de uno illorum, scilicet de praesentia reali futurorum in aeternitate, nulla mentio facta est in praemissis nec explicite nec implicite. Ineptam ergo illationem S. ThOMAE attribuunt, qui illum citatis verbis realem praesentiam aeternam futurorum intulisse contendunt. Non ergo eam intulit S. Doctor, sed eam, quae legitime ex positis praemissis infertur, nempe intentionalem. Quam per divinam cognitionem habent futura. Haec enim legitime sequitur. Nam, divinam cognitionem mensurari aeternitate, et, aeternitatem esse totam simul, [855r] probant manifeste, Deum ab aeterno omnia quae cognoscit, simul cognoscere, seu, quod idem est, omnia ab aeterno intentionaliter praesentia habere. Et ne praesentiam intentionalem discursu nostro inferri putes a non S. Doctoris expressis verbis, lege integram propositionem, qua consequens ex praemissis supra positis illatum explicat: „Unde omnia, quae sunt in tempore, sunt Deo ab aeterno praesentia [...]“ praesentiamque explicans subiungit: „[...] non solum ea ratione, qua habet rationes rerum apud se praesentes, ut quidam dicunt, sed quia eius intuitus fertur ab aeterno super omnia, ut sunt in sua praesentialitate." Praesentia ergo futurorum in hoc intuitu est intentum, quod S. THомаs ex praemissis, quae proposuerat, concludit.

178. ad suppl. 
233. Tertium denique, scilicet, nec infallibilitatem nec aeternam antecessionem praescientiae obstare contingentiae futurorum, probat ex eo, quod infallibilitas aeterna cognitionis fertur ad futura cognoscendo, ea esse contingentia suis causis et in se ipsis determinata determinatione consequente indifferentiam causarum seu, quod idem est, supponendo in causis omnimodam indeterminationem ad unum et indifferentiam ad opposita. „Unde manifestum est“, ait S. Doctor, „quod contingentia et infallibiliter a Deo cognoscuntur, inquantum subduntur divino conspectui secundum suam praesentialitatem: et tamen sunt futura contingentia suis causis comparata."

Haec, ni fallor, est legitima et conspicua interpretatio Angelicae mentis in hoc articulo, aliamque nec dictorum cohaerentia nec verborum contextus patitur.

234. Ergo cum S. Thом dicimus, futura esse ab aeterno praesentia intentionaliternon vero realiter -, praesentiamque hanc cum ipso dicimus constitui per divinam cognitionem, qua Deus futura intuetur ut coexistentia sibi realiter non ab aeterno, sed in sua praesentialitate temporali.

Conclusio haec probatur, quia nulla est ante scientiam aeterna praesentia futurorum. Ergo nullam ante scientiam habent praesentiam ab aeterno.

Consequentia manifesta est, cum praesens ab aeterno nonnisi per aeternam praesentiam constituatur.

Ante probationem vero antecedentis notandum est, RECENTIORES quosdam ТноміsтAs non aliam praesentiam aeternam futuris concedere nisi quam habent in decreto praedeterminante ad eorum existentiam: et hanc esse praesentiam ab aeterno, quam S. Тномаs futuris concedit.

Sed nil apertius cum S. Tнома [855v] pugnat quam haec interpretatio. Nam praesentia futurorum in decretis est praesentia, quam habent in rationibus aeternis, quae sunt illorum causae. Haec autem praesentia non est, quam S. THOMAS asseruit: tum, quia expresse dicit, suam praesentiam non esse eam, quam „quidam“ ponunt in rationibus aeternis, sed aliam superadditam, - tum, quia rationes aeternae a RECENTIORIBUs illis explicatae per decreta praedeterminantia, repugnant contextui S. Doctoris, cum in illis futura contingentia sint determinata ad unum. Hanc autem determinationem contingentium in causis S. THомаs expresse inficiatur.

235. Antecedens ergo, scilicet, futura non habere ante scientiam ullam aeternam determinatam praesentiam, probatur: quia nec illam habent intra Deum, cum in Deo nihil praecedat ad futurorum praescientiam nisi praedicata per quae Deus est causa illorum - in hac autem causa, late probatum est libro $2^{\circ}$, nullam esse posse contingentium determinationem et consequenter nec determinatam praesentiam -, neque etiam datur aeterna futurorum praesentia realis extra Deum, cum nihil extra ipsum sit realiter nisi dependenter ab eius voluntate ut dante aut permittente illi esse et consequenter ut illud producente. Deus autem noluit ullum extra se esse 
producere ab aeterno, sive talis productio dicatur possibilis, sive non: cum de Fide sit, rerum creatarum productiones et existentias incepisse et consequenter extitisse post non-esse sui.

236. Nec iuvat, res creatas eo ipso, quod quovis tempore existunt, praesentes esse toti aeternitati. Hoc enim non probat, quod sint praesentes per aeternam praesentiam, sed per eam, quam habent, nempe temporalem. Rerum enim praesentia ad aeternitatem est illarum coexistentia aeternitati. Coexistentia autem illarum non potest aeterna esse, quia constituitur partialiter per existentiam illarum, quae temporalis est. Praesentes ergo sunt creaturae toti aeternitati non totali et illimitata praesentia - antequam scilicet non possit esse alia duratio coexistens aeternitati -, sed praesentia limitata et incipiente: sicut res, quae finiuntur, etsi toti aeternitati, quae nunquam finietur, coexistant, non habent a parte post aeternam et indeterminatam durationem.

237. Idem patet in „praesentia“ creaturae ad immensitatem. Ea enim praesentia immensa non est, etsi creaturam faciat praesentem toti immensitati. Cur ergo aeterna debet esse praesentia ex eo, quod faciat creaturam praesentem toti aeternitati? Similiter de plaga v.g. occidentali mundi dici non potest, quod sit „ab oriente ${ }^{179^{\prime \prime}}$ praesens immensitati, licet immensitas sit [856r] indivisibiliter praesens orienti et occidenti. Similiter ergo nec „ab aeterno praesens realiter“ aeternitati dici potest res, quae incipit, nec „, in aeternum praesens“ res, quae desinit, licet aeternitas per indivisibilem durationem ab aeterno et in aeternum existat. Utriusque ratio est, praesentiam ab oriente esse orientalem, et praesentiam ab aeterno aeternam, ideoque prima convenire nequit plagae occidentali nec secunda creaturae incipienti.

238. Neque etiam iuvat dicere, aeternitatem esse ab aeterno praesentem futuris eo quod praesens illis sit per se ipsam; at praesentia, inquis, secundum durationem est duorum simultas: ergo Deo quaevis creatura est ab aeterno praesens.

Non, inquam, hoc iuvat, quia Deus ab aeterno non habet esse praesens simpliciter creaturis, sed cum addito „ex parte sua“, quia esse simpliciter praesentem creaturis requirit, quod creatura quoque praesens Deo sit; divina autem duratio seu aeternitas - non facit creaturam realiter sibi praesentem, quia non facit illam durantem. Duratio enim est modus aut perfectio intrinseca se tenens ex parte rei durantis. Et licet Aliqui dixerint, per tempus extrinsecum, seu per coexistentiam ad illud, res durare, attamen coexistentia haec aliquid petit, quo res ad tempus, cui coexistit, determinetur, cum sine hac determinatione possit res esse existens existente etiam tempore, quin tempori coexistat nec simul cum illo, sed divisim,

179. occidente corr. 
existentiam habeat. Et licet res per semetipsam determinata sit ad coexistendum aeternitati eo ipso, quod existat, at non est determinata ad coexistendum illi per determinationem aeternam ad aeternitatem, sed per temporalem, qua ipsa existit. Praesentia ergo, qua aeternitas est praesens simpliciter, seu mutua praesentia ad creaturas non est sola aeternitas, sed praeterea dicit determinationem creaturae ad aeternitatem, quae huic extrinseca est. Modi autem loquendi, quibus haec rerum praesentia a NonNulLis explicatur, capite sequenti a nobis examinabuntur.

239. Ex dictis in hoc capite sequitur, futura ante praescientiam non habere ab aeterno praesentiam ullam determinatam ad aeternitatem, habere tamen temporalem praesentiam ad aeternitatem ante scientiam non quidem antecessione in quo, sed a quo.

Sequitur etiam, res futuras non prius esse praesentes realiter aeternitati quam tempori, quia solum sunt praesentes realiter aeternitati per temporalem suam existentiam. Intentionaliter tamen prius existunt in aeternitate quam in tempore non prioritate a quo, sed in quo aeternae durationis, quia futurorum scientia praecedit illorum existentiam.

Denique sequitur, ab aeterno praesupponi ad scientiam $[856 \mathrm{v}]$ realem praesentiam futurorum in aeternitate: quia temporalis praesentia, per quam aeternitati coexistunt, praesupponitur ad scientiam per intrinsecum modum se habendi scientiae ad realem praesentiam. Hic enim talis est, ut scientia per se ipsam sit praesuppositio obiecti tanquam prioris a quo respectu praescientiae (ut saepe dictum est).

240. Ad secundum vero quod proposuimus [\$222], an scilicet deserviat ad cognitionem futurorum praesentia quam habent in aeternitate, P. Molina Prima parte q. 14 art. 13 disp. 14 conclus. 2 asserit, ${ }^{180}$ nec ad certitudinem nec ad concordiam praescientiae cum libertate eam praesentiam deservire, absolute tamen non negat, eam ad divinam cognitionem conducere. Nec meo iudicio ${ }^{181}$ videri negari potest, quia divina cognitio non potest affirmare temporalem existentiam obiecti ut sibi futuram nec praeteritam, sicut possunt creatae cognitiones. Ergo, cum necesse sit, quod illam cum habitudine aliqua ad semetipsam affirmet, solum potest illam affirmare ut sibi praesentem praesentia, quae ex parte obiecti sit temporalis, non tamen, quae posterior sit successive divino cognoscente aut cognitione, sed, quae simul cum illis existens sit simultate temporalis ad aeternum. Haec ergo simultas et praesentia obiecti futuri ad aeternitatem cognitionis et cognoscentis necessaria omnino est ad divinam cognitionem eadem ratione, qua ad illam necessaria est obiecti futuri temporalis existentia.

180. Ludovicus Molina: Commentaria in Primam D. Thomae partem, Cuenca 1592, 582D.

181. iudicio suppl. 
241. Nec reputari debet imperfectio, sed potius summa perfectio, quod Deus nil existens cognoscere possit nisi ut coexistens sibi, quamvis creaturae possunt cognoscere aliarum existentias, quae ipsarum durationi non coexistant; possunt enim cognoscere praeterita et futura, quae nec coextiterunt nec coexistent durationi suae cognitionis aut substantiae. Hoc, inquam, summa perfectio divinae cognitionis est, quia coniungit perfectionem, quam admiramur in creaturis cognoscentibus obiecta longe a se distantia secundum durationem, cum alia suprema cognoscendi perfectione, qua creaturae carent. Etenim Deus, etsi nil absens simpliciter secundum durationem a sua aeternitate, id est carens omni praesentia ad illam, cognoscere valeat ut existens - quia existere non potest nisi per aliquam praesentiam ad aeternitatem -, attamen cognoscit ab aeterno obiecta, quae non sunt ab aeterno, id est per aeternam praesentiam illi realiter praesentia; ac proinde cognoscit obiecta, quae absunt et distant ab aeternitate per aeternae praesentiae carentiam. In quo mirabiliter relucet divini intellectus infinita perspicacia, qua obiecta infinite distantia in duratione cognoscit aeque distincte, ac si ipsi coaeterna essent.

242. Huius perfectionis participationem quandam [857r] supernaturaliter habent creaturae intellectuales, quando futura contingentia cognoscunt, sed tamen longe diverso modo, quia, etsi extendatur creaturae intuitus intellectualis ad obiecta distantia in duratione, extenditur tamen cum duplici imperfectione. Prima est, quod egeat praedeterminativo aliquo aequalis durationis cum cognitione, quia illa eget creatura ex eo, quod per se ipsam non sit virtus adaequata et completa ad cognitionem futuri; ac proinde eget complemento determinante ad cognitionem eiusdem durationis cum ipsa, eo quod natura et causalitate praecedat cognitionem. Secunda imperfectio est, creatam cognitionem futurorum respicere suum obiectum ut sibi futurum, id est ut habiturum existentiam post transactam cognitionem vel saltem post transactam durationem, quae incepit.

A Deo autem longe absunt imperfectiones istae, quia, cum sit adaequata virtus cognitionis futuri liberi et etiam cognitionis liberae carentiae eiusdem, non potest nec egere nec habere praedeterminativum coaeternum suae cognitioni. Sufficit enim ipsi temporalis futuri existentia, quia obiecti determinationem solum requirit ut terminum intentionalis tendentiae suae cognitionis, non ut complementum suae virtutis. Praeterea, cum sit eximia perfectio, non posse non scivisse semper quod scitur, nec unquam oblivisci quod scitum est, Deo essentialis esse debet huiusmodi perfectio, et ideo cognoscere debet aeterna et indefectibili cognitione; ac proinde de nullo obiecto affirmare poterit, quod ante ipsam fuerit vel post ipsam transactam extiturum sit. Ideoque idem in divina cognitione erit affirmare de obiecto existentiam ac affirmare, quod sibi coexistat.

243. Ex quibus statui potest regula quaedam communis omni cognoscenti tam creato quam increato, scilicet, nullum posse aliquod obiectum existens cognoscere, 
nisi tale obiectum cognoscenti coexistat vel in se vel in aliquo praedeterminante ad eius cognitionem, et generaliter, nil cognosci posse, nisi cognoscenti et cognitioni coexistat determinatio cognitionis coexistentia durationis - vel adaequantis vel non-adaequantis - durationem cognitionis.

Deus enim nec se nec creaturas ut possibiles cognoscit nisi coexistente sibi per aeternam coexistentiam aliquo determinante tam ad sui quam ad possibilium cognitionem. Hoc determinativum est divina ipsa essentia, quam sibi praesentem per identitatem et coexistentem divino cognoscenti et cognitioni dicimus ob distinctionem $[857 \mathrm{v}]$ rationis, qua ab illis secernitur. Futura autem cognoscere nequit nisi ut coexistentia sibi per temporalem illorum praesentiam, quae est obiectiva determinatio ad divinam cognitionem, quia est praevia exigentia determinata illius.

244. Cognoscentia autem creata nil cognoscunt determinate absque determinatione sibi coexistente coexistentia adaequante cognitionis - quam exercent - durationem: ita, ut cognitio nequeat prius existere quam determinatio ad cognoscendum, quia determinatio obiecti ad sui cognitionem habendam a creato cognoscente, est, in genere productivi, causa cognoscentem adiuvans ad cognoscendum. Haec vero determinatio exercetur ab obiecto respectu cognitionis creatae aliquando immediate, aliquando vero medio alio. Sic determinat obiectum materiale per formale, seu - ut proprius loquamur - formale determinat ratione sui ad cognitionem materialis, et formale saepe per speciem a se distinctam. Quando autem exercetur per speciem distinctam et ab obiecto actu conservatam, sufficit ad cognitionem, quod ipsi coexistat determinatio ab obiecto distincta, si haec determinatio absoluta sit et per se connexa cum cognitione obiecti.

245. Hinc inferes, in sententia Thomistica concedente Angelis inditas a creatione species omnium quae decursu ${ }^{182}$ temporis ipsis coextitura sunt, et consequenter agnoscente in illis ante obiectorum existentiam totam virtutem causativam cognitionis illorum, - in hac, inquam, sententia dicendum esse, ipsam obiectorum existentiam ut Angelis praesentem, esse immediatam conditionem, qua virtus causativa cognitionis completur et qua constituitur absoluta determinatio cognitionis: sicut approximatio combustibilis est immediata conditio praecedens combustionem et constituens praeviam determinationem ad illam. Nam sicut combustibile non approximatum est extra sphaeram combustivi, licet in hoc resideat tota virtus causativa combustionis, ita obiectum non coexistens cognoscenti, nec in se nec in sui determinatione, absolute est extra sphaeram cognoscitivae virtutis. Per existentiam vero intra illam constituitur et exercet munus determinantis cognitionem: ut approximatio determinantis combustionem.

182. discursu corr. 
246. Ex quibus concluditur, Deum ab aeterno obiectis etiam contingentibus antequam existant, sufficienter approximatum esse ad illa cognoscenda, quia aeterna duratio, per quam praecedit ad illa obiecta, est indivisibiliter eadem qua illis advenientibus coexistit nulla adveniente nova duratione [858r] ex parte Dei, qua illis approximetur.

Ex quo etiam patet, futura etiam contingentia esse Deo ab aeterno approximata et praesentia cognoscibiliter per temporalem praesentiam realem, quam habent ad aeternitatem: quia aeterna approximatio quasi activa Dei ad illa cognoscenda, in ipsorum praesentialitate denominat extrinsece futura ab aeterno approximata, sicut cognoscibilitas extrinseca activa - quae ab hac approximatione indistincta prorsus est - denominat futura ab aeterno cognoscibilia. Unde quae de eorum cognoscibilitate aeterna affirmanda aut neganda docuimus capite $13^{\circ}$, eodem sensu de aeterna approximatione eorum ad hoc, ut cognoscantur, dicendum est. Eodem etiam sensu, per extrinsecam denominationem ab activa continentia futurorum intra sphaeram virtutis cognoscitivae divinae, denominantur futura ab aeterno contenta intra sphaeram talis virtutis. Haec autem continentia et approximatio sicut et cognoscibilitas formaliter, quatenus est aeterna, non est determinata ad unum, sed indifferens ad quodcunque futurum cognoscendum. In ratione vero determinatae ad unum - cum exclusione continentiae et approximationis ad aliud - constituitur continentia et approximatio partialiter per aliquid temporale; ac proinde ab aeterno non datur. Temporalem vero existentiam esse realem approximationem et praesentiam ad aeternitatem, in qua exercenda est cognitio, est omnino necessarium ad hoc, ut possit ab aeterno cognosci.

247. Sed inquires, an necessitas praesentiae futurorum in aeternitate ad hoc, ut cognoscantur, de solis absolute futuris intelligenda sit, an etiam de conditionatis? Ratio dubitandi est, quia innumera conditionata sunt pure conditionata nullam unquam habitura praesentiam ad aeternitatem. Quo ergo pacto cognoscibilia dici poterunt ob praesentiam illorum ad aeternitatem aut aeternitatis ad ipsa?

Respondeo, in rebus omnibus idem esse existere ac aeternitati praesentes esse; ac proinde eodem iure et modo, quo existentiam sortiuntur, sortiri aeternitatis praesentiam, scilicet, vel possibiliter vel actualiter, et actualiter vel absolute vel conditionate. Futura ergo conditionata sunt conditionate cognoscibilia ob praesentiam aeternitatis, quam haberent, si poneretur conditio: sicut absolute futura sunt cognoscibilia absolute, quia habebunt praesentiam ad aeternitatem. Ideoque ad ipsa quoque extendi debet explicatio cognoscibilitatis per praesentiam ad aeternitatem, ut sapienter adnotavit SuAREZ tom. $1^{\circ}$ De Gratia Proleg. 2 cap. 9 n. 6 (post medium), ${ }^{183}$ et $[858 \mathrm{v}]$ nos late explicabimus libro $6^{\circ}$.

183. Franciscus Suarez: Opera omnia, Paris 1856-78, t.7, 110 . 


\section{Caput 20. Iudicium fertur de aliorum sententiis circa futurorum praesentiam in aeternitate}

248. A futurorum in aeternitate praesentia insalutato CAIETANO recedere nefas foret, cum nil de illa a Theologis agatur, quod CAIETANi lucernam non oleat, illam scilicet, quam ipse „nudiustertius“ singulariter sibi affulsisse scribit Prima parte q. 14 art. $13 \S$ „Ad has obiectiones“, ${ }^{184}$ post quindecim annorum tenebras. ${ }^{185}$ Tria asserit CaIETAnus in commentario illius articuli.

Primum est, $\mathrm{S}$. Thома assertum de praesentia rerum ab aeterno adeo obscurum reputatum fuisse a Tноміsтis, ut nullus nec scripto nec verbo ausus fuerit ante Caietanum illud assertum tueri.

Secundum, hanc praesentiam non de intentionali tantum aut obiectiva, sed de reali praesentia rerum, ut sunt in actu, intelligendam esse ita, ut, etiamsi Deus non foret cognosciturus, haberet ab aeterno sibi res realiter praesentes, et hoc esse intentum S. Thомав.

Tertium, hanc praesentiam rerum non esse in nunc temporis, in quo de futuris loquimur, quia huic non coexistunt futura, sed in nunc aeternitatis mensurantis omnia non ut mensura adaequata, sed excessiva, cui necesse est coexistere quae erunt. Quod autem in toto nunc aeternitatis mensuratur ab illa, mensuratur ab aeterno ut praesens a praesenti, quia in aeternitate non est ad res creatas alius ordo.

249. De primo asserto mihi satis obscurum videtur, quo pacto potuerit articulus luce clarior obscurus apparere antecessoribus CAIETANI, et quod nullus eorum S. Thомам defendere ausus sit: cum nihil propugnatu facilius sit quam eius articuli intellectus capite praecedenti a nobis propositus et ex tribus ipsius articuli propositionibus manifeste probatus.

In secundo asserto CAIETANUm et a veritate et a S. Thoma recedere, satis ex eodem capite constat.

Tertium assertum defendit etiam P. Ludovicus Molina ad citatum articulum 13 disput. $13,{ }^{186}$ et CAIETANUM carpit, quod se primum eius praesentiae explicatorem iactet, cum illam eodem modo explicuerint Ricardus Quodlibet 3 q. 1, CAPreOlus in $1^{\circ}$ [Sententiarum] dist. 36 q. 1, et dist. 38 quaestione etiam 1, et alii Caietano priores. ${ }^{187}$

184. Caietanus: In Primam partem Q. 14 art. $13 \$ 10$, ed. Leon. t.4, 188 b.

185. Der Spott über Cajetan hatte in der Jesuitenscholastik Tradition. Vgl. Gabriel VazQuez: Commentaria ac Disputationes in Primam partem S. Thomae 64, 5, Opera omnia, ed. M. Chossat, Paris 1905, t.1, 518a.

186. Ludovicus Molina: Commentaria in Primam D. Thomae partem, Cuenca 1592, 568D-69C. 187. Molina, In Primam D. Thomae partem Q. 14 art. 13, 13, col. 569C. 
250. Mihi tamen explicatio Caietani et [859r] Molinae nec legitima videtur nec ad ipsorum intentum sufficiens.

Nam imprimis, etsi verum sit, res, quae erunt, esse in nunc aeternitatis ob coexistentiam cum aeternitate, quae „,aeternum nunc" dicitur - eo quod sit stabilis praesentia repugnans cum non-esse sui tam antecedente quam subsequente ipsam -, attamen id non sufficit, ut a nobis dicatur, Antichristum esse nunc, quia, licet enunciatio nostra possit habere nunc aeternitatis pro obiecto et etiam pro extrinseca mensura generali, cui eo ipso, quod aliquid in quavis duratione existat, coexistens esse debet, non tamen est mensura propria et singularis, qua propositio nostra incipit durare. At haec singularis mensura inceptionis est quam necessario consignificat propositio et cui necessario comparat omnem aliam durationem, quam obiecto tribuit. Ergo, licet affirmet, Antichristum non esse „futurum“ aeternitati, sed illi „praesentem“, necesse tamen est, quod dicat, illam praesentiam aut esse futuram aut praeteritam aut praesentem durationi temporali, per quam ipsa propositio incipit existere. At non potest vere affirmare propositio, quod praesentia futuri ad aeternitatem sit praesens sibi: ergo nec simpliciter, quod sit nunc praesens, quia adverbium „nunc“ in propositionibus supponit pro duratione, qua incipit esse propositio, non pro extrinseco termino communi, cui ipsa est nunc coexistens et res omnes, quando existunt, coexistentes esse debent. ${ }^{188}$

251. Si autem, cum Caietano et Molina, opponas:

$1^{\circ}$ Ad hoc, ut de praesenti enuncietur aliquid, sufficere, quod habeat durationem coexistentem durationi, in qua existit enunciatio: ergo, cum quaevis existat in nunc aeternitatis, potest de qualibet re, etiam futura, vere affirmari, ${ }^{189}$ quod est „nunc“, seu - quod idem est - in nunc ipsius enunciationis: intelligendo non nunc temporis, in quo est, sed nunc aeternitatis;

$2^{\circ}$ Enunciationes veritatis aeternae eo quod affirment res pro nunc aeternitatis, absolvere a nunc temporali talium enunciationum. Ergo qui, iuxta eundem sensum „praesentiae“, velit affirmare res contingentes, poterit illas, etiamsi futurae sint, de praesenti affirmare, quia, in hoc sensu, affirmare de praesenti existentiam futurorum solum est affirmare illorum coexistentiam ad aeternitatem et connotare aeternitatem ut mensuram durationis, in qua existit ipsa enunciatio. In quorum neutro falsitas illa reperitur. -

252. Ad primum respondeo, falsum esse antecedens: quia, ut vere aliquid enuncietur de praesenti, est necesse, quod habeat [859v] durationem coexistentem durationi,

188. Zur Ampliation des nunc vgl. auch Franciscus Suarez: Varia opuscula theologica 2, 1, 7 , 14-15, Opera omnia t.11, 324b/25a.

189. affirmare corr. 
per quam incipit esse propositio. Cum hac enim comparat propositio omnia, quae affirmat, vel tanquam praeterita ad ipsam, vel tanquam praesentia, vel tanquam futura. Et licet possit etiam attendere ad nunc aeternitatis et agnoscere, suam inceptionem illi nunc coexistentem esse, et tam suae inceptioni quam aeternitati comparare futura, attamen non potest vere affirmare, quod futura coexistant aeternitati per coexistentiam praesentem inceptioni propositionis. Ergo, cum necesse sit, coexistentiam futuri ad aeternitatem comparari a propositione nostra cum sua ipsius inceptione, necesse est ad veritatem, quod affirmetur ut subsecuta ad ipsam, non ut ipsi praesens. Quod sufficit ad hoc, ut simpliciter non de praesenti, sed de futuro, enuncietur. Etenim enunciari de praesenti non est enunciari praesentiam obiecti ad alia, sed eam, quam habet, ad durationem ipsius enunciationis, eam scilicet, qua incipit esse - si est enunciatio incipiens -, vel, qua sine inceptione durat - si est enunciatio aeterna. Ideo diximus capite $18^{\circ}$, Deum omnia ut sibi praesentia enunciare, quia nil futurum aut praeteritum est respectu durationis propriae divinae enunciationis simpliciter. Ergo enunciare de praesenti requirit, quod obiectum enuncietur ut coexistens propriae durationi ipsiusmet enunciationis. ${ }^{190}$

253. Ad secundum respondeo, commune illud proloquium, propositiones aeternae veritatis "absolvere“ a tempore, non significare, quod semetipsas absolvant a consignificando tempore, quo efferuntur, et a comparando obiecto, quod affirmant, cum tali tempore - hoc enim impossibile est -, sed, quod absolvant obiectum ab alligatione ad tempus consignificatum a propositione unionemque praedicati cum obiecto extendant ad omne tempus. Etenim essentialis necessitas, quae in propositionibus illis asseritur, mensuratur aeternitate; ac proinde omni tempori ${ }^{191} \mathrm{co}-$ existere debet. Hinc est, quod necessitas illa, ut vere affirmetur, non possit alligari ad instans temporale propositionis illam iudicantis: non, quia propositio aeternae veritatis non comparet cum temporali sua duratione obiectum, quod affirmat, et dicat „nunc - id est, in instanti mihi coexistenti - homo est animal rationale“, sed, quia non limitat veritatem obiectivam ad coexistentiam cum tali instanti, immo potius eam extendat ad omnia tempora et durationes. Sensus enim enunciationis est, hominem esse essentialiter animal rationale, id est, nunc dari essentialem necessitatem, ut, quandocunque fuerit homo, identificetur cum animali rationali. Dicere autem, „nunc“ dari necessitatem, idem est ac dicere, illam in nullo tempore aut duratione posse non esse. Quod [86or] est absolvi ab alligatione ad tempus aliquod determinatum, quia independenter ab omni temporali duratione salvatur omnis aeterna et essentialis veritas eiusque obiectum revera dari verissimum est.

190. Ein in Salamanca kontroverses Lehrstück. Kritisch dazu Bernardus Aldrete: Commentaria et disputationes in Primam partem D. Thomae 21, 2, 13, Lyon 1662, t.1, 288a.

191. tempore corr. 
254. Quod ulterius potest confirmari ex eo, quod nulla essentialis veritas - sicut nec bonitas nec entitas - distincta esse possit a Deo, qui ab omni tempore absolutus est utpote aeternitate mensuratus. Unde ipse est essentialis rerum possibilitas essentialisque impossibilium impossibilitas - haec enim est realis veritas et entitas -, constituitque essentialem omnium essentiarum statum. Hae enim nullum in se praedicatum habent, quod absolute essentiale sit, cum per nullum praedicatum illis sit essentiale esse in se ipsis. Cum ergo status essentialis vere detur a parte rei, necesse est illum non constitui praedicato aliquo identificato cum entitate essentiae creatae, sed constitui per essentialem necessitatem - seu necessitatem essentialiter existentem - ad hoc, ut, si detur homo, v.g., identificetur cum animali rationali. Cum ergo haec essentialis necessitas absolute existens essentialiter debeat in aliquo essentialiter existente esse nullumque huiusmodi sit nisi Deus, sequitur, cum ipso omnes essentiales veritates identificari. Quod non est, essentias rerum identificari cum Deo, sed indefectibiles earum veritates - seu indefectibilitatem veritatum, quae de ipsis enunciantur - identificari cum Deo. Nec tamen ideo negamus, praedicata aliqua ut distincta a Deo esse aliquibus subiectis essentialia, et aliqua indefectibiliter per se ipsa exigere identificationem cum aliis praedicatis. Sed dicimus, hanc essentialem et indefectibilem exigentiam talem esse in creaturis ex suppositione non absolute necessaria, sed contingenti, et consequenter, absolute contingens esse, quod existat exigentia et identificatio hominis, v.g., cum animali rationali; ac proinde, necessitatem absolute indefectibilem et essentialiter existentem identificationis humanorum praedicatorum non esse entitatem neque existentiam hominis quae idem sunt -, sed aliquid ab homine distinctum. Quod est ens per essentiam et veritas essentialis. Et sicut solus Ipse est ens per essentiam, ita solus Ipse est per essentiam veritas. Omnis autem essentialis veritas per essentiam veritas est.

255. Quod obiter notatum, si minus alicui placuerit ${ }^{192}$ Nulli tamen, ut credo, displicere poterit, quod obiectivae veritates essentiales sint aeternae et indefectibiles,

192. Die höchstkontroverse These des sog. ,Konnexionismus'. In einem von Wadding herausgegebenen Nachlaßwerk eines anderen Autors wird diese Modalmetaphysik folgendermaßen auseinandergesetzt: „[...] Deus essentialiter et transcendentaliter respicit creaturas in communi et in particulari, sic, ut data impossibilitate creaturarum in genere aut cuiusvis creaturae in specie, sequatur necessario, Deum quoque de medio tolli. Probatur: Nequit Deus non esse causativus creaturae, modo non repugnet creaturae causari posse, seu, quod idem est, modo creatura sit possibilis; sed nequit creatura absolute et simpliciter non esse possibilis: igitur nequit Deus absolute et simpliciter non esse causativus creaturae. [...] Tam impossibile est, creaturam non esse ens non repugnans, quam Deum non esse; sed repugnat absolute et simpliciter, Deum non esse: igitur repugnat omnimode, creaturam non esse ens non repugnans. Ostendo maiorem: Tam impossibile est, hominem non esse animal rationale, seu non esse hominem, quam, Deum absolute non esse; etenim homo et non-homo contradictorie opponuntur, sicut Deus et non-Deus, quae, cum sit summa contradictio, neque magis neque minus admittit; sed homo - vel animal rationale - est 
sive a Deo distinguantur, sive non. Id autem sufficit ad hoc, ut, in sensu a nobis explicato, [860v] propositiones nostrae de aeternis et indefectibilibus veritatibus eas a tempore „absolvant", licet se ipsas non absolvant a tempore suae inceptionis nec obiectum a comparatione cum tali tempore. Comparatur autem cum illo essentialis veritas ut aeternum et indefectibile cum temporali et defectibili: ut ita scilicet illi coexistens, quae non sit alligata ad ullam temporalem durationem.

256. $2^{\circ}$ Impugnantur [ $\$ 251$ ] Caietanus et Molina, quia, etsi vero aliquo sensu dici posse admittatur, res futuras esse nunc praesentes aeternitati - id est, habere praesentiam temporalem durationis ad aeternitatem - significante particula „nunc“ aeternitatem, et non suam ${ }^{193}$ durationem, eadem etiam proprietate sermonis, et longe maiori, dici potest, quod res futurae non sint nunc praesentes aeternitati: quia adverbium „nunc“ maiori proprietate significat durationem propriam propositionis, cuius est constitutivum, quam communem omnibus aeternam.

Deinde, quid refert, ea locutione nos posse uti, ut inde inferant, res futuras esse praesentes ab aeterno? Nam praesentia habita ab aeterno est aeterna. At ex eo, quod praesentia temporalis rerum futurarum affirmetur de praesenti, non conceditur illis aeterna praesentia, sed sola temporalis de praesenti affirmata. Ergo non recte, ex admissa eius locutionis veritate, concluditur, quod res futurae sint praesentes aeternitati ab aeterno.

257. Et - a fortiori - nullatenus poterit inferri, res temporales fuisse „ab aeterno“, quia, etsi dicatur, praesentiam significatam per „nunc“ esse duplicem, scilicet aeternam, et temporalem, at non sic est duplex praeteritum, scilicet aeternum, indefectibile, et successivum; ac proinde, rem „fuisse ab aeterno“ solum pro successiva duratione aeterna, quae praeterierit, supponere potest. Nulla autem eiusmodi aeterna duratio datur.

essentialiter ens non-repugnans: ergo tam impossibile est, hominem non esse ens non-repugnans, quam impossibile est, Deum absolute non esse. Igitur tam necessarium est, Deum esse causam non-repugnantiae - seu possibilitatis - creaturarum, quam, esse Deum, quia, quanta est necessitas non-repugnantiae, tanta est, ut Deus sit causa non-repugnantis seu possibilis. Sed necessitas non-repugnantiae tanta est quanta, ipsum non repugnare Deum. Igitur necessitas, ut Deus sit causa possibilium, tanta est quanta, ipsum non repugnare Deum; ac proinde, data hypothesi, quod creaturae repugnent, sequitur pariter, et repugnare Deum. [...] Ac quidem horum dictorum praecipuum effatum, videlicet, pari necessitate res esse possibiles, seu, eis convenire, ut non repugnent, ac Deo ipsi convenit non repugnare [...], deosculantur Zuniga De Trinitate disputat. 9 dub. 6 num. 5; Fasolus In Primam partem tom. 3 quaest. 34 art. 3 dubit. 6 num. 55; Maeratius Tract. de Deo disput. 50 sect. 3; Suarez lib. 9 De Trinitate cap. 6 num. 19 [...] " Paulus Sherlog: Antiquitatum Hebraicarum Dioptra 1, 2, 38-39, ed. L. Wadding, Lyon 1651, 57b-58b.

193. Sc. propositionis 
Ex quibus patet, quod Molina advertit, ${ }^{194}$ nec posse dici - quod saepe audent NoNNULLI -, res „fuisse prius praesentes“ realiter aeternitati quam tempori. Quia assertum hoc, tam ratione prioritatis quam ratione praeteritionis durandi, implicatoria involvit, cum nec praeterierit ulla rerum duratio ab aeterno, nec res habeant coexistere aeternitati nisi per aliquam durationem propriam suae existentiae, quae temporalis tantummodo est.

258. Omitto alia plurima, et CAIETANUm hactenus impugnatum in eo propugnandum iudico, quod in reali praesentia futurorum ad aeternitatem - quam ipse ab aeterno dari existimavit, nos vero solum in tempore - proportionem cognoscibilis ab aeterno penetraverit. Eam proportionem nos capite superiori explicuimus. Et, licet [861r] S. Thomas eam expresse non docuerit, eius tamen principia iecit inferens ex praesentia rerum in se ipsis certam cognitionem divinam, et, ex cognitionis et divini esse aeternitate, ea, quae successive existunt, simul ab aeterno cognosci.

Haec de Caietani, et Molinae explicatione praesentiae realis futurorum ab aeterno. Pro qua complures Theologos citatos video a P. RuIz [De Scientia Dei] disp. 28 sect. 1 .

259. Eandem sententiam Ruizius ipse sequitur sect. 7 et $8,{ }^{195}$ licet Caietani explicationem late impugnet sect. $3 .{ }^{196}$ Explicatio tamen, quam ipse probat, implicatior est Caietanica et a veritate longius aberrans. Dicit enim, futura, eo quod temporaliter praesentia sint Deo, habere obiectivam praesentiam aeternam non per divinam cognitionem, sed ante illam. Quae praesentia, inquit, est „aptitudo“ futurorum, ut cognoscantur. Quo spectare, dicit, ${ }^{197}$ quod SuAREz lib. $1^{\circ}$ De Scientia Futurorum Absolutorum docet cap. 8 n. 9, scilicet, quod futura habent "actum primum" cognoscibilitatis ante esse cognitum a Deo. ${ }^{198}$ A SuARIo tamen nil habet praesidii explicatio haec, quia "actum“ hunc „primum“ seu „,aptitudinem“ futuri ad terminandam cognitionem divinam manifeste docet, non ab aeterno, sed temporaliter existere.

260. Aeternam hanc Ruizir praesentiam realem satis, ut credo, refutavimus capite $13^{\circ}$, et sane nulla opus erit impugnatione, si duo, quae hic Author componere nititur sect. 8, invicem conferantur. Primum est, futurum ob praedictam aptitudinem, ut ab aeterno cognoscatur, esse ab aeterno realiter praesens aeternitati.

194. Ludovicus Molina: Commentaria in Primam D. Thomae partem Q. 14 art. 13, 13, Cuenca $1592,573 \mathrm{C} / \mathrm{D}$.

195. Didacus Ruiz de Montoya: Commentarii ac Disputationes de scientia Dei, Paris 1629, 236-40.

196. Ruiz de Montoya, De Scientia Dei, 229b-3ob.

197. Ruiz de Montoya, De Scientia Dei 28, 7, 1, p. 236 a.

198. Franciscus Suarez: Opera omnia, Paris $1856-78$, t.11, 329 b. 
Secundum, esse sic praesens formaliter sumptum non esse aliquod esse reale futurorum, sed tantum esse quoddam rationis.

Imprimis supponimus, cum ipso, illud aeternum esse futurorum ante scientiam reale non esse, quia neque est reale aliquid intra Deum - cum intra ipsum ante scientiam solum dentur aeternae rationes essentiales, per quas Deus potest futura causare; in causis autem non habent futura aliquod esse determinatum - nec illud habent extra Deum ita, ut detur aeternum aliquod esse, quod, quatenus a Deo distinctum, reale sit et aeternum (ut in superioribus probatum est). His ab ipso RUIZIO admissis implicare videtur in assertione sua de reali praesentia futurorum $\mathrm{ab}$ aeterno. Eam enim, dicit, de formali non importare esse aliquod reale, sed $\mathrm{ra}$ tionis. Ex quo manifeste sequitur, praesentiam illam ut ab aeterno existentem, non esse realem: quia formale realis constitutivum reale esse debet. [861v]

261. Si vero dicas, eam praesentiam ab aeterno esse realem materialiter et formaliter esse rationis, -

Contra: Ergo futurum esse ab aeterno praesens secundum formalem conceptum praesentiae ab aeterno non est reale aliquid, sed rationis. Ergo formalis ille conceptus - seu quod formaliter significat „praesentia rerum ab aeterno“ - vere et realiter non datur, sed solum per rationem nostram.

Dicentem vero, quod ille conceptus sit materialiter realis, interrogo, an hoc reale materiale sit aliquid a Deo et temporali praesentia obiecti distinctum realiter, an non?

Si est: ergo datur aliquis conceptus veri et realis ${ }^{199}$ entis aeterni praeter Deum.

Si non datur: ergo nil habemus reale a Deo distinctum - in hac sententia P. RUIZII - nisi temporalem praesentiam obiecti, quae fit - aut fieri potest - aeterna per rationem nostram. Hoc autem fundamento dicere, quod datur "realis“ praesentia futurorum ab aeterno, frivolum est. Cum eodem fundamento dici possit, hominem, v.g., esse „realiter“ constantem tribus formis, quia per rationem distingui potest eius anima in triplicem formam; Angelum esse corporeum „realiter", quia per rationem nostram corpore convestiri potest; et Deum habere essentiam „realiter" distinctam a personis, quia illam ratio nostra distinguit; et denique, omnia entia realia esse „realiter“ omne id quod de illis ratio nostra fabricare potest. Quod ridiculum est et a Fidei principiis alienum.

262. Fundamentum Patris RuIz iam saepe evertimus, nam, licet motiva cognoscibilitas futuri aeterna sit, terminativa tamen temporalis est, nec, eam esse aptitudinem ad aeternam cognitionem, probat, debere esse aeternam, cum aeternum cognoscitivum sit potens cognoscere ab aeterno temporalia. Haec ergo ex parte sua apta sunt, ab aeterno terminare cognitionem: non aptitudine ab aeterno existente, sed

199. reali corr. 
aptitudine temporali ad cognitionem ab aeterno existentem, quia ab aeterno datur integra virtus illam habendi respectu omnis obiecti in tempore extituri.

263. Ex quo patet, futura esse intra sphaeram cognoscitivi aeterni per temporalem existentiam, - esse, inquam, seu constitui, intra illam sphaeram, non ab aeterno, sed in tempore: quia constituuntur intra illam per coexistentiam ad aeternitatem. Quam non ab aeterno, sed in tempore habent.

264. Obiicies: Futura non sunt ab aeterno extra sphaeram divinae virtutis cognoscitivae. Alias forent ab aeterno ignota Deo. Ergo ab [862r] aeterno sunt intra illam sphaeram.

Distinguo antecedens: „non sunt ab aeterno extra illam “ per carentiam aeternam omnis praesentiae, tam aeternae quam temporaliter futurae: concedo; per aeternam carentiam aeternae praesentiae: ${ }^{200}$ nego, quod non sint extra sphaeram cognoscitivi divini, quia revera habent negationem essendi intra illam per aeternam praesentiam. Negationem vero temporalis praesentiae negationemque temporalis inclusionis intra sphaeram aeterni cognoscitivi non habent ab aeterno futura. Nego tamen, inde sequi, quod habeant ab aeterno, ante divinam scientiam, inclusionem positivam intra sphaeram cognoscitivi: sed indifferentiam, ut intra illam claudantur in tempore, vel ab illa excludantur, sicut ante scientiam indifferentia sunt ad esse et non-esse in tempore. Sphaera enim cognoscitivi futurorum est temporalis existentia; ac proinde indifferentia ad hanc existentiam habendam est indifferentia ad inclusionem intra sphaeram aeternae virtutis cognoscitivae futurorum; ac proinde inclusio actualis intra sphaeram illam non aliud erit quam temporalis futuri existentia.

265. Aeterna ergo praesentia realis futurorum etiam in ordine ad cognitionem nullo nititur fundamento et, ut a P. Ruiz explicatur, implicatoria est. Posset autem dici, in ordine ad cognitionem Dei temporalem praesentiam futurorum ad aeternitatem aeternam esse, non quidem formaliter, sed tantum aequivalenter: quia in ordine ad divinam cognitionem exercendam perinde est, res temporaliter coexistere aeternitati, ac si ab aeterno coextitissent.

266. Hinc est, absolute probandam esse sententiam, quae negat omnem realem praesentiam futurorum ab aeterno solumque intentionalem concedit, quam habent futura in divinis actibus scientiae et voluntatis a scientia pendentibus.

Quam docuit SubTilis Doctor in $1^{\circ}$ dist. 36 q. unica, et dist. 38 q. 3 art. $2,{ }^{201}$ Ochamus, Gabriel, Gregorius, Aegidius, Herveus, Silvester, Carthusianus,

200. praescientiae corr.

201. Vielmehr IoAnnes Duns Scotus: I Ord. dist. $39 \$ \$ 9-10$, Opera omnia ed. L. Wadding, Lyon 1639, t.5, 1295. 
Suarez, Vazquez, Valentia, Lessius, et alii, quos refert Ruiz disp. illa 28 sect. 1, et communiter Doctores Societatis secuti Magistrum Sententiarum in $1^{\circ}$ dist. 35 et 36 , in quibus expresse negat realem praesentiam futurorum ab aeterno et solam intentionalem, quam in divina cognitione habent, concedit. Quod Patres communiter exprimunt, praesertim Augustinus a MAgistro duplici illa distinctione citatus. Dicuntur autem futura Deo praesentia intentionaliter [862v] non, quia utcunque cognoscuntur, sed, quia cognoscuntur modo quodam speciali, quem Augustinus a Magistro citatus dist. 35, ,,infallibilem“ dixit: „cum illa sunt omnia cognitione quadam infallibili sapientiae Dei“. Hanc specialitatem in eo consistere, diximus capite $7^{\circ}$, quod ea, quae sunt futura, non cognoscuntur a Deo tanquam futura - sicut nec tanquam praeterita - realiter divinae cognitioni, sed, ut realiter illi praesentia, non tamen ab aeterno, sed in ipsa temporali rerum duratione et praesentia ad aeternitatem divini cognoscentis et cognitionis. Quam praesentiam capite praecedenti probavimus esse determinativam rationem futura cognoscendi.

267. De SuARIO, quem reali futurorum praesentiae ab aeterno adversari diximus, asserit RuIz, quod praesentiae ab aeterno, quam ipse defendit, favet, quia praesentiam obiectivam concedit divina cognitione priorem. Attamen prioritas haec non in alia quam in temporali ipsa praesentia rerum constituitur a P. SUAREz (ut supra advertimus).

268. Anonymus vero Theologus, Author libelli De ordine, etsi cap. 19 SuARI de praesentia rerum in aeternitate doctrinam sectetur, vult tamen SUARII adversarius videri vel ignorans vel dissimulans, ipsum concedere temporalem praesentiam rerum ad aeternitatem et solam aeternam negare. Eiusdem ipse ANONYmus sententiae est, et tamen sibi obiiciens ex SUARIo lib. $1^{\circ}$ De Scientia Absoluta Futurorum cap. $7 \mathrm{n} .12$ argumentum hoc „Nullum non existens potest esse coexistens aeternitati et consequenter nec illi realiter praesens ab aeterno" illud reputat inerme et vitiosum esse, eo quod sit a propositionibus pure negativis et plus quam quatuor terminis constet, additque, ad summum probare, quod futura non habeant realem praesentiam aeternam ad aeternitatem, non vero, quod nullam habeant. ${ }^{202}$

202. „[...] Suarez [...] sic argumentatur: Quod in se non existit, quando non existit, non potest dici praesens aeternitati eique coexistere. Sed nulla creatura in se ipsa et propria suae existentiae duratione extitit $\mathrm{ab}$ aeterno. Igitur nulla creatura realiter ab aeterno extitit in aeternitate seu coextitit aeternitati. - Respondeo $1^{\circ}$, hoc argumentum nullum esse, quod solis propositionibus negativis et plus quam quatuor terminis constet. Respondeo $2^{\circ}$, ut in bona forma dispositum fuerit, aliud nihil probare, quam rem, quae non existit, quando non existit, non coexistere nec praesentem esse aeternitati divinae: quod verissimum est et ultro ab omnibus conceditur. Quod enim non est, quando non est, nulli rei praesens esse potest. At non probat simpliciter, id, quod non est, non coexistere realiter aeternitati." (Claude Tiphaine SJ.): De ordine deque priori et posteriori liber 19, 10, Reims 1640, 119. 
Sed solutio haec pure et prave negativa est, quia omni rationis bono privatur et quatuor vitiis laborat. Primum est, quod supponat, SUARIUM negare omnem realem praesentiam futurorum ad aeternitatem. Secundum, quod dicat, propositiones illius argumenti esse pure negativas. Tertium, quod constet quatuor terminis. Quartum, quod plus quam quatuor terminis constet.

269. Primum vitiose supponi, non alia eget probatione quam lectione Patris SUAREZ tam citato capite quam cap. 8, praesertim n. 10, quem his verbis concludit: „Ex parte autem rerum, ut absolute sciri ab aeterno possint, necesse est, ut aeternitati aliquando coexistant, quamvis illa [863r] coexistentia aeterna non sit, ut saepe dixi. Tamen, ut ex parte obiecti terminare possit aeternam scientiam, necesse est, ut aliquando saltem sit. ${ }^{\text {"203 }}$

270. Secundum vitium in eo consistit, quod non agnoverit Theologus Ille, maiorem argumenti, quod despicit, etsi ad sonum negativa sit, quoad sensum tamen esse affirmativam modo sufficienti ad legitime concludendum, quia haec propositio „Nullum non existens potest esse coexistens“ aequivalet huic „Impossibile est aliquid non existens coexistere“ et huic „Omne coexistens debet esse existens“. Unde huic maiori subiuncta hac minori ${ }^{204}$ "Sed nulla creatura est ab aeterno existens“ legitime concluditur „Ergo nulla creatura coexistens est ab aeterno“. Defectus enim syllogisticus constandi solis negativis propositionibus est, quando nulla ex praemissis est neque aequivalenter affirmativa, nam quando per hanc aequivalentiam affirmat praedicatum de subiecto ut distributo per omnia, quae sub ipso continentur, syllogismus potest evidenter concludere. Qui enim propositionem negativam affirmativae aequivalentem concederet, aequivalentem quoque affirmativam concedere cogeretur. Ea autem concessa non posset se munire summulistico illo clypeo argumentum a puris negativis desumptum despiciente. Ergo nec potest illo muniri, etiamsi argumentum formetur per propositionem aequivalentem negativam, quia $\mathrm{ab}$ aequivalentibus eadem est consequentia, etsi pueris et rudibus explicare oporteat consequentias per formales, et non per solos aequivalentes, terminos.

271. Tertium vitium - calumniae quatuor terminorum - satis apparet ex praecedenti. Nam ex dictis constat, syllogismum, de quo agimus, esse hunc: Omne coexistens debet esse existens semper ac est coexistens; sed nulla creatura est existens ab aeterno: ergo nec ab aeterno coexistens. Terminus medius in hoc syllogismo est „existens“, extremi vero sunt „omne coexistens“ et „nulla creatura“. Particula autem „ab aeterno“ est modificatio, sub qua de creatura negatur existentia, et de existentia negatur, quod fuerit. Hos esse tres tantum terminos qui negaverit, negabit

203. Franciscus Suarez: Opera omnia, Paris 1856-78, t.11, 33 oa.

204. haec minor corr. 
consequenter, unum terminum medium et duos extremos ternarium numerum terminorum constituere, eademque fronte negabit consequentiam syllogismi facti, nam syllogismi quatuor terminis constantis nulla est consequentia. Huius vero [863v] syllogismi „Omne coexistens Deo debet esse existens; nulla creatura est ab aeterno existens: ergo nulla est Deo ab aeterno coexistens“ nullus sanae mentis consequentiam esse legitimam negare potest, quum certum sit, medio termino affirmato de termino extremo maiori perfecte distributo per omnia sua inferiora et negato eodem termino medio, cum aliqua modificatione, de termino minori, necessarium esse, quod sub eadem modificatione negetur in consequenti terminus maior de minori iuxta regulam Dici de omni, dici de nullo. Quod enim repugnare dicitur alicui quod supponitur esse de essentia alterius, huic alteri repugnare necesse est. Si ergo creaturae repugnat existentia ab aeterno, necesse est, quod illi repugnet coexistentia, cui supponitur essentialem esse existentiam. Puerilia haec sunt, fateor, sed inconsiderata propositionum negativarum et quatuor terminorum calumnia coegit nos ad puerorum rudimenta calumniatori recolenda.

272. Sed quid illi dicemus ad ultimum, quod scilicet syllogismus SuARI plus quam quatuor terminis constet? Satis sit respondere, syllogismum solis tribus terminis constantem non posse plus quam quatuor terminis constare. Satis, inquam, hoc sit, ut sapientissimi et modestissimi Doctoris defensio eius in respondendo similibus impugnationibus moderationem sectetur. Sane impugnator iste ANONYMUs in hac et aliis Nostrorum impugnationibus non tam intellectu pugnare mihi videtur quam affectu. Quem parum moderatum esse, et evidentia veritatum, quas impugnat, et impugnationum inanitas satis patefaciunt.

\section{Caput 21. Explicatur, quomodo divina scientia futurorum contingentium non sit actus Deo formaliter liber, si ad illam non praecedit decretum praedeterminativum}

\section{Ratio dubitandi est:}

Nam, ex una parte, necessario ab utriusque factionis Doctoribus supponendum est, scientiam futurorum contingentium non esse formaliter et immediate, ratione sui, liberam Deo. Id supponunt ADVERSARII ob decretum praedeterminativum futuri inferens naturali necessitate in [864r] Deo scientiam. Doctores vero Nostri id supponunt ex eo, quod, si libera formaliter esset scientia illa Deo, ipse se ad ipsam libere determinaret sine ulla subsecutione ad obiectum (ut infra videbimus); ac proinde non esset suppositio consequens. Quod plures Nostrorum doctrinas everteret.

Ex alia vero parte non videtur, scientiam divinam carere posse formali libertate, si Deus illam non habet ex decreto praedeterminante obiectum. Ut enim libertate 
careat, debet saltem ex suppositione aliqua libera necessario exerceri; ac proinde dari debet ante ipsam suppositio praedeterminans ad eius existentiam, nam ab indifferentibus principiis orta actio non potest necessaria esse. Ea autem suppositio praedeterminans non potest non esse ab aeterno, quum scientia ab aeterno necessaria et consequenter praedeterminata sit. At suppositio aeterna praedeterminans ad scientiam futuri non alia potest esse nisi aeternum decretum praedeterminativum obiecti per scientiam illam cognoscibilis. Ergo huiusmodi decretum ad scientiam praecedere necesse est.

Quod argumentum commune est tam absolutae quam conditionatae scientiae futurorum contingentium, quia neutra exercetur cum immediata libertate, sed ex suppositione libere quidem existente in se, sed tamen necessitante ad praescientiam sui.

274. Ad responsionem suppono ex Caietano Prima parte q. 14 art. $13 \$$ „Ad secundum autem, et reliqua "205 divinam essentiam esse repraesentativam aliquorum mere naturaliter, omnium scilicet essentialium, quae sunt praedicata divina et creata ut possibilia; aliorum vero naturaliter quidem et necessario, non tamen „mere naturaliter, sed naturaliter ex suppositione libera“. Hoc sensu „naturaliter“, repraesentat futura contingentia; ac proinde ipsa divina essentia est praedeterminatio ad scientiam futuri ex tali suppositione libera seu sub conditione, quod ponatur. Unde ea posita exercebit naturaliter et necessario actum praesciendi futura transibitque ad statum absolutae praedeterminationis scientiae futuri - non, quia aliud distinctum ab essentia et suppositione illa detur, quod absoluta praedeterminatio sit, sed, quia illa suppositio partialiter constituit praedeterminationem in ratione absolutae: ut conditionatum „transire“ dicitur „in absolutum“ per purificationem conditionis.

275. Si autem quaeras, quae sit suppositio haec, quae simul cum essentia constituit absolutam praedeterminationem sciendi futurum? - [864v]

Respondeo, esse ipsummet temporale obiectum quod futurum esse cognoscitur. Hoc enim est praevium determinativum aeternae scientiae sui, quia est determinate connexum cum scientia et illam praecedens. Est ergo praedeterminatio illius, qua posita in tempore Deus per intrinsecam suam perfectionem necessario exercet actum praescientiae illius.

276. Ex quo respondetur ad rationem dubitandi, ab aeterno dari praedeterminationem divinae scientiae futurorum non quidem absolutam, sed conditionatam. Haec autem sufficit ad exercendam sine libertate scientiam, quae conditionem, sub qua praedeterminat, purificatam in tempore supponit. Non nego, praedeterminationem aeternam scientiae debere esse absolutam, sed, eam esse absolutam formaliter qua

205. Caietanus: In Primam partem Q. 14 art. $13 \$ 17$, ed. Leon. t.4, 190 ob. 
aeterna est. Aeterna quidem debet esse, qua parte continet virtutem dandi esse divinae scientiae. At qua parte non est virtus sciendi, sed pura exigentia obiectiva, ut virtus illa actum sciendi exerceat, non opus est, quod ab aeterno existat. Existit ergo ab aeterno praedeterminatio conditionata scientiae cuiusvis futuri: sub conditione scilicet, quod hoc ponatur in tempore. Id est, datur ${ }^{206}$ aeterna virtus, quae naturaliter et necessario operatur in aeternitate scientiam determinatam futuri, si hoc in tempore existat. Unde, quoties existit in tempore, datur absoluta praedeterminatio non adaequate aeterna, sed constituta ex temporali et aeterno, quia redditur absoluta praedeterminatio illa intrinseca ex se conditionata, per purificationem conditionis: quae est obiectum. Purificatur autem in tempore, non ab aeterno.

277. Replicabis: Ergo aeternum principium scientiae de obiecto futuro, quatenus est principium completum ipsius, indifferens omnino est absolute ad hanc scientiam et oppositam: ergo, quantumcunque exerceat, exercebit illam ut actionem sibi ab aeterno liberam formaliter.

Consequentia patet, quia exercet illam ut principium ab aeterno non praedeterminatum ad eius aeternum exercitium, quum nulla ab aeterno sit ad talem scientiam praedeterminatio absoluta. Quod autem detur ab aeterno conditionata praedeterminatio illius, nihil refert: quia praedeterminatio conditionata non necessitat ad actionem, quae prius exercetur quam ponatur conditio, sub qua praedeterminat, quum actio sic exercita sit absolute indifferens eo quod sit absolute impraedeterminata. Ergo, quum scientia ab aeterno ponatur et conditio in tempore, necesse est, ante positam conditionem iam esse exercitam praescientiam, et consequenter, quod exercita sit [865r] ante praedeterminationem absolutam. Exercetur ergo sine ulla et sine ulla absoluta necessitate. Quod est libere exerceri.

278. Ad replicam hanc, videbitur ALICUI ${ }^{207}$ responderi posse, indifferentiam principii aeterni divinae scientiae esse pure effectivam et non electivam. Deus enim non eligit habere hanc scientiam potius quam oppositam, quia nec ipsa scientia est formaliter actus electionis - eo quod non sit volitio -, nec a divina volitione antecedente, illam infallibiliter inferente, dependet. Indifferentia autem pure effectiva non sufficit ad libertatem. Ut patet in eo, qui affectu charitatis se determinavisset ad Evangelium praedicandum Indis Orientis vel Occidentis, et ${ }^{208}$ qui ex hac suppositione indifferens manet ad duos tantum actus supernaturales oppositos eliciendos ex motivo charitatis, scilicet vel navigare ad Indos Orientales, vel Occidentales.

206. detur corr.

207. Vgl. Antonius Perez: In Primam partem D. Thomae opus posthumum: De providentia Dei 3, 59, Rom 1656, 327b.

208. et suppl. 
Habitus, in hoc casu, est principium indifferens illorum actuum, et tamen, quia non est electivum nec volitivum, per illos non habet indifferentiam libertatis, licet effectivam indifferentiam habeat. Similiter ergo, cum indifferentia divina ad oppositas scientias non sit electiva - quia scientiae non sunt electiones, cum non sint volitiones -, non poterit esse indifferentia sufficiens ad libertatem, licet effectiva virtualiter sit oppositorum actuum.

279. Sed haec solutio, quamvis veram doctrinam contineat et a me non semel probatam, non est adaequata: nam, principium actus electivum non esse, probat quidem, actum non esse formaliter liberum a tali principio - ut probatum est de habitu illo supernaturali -, non tamen probat, actum sic elicitum non esse formaliter liberum alicui principio; nec satisfacit obiectioni, qua contenditur, scientiam divinam futurorum esse formaliter liberam ex eo, quod completum eius principium activum liberum sit in actu primo. Etenim actus, cuius integrum principium indifferens est, debet esse formaliter indifferens in actu secundo; ac proinde necesse est, quod alicui principio liber sit.

Ex quo fit, bene sequi - ut allatum exemplum habitus in solutionis Authores retorqueamus -, bene, inquam, sequi ex eo, quod habitus supernaturalis sit effectivus duorum actuum sine ulla praevia determinatione ad aliquem illorum determinate, quod, quamvis ipse habitus non sit principium liberum nec actus sit illi ${ }^{209}$ liber, attamen coniungi debeat cum principio, cui actus ille ${ }^{210}$ liber sit: quum indifferentia illa actus constituat formaliter ipsum in se liberum, ut patet ex libertatis definitione. [865v] Si ergo nulla inveniatur determinatio praevia respectu divinae scientiae, sed omnimoda indifferentia principii adaequati illius, non poterit defendi, quod formali careat libertate, nec dici, quod non sit volitio, si ad formalem conceptum libertatis requiratur volitionis conceptus.

280. Ut ergo obiectioni respondeatur, advertendum est, divinae scientiae futurorum duplex esse principium:

Aliud virtualiter productivum dans illi esse. Quod principium est divina essentia ut est potentia intellectiva, obiectum motivum et species intelligibilis futurorum.

Aliud vero extrinsece determinativum per positionem obiecti praesciendi, et impeditivum per talis obiecti suspensionem.

Duplex hoc principium suo modo praecedit scientiam: alterum ut id, a quo scientia habet suum esse, alterum ut id, a quo pro libito vel impediri potest vel determinari, id est, per determinatam exigentiam praeviam exigi a suo principio aeterno ponendum.

209. ille corr.

210. illi corr. 
Scientia ergo non respicit immediate $u$ trumque hoc principium ut indifferens ita, ut ipsa sit immediatum exercitium indifferentiae utriusque -, quia, licet sit exercitium immediatum sui principii activi - eo quod hoc non producat scientiam medio alio producente aut constituente virtutem ad producendum -, attamen non est exercitium immediatum arbitrii creati ut potentis scientiam illam determinare et impedire: quia illam determinat aut impedit arbitrium creatum mediis suis actibus ut determinate exigentibus scientiam poni, aut impediri. Unde scientia a principio libere impeditivo sui dependet tanquam a praedeterminante ad eius esse et impeditur tanquam a praedeterminante ad non-esse. Impeditur enim, ut dixi, et praedeterminatur mediis actibus creati arbitrii, quos praevios esse ad scientiam probavimus. Unumque illorum esse determinationem ad esse scientiae sui, et alium ad non-esse eiusdem scientiae, probatione non eget. Uterque ergo est determinatio praevia ad sui scientiam et negationem scientiae oppositae.

281. Ex quo sequitur, quod per hanc praedeterminationem extrinsecam obiectivam, quam libere ponit principium impeditivum scientiae, maneat extrinsece praedeterminatum divinum principium productivum ad eiusdem scientiae virtualem productionem: quia extrinseca illa praedeterminatio eatenus est praedeterminatio ad scientiam, quatenus praevie exigit illam a suo principio poni. [866r]

282. $2^{\circ}$ Advertendum est, principium activum oppositorum actuum, ut liberum principium sit, debere esse pro libito suo impeditivum eius quod efficit; et principium impeditivum, ut sit immediate liberum respectu eius, quod impedire potest, debere immediate influere in illud. Ex quo fit, nec divinam scientiam esse principium formaliter liberum respectu scientiae futurorum contingentium - quia illam, positis omnibus praerequisitis, non potest pro libito impedire -, nec scientiam illam esse immediate liberam principio creato, quod pro libito impedire potest: quia hoc non influit immediate in ipsam, sed mediis suis actibus. Influxus autem, quem per hos actus exercet, non est, ut suppono, causalitatis, sed impedibilitatis et determinationis.

283. $3^{\circ}$ Advertendum est, etsi non admodum facile intelligatur, quo pacto activum principium adaequatum duorum actuum, quorum quilibet impediri potest per exercitium alterius, distingui possit a principio impeditivo cuiuslibet illorum quum impeditio non videatur posse fieri nisi vel per immediatam suspensionem concursus praestandi ad id quod impeditur, vel per ablationem alicuius praevii requisiti natura praecedentis ad id quod impeditur; primum autem non potest convenire nisi principio vere influenti in id quod impeditur, secundum vero probat, principium, quod per praerequisiti natura praecedentis ablationem impeditur ab operando, non esse sine illo requisito adaequatum et completum: Quod ergo completum et adaequatum est in genere activi nullo alio a se distincto egens 
tanquam natura praecedente ad effectum, quomodo potest ab eius productione nisi per suspensionem liberam concursus ad ipsum impediri? Debet ergo esse per se impeditivum sui actus, si adaequatum et completum sit, et actus ex suppositione huius completionis sit impedibilis - licet, inquam, id non facile intelligatur, attamen respectu divinae scientiae contingentium necessario distinguendum esse a principio adaequato productivo illius, principium impeditivum eiusdem: quia Deus est principium adaequatum aptum ad oppositorum scientiam habendam ita, ut concedat creaturae libertatem ponendi obiectum, quod ab ipso cognoscendum est nolens praevie per se determinare, ut hoc vel illud ponat: Hoc autem statuto necesse est, Deum esse adaequatum principium virtualiter activum dans esse scientiae cum nil creatum possit ad hoc munus admitti -, et arbitrium [866v] creatum esse principium impeditivum et extrinsece praedeterminativum scientiae: quia haec petit essentialiter obiectum cognoscendum, et obiecto in tempore posito necesse est ad illud ferri scientiam; ac proinde eo ipso, quod constituatur in potestate creaturae, quod obiectum sit aut non sit, constituitur creatura principium impeditivum et determinativum scientiae. Determinatio autem extrinseca, qua dicitur creatura scientiam determinare, praedeterminatio extrinseca est (ut dixi), cum exerceatur mediis actibus creatis determinate exigentibus scientiam et ad illam praecedentibus. Principium vero productivum ideo ab hac extrinseca praedeterminatione praedeterminari absolute dicitur, quia est productivum scientiae cum attemperatione ad principium impeditivum illius, id est: cum essentiali habitudine operandi pro eius libito et ad exigentiam actuum, qui a tali principio libere elici possunt.

284. $4^{\circ}$ Advertendum est, non repugnare conceptum extrinsecae „praedeterminationis" temporalis respectu actus ab aeterno existentis, quia extrinseca haec praedeterminatio nil aliud est quam praevia exigentia obiectiva. Haec autem temporalis esse potest respectu actus aeterni. Unde nil requiri potest ad praedeterminationem aeterni actus nisi quod requiritur ad obiectivam cognoscibilitatem determinatam, comparatam ad aeternam cognitionem. Nam cum haec cognoscibilitas cognitionem illam exigat et praecedat, non potest non esse praevia exigentia et determinatio illius.

Quomodo autem cognoscibilitas et obiectiva determinatio praevia temporalis esse possit respectu actus aeternitate prioris, ex eo intelligibile redditur, quod temporalia obiecta eo ipso, quod temporaliter existant, coexistere debeant cognoscitivo aeterno et consequenter intra sphaeram activitatis cognoscitivae ipsius constitui. Nam ad hoc sufficit, quod obiectum coexistat durationi, in qua cognoscens exercere debet cognitionem. Implicat autem, aliquid temporaliter existere, quin Deo coexistens sit secundum durationem, in qua exercere debet cognitionem. Poterit ergo obiectum sic existens „praedeterminare“ extrinsece ad aeternam sui cognitionem - Deus enim aliam nequit exercere - sicut approximatum agenti passum potest „praedeterminare“ virtutem activam ad productionem. Itaque non maiori 
proprietate „praedeterminatur“ ignis ad combustionem ex eo, quod ipsi applicetur combustibile per praesentiam ad locum et tempus, in quo exercenda est combustio, quam Deus ad aeternam cognitionem per [867r] praesentiam obiecti, etsi temporalem, ad aeternam durationem, in qua exercenda est cognitio. Applicatur autem obiectum ad eam durationem eo ipso, quod quovis tempore existat, cum in quolibet coexistat toti aeternitati.

285. $5^{\circ}$ Tandem advertendum est, dupliciter intelligi posse „principium praedeterminatum":

$1^{\circ} \quad$ ita, ut significet principium affectum praedeterminatione ad operandum;

$2^{\circ}$ ita, ut significet principium ex praedeterminatione operans.

Primum facit principium esse praedeterminatum formaliter, secundum vero, esse praedeterminatum ${ }^{211}$ praesuppositive. Quod est, habere in se praesuppositionem praeviae determinationis.

In hac secunda acceptione „praedeterminati“ facile intelligitur, Deum ab aeterno absolute praedeterminatum esse ad sciendum, cum absolutae praedeterminationis, etsi per temporale aliquid constituatur, detur aeterna praesuppositio non quidem distincta a divina scientia, sed per illam ipsam formaliter constituta. Ipsa enim est praesuppositio temporalis obiecti ad se ipsam tanquam praecedentis et exigentis ipsam.

Solum ergo restat dubium de „praedeterminato“ ut significat principium affectum formali praedeterminatione scientiam antecedente. De qua contendit obiectio, quod ab aeterno dari debet, et consequenter, quod nequeat per temporale ipsum obiectum constitui.

286. Ex his ergo ad replicam superiorem $[\$ 277]$ respondeo, Deum esse ab aeterno praedeterminatum absolute ad scientiam futuri non formaliter, sed praesuppositive, quia ab aeterno habet scientiam dependentem a praedeterminatione temporali. Hoc autem sufficere ad hoc, ut scientia non sit formaliter libera, patet ex praesuppositis, nam ad libertatem scientiae non sufficit, nullam dari aeternam praedeterminationem illius, sed requiritur simpliciter nullam dari, nec aeternam nec temporalem: quum libertas actionis requirat, quod actio simpliciter impraedeterminata sit. Unde, quae potest praerequisitum aliquod temporale habere, requirit, nullam esse in tali praerequisito praedeterminatam connexionem cum actionis existentia. Alias actio erit simpliciter praedeterminata. Sicut a praerequisitis praesentibus, quia requiruntur et praecedunt, praedeterminari potest actio, ad quam sola praesentia requisita praecedere possunt. Scientia ergo divina, quae futurum obiectum

211. praedeterminativum corr. 
ut praevium [867v] requisitum respicit, dependet ab illo ut praedeterminativo ita, ut simpliciter non ponatur indifferentia comparatione omnium praerequisitorum, sed ex praevia praedeterminatione per aliquod illorum constituta.

287. Quare propositio haec „Deus antecedenter ad scientiam est absolute non praedeterminatus ab aeterno ad illam" vera quidem est de negatione omnis absolutae praedeterminationis aeternae, non tamen de aeterna negatione omnis absolutae praedeterminationis, tam aeternae quam temporalis. Primum autem non sufficit ad scientiae libertatem. Secundum vero - quod ad illam sufficeret - negamus ab aeterno dari in principio scientiae: quia hoc non constituitur praedicato ullo negante omnem praedeterminationem - etiam temporalem - scientiae exercendam a tali principio, immo illam omnino dandam esse ad scientiam, quae exercenda fuerit, petit; ac proinde petit, eam exerceri dependenter a praedeterminatione.

288. Quod autem additur in obiectione [ $\$ 277$ ], praedeterminationem conditionatam non necessitare ad actum, qui ponitur ante conditionem, -

Distinguendum est, verum id esse de actu, qui ponitur „ante conditionem“ per antecedentiam independentiae a conditione, non vero de eo, qui ponitur ,ante conditionem" per solam antecedentiam durationis cum subsecutione dependentiae a conditione. Nam quod dependenter a conditione futura ponitur, si haec sit praedeterminativa, non potest non existere de praesenti ut absolute praedeterminatum, quia de praesenti debet absolute praesupponere futuram praedeterminationem sui.

289. Sed contra haec replicabis $2^{\circ}$, antecedenter ad scientiam, nullam dari coniunctionem inter essentiam divinam et obiectum futurum nec intentionalem nec physicam, per quam coniungi possint ad constituendam absolutam praedeterminationem ad scientiam. Ergo illam non constituunt.

Respondetur, antecedenter ad scientiam - antecedentia a quo - dari hanc coniunctionem et esse coniunctionem realem, scilicet coexistentiam utriusque, quae ex parte Dei aeterna est, temporalis vero ex parte obiecti creati. Ideo autem haec coexistentia est coniunctio sufficiens ad scientiae praedeterminationem, quia essentia divina ad scientiam amoris liberi, v.g., petit amoris existentiam ut conditionem non aeternam, sed temporalem, et quod ea conditione posita existat amor; et amoris existentia petit, quod essentia [868r] per modum principii exerceat scientiam aeternam amoris; scientiaque ipsa essentialiter exigit et praesupponit utrumque, scilicet et esse Dei et esse obiecti: alterum ut principium aeternum dans illi esse, alterum ut terminum temporalem, sine cuius temporali existentia nequit a suo principio oriri scientia. Praedictae autem exigentiae faciunt sufficienter coniungi temporale et aeternum ad praedeterminandam scientiam, a qua exiguntur. Sicut approximatio combustibilis ad ignem in determinata quadam distantia est coniunctio sufficiens ad praedeterminationem absolutam combustionis: ex eo, quod combustio agens 
suum et passum in illa distantia sibi approximata supponat, et ignis petat approximationem illam ad comburendum et combustionem, sub conditione, quod ea applicatio detur, et denique approximatio petit, ut ignis comburat.

\section{Caput 22. Explicatur, quomodo praedeterminatio obiectiva obstet formali libertati scientiae de futuro contingenti, quamvis illam non praecedat natura}

290. Contra superius dicta replicabis $3^{\circ}$, praedeterminationem, etiamsi absoluta sit, non imponere necessitatem nec libertati ullo modo obstare, nisi antecedat natura actum ad quem praedeterminat; at creatum obiectum non praesupponitur natura ad divinam scientiam: ergo non potest ad illam „necessitare“, etsi aliquo modo praevie determinare dicatur.

Minor et consequentia certae sunt.

Maior autem patet: quia necessitas et contingentia effectus ab indifferentia et determinatione causae desumitur. Ergo, ut necessarius sit, debet esse determinatus in causa et consequenter existere vi determinationis natura et causalitate praecedentis.

291. Si respondeat quis, sufficere ad actus necessitatem, quod praedeterminatus sit vi alicuius praerequisiti ad ipsum: nam, ut sit liber, debet oriri a causa, quae positis omnibus praerequisitis possit non operari, ${ }^{212}$ -

Sed contra, nam praerequisita cum quibus debet causa posse operari et non operari, sunt, quae praevie requiruntur prioritate naturae ut constituentia completam virtutem causae: nam, si alia prioritate aliquid antecedat - v.g., in subsistendi consequentia $^{213}$ aut alia simili -, etiamsi praedeterminet in hoc genere praecedendi, non obstat actus libertati. Ut videre est in scientia conditionata. Quae, simul cum voluntate ponendi conditionem, constituit praeviam determinationem ad actum absolutum et tamen, quia non est praerequisita [868v] per prioritatem naturae, sed per prioritatem in subsistendi consequentia, non constituit praedeterminationem libertati contrariam.

212. „Supponenda est definitio libertatis. Illa causa libera est, quae positis omnibus requisitis ad agendum, potest agere, et non agere." Dominicus Sotus: De natura et gratia 1, 16, Paris 1549, 58r. Zur Geschichte dieser seit dem 14. Jh. bezeugten Definitionsformel vgl. DidAcus RuIZ DE Montoya: Commentarii ac Disputationes de scientia Dei 50, 4, Paris 1629, 472b-76b. Er merkt an (477a): „[...] ablativus absolutus positis omnibus requisitis ad operandum apud omnes denotat sensum compositum $[\ldots]^{“}$

213. „[...] prioritas logica [...] vocatur a subsistendi consequentia, non fundata in causalitate et dependentia [...]" Rodericus de Arriaga: Disputationes theologicae in Primam partem D. Thomae 20, 51, Antwerpen 1643, t.1, 214a. Dahinter steht Aristoteles: Cat. 12, 14a29-35. 
292. Hinc probatur, insufficientem esse aliam solutionem, qua usi sunt NonNULLI, scilicet, praedeterminationem obiectivam, licet non praecedat natura per modum determinantis quasi active divinam scientiam, esse tamen aliquid, in ordine ad quod Deus est per se ipsum praedeterminatus; id autem, per ordinem ad quod aliquid habet rationem praedeterminationis tanquam ad conditionem, sub qua praedeterminat, non oportet, quod praecedat natura actum praedeterminatum, ad hoc, ut eius libertatem tollat.

Sed insufficiens est solutio, nam Deum esse ex se praedeterminatum ad actum comparative ad aliquam suppositionem aut conditionem, est, quod non possit data illa actum omittere. Haec autem praedeterminatio non obstat libertati, quando suppositio, in ordine ad quam principium actus dicitur esse "praedeterminatum“, non praecedit natura ad actum. Si enim illa suppositio actum subsequatur aut comitetur, nil refert, quod principium ex suppositione illius non possit actum omittere. Ut patet in principio libero. Quod est ex se praedeterminatum ad non omittendum actum ex suppositione, quod Deus sciat, illum esse extiturum, aut ex suppositione, quod alius actus cum illo concomitanter connexus exerceatur. V.g., in sententia asserente, quod, quoties exercemus actum supernaturalem, simul exerceri necesse est actum naturalem circa idem obiectum - si hoc capax sit naturalem tendentiam determinare -, praedeterminatum est principium ad exercendum unum, si habeat alterum. Quod est, esse praedeterminatum ad non-componendam negationem unius cum existentia alterius. Ea tamen praedeterminatio non obstat libertati, quia suppositio, in ordine ad quam praedeterminatur principium ad habendum actum, non est natura antecedens illum, sed concomitans. Ergo, licet divinus intellectus praedeterminatus sit ad scientiam futuri habendam sub conditione, quod futurum in tempore existat - eo quod non possit data hac suppositione actum scientiae suspendere -, hoc tamen obstare non poterit libertati formali ipsius scientiae, si obiectum non sit suppositio praecedens natura ad ipsam.

293. Si vero dicat quis, principium praedeterminatum ad exercendum actum sub aliqua conditione aut suppositione, illum necessario exercere, quoties suppositio non est illi libera; at suppositio illa potest non esse libera principio actus, quamvis non praecedat natura actum: ergo sine hac suppositionis praecedentia potest, in ordine ad illam, ita praedeterminari [869r] principium, ut actum sine libertate exerceat; hoc autem modo se habet divinus intellectus respectu scientiae habendae ex suppositione obiecti libere futuri, quia haec suppositio non est Deo elective libera, sed nobis, -

Contra, quia, si suppositio haec non sit natura antecedens divinam scientiam, erit Deo libera concomitanter: sicut nobis libera dicitur esse scientia Dei. Etenim aeque essentialiter requirit obiectum creatum, quod Deus sciat illud existere, ac scientia requirit existentiam obiecti, cum aeque implicet, obiectum existere et non sciri a Deo, ac scientiam existere, quin extiturum sit eius obiectum. Ergo, sicut divina scientia nobis est libera, quia non est causa nostrae operationis, sed illam 
supponit esse in nostra libera potestate, et operationem respicit ut requisitum sine quo non potest esse et quo posito non potest non esse: ita similiter, si obiectum non est causa, quod Deus sciat, nec praecedit natura ad eius scientiam, quum ex alia parte essentialem connexionem habeat cum scientia ita, ut sine illa esse non possit et illa existente non possit non esse, sequitur, Deo, qui indifferens est ad scientiam obiecti et carentiae illius, liberum esse concomitanter, quod ponatur vel non ponatur obiectum. Ut ergo huius connexio libertati divinae scientiae obstet, debet natura praecedere ad ipsam.

294. Ad responsionem ergo dicendum est $1^{\circ}$, duplicem esse praedeterminationem effectivi principii ad suum actum: alia est positiva, per connexionem cum positione actus, alia negativa, per exclusionem potestatis omittendi actum pro libito principii, a quo efficitur. Itaque positiva praedeterminatio est praevia exigentia actus, negativa vero est praevia repugnantia cum actus omissione non simpliciter sumpta - nam repugnantia cum illa, sic sumpta, est positiva exigentia existentiae actus -, sed cum omissione ut ponenda "pro libito principii, a quo actus efficitur". Principium ergo ita efficere actum, ut omissionem actus - actumve positivum oppositum - non possit pro libito suo habere, est, esse negative praedeterminatum.

Secundam ergo hanc praedeterminationem fatemur necessario debere praecedere natura ad actum, ut hic sine libertate exerceatur, quia principium illa praedeterminatione carens habet perfectam definitionem principii liberi, scilicet, exercentis actum per indifferentem potestatem, qua posset pro libito illum omittere. E contra vero, quoties actus supponit natura praecedentem in suo principio praedeterminationem illam negativam ad non-suspendendum pro suo libito talem actum, non potest [ $869 \mathrm{v}$ ] tali principio esse liber. Libertas enim requirit in principio libero indifferentiam ad opposita non qualemcunque, sed electivam inter opposita, ut expresse docet S. Thomas Prima parte q. 83 art. 4 definiens libertatem per „vim electivam ${ }^{214}$ “ $s e u$ dominativam, qua, pro libito, quodcunque illorum exerceri possit, ac proinde quodlibet exercere cum potestate illud omittendi pro suo libito. Quod late ostendimus libro $2^{\circ}$ capite $3^{\circ}$ ex D. Augustino et communi Theologorum consensu. Ex quo firmum manet principium, quod statuimus, nempe, praedeterminationem negativam principii ad hoc, ut non possit pro libito suo omittere actum, quem exercet, sufficere, ne actus liber sit.

295. $2^{\circ}$ Adverto, praedeterminationem hanc negativam duplici titulo posse convenire alicui principio:

Primo, quia principium in se volitivum non sit. Quod enim volitivum non est implicat, quod actum efficiat aut suspendat pro suo libito; ac proinde ex se, quatenus praecedit natura suum actum, praedeterminatum est, ne possit illum pro suo 
libito omittere; ac proinde, etsi duplicem actum oppositum efficere possit, quorum quilibet in se sit libera volitio, attamen efficiet actus illos sine libertate, licet cum attemperatione ad aliud comprincipium, cui actus illi liberi sint.

Secundus titulus est, principium, etsi volitivum ex se sit, attamen in actus effectione non procedere volitive aut elective. Procedere autem elective in effectione est, quod haec vel sit actio electiva et volitiva principii, a quo oritur, si sit immediate illi libera, vel ab eius electione inferatur, si sit solum mediate libera. Itaque, etsi principium sit volitivum, si tamen actio, quam exercet, nec electio - seu volitio - formaliter est nec vi connexionis cum electione talis principii exercetur, non procedit principium elective seu volitive in exercitio talis actionis nec ita ponit actionem, ut illam possit pro libito suspendere, quia influit ut praedeterminatum ad illam non sic suspendendam.

296. $3^{\circ}$ Adverte, principium negative praedeterminatum aliquando non egere ad actionem suam praedeterminatione positiva, immo nec illam admittere posse: quando scilicet actio, quam exercet, est alteri principio immediate ${ }^{215}$ sui formaliter libera. Hoc modo comparatur habitus ad actionem liberam, quam immediate efficit. Est enim praedeterminatus negative ad illam - non solum quoad speciem, sed etiam quoad exercitium, quum non possit pro libito suo nec aliam speciem actionis exercere nec actionis, quam exercet, exercitium pro libito suo suspendere -, et tamen nullam praeviam determinationem positivam [87or] ad actionem illam petit nec admittit.

Aliquando vero principium negative praedeterminatum eget etiam praedeterminatione positiva, scilicet, quando actio, quam exercet, non est ulli alteri principio libera immediate. Tunc enim necesse est, ut ab aliqua praevia exigentia determinetur actio. Nam omne existens ab alio, quamvis contingens sit, determinatur ad esse per alicuius liberi agentis electionem vel $^{216}$ per se ipsum - si sit immediatum exercitium indifferentiae electivae - vel per determinationem praeviam ad eius esse - si per se ipsum non sit immediatum exercitium eligendi.

297. $4^{\circ}$ Adverte, hanc praedeterminationem positivam aliquando debere praecedere natura ad actum, qui formali libertate caret, aliquando vero non natura, sed alio prioritatis genere, praecedere.

Praecedit natura, quando praedeterminatio additur principio ut complementum virtutis. Sic praedeterminatur omnis creata indifferentia ad duo, quando non ut indifferens operatur, sed cum determinatione ad unum. Nulla enim est indifferentia creata ad actum nisi vel per dominium potentiae completae cum omnibus

215. immediato corr.

216. et corr. 
praerequisitis ad ipsum, vel per indifferentiam habendi aliquod praerequisitum, quo posito non potest non sequi actus.

Prima indifferentia, si completa sit, ut supponitur, praedeterminari non potest, quia essentialiter constituitur per negationem omnis praeviae determinationis seu per aliquid repugnans essentialiter cum illa, scilicet per primae causae indifferentem ${ }^{217}$ concursum et applicationem.

Secunda autem indifferentiae determinatio est positio praerequisiti complentis virtutem principii et praecedentis natura ad actum. Praedeterminatio ergo virtutis creatae ad agendum debet natura praecedere actionem. Quando autem praedeterminatur ad actum, principium habens virtutem omnino completam, praedeterminatio non antecedit natura ad actum, cum non sit tunc virtutis complementum.

298. Si autem quaeras, quomodo possit esse praedeterminatio actionis, quod non est complementum virtutis agendi per modum praerequisiti natura praecedentis ad actionem? -

Respondeo, ideo aliquid posse sortiri rationem praedeterminationis sine hac praecedentia naturae, quia potest esse praerequisitum ad actum et tamen non praerequiri ut coexistens actui eo genere coexistentiae, quam requirit principium productivum. Quae est coexistentia per durationem ipsi actui aequalem. Quum enim actus non possit ante principium suum productivum existere, necesse est hoc esse actui in duratione [870v] aequale seu non inferius, idemque est de praerequisitis quibusdam, quae ob specialem modum, quo exiguntur ab actu, sunt illo priora causaliter, ita, scilicet, ut, licet causae non sint, causam tamen imitantur non solum in eo, quod sint utcunque ratio, ob quam existat actus, sed etiam in coexistentia, quam requirunt cum actu per durationem illi non inferiorem. Ex quo fit, ea, quae praerequiruntur ad actum et non petunt illi coexistere per durationem illi aequalem, sed per inferiorem, ${ }^{218}$ non praecedere natura ad actum, et consequenter praedeterminationem per haec requisita constitutam non esse praecedentem causalitate aut $n a-$ tura, sed prioritate alterius generis, scilicet determinationis vel attemperationis. Qua eligibile supponit electivum principium, et impedibile principium impeditivum.

299. Si vero iterum quaeras, quo pacto praedeterminatio, cuius prioritas non est naturae nec complementi virtutis, possit sufficere ad virtutem illam - etsi de se sufficientem et indifferentem ad opposita - ita praedeterminandam, ut neutrum illorum libere operari valeat, cum tamen ad libertatem sufficiat causalis indifferentia principii activi? -

217. Dazu Franciscus Suarez: Varia opuscula theologica 1, 1, 14, 5-7, Opera omnia, Paris 185678, t.11, 69-70.

218. posteriorem corr. 
Respondeo, indifferentiam causalem, etiamsi sit principii activi, ${ }^{219}$ non sufficere ad libertatem suae actionis, si sit indifferentia non determinabilis pro libito proprio, sed pro alieno: alterius scilicet electivi principii, ${ }^{220}$ cuius libito activum principium attemperatur. Unde, quando electivum principium alicuius actionis distinctum est ab activo eiusdem, non potest ea actio esse ulli principio immediate libera: non enim activo, quia, si hoc est omnino distinctum ab electivo, actio non est determinabilis nec impedibilis pro libito sui principii activi. Neque etiam est libera immediate principio electivo, quia huic nihil est immediate liberum nisi quod ab illo effici aut non effici potest.

30o. Ex quo sequitur, electivam indifferentiam ad hoc, ut sit, et non sit, actio non ab ipso electivo principio, sed ab alio, causanda, non posse immediate determinari per talem actionem, sed per intermediam aliam, productam a principio electivo et praedeterminantem ad esse aut non-esse illius actionis, quae pure elective et sine causalitate a principio electivo dependet (ut capite praecedenti dicebamus). Nam id, per quod electivum principium determinat suam indifferentiam ad esse aut non-esse alterius, debet esse connexum cum tali esse aut non-esse, ut per se patet. Eo autem ipso, quod principium electivum determinet suam indifferentiam ad aliud non productum ab ipso, per intermediam actionem a se productam, haec praecedere debet in genere [871r] electivi, quia propinquius accedit ad electivum principium. Ergo necesse est, quod habeat duo, quae praedeterminationis essentiam constituunt, scilicet praecedentiam et determinatam connexionem et exigentiam eius, ad quod principium electivum suam indifferentiam determinat. En, ergo, praedeterminationem - non natura, sed attemperatione, praecedentem - et rationem, cur obstet immediate libertati actus praedeterminati.

301. Ex his ad obiectionem propositam $[\$ 290]$ respondetur, scientiam divinam nostri actus liberi „praedeterminari“ ab obiecto suo: praedeterminatione non antecedente nec causalitate nec origine, sed alio prioritatis genere, scilicet prioritate electionis vel attemperationis, qua scientia attemperatur obiecto - et arbitrio creato - tanquam impedibile ad impeditivum. Haec autem praedeterminatio sufficit ad impediendam scientiae libertatem, quia facit, ut a nullo principio suo sit immediate impedibilis pro eius libito. Etenim electivum principium, in cuius libito seu libertate constitutum est, quod existat vel non existat scientia, - quod est creatum arbitrium - non est immediate electivum illius per ipsammet scientiam, sed per aliud, scilicet per positionem creati obiecti determinate exigentis scientiam. Principium vero productivum scientiae non est impeditivum illius pro libito

219. Sc. Dei

220. Sc. arbitrii creati 
suo, quia est determinatum et attemperatum ad sciendum quidquid arbitrio creato placuerit divino conspectui obiicere: ita, ut hoc arbitrium sit unicum principium electivum divinae scientiae, et Deus principium activum sine ratione electivi.

Praedeterminatio ergo divinae scientiae per obiectum libere positum ab arbitrio creato petit, ut scientia nullam formalem libertatem habeat.

302. Quod autem attemperatio divini intellectus ad cognoscendum quicquid arbitrio ipsi placuerit obiicere, faciat, scientiam non esse pro libito divino ponibilem aut impedibilem ex suppositione liberae potestatis concessae creaturae ad obiectum ponendum et non-ponendum, patet: quia Deus concessa illa potestate, etsi indifferens active maneat ad habendam scientiam unius extremi vel scientiam oppositi, ${ }^{221}$ non tamen manet indifferens elective, quia non est potens ad habendam aut non-habendam scientiam, quia vult. Non enim vult nec velle efficaciter potest, ex suppositione libertatis concedendae arbitrio creato, habere hanc determinate ${ }^{222}$ scientiam prae altera. Nam vel nec scientiam illam eligere potest per decretum efficax antecedens ad ipsam, quia hoc esset praedeterminare creatam libertatem, nec per voluntatem sciendi formaliter identificatam cum ipsa scientia, quia haec non est formaliter volitio, sed [871v] intellectio: ergo Deus non potest habere scientiam nostri actus eligendo ipsam prae alia extremi oppositi eo ipso, quod creaturae concedatur libera facultas eligendi obiectum quod a Deo sciendum est. Nec Deus habere potest scientiam nostri actus pro eius divino libito impedibilem eo ipso, quod verum sit, ideo Deum scire, quia creatura libere operatur obiectum ab ipso sciendum.

303. Quod si opponas, Deum ita habere scientiam futuri amoris liberi, v.g., ut illam impedire possit pro suo libito: decernente non concedere creaturae facultatem ad amandum, -

Respondeo imprimis, hanc obiectionem nullatenus urgere contra scientiam conditionatam amoris, nam, cum haec non dependeat ab ullo decreto Dei existente, per nullum impediri potest. Quamvis enim Deus decernat, neque amorem nec libertatem ad illum unquam danda esse, non posset non scire, quid contingeret, si non id vellet, sed oppositum, nempe, liberam constituere voluntatem ad amandum.

Ad absolutum vero statum - et scientiam -, fateor, praerequiri decretum indifferens Dei, quo liberam agendi potestatem concedat; ac proinde concedo, ipsum posse pro libito impedire scientiam absolutam cuiusvis extremi: non quidem ponendo oppositi extremi scientiam, sed carentiam scientiae utriusque extremi

221. Vgl. Franciscus Suarez: Varia opuscula theologica 2, 1, 5, 4, Opera omnia, Paris 1856-78, t.11, $309 b$.

222. praedeterminate corr. 
reddendo utrumque impossibile ob negatam ad illa extrema libertatem. At vero neque hoc ipso modo potest Deus pro libito impedire absolutam ullius extremi liberi praescientiam ex suppositione, quod decreverit liberam facultatem creaturae concedere ad obiecti praesciendi determinationem.

304. Ex quibus sequitur, de scientia conditionata simpliciter verum esse, quod Deus ita illam habeat, ut non possit illam pro libito suo non habere: quum simpliciter non possit illam ullo suo libito impedire. ${ }^{223}$ Absolutam vero scientiam, quam impedire aliquo modo pro libito suo potest, nequit pro libito impedire ex suppositione libertatis concessae arbitrio creato ad obiectum suae scientiae, nec simpliciter potest ita impedire scientiam unius extremi liberi, ut pro libito suo habere possit scientiam oppositi extremi libertatis. Quum ergo scientia absoluta extremi liberi haberi a Deo non possit nisi ex suppositione decreti concedentis arbitrio creato libertatem, sequitur manifeste, Deum ut proxime potentem habere scientiam etiam absolutam futuri liberi, non posse illam pro suo libito impedire.

305. Ea ergo scientia pro arbitrii creati libito ponenda et determinanda est et consequenter praedeterminanda, id est - ex vi praeviae exigentiae obiecti creati - determinanda a creato $^{224}$ principio. Obiectum enim (ut saepe diximus) est [872r] exigentia divinae praescientiae sui, et est exigentia praevia, quia (ut ex dictis patet) creatum arbitrium est unicum principium libere electivum scientiae divinae per positionem obiecti illam determinate exigentis, et libere impeditivum eiusdem scientiae per positionem obiecti oppositi illam impedientis; at certum est (ex capite $9^{\circ}$ ), principium electivum eiusque electionem et principium libere impeditivum eiusque liberam non-impeditionem praecedere realiter ad impedibile et eligibile quando hoc non est ipsa electio, sed aliquid realiter distinctum ab illa -, eo quod sint ratio, cur existat id quod eligibile et impedibile dicitur, et ratio, cui attribuitur, quod illud existat, et, per quam respondetur directe quaerenti, cur existat. Nam quaerenti, cur Deus sciat, peccatum, v.g., existere, respondemus naturali et directa responsione: quia creata voluntas peccare vult. Sequitur ergo manifeste, per obiectum liberum praevie determinari divinam scientiam praedeterminatione pugnante cum formali eius libertate.

223. Vgl. Ludovicus Molina: Liberi arbitrii cum gratiae donis etc. Concordia Q. 14 art. 13, 52, 10, ed. J. Rabeneck, Oña-Madrid 1953, 340.

224. ab increato corr. 


\section{Caput 23. An ad hoc, quod scientia futurorum contingentium non sit formaliter libera, opus sit, illam non esse formaliter volitionem?}

306. Id discutere oportet, quia -

Contra superius dicta replicari potest $4^{\circ}$, scientiam divinam futuri contingentis esse formaliter electionem sui: ergo Deus illam ut actionem formaliter liberam exercet.

Consequentia legitima est, nam, cum duplex sit opposita extremorum libertatis creatae scientia, si utraque est formaliter electio indifferentiae, ad utramque erit indifferentia electiva ad libertatem sufficiens. Electiva enim indifferentia est, quae immediate determinabilis est per duas electiones seu volitiones oppositas.

Antecedens vero probatur, quia scientia futuri contingentis formaliter per se ipsam est complacentia et volitio sui. Etenim essentialiter connexa est scientia illa cum hoc. Quod est Deum in illa complacere et eius existentiam affective prosequi. Nulla autem est ratio ad distinguendum hunc affectum ab ipsamet scientia, quum non sint praedicata re ipsa opposita, Deum scire, et, velle suam scientiam: ut patet in scientia essentiali et amore eiusdem scientiae. Quae, in nostra doctrina, nullam habent virtualem oppositionem ac proinde eidem formalitati divinae scientiae sine ulla virtuali distinctione intrinseca ${ }^{225}$ conveniunt. Ergo similiter Deus per eandem formalitatem virtualiter intrinsece indivisibilem cognoscet futura contingentia et suam ipsam cognitionem amabit.

307. Si respondeat quis, etiamsi duae scientiae [872v] divinae de extremis oppositis creatae libertatis sint formaliter volitiones, attamen divinam indifferentiam ad illas habendas non esse indifferentiam libertatis, quia est indifferentia praedeterminanda extrinsece per obiectum: quia neutram ex illis scientiis potest velle Deus nisi pro libito arbitrii creati; ac proinde hoc, suo actu, praedeterminare extrinsece debet ad determinatam scientiam a Deo exercendam et ad volitionem cum illa virtualiter indistinctam, -

Contra: Nam, si divina scientia creati actus liberi sit formaliter volitio, arbitrium creatum nequaquam praedeterminabit extrinsece divinam scientiam, quia respectu illius nullam habebit prioritatem electivi principii talis scientiae. Haec enim suum proprium electivum principium habebit, si ipsa sit formaliter electio, nempe divinam voluntatem eligentem per ipsam.

225. Vgl. $\$ 438$. Antonio Perez war damals der Hauptvertreter dieses Distinktionstyps, in bezug auf den vor allem kontrovers war, ob mit ihm auch außerhalb der Trinitätstheologie argumentiert werden darf. Zum weiteren Kontext vgl. Historisches Wörterbuch der Philosophie s.v. „Virtualität I“, hgg. von J. Ritter / K. Gründer / G. Gabriel, Basel 1971-2004, Bd. 11, 1062-66. 
Non ergo magis praecedere poterit ad divinam scientiam creatum obiectum aut obiecti principium - quam scientia ad ipsum obiectum; ac proinde neutrum se habebit ut prius comparatione alterius, sed utrumque simul exercebitur ut duo actus liberi concomitanter inter se connexi.

Utraque consequentia patet, quia, si divina scientia existere non potest sine temporali obiecto, ita neque hoc sine eo, quod a Deo sciatur, nam Deo repugnat aliquid in tempore causare, quin ab aeterno intueatur id, quod causaturus est. Obiectum ergo creatum petens a Deo causari, petit essentialiter aeternam eius intuitionem terminare.

Praeterea, sicut creatum obiectum liberum est formaliter volitio et supponit integram causam activam sui indifferentem ad ipsum et oppositam volitionem producendam, sic similiter divina scientia. Ergo, sicut arbitrium creatum potest pro libito suo actum volitionis, quem exercet, suspendere - eo quod actus oppositus, quo suspendi potest, est formale libitum arbitrii -, ita similiter Deus pro libito suspendere poterit actum scientiae, quem exercet, quia potestatem habet ad suspensionem, nempe oppositam scientiae: quae est formale libitum Dei.

Et denique, sicut arbitrium creatum potest pro libito suo impedire divinam scientiam sui actus - eo quod possit immediate impedire actum ipsum, sine quo implicat esse scientiam illius -, sic etiam Deus ut indifferens ad hanc et illam scientiam - quae formales volitiones et libita Dei esse supponuntur - poterit pro suo libito impedire obiectum creatum, quia poterit pro libito impedire intuitionem illius: sine qua impossibile est, quod creatum obiectum existat.

Nulla ergo erit arbitrii - aut obiecti creati - liberi prioritas ad scientiam, sed pura concomitantia, si dicatur, duplicem scientiam oppositorum, ad quam divina [873r] virtus indifferens est, esse formaliter volitiones.

308. Ob haec mihi videtur,

$1^{\circ}$, necessarium esse ad hoc, ut divina scientia futurorum careat formali libertate, quod non sit formaliter volitio, sed virtualiter intrinsece distincta ab omni volitionis conceptu. Si enim volitio formaliter sit indifferentia divini principii ad ipsam, erit formaliter indifferentia volitiva. Quae formalem rationem principii liberi constituit, quum lumine naturali manifestum sit, indifferenter volitivum esse $l i$ berum. Quod autem contra hanc indifferentiam obiici posset, scilicet, illas scientias, etsi volitiones sint, haberi ex praedeterminatione obiecti creati, iam refutavimus [ $\$ \$ 292-93]$ probantes, nullam fore in obiecto creato prioritatem ad scientiam, sed parem duplicis exercitii - aequaliter suo principio electivo liberi - concomitantiam, si divina scientia sit Deo formale exercitium volendi.

Neque etiam obstat, posse conceptum intellectionis habere sibi formaliter identificatum obiectum volitionis: quia, licet hoc ita sit respectu alicuius specialis intellectionis et volitionis, attamen non repugnat, aliquam intellectionem divinam 
virtualiter distingui ab omni volitione: ut patet in intellectione notionali tam activa quam passiva, quarum neutra est volitio formaliter, sed solum identice ${ }^{226} \mathrm{cum}$ intrinseca distinctione virtuali ab omni volitione. Similiterque non repugnat, volitionem aliquam divinam ab omni intellectione distinctam virtualiter esse: ut patet in volitione notionali activa et passiva, quae solum identice intellectionis rationem participant. $^{227}$

309. Ex quo sequitur, ad intellectiones et volitiones in divinis distinguendas aut non distinguendas attendendum esse ad specialia praedicata, quibus constituuntur, et iuxta eorum quidditatem vel dandum esse formaliter intellectioni praedicatum volitionis - et e contra -, si capax sit illud secum formaliter identificandi, vel negandum, si incapax illius sit ob praedicati oppositi formalem continentiam. At praedicatum formalis necessitatis seu carentiae libertatis, quam scientia futurorum contingentium formaliter continet, opponitur virtualiter cum formali continentia praedicati volitionis, quia, si hoc haberet, esset scientia formaliter libera. Ergo necesse est illam non esse formaliter volitionem, sed virtualiter intrinsece ab illa distingui.

Dico „intrinsece“, quia non sufficit ad carendum formali libertate, quod scientia virtualiter extrinsece distinguatur a voluntate. Nam virtualis distinctio extrinseca non facit, ut praedicata opposita conveniant perfectioni, quae sic distinguitur, ut se [873v] habet intrinsece in se ipsa, sed secundum statum extrinsecum, quem habet in cognitione nostra; ac proinde, scientiam non esse volitionem, per distinctionem illam extrinsecam est, quod in cognitione nostra non exprimatur ut volitio, non vero, quod intrinsece in se ipsa ullo modo careat conceptu volitionis; ac proinde nec faciat ea distinctio, quod scientia non habeat formalem libertatem et quod re ipsa non sit libera, sed aliquo modo necessaria.

310. $2^{\circ}$ Dico, necessarium esse, quod scientia contingentium non sit formaliter volitio, ad hoc, ut obiectum scientiae sit ratio a priori, cur haec existat.

Hoc patet manifeste ex dictis, quia scientia contingentium ex praedicato volitionis esset aeque libera ac obiectum creatum. De se autem est aeque connexa cum obiecto ac obiectum cum ipsa. Ergo obiectum creatum aeque eligitur a Deo volente illud scire ac scientia ab arbitrio creato volente suum actum a Deo sciri; ac proinde defendi nequit - quod Patres communiter docent -, ideo Deum scire peccatum nostrum, quia nos peccare volumus, non vero e contra ideo nos peccare, quia Deus scit, nos esse peccaturos.

226. Zur Unterscheidung ,formaliter / identice' IoAnnes Duns Scotus: I Ord. dist. 8 q. $4 \$ 25$, Opera omnia ed. L. Wadding, Lyon 1639 / Repr. 1968, t.5, 771.

227. Weitere Andeutungen aus der Trinitätstheologie $\$ 439$. 
Si enim non esset prius, nos peccare, quam Deum scire, vel neutra causalis esset vera vel utraque aequaliter vera esset. Etenim, vel requiritur ad veritatem illius causalis, ut id, quod assignatur pro causa et ratione, cur sit aliud, prioritatem habeat respectu illius, vel non? Si requiritur: ergo peccatum, quod a Patribus assignatur pro ratione, cur Deus illud sciat, debet esse prius quam scientia. Si vero non requiritur: ergo eodem iure dicetur, nos peccare, quia Deus scit, nos esse peccaturos, $\mathrm{ac}^{228}$ Deum scire peccatum, quia peccaturi sumus. Cum ergo utrumque hoc verum non sit, sed solum, quod Deus ideo scit, nos esse peccaturos, quia peccaturi sumus, necesse est, prius esse, quod nos peccemus, quam, quod Deus sciat, nos peccare, et nobis tribui, quod Deus sciat, ut libere scientiam determinantibus, et non sic tribui Deo. Tribueretur autem (ut probavimus), si divina scientia esset formaliter volitio. Quam Deus libere a se ipso habens esset sciens peccatum, quia illud libere scire vellet, non, quia ab alio, sine propria libertate, determinatur ad sciendum.

311. $3^{\circ}$ Dico, aliis quoque titulis repugnare plurium futurorum scientiae, quod sit formaliter volitio sui, v.g. scientiae futuri peccati. Deo enim repugnat velle absolute scientiam peccati nisi ex suppositione peccati per ipsam scientiam praevisi. Ex hac quidem suppositione potest ipsi placere, quod detur scientia, simpliciter vero, non facta et praecognita peccati suppositione, repugnat, Deum absolute velle scire, quod peccabimus: quia hoc esset [874r] a se ipso absolute velle illam scientiam, id est, sine ulla a nobis oblata occasione ob quam praecognitam velit; at, Deum a se absolute velle scire, quod peccabimus, repugnat; nam Deus simpliciter, quantum est de se, vult, ne peccemus: ergo, quantum ex se est, vult dari omnia sine quibus impossibile est, dari finem illum non-existentiae peccati; at impossibile est, dari non-existentiam peccati, existente divina praescientia illius: ergo Deus, quantum est ex se, vult hanc non existere. Implicat ergo, quod, quantum est ex se - scilicet nulla a nobis data et ab ipso praevisa occasione peccati absolute -, velit scientiam illius existere. Sic autem vellet peccati scientiam (ut dixi), si ipsa scientia formaliter esset volitio sui, quia tunc volitio non esset habita ex suppositione scientiae, sed esset formalis positio voluntaria scientiae. Hanc ergo necesse est volitionem sui formaliter non esse.

312. Dices, Deum, etsi velit, quantum est de se, ne sit peccatum, non ideo debere velle, quantum est ex se. Nam peccatum vult non esse, quia est obiectum, in quo iuste displicet. In scientia autem sua displicere non potest.

Sed contra, quia Deum - quantum est ex se - velle, ne homines peccent, non consistit in peccatorum displicentia. Nam plura nobis displicent, de quibus nolumus, ne sint, sed potius saepe volumus a nobis, quod sint, quia, licet displiceant in se spectata, requiruntur tamen ad alia quae placent. Et e contra, plura quae in 
se spectata nobis placent vel saltem non displicent simpliciter - quantum ex nobis est -, volumus, ne sint, quia non possunt sine aliis quae plus displicent existere. Non ergo sufficit, Deum displicere in peccato, nisi haec displicentia specialem oppositionem cum peccato habeat, tam in se quam in connexis cum illo, ut simpliciter dicatur velle - quantum ex se est -, ne sit peccatum.

313. Dices, Deum ita displicere in peccato, ut non possit illud velle, et ideo, quantum est ex se, velle, ne sit.

Sed neque hoc sufficit, quia plus est velle, ne peccatum sit, quam, in illo displicere et non posse ipsi placere, quod sit. Etenim, etsi quis vel a sua voluntate vel a divina praedeterminatione impeditus sit, ne possit crudelem alterius occisionem, v.g., directe velle, si tamen velit a se ipso aliquid essentialiter connexum cum illa, non potest dici, quod - quantum ex se est - nolit occisionem. Irridendus enim esset qui diceret, se optare - quantum ex se est -, ne alius occidatur, sed tamen efficaciter velle eius mortem intueri non ex conditione, quod accidat, sed absolute et nulla facta suppositione; vel, qui diceret „Quantum est ex me, volo, ne homo moriatur, volo tamen absolute, quod resurgat“, vel „Volo, quod non [874v] peccet, ita tamen, ut pro peccato puniendus sit“: quia hoc esset aliquem - quantum ex se est - absolute velle contradictoria et tam dignum esse risu, ac si diceret, se velle, quod aliquid existat in tempore, et tamen, quod non producatur a Deo, vel, quod sit homo, et non sit animal rationale. Quum non magis haec quam illa contradictorie pugnent.

314. Ratio autem a priori praecedentis doctrinae est: Nam qui - quantum ex se est plus recedit affective ab aliquo fine, v.g. carentia peccati, quam ad illum accedit, non potest dici, quod finem illum - quantum est ex se - velit esse potius quam non esse; sed qui a se ipso vult aliquid efficaciter fini illi essentialiter oppositum, plus recedit a fine quam accedit, etiamsi habeat complacentiam in fine et displicentiam in eius directo contradictorio: ergo, qui a se efficaciter vult aliquid oppositum essentialiter fini constituto in carentia peccati, non potest dici, quod illum finem - quantum est ex se - velit, etsi complacentiam in illo habeat et displicentiam in eius directo contradictorio, scilicet in peccato.

Maior, et consequentia manifesta sunt.

Minor autem patet, quia, qui efficaciter vult a se ipso aliquid contradictorie pugnans cum peccati carentia, ad summum potest affective ${ }^{229}$ ad illam accedere, per simplicem complacentiam, non enim potest carentiam illam efficaciter velle, nec in se ipsa nec in alio connexo cum illa. Sed qui efficaciter vult contradictorium illius finis carentiae peccati, multo magis opponitur effective cum illo fine, quam

229. effective corr. 
ad illum accedit per complacentiam simplicem, quia recessus ille affectivus est ${ }^{230}$ inefficax. Ergo magis recedit quam accedit, qui eiusmodi affectum habet. ${ }^{231}$

315. Hinc patet, ut Deus - quantum ex se est - velit peccati carentiam, ipsum ${ }^{232} \mathrm{de}$ bere nec peccatum in se velle nec ex se efficaciter velle absolute aliquid essentialiter pugnans cum peccati carentia. Sicut volens omnes homines salvos fieri, non potest a se aliquid velle eorum saluti repugnans, et nolens peccatoris mortem non potest a se velle aliquid inevitabiliter connexum cum illa. Hic est modus volendi salutem et nolendi peccatum, ob quem Deus iure laudatur et extollitur in divinis litteris, nec sane ulla laude dignus esset neque nobis ut a malis nostris aversus aut ad bona nostra conversus amabilis, si cum bonorum existentia et malorum carentia contradictorie pugnantem affectum ex se haberet, etiamsi dicatur, mala nostra ipsi displicere et placere bona. Sed de his latius dicemus libro $10^{\circ}$ ostendentes, quod velle aliquid cum peccato essentialiter connexum sine peccati praevisa suppositione est inordinatum affectum habere, quia nil sic connexum habet rationem boni nisi occasionati - ex occasione scilicet - et non sine [875r] illius praevisa suppositione recte volibilis.

316. Denique necesse est praescientiam saltem conditionatam non esse formaliter volitionem sui, ut possit utilis esse ad concordiam libertatis cum absoluta operationis liberae praedestinatione per efficacem praefinitionem. Quia non esset suppositio consequens libertatem nostram, sed per divinam libertatem existens. Ex quo etiam fieret, illam non esse mediam inter liberam et necessariam, sed formaliter per se liberam.

Quae omnia in nostris principiis absurda sunt.

317. Conclusiones omnes hactenus traditae confirmari possunt ex eo, quod, si quis diceret, Deum - supponendo tantum cognitionem mali et boni ut possibilium velle per decretum antecedens habere scientiam peccati futuri, si haec aut illa conditio ponatur, et, ex suppositione decreti conditione ponenda, eligere (similiter per decretum antecedens ad absolutam scientiam) scire absolute peccatum et non bonum illi oppositum - ita, ut libera volitio, quam Deus a se ipso concipit, sit causa impediens scientiam boni et ponens scientiam mali -, nemo, ut credo, ex negantibus praedeterminantia decreta ad bonum et malum dubitaret, sic asserentem et peccare in Dei sanctitatem et in libertatem creatam. At idem prorsus est, Deum velle a se illas scientias habere per decretum antecedens, ac, illas velle per semetipsas

230. efficax et del.

231. Die, in der Handschrift verunglückte, Entgegensetzung, affectus / effectus' z.B. bei Durandus a S. Porciano: In Sententias theologicas commentaria: III Sent. dist. 29 q. $1 \S 10$, Venedig 1571, 263vb.

232. ipsum suppl. 
tanquam per formales volitiones, quas Deus a se habet. Nam aeque voluntarie et libere electa erit scientia illa per se ipsam, si ipsa sit formaliter electio, ac si electa esset per antecedentem actum, sicut aeque voluntarie et libere eligimus amare - et non odio habere -, quando exercemus immediate amorem, qui est electio sui, ac, quando illum per electionem distinctam et antecedentem volumus. Eodem ergo iure repugnabit, scientiam esse volitionem sui, ac, ab antecedente sui volitione ortam.

318. Ex dictis ergo concludimus veritatem resolutionis, qua ad quaestionem in titulo propositam respondimus, scilicet, ad hoc, ut scientia formali libertate careat et ad obiectum, tanquam ad praedeterminationem sui, subsequatur, opus esse, quod non sit formaliter electio, qua principium divinum ad duplicem scientiam oppositam indifferens velit hanc determinate et non illam habere. Ex quo colligitur, Deum habere singularem indifferentiam nulli creaturae communicatam, vi cuius sit adaequatum principium effectivum duplicis actus oppositi, quorum nullus sit volitio formaliter. In creatis enim, [875v] ubicumque invenitur activa indifferentia ${ }^{233} \mathrm{com}$ plete indifferens ad duos actus, uterque est formaliter electio, quia non invenitur integrum principium activum creatum attemperatum alteri electivo principio, pro cuius libito operari debeat. Creatum enim principium ab alterius electione dependens in operando eget illo ut virtutem propriam suam complente ad operandum, et ideo sine illo non habet virtutem completam; ac proinde in creatis completa virtus indifferens ad duo electiva est, virtusque completa non electiva semper ad unum determinata invenitur.

Ex quo sequitur (quod paulo ante statuimus), virtutem completam activam indifferentem ad duos actus et non electivam per illos esse perfectionem, quam creaturis communicatam non videmus. Eam vero fundamus in divina perfectione cognoscendi, quae non eget ullo alio ad cognoscendum futurum contingens nisi ipsa huius existentia. Eget autem illa non ut influente in eius cognitionem, sed ut pure illam terminante, et ita ad illam terminatur, ut vi eiusdem divini principii et virtutis cognoscitivae, qua cognoscit unum extremum futurum, posset terminari ad oppositum, si illud Deo conspiciendum a creato arbitrio obiiceretur. Libertas haec arbitrio concessa ad obiectum scientiae, et vis intellectiva divina ad quodvis obiectum futurum sciendum per ea praecise quae sufficiunt ad esse talis obiecti, facit, ut divina scientia oriatur a principio adaequato activo sui ut indifferenti in ratione principii per omnia, quae eius virtutem ut ordine naturae antecedentia complent, ad illam scientiam et oppositam, et tamen, quod non oriatur ab illo principio ut electivo scientiae, quam habet, sed, quod tota ratio electivi talis scientiae et, per electionem, praedeterminantis ad illam, creato arbitrio tribuenda sit.

233. Zu ,indifferentia activa' vgl. Franciscus SuArez: Varia opuscula theologica 1, 1, 3, 1, Opera omnia, Paris 1856-78, t.11, 13b/14a. 
319. Ex quibus tandem colligere licet, divinam praescientiam contingentem - tam conditionatam quam absolutam -, qua Deus obiecta aliqua libera cognoscit, quin illa per decretum ex se efficax praedefiniat, habere intrinsecum quendam tendendi modum, qui sensu aliquo nequaquam incongruo medius dici possit inter liberum et necessarium, licet, magis proprie loquendo, necessitatem ex praesuppositione participare dicatur. Quae tamen necessitas, ex intrinseco modo tendendi utriusque praescientiae, non obstat, quominus absoluta dicatur libera ex parte Dei - quod intelligendum est praesuppositive, quia haberi non potest sine praesupposito exercitio divinae libertatis -, nec quod conditionata dicatur media inter liberam - hoc modo sumptam - et necessariam: pro ea, quae talis est simpliciter, absque ulla libera suppositione.

Totam huius illationis doctrinam [876r] invenies explicatam et probatam libro $2^{\circ}$ capite $10^{\circ}$ conclusione 4 .

\section{Caput 24. Concordia certitudinis divinae praescientiae futurorum contingentium cum creata libertate}

320. Concordiam hanc ita impossibilem iudicaverit Cicero lib. $2^{\circ}$ De Divinatione, et etiam $2^{\circ}$ lib. De natura Deorum, aliique plurimi - inter quos multi ex Patribus et Theologis recensendum iudicant Aristotelem, quem tamen alii ab eo errore liberum satis probabiliter defendunt -, ut Deo negaverint futurorum praescientiam, ne creaturis negarent operandi indifferentiam, ideoque, ut Augustinus lib. $5^{\circ} \mathrm{De}$ Civitate cap. 9 ait, ${ }^{234}$ homines fecerunt sacrilegos, ut facerent liberos.

Ex adverso vero STOICI, ne Deos ignaros futurorum concederent, omnia ab illis effata et praescita fatali necessitate evenire dixerunt. Licet enim multi fatum in astrorum, sub quibus nascimur, dominatu posuerint, ut constat ex AUgustino, libro illo $5^{\circ}$ cap. 1 , at fati defensorum plures et peritiores eam fatalem necessitatem ex Deorum effatu - decretis scilicet et scientia - emanare et per sidera ad mortales derivari dixerunt, ut ibidem notat Augustinus, et de Cleanthe ${ }^{235}$ specialius notavit cap. 8, eum fati necessitatem in divina voluntate constituisse. Nam relatis illis eius carminibus „Duc me, summe Pater etc.“ ait: ${ }^{236}$ „Nempe evidentissime ea ,fata' appellavit, quam supra dixerat summi patris voluntatem. “ Hi ergo, ut fatalem infallibilitatem a divina scientia ortam defenderent, humanam libertatem inficiati sunt.

234. Augustinus: De civ. Dei V, 9, 2, PL 41, 150.

235. Richtig: Seneca.

236. Augustinus: De civ. Dei V, 8, PL 41, 148. 
321. Utrosque tamen errare, non solum Fidei, sed etiam rationis luce manifestum est, cum Fides et ratio ostendant, Deum nihil ignorare eorum quae ab hominibus aguntur, et homines nulla agi necessitate in bonis praesertim et malis quibus laudem merentur et vituperium. „Ideo nullo modo cogimur", ait Augustinus citato lib. $5^{\circ}$ De Civitate cap. 10, „aut retenta praescientia Dei tollere libertatis arbitrium, aut retento voluntatis arbitrio Deum“ - quod nefas est - „negare praescium futurorum, sed utrumque amplectimur, utrumque fideliter et veraciter confitemur: illud, ut bene credamus, hoc, ut bene vivamus. “237

Modus autem conciliandi certitudinem praescientiae cum potestate agendi et non agendi id, quod Deus agendum esse praescivit, Ochamo, Gregorio, GABrieLI et caeteris Nominalibus ad distinctionem 38 lib. $1^{\circ}$ Sententiarum inexplicabilis videtur. Quibus consentit CaIeTanus Prima parte q. 22 art. $4 .{ }^{238}$

322. Ratio difficultatis reducenda est ad influxum determinatum in futurum obiectum, qui ex praescientia illius ab aeterno habita derivandus [876v] videtur. Nam praescientia habita ab aeterno Deus procedit in tempore ad agendum ex praescientiae certitudine. Ex illa autem influens non potest non determinare ad unum et repugnare cum eius opposito: ut repugnat certitudo cum non-esse, immo cum contingentia, eius quod certo praenoscitur. Dixi, ad hunc influxum reduci debere difficultatem concordiae: nam, si supponat quis, scientiam illam non influere ullo modo, ut effectus liber existat, nec, Deum vi huius scientiae et eo fine, ut eius certitudo firma subsistat, concurrere ad obiecti positionem, non est, cur ulli difficilis appareat concordia, ut dicemus.

323. Tria mihi de hac concordia videntur:

Primum, improbabiliter et non sine temeritatis periculo dici, quod non valeat in hac vita sufficienter explicari concordia certitudinis praescientiae divinae futurorum contingentium cum arbitrii creati libertate.

Secundum est, hanc concordiam praesuppositive difficilem esse, scilicet in quidditate ipsius divinae praescientiae futurorum. Quam ostendimus consistere in eo, quod Deus illa in se ipsis ut obiecto materiali determinativo, et in divina essentia simul cum indifferenti decreto tanquam in motivo, cognoscat.

Tertium est, ea quidditate supposita nullam esse in concordia intelligenda difficultatis occasionem, quia ex hac quidditate eam manifeste probant et explicant Patres et Theologi.

237. Augustinus: De civ. Dei V, 10, 2, PL 41, 153.

238. Autorenkatalog nach Didacus RuIz de Montoya: Commentarii ac Disputationes de scientia Dei 30, 1, 1, Paris 1629, 246a. Mit „caeteri Nominales“ bezieht sich Wadding auf die dort außerdem genannten Adam Wodeham und Marsilius de Inghen. 
324. Primum satis constabit ex secundi et tertii asserti probatione. Constat etiam ex communi caeterorum fere Scholasticorum et Patrum consensu, qui ita contra ethnicos et haereticos agunt, ut putent, negantes praescientiam Dei - ob libertatem creaturae -, vel libertatem - ob praescientiae certitudinem - non recte intelligere, ignorare, insanire. Primum habes in Anselmo, tractatu De Concordia Praescientiae cum Libertate cap. 1: „Nequaquam recte intelligenti haec repugnare videntur: praescientia, quam sequitur necessitas, et libertas arbitrii, a qua removetur necessitas, quoniam et necesse est, quod Deus praescit, futurum esse, et Deus prae-

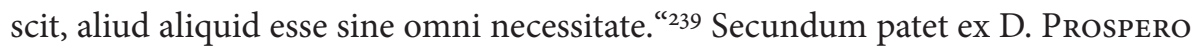
lib. $2^{\circ}$ De Vocatione Gentium cap. 34 , ubi relata obiectione contra hanc concordiam ait: ${ }^{20}$ "Sed qui se ingeniose hoc arbitrantur opponere, non intelligunt scientiam Dei.“ Tertium vero ex Augustino lib. $3^{\circ}$ De Libero Arbitrio cap. 2: „Quisquis“ - ob arbitrii libertatem - „dixerit, aliter evenire posse aliquid, quam Deus ante praescivit, praescientiam Dei destruere insanissima impietate molitur.“241 In negantes ob difficultatem concordiae aliquod extremum ex discordibus non possent prudenter invehere Patres nec eos „ignorantes“ aut „insanientes“ appellare, ${ }^{242}$ nisi iudicarent, concordiam esse explicabilem, nec eam tam Patres citati quam Iustinus Martyr, Magnus Athanasius, [877r] Chrysostomus, Cyrillus, Alexander, Hieronymus, Epiphanius, Damascenus et alii Patres, quorum testimonia profert Ruiz disp. 33 De Scientia Dei, necnon et D. Thomas, D. Bonaventura eorumque Magistri Alexander, et Albertus cum caeteris scholasticis tot argumentis explicare et suadere conarentur hanc concordiam, si eam inexplicabilem putarent. Etenim in eius explicatione non solum se ab obiectis telis muniunt - vel quod in ipso Trinitatis mysterio et in quibuscumque abstrusis Theologus, ne suo desit muneri, praestare tenetur, iuxta illud PeTRI 1, 3 [v. 15] „parati semper ad satisfactionem omni poscenti vos rationem de ea, quae in vobis est spe et fide“, ut eo loco ${ }^{243}$ legit et probat S. Thomas -, sed etiam validissima tela in adversarios contorquentes rationum vi concordiam hanc agnoscendam evincunt; eamque persuasibilem et explicabilem ratione naturali esse, vel ex eo mihi evidens videtur, quod evidens sit, utrumque extremum - nempe, Dei praescientiam et libertatem creatam - existere:

239. Anselmus Cantuariensis: De concordia praescientiae et praedestinationis et gratiae Dei cum libero arbitrio 1, 1, Opera omnia vol. 2, 246. Waddings Zitat folgt dem Wortlaut bei RUIZ DE Montoya: De Scientia Dei 32, 1, 16, p. 260 .

240. Prosperus Aquitanus: De vocatione omnium gentium II, 34, PL 51, 719. Zitiert bei RuIZ De Montoya: De Scientia Dei 33, 3, 17, p. 269a.

241. Augustinus: De libero arbitrio III, 2, 14, PL 32, 1272.

242. compellare corr.

243. loci corr. 
ergo evidens est, eas recte inter se cohaerere. Quod autem evidenti ratione probatur esse possibile et existere, sufficienter explicabile iudicari debet per attentam eiusdem evidentiae considerationem.

325. Secundum vero ex tribus propositis [ $\$ 323$ ] patet ex disputatis toto hoc libro. Ex iis enim constat, quam difficile intelligatur certa notitia futuri contingentis aeternitate praecedens eius existentiam, nulli innixa aeterno praedeterminativo, solum temporalem terminationem requirens non ut iuvante nec cognoscitivam potentiam Dei complente, sed eius potentiam - ex se completam ad duos actus scientiae oppositos - determinante ad unum potius quam alterum exercendum, quin haec determinatio concessa obiecto vel indifferentia cognoscitiva, quam agnoscimus in Deo, faciat, quod vel obiectum ullam exerceat causalitatem erga cognitionem Dei, vel Deus formalem aliquam libertatem in habenda huius potius quam oppositi futuri praescientia exerceat. Difficilia haec intellectu esse, quis dubitet? Sunt autem aeque difficilia: prioritas futuri ad divinam scientiam eiusque prioritatis aeternum exercitium sine aeterna ulla existentia obiecti aut ullius praevii determinativi, quod eius vice scientiam determinet; eiusdem prioritatis temporale exercitium, quo obiectum liberum petit existere vi causae creatae, quae, licet temporalis sit, habeat in sua potestate, quod fuerit aut non fuerit aeterna scientia sui actus, ut principium electivum et libere impeditivum talis scientiae. Haec et alia quae de quidditate scientiae divinae contingentium hactenus discussimus, [877v] sunt fundamentum concordiae ipsius cum arbitrii creati libertate. Cum ergo ea quidditas intellectu difficilis sit, non potest absolute concordia censeri facilis.

326. Tertium vero probatur ratione fundamentali, quam desumo ex Divis Augustino et Anselmo.

Augustinus autem lib. $5^{\circ}$ De Civitate Dei (ad finem) ait: „Neque enim ideo peccat homo, quia Deus illum peccaturum esse praescivit: imo ideo non dubitatur ipsum peccare, cum peccat, quia ille, cuius praescientia falli non potest, non fatum, non fortunam, non aliquid aliud, sed ipsum peccaturum esse praescivit. Qui si nolit, utique non peccat: sed si peccare noluerit, etiam hoc ille praescivit." ${ }^{244}$ IDEM lib. $3^{\circ}$ De Libero Arbitrio cap. 3 (fine) ait: „Non igitur per Dei praescientiam mihi potestas adimitur, quae propterea mihi certior aderit, quia ille, cuius praescientia non fallitur, adfuturam mihi esse praescivit. ${ }^{245}$ Quibus verbis duplicem agnoscit necessitatem: aliam, quam libertas excludit, nempe eam, quae causa est, quod peccemus aut bene operemur; aliam, quam adducit scientia, quae scilicet non adimit potestatem oppositi eius quod cognoscit, sed potius eam petit; ac proinde, nullam

244. Augustinus: De civ. Dei V, 10, 2, PL 41, 153.

245. Augustinus: De libero arbitrio III, 3, 8, PL 32, 1275. 
esse impossibilitatem negationis obiecti nisi eam, quam veritas ipsa per scientiam affirmata - nempe, quod obiectum erit - exigit. Quae est impossibilitas consequens.

Idem docuit Anselmus tractatu De Concordia Praescientiae cum Libero [Arbitrio] cap. 1 sub initio: „Nequaquam recte intelligenti haec repugnare videntur: praescientia quam sequitur necessitas et libertas arbitrii, a qua removetur necessitas, quoniam et necesse est, quod Deus praescit, futurum esse, et Deus praescit, aliud aliquid esse sine omni necessitate. ${ }^{\text {246 }}$

Ex quibus fundamentalem concordiae rationem sic efformare possumus:

Etsi praescientia infallibilis secum afferat necessitatem existentiae obiecti quod affirmat, et libertas eiusdem obiecti auferat necessitatem, attamen non affert scientia necessitatem eandem, quam libertatis conceptus aufert, sed aliam, quam admittit. At nulla est discordia auferentis et afferentis necessitatem, quando non contendunt de eadem auferenda et afferenda. Ergo nulla potest esse discordia praescientiae divinae et libertatis creatae.

Minor et consequentia evidentes sunt.

Maior vero probatur, quia necessitas operandi, quam affert scientia futuri contingentis, non est necessitas antecedens - quae faciat illud existere, id est, quae, quatenus causa potens facere, quod existat, sit determinata ad eius existentiam et repugnans cum eius carentia -, sed necessitas operandi consequens ad causam et praerequisita omnia, et quam proinde ipsa causa operando facit: nam, cum omne quod est, dum est, necesse sit esse, eo quod non possit simul esse et non esse, causa, quae operando facit operationem existere, facit in operatione consequentem et causatam necessitatem essendi ab ipsa operatione indistinctam; at libertas non removet ab operatione necessitatem consequentem, immo illam omnino admittit et solum excludit antecedentem: ergo necessitas, quam affert scientia, non est ea, quam excludit libertas, sed alia longe diversa.

Consequentia est evidens, minor vero indubitata et satis probata libro $2^{\circ}$ a capite 8 .

327. Maior autem probatur, quia, ut divina scientia necessitatem afferret plus quam consequentem, opus esset vel illam imponere per se ipsam vel illam supponere aliunde positam; at neutrum praestat: ergo non antecedentem, sed solum consequentem, sui obiecti necessitatem affert.

Maior et consequentia evidentes sunt.

Minor autem probatur, nam divina scientia imprimis non supponit aliunde necessitatem nec - quod idem est - praedeterminatam nostram operationem. Nam eo ipso, quod dicatur, eam videri a Deo contingentem, necesse est videri, quod prodeat

246. Anselmus Cantuariensis: De concordia praescientiae et praedestinationis et gratiae Dei cum libero arbitrio 1, 1, Opera omnia vol. 2, 246. 
a principiis carentibus praevia necessitate ad illam et consequenter carentibus determinatione omnino praevia ad operationem: quia haec determinatio necessitas operandi est, cum sit impossibilitas non-operandi, estque necessitas praevia, cum praecedat natura operationem. De quo late libro $2^{\circ}$.

Deinde, nec [878r] ipsa praescientia futuri imponit antecedentem necessitatem, ut futurum existat, quia ipsa non facit existere futurum:

$1^{\circ}$ Quia non est futuri causa, sed intuitio et praenotio, quae contemplatur existentiam futuri ab aliis causis positam (ut libro praecedenti ostensum est). Idque probant omnes rationes, quibus libro $2^{\circ}$ ostendimus, nil determinate connexum cum futuro contingenti posse esse praerequisitum ad illud; scientia autem futuri est determinate connexa cum illo. Deinde, quia specialis est deformitas in causando futuro quod est in se pravum. De quo plura contra praedeterminationes pravorum actuum libro $2^{\circ}$ a capite $[\ldots]^{247}$ diximus.

$2^{\circ} \quad$ Quia futurum supponitur ad divinam scientiam contingentium - cum ideo illa cognoscat Deus, quia futura sunt, non e contra (ut libro praecedenti ostensum est) -, et quia eo ipso, quod in potestate arbitrii creati constituatur esse et non-esse obiecti scientiae, haec debet in illius electione posita esse (ut a capite $9^{\circ}$ huius libri ostensum est); id autem repugnaret, si praescientia deberet per modum causae antecedere ad creatae voluntatis operationem, aut praescientia ${ }^{248}$ necessitatem ${ }^{249}$ imponeret ad eligendum: quia potestas electiva et impeditiva scientiae essentialiter requirit, quod eligibile et impedibile per operationem talis potentiae sit posterius quid ad ipsam et ad eius operationem. Manifeste ergo concluditur ex quidditate praescientiae futurorum, quod necessitas, quam affert aut requirit in suo obiecto contingenti, non sit ea, quam aufert ab obiecto libertatis conceptus, et consequenter, quod nulla sit discordia certitudinis praescientiae cum contingentia obiecti.

328. Sed contra rationem hanc obiicies duo:

Primum est, scientiam effectus duratione praecedentem in eo, qui effectum causaturus est, non posse illum non instruere de effectus productione, et consequenter, causantem debere dirigi vi illius in productione. Debet ergo scientia illa natura praecedere effectum: ac proinde ad illum determinare causaliter.

Utraque haec consequentia legitima est.

Antecedens vero patet, quia aggrediens actionem aliquam non potest non dirigi a notitiis, quas actualiter habet de tali actione. Alias posset quis aggrediens

247. Textlücke.

248. praescientiam corr.

249. necessitate corr. 
actionem, quam scit esse prohibitam, nolle uti directione talis scientiae, sed ita actionem exercere, ac si prohibitionis notitia careret, ac proinde non peccare. Qui enim actionem non exercet ex scientia prohibitionis, non peccat in eius exercitio.

329. Secundum est, rationem Nostram fundari in subsecutione divinae praescientiae ad creatum obiectum [878v] liberum. At haec subsecutio necessaria non est ad concordiam. Ergo ratio NosTRA principio saltem non necessario innititur.

Minor patet, quia sufficiens concordia est inter necessitatem, quam requirit scientia in obiecto, et libertatem per hoc, quod scientia requirat solam necessitatem consequentem, et libertas solam antecedentem excludat. Ad hoc vero non requiritur scientiam ipsam esse consequentem ad obiectum, sed necessitatem, quam in illo requirit, esse consequentem. Hanc enim potest scientia requirere in obiecto suo per hoc, quod nec determinatio ad obiectum, quam scientia includit, sit causa seu requisitum natura praecedens obiectum, nec aliud determinate connexum respiciat quod sit natura praecedens ad tale obiectum, sed potius omnis determinati praecedentis natura exclusionem petat. Id autem potest petere scientia, quamvis non sit consequens obiectum, sed concomitans ad ipsum (ut ex libro praecedenti constat). Ergo subsecutio scientiae ad obiectum nequaquam necessaria est ad concordiam certitudinis praescientiae cum obiecti contingentia.

330. Ad primum $[\$ 328]$ respondetur supponendo, vim determinativam agentis ad causandam obiecti existentiam non posse provenire praecise ex eo, quod scientia, quae habetur de effectus existentia, praecedat duratione existentiam effectus: nam, quod praecesserit, nihil refert, si, dum producitur effectus, non existat scientia. Si vero existat, dum actu producitur effectus, nil refert in ordine ad influendum et consequenter in ordine ad determinandum, quod praecesserit duratione. Quod enim per se conducere potest ad effectum, est actualis existentia sui principii influentis. Unde, si hoc est vi sua determinans, id habebit per actualem existentiam, etsi non praecesserit antea, quin possit ob praecedentiam in duratione actualis existentia determinare, si absque illa vim determinandi non habet. Non ergo magis exiget divina praescientia obiecti efficiendi, quod Deus per illam influat et causaliter determinet, quam scientia, qua artifex eodem instanti quo operatur, suum contemplatur artefactum.

331. Si autem respondeat quis, cognitionem, quae duratione praecessit in agente ad effectus productionem, speciali titulo exigere praecedentiam naturae, si perseveret usque ad effectus productionem, -

Refellitur manifeste responsio: tum, quia voluntaria est omnique fundamento destituta, tum, quia repugnat philosophiae principiis. Ex quibus certum est, actionem intentionalem, etsi duratione praecedat suum obiectum, posse illud non praecedere natura: eisdem de causis ob quas cognitio simul existens et incipiens cum 
obiecto potest non praecedere natura ad illud. Cum enim cognitio praecedens duratione possit obiectum futurum contemplari ut praesens et ipsum, non ut sit, sed, quia est, intueri - eodem modo, quo cognitio cum obiecto incipiens -, poterit etiam eisdem titulis impediri a causalitate et praecedentia naturae respectu sui obiecti ac cognitio non-praecedens, sed concomitans, duratione obiectum. [879r]

\section{Hoc supposito:}

Primum: Quod rationi NosTRAe obiicitur, inaniter obiici potest a paritate cognitionis simultaneae de actus liberi existentia. Hanc enim habet, qui libere exercet actum, cum non possit libere amare, v.g., quin se amare experiatur. Haec autem experimentalis scientia amoris, etsi eodem instanti, quo amamus, habeatur, nec instruit nec dirigit amantem nec ullam veram prioritatem erga amorem exercet.

$2^{\circ}$ A priori, quia cognitio amoris existens in amante, dum amat, etsi antea extiterit, potest esse incapax de se influxus et directionis: ergo potest esse in amante, quin dirigat aut praecedat.

Antecedens patet, quia potest esse pure speculativa - cognoscens, quid agatur - et non practica iuvans operantem, ut agat. Potest enim cognitio existentiae effectus illum considerare ut existentem vi aliorum principiorum et cognitionis, quin proponat, obiectum illud esse vi talis cognitionis volibile aut operabile a cognoscente, sed potius oppositum. Practica autem et operativa cognitio existentiae obiecti debet proponere illud ut - vel directe, vel reflexe - volibile et operabile vi ipsiusmet cognitionis et non solius cognitionis ab ipsa distinctae. Hoc sensu intellige vulgatum illud, quod operativa cognitio non solum debet cognoscere operationem, sed et cognoscere illam modo operabili, id est, proponere, quod vi ipsius operabilis sit. Evidens autem est, posse amantem, dum amat, et prius duratione, quam amet, habere scientiam sui amoris, quae illum non cognoscat ut operabilem vi talis scientiae, sed potius ut inoperabilem per illam et operabilem - vel operatum - vi alterius cognitionis.

333. Hinc patet, frivolum esse, quod opponitur de cognitione prohibitionis. Quando enim haec repraesentat actionem prohibitam ut operabilem aut impedibilem vi talis notitiae, non potest non exerceri actio dependenter a cognitione prohibitionis. Quando vero non sic repraesentatur, potest actio exerceri independenter a cognitione prohibitionis et inculpabilis esse, licet prohibitio cognoscatur. Quid enim refert, hanc cognosci, si ita cognoscatur, ut iudicetur, vi notitiae prohibitionis non posse cognoscentem velle abstinere ab actione aut illam aggredi, sed potius non posse: vel, quia cognitio prohibitionis respicit actionem ut exercitam vi alterius adaequati principii et cognitionis, vel, quia aliud, a Deo aut a natura cognitionis positum, agnoscatur impedimentum ad agendam aut suspendendam actionem vi praedictae cognitionis? 


\section{Ad rem ergo nostram:}

Deus, etsi cognoscat ab aeterno existentiam futurae actionis liberae, non potest vi talis cognitionis ad futurorum productionem dirigi nec per illam constitui in actu primo productivus futuri, quia scientia illa capax non est ad dirigendum nec ad praecedendum natura obiectum libere producendum ab obiecto creato.

Ratio autem huius incapacitatis non est: quia [879v] scientia illa cognoscit existentiam; quae autem capax est dirigendi ad alicuius productionem, non debet affirmare eius existentiam, sed tantum possibilitatem.

Nam haec ratio deficit in multis quae fiunt per cognitionem, qua cognoscuntur existere. Verbum enim divinum per cognitionem suae existentiae producitur, et etiam creaturae, quas Deus decreto de se efficaci statuit producere. Licet enim ad illas decernendas non praecedat scientia affirmans illarum existentiam, sed solum affirmans, quod possunt esse, et, quod Deus potest illas decernere, at, cum non sola haec scientia, sed etiam decretum subsequens ad illam praecedat et causet operationem, scientia quoque huius decreti ad futuri existentiam praecedere debet, vel, quia indistincta virtualiter est a decreto, vel, quia, licet distincta dicatur, aptissime potest praecedere, cum Deus vi decreti sui ut sibi noti et consequenter vi notitiae existentiae obiecti decreti, quam in illo habet, determinetur ad volendum exequi quod decrevit.

335. Ubi adverte, Deum duo genera futurorum efficaciter decernere. Primum est omnium, quae sine arbitrii creati libertate fiunt; aliud aliquorum, quae, etsi libera sint creaturae, Deus tamen vi certae praescientiae conditionatae, qua novit, ea mediis indifferentibus infallibiliter consequibilia esse, decrevit absolute esse futura. Priorum potest esse causa - non solum remota et non requisita, sed etiam proxima et necessario praerequisita - scientia absoluta de illorum futuritione, posteriorum vero nec potest esse proxima causa nec necessario praerequisita, et ideo, etsi aliquo modo antecedens sit, quia tamen non est omnino antecedens, sed aliquo modo subsequens, non obstat libertati: ac proinde, dum in praesenti improbamus antecessionem causalem scientiae absolutae ad suum obiectum, nec negamus antecessionem illius ad futura non-libera, nec antecessionem remotam et non-omnimodam illius ut principii non necessario requisiti ad libera futura, quae Deus ex praevia directione scientiae conditionatae efficaciter decernit.

336. Ratio autem, cur non sit capax scientia absoluta directionis causalis et remotae antecessionis ad futura libera, est, quia cognoscit, haec esse futura libere et consequenter vi principiorum indifferentium. Ergo cognoscit, ea non esse operabilia a Deo per ipsam illorum praescientiam, quae cum illis essentialiter connexa est.

Praeterea, quia scientia absoluta futurorum supponit principium adaequatum actus liberi. Supponit enim ut virtuale principium sui, decretum quo Deus statuit dare arbitrio creato adaequatam sufficientiam ad opposita extrema libertatis; nam 
sine hac sufficientia non stat libertas arbitrii ad utrumque extremum. Ergo necesse est, scientiam absolutam cognoscere, quod futurum non est operabile vi ipsius, sed [88or] vi adaequatae sufficientiae, quam supponit.

Denique, quia scientia absoluta supponit ipsummet futurum ut existens, quia principium electivum futuri est libere impeditivum scientiae de tali futuro: ita, ut per futuri productionem determinet existentiam divinae praescientiae et per eius futuri suspensionem posset illam impedire. Hoc autem implicaret, si ipsa scientia esset causa praevie requisita aut directiva ad futurum. Ergo repugnat, quod haec causae rationem habeat, et consequenter ipsa cognoscit, futurum vi sua non esse operabile. Quid ergo mirum, quod, licet in Deo existat, non possit ipsum dirigere ad futuri productionem nec facere, quod existat, sed illud ut existens vi alterius praescientiae et adaequati principii speculari?

337. Confirmatur haec ratio ex divino modo cognoscendi. Deus enim ab aeterno intuetur existentiam obiecti ut praesentem sibi et cognitioni suae: ita, ut modus cognoscendi, quo ultimate tenditur ad obiectum - ut iam praesens, sine expectatione obiecti ut aspiciendi per novam intuitionem, ad quam obiecti praesentia movet aut determinat -, inveniatur infinite perfectus in aeterna scientia futuri. Ergo, sicut ex praesentia ortae intuitiones in creatis nullam habent vim determinandi aut dirigendi obiectum quod intuentur, ita nec in ${ }^{250}$ divina scientia futuri.

Hinc corrigenda est in aliis deceptio circa divina, ad quam inclinamur ex cognitionum humanarum experientia. Consuetus enim modus concipiendi hominum circa actiones, quas causare possumus, est, ut tempore antecedenti illarum productionem cognoscantur a nobis ut possibiles a nobis fieri, postquam vero factae sunt, illas intueamur notitia non-operativa. Hinc est, ut notitiam, qua Deus operationes, quas nobiscum acturus est, cognoscit, antequam existant, apprehendamus ad modum notitiae nobis familiaris, qua operanda, antequam fiant, cognoscimus ut possibilia fieri a nobis, per eiusmodi notitias. Ideoque divinam scientiam etiam apprehendimus ut operativam operationum, quas cognoscit. - Haec apprehensio corrigenda est per iustam divinae scientiae intelligentiam, qua nobis persuademus, eam esse ab aeterno ultimam intuitionem, quae non expectat praesentiam obiecti, sed ad illud ut praesens ultima intuitionis perfectione fertur, et ideo est incapax dirigendi et determinandi, ut sit.

Considerationem hanc a D. Prospero traditam habemus lib. $2^{\circ}$ De Vocatione Gentium cap. 34, ubi obiectionem aeternae determinationis praescientiae contra libertatis indifferentiam sic dissolvit: ${ }^{251}$ „Sed qui se ingeniose hoc arbitrantur

250. in suppl.

251. Prosperus Aquitanus: De vocatione omnium gentium II, 34, PL 51, 719. Zitiert bei Didacus Ruiz de Montoya: Commentarii ac Disputationes de scientia Dei 33, 3, 17, Paris 1629, 269 . 
opponere, non intelligunt scientiam Dei, quae et praeterita, et futura, et praesentia complectitur, tempore non teneri, et tam in conspectu eius astare [88ov] ea, quae gerenda sunt, quam ea, quae geruntur, aut gesta sunt.“ Et post pauca: „Haec [...] aeterna et $[. .$.$] tranquilla cognitio nulla nos urget necessitate. “ Causam ergo errandi$ censuit esse, quod scientiam Dei non intelligimus nec bene capimus, quomodo cognitio infinita duratione praecedens nostram operationem sit ultima intuitio illius ut praesentis. Hoc enim intellecto non est captu difficile, quod tranquilla Dei intuitio nec mota nec movens aut curans operationem nostram nulla nos urgeat operandi necessitate.

338. Ad secundum vero ex duobus supra obiectis [ $\$ 329$ ] respondetur, non esse opus proferri subsecutionem praescientiae divinae ad futurum liberum, ut rationem necessariam ad concordiam omnis libertatis et praescientiae, nam ad concordiam sufficeret, quod scientia non esset suppositio antecedens, licet subsequens non esset, sed concomitans (ut libro praecedenti capite 14 notavimus). Subsecutionem ergo adducimus ut rationem, qua superabundanter probatur concordia; nam, si per solam concomitantiam - casu, quo daretur - salvari posset concordia, multo securius servatur per subsecutionem.

339. Unde obiectioni damus ultro, quod non probetur subsecutio praescientiae ad obiectum liberum ex eo, quod conciliabilis sit eius certitudo cum libertate obiecti: sicut non probatur ex animali hinnibile. At inde non sequitur, non probari evidenter concordiam ex subsecutione praescientiae ad obiectum: sicut probatur ex hinnibili animal. Implicat enim, praescientiam, quae subsequitur existentiam obiecti illud nullatenus causando - sed potius existendo, quia obiectum existit -, posse eius indifferentiam impedire; nam talis praescientiae certitudo, cum non faciat obiectum existere, non facit, quod non possit non existere. Cum enim non ponat, sed supponat, illud, supponit quoque integram illius causam ac proinde omnimodam illius indifferentiam in causa. Quae est indifferentia constituens libertatem. Et licet certitudo scientiae petat, obiectum non posse aliter se habere, et consequenter, quod habeat aliquam essendi necessitatem, petit tamen hoc non ponendo, sed supponendo, hanc impossibilitatem non-essendi et essendi necessitatem. Supponit vero illam, quatenus supponit ipsam obiecti existentiam. Quae est necessitas consequens existendi, qua „omne, dum est, necesse est esse“, et impossibilitas non-essendi, quam habent omnia, quae sunt ex suppositione, quod sint.

340. Hanc autem subsecutionem divinae scientiae ad futura libera, etsi ad communem conceptum concordiae certitudinis cum libertate necessaria non sit, dandam esse, supposuimus in concordiae probatione,

$1^{\circ} \quad$ quia eam supponit communis Patrum et Theologorum [881r] sententia Deum asserens praescire, quia nos operamur, non e contra; 
$2^{\circ} \quad$ quia praescientiam futuri peccati necesse est consequentem esse, et consequenter praescientiam boni: inter quod et peccatum ipsum datur optio voluntati;

$3^{\circ}$ quia modus libertatis nostrae et defectibilitas a divina voluntate non solum praecipiente, sed eligente inter bona, probat, non simul nos eligere bonum et Deum determinate velle, quod existat et sciatur, sed, Deum ex nostra praeelectione praescire hoc potius bonum quam illud, quando inter duo bona nos constituit liberos.

His - et aliis - subsecutionem hanc divinae praescientiae ad futura libera probavimus libro $3^{\circ}$ a capite $5^{\circ}$ et in praesenti libro capite $9^{\circ}$ et sequentibus. Ex illa vero manifeste probari concordiam, dicta in hoc capite - et dicenda in sequentibus capitibus - satis ostendunt.

\section{Caput 25. Praecedentem rationem probandi concordiam certitudinis prae- scientiae cum libertate obiecti familiarem esse Patribus et Theologis}

341. Praecedentem rationem concordiae, quam caeterarum fundamentum dixi, opere pretium erit authoritate Patrum et Scholasticorum confirmare, antequam caeteras proponamus. Quod etsi alicui videri possit actum agere, cum libro praecedenti a capite $6^{\circ}$ ostenderimus, quam commune Patribus fuerit in praescientia futurorum contingentium agnoscere suppositionem consequentem, attamen, quia ibi dictis solum contenditur, quod Patres agnoverint suppositionem hanc consequentem quoad an est, non vero, quod eius consecutionis quidditatem hactenus explicatam agnoverint, nec, quod concordiam praescientiae cum libertate per quidditativam huius subsecutionis explicationem tradiderint, ideo rationem concordiae - ut a nobis capite praecedenti explicatam - a Patribus traditam esse, opere pretium erit ostendere.

342. Nullus eam nec subtilius nec clarius proposuit quam D. Anselmus, et ideo ab illius authoritate probationem exordimur.

Ergo in Elucidario difficultatem, de qua nunc agimus, ita proposuit (ad medium illius opusculi): ${ }^{252}$ „Si Deus cuncta futura praescivit, [...] et non potest falli eius providentia [...], videtur, quod ex necessitate cuncta veniant.“ Sic vero respondet: „Duae necessitates sunt: una naturalis, ut solem [in oriente] oriri [...], altera voluntaria, ut hominem ambulare. Quae, ergo, Deus vult, ut fiant“ - id est, pro suo libito tantum esse decernit - „ut coelum et terram, inevitabile est non evenire, sed per omnia necesse est [ita] contingere. Quae autem fieri tantum

252. PS.-Anselmus Cantuariensis: Elucidarium sive Dialogus de summa totius christianae theologiae II, 8, PL 172, 1139/40. Zitiert bei RuIZ De Montoya: De Scientia Dei 33, 2, 22, p. 266 a. 
permittit“ - id est, quae committit arbitrio, ut eligat, quod maluerit - „ut homines per liberum arbitrium bonum, et malum facere, non est necesse evenire", subintellige: necessitate naturali. Nam voluntaria necessitate - id est, quam facit voluntas per ipsum volendi actum - affirmat necessario evenire id quod Deus praescit, ideoque scientiam, quae falli non potest, libertati actus nostri non obstare, quia nullam in eo requirit necessitatem essendi nisi tantummodo voluntariam, qua necesse est hominem velle, quia vult.

343. Clarius idem et magis ex professo docet libro De Concordia Arbitrii cum Praedestinatione et Gratia cap. 1 (paulo [881v] post initium): ${ }^{253}$ „[...] cum dico, si praescit aliquid, necesse est, illud esse futurum: idem est, ac si dicam: Si erit, ex necessitate erit. Sed haec necessitas non cogit, aut prohibet aliquid esse, aut non esse. Ideo enim, quia ponuntur res esse, dicuntur ex necessitate esse, aut quia ponuntur non esse, affirmantur non esse ex necessitate: non vero, quia necessitas cogat, aut prohibeat rem esse, aut non esse. Nam cum dico, si erit, ex necessitate erit, hic sequitur necessitas, quae rei positionem non praecedit. Idem valet, si sic pronuncietur: Quod erit, ex necessitate erit. Non enim aliud significat haec necessitas, nisi quia quod erit, non poterit simul non esse." Ex quibus verbis evidenter colligitur, ideo, iuxta Anselmum, necessitatem obiecti, quae ad praescientiae certitudinem requiritur, non obstare libertati illius, quia solum est necessitas, qua obiectum non potest non esse, dum est. Quae est necessitas consequens integram principii libertatem et indifferentiam praeviam ad esse et non-esse praesupponens. Ideo subiungit: ${ }^{254}$ „Necessitate omne futurum futurum est [...], sed necessitate sequente.“ Et (prope medium eiusdem capitis): ${ }^{255}$ „Itaque quod vult libera voluntas, et potest [...] non velle, et necesse est eam velle. Potest namque non velle, antequam velit, quia libera est, sed cum vult, non potest non velle, sed eam velle necesse est, quoniam impossibile est illi, id ipsum simul et velle, et non velle. [...] Sed has necessitates facit voluntatis libertas, quae priusquam sint, eas cavere potest. Haec omnia Deus, qui scit omnia, videt sicut sunt, et sicut videt, ita sunt. Hac, ergo, consideratione palam est, quia sine omni repugnantia Deus praescit omnia,

253. Anselmus Cantuariensis: De concordia praescientiae et praedestinationis et gratiae Dei cum libero arbitrio 1, 2, Opera omnia vol. 2, 249. Zitiert bei RuIz de Montoya: De Scientia Dei $33,2,12$, p. 265 a.

254. Anselmus Cantuariensis: De concordia praescientiae et praedestinationis et gratiae Dei cum libero arbitrio 1, 2, Opera omnia vol. 2, 250. Zitiert bei RuIz De Montoya: De Scientia Dei $33,2,14$, p. 265 a.

255. Anselmus Cantuariensis: De concordia praescientiae et praedestinationis et gratiae Dei cum libero arbitrio 1, 3. Ebd. 251-52. Exzerpiert aus Ruiz De Montoya: De Scientia Dei 33, 2, 15, p. $265 \mathrm{a} / \mathrm{b}$. 
et multa fiunt ex libera voluntate, quae antequam sint, fieri potest, ut nunquam sint, et tamen quodammodo sunt necessitate. Quae necessitas, ut dixi, descendit de libera voluntate."

344. Ergo, iuxta Anselmum, habemus tria:

Primum, voluntatem, antequam velit, id est, pro omni signo volitionem antecedenti, posse non velle idque in sensu composito omnis suppositionis antecedentis. Nam ante volitionem negat necessitatem essendi - quae idem est ac impossibilitas non-essendi -, quam concedit dari existente iam volitione. Haec autem solum facit necessitatem sui esse - et impossibilitatem oppositi - in sensu composito. Ergo, in hoc sensu, docet Anselmus, nullam in signo antecedente volitionem dari necessitatem ad illam aut impossibilitatem cum eius carentia.

Secundum est, nullam esse necessitatem volendi, quae non descendat de libera voluntate, et quam non possit ipsa praecavere, ac proinde, quae non sit consequens eius libertatem.

Tertium est, ob haec non repugnare scientiam infallibilem Dei cum libertate obiecti quod cognoscit. [882r] Ergo, quia praescientia Dei nullam affert necessitatem antecedentem, quae faciat rem esse, sed solam consequentem, quae descendit de libera voluntate, et quam ipsa voluntas operando facit, ideo eius libertati non obstat. Evidens ergo est, iuxta Anselmum, nec praescientiam Dei esse causam, ut sint futura libera, nec aliam causam praedeterminantem illius futuri praescientiam cognosci.

345. Negabit forte aliquis hanc ultimam consequentiam, quia ANsELmus solum negat, dari antecedentem necessitatem, non vero, antecedentem determinationem essentialem ad unum: quia potest dari eiusmodi antecedens determinatio, quin inferat necessitatem.

Sed hoc frivolum est omnino. Nam Anselmus supponit communem apud omnes homines ,necessarii' usurpationem, qua significat, quod non potest non esse. Ideoque ipse, cum ArISTOTELE doctisque et indoctis omnibus, „necessarium“ dicit esse, rem esse, dum est: quia, dum est, non potest non esse. Ergo negans antecedentem necessitatem negat omne antecedens, quo posito aliud non potest non esse, etiamsi sit impotentia in sensu solum composito, sicut, ob eandem impossibilitatem in sensu composito, dicitur ,necessarium' esse, quod res existat, dum existens est. Vide dicta libro $2^{\circ}$ capite $1^{\circ}$, ubi ostendi, nullum, qui terminorum significationem percipiat, negare posse, quod omnis determinatio essentialis ad aliud sit necessitas seu necessaria exigentia illius eo modo, quo non potest sine illo esse, scilicet vel antecedenter, vel consequenter, absolute, vel ex suppositione, in sensu composito, vel in sensu diviso, vel quocunque alio modo, quocum non-esse rei, quam exigit, repugnat. Unde S. Thomas $2^{\circ}$ Contra Gentiles cap. 30 ait: „Illas [...] res simpliciter et absolute necesse est esse, in quibus non est possibilitas ad non esse." Ergo 
antecedens determinatio essentialis ad unum, quae facit impossibilitatem carentiae illius, est necessitas ad illud, iuxta omnes et singulariter iuxta Anselmum, cuius egregia alia testimonia pro omnis antecedentis necessitatis repugnantia cum libertate eo loco adduximus. In eius vero exclusione concordiam praescientiae fundavit, ut vidimus, viderique possunt pulcherrima alia ad idem confirmandum, toto illo cap. 1 tractatus De praescientiae concordia et etiam capite sequenti De concordia praedestinationis.

346. $2^{\circ}$ Divus Augustinus in eadem saepe est sententia. $5^{\circ}$ enim De Civitate cap. 10 „ex hoc principio“, ait, „non minuitur libertas nostra, eo quod necesse sit, ut, cum volumus, libere velimus arbitrio, sed potius ex opposito minueretur nostra libertas", libertatemque nostram cum divinae praescientiae certitudine sic conciliat: „Neque enim ideo peccat homo, quia Deus illum [882v] peccaturum praescivit. Immo ideo non dubitatur, ipsum peccare, cum peccat, quia ille, cuius praescientia falli non potest, ipsum peccaturum esse praescivit. " ${ }^{256}$ Ergo Augustini sententia est, quod, quamvis dubitari non possit, Deo sciente peccatum, hominem esse peccaturum, attamen, quia non ideo peccat, quia Deus id praescivit, relinquitur, nullam esse peccandi necessitatem nisi eam, qua necesse est, quod velimus, dum volumus. Quae libertatem non minuit, sed confirmat.

De aliis autem Augustini testimoniis, in quibus videtur asserere, quod res sunt futurae, quia a Deo futurae sciuntur, vide dicta libro praecedenti capite $9^{\circ}$, ubi ostendimus, id ab Augustino dici, vel, quia identice scientia futurorum est efficiens illorum causa - quando bona sunt, ratione simplicis intelligentiae, cum qua identificatur -, vel, quia formalis causa est infallibilitatis aeternae, quam habent, quatenus intentionaliter futura sunt: cum nulla alia sit aeterna causa nec ratio determinata, cur infallibile aeternaliter sit, ea, quae existent, futura esse, nisi quia Deus illa infallibiliter praescivit fore. Dixi, non esse aliam rationem „aeternam“, cur aeternaliter futura et praescita sint, non vero, nullam simpliciter esse aliam rationem: quia temporalis alia ratio datur, cur Deus praesciat, nempe, ipsa futuri libera existentia.

347. Eandem rationem concordiae - ob exclusionem causalitatis et prioritatis praescientiae Dei ad obiectum liberum - tradit luculenter idem Augustinus lib. $3^{\circ} \mathrm{De}$ Libero Arbitrio cap. 3. Evodium enim instruens de concordia praescientiae futurorum cum libertate, eam explicat dupliciter:

$1^{\circ}$ Quia si alius quispiam sciret me peccaturum, non cogeret me peccare, ${ }^{257} \mathrm{id}$ est, non necessitaret. Sumit enim ,coactionem' non in acceptione scholastica - ut

256. Augustinus: De civ. Dei V, 10, 2, PL 41, 153.

257. Augustinus: De libero arbitrio III, 4, 38-39, PL 32, 1276. 
significat id, quod non fit per voluntatis actum -, sed ut opponitur libero. ${ }^{258}$ Totus enim capitis contextus et proposita ab Evodio quaestio initio capitis id ita manifeste ostendunt, ut nil ad propositum responderet Augustinus, si ,coactionem' non sumeret pro non-libero, ut saepissime sumitur a Patribus et ab ipso D. Anselmo loco iam citato, ubi adeo exacte et subtiliter de libertate et necessitate disseruit. Ex eo ergo, quod non „cogamur“ - aut necessitemur - ab alio quopiam certo praenoscente quod operabimur, idem sequitur de divina cognitione. At ideo cognitio certa, quam habemus de futura alterius actione, non necessitat ad illam, quia illius causa non est, sed intuitio eius quod erit. Idem ergo de divina cognitione dicendum est.

$2^{\circ}$ Id explicat per recordationem praeteritorum „sicut tu“, inquiens, „memoria tua non cogis facta esse, quae praeterierunt, sic Deus praescientia sua non cogit facienda, quae futura sunt ${ }^{\text {“ }}{ }^{259}$ quia, scilicet, sicut memoria est [ $883 \mathrm{r}$ ] praeteriti contemplatio nihil in eius esse ponens, sed illud omnino supponens, et ideo, licet essentialem connexionem habeat cum praeterito, nullam tamen imponit illi necessitatem, sic divina intuitio futurorum contingentium nullum dat eis esse, sed omnino illud supponit, et ideo nullam illis imponit necessitatem.

348. $3^{\circ}$ Magnus Athanasius Sermone de Passione et Cruce Domini, ut ostendat, Iudaeos libere et sponte sua volentes Christum Dominum occidisse, quamvis divinae scientiae oraculis occisio praedicta fuerit, id probat, quia praedictio non fuit ipsis causa occidendi, sed propria voluntas, qua causam dedere praedictioni: „Neque ut inservientes propheticis verbis ista contra Christum ausi sunt, sed suo ipsimet studio sponte volentesque illa perpetraverunt, ut non propheta istarum rerum author sit aut causa, sed ipsorum voluntas: quin potius ipsi in causa fuerunt, ut prophetae de illis talia praedivinarent, siquidem prophetae proprium est futura prospicere et in eis non hallucinari, hominum autem proprium est agere, quod velint. "260 Quod aptissime exemplo Scholasticis antiquis (ut statim videbimus) familiari explicat: „Sicut oculis contuentes in contuendo non fallimur neque aliter videmus, et aliter res agitur, sed ut agitur, videmus, et, ut videmus, agitur, ita quoque prophetae futura, et praesentia cernebant. Verum quae cernebant, oportebat fieri, et ea, quae fiebant, non poterant non videre. Rursum, ut ea, quae nos nostris oculis conspicimus, necesse est omnino esse, cum ea tantum quae sunt, sub conspectum

258. Vgl. Didacus Ruiz de Montoya: Commentarii ac Disputationes de scientia Dei 33, 3, 8, Paris 1629, 268a. Eine darum wichtige Feststellung, weil es in dem Jansenismusstreit darum ging, ob ,Freiheit' mit der Freiheit von Zwang identisch ist, was die Jesuiten verneinten.

259. Augustinus: De libero arbitrio III, 4, 40, PL 32, 1276.

260. PS.-Athanasius: De passione et cruce Domini, PG 28, 200. Zitiert bei RuIz De Montoya: De Scientia Dei 33, 4, 2, p. 27 ob. 
veniant, ita quoque, quae a prophetis prospicebantur, necessarium erat esse, neque fieri poterat, ut aliter essent, quam illi praeviderant. ${ }^{\text {261 }}$

Quam doctrinam statim extendit ad gesta in Virgine Maria et in aliis eventibus liberis sanctitate plenis, ne putaretur, superiorem doctrinam de solis pravis actionibus accipiendam esse. ${ }^{262}$ Necessitatem ergo liberi eventus prophetati agnoscens eam libertati non obstare docet, quia non alio modo est necessitas nisi eo modo, quo necesse est esse quod oculis cernitur, quia sub conspectum non cadit, nisi quod est. Ex quo deducit, prophetam sua praedictione causam non esse eventus futuri et ideo nullam illi necessitatem imponere, sed consequentem necessitatem, quam existendo habet, supponere.

349. Si autem obiicias, Athanasium de solis praedictionibus prophetarum id dixisse, aliter vero sentire potuisse de concordia divinae scientiae, a qua prophetiae illae emanarunt, quia prophetae non sunt causa eorum quae praedicunt, sic tamen Deus, -

Respondetur, ${ }^{263}$ ATHANASI rationem inanem fore, si non idem de divina praescientia [883v] sensisset quod de prophetica praedictione; nam, si divinae praescientiae evenire posset causalitas futuri, quod Deus prophetae revelat et in cuius revelatione praescientiam suam illi communicat, quo iure concluderetur illud, eos sponte sua - et non, ut compleretur divina revelatio - Christum occidisse? Etenim eo ipso, quod revelatio - sive per se ipsam, sive per divinam scientiam, quam supponit - sit causa determinate et necessario inferens futurum, inaniter concluditur, homines libere operari, ex eo, quod revelatio per se ipsam nullam operandi necessitatem afferat: cum sufficiat, afferre illam per aliud quod essentialiter supponit, ut omnino libertatem auferat.

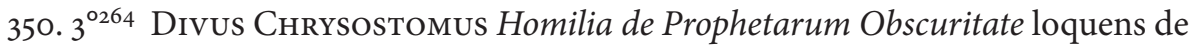
peccati - sub quadam dubitationis specie - praedictione sic eandem concordiae rationem docuit: ${ }^{265}$ „Sed ne vim aut necessitatem aliquam ad [non] parendum afferre ipsius praescientia putaretur, propterea cum dubitatione quadam haec verba protulit, ne forte dicerent aliqui: Praedixit Deus, et omnino, ut eveniret, oportebat. [...] O dementiam! O impudentiam! Neque enim praescientia malitiae causa fuit mi homo: absit. Non enim rebus futuris adfert necessitatem, sed praevidet tantum.

261. Zitiert bei RuIz de Montoya: De Scientia Dei 33, 4, 3, p. 27ob/71a.

262. Zitiert bei Ruiz de Montoya: De Scientia Dei 33, 4, 4, p. 271 .

263. Ähnlich Rodericus de Arriaga: Disputationes theologicae in Primam partem D. Thomae 20, 37, Antwerpen 1643, t.1, $210 a$.

264. So irrtümlich in der Handschrift.

265. Ionnnes Chrysostomus: De prophetiarum obscuritate 1, PG 56, 170-71. 
Non quia praedixit Christus, factus est proditor ille, sed quia proditor futurus erat, idcirco Christus praedixit." Ergo ideo, iuxta Chrysostomum, ex praedictione et praescientia nequit dici, quod fieri oportet sine libertate quae praesciuntur et praedicuntur, quia praescientia non est causa, ut fiat id quod praescitur, nec ideo futurum est, quia praescitur, sed potius ideo scitur, quia futurum est.

351. $4^{\circ}$ Divus Hieronymus eandem conciliandi rationem aperte tradit Hieremiae 26 ad illa verba „Noli subtrahere verbum, si forte audiant“. Ea enim dicta a Deo esse docet, ${ }^{266}$ „ut liberum homini servetur arbitrium, ne ex praescientia eius, quasi ex necessitate facere aliquid, vel non facere, cogatur". Rationem autem, cur nullam eiusmodi necessitatem imponat praescientia, immediate subiungit: „Non enim ex eo, quod [Deus] scit futurum aliquid, idcirco futurum est, sed, quia futurum est, Dominus novit, quasi praescius futurorum."

352. $5^{\circ}$ Divus Damascenus Dialogo adversus Manichaeos (non longe ante finem) eiusdem sententiae est. Agens enim de modo, quo Deus facta hominum praesciat et iudicet, antequam existant, et providentiam, qua disponit ea, quae non subduntur creato arbitrio, a providentia, qua de virtute et vitio nobis liberis curat, distinguens in eo, quod prima necessitatem imponit, non vero secunda, quamvis inviolabili scientia, quod futurum est, praenoscat, sic ait: ${ }^{267}$ „Quae cum ita sint, Deus ea, quae voluntarie a nobis futura sunt, hoc est, ea, quae in potestate nostra sita sunt, nimirum virtutem, ac vitium [884r] praesciens, ea demum praefinit, quae in arbitrio nostro minime constituit.“ Quae verba S. Thomas Prima parte q. 23 art. 1 ad 1 , et $3^{\circ}$ Contra Gentiles cap. 90 interpretatur de praefinitione necessitatem inducente, asserens, hanc agnovisse Damascenum respectu eorum, quae arbitrio non subduntur, et negasse respectu eorum, quae nobis sunt libera. ${ }^{268}$ Cuius diversitatis rationem subnectit DAMASCENUS eam desumens ex eo, quod praescientia et providentia quovis illi subnixa, etsi inviolabilis sit, non tamen sit causa, cur operemur, sed potius nos simus in causa, quod Deus praesciat quae libere facturi sumus - non quidem ut influentes, sed ut determinantes Deum ad praesciendum -, etiamsi virtus cognoscitiva, per quam praescit, nullo modo a nobis sit. Prosequitur ergo DAMASCENUS: „Ac quidem vis Dei praesciens a nobis causam nequaquam habet; at vero, ut ea, quae facturi sumus, praesciat, a nobis proficiscitur. Nam si facturi non essemus, nec ipse quidem, quod futurum non esset, praenosceret. Et quidem Dei praescientia vera atque inviolabilis est. Verum ipsa haudquaquam causa est, cur

266. Hieronymus: In Ierem. 26, 2, PL 24, 844. Zitiert bei Ruiz de Montoya: De Scientia Dei $33,4,11$, p. 271 b.

267. Ioannes Damascenus: Dialogus contra Manichaeos 78, PG 94, 1576.

268. Vgl. Ruiz de Montoya: De Scientia Dei 33, 5, 10-12, p. 276 a. 
omnino fiat id, quod futurum est, quin potius, quia hoc, vel illud, facturi sumus, idcirco praenoscit." ${ }^{269}$

353. $6^{\circ}$ Bozthius eandem concordiae rationem inivit duplicem distinguens necessitatem, simplicem scilicet - quae est antecedens rei existentiam, eo quod habeat illam res in causa - et conditionis seu suppositionis, quam rem habere necesse est, si existat, et similiter, si illam Deus sciat, quia scientia ideo habetur, quia res existit; ac proinde, sicut necessitas rei ab eius existentia proveniens non est simplex, sed conditionis, seu constituta per conditionis adiectionem, ita et necessitas proveniens a praescientia Dei. Ait ergo Boethius lib. $5^{\circ}$ De Consolatione prosa ultima: „Duae sunt necessitates: simplex una, veluti quod necesse est, omnes homines esse mortales, altera conditionis, ut si aliquem ambulare scias, eum ambulare necesse est. Quod enim quisque novit, id esse aliter, quam notum est, nequit. Sed haec conditio minime secum illam simplicem trahit. Hanc enim necessitatem non propria facit natura, sed conditionis adiectio. Nulla enim necessitas cogit incedere voluntarie gradientem, quamvis eum tamen, cum graditur, incedere necessarium sit. Eodem igitur modo, si quid providentia praesens videt, id esse necesse est, tametsi nullam habeat naturae necessitatem. Atqui Deus [ea] futura, quae ex arbitrii libertate proveniunt, praesentia contuetur. Haec igitur ad intuitum relata divinum necessaria fiunt per conditionem divinae notionis. Per se vero considerata [ab] absoluta naturae suae libertate non desinunt. “270

354. $7^{\circ}$ Venerabilis Beda lib. Variarum q. 13 (post medium) ex eodem fundamento concordiam probavit: „Pravitas nostra ab aeterno mala [884v] in conspectu Dei ex sua nequitia praesentavit, Deus illam ad mortem destinavit. Quid ergo? Coegit nos Deus, ut mali sibi videremur ab aeterno? Absit. Nam potius nos coegimus eum, ut nos malos videret. V.g., si video iacere aliquem, necesse est, ut ille iaceat, quem iacere video, aut falsum est, quod ego eum iacere video. Illa [ergo] necessitas a iacente est, an a vidente? Utique non a vidente infertur necessitas, ut iaceat, sed ab ipso, qui se disposuit, ut iaceret. “" ${ }^{271}$ Quod de praedestinatione executiva gloriae meritis debitae intelligendum est. Praedestinatio autem gratiae, etsi meritis non obtineatur, tamen, quatenus infallibilis est, ad opera libera a nobis pendere debet, ita, ut possimus id, quo voluntas indifferens dandi gratiam redditur praedestinativa

269. IoAnnes Damascenus: Dialogus contra Manichaeos 79, PG 94, 1577B. Zitiert bei RuIZ DE Montoya: De Scientia Dei 33, 4, 13, p. 271b/72a.

270. Boethius: De consol. philos. 5, 6, PL 63, 861B. Zitiert bei Ruiz de Montoya: De Scientia Dei 33, 4, 19, p. 272 b.

271. PS.-Beda: Aliquot quaestionum liber q. 13, PL 93, 468B. Zitiert bei RuIz DE Montoya: De Scientia Dei 33, 4, 25, p. 273b. 
nostrae operationis bonae - nempe, praescientiam eius, quod per gratiam acturi sumus -, vel impedire, vel determinare (ut libro praecedenti late explicui).

355. $8^{\circ}$ Tandem, pro eadem concordiae ratione statuenda referri debent Patres omnes, quas praecedenti libro a capite $5^{\circ}$ adduximus pro confirmanda propositione illa apud ipsos frequentissima, quod scilicet „non ideo futura esse, quae sunt arbitrio nostro subdita, quia Deus praescit, illa esse futura, sed potius e contra, ideo illa praescire Deum, quia futura sunt“. Nam fere omnes Patres, qui id asserunt, contendunt eo principio ostendere, quod nulla necessitate compelluntur homines ad bene aut male operandum, sed omnino libere bonum et malum operentur. In malorum autem libertate frequentius insistunt, quia execrabilius est, Deum ad illa necessitare, quam ad bona. Ex qua concordiae ratione concluditur (quod libro $2^{\circ}$ capite $11^{\circ}$ notavi), quam sanctum apud Ecclesiae Patres sit, antecedentem naturae determinationem obstare libertati, cum ideo ad obiecta libera praescita negaverint praescientiae causalitatem, quia inevitabilis est connexio praescientiae cum suo obiecto; ac proinde, si illud causaret, daretur causa nostri actus illum inevitabiliter operans et consequenter ad illum necessitans.

\section{Caput 26. Eandem concordiae rationem probarunt antiqui Scholastici}

356. In praecedenti ratione concordiae libertatis et praescientiae antiquis Patribus consonant Scholastici Doctores. Apud quos nil est frequentius quam, ideo libertati non obstare praescientiam divinam, quamvis non posset non esse futurum quod Deus praescit futurum esse, quia hoc non posse non esse obiectum quod scientia inducit, solum est necessitatis consequentis, conditionalis, vel ex suppositione, qua „omne, quod [885r] est, dum est, necesse est esse“, non vero necessitatis antecedentis causalitate liberi obiecti existentiam. Qui ergo concordiam quaerunt agnoscentes in praescientia aut in motivo, cui innititur, antecedentem determinationem causalem ad obiectum, qua prius natura quam sit, impossibile sit, illud non esse - seu, quod idem est, qua impossibile sit, obiectum non esse impossibilitate non orta ab ipsa eius existentia -, ab antiqua Patrum et Scholasticorum concordia recedunt.

357. Consequentia est evidens.

Antecedens vero probatur ex D. Thома (quem e Sanctorum Patrum choro evocamus, ut prosit Scholasticis, utpote qui scholarum princeps est), cuius manifesta et saepe repetita suffragia pro ratione concordiae hucusque a nobis propugnata sunt. ${ }^{272}$

272. sunt suppl. 
Incipiamus a q. 14 Primae partis, in cuius 13. articulo ad 2 ait: „[...] si dicam, si Deus scit aliquid, illud erit: consequens intelligendum est, prout subest divinae scientiae, scilicet prout est in sua praesentialitate. Et sic necessarium est, sicut et antecedens. Quia omne, quod est, dum est, necesse est esse." En explicatam necessitatem, qua obiectum liberum necesse est fore: quia certo scitur esse futurum sine praeiudicio contingentiae et libertatis ex eo, quod consequens illius conditionalis, scilicet „illud erit“, intelligendum est prout subest divinae scientiae, id est, secundum suam praesentialitatem. Hoc autem modo „necessarium“ est, inquit, „sicut antecedens“, quod est „si Deus scit aliquid“: necessitate, qua omne, quod est, dum est, necesse est esse. Ergo antecedens hoc, nempe, Deum scire me operaturum libere, solum est „necessarium“ - id est, necessitatis inductivum -, quia omne, dum est, necesse est esse, et ideo nil obstat libertati sui obiecti. Thomistica ergo concordia necessitatis cum libertate est, nullam dari necessitatem obiecti liberi a Deo praesciti, quae non sit consequens: ea scilicet, qua rem esse necesse est, dum existit.

358. Quod confirmat diligens studium, quo S. Doctor toto illo articulo (praesertim in corpore) abhorret a certitudinali cognitione contingentis in causa tanquam in obiecto determinativo cognitionis, eo quod in illa non possit dari determinatio ad unum, sed omnimoda indifferentia, qua se habeat ad opposita. Scientia autem certa debet ferri ad obiectum ut determinatum ad unum et aliquo modo necessarium. Ideoque, ait, certo non cognosci contingentia ut sunt futura contingenter in suis causis, sed, ut praesentia in se ipsis, quia hoc tantummodo determinationem habent. „Alio modo potest considerari contingens, ut est in sua causa. Et sic consideratur ut futurum et ut contingens nondum determinatum ad unum, quia causa contingens se habet ad opposita. Et sic contingens non subditur per certitudinem alicui cognitioni. Unde quicumque cognoscit effectum contingentem in causa sua tantum, non habet de eo nisi coniecturalem cognitionem. Deus autem cognoscit omnia contingentia, [885v] non solum prout sunt in suis causis, sed etiam prout unumquodque eorum est actu in se ipso“ etc. „Unde manifestum est, quod contingentia infallibiliter a Deo cognoscuntur, inquantum subduntur divino conspectui secundum suam praesentialitatem: et tamen sunt futura contingentia suis causis [...] comparata." Quid clarius pro concordia, quam proposuimus, dici potuit?

359. Verba haec Doctoris Angelici adduximus capite $16^{\circ}$. Quibus omnino consonat CAIETANi commentarium, quamvis commentario clarior sit textus, tum loco citato, tum etiam q. 2 De Veritate art. 12 in corpore, ubi ait: „[... [ Ex quo patet, contingens, ut futurum est, per nullam cognitionem sciri, cui falsitas subesse non possit. Unde, cum divinae scientiae non subsit falsitas nec subesse possit, impossibile esset, quod de contingentibus futuris scientiam haberet Deus, si cognosceret ea ut futura sunt", id est, ut pure futura prius natura, quam existant; quia futuritio, quam ante existentiam habent, est contingens, ut capite $16^{\circ}$ ex eodem Doctore explicui. Rationem 
vero asserti sui tradit in responsione ad 1: „Dicendum, quod licet contingens non sit determinatum, quandiu futurum est, tamen ex quo productum est in rerum natura, veritatem determinatam habet, et hoc modo fertur super illud intuitus divinae cognitionis." Quem locum citans Ferrariensis $1^{\circ}$ Contra Gentiles cap. 67 ait, contingens, quandiu futurum est, posse impediri, ne eveniat, et posse non esse, sed, cum iam est praesens et non amplius futurum, non pro illo tempore impediri, ne sit, sed non posse non esse necessitate illa, qua omne, quod est, dum est, necesse est esse. Ideoque „ut futurum“, id est, secundum habitudinem ad esse antecedens natura ipsum, non subdi certae cognitioni, sed tamen „bene ut praesens“.273

Concordia, ergo, certitudinis scientiae cum contingentia obiecti, ex S. Tнома et Caietano et Ferrariense, in eo consistit, quod contingens non subdatur certae cognitioni, secundum quod est futurum seu antecedens praesentialitate existentiae, sed solum, secundum quod praesens est: quia impossibilitas aliter se habendi, quam habet ex eo, quod sit, non obstat contingentiae. Sic vero omnis alia.

360. Prosequitur S. Doctor eodem articulo 12 q. 2 De Veritate in eadem semper concordiae ratione insistens. Nam ad secundum argumentum sic respondet: „Contingens refertur ad divinam cognitionem, secundum quod ponitur esse in rerum natura. Ex quo autem est, non potest non esse [...] Non tamen sequitur, quod simpliciter dicatur necessarium, nec quod scientia Dei fallatur: sicut et visus meus non fallitur, dum video Petrum sedere, quamvis hoc sit contingens. "Ergo ideo scientiae infallibilitas compatitur [886r] obiecti contingentiam - seu quod non sit simpliciter necessarium -, quia non petit, quod non possit non esse, antequam sit, sed solum, quod non possit non esse, postquam est.

Quod subtili consideratione explicatius tradit ad 3: „Contingens pro tanto dicitur necessarium esse, secundum quod scitum est a Deo, quia scitur ab eo, secundum quod est iam praesens, non secundum quod futurum est. Nec ex hoc aliquam necessitatem sortitur, ut possit dici, quod necessario eveniet. Eventus enim non est nisi eius, quod futurum est, quia id, quod iam est, non potest ulterius evenire; sed verum est id evenisse, et hoc est necessarium. "Paulo aliter legebatur in codicibus antiquioribus, quas secutus videtur P. RuIz transcribens disp. 33 De Scientia Dei sect. 7 pro „non potest ulterius evenire“: „,non potest non evenire“. 274 Sed verba, ut a nobis transcripta sunt, habentur in editione Antverpiensi anni 1612, quae dicitur, in ipsa operis inscriptione, a plurimis quibus aliae editiones scatebant, mendis correcta per Cosmam Morelles Praedicatorum ordinis Doctorem, et sane, correctionem hanc

273. Franciscus de Sylvestris Ferrariensis: In Summam contra Gentiles I, $67 \S 2$, 2, ed. Leon. t.13, $192 \mathrm{a}$.

274. Didacus Ruiz de Montoya: Commentarii ac Disputationes de scientia Dei 33, 7, 3, Paris 1629, 279 a. 
iustam esse, praecedentium et sequentium verborum contextus et rationis - alias languentis - energia requirit.

361. Ratio enim haec est: Contingens ideo contingens remanet, quamvis eius infallibilis praescientia petat, quod aliquo modo „necessarium“ sit - id est, quod non possit aliter se habere -, quia - cum pro tanto, seu in tantum, est necessarium, quatenus a Deo scitur, scitur autem non ut futurum, sed ut iam praesens; ac proinde - necessarium est solum ut praesens seu necessitate non antecedente praesentiam, sed per illam ipsam inducta: „ex quo non sequitur“, inquit, „effectum evenire necessario“, quia eventus est futuri et posterioris consecutio ad prius, nulla autem est necessaria consecutio contingentis ad ea quae ipsum praecedunt, quia ipsis contingenter evenit, ac proinde ita, ut ipsis praecedentibus possit, quod contingenter futurum est, non sequi. Nec obstat concessa necessitas, quam inducit existentia, ne dicatur ,contingenter' evenire et ,non evenire posse' futurum, „quia id, quod iam est, non potest ulterius evenire, sed verum est evenisse, et hoc necessarium est“. Necessitas enim, quae intelligitur in ipsa existentia ad existendum, quando iam praesens in se est, non est in signo, in quo intelligitur posse evenire seu physica potentia ad esse, "quia quod est iam, ulterius evenire non potest", ac proinde non impedit contingentiam eventus - quae salvatur per indifferentiam ad esse intellectum in signo, quo datur posse evenire -, „sed verum est iam evenisse“, id est, vere enunciatur ut praesuppositum aliquo modo ad affirmationem et praescientiam. Quae enim praesupponuntur, explicantur a nobis quasi de praeterito [886v] adveniente iam eo quod ad ipsa consequitur. Tandemque concludit „et sic necessarium est“. Haec est necessitas, qua praescientia affirmat, obiectum liberum non quidem infallibiliter sequi ex causis, sed, infallibiliter in se ipso existere.

362. Haec est concordia Angelice Thomistica, quam explicatam quoque habes $1^{\circ}$ Contra Gentiles cap. 68 aureis verbis (a nobis relatis capite $3^{\circ}$ huius libri) et aliis locis et verbis (eodem capite conscriptis), a qua quantum discordent NovionUm Thomistarum concordantiae facile est dignoscere. Antiqui Thomistae Thomae in hac concordia subscripserunt. CAIETANI et Ferrarae subscriptiones vidimus.

Capreolus, Thomistarum Princeps, subscripsit in $1^{\circ}$ Sent. dist. 38 q. 1 art. 2 quatuor primis conclusionibus, et etiam conclusione 7 , et dist. $40,{ }^{275}$ multis S. THOMAE sententiis et rationibus ostendens, non alia ratione cohaerere infallibilitatem praescientiae cum libertate obiecti, nisi quia infallibilitas, qua scientia petit obiectum non posse aliter se habere, non respicit obiectum illud ut futurum - loquitur semper de futuritione, quam obiectum illud prius natura, quam praesens sit, habet in suis causis -, sed secundum esse, quod habet in sua praesentialitate, quo ex suppositione,

275. Ioannes Capreolus: Defensiones theologiae D. Thomae Aquinatis, Tours 1900-07, t.2, 447ff. 452f. Die Stellenangaben aus Ruiz De Montoya: De Scientia Dei 33, 7, 10, p. 280 o. 
quod sit, non potest non esse: impotentia sensus compositi, quam constituit ipsa libera existentia obiecti. Ergo, ut praescientia non obstet indifferentiae, opus est, iuxta Thomistarum proceres, quod non respiciat obiectum liberum ut futurum vel oriturum a suis causis - futuritione, qua illis praesuppositis non possit, in sensu composito illarum, non existere -, cum requirant, quod solum illi repugnet non esse ex suppositione praesentialitatis, qua in se existens est. Videatur, inter alia, quae expendit circa locum quendam S. Thомаe ex lib. $1^{\circ}$ Contra Gentiles cap. 67 (prope finem), ubi - postquam dixisset, sicut unumquodque cognoscitur a Deo ut praesentialiter visum, sic necessarium fore id quod Deus cognoscit: sicut necessarium est Sortem sedere, ex eo, quod videatur sedere: quae necessitas non est absoluta nec consequentis, sed conditionalis et consequentiae - subdit, propositionem hanc „si Sortes videtur sedere, necesse est Sortem sedere“ veram esse in sensu composito et falsam in sensu diviso. CAPreolusque idem prorsus dicendum esse addit ${ }^{276} \mathrm{de}$ necessitate obiecti ut a Deo praesciti, scilicet, solum esse necessarium, quod sit, et impossibile, quod non sit, in sensu composito cum praescientia libera obiecti seu cum intuitione non ponente, sed supponente, illud ut praesens.

$\mathrm{Nec}$ poterat aliud concordiae genus placere CAPREOLO, quem (ut libro $2^{\circ}$ capite $13^{\circ}$ notavimus) adversarii ipsi, praesertim BAÑEZ et LEDESMA, fatentur praeviis actionum liberarum determinationibus [887r] repugnare. Quam etiam laudem Caietano defert Ledesma (ut ibidem vidimus). Pro eadem stabilienda concordia alias Thomistas vide apud P. RuIz disp. 33 De Scientia Dei sect. 7.

363. Quia vero apud citatos hactenus - et apud S. Tномам - frequens est, scientiam Dei non cognoscere contingentia futura ut futura sibi, sed ut iam praesentia et coexistentia, notandum est, duplici titulo ab illis negari, quod futura respiciantur ut futura comparative ad scientiam:

$1^{\circ}$ quia non sunt illi futura per subsecutionem durationis, cum non habeant durationem, quae post transactam durationem divinae cognitionis extitura sit (ut capite $18^{\circ}$ explicatum est);

$2^{\circ}$ quia non habent esse futura cognitioni per subsecutionem causalitatis, cum non consequantur illam ut causam, ideoque solum recipiantur ab illa ut coexistentia per praesentiam temporalem, quam habent ad aeternitatem divinae cognitionis (ut loco citato explicuimus).

Et hac de causa toties advertunt, contingentium cognoscibilitatem a praesentia, quam habent ad aeternitatem, omnino petendam esse, et ante illam non posse dari cognoscibilitatem determinatam in ordine ad certitudinalem cognitionem. Si enim haec daretur, oporteret certam praescientiam futurorum illa respicere ut causaliter

276. Das bemerkt Ruiz de Montoya: De Scientia Dei 33, 7, 10, p. $280 a$. 
futura comparatione sui tanquam praecedentis natura ad illorum existentiam; nam, si futura essent cognoscibilia prius natura, quam haberent praesentialitatem essendi in se ipsis, cognoscerentur a Deo priusquam in se ipsis essent, nam praescientia, per quam vi antecedentis cognoscibilitatis cognoscerentur, iustissimam praecedendi rationem haberet. Futuris enim sic cognitis procederet Deus ad executionem eorum quae decrevit, quia scit se illa decrevisse; ac proinde, sicut ideo existerent futura, quia determinata sunt a Deo, sic et, quia determinata esse, cognoscuntur et consequenter praescientia cognosceret illa ut sibi causaliter futura.

Haec de S. Thoma et antiquis eius discipulis, a quibus Noviores, post Dominicum BAÑEZ, discessere antiquas concordiae leges novis pactionibus violantes et pacem frustra in implacabilis belli discordia quaerentes. His novissimus auxiliator accessit Ionnnes a S. Thoma cum ipsis recedens disp. 20 Primae partis art. 7:277 discordem cuius concordiam libro praecedenti (a capite $10^{\circ}$ ) discussimus, et $\mathrm{S}$. Thомав loca, quae adducit, sinistre ab ipso interpretata ostendimus, aliasque ex S. Thomae testimoniis obiectiones dissolvimus.

364. S. Doctori et antiquis eius discipulis pro concordia nostra formanda addendi sunt Angelici Doctoris Magister Albertus Primae partis q. 61 memb. 8, ${ }^{278}$ Alensis partis etiam Primae q. 24 [887v] memb. $5,{ }^{279}$ et RicA RDus in $1^{\circ}$ dist. 38 q. 6 (in corpore). ${ }^{280}$ Qui tres, citato Anselmo, notant ex illo duplicem necessitatem, antecedentem scilicet, quae est causa, ut res sit, et consequentem, quam facit positio rei, et expresse dicunt, primam non concordare libertati, sed solam secundam; et praescientiam, quia hanc solam habet, libertati obiecti praesciti concordari. Eorum verba habes libro praecedenti capite $5^{\circ}$. Idem non minus clare docent alii Theologi praemissa, ex Bozthio, distinctione duplicis necessitatis, absolutae scilicet et conditionalis, quam Aegidius in $1^{\circ}$ dist. 38 q. ultima, ${ }^{281}$ Carthusianus eadem dist. q. 1 et $2,{ }^{282}$

277. Ionnnes A S. Thoma: Cursus theologicus in Primam partem D. Thomae, Alcalá 1637, t.1, 691-96.

278. Albertus Magnus: Prima pars Summae Theologiae, in Opera, ed. P. Jammy, Lyon 1651, t.17, 347b. Zitiert bei Ruiz de Montoya, De Scientia Dei 33, 6, 2, p. 277 b.

279. Alexander de Hales: Summa theologica, Quaracchi 1924-79, t.1, 270-71. Zitiert bei Franciscus SuAReZ: Varia opuscula theologica 1, 1, 14, 12, Opera omnia, Paris 1856-78, t.11, 72b, und wörtlich bei RuIz DE Montoya: De Scientia Dei 33, 6, 3 p. 277 b.

280. Ricardus de Mediavilla: Super quatuor libros Sententiarum Petri Lombardi Quaestiones subtilissimae, Brescia 1591, t.1, 341b. Zitiert bei Ruiz De Montoya: De Scientia Dei 33, 6, 4, p. $277 \mathrm{~b} / 78 \mathrm{a}$.

281. Aegidius Romanus: Primus Sententiarum, Venedig 1521, 203V-04v. Hinweis bei RuIZ DE Montoya: De Scientia Dei 33, 6, 3, p. 277 b.

282. Dionysius Carthusianus: Opera omnia, Tournai 1896-1913, t.20, 474-9o. Zitiert bei Ruiz De Montoya: De Scientia Dei 33, 8, 13, p. 285b/86a. 
et Argentinas dist. 40 art. 3 ad 8, eandem esse, ait, cum distinctione Anselmi; ${ }^{283}$ et per illam hi tres Theologi libertatem cum praescientia conciliant, eo quod soli illi conditionalis et consequens necessitas existentiae obiecti liberi conveniat. Idem, sub eisdem terminis, docet Divus Bonaventura citata dist. 38, 40, et 47 (ut libro praecedenti capite $25^{\circ}$ ostendimus). Eiusdem sententiae est insignis Hibernus noster Armachanus ${ }^{284}$ (ut ibidem vidimus). De Scoto et eius discipulis sufficiant dicta libro $2^{\circ}$ cap. $14^{\circ}$. Henricum, Durandum et alios plurimos Antiquorum pro eadem concordia suffragium ferentes vide in P. RuIz disp. 33 De Scientia Dei sect. 6, 8, et 9. Quibus omnibus facem praetulit Magister Sententiarum in $1^{\circ}$ dist. 38, 39 et 40 , in quibus, ex duplicis huius necessitatis distinctione, antecedenti exclusa per consequentem explicuit divinarum determinationum, praesertim divinae praescientiae, concordiam.

\section{Caput 27. Aliae probationes concordiae praescientiae cum libertate ex Patribus et Scholasticis proferuntur}

365. Fundamentalem diximus [ $\$ 325]$ eam quam hactenus stabilivimus. Alias producunt antiqui Patres et Doctores, quae huius explicationes potius sunt quam distinctae probationes.

Prima harum sit, determinationem, qua certitudo praescientiae petit nostram operationem, esse determinationem a nobis ut potentibus operari impedibilem: ergo non magis impediet libertatem nostrae operationis quam ipsa nostrae operationis existentia.

Antecedens probatum est a capite $10^{\circ}$.

Consequentia autem est evidens. Nam ideo nostrae operationis existentia, quamvis sit determinatio sui esse, non obstat huius libertati, quia ita existit, ut eius principium quatenus potens illam ponere sit potens illam impedire. Ergo, si determinationem praescientiae ad eandem operationem eodem modo potest impedire, non poterit ea determinatio obstare operationis [888r] libertati.

366. Negabis consequentiam: Quia determinatio operationis ad se ipsam est determinatio formalis - unde potestas vitandi illam non potest non esse potestas et indifferentia ad vitandam et ponendam operationem -, determinatio autem scientiae ad operationem, quam cognoscit, non est formalis, per identitatem cum illa, sed virtualis, per exigentiam illius, et ideo, etsi evitabilis a voluntate sit, potest libertati

283. Thomas ab Argentina: Commentaria in IV libros Sententiarum, Venedig 1564, 111va. Referiert von Ruiz de Montoya: De Scientia Dei 33, 6, 7, p. 278 a.

284. Richard Fitzralph (Armachanus): Summa in quaestiones Armenorum 16, 5, Paris 1511, 130rb/vb. Referiert und zitiert bei Ruiz De Montoya: De Scientia Dei 33, 8, 25, p. 287a/b. 
obesse: ut praedeterminatio ad amorem, si concederetur homini, quia libere illam petit, evitabilis esset et libertati amoris repugnans.

Sed contra, quia probatio nostra non infert concordiam praescientiae cum operatione, quam cognoscit, ex eo, quod utcunque possit impediri a nobis praescientia, sed, quia potest impediri a nobis ut potentibus operari actum, qui praescitur; nam determinatio, quae a nobis ut sic potentibus evitabilis est, non potest esse praerequisita ad operationem nec constituens potestatem operandi illam, sed potius ad illam subsequens ut ad principium electivum: unde, vel debet esse ipsa operatio, ad quam datur talis potentia, vel aliquid consequens, quod per operationem dependet a potestate illam operandi ideoque huius potestatis indifferentiam integram relinquit. Praedeterminatio autem evitabilis, quae nobis opponitur, non est immediate evitabilis a potente proxime et expedite amorem praedeterminatum, quia sic potens constituitur per ipsam praedeterminationem: unde non mirum est, quod amoris immediatam libertatem tollat, licet compatiatur mediatam, qua, per petitionem, impediri potest praedeterminatio.

367. Haec ratio [ $\$ 365]$ Patribus familiaris est, dum dicunt, non obstare nostrae indifferentiae determinationem divinae scientiae, quia nos libere facimus, quod Deus praesciat - „facimus“, inquam, non influendo, sed determinando -, cum potestate faciendi, quod sciret oppositum, si illud vellemus: ergo, quia ut potentes operari possumus non operando facere, ne Deus praesciat determinate operationem, ideo praescientiae determinatio ad operationem huius indifferentiae non contradicit.

Quam doctrinam expressit Hugo Victorinus lib. $1^{\circ}$ De Sacramentis p. 2 cap. 22 „Possibile est“, inquiens, „, non fieri, quod futurum est. Et si non fieret, quod fiet, et possibile est non fieri, nunquam futurum fuisset nec praevisum. Quod quia fiet, futurum semper est, et praevisum est." Et post pauca ait, quod, si non fieret, quod futurum est, praescientia et "providentia constaret tunc in eo, ut non fieret“ - id est, esset de non facienda re - „non mutata, ut post aliam [alia] esset, sed ut nunquam alia esset. ${ }^{\text {“285 }}$ Ex possibilitate ergo, qua potentes non facere quod futurum est, possibile [888v] nobis est non fuisse hoc, quod agimus, praevisum non ita, ut, post habitam unius extremi scientiam, possibile sit, aliam oppositam haberi, sed ita, ut potuerit, ex libertate nostra, ea, quae habetur, nunquam habita fuisse -, ex hoc, inquam, praescientiae et providentiae determinationes cum libertate contingentium obiectorum cohaerent. Idem expresse docet IoANNES MAIOR in $1^{\circ}$ dist. 38 q. 2 ad 8. et 10. argumentum, ${ }^{286}$ ex eo praescientiam pec-

285. Hugo de S. Victore: De sacramentis christianae Fidei I/2, 22, PL 176, 215. Zitiert bei RuIZ De Montoya: De Scientia Dei 33, 4, 28, p. 273b.

286. IoAnnes Maior: In Primum Magistri Sententiarum disputationes et decisiones nuper repositae, Paris 1530, 7ov/71r. Referiert von Ruiz de Montoya: De Scientia Dei 33, 8, 17, p. 286 b. 
cati cum libertate ad peccandum concilians, quia in potestate potentis peccare est, ne Deus habeat praescientiam de eius peccato; et MARsilius in $1^{\circ}$ q. $40 .{ }^{287}$ Eaque videtur communis Scholasticis, quorum cum Magistro Sententiarum sententia antiqua et communis est, possibile in tempore esse homini libero ad operandum, quod non fuerit scientia de eius operatione hac potius quam illa. (Quos citavimus capite $1^{\circ}$ et sequentibus). Nam ex eo id statuunt, quia putant, determinationem praescientiae ad nostram operationem, nisi haec in nostra potestate sit, non posse in nobis liberam facultatem ad operationem compati; et hac data scientiam quoque cum operatione connexam in nostra esse potestate et ideo libertati nostrae non obstare.

368. Secunda ratio est, qua utitur Divus Augustinus lib. $3^{\circ}$ De Libero Arbitrio cap. 3: quia, si homo sciret alium peccaturum, non ideo alter ${ }^{288}$ ad peccandum cogeretur nec determinaretur: ergo neque ex eo, quod a Deo praesciatur peccaturus, quia in Dei scientia nihil obstare potest libertati obiecti sui nisi certitudo, qua illud cognoscit. Ergo, si cum omnimoda certitudine, quam homo haberet peccati futuri, compatitur libertas peccandi, compatitur etiam cum praescientia Dei.

Si autem dicas, disparem esse rationem praescientiae divinae: quia haec est causa operandi, -

Imprimis Augustino repugnabis, qui dicto loco cum Evodio consentit in eo, quod nulla possit esse ratio, cur divina potius scientia necessitet quam humana, supponendo omnimodam in utraque certitudinem. Non autem esset par, sed omnino dispar ratio, si divina praescientia esset causa sui obiecti.

Deinde, nullo fundamento dicitur, praescientiam Dei esse causam potius quam humanam: quia, etsi Deus debeat esse causa permissiva mali quod cognoscit, non tamen potest causa esse per praescientiam, quia haec supponit illud permissum esse.

369. Tertia ratio est Patribus et Theologis valde communis, quia scilicet visus, quo ut praesentem intuemur alterius motum, non obstat motus contingentiae, etsi necesse sit, ita esse, quod esse videmus. Ergo nec divinus intuitus, qui ab aeterno fertur ad omnia ut praesentia, potest illorum contingentiae obstare, [889r] quamvis necesse sit esse, quod intuetur ab aeterno Deus.

Consequentia probatur: Quia, sicut humanus intuitus non est positio motus, quem intuetur, sed suppositio illius, ideoque nihil ponit in causa, ut operetur,

287. Marsilius de Inghen: Quaestiones super IV libros Sententiarum I, 40, ed. M.J.F.M. HoENEN: Marsilius van Inghen $(\dagger 1396)$ over het goddelijke weten. Zijn plaats in de ontwikkeling van de opvattingen over het goddelijke weten ca. 1255-1396, Nijmegen 1989, Deel II, 108-110. Zitiert bei RuIz De Montoya: De Scientia Dei 33, 8, 19, p. 286b.

288. aliter corr. 
sed expectat, quid per principia, quae habet, operatura est, et ob hanc rationem nec motum facit necessarium nec liberum, sed illum, prout est, intuetur iam productum, sic intuitus divinus, quatenus a simplici intelligentia distinctus, non ponit liberum obiectum quod intuetur, sed illud alia scientia et voluntate indifferentibus ponendum supponit ideoque illud ut praesens intuetur. Quomodo ergo eius contingentiae obstabit?

370. Quarta denique ratio est D. Augustini locis citatis et fere omnium Patrum et Theologorum, qui de hac concordia disserunt. Nam cognoscibile est, aliquid libere futurum esse, sicut cognoscibile est, illud esse existens, praesertim, quando cognoscens ea quae futura sunt, ut praesentia sibi intuetur. Sicut enim cognitio simul duratione incipiens cum obiecto libero potest sine praeiudicio contingentiae illius cognoscere, quod ab indifferentibus causis ortum est, sic et cognitio duratione et aeternitate praecedens obiectum. Ex quo sic infero: Ergo, sicut ex eo, quod cognitio certa est, oportet fore id, quod Deus cognoscit, ita etiam oportet, illud fore eo modo, quo illud futurum esse cognoscit. Cum ergo illud libere futurum cognoscat, necesse est illud ita evenire. At necessarium esse, quod libere eveniat, est, iuxta citatos Patres et Theologos, eventum necessarium esse necessitate consequente, quam res ipsa existens facit et ad quam nulla supponatur in causis essendi necessitas ac proinde nec determinatio essentialis ad essendum: quia, hac data necesse est rem esse, cum impossibile sit non esse. Per consequentem ergo necessitatem clarissime explicatur concordia infallibilis praescientiae cum contingenti obiecto.

371. Dicet forte aliquis, hac ratione muniri concordiam Praedeterminantium: Quia, sicut ex praescientiae certitudine necesse est esse quod Deus praescit, et, esse eo modo, quo praescit, illud esse futurum, ita ex divinae voluntatis infallibili efficacia non solum necesse est esse quod Deus vult, sed etiam, esse eo modo, quo vult: ergo, si velit, illud esse libere, ita erit. Praevia ergo voluntatis divinae determinatio potest, sine his praesuppositionum ambagibus, per se ipsam libertati consonare eamque invictissime conservare.

De huius obiectionis concordia late egimus libro $2^{\circ}$, eamque repugnare, ostendimus, in divina voluntate causante suum obiectum, quando est causa omnino antecedens; nam, Deum velle hanc voluntatem habere, est velle, dari antecedentem et absolutam actus voliti necessitatem; sed hac volita repugnat velle, quod actus fiat libere: ergo repugnat cum [889v] eiusmodi voluntate libertatem obiecti, quod respicit, componi.

Minor et consequentia evidentes sunt.

Maior autem patet, quia voluntas illa est per se ipsam absoluta et antecedens necessitas: ergo, eam habere, et, velle Deum, est velle absolutam necessitatem actus nostri. 
Antecedens loco citato probavimus ex illa vulgata D. Augustini propositione in Enchiridio cap. 103: „Necesse est fieri, si Deus voluerit. “289 Ergo, quae antecedente et absoluta voluntate decernit, absoluta et antecedente necessitate fieri necesse erit. Ideo S. Thomas Prima parte q. 19 art. 8 ad 1, hanc Augustini assertionem referens ${ }^{290}$ ait: „[...] intelligenda est necessitas in rebus volitis a Deo non absoluta, sed conditionalis: necesse est enim, hanc conditionalem veram esse: si Deus hoc vult, necesse est hoc esse. “ Non est sensus, omnia volita a Deo habere solam conditionalem necessitatem, nam, ut ad tertium argumentum docet, „[...] ea, quae sunt a voluntate divina, talem habent necessitatem, qualem Deus vult ea habere, scilicet vel absolutam vel conditionatam“. Absolutam habent, quae necessaria sunt; quae vero sunt nobis libera, solam conditionalem, qua, si aliquid sit, impossibile est illud non esse (ut ex eodem Doctore et caeteris explicuimus capite $1^{\circ}, 2^{\circ}$ et $3^{\circ}$ ).

372. En ergo disparem scientiae et voluntatis divinae rationem. Scientia enim futurorum non est illorum causa nec praerequisitum natura antecedens, et ideo potest suum obiectum ut per alias causas futurum libere videre et eius libertatem sua certitudine comprobare. Voluntas autem absoluta et antecedens Dei, etsi decernere possit, operationem creatam non esse necessario et inevitabiliter connexam cum hac aut illa causa ipsius secundum se spectata, at non potest decernere, quod necessario et inevitabiliter non sequatur ad aliquam sui causam, nempe, ad ipsam eiusmodi voluntatem Dei. Quae est causa inevitabiliter et necessario inferens operationem quam decernit, et eadem inevitabilitate et necessitate praedeterminans causam creatam, ut illam exerceat, et consequenter vult illam operari per antecedentem et absolutam necessitatem. (De quo latius libro $2^{\circ}$ capite $8^{\circ}$ et $23^{\circ}$.)

373. Quod vero S. Thomas addit, res habere necessitatem, quam divina voluntas „vult", quod habeant, significat quidem (ut loco citato observavimus), Deum aliqua voluntate posse decernere in obiectis liberis necessitatem, quae illis salva libertate convenire potest - scilicet necessitatem ${ }^{291}$ conditionalem, qua necesse sit illa esse, quia sunt -, sed hoc ipsum probat, voluntatem, quae solam eiusmodi necessitatem in liberis dari decernit, non esse absolutam et omnino antecedentem unius extremi libertatis praedeterminativam, nam haec esset antecedens et absoluta necessitas respectu talis extremi (ut saepe ostendi). Voluntas, ergo, qua supponit S. THomas, Deum posse „velle“, quod libera habeant [89or] solam „conditionalem necessitatem“, potest tripliciter intelligi:

289. Augustinus: Enchiridion, PL 40, 280.

290. Vgl. Ruiz de Montoya: De Scientia Dei 33, 1, 16, p. 263 a.

291. libertatem corr. 
$1^{\circ}$ de voluntate conditionali, qua Deus velit, quod, si libera existant, habeant conditionalem necessitatem essendi;

$2^{\circ}$ de absoluta, sed indifferenti, qua velit unum e duobus extremis liberis existere hic et nunc, et consequenter, dari in aliquo illorum conditionalem illam essendi necessitatem - qua ipsis essentiale est esse, si sint - reductam ad absolutum actum;

$3^{\circ}$ de absoluta voluntate determinante ad unum, quae tamen non sit omnino antecedens, sed aliquo modo consequens. Haec voluntas est praedefinitio efficax attemperata praescientiae conditionatae.

Deus enim praesciens de mediis, quod, licet indifferentia sint, tamen, si applicentur voluntati, infallibiliter obtinebunt consensum, potest, si velit, efficaciter decernere, quod per illa media obtineatur consensus, et, quod detur in illo „conditionalis necessitas" reducta ad absolutum essendi actum. Huius autem voluntatis concordia cum libertate satis intelligibilis est, quia determinatio, quam habet ad unum, consequens est (ut libro $7^{\circ}$ late explicabitur).

\section{Caput 28. De scientia absoluta futurorum contingentium eiusque formali obiecto}

374. De scientia hac, quam naturalis ratio et Fides divinarum praedictionum Deo concedendam probat, quaeritur $1^{\circ}$, quid ${ }^{292}$ sit eius formale obiectum?

Respondetur, esse divinam essentiam libero Dei decreto determinatam.

Sic communiter Theologi, etsi inter illos non conveniat, quale debeat esse decretum, nec, qualiter ad futurorum cognitionem debeat concurrere; etenim, quod divina essentia - ut idea eorum quae Dei perfectionem imitantur, scilicet bonorum, et ut causa positiva bonorum et permissiva malorum - sit formale obiectum prius cognitum dans esse et speciem divinae cognitioni futurorum, S. THOMAE et Scholasticorum communem esse sententiam, vidimus capite $5^{\circ}$.

Et videtur manifestum, cum divina essentia sit obiectum quod scientia futurorum supponit cognitum per scientiam necessariam, et quod ipsa necessario cognoscit, cum non possit Deus cognoscere creaturam futuram nisi ut a se faciendam. Cognoscit autem se ipsum, ea cognitione, propter se - et non propter aliud -, quia creatum obiectum, quod propter Deum attingit, non potest attingere ut formale obiectum propter quod sit cognitio (ut probavimus capite illo $5^{\circ}$ et sequentibus). Divina ergo essentia est obiectum, quod propter se cognoscit futurorum scientia, et propter quod ipsa est: est ergo eius scientiae formale obiectum. Et, ne desit, 
[890v] quod aliqui ad formale obiectum requirunt, scilicet esse prius cognitum, hoc etiam divinae essentiae respectu scientiae futurorum convenire certum est (ut ibidem vidimus).

375. Quod vero divinum etiam decretum praerequiratur ex parte essentiae ad futurorum cognitionem, docent, cum S. Thoma, Caietanus parte Prima q. 14 art. $13 \S$ „Ad secundum autem“, 293 caeterique Thomistae, et Scotistae, cum Scoto in $1^{\circ}$ dist. 39 quaestione unica $\S$ „Viso de contingentia“.294 Quos Nostri communiter sequuntur in eo distinguentes scientiam conditionatam futurorum ab absoluta, quod illa non praesupponat existens aliquod decretum Dei, sic vero absoluta: quae proinde scientia libera dicitur. ${ }^{295}$

Ratio est manifesta, quia divina essentia, imprimis respectu futurorum quae sola sua libertate operatur Deus, determinanda est per decretum ut causam praedeterminativam futuri et cognitionis ipsius, cum ideo sint et cognoscantur illa futura, quia Deus decrevit illa esse. Ad futura vero, quae in libertate creata constituuntur, cognoscenda aeque manifesta est decreti divini necessitas; etenim ad futura illa cognoscenda praerequiritur aeterna praedeterminatio disiunctiva Dei ad hoc, ut futura sint pro libito creaturae, id est, ad hoc, ut ipsa eligat unum eo duobus extremis liberis, quin utrumque omitti possit. Hanc determinationem habet futurum liberum a decreto Dei, et per illam constituitur proxime in libertate creaturae. Ergo, ut futurum liberum sit, et, consequenter, ut a Deo cognoscatur, necesse est divinam essentiam determinari per huiusmodi decretum. De se enim indifferens est Deus ad volendum et nolendum dare creaturis potestatem et concursum indifferentem ad operandum.

376. Si autem dicas, decretum illud requiri quidem ad esse futuri liberi, attamen ad divinam eius cognitionem per accidens se habere, -

Implicas manifeste in terminis, nam aeterna cognoscibilitas futurorum non potest materialiter se habere ad illorum cognitionem. Si haec perfecta sit, cognoscibilitas illa necessario includere debet aeternam aptitudinem futurorum ad existendum,

293. Caietanus: In Primam partem q. 14 art. $13 \$ 17$, ed. Leon. t.4, 190 ob.

294. Ionnnes Duns Scotus: I Ord. dist. $39 \$ 23$, Opera omnia ed. L. Wadding, Lyon 1639, t.5, 1307-08.

295. „Dici [...] valeat, illam causalem, ideo existit scientia, quia decretum praeextitit, vel, ideo Deus cognoscit creaturas futuras, quia decrevit earum futuritionem' non probare, decretum habere rationem causae cum vera et stricta prioritate ad scientiam visionis, sed innuere solum, dari connexionem inter decretum et scientiam liberam. [...] Adde [...], priusquam intelligatur decretum aliquod liberum, in Deo dari scientiam liberam, videlicet scientiam conditionatam seu mediam: nam huius obiectum contingens est [...] "PAulus Sherlog: Antiquitatum Hebraicarum Dioptra 1, 2, 47, ed. L. Wadding, Lyon 1651, 63 b. 
cum non sit aptum cognosci tanquam existens, nisi quod aptum est existens esse; aptitudo autem aeterna futurorum ad esse habetur per divinum decretum.

Praeterea: Deus, ut proxime aptus cognoscere futura, debet esse determinatus ad cognoscendum vel hoc vel illud extremum eligendum esse a creato arbitrio. Est enim aptus cognoscere futura per adaequatam sufficientiam proximam ex parte sua ad cognoscendum quod creatura libuerit: ita, ut nullo egeat ad cognoscendum nisi positione termini cognoscendi. Ergo Deus - ut aptus cognoscere absolute futura requirit, ex parte sua, decreta esse omnia illa quae creatum arbitrium proximum operationi constituunt, et consequenter, quod creatura determinata disiunctive sit ad aliquod e duobus extremis libertatis eligendum, et Deus ad aliquod ex illis cognoscendum. Hoc autem non [891r] praestat divina essentia sola, sed essentia ut determinata per decretum constituendi in tempore creatum arbitrium cum omnibus praerequisitis ad operandum. Hoc ergo praerequiritur ex parte Dei ut proxime cognoscitivi futurorum, et ex parte divinae essentiae ut proxime motivi ad illorum cognitionem.

Denique hoc idem probatur et explicatur, quia scientia futurorum affirmat duo: unum est ipsum futurum liberum, alterum vero existentia integrae causae et sufficientiae ad ipsum. Haec autem sufficientia ideo existit, quia Deus illam decrevit, ac proinde Deus ad illam cognoscendam determinatur vi sui decreti. Cum ergo scientia futuri sufficientiam illam affirmare debeat, necesse est decretum, vi cuius affirmatur, ad scientiam praecedere. Essentia ergo divina nonnisi decreto hoc affecta et determinata potest munus obiecti formalis scientiae futurorum exercere.

377. Sed quaeres $2^{\circ}$, quomodo requiratur determinatio essentiae divinae per decretum, ad rationem formalis obiecti futurorum - an scilicet ut conditio ad hoc, ut essentia exerceat adaequatum munus obiecti formalis, vel tanquam participans partialiter rationem formalem obiecti?

Respondeo, hoc secundo modo requiri. Quod supponunt proxime citati Doctores.

Et probatur, quia scientia absoluta futurorum necessario cognoscit decretum, a quo futurum dependet. Illud autem non cognoscit ut obiectum materiale, scilicet ut cognitum adaequate propter aliud: ergo ut formale.

Minor patet, quia imprimis nil datur, ob quod tanquam ob praedeterminativum et connexum cum decreto possit hoc cognosci, cum nil ad decretum indifferens, quo Deus ad futura concurrit, praerequiratur nisi divina essentia et cognitio possibilium, quae de essentiae divinae formali conceptu est. In his autem nil est quod praedeterminet ad decretum neque ad eius cognitionem. Sed neque datur aliquid distinctum a decreto, quod sit etiam sine praedeterminatione adaequatum motivum scientiae ipsius: quia, etsi divina essentia necessario debeat esse motivum scientiae decreti, at non est motivum adaequatum, cum decretum ipsum, ob suam 
infinitatem, sit propter se cognoscibile per infinitam cognitionem et aptum ad dandum illi esse. Cur ergo scientiam futurorum, per quam cognoscitur, non terminabit ut partiale obiectum formale motivi illius?

378. $3^{\circ}$ Quaeres, an decretum Dei sit obiectum formale non solum motivum, sed etiam absolute determinativum, divinae scientiae absolutae futurorum?

Respondeo et dico $1^{\circ}$, ad futura, quae a sola divina libertate pendent - quae scilicet in arbitrii creati electione non constituuntur -, decretum divinum esse non solum formale motivum, sed etiam determinativum, quia connectitur absolute cum illorum cognitione decretum, quo Deus ad illa concurrit, quia est decretum praedeterminativum ad unum. [891v]

379. Dico $2^{\circ}$ : Decretum indifferens, quo Deus ad futura nobis libera concurrere immediate debet, est non solum motivum, sed etiam determinativum absolute ad scientiam liberam disiunctivam, qua Deus cognoscit, futurum vi talis decreti fore, nisi libere impediatur a sua causa, ac proinde necessarium esse, quod existat vel quod libere a causa creata impediatur eius existentia. Quod non esset necessarium, nisi Deus id statuisset. Si enim statuisset oppositum, ut posset decernendo, quod vel unum extremum determinate existeret sine creata libertate ad oppositum, vel quod neutrum extremum libertatis existat, eo quod ad neutrum Deus potestatem concedat, nil esset a potentia nostra libere futurum nec cognitum a Deo. In decreto ergo, quo concedit Deus creaturae liberam potestatem operandi unum e duobus - quam in suo conceptu, saepe diximus, includere essentialem necessitatem disiunctivam eligendi unum vel alterum -, cognoscit Deus, unum vel alterum libertatis extremum fore, et consequenter de quolibet cognoscit, quod erit per causae creatae electionem, nisi ab ipsa libere eligente oppositum impediatur. Et cum hac scientia absolute et essentialiter connectitur decretum indifferens, quo Deus ad futura libera concurrere debet.

Conclusionem hanc invenio in S. Thома q. 16 De Malo art. 7 sub his verbis: "Quae sunt ad utrumlibet, non possunt praecognosci in suis causis determinate, sed sub disiunctione, utpote quod erunt vel non erunt: sic enim habent veritatem." Effectus ergo liber, qui per habitudinem ad causam se habentem "ad utrumlibet“ explicatur, licet non possit, iuxta S. Tномам, cognosci determinate in suis causis, potest tamen cognosci per scientiam disiunctivam, quia in illa ut complete potente, habet effectus contingens veritatem disiunctivam: quia necesse est, illud libere oriri a tali causa vel libere ab illa impediri. Ergo, cum a divino decreto indifferenti constituatur causa libera sic potens, ab illo determinabitur divinus intellectus ad disiunctivam scientiam liberam effectus aut libere futuri aut libere omittendi a sua causa.

$380.3^{\circ}$ Dico, decretum illud indifferens esse obiectum formale motivum scientiae absolutae, quam Deus habet de extremo libero, quod determinate futurum est, non tamen esse obiectum absolute determinativum talis scientiae. 
Conclusio est Authorum omnium, qui negant decreta praedeterminantia et concedunt, decretum, quo Deus concurrit ad futura, esse obiectum formale illorum. Ex his enim duobus evidenter sequitur, decretum esse formale motivum non determinativum determinatae scientiae futuri: eodem modo, quo diximus, divinam essentiam esse formale obiectum cognitionis futuri.

Probatio conclusionis aperta est, quia decretum illud ex una parte formaliter [892r] cognoscitur per determinatam scientiam futuri ab ipso pendentis (ut probavimus), ex alia vero parte non habet absolutam connexionem cum illa, quum indifferens sit ad scientiam oppositam: ob indifferentiam, quam habet ad oppositum obiectum. Ergo non est absolute determinativum talis scientiae.

381. $4^{\circ}$ Dico, in aliquo decreto non necessario ad futuri existentiam posse illud cognosci tanquam in absolute determinativo ad eius scientiam.

Haec conclusio explicabitur latius capite sequenti. Nunc breviter probatur, quia Deus potest absolute et efficaciter praedefinire actum bonum ut absolute futurum per media indifferentia, de quibus praecognovit per scientiam conditionatam, quod, quamvis indifferentia sint, si tamen ponantur, inferent effectum (ut libro $7^{\circ}$ ostendemus). Hoc autem decretum determinat absolute et essentialiter ad sui cognitionem et consequenter ad cognitionem futuri quod essentialiter infert.

382. Tandem dico $5^{\circ}$, in decreto indifferenti requisitorum et divini concursus indifferentis ad libere operandum ut coniuncto cum scientia conditionata operationis futurae sub illis requisitis - seu, quod idem est: in complexo ex scientia conditionata et decreto indifferenti, quo ponitur conditio - absolute cognosci futurum tanquam in obiecto formali determinativo.

Etenim complexum illud necessario cognoscitur per absolutam scientiam futuri, cum implicet, futurum absolute cognosci, et non cognosci ea sine quibus implicat, aliquid esse absolute futurum; implicat autem, aliquid absolute esse futurum, quin Deus cognoscat, illud conditionate futurum esse sub eisdem requisitis, a quibus habet absolute existere.

Deinde, complexum hoc cognoscitur a scientia absoluta ut formale obiectum, quia cognoscitur propter se. Licet enim non semper det esse divinae cognitioni per modum principii seu prius natura existentis (ut capite sequenti videbimus), attamen cognitio est propter ipsum tanquam propter finem, ob quem dignissimum est existere infinitam cognitionem.

Denique, complexum illud est obiectum essentialiter connexum cum absoluta scientia determinata futuri: ergo est obiectum formale determinativum illius.

An autem haec ratio determinativi conveniens absolutae praefinitioni ex se determinatae efficaciter ad unum, et complexo ex conditionata scientia et voluntate, qua ponitur conditio, ex se indifferenti ad duplex libertatis extremum, sit ratio determinativi primarii - et quo pacto habeat determinare -, dicemus capite sequenti. 


\section{Caput 29. [892v] An scientia absoluta futurorum cognoscat divinum decretum ad futura necessarium, ut existens prius ratione, aut etiam natura, quam ipsa scientia?}

383. Videbitur alicui, quaestionem hanc solutam iam esse in resolutione quaestionis secundae $[\$ 377]$, qua ostendimus, divinum decretum esse obiectum formale cognitionis futurorum. Ex hoc enim necessario sequi videtur, quod prius ratione existat quam cognitio illa.

Sed tamen haec sequela necessaria non est. Non enim ex eo, quod aliquid sit obiectum formale divinae cognitionis, oportet, quod prius ratione, nedum natura, existat quam talis cognitio: ut patet in cognitione essentiali personarum divinarum, ad quam non praeexistunt personae, sed potius sequuntur ad illam; ac proinde sunt obiectum formale essentialis cognitionis non ut infinientia per modum principii, sed per modum finis. Ad quem, propter se ipsum, tendit essentialis cognitio ut intrinsecam et necessariam perfectionem sui.

384. Respondeo ergo, decretum, quo Deus concurrit ad futurum contingens, non hoc secundo modo, sed ut existens prius ratione formaliter - et re ipsa prius fundamentaliter tanquam virtuale principium - exercere rationem obiecti formalis respectu scientiae absolutae futuri.

Hanc in decreto prioritatem rationis ad cognitionem absolutam futuri agnoscunt S. Tномаs, Scotus et caeteri Doctores citati initio huius capitis [ $\$ 375$ ] pro necessitate decreti ad hoc, ut essentia divina determinetur ad repraesentanda absolute futura. Et praeter communia S. Tномав loca singulariter facit ad hanc praecedentiam quod docet in $1^{\circ}$ [Sententiarum] dist. 39 q. 1 art. 1 ad ultimum argumentum, quo contenditur probare, Deum non posse non scire id quod scit futurum esse, ex eo, quod scire Dei sit eius esse; non potest autem non esse, quod est: ergo nec non scire quod scit. Respondet: Licet idem realiter sint scire et esse, „tamen scire sequitur voluntatem ut imperatum ab ipsa, esse autem non“.

385. P. Ruiz disp. 26 De Scientia Dei sect. 5, respondet huic probationi, scientiam „sequi“ voluntatem divinam non sufficienter probare, quod voluntas sit prius ab aeterno existens quam scientia; etenim divina scientia nostram etiam voluntatem sequitur, et tamen non supponit illam prius existentem. ${ }^{296}$

296. „Scire futura contingentia ,sequitur' divinam volitionem, quantum ad indifferentiam, ut Deus sciat, hanc rem esse futuram, vel sciat, illam non esse futuram. Sicut enim Dei voluntas impedire potuit, ne talis res esset futura, sic etiam potuit efficere, ut ab aeterno Deus non sciret esse futuram. Sic etiam creata voluntas potest efficere, ut non sit eius volitio: unde sequeretur, suam volitionem non fuisse ab aeterno praecognitam ut futuram. Sicut autem haec consecutio divinae scientiae ex voluntate humana non infert, humanam voluntatem actualiter existere 
Sed hoc dupliciter refellitur:

$1^{\circ}$ Quia eo ipso, quod dicatur, aliquid esse "prius“ alio existens, si eius existentia sit essentialiter aeterna, non potest non esse prius existens ab aeterno: sicut, quod temporaliter solum existit, si existat „prius“, existet prius temporaliter saltem quoad exigentiam temporalis durationis; non enim semper in omni priori naturae, quo res [893r] temporalis existens est, existit formaliter eius duratio, cum ipsa - in communi sententia - praecedat natura ad suam durationem et tamen in illo ipso priori est temporaliter existens quoad exigentiam temporalis durationis. Si ergo „sequitur" ad divinam voluntatis existentiam scientia futurorum, necesse est, quod ad illam ut existentem ab aeterno - per essentialem saltem determinationem ad aeternitatem - subsequatur.

$2^{\circ}$ Refellitur, quia S. Doctor specialiter indicat eam voluntatis praecedentiam per imperium, vi cuius, dicit, „sequi“ divinam scientiam ad divinam voluntatem; nam „imperium“ hoc est principium imperati. Advertendum tamen est, „imperium" hoc, quo S. Doctor docet, divinam scientiam absolutam imperari a voluntate, non esse determinatum ad unius potius quam alterius extremi praescientiam, sed indeterminatum et disiunctivum, quo Deus efficaciter statuit, quod creata voluntas unum aut alterum extremum determinet, et consequenter, quod extremi alicuius ab ipsa determinandi habeatur praescientia. S. Tномам sequuntur SuAREz lib. $1^{\circ}$ De Scientia Contingentium cap. $6 \mathrm{n} .1,{ }^{297}$ et tomo $1^{\circ} \mathrm{De}$ Gratia Proleg. 2 cap. 9 n. $8,{ }^{298}$ Vazquez Prima parte disp. 64 cap. 4 , et disp. 65 cap. etiam $4{ }^{299}$ Becanus Prima parte cap. 10 q. $11,{ }^{300}$ et caeteri Recentiones communiter, a quibus sine causa recedit P. RuIz loco supra citato.

386. Resolutio ergo nostra et communis probatur: quia Deus intuetur decretum liberum suum non ut existat, sed, quia existens est; nam licet, se posse libere decernere hoc vel illud ideo cognoscat, ut decernat alterutrum: at, se unum illorum decernere, ideo cognoscit, quia decernit: cum in ipsius potestate sit, per decretum

prius ratione, quam divinam praescientiam, ita non infert, voluntatem divinam prius actualiter existere." Didacus Ruiz de Montoya: Commentarii ac Disputationes de scientia Dei 26, 5, 12, Paris $1629,223 \mathrm{~b}$.

297. Franciscus Suarez: Opera omnia, Paris 1856-78, t.11, 312a. Das ist aber lediglich Referat. Anschließend (Varia opuscula theologica 2, 1, 6,3) wird festgestellt: „Haec sententia, ita generatim proposita, mihi non probatur.“

298. Franciscus Suarez: Opera omnia, Paris $1856-78$, t.7, 111a/b.

299. Gabriel Vazquez: Commentaria ac Disputationes in Primam partem S. Thomae 65, 23, Opera omnia, ed. M. Chossat, Paris 1905, t.1, 539b. Die andere Referenz ist nicht verifizierbar.

30o. Martinus Becanus: Summa theologiae scholasticae 1, 1, 10, 11, 2, Rouen 1657, 67b. 
determinare scientiam decreti, aut per decreti suspensionem determinare carentiam scientiae de existentia talis decreti. Ob quam rationem creatos ipsos actus liberos cognoscit Deus, quia existunt, et non, ut existant. Prius ergo est ratione nostra, et creatos et increatos actus liberos existere, quam, Deum de illis scientiam habere. Prius enim existit id, quo libera causa determinat suam potestatem indifferentem ad esse aut non-esse alterius, quam, hoc esse aut non esse, quando tale esse distinguitur ab ipsa libera determinatione talis indifferentiae. Ex hoc - de quo non dubitat RuIz - manifeste sequitur, prius ratione existere ab aeterno decretum Dei quam scientiam de illo: quia non potest aliter existere nisi ab aeterno. Ergo, si ad scientiam supponitur decretum existens, necesse est, quod supponatur ut ab aeterno existens.

387. Ex quo patet, inanem esse considerationem, qua huic veritati opponitur P. RuIz, scilicet, quod decretum Dei, etsi "non existeret ab aeterno, sed in tempore“, sufficeret ad futuri existentiam et ad aeternae cognitionis determinationem. ${ }^{301}$

Hoc enim assumptum omnino falsum est, quia existentia futuri requirit decretum Dei formaliter ut aeternum. [893v] Requirit enim illud ut divinum, cum requirat Deum ut voluntarie causantem. Sicut ergo virtus non-divina insufficiens foret ad esse futuri, sic decretum non-divinum; omne autem divinum vel est formaliter aeternum vel saltem essentialiter determinatum ad non-existendum nisi ab aeterno: ergo eo ipso, quod futurum petat et supponat decretum ut divinum, supponit et petit essentialiter, quod existat ab aeterno. At scientia futuri supponit decretum Dei eo modo, quo requiritur ad futurum: supponit ergo illud formaliter ut aeternum.

Dices: Si - per impossibile - decretum Dei inciperet in tempore, Deus illud cognosceret: ergo non requirit eius aeternam coexistentiam ad hoc, ut illud cognoscat.

Respondetur distinguendo antecedens: „cognosceret“ illud ut divinum: nego; ut non-divinum: concedo et nego consequentiam: quia decretum suum cognoscit Deus ut divinum ac proinde ad illud cognoscendum requirit aeternam eius coexistentiam non minus quam requirit eius existentiam.

Quod si ob hanc cognoscibilitatem decreti - in suppositione impossibili, qua inciperet esse in tempore - liceret inferre, quod nunc non cognoscatur ut prius ratione nostra existens ab aeterno, sed ut futurum, nullum ex divinis praedicatis, quantumcunque necessariis, cognosceret Deus ut existens, sed omnia ut ratione nostra futura, quia si, per impossibile, non essent ab aeterno, sed inciperent esse, cognoscerentur a Deo ab aeterno.

Quod si dicas, eo ipso, quod praedicata necessaria Deum constituentia temporalia essent, nullum ab aeterno dandum foret cognoscitivum, ac proinde praedicata illa non essent ab aeterno cognoscibilia, -

301. Didacus Ruiz de Montoya: Commentarii ac Disputationes de scientia Dei 26, 5, 10, Paris $1629,223 \mathrm{a}$. 
Contra, quia idem de decreto divino dici necesse est: quia eo ipso, quod temporale foret, non posset ab aeterno cognoscibile esse ut divinum, nec posset Deus esse illius ut divini cognoscitivus. Similiter nec futurum obiectum creatum esset $\mathrm{ab}$ aeterno cognoscibile, quia implicat futurum esse, nisi dependenter a decreto ut divino et consequenter ut aeterno.

Denique, contra P. RuIz manifesta - ni fallor - ad hominem argumentatione uti possumus, quia IPSE disp. 28 sect. 7 et 8 defendit, ad hoc, ut Deus futura cognoscat necessarium esse, quod ab aeterno praesentia sint aeternitati, eo quod ad aeternam cognitionem obiecti etiam temporalis necessaria sit aeterna eius cognoscibilitas: ergo, ut decretum Dei sit ab aeterno cognoscibile, praeexistere debet ad cognitionem aeterna decreti cognoscibilitas aeternaque praesentia decreti ad aeternitatem; at praesentiam hanc ad aeternitatem non habet decretum per aliquod esse a se ipso distinctum: nam, si per se ipsum praesens est aeternitati, irrationabiliter quaeritur aliud ab ipso distinctum, ut praesens sit.

388. Sed tamen pro absoluta scientia decreti divini ut ratione nostra futuri obiicies, ante decretum dari signum indifferentiae ad eius esse et non-esse cum necessitate ad hoc, ut sequatur determinate unum [894r] vel alterum decretum liberum: ergo in illo priori cognoscibile a Deo erit determinate, quodnam illorum decretorum subsequetur ad divinam indifferentiam.

Consequentia probatur, quia ex eo, quod ab aeterno necesse sit, unum vel alterum extremum libertatis creatae in tempore sequi, cognoscibile est a Deo in illo priori reali aeternitatis, quodnam illorum determinate sequetur: ergo, cum eadem necessitas praecedat in signo indifferentiae divinae ad decreta libera opposita, cognoscibile erit in illo - vel saltem in alio subsecuto ad ipsum, sed tamen ratione nostra praecedente decretum -, quodnam determinate exercebit Deus. Cognosci ergo debet a Deo decretum ut futurum, id est ut subsequens ad cognitionem, qua cognoscitur. ${ }^{302}$

389. Respondetur concedendo primum antecedens et negando consequentiam.

Ad cuius probationem respondeo, ex necessitate aeterna disiunctiva obiecti $f u$ turi in tempore sequi, dandam esse aeternam cognitionem determinatam eius quod futurum est, non tamen ex necessitate disiunctiva decreti virtualiter praecedente sequi determinatam cognitionem - virtualiter aut ratione nostra - praecedentem ad existentiam decreti: quia ex eo, quod necesse sit, aliquod e duobus determinate sequi, quod infertur est, Deum debere determinate cognoscere, quodnam illorum sequetur cognitione Deo possibili; nulla autem possibilis est nisi aeterna: cum aeternitas sit apta et necessaria mensura omnium divinorum. Unde, quod probat, dari in

302. Vgl. Franciscus Suarez: Varia opuscula theologica 2, 2, 3, 6, Opera omnia, Paris 1856-78, t.11, p. 353b. 
Deo cognitionem futurorum, probat, dari cognitionem aeternam prius existentem quam obiectum suum temporale, cum aeternum necesse sit prius esse temporali. Ex quo patet, nullam esse consequentiam a prioritate cognitionis futurorum ad prioritatem cognitionis decretorum Dei: quia illa cognoscuntur ut temporalia per cognitionem aeternam, decreta vero ut aeterna et consequenter ut duratione aequalia suae cognitioni.

390. Patet etiam, rationem inferendi illam consequentiam [ $\$ 388]$ esse nullam; nam aeterna necessitas, ut existat hoc vel illud futurum, non ideo probat cognitionem aeternam, quia necesse sit pro priori, in quo datur disiunctiva necessitas, existere scientiam determinatam eius quod sequetur in posteriori. Hoc enim falsum esse, patet in ipsamet cognitione determinata futuri: quia illam non habet Deus pro priori, in quo datur necessitas disiunctiva, ut hoc vel illud determinate sequatur in tempore. Illud enim signum prius disiunctivae necessitatis est indifferentis causae futurorum ac proinde nil continet quod non habeat rationem indifferentis et causativi; scientia autem futuri contingentis nec est indifferens ad eius existentiam nec causa illius: existere ergo nequit in priori disiunctivae necessitatis ad hoc, ut sequatur unum vel alterum extremum libertatis creatae.

391. Ratio ergo, cur aeterna necessitas disiunctiva futuri huius vel [894v] illius extremi probat determinatam cognitionem aeternam, est, quia necessario infert illam pro signo posteriori naturae; et quia hoc signum, etsi posterius natura sit ad signum necessitatis disiunctivae, mensurandum necessario est per aeternitatem - eo quod sit divinum -, ideo disiunctiva necessitas ad hoc, quod in tempore sequatur unum vel alterum, infert cognitionem obiecto aeterna duratione priorem. Cognitio autem, quam praevia necessitas divina habendi aliquod decretum infert de decreto, quod determinate exercetur, non habet similem ullam formalitatem ratione cuius prioritatem respectu decreti participet: nam nec participat prioritatem durationis - quia duratio aeterna, quam habet, non excedit durationem decreti, quae aeterna quoque est - nec habet prioritatem naturae (ut vidimus) neque etiam rationis, cum potius decretum ratione praecedat sui cognitionem, cum ideo cognoscatur, quia est, et non e contra, et influat per se in sui cognitionem (ut videbimus). Nullo ergo titulo ad decretum praecedit eius cognitio ac proinde nec ipsum ut futurum cognoscit.

Haec satis probant in decreto indifferenti Dei prioritatem rationis respectu scientiae determinatae futuri, cuius decretum illud est necessarium obiectum.

392. Virtualis autem prioritas principii respectu eiusdem scientiae, quam in quaestionis praesentis resolutione asseruimus [ $\$ 384$ ], habere decretum indifferens Dei, patet ex proportione decreti divini cum scientia futurorum in ordine ad illam virtualiter causandam:

Quia, imprimis, aeque infinitum essendi modum habet decretum ac scientia. 
Deinde, ab illa virtualiter distinguitur, cum - habito decreto concurrendi ad futura - indifferens sit Deus ad habendam scientiam huius determinate futuri vel illius: cum decretum ad utrumque indifferens sit.

Et denique, est prius existens quam scientia: quia hanc prioritatem indifferentia ipsa decreti ad esse et non-esse scientiae huiusque determinata connexio cum decreto probat, decretum prius existens esse. Cum ergo debeat per modum obiecti formalis influere in scientiam, influet praeexistendo. Quod est esse virtuale principium scientiae.

393. Hac ratione non convincitur in decreto indifferenti Dei habitudo virtualis principii respectu omnis scientiae absolutae ipsius decreti, sed respectu scientiae, qua decretum cognoscitur cognoscendo eadem indivisibili tendentia futurum quod ex illo decreto consequetur: quia futuri scientiam necesse est a decreto virtualiter distingui et ad illud subsequi, non tamen est necesse omnem divinam cognitionem etiam absolutam - eiusdem decreti ad illud subsequi nec virtualiter intrinsece ab illo distingui: quia Deus independenter a futuro, quod aeternitate consequetur in tempore ad suum decretum indifferens, et prius ratione aut etiam natura, quam illud cognoscat, cognoscit suum ipsum decretum. Huius [895r] enim cognitio essentialiter connectitur cum decreti ipsius existentia, non vero determinata ea creati obiecti liberi ex decreto secuturi praescientia. Ante hanc ergo dicimus Deum decretum suum in se ipso cognoscere, nullumque esse fundamentum ad hanc scientiam a decreto ipso virtualiter intrinsece distinguendam, cum nulla dentur opposita praedicata, quorum unum necesse sit re ipsa convenire decreto et alterum scientiae. Solum ergo distinguetur a scientia ratione nostra et distinctione virtuali extrinseca: qua scilicet opposita praedicata conveniant scientiae et decreto non secundum esse suum intrinsecum, sed secundum extrinsecum, quod in ratione nostra habent, fundamentum aliquod praebente divina illarum formalitatum eminentia, qua obiectis et scientiis creatis ad invicem realiter distinctis aequivalent.

\section{Caput 30. Tres aliae quaestiones solvuntur}

394. Prima quaestio sit, quo sensu decretum Dei respectu scientiae futurorum sit obiectum formale „prius cognitum“?

Respondetur, duplici sensu id verum esse:

$1^{\circ}$ quia cognitio decreti est prior cognitione futurorum; nam Deus (ut iam probavi) ante scientiam futurorum, qua cognoscit suum decretum, habet aliam priorem eiusdem decreti ut existentis cognitionem;

$2^{\circ}$ quia Deus per ipsam futurorum praescientiam cognoscit, decretum esse prius ipsamet scientia ut rationem cognoscendi futura et dantem esse cognitioni illorum, - cognoscit, inquam, hoc indivisibiliter per ipsam tendentiam qua respicit 
futurum ut a decreto dependens, sine ulla virtuali distinctione intrinseca inter tendentiam ad futurum et tendentiam ad decretum: quia ad futurum tendit cognitio divina tendentia comparante ipsum cum causis, a quibus oritur tam futurum quam ipsa cognitio, ac proinde necessario tendit ad decretum tanquam ad rationem dantem esse divinae cognitioni.

Ex quo fit, decretum esse existens in cognitione decreti cum prioritate dantis esse cognitioni. Qua prioritate carent futura. Licet enim dicantur "prius esse quam cognosci“, attamen haec prioritas non est principii dantis esse, sed pure determinantis; ideoque decretum, et non futurum, est prius cognitum - seu cognitum ut prius et dans esse - per scientiam absolutam futurorum.

395. Secunda sit, an ipsamet absoluta scientia futuri est formale obiectum sui?

Respondetur affirmative ac proinde, esse formale obiectum ad cognoscendum futurum. Etenim haec scientia necessario cognoscit [895v] se ipsam reflexe per eandem indivisibilem tendentiam, qua cognoscit secum obiectum directum, sine intrinseca distinctione virtuali inter huiusmodi tendentias. ${ }^{303}$ Sine fine enim procedendum esset in formalitatibus distinguendis, si, quae tendit directe ad obiectum quodlibet, non posset in se ipsam reflecti. Est ergo cognitio illa obiectum sui; at non materiale - id est, cognitum praecise propter aliud, et non propter se -, quia est propter se cognoscibile, cum infinitam habeat cognoscibilitatem obiectivam: ergo est formale obiectum sui ac proinde specificativum et dans esse sibi - non quidem effective ut quid praesuppositum, sed - ut specificativum formale seu formaliter constituens, quod ita solum est obiectum, ut sit etiam forma et essentia cognitionis, quae propter se dicitur cognita a se ipsa: quia est cognitio sui propter se existens. Quod non tollit, quin etiam existat propter caetera praedicata Dei, quae cognoscit, ac proinde haec quoque sint formale obiectum talis cognitionis. Nullum enim praedicatum Dei est ita existens propter se, ut non existat etiam propter caetera, ideoque quodlibet sibi ipsi et omnia ad invicem sunt sibi ipsi fines et rationes propter quas existunt, cognoscuntur et amantur, ut Tractatu de divinis perfectionibus ${ }^{304}$ in communi late ostendi.

396. Tertia quaestio sit, an ad scientiam futuri liberi requiratur decretum Dei formaliter liberum: ita ut implicaret futuri libertas et consequenter eius - inquantum liberi - praescientia, si Deus decreto non libero, sed ex naturae necessitate orto, concurreret?

Scotus supra $[\$ 375]$ citatus respondet affirmative, quia divinam libertatem ait esse radicem omnis contingentiae et libertatis creatae, ita, ut, si Deus ex necessitate naturae operaretur, nulla dari posset creata libertas. CAPREOLUS vero, CONRADUS,

303. Die seit Suárez (Franciscus Suarez: Disputationes metaphysicae 25, 1, 39, Opera omnia, Paris $1856-78$, t.25, 910a) sogenannte Virtualreflexion. Vgl. $\$ 438$.

304. Das I. Buch des vorliegenden Werks. 
Caietanus et antiquiores Thomistae, quibus consentiunt Suarez, Vázquez et caeteri Nostrorum communiter, quos citat et sequitur Ruiz De Scientia Dei disp. 52 sect. 3, docent, quod, quamvis Deus ex naturae necessitate produceret creaturas et cum illis concurreret, nihilominus hae libere operarentur, si indifferentem illis Deus concursum praestaret; nec sequi, quod praestare deberet determinatum et necessitantem ex eo, quod ipse naturae necessitate operaretur. ${ }^{305}$ Ex quo principio colligunt NonNulli, decretum Dei formaliter ut liberum non requiri ad futurorum praescientiam.

397. Sed imprimis, collectio haec inepta est. Nam necessitas decreti liberi ut liberi est ad scientiam futurorum simpliciter possibilem. Ergo, licet posset Deus in casu impossibili per decretum ex naturae necessitate ortum habere aliud genus scientiae futurorum contingentium, non sequitur, quod ad scientiam futurorum contingentium simpliciter dictam, quae est scientia simpliciter possibilis, non requiratur Dei decretum formaliter ut liberum. Requiritur ergo, quia simpliciter aeque [896r] impossibile est, Deum non esse creaturarum dominum illis pro libito suo utentem et illis libere dantem esse, ac, Deum non esse illarum causam. Ergo non minus formaliter requiritur decretum Dei ut liberum ad creaturarum existentiam quam requiritur eius decretum, eius omnipotentia, et essentia.

398. Hinc patet, minus recte Scotum dixisse, quod, si Deus necessitate naturae moveret creaturas, earum operationes essent necessariae. Quod enim directe sequitur, est, creaturas nec operari nec existere posse: quia ad existendum petunt ex formali conceptu suo, Deum non utcumque, sed dominative, causantem ipsas, scilicet pro libito dantem illis esse, quod negare posset, si vellet. Si autem existerent et operarentur per concursum, quem nunc illis praestat Deus, quamvis illum necessario praestaret, libere operarentur.

Sequeretur tamen in illo casu aliqua necessitas simpliciter in operationibus creatis, quae modo non datur, scilicet necessitas disiunctiva ad aliquod e duobus liberis extremis operandum. Quae extremorum libertati nequaquam repugnat. ${ }^{306}$

305. Didacus Ruiz de Montoya: Commentarii ac Disputationes de scientia Dei, Paris 1629, 499-501.

306. Zur formalen Struktur dieser, disjunktiven Notwendigkeit' vgl. die folgende Stelle aus Lib. II cap. 1 An omnis determinatio ad unum sit necessitas, et omnis necessitas determinatio ad unum?: [fol. 176r] „[...] ad secundam quaestionis partem respondendum est, omnem necessitatem esse determinationem ad unum, quia, unum aliquod esse necessarium, est, non posse illud non esse, impossibilemve esse eius carentiam. Omnis ergo necessitas est determinatio ad unum illud quod denominat necessarium, talis scilicet connexio cum eius existentia, ut repugnet eius carentia. Haec, licet vel ex ipsis terminis sint nota, in dubium revocare videtur conceptus necessitatis disiunctivae, qua unum e duobus haberi $[176 \mathrm{v}]$ aut fieri necesse est, quin ad aliquod illorum determinate sumptum necessitas illa feratur. Quo ergo sensu de hac necessitate verum est, quod de 
Hanc necessitatem disiunctivam de facto habet creatura, quae libere operatur, sed tamen contingenter et libere collatam a Deo: quia posset, creatis voluntatibus existentibus, nolle, quod aliquid extremum libertatis operarentur; sed, quod in suspensione necessaria ab omni actu manerent, vel, quod unum extremorum ex necessitate operarentur. In casu vero impossibili, quod ex necessitate naturae vellet quae nunc vult libere, non esset contingens, sed necessarium simpliciter, creaturas habere actum primum proximum libertatis, quem nunc ex divino beneplacito habent. In hoc autem actu primo includitur necessitas disiunctiva eligendi alterutrum e duobus extremis. Ergo haec necessitas disiunctiva aliquid operandi non foret - in eo casu - contingens, sed simpliciter necessaria creaturis. Attamen id (ut dixi) non obstaret libertati creatae, quia haec non petit indifferentiam habendi et non habendi actum primum operativum oppositorum et consequenter indifferentiam habendi et non habendi disiunctivam necessitatem operandi in illo inclusam. Sufficit enim

necessitate in communi diximus, eam scilicet esse debere determinationem ad unum? Respondeo, unum illius extremum, ad quod dicimus determinari necessitatem, non oportere quod sit tale per unitatem indivisibilitatis in pluras, circa quae possit esse indeterminatio, sed posse esse unum per collectionem plurium. Hoc modo ,unum' est id, ad quod determinat necessitas disiunctiva duorum. Nam utrumque respicit cum determinatione excludente indifferentiam ad totius collectionis carentiam, id est ad carendum simul utraque parte talis collectionis. Hanc enim respicit cum determinatione ad non-carendum utraque illius parte simul ac proinde cum necessitate respiciente utramque partem ut oppositam carentiae utriusque simul sumpti. Necessitas enim disiunctiva non fertur ad unam tantummodo partem collectionis, circa quam est disiunctio, sed ad utramque, non colligendo utramque seu utramque ut collective et simul habendam exigendo, sed disiunctive, ita scilicet, ut eius exigentia sufficiat haberi quamlibet collectionis partem sine altera. Determinat ergo et necessitat ad collectionem disiunctiva necessitas tanquam ad unum excludendo indifferentiam ad carentiam collectivam totius collectionis, etsi includat indifferentiam ad eandem collectionem seu quamlibet eius partem ut comparatam cum carentia divisiva sui, id est cum carentia non negante simul alteram partem, sed potius illam ponente, ut negatam tollat. Indifferentia ergo disiunctivae necessitatis ad amorem, v.g., aut odium hic et nunc habendum est capacitas habendi quemlibet horum actuum et carendi quolibet per alterius existentiam. Determinatio vero eiusdem necessitatis est haec eadem capacitas cum incapacitate carendi utroque simul sumpto. In hac ergo necessitate datur determinatio ad unum, id est capacitas ad illud cum incapacitate ad oppositum. - Si autem opponas, hanc determinationem - etiam ut ,determinationis' et ,necessitatis' conceptum habet - esse disiunctivam; ut disiunctiva autem est, non determinat ad unum, sed cum disiunctione respicit plura: ergo, - respondetur distinguendo antecedens: „est disiunctiva“ inter partes collectionis ad invicem comparatas: concedo; „est disiunctiva“ inter has partes et collectivam earum carentiam: nego. Ex quo fit, eam non esse necessitatem aut determinationem ad partes ut invicem comparatas, id est ad unam prae alia habendam - ad hoc enim datur indifferentia -, esse vero necessitatem et determinationem ad easdem partes ut comparatas cum negatione collectiva [177r] sui: quia partium capacitatem et exigentiam habet cum incapacitate simul carendi utraque: determinat ergo ad non carendum utraque parte simul cum indifferentia ad cuiuslibet existentiam et negationem unius divisim ab alia habendam." 
libertati indifferentia ad determinationem actualem huius potius operationis quam illius: ut patet in Deo, qui simpliciter, sine ulla contingentia, necessitatus disiunctive est ad aliquid decernendum circa creaturas - quod, scilicet, sint aut non sint -, etsi summa libertate circa illas versetur.

\section{Caput 31. De obiecto determinativo divinae scientiae absolutae futurorum contingentium}

[896v]

399. Ratio obiecti determinativi est praedicatum quoddam commune, quod non solum obiecto formali, sed etiam obiecto materiali, convenire potest. „Obiectum“ enim „determinativum“, ut ad praesens attinet, vocamus id, quo divina indifferentia cognoscendi hoc vel illud determinatur ad hoc potius cognoscendum quam illud. Sic autem determinatur per obiectum, quod ex una parte habeat determinatam exigentiam, ut ipsum - et non oppositum - cognoscatur a Deo, et ex alia supponat, indifferentiam Dei ad oppositas cognitiones non esse antecedenter determinatam.

Ut haec praenotatio probetur, adverto, illam non procedere de cognitione, quae vel nullum habeat principium, etiam virtuale, vel illud habet omnino determinatum ex se ad cognitionem, quam exercet, et repugnans cum eius carentia. Huiusmodi enim cognitio alio sensu obiectum „determinativum“ habere dicitur, scilicet vel negative - quatenus petit, non dari aliud prius determinans ad cognitionem; unde ipsa, quando principio virtuali caret, dicitur obiectum „negative determinans“ ad se ipsam: sicut dicitur „esse a se“, quia non est ab alio -, vel etiam positive dici poterit „determinativum sui“: sicut et „esse a se“, quia est positive sibi sufficiens ad esse et repugnans cum non-esse sui. Haec sufficientia ad esse et repugnantia cum non-esse sui excludens aliud prius, a quo sit, dicitur in cognitione nullum habente principium „habere rationem determinativi sui ipsius ad esse“. In iis vero cognitionibus, quae principium habent, si hoc careat indifferentia ad cognitiones oppositas, principium ipsum est determinativum cognitionis, si sit prima ratio exigendi ipsam. Unde generaliter respectu cognitionis necessariae: Ratio determinativi solum constituitur per hoc ${ }^{307}$ esse primam rationem exigendi determinate cognitionem, diciturque "determinativa" non determinatione primo tollente indifferentiam praecedentem, sed primo repugnante cum eo, quod ulla indifferentia praecedat.

40o. Praecedens ergo adnotatio procedit de cognitione, quae virtuale principium habet, et contingentiam ad esse. Quorum utrumque habet divina futurorum cognitio. De hac ergo patet, quod eius obiectum determinativum debeat esse determinata exigentia cognitionis supponens indifferentiam ad ipsam et oppositam. Etenim, si 
obiectum aliquod supponat hanc indifferentiam per aliud determinatam ad huiusmodi obiectum cognoscendum, non poterit hoc proprie dici „determinativum“ ad sui cognitionem, quia determinatio contingens est alicuius determinabilis: non est autem aliquid proprie determinabile ab alio ad id, ad quod ex se determinatum supponitur: obiectum ergo, quod proprie determinat Deum ad cognoscendum, debet esse determinata exigentia cognitionis non utcumque, sed prima, id est, non supponens cognitionem ab alio determinate petitam.

401. Ex quo patet, in sententia asserentium, quod ad scientiam [897r] futuri contingentis necessario debet praecedere decretum determinans ad esse et scientiam talis contingentis, non posse ipsum futurum contingens dici obiectum determinativum praescientiae sui: quia ante esse futuri supponitur Deus determinatus ad illud sciendum, cum hanc determinationem inducat decretum efficax futuri, quod id huius existentiam natura praecedit, ideoque admittentes eiusmodi decreta omnino negant, futura esse obiectum determinativum divinae scientiae. Et qui decreta illa inficiantur, supponunt, consequenter procedere eorum assertores, dum futuris negant rationem obiecti determinativi.

402. Hinc consurgit in nostra sententia - et decreta inficiante - ratio dubitandi de divinae scientiae absolutae obiecto determinativo.

Nam, ex una parte, videtur, eiusmodi determinativum esse ipsummet obiectum futurum, cum negetur praedeterminatio ad illud. Ex alia vero parte videtur neganda futuro ratio obiecti determinativi, quia agnoscendum videtur aliud determinativum ipso absoluto obiecto prius. Nam, imprimis, ad aliqua obiecta contingentia absoluta praecedit praedefinitio absoluta ipsorum ex intrinseco suo modo tendendi efficax. Haec autem necessario determinare debet Deum ad absolutam futuri praescientiam, quia essentialem connexionem habet cum illa et non supponit aliud obiectum cum illa connexum.

Deinde, ad omnium obiectorum contingentium absolutam scientiam supponitur, Deum scire conditionate, quod erunt, et supponitur voluntas ponendi conditionem, sub qua praevisum est conditionate, quod erunt. Quae conditio constituitur causis et requisitis, per quae futurum absolute existit. At complexum ex scientia conditionata et voluntate ponendi conditionem est obiectum formale scientiae futurorum et determinativum illius, quia est obiectum connexum cum ipsa et non supponens aliud determinans ad eius esse. Hoc ergo complexum - et non ipsum futurum - est obiectum determinativum scientiae, quam Deus de eius futuritione habet.

403. Prima conclusio: Quoties Deus efficaciter praedefinit futura contingentia per efficaciam natura praecedentem ad illa, obiectum determinativum scientiae absolutae illorum est praedefinitio. 
Patet conclusio ex ratione dubitandi, quia eiusmodi praefinitio est essentialiter connexa cum absoluta scientia actus praedefiniti nil aliud praesupponens cum tali scientia connexum. Solum enim supponit conditionatam futuritionem et scientiam actus liberi per media indifferentia, ex qua immediate procedit Deus ad praedefiniendum futurum per illorum mediorum positionem. Hac ergo praedefinitione se determinat ad sciendum absolute futurum vel inferendo scientiam illius virtualiter intrinsece distinctam a praefinitione, [897v] ut ALIQui existimant, vel - quod EGO verius iudico [\$393] - habendo identificatam formaliter cum praedefinitione scientiam illius et futuri in illo.

Haec ratio probat manifeste, aliquem actum scientiae divinae absolutae habere praedefinitionem hanc, quando datur, pro obiecto determinativo, et non ipsum futurum, quia antecedenter ad illud determinatus est Deus vi praedefinitionis, quae futurum causaliter antecedit, ad absolutam eius cognitionem habendam. (An autem futura eo modo praedefinita cognoscantur alio actu scientiae absolutae, ad quem non praedefinitio, sed ipsum obiectum futurum, determinat, dicemus conclusione tertia.) Praesens conclusio supponit, non esse necessarium, quod Deus hoc genere praedefinitionis omnia futura contingentia, etiamsi bona et supernaturalia sint, praedefiniat. ${ }^{308}$ Quod docet SuArez lib. $2^{\circ}$ De Concursu Dei cap. 7, ${ }^{309}$ RuIz disp. 25 De Scientia Dei sect. 8, et disp. 26 sect. $2,^{310}$ et nos late ostendemus libro $7^{\circ}$, immo etiam probabimus, non esse de facto sic praedefinita omnia libera bona naturalia.

404. Secunda conclusio: Obiectum determinativum ad absolutam scientiam futurorum non sic praedefinitorum - qualia sunt non solum omnia mala, sed etiam plurima bona - est ipsa futurorum existentia et non aliud antecedens.

Haec est sententia omnium, qui negant determinationes antecedentes ad futura contingentia; et probatur, quia ad futura, de quibus conclusio procedit, non datur aliquid antecedens quod ad absolutam illorum scientiam determinare possit. Nil enim natura praecedit quod indifferens non sit ad futurum et eius negationem.

405. Dices, praecedere complexum ex scientia conditionata et voluntate ponendi conditionem.

Sed contra, quia, licet voluntas ponendi conditionem - seu requisita, a quibus futurum absolutum habet suum esse - praecedat ad futuri absoluti existentiam, attamen scientia conditionata nequaquam praecedit natura ad eiusmodi futura,

308. praedefiniant corr.

309. Franciscus Suarez: Varia opuscula theologica 1, 2, 7, 11, Opera omnia, Paris 1856-78, t.11, $143 \mathrm{a} / \mathrm{b}$.

310. Didacus Ruiz de Montoya: Commentarii ac Disputationes de scientia Dei 25, 8, 1; 26, 2, 1, Paris 1629, 210b. 218a. 
cum voluntas divina determinet positionem requisitorum, a quibus futura dependent, omnino independenter a praescientia conditionata extremi libertatis, quod futurum est; nam, si dependenter a tali praescientia decerneret requisita, esset voluntas praedefinitiva absolute et efficaciter obiecti, quod sub illis requisitis cognitum praesupponitur: futurorum ergo, quae non sic praedefiniuntur, requisita decernuntur per voluntatem, cuius conditionata scientia principium non sit, immo ad quam nec prioritate in subsistendi consequentia praecedat scientia conditionata: ut praecedere dicitur a Nostris Doctoribus ad futurum absolutum et ad absolutam eius providentiam. Nam illa prioritas consistit in exigentia non-mutua, qua conditionata scientia exigatur ab aliquo, quod ipsa non exigit; ${ }^{311}$ at voluntas indifferens, qua ponuntur requisita ad libere operandum, non exigit determinate scientiam conditionate affirmantem, quod erit -, nec scientiam affirmantem, quod non erit extremum aliquod creatae [898r] libertatis: solum enim exigit indeterminate, quod existat in Deo vel scientia unius extremi vel alterius, quia alterutram habere Deum necesse est; at hoc etiam modo voluntas requisitorum exigitur a scientia conditionata, quia non potest dari, quin Deus aut velit requisita esse aut non esse, cum alterutrum horum velle sit Deo omnino necessarium. Concludo ergo, nec causaliter nec in subsistendi consequentia prius esse, Deum scire conditionate, quam velle, requisita ad operationem, quae per praedefinitionem causaliter efficacem decreta non est. Tum sic: Ergo praerequisitis ad futurum liberum existentibus non intelligitur praecessisse aliquid, quod determinare possit ad absolutam eius futuri praescientiam. Ergo futurum absolute, quod immediate subsequitur ad requisitorum positionem, est obiectum determinativum absolutae scientiae, id est obiectum immediate determinans divinam indifferentiam ad sciendum unum vel alterum, vel - quod idem est - obiectum determinate connexum cum absoluta scientia non praesupponens aliud, a quo determinate exigatur.

406. Obiicies: Etsi positis requisitis independenter a scientia conditionata haec non praesupponatur ad illa nec ad divinam voluntatem, qua producuntur, attamen praesupponitur ad absolutam scientiam futuri, quia indifferentia requisitorum ad esse et non-esse obiecti liberi est indifferentia tam ad absolutam quam ad conditionatam scientiam talis obiecti, sed tamen ad conditionatam ut prius exercendam prioritate tam affirmabilitatis quam independentiae: quia scientia conditionata independens est a scientia absoluta, quia nullius extremi liberi absolutam scientiam

311. Ähnlich Rodericus de Arriaga: Disputationes theologicae in Primam partem D. Thomae 21, 30, Antwerpen 1643, t.1, 22ob: „Respondendum [...] est, eam futuritionem conditionatam, etiamsi logice sit prior quam futuritio absoluta, non tamen esse priorem natura [...] Futuritio conditionata est prior logice futuritione absoluta, quia non valet Est futurum conditionate: ergo et absolute, bene autem e contrario Est futurum absolute cum hoc auxilio: ergo et conditionate, si ponatur hoc auxilium [...]" 
exigit, scientia vero absoluta exigit conditionatam eiusdem obiecti, quod ipsa absolute affirmat.

Hinc etiam est, scientiam absolutam non posse non habere scientiam conditionatam pro obiecto affirmato. Necesse est enim, ut affirmet omne id sine quo impossibile est ipsammet existere; at vero scientia absoluta non est obiectum affirmatum nec ullo modo affirmabile per scientiam conditionatam. Prius ergo determinatur indifferentia divini intellectus ad obiectum secuturum ex requisitis indifferentibus per scientiam conditionatam, et posterius ad absolutam. Ergo haec semper habet determinativum praecedens ad ipsa futura absoluta: nempe complexum ex scientia conditionata obiecti futuri sub requisitis, et voluntate ponendi ipsa requisita.

407. Respondeo: Non posse negari, quod ratione nostra - in subsistendi consequentia - scientia conditionata praecedat ad absolutam, et ideo, simul cum voluntate ponendi conditionem, sit in nostra ratione „determinativum“ absolutae scientiae. Attamen non est determinativum [898v] in re: quia hoc petit esse determinativum se tenens ex parte principii, quod revera dat esse cognitioni ut virtuale saltem principium, aut quod potest revera eius esse impedire. Scientia autem conditionata non sic se habet ad absolutam scientiam, quia nec est praerequisita pro priori naturae ex parte principii activi scientiae absolutae obiecti non praedefiniti - cum ad hanc scientiam nihil praerequiratur, nisi quod praerequiritur ad existentiam obiecti quod cognoscit: nam obiecto existente necesse est infinite cognoscitivum, etsi ex se indifferens ad ipsum et eius oppositum, determinate illud cognoscere - nec est praerequisita ex parte principii impeditivi seu electivi, in cuius scilicet libertate constituitur, quod Deus hoc potius quam illud obiectum cognoscat: quia hoc principium - quod est creata voluntas - determinat indifferentiam et libertatem, quam habet ad hoc, ut Deus habeat scientiam absolutam huius extremi, eam, inquam, indifferentiam determinat per proprium suum actum et electionem, quin ullo alio determinativo egeat; nam electio libera unius extremi petit essentialiter scientiam absolutam illius. Unde, cum ad electionem determinate ponendam nullo egeat principium electivum nisi indifferenti virtute electiva et indifferenti concursu causae primae, non poterit ex parte illius requiri aliquid aliud ad determinandam obiective praescientiam futuri liberi.

Revera ergo nullum determinativum scientiae absolutae obiecti liberi efficaciter non praedefiniti antecedit ad ipsum obiectum. Hoc ergo est re ipsa primum determinativum absolutae praescientiae sui, id est, ad quod non antecedit re ipsa aliud determinativum talis scientiae, quamvis antecedat ratione nostra. 


\section{${ }^{312}$ Tres aliae conclusiones}

408. Tertia conclusio (quae ex duabus praecedentibus sequitur) est, futura libera, quae Deus specialiter praedefinit - praedefinitione illa causaliter efficaci -, non cognosci ullo actu scientiae absolutae, cuius obiectum determinativum adaequatum non sit praefinitio ipsa, et consequenter obiectum futurum ${ }^{313}$ praedefinitum non est determinativum scientiae absolutae sui. Loquor de determinativo immediato, de mediato enim dicetur conclusione sequenti.

Ratio est, quia nullus datur actus divinae scientiae absolute affirmans futurum, quod non affirmet causas, a quibus dependet. At futura dicto modo praefinita pendent a praefinitione tanquam a causa. Ergo omnis actus absolutae scientiae praedefinitorum cognoscit illa dependenter a praefinitione.

Minor et consequentia manifestae sunt.

Maior autem patet, quia non potest - nisi ab imperfecte cognoscente - attingi effectus supponendo, [899r] ipsum existere, et consequenter, causam, a qua de facto pendet, existentem esse, et hanc non cognosci: quia id esset non attingere cognoscibile supponendo eius cognoscibilitatem; cognoscibile enim determinate est, quod determinate existens supponitur. Futurum itaque a praefinitione dependens nullo actu absolute affirmatur a Deo, quo non affirmetur praedefinitio. Tum sic: Praedefinitionem hanc attingit scientia futuri non solum ut obiectum formale et determinate connexum cum futuro, sed etiam ut connexum connexione praevia naturae et causalitatis ordine ad ipsum futurum: ergo huius scientia respicit praedefinitionem ut obiectum immediatum adaequate determinativum.

Consequentia est manifesta, quia eo ipso, quod sit determinativum, quatenus antecedens est ad ipsum futurum, non potest hoc determinativum esse ad cognitionem absolutam sui: quia supponit Deum prius determinatum ad illam.

409. Si vero obiicias, causas immediatas futuri, simul cum futuro ipso, esse sufficiens determinativum ad eius cognitionem, quia, etsi nulla antecessisset praedefinitio, vi illorum cognosceret Deus obiectum futurum: ergo etiam, quando adest praedefinitio, poterit Deus vi eiusdem determinativi habere actum aliquem scientiae absolutae futuri independenter a praedefinitione, -

Respondetur distinguendo antecedens: Sunt sine praefinitione „sufficiens“ motivum, quando praerequisita immediata ad futurum habent aliam causam sui esse distinctam a praedefinitione: concedo; quando non habent aliam: nego. Etenim impossibile est per divinam scientiam cognosci, quod haec requisita existant, quin cognoscantur, quod existunt vi alicuius divini decreti. Ergo, quando Deus illa ponit

312. Cap. $31 \mathrm{del}$.

313. non del. 
dependenter a praedefinitione et ita, ut hic et nunc non ponerentur a Deo, nisi sciret, secuturum esse effectum, non potest Deus cognoscere, quod posita sunt, quin cognoscat hoc praedefinitivum decretum natura praecedens ad requisita et, quatenus praecedens, determinate exigens absolutam futuri cognitionem.

410. Instabis: Etsi Deus vi praedefinitionis habeat cognitionem absolutam, cuius adaequatum determinativum sit praedefinitio, attamen aliam dandam esse, quae absolutam futuritionem consequatur et ab illa determinetur; nam etiam respectu futuri, quod praedefinitur, necessario concedendum est, quod immediatum principium illius non sit praedefinitio ipsa, sed alia voluntas indifferens, quam praedefinitio infert: quae constituit creatum arbitrium indifferens ad operandum et non-operandum et consequenter Deum indifferentem ad absolute sciendum et non-sciendum, quod operabitur. Eo enim ipso, quod arbitrium creatum sic indifferens constituatur ad obiectum, constituitur potens ad determinandam sua operatione scientiam Dei, et ad illam per operationis suspensionem impediendam. Necesse ergo est, Deum posse in signo posteriori ad eiusmodi indifferentiam cognoscere operationem, ad quam se determinat voluntas. Potestas enim determinandi et impediendi, [899v] cognitionem necessario debet esse ad cognitionem, quae ad talem indifferentiam subsequatur. Ergo praeter absolutam scientiam, quam Deus antecedenter ad decretum immediate concurrens ad operationem liberam habet vi ipsius praedefinitionis -, necesse est, quod habeat aliam posteriorem, cuius determinativum sit ipsum obiectum futurum. Nil enim aliud ab obiecto distinctum determinat ad absolutam eius cognitionem, quae requisitorum indifferentiam et existentiam subsequatur.

411. Ad hanc obiectionem responderi potest dupliciter:

$1^{\circ}$ admittendo eiusmodi secundam cognitionem absolutam futuri et negando, quod futurum ipsum ad illam determinet: eo quod supponat cognitio illa aliud prius determinativum. Nam, licet in requisitis immediate concurrentibus ad futura nullum detur antecedens determinativum ad eius cognitionem - eo quod in illis detur omnimoda indifferentia ad cognitionem futuri et ad oppositum -, attamen in causa, a qua de facto requisita illa indifferentia dependent, datur aliquod antecedens determinativum absolutae scientiae futuri - „scientiae“, inquam, non solum antecedentis absolutam futuri existentiam, sed etiam subsequentis, si haec danda esse dicatur - quasi efficax praedefinitio futuri. Quae est requisitorum indifferentium causa et ${ }^{314}$ petit ex illis inferri futurum et absolutam futuri cognitionem, et etiam petit, quod ipsamet praedefinitio per talem cognitionem attingatur, quia petit illam cognitionem esse divinam et infinite perfectam ac proinde (ut supra dicebamus), 
quod cognoscat dependentiam futuri a requisitis et horum a praefinitione ipsa causante. Petit ergo praedefinitio esse obiectum praevie determinativum talis cognitionis; et consequenter ad illam non determinabit ipsum futurum, sed supponet - non quidem per se et necessario, sed ex accidentali et libera suppositione Dei -, quod prius determinatum sit, talem cognitionem dandam esse.

412. $2^{\circ}$ Responderi potest negando secundam illam cognitionem absolutam futuri: ad nil enim deservit, cum totam obiecti cognoscibilitatem, etsi posterius natura positam, exhauriat cognitio prior. Integre enim et plenissime cognoscitur futurum vi antecedentis praedefinitionis.

Quod vero opponitur de indifferentia ad habendam et non-habendam cognitionem absolutam futuri, non urget. Ut autem hoc constet, notandum est,

$1^{\circ}$ duplicem indifferentiam considerari posse in praerequisitis immediatis ad liberam operationem. Prima consistit in eo, quod illa ex se ipsis nullam habeant determinationem ad unum et consequenter nec determinationem ad divinam praescientiam unius; secunda vero in eo, quod nullam absolute habeant, ex ullo capite, determinationem ad unum, quae natura praecedat ad operationem. Prima indispensabiliter requiritur ad operationis libertatem, et etiam secunda quoad exclusionem determinationis omnino antecedentis in se, undecumque proveniat, [9oor] non tamen quoad exclusionem determinationis antecedentis natura, quae subsequens aliquo modo sit ad eandem operationem, quam antecedit: id est posita dependenter a praescientia conditionata eius, quod voluntas creata per immediata, quae de facto per praedefinitionem causantur, faceret, etiamsi absque ulla antecedente praedefinitione aut determinatione causarentur.

413. Notandum $2^{\circ}$ est, voluntatem nostram ut indifferentem ad absolutam operationem, indifferentem quoque esse debere ad absolutam scientiam eiusdem operationis impediendam et determinandam - per operationem aut eius carentiam -, sed tamen non semper eodem modo indifferentiam hanc respicere divinam scientiam absolutam. Etenim, quando nulla determinatio absoluta futuri liberi praecedit $n a-$ tura ad immediatas eius causas, arbitrium creatum est determinativum et impeditivum scientiae absolutae futuri immediate: per ipsum futurum aut per eius liberam carentiam. Quando vero eiusmodi determinatio praecedit modo iam explicato, potestas arbitrii creati non est ad impediendam et determinandam scientiam absolutam immediate per suam operationem, sed mediate: quatenus potest impedire scientiam conditionatam, sine qua Deus nec praedefinire operationem potest absolute et efficaciter nec in praedefinitione anterequisitorum positionem cognoscere, absolute futuram esse operationem. Quo autem pacto voluntas ut habens requisita ad operandum sit potens ad impediendam conditionatam scientiam operationis faciendae per illa requisita, explicuimus libro $2^{\circ}$ capite $50^{\circ}$, et libro $3^{\circ}$ capitibus $18^{\circ}$ et $26^{\circ}$, et latius explicabitur libro $7^{\circ}$. 
414. Ex his deducitur secunda solutio obiectionis [ $\$ 410]$ : quia indifferentia, quam habet creata voluntas a praerequisitis productis per efficacem praedefinitionem actus libere futuri, est quidem indifferentia ad scientiam absolutam, non tamen ut immediate impedibilem et determinabilem per operationem, sed mediate: quatenus constituit potestatem impediendi scientiam conditionatam operationis mediaque illa praedefinitionem et scientiam absolutam, et etiam potestatem determinandi scientiam conditionatam, et absolutam, media illa, si Deus illam velit praedefinire, vel etiam sine praedefinitione habendam, si Deus requisita causare velit independenter a praedefinitione operationis.

415. Quarta conclusio: Futura, etiam praedefinita, sunt obiectum determinativum absolutae cognitionis sui: non quidem immediatum (ut ostensum est), sed mediatum, quia ipsamet obiecta contingentia, quae futura absolute sunt, determinant ad conditionatam scientiam sui. Scientia enim conditionata determinatur ab obiecto quod cognoscit futurum esse sub conditione (ut libro sequenti ostendemus). Quod autem cognoscitur sub conditione futurum, est ipsum obiectum absolutum; de hoc enim dicitur, quod absolute erit, [9oov] „si ponatur conditio“. Ipsum ergo absolutum obiectum determinat conditionatam scientiam. Ab hac autem scientia dependet praedefinitio absoluta, in qua absolute cognoscitur futurum contingens, quod Deo placuit praedefinire: ergo ad hanc futuri cognitionem determinat mediate futurum ipsum absolutum. Determinat, inquam, mediate - per scientiam conditionatam -, non omnino absolute, sed conditionate: quia conditionata tantum est exigentia scientiae absolutae, quam habet scientia conditionata, scilicet sub conditione, quod ponantur requisita.

416. Quinta denique conclusio sit: Scientia ipsa absoluta, quam capite praecedenti [\$ 395] duximus esse obiectum formale ad se ipsam et, consequenter, ad cognoscenda futura, non est obiectum formale determinativum ad se ipsam, sed tantum motivum. Licet enim habeat cum se ipsa determinatam et essentialem connexionem, non tamen connexionem, quae sit prima ratio determinate exigendi ipsam, quia aliam supponit priorem, nempe ipsum obiectum aut huius praefinitionem. Ipsa ergo non est determinativa indifferentiae divinae ad ipsam habendam et non-habendam, sed aliud eius indifferentiae determinativum supponens. 


\section{Caput 32. An futura contingentia absoluta cognoscat Deus in se ipsis, vel in divinis praedefinitionibus et permissionibus?}

417. Quo sensu possit quaeri, an in „se ipsis“ cognoscantur futura, explicatum est capite 6, et statutum, non posse illa a Deo cognosci in „se ipsis“ tanquam in motivo et formali obiecto - quia nil creatum potest esse formale obiectum cognitionis divinae -, posse autem dici, quod cognoscantur a Deo futura in „se ipsis“ tanquam in obiecto determinativo, quia, licet cognosci aliquid „in se“ petat cognosci immediate, non tamen petit cognosci immediate simpliciter - per exclusionem omnis intermedii obiecti quod sit ratio cognoscendi -, sed immediate in quodam genere. Quod in obiectis creatis, respectu divinae cognitionis, est genus obiecti determinativi: quod scilicet absolute et determinate exigit cognitionem sui et non supponit aliud, a quo prius exigatur. Quod (ut dixi capite praecedenti) non solum obiecto formali, sed etiam aliquando obiecto materiali convenire potest. In hoc ergo sensu quaerimus, an futura absoluta cognoscantur a Deo ,in se ipsis“.

418. Prima conclusio sit: In se ipsis absolute cognosci a Deo futura contingentia, quae ab ipso non praedefiniuntur efficaciter - efficacia causaliter antecedente absolutam illorum existentiam -, seu, quod idem est, futura, quorum praerequisita immediata non decernit Deus dependenter a praecognita futuritione illorum sub conditione, quod praerequisita illa ponantur.

Conclusio est omnium, qui negant decreta praedeterminantia respectu futurorum contingentium. Eam [9oir] S. Thomae et Antiquorum authoritate confirmavimus capite $1^{\circ}$ et $2^{\circ}$, patetque ex capite praecedenti, in quo probavimus, ad huiusmodi futura cognoscenda non dari aliud obiectum ad illa antecedens quod determinet ad absolutam illorum cognitionem. Ergo ipsa obiecti determinativi rationem habent.

Antecedens ibi [ $\$ 404]$ probatum est ex eo, quod, licet cognitio illorum futurorum respiciat aliquod obiectum ab ipsis distinctum, quod cum absoluta illorum cognitione connexionem habeat, attamen non est obiectum prius determinans ad illam quam ipsum futurum. Nam praeter futurum ipsum non respicit eius cognitio absoluta aliud obiectum connexum cum ipsa nisi vel se ipsam vel complexum ex scientia conditionata futuri, quod cognoscit, et decreto ponendi conditionem et requisita, sub quibus conditionate futurum cognoscitur.

At nec scientia ipsa absoluta antecedit futurum liberum, quod cognoscit, sed potius anteceditur ab illo, nec etiam complexum illud integre sumptum antecedit ad obiectum absolute futurum; solum enim antecedit secundum unam partem sui, scilicet secundum voluntatem ponendi requisita: quae nequaquam determinat ad futurum hoc potius quam oppositum. Scientia enim conditionata nequaquam antecedit 
ad futurum - praedicto modo non praedefinitum - antecedentia reali, cui tribuatur, quod futurum existat, vel tanquam principio productivo vel tanquam electivo: neutro enim ex his modis concurrit scientia conditionata ad eiusmodi futurum.

Hoc ergo non supponit ullum aliud obiectum, quod divinam indifferentiam et absolutam scientiam determinet antecedenter id ipsum antecedentia, quae in re ipsa datur. Antecedentia autem in nostra ratione, quam habet scientia conditionata ad futurum absolutum, non facit, quod revera antecedat ad ipsum aliud determinativum. Ergo minus hoc ipsi futuro concedendum est.

419. Confirmatur haec ratio: quia Deus est proxime aptus - quantum de se est cognoscere quod absolute operabitur voluntas creata per ea, quibus ipse constituit voluntatem illam proxime potentem operari libere; non enim eget ad cognoscendum nisi iis, quibus eget obiectum ad essendum: ergo, quando proximam hanc aptitudinem creatam decernit independenter a praescientia conditionata huius aut illius extremi, constituitur - independenter ab illa - proxime aptus, quantum est ex se, cognoscere absolute futurum cum indifferentia ad hoc aut illud determinate cognoscendum. Sed hanc indifferentiam immediate determinat ipsum obiectum absolutum; hoc enim immediate consequitur ad proximam aptitudinem sui esse in actu positam. Ergo futurum absolutum, cuius principia immediata decernit Deus independenter a praescientia conditionata, determinat immediate divinam indifferentiam ad ipsum absolute cognoscendum. Est ergo obiectum determinativum absolutae scientiae, quam de ipso habet Deus, et in se tanquam [901v] in determinativo cognoscitur.

420. Secunda conclusio: Futurum contingens, cuius requisita decernit Deus dependenter ab eo, quod conditionate praesciat, illum futurum esse, si haec ponantur, aliquo etiam modo cognoscit absolute in se ipso, licet non ita proprie: quia, licet futurum hoc supponat mediate praedefinitionem efficacem sui, attamen non supponit illam ut principium necessarium neque ut principium omnino antecedens, quia ipsum esse absolutum futuri supponitur conditionate a conditionata scientia, quae praedefinitionem illam antecedit. Ergo, licet futurum supponat, in praedefinitione illa, determinativum absolutae scientiae ipsius futuri, non tamen determinativum omnino antecedens et consequenter nec omnino necessarium. Licet ergo futura huiusmodi non dicantur omnino stricte cognosci „in se ipsis“ absolute, eo quod aliud determinativum absolutae scientiae sui supponant, quia tamen hoc non est determinativum omnino antecedens ad ipsa, sed ad quod ipsa aliquo modo antecedunt, ideo aliquo modo ,in se ipsis“ cognosci per absolutam scientiam dicentur. Cui doctrinae non obstat, quod in praedefinitione quoque cognoscantur, quia bene potest aliquid in se et in alio cognosci: non solum diversa, sed etiam eadem cognitione (ut ad finem huius capitis dicemus). 
421. Tertia conclusio: Omnia futura contingentia, quae bona et a Deo amabilia sunt, cognoscit Deus absolute in aliqua absoluta illorum praedefinitione tanquam in obiecto formali non solum motivo, sed etiam determinativo absolutae cognitionis.

Haec conclusio sic est communis inter Theologos, ${ }^{315}$ cum inter illos ex Sanctis Patribus solemne sit, bona omnia esse a Deo praedefinita et, quando supernaturalia sunt, stricte praedestinata, licet de modo praedefinitionis et praedestinationis inter illos non conveniat.

Fautores Praedeterminationum omnino Antecedentium similem quoque praedefinitionem et praedestinationem bonorum constituunt: decretum scilicet efficax illorum nil praesupponens nobis liberum, sed omnino antevertens libertatem ita, ut a nobis nec impedibile sit quoad existentiam suam nec etiam quoad executionem obiecti, quod decernit in sensu composito decreti. Qui vero has praedefinitiones et praedestinationes NEGANT - qui sunt Doctores citati capitibus $1^{\circ}$ et $2^{\circ}$ huius libri, et capitibus $11^{\circ}, 13^{\circ}$ et $14^{\circ}$ libri 2 -, docent, absolute cognosci futura in praedestinatione, cuius efficacia constituatur per suppositionem consequentem. Simpliciter vero ab OмNiвus necessario dicendum esse, quod futura bona in praedestinatione cognoscantur absolute, patet, quia in nulla sententia negari potest, bona omnia, praesertim supernaturalia, esse a Deo praedestinata, ita ut implicet bonum existere et praedestinatum a Deo non esse (ut libro praecedenti capite $26^{\circ}$ explicuimus).

Ex quo manifeste sequitur, nullam posse esse [902r] cognitionem absolutam boni futuri, quae non affirmet, illud per praedestinationem existere; at per hanc absolutam cognitionem cognoscitur praedestinatio ut obiectum formale, id est cognitum propter se et propter quod est cognitio (modo explicato capitibus praecedentibus): ergo in praedestinatione tanquam in obiecto formali necesse est, in omni sententia, fateri, quod Deus habeat absolutam scientiam futurorum bonorum. Addo autem, formale hoc obiectum non solum esse motivum, sed etiam absolute determinativum, quia praedestinatio et absoluta praedefinitio est essentialiter connexa cum absoluta existentia obiecti futuri et absoluta cognitione divina illius. Est autem haec connexio "determinativa“ divinae indifferentiae ad cognoscendum, quia non supponit illam absolute determinatam per aliud.

422. Si autem quaeras, in qua praedestinatione cognoscat Deus bona futura? -

Respondeo (ex libro $2^{\circ}$ supponendo, quod nulla contingentia cognosci possunt in omnino praevia determinatione), bona opera libera, quae Deus decernit et causat per affectum ex se efficacem, etsi non omnino antecedentem - eo quod ex suo intrinseco modo tendendi praesupponat scientiam conditionatam liberi actus,

315. Vgl. Franciscus Suarez: Varia opuscula theologica 2, 1, 6, 4, Opera omnia, Paris 1856-78, t.11, 313a. 
quem decernit ut futuri per media indifferentia, quae per talem affectum decernuntur, quamvis non per illum, sed per alium, omnino indifferentem, decernerentur -, haec, inquam, futura contingentia cognosci a Deo absolute in ipso suo affectu praedefiniente et praedestinante vi quidditativi modi tendendi ipsius (ut capitibus praecedentibus notavimus, et duobus libris praecedentibus saepe explicuimus). At vero, quia non omnia, sed aliqua futura sic praedefiniri supponimus (de quo libro $7^{\circ}$ agendum est), sequitur, non omnia, sed aliqua bona absolute futura cognosci in affectu ipso praedestinante secundum se sumpto.

423. Attamen omnia bona alio modo (libro praecedenti capite $26^{\circ}$ explicato) praedefiniri ac praedestinari - et in praedefinitione ac in praedestinatione cognosci necesse est. Modus autem hic est:

Deus per decretum, quo confert omnia requisita ad libere operandum et affert concursum indifferentem ad duplex libertatis extremum, intendit positive fieri quod bonum est, licet non intentione omnino efficaciter et inimpedibiliter inferente ipsum, sed solum efficaciter, quantum est ex parte Dei, id est efficacia, qua intentio Dei infallibiliter causabit bonum, quod intendit, nisi libere impediatur ab arbitrio creato. Hoc ergo decretum, quando re ipsa coniungitur cum scientia conditionata, qua Deus novit, quod, si ipse tale decretum habeat, homo bene operabitur - etiamsi decretum non habeat dependenter a tali praescientia, sed omnino independenter ab illa -, redditur efficax praedefinitio et praedestinatio bonae operationis: non, quia Deus habeat secundum affectum ex se determinatum ad bonum, sed [902v] quia indifferens affectus illius decreti redditur determinate connexus cum operatione bona per identificationem realem sui cum scientia conditionata de tali operatione ut futura - sub conditione, quod Deus decretum illud habeat -; redditurque "determinate connexus" connexione antecedente futurum absolutum non solum per aeternam durationem, sed etiam - ex modo nostro concipiendi - per habitudinem principii: quia decretum praedictum vere est principium futuri absolute, scientia autem conditionata, etsi aliquando non sit vere principium illius, attamen apprehenditur a nobis ad modum principii ob necessariam connexionem, qua futurum absolutum existentiam eius scientiae exigit, et ob independentiam, qua ipsa cum absolute futuro non connectitur. Decretum ergo - de se indifferenter intendens bonum - per consortium talis scientiae et per identificationem cum illa redditur praevie definitivum et praedestinativum futuri boni (ut citato loco dicebamus). In hac ergo praedefinitione omnia bona - quantumcumque contingentia et cuiuscumque ordinis sint - futura cognoscuntur. Quando vero bona sunt supernaturalia, decretum praedictum, quia in ordine ad talia bona est praeparativum gratiae, redditur, ex consortio conditionatae scientiae, infallibiliter connexum: ut vera stricta praedestinatio talis boni (ut ibi ostendimus). 
424. Quod vero in hac praedestinatione tanquam in obiecto non solum motivo, sed etiam determinativo sui, cognoscat scientia absoluta futurum, patet: quia praedestinatio respectu talis scientiae est obiectum determinate connexum et ad quod nil aliud cum illa connexum - et determinans divinam indifferentiam ad absolute sciendum hoc vel illud - praesupponitur; etenim praeter praedestinationem illam non datur aliud obiectum connexum cum absoluta scientia futuri nisi futurum ipsum. Hoc autem ut absolutum non praesupponitur ad sui praedestinationem constitutam ex decreto concurrendi et scientia conditionata boni ut futuri sub conditione, quod tale decretum habeatur: nam potius una illius complexi pars, nempe voluntas Dei, supponitur ad futurum absolutum ut vera causa illius, ad alteram vero, quae est scientia conditionata, non supponitur absolute obiectum futurum, sed solum conditionate. Non ergo est prius determinativum absolutae scientiae quam complexum ex scientia conditionata et voluntate apponendi conditionem, sed - sine prioritate unius ad alterum in determinando - utrumque rationem determinativi exercet circa absolutam futuri scientiam, praedestinatio vero magis praecipue: quia est obiectum determinativum simul et motivum. In illa ergo cum omni proprietate bonum absolute futurum esse cognoscitur.

425. Quarta conclusio: Malum culpae absolute futurum non cognoscit Deus in voluntate ulla permissiva illius secundum se sumpta tanquam in obiecto determinativo. Loquor de voluntate, quae non supponat absolutam aliquam scientiam illius mali ut futuri.

Conclusio est contra eos, qui [903r] defendunt, entitates actuum malorum, etiam ut producendas in circumstantiis, in quibus actus non possunt non esse mali, esse a Deo efficaciter decretas et ideo cognitas, quia decretae sunt, malitiamque iis entitatibus in illis circumstantiis annexam ratione ipsarum entitatum aut decreti illarum cognosci. Cuius sententiae sunt Bañez, Alvarez, Ledesma, Navarrete et communiter recentiores Тноміsтав. Nostram tamen defendunt caeteri fere Doctores, qui materiales entitates peccatorum ut producendas in his circumstantiis, in quibus non possunt non esse malae, negant posse a Deo decerni. ${ }^{316}$ Quos libro ${ }^{\circ}$ a capite $36^{\circ}$ citavimus. Nam fere omnes generaliter negant, Deum ante absolutam peccati praevisionem posse absolute et efficaciter decernere aliquid cum peccati existentia connexum, v.g. peccatorum redemptionem, poenitentiam, vindictam. De quo late citato loco, praesertim capite $43^{\circ}$.

Nunc pro ratione conclusionis sufficiat, Deo repugnare ante praevisum absolute peccatum, quod habeat decretum essentialiter connexum cum illo: ergo repugnat,

316. Vgl. z.B. Hieronymus Fasolus: In Primam partem Summae D. Thomae commentaria Q. 14, art. 13, 365, Lyon 1623-36, t.2, 226 a. 
quod habeat voluntatem permissivam, in quo tanquam in decreto determinativo cognosci possit peccatum.

Consequentia est evidens.

Antecedens vero patet, quia Deus non potest ante praevisum absolute peccatum velle aliquid essentialiter connexum cum absoluta eius existentia. Hoc enim esset praedefinire a se ipso, ne peccatum absolute omitti possit: quod Deo omnino repugnat. Non ergo potest ante absolutam peccati praevisionem habere decretum ex se connexum cum absoluta eius existentia.

Consequentia haec patet, quia decretum hoc, si haberetur, non posset non esse a Deo volitum per semetipsum, cum omnis divinus actus voluntarius sit sui ipsius volitio.

Dixi in conclusione, voluntatem divinam non posse secundum se esse obiectum determinativum cognitionis peccati; nil enim prohibet, quod sit obiectum formale motivum illius, non quidem ut idea aut causa positiva, sed ut causa tantum permissiva illius.

426. Quinta conclusio: Voluntas permissiva peccati, licet de se indifferens ad hoc, ut peccatum per illam - quantum est ex parte Dei permissum - sequatur cum effectu vel non sequatur, haec, inquam, voluntas redditur determinata et infallibilis permissio peccati ut simpliciter secuturi per coniunctionem cum scientia conditionata, qua Deus scit, ea voluntate a se habita secuturum esse peccatum ex arbitrii creati determinatione; ac proinde in permissione, ut sic sumpta, cognoscitur a Deo absolute peccatum tanquam in obiecto determinativo talis cognitionis.

Conclusio haec est communis Theologis. In permissione enim ut non solum ex parte Dei - seu in actu primo -, sed ut simpliciter permissio est per infallibilem respectum ad actum secundum, omnes dicunt cognosci futurum peccatum. Quam infallibilitatem Doctores Negantes praeviam determinationem peccatorum explicant per coniunctionem voluntatis permissivae cum scientia conditionata peccati ut futuri sub conditione talis voluntatis, [903v] et in ea, sic sumpta, peccatum cognosci docent. Sic SuAREz lib. $1^{\circ}$ De absoluta scientia futurorum cap. 6 n. 15 (ad finem), ${ }^{317}$ Ruiz disp. 26 De Scientia Dei sect. 1 et $3,{ }^{318}$ Fasolus et caeteri ReCentiones ad art. 13 quaestionis 14 Primae partis.

Ratio conclusionis est manifesta, nam voluntas permissiva peccati est, qua Deus potens impedire peccatum per negationem expeditae libertatis ad illud, vult non sic impedire, sed permittere, quod peccatum sit, si voluntati libuerit: quod est velle, ut ipsa possit pro libito suo peccare aut non peccare. Deo autem sciente, quod, si

317. Franciscus Suarez: Opera omnia, Paris 1856-78, t.11, 320 .

318. Didacus Ruiz de Montoya: Commentarii ac Disputationes de scientia Dei, Paris 1629, 217-21. 
ipse hanc voluntatem habeat, arbitrium creatum se determinabit ad peccandum, infallibile est - illa voluntate habita - arbitrium creatum se determinaturum esse ad peccatum. Ergo in voluntate illa permissiva ut coniuncta tali scientiae tanquam in obiecto formali determinativo cognoscit Deus, quod absolute erit peccatum.

427. Sexta conclusio: In ipsa absoluta futurorum contingentium scientia cognoscit Deus futura. Ea enim se ipsam cognoscit ut essentialem respectum ad futura et ut motivum ad illa cognoscenda, quia est obiectum motivum sui, licet non determinativum (ut duobus capitibus praecedentibus probatum est). Ut autem aliquid in alio cognoscatur, sufficit, ut hoc sit obiectum, quod cognitum faciat illud cognosci eadem indivisibili cognitione, qua ipsummet cognoscitur. ${ }^{319}$ Hoc autem convenit omni obiecto formali immediate terminanti cognitionem de altero obiecto distincto, quia, inquantum est obiectum formale, habet dare esse cognitioni sui et alterius obiecti quod cognoscitur, ac proinde facere, quod hoc cognoscatur. Ut vero est obiectum formale immediatum cognitionis de altero obiecto, habet facere illud cognosci per eandem indivisibilem cognitionem, qua ipsummet formale cognoscitur. Faciet ergo illud cognosci in ipsomet formali obiecto. Quod speciali titulo locum habet in obiectis illis formalibus, quae cognosci non possunt nisi simul cognoscendo aliud ob essentialem connexionem, quam habent cum illo. Quem quoque titulum invenimus in scientia absoluta respectu obiecti quod futurum esse cognoscit.

428. Obiicies, non videri inter se cohaerere conclusiones praecedentes, nam, futura cognosci in se ipsis, est, cognosci immediate - id est, sine medio -, ea vero cognosci in alio, scilicet in scientia et praedestinatione aut permissione, est, cognosci per medium. Repugnat autem, per medium et sine medio cognosci idem obiectum per eandem cognitionem.

Respondetur, idem posse per se et per aliud medium cognoscendi simul et eadem indivisibili formalitate cognitionis attingi, quando neutrum est adaequata ratio cognoscendi: quia, licet verum sit, adaequatam cognoscendi rationem attributam omni obiecto exigere, ne aliud ad rationis cognoscendi consortium admittatur respectu eiusdemmet cognitionis, at ratio inadaequata cognoscendi compatitur, immo et petit aliam dari rationem eiusdem [904r] cognitionis. Ex quo patet, immediationem inadaequatam obiecti - sive in genere motivi, sive in genere determinativi - non tollere, quod eius cognitio medio etiam alio obiecto - motivo aut terminativo - specificetur aut determinetur, quia, licet „immediate cognosci“ significet cognosci sine medio, non semper significat cognosci sine ullo medio. Sufficit enim ad aliquam immediationem excludere medium, quod sit tota ratio cognoscendi. Hinc ad obiectionem propositam respondetur concessa maiori minorem

319. Vgl. $\$ \$ 393-95$. 
sic distinguendo: repugnat „cognosci per medium et sine medio“ simpliciter, id est, sine ullo medio: concedo; repugnat „cognosci per medium aliquod, et sine alio speciali genere medii cognosci“, scilicet adaequati: nego. Futurum ergo, etsi cognoscatur per aliud medium et admittatur, hoc non solum esse motivum, sed etiam determinativum, attamen, quia non est adaequatum determinativum - cum probatum sit, obiectum futurum, quando non praedefinitur praedefinitione causaliter efficaci, esse ita determinativum cognitionis sui, ut non praesupponat aliud determinativum illius -, sequitur, rationem determinativi obiecto ipsi futuro convenire et compati cum ratione determinativi inadaequati eiusdem cognitionis - aliis obiectis concessa -, ac proinde, futurum et in se et in aliis per absolutam scientiam cognosci.

\section{Caput 33. De scientiae absolutae futurorum contingentium libertate}

429. Capite $21^{\circ}, 22^{\circ}$ et $23^{\circ}$ huius libri ostendimus, divinae scientiae contingentium ex suo conceptu non competere formalem libertatis conceptum, quamvis Deus ad huius et illius obiecti scientiam habeat indifferentiam activam: quia electiva ad libertatem necessaria est. Quod, dixi, ita se habere ex conceptu scientiae contingentium ut sic. Cum quo recte cohaeret, aliquos actus scientiae contingentium liberos Deo esse, eos scilicet, qui a divina electione dependent et cum ipsa electione formaliter identificantur.

430. Est autem advertendum,

$1^{\circ} \quad$ duplicem esse posse dependentiam praescientiae divinae ab electione libera Dei: $1^{\circ}$ tanquam a causa illam prae opposita determinante, $2^{\circ}$ tanquam a causa determinante, ut sit ipsa vel opposita: ut quando Deus vult liberam causam operari hoc vel illud, et consequenter, quod in ipso Deo sit huius vel illius extremi determinata praescientia.

$2^{\circ} \quad$ Advertendum est, plures esse divinae scientiae absolutae actus: alios quibus cognoscit futura a se solo pendentia, alios [904v] quibus cognoscit futura pendentia a libertate creata. De his vero alia est scientia disiunctiva, qua unum vel alterum futurum esse cognoscitur, alia determinata. Haec autem aliqua respicit ut praefinita a Deo efficaciter efficacia causaliter antecedente; alia quae non sic praedefiniuntur, sed, ad summum, efficacia solum antecedente ratione; alia denique quae non praedefiniuntur nec intenduntur, sed solum permittuntur.

431. Prima ergo conclusio sit: Omnis absoluta scientia futurorum est aliquo modo libera.

Sic Theologi Omnes, quia eiusmodi scientia est dependens a libera voluntate Dei, cum nihil absolute futurum esse possit, nisi Deus ad illud libere velit concurrere 
aut illud permittere. „Non enim fit aliquid“, ait Augustinus in Enchiridio cap. 95, "nisi omnipotens fieri velit, vel sinendo, ut fiat, vel ipse faciendo, ut fiat. “" ${ }^{20}$ Omnis ergo praescientia futuri ita habetur a Deo, ut posset, ex eius libertate, non haberi: nolente ipso aliquid sinere vel causare.

432. Secunda conclusio: Scientia absoluta futurorum, quae a sola divina voluntate pendent, est libera Deo tanquam determinanti hanc scientiam prae opposita, quia obiectum illius a solo Deo determinandum est.

433. Tertia conclusio: Idem dicendum est de scientia disiunctiva, qua Deus cognoscit, hoc vel illud extremum liberum a voluntate creata operandum esse..$^{321}$

Haec conclusio est expressa S. Thомae q. 16 De Malo art. 7, cuius verba non semel in superioribus retulimus expresse.

Estque manifesta, quia esse futurum disiunctive hoc vel illud extremum libertatis creatae, a sola divina libertate efficaciter statuitur. Nam, esse potentem proxime et expedite ad liberam operationem, habet creata voluntas a divina ante omne liberum exercitium creatum; sed proxima et expedita libertas ad duo includit disiunctivam necessitatem ad hoc, ut unum vel alterum fiat, quia libera potentia non potest libere ferri extra omnia extrema libertatis et consequenter nec omnia illa libere omittere nec etiam ad illa omittenda determinari ab alio - ex suppositione datae potestatis ad eligendum inter illa -, ac proinde ut libere et expedite potens nequit utrumque omittere: Deus ergo vi decreti, quo statuit, arbitrium creatum constituere libere et expedite potens ad duo, determinat disiunctive sequelam unius aut alterius, et consequenter scientia libera huius disiuncti est Deo libera ut determinanti ipsam prae opposita: eam scilicet, qua Deus scire posset, si vellet, nil libere operandum esse a voluntate creata. Decernere enim posset non dare illam liberam operandi facultatem.

434. Quarta conclusio: Futura, quae Deus efficaciter praedefinit efficacia causaliter antecedente, cognoscit per scientiam absolutam determinatam. Quae Deo libera est ut eligenti et determinanti illam.

Haec conclusio, si debite explicetur, negari non potest. Nam Deus libere praedefinit actus [905r] nostros ex suppositione praescientiae conditionatae, qua novit, per media indifferentia, si dentur, nos esse operaturos; licet enim Deo non sit libera

320. Augustinus: Enchiridion 95, PL 40, 276.

321. Vgl. Antonius Perez: In Primam partem D. Thomae opus posthumum: De intelligentia Dei 5, 5-6, Rom 1656, 182b: „Quidam recentiores [...] existimant, Deo repugnare omnem cognitionem disiunctivam, quasi omnis huiusmodi sit imperfecta et orta ex ignorantia [...] Nihilominus dicendum est [...] veram esse aliorum Recentiorum sententiam Deo concedentium cognitiones disiunctivas." 
suppositio haec praescientiae - quae omnino praerequiritur ad praedefinitivam voluntatem, quae ex se praedefinitiva et efficax sit -, attamen ea data liberum est Deo praedefinire efficaciter operationem bonam: ergo liberum est illo determinare ad absolutam praescientiam illius. Quia vero ad quemcumque actum liberum necesse est dari media aut conditiones aliquas, quibus positis sequetur talis actus, necesse est fateri, Deo liberum esse ante omnem praescientiam contingentem etiam conditionatam velle habere absolutam de actu nostro non malo. Potest enim ante omnem praescientiam conditionatam velle efficaciter, quod existat talis actus et consequenter, quod ab ipso Deo absolute praesciatur; potest, inquam, velle eiusmodi ut futurum per aliquod medium disiunctive, non tamen ut futurum per hoc determinate: quia necesse est actum esse conditionate futurum per aliquod ex collectione ${ }^{322}$ mediorum indifferentium, non tamen, esse futurum per hoc medium determinate. Unde, licet possit Deus - ante praescientiam conditionatam - velle, quod existat disiunctive per hoc medium vel illud, non tamen determinate per hoc (ut capite $18^{\circ}$ libri praecedentis explicui). Hinc est, scientiam absolutam actus cuiusvis non mali esse Deo ut determinanti liberam ante omnem contingentem praescientiam conditionatam, - scientiam vero absolutam actus ut futuri per hoc medium determinate esse Deo ut determinanti liberam ex suppositione praescientiae conditionatae eiusdem actus ut futuri per tale medium.

435. Quinta conclusio: Non omnium futurorum contingentium scientia absoluta est libera Deo ut actu eligenti determinate et efficaciter illam habere, sed ut libere decernenti illam vel oppositam extremi liberi scientiam haberi cum potestate decernendi, quod neutrius extremi scientia habeatur.

Haec conclusio est contra Doctores, qui opinantur, omnia contingentia praedeterminanda esse a Deo. Eam vero defendunt imprimis respectu contingentium, quae sunt peccata, omnes Authores, qui praevias determinationes liberorum inficiantur. Deinde, respectu plurium, quae bona sunt, eam defendunt, qui iudicant, non omnia bona praedefiniri a Deo praedefinitione ex se efficaci etiam attemperata praescientiae conditionatae. Quod de omnibus actibus naturalibus - quando non ordinantur singulariter ad finem aliquem supernaturalem - docuit SuAREZ in Opusculis lib. $2^{\circ}$ De Divino Concursu cap. 7 a $\mathrm{n}^{\circ} 11 ;^{323}$ de supernaturalibus vero pro utraque parte opinabile esse docet, an omnes praedefiniantur. De quo agemus libro $7^{\circ}$, ubi ostendemus, omnium naturalium actuum praefinitionem ex se efficacem nec authoritate nec ratione posse persuaderi.

322. collatione corr.

323. Franciscus Suarez: Opera omnia, Paris 1856-78, t.11, 143a/b. 
436. Conclusio vero probatur: Quia circa peccata et caetera, de quibus Deus statuit singulari hoc praefinitionis affectu, non providere actum malum, [905v] versatur eius voluntas dando concursum indifferentem, quo possunt ab arbitrio creato determinari, et quo necesse sit unum aut alterum illorum ab arbitrio determinandum esse: ergo neutrum extremorum est Deo sic providenti liberum ut actu praeeligenti determinate unum prae alio, sed ut determinanti, quod unum vel alterum fiat, cum potestate, ut quodlibet omittatur per omissionem collectivam utriusque extremi (ut libro $2^{\circ}$ capitibus $54^{\circ}, 55^{\circ}$ et $56^{\circ}$ explicatum est). Ergo hoc eodem modo erit libera Deo scientia absoluta cuiusvis illorum extremorum, et non alio.

Consequentia est manifesta, quia Deus non alio modo vult voluntate antecedenti scire, quid voluntas creata operatura est, quam, quo vult id, quod est operatura; si enim determinaret, ut hoc determinate et non aliud sciendum esset, determinaret quoque, ut hoc et non aliud faciendum esset vel permittendum, ita, ut ipsius voluntas non magis cum scientia quam cum obiecto sciendo connexa esset: ergo, cum eiusmodi voluntatem antecedentem erga peccata habere non possit (ut libro $2^{\circ}$ a capite $36^{\circ}$ ostensum est) et circa plura bona de facto illam non habeat, necesse est, quod nec circa illorum scientiam eiusmodi voluntatem habeat, sed solum voluntatem, qua libere decernat, unum aut alterum extremum absolute praesciri: sicut decernit, unum vel alterum absolute futurum esse.

437. Obiicies, hoc genus libertatis non sufficere ad hoc, ut Deo libera sit scientia huius determinate extremi prae alio; at necessario dicendum videtur, scientiam absolutam esse Deo liberam, ut est determinate haec prae alia, nam alius modus libertatis imperfectus videtur: ergo.

Respondetur (ex libro $2^{\circ}$ capite $57^{\circ}$ ), scientiam hanc prae alia esse Deo „liberam“, posse dupliciter intelligi:

$1^{\circ}$ ita, ut significet, extremum, per ordinem ad quod haec scientia, amoris v.g., est Deo libera prae opposita odii, sit Deo liberum: ita, ut posse omitti scientiam amoris eatenus sit liberum Deo, quatenus potest velle habere scientiam odii;

$2^{\circ} \quad$ ita, ut significet, scientiam amoris prae ${ }^{324}$ praescientia odii - id est, quatenus distincta est a scientia odii - esse liberam aliqua libertate, quae ipsam, ut talis est, pro obiecto habeat.

Dico ergo, primo modo non esse liberam Deo scientiam hanc prae oppositi extremi liberi scientia, esse vero liberam unam prae alia secundo modo: quia libertas divina ad absolutam scientiam amoris eam in particulari - ut distinguitur a scientia odii respicit et denominat, quia est potestas habendi hanc scientiam vel illam - cognitas a Deo infinita distinctione et perfectione - et carendi utraque, atque ideo quamlibet 
habet ita, ut libera sit Deo illam non habere: carendo tam ipsa quam scientia extremi liberi oppositi. Nec alio modo oportet Deo liberam esse scientiam, quam comparative ad scientiam extremi liberi oppositi relinquit in arbitrio hominis volendo scire quod ipsi libuerit operari. [906r] Vide plura loco citato de modo, quo Deo dicimus esse liberum concurrere ad hunc liberum actum prae alio.

438. Sexta conclusio sit: Scientiam absolutam futuri contingentis praedefiniti absolute et efficaciter a Deo liberam esse non denominative - ab actu, quo Deus libere decernit dari illud futurum -, sed formaliter: ita, ut ipsa scientia sit immediatum et formale exercitium libertatis.

Conclusio haec pendet ex principiis, quae libro $1^{\circ}$ statuta sunt circa distinctionem virtualem scientiae et volitionis divinae, eaque explicuimus hoc libro a capite $21^{\circ}$, ubi supposuimus, virtualem distinctionem intrinsecam eam esse, qua secundum esse intrinsecum, quod res habet in se, conveniunt illi revera opposita praedicata - ut divinae entitati, communicari' et ,non-communicari' -, extrinsecam vero distinctionem virtualem esse, qua opposita praedicata conveniunt rei secundum esse extrinsecum quod habet in cognitione, fundamentum praebente re ad cognitionum diversitatem ob aequivalentiam, quam habet ad plura.

Ex quo principio deduximus, quod, licet omnis intellectio distinguatur virtualiter a volitione per distinctionem virtualem extrinsecam, attamen per distinctionem intrinsecam aliquas quidem intellectiones distingui ab omni volitione, non vero omnes. Et huius secundi generis dico esse scientiam absolutam futuri, quam Deus habet vi absolutae et efficacis praedefinitionis illius: quia hanc scientiam non video, cur oporteat distinguere virtuali distinctione intrinseca ab ipsa praedefinitione, licet distinguatur ratione nostra et distinctione virtuali extrinseca. Nullam enim video rationem, quae probet, conceptus sciendi et volendi in genere ita esse oppositos, ut revera contradicentia praedicata secum afferant. Quod late ostendi agens libro $1^{\circ}$ de volitione et intellectione essentiali. Et in casu nostro ex eo patet, quia optime potest eadem indivisa intrinsece formalitas velle, obiectum futurum esse, et sciri et esse scientia ipsa, qua scitur: nam, volitionem esse cognitionem sui, sicut est volitio sui, ${ }^{325}$ quam habet terminorum repugnantiam? ${ }^{326}$

325. „Nam qui vult, etiamsi formaliter non reflectatur, tamen volendo obiectum, vult etiam implicite et virtualiter actum suum circa illud obiectum: quae est ,virtualis reflexio supra talem actum.“ Theophilus Raynaud: De virtutibus et vitiis 1, 146, ( $\left.{ }^{1} 1631\right)$ Lyon 1665, 68b. Vgl. Franciscus SuArez: In Primam Secundae D. Thomae 2, 1, 1, 2, Opera omnia, Paris 1856-78, t.4, $160 a$.

326. Vgl. Ugolinus ab Urbe Veteri: Commentarius in quattuor libros Sententiarum (ca. 1348/49), ed. W. Eckermann, Würzburg 1980-88, Bd. 1, 188: „Volitionem esse cognitionem [...] intelligitur [...], quod sit quaedam experimentalis notitia sui ipsius veluti actus vitalis, quoniam omnis perceptibiliter sibi ipsi operans habet evidentiam se operari, et non oportet, quod per alium actum: igitur sic est de amore vel volitione $[\ldots]^{\text {“ }}$ 
439. Dices, repugnare, quia volitio debet esse a cognitione, cum cognitio debeat dirigere ad volendum: debet ergo a volitione distingui.

Sed, imprimis, citato loco ostendi, volitionem, quae omnino est $a$ se, posse esse a cognitione per hoc, quod ipsa sit cognitio eadem proprietate, qua dicitur, illam esse $a$ se, scilicet tam negative - quia non est $a b$ alio - quam etiam positive, quia est sibi sufficiens ratio essendi: non per influxum, sed per essentialem determinationem ad esse sine ullius alterius ope. Hoc modo probavi, volitionem essentialem esse $a$ cognitione, et etiam, essentialem cognitionem a volitione, esseque directionem seu illustrationem scientiae suae dilectionis, quia est ardor suo igne lucens et lux [906v] suo ardens fulgore. Explicui etiam, amorem et cognitionem essentialem habere distinctionem non solum in ratione nostra, sed etiam in termino intrinseco suo, quia petunt Verbum et Spiritum, quae sunt notionalis cognitio et notionalis amor passivus ad illam revera subsecutus; ac proinde omnem amorem et cognitionem distingui vel in se ipsis vel in sui terminis. Sic essentialis amoris, qui omnino est $a s e-$ absque ullo principio etiam virtuali -, dependentiam a cognitione explicui.

440. Sed, quia in praesenti agimus de amore praedefinitivo creaturae, qui liber est cuiusque proinde necesse est dari principium virtuale indifferens et consequenter cognitionem indifferentem ad hoc, ut sequatur et non sequatur ille praedestinativus seu praedefinitivus amor -, necesse est concedere dependentiam praedefinitionis a cognitione distincta et praecedenti ipsam. Huiusmodi autem cognitio non est ea, quam diximus a praedefinitione indistinctam esse virtualiter, nam haec est cognitio, qua Deus scit, se actu praedefinire, et qua vi praedefinitionis scit, futurum esse, quod praedefinit. Quae vero distinguitur et praecedit praedefinitionem, est cognitio, qua cognoscit Deus, se posse praedefinire et velle scire suam praefinitionem et, in illa, obiectum praedefinitum. Praedefinitio ergo dependet et dirigitur non a cognitione, quae cum ipsa virtualiter identificatur, sed ab illa, quae distinguitur et praecedit.

Nulla ergo est ratio, cur repugnet, praedefinitionem ipsam esse scientiam sui et futuri in se ipsa. Ergo nulla est, cur scientia futuri efficaciter praedefiniti non sit formaliter libera, formaliter, inquam, per indistinctionem formalem intrinsecam a volitione libera, non „formaliter" tam intrinsece quam extrinsece. Nam in consideratione nostra, concedimus, hanc scientiam non esse formaliter liberam, quia - in nostra ratione - non est formaliter identificata, sed distincta a volitionis liberae conceptu: quia ex modo nostro concipiendi eam supponit ut principium sui, cum prius sit esse praedefinitionem quam cognosci, quod est. Hoc, inquam, est prius in nostro modo concipiendi, licet non sit prius in re.

441. Septima conclusio: Scientia absoluta futuri contingentis pravi - et bonorum, quae dicto modo praedefinita non sunt - non est formaliter libera, sed praesuppositive.

Probatur conclusio, quia absolutam horum obiectorum scientiam determinate sumptam non habet Deus, quia illam ipse eligat habere, sed quia ad illam habendam 
determinatur a creata libertate (ut capite praecedenti conclusione 4 ostensum est): ergo scire hoc potius quam illud non est actus formalis libertatis divinae, sed actus purae scientiae necessario consecutus ad libertatem creatam et Deo eatenus liber, quatenus supponit liberum actum, quo voluit creaturam liberam constituere ad hoc aut illud obiectum cum necessitate eligendi alterutrum e duobus. Hic actus liber Dei, ut infert hanc aut illam scientiam [907r] cum potestate utramque collective sumptam impediendi - nolendo cum creatura ad ullum extremum concurrere -, eam scientiam, quae actu habetur, sive sit huius, sive illius obiecti, denominat liberam simpliciter Deo: quia denominative a libero actu suspendi a Deo posset omnis futuri nobis liberi absoluta praescientia. Omnis ergo, quae habetur, Deo libera est utpote impedibilis per nolitionem habendi ullius obiecti liberi creati praescientiam.

\section{Caput 34. De concordia praescientiae absolutae cum libertate obiecti liberi, quod praescit esse futurum}

442. De hac concordia actum fere agimus, cum libro praecedenti omnes eius leges et conditiones - de scientia futurorum contingentium in communi agentes - explicuerimus. Ideo brevissime quae propria sunt scientiae absolutae adnotabimus.

443. Dicimus ergo, ideo illam non obstare indifferentiae et libertati obiecti quod cognoscit, quamvis essentialem habeat determinationem ad unum, quia haec determinatio nec est determinatio causalis respectu obiecti liberi nec in causali determinatione omnino praevia - quae illi sit medium cognoscendi - fundatur, sed in sola determinatione formali, quam obiectum habet per suam existentiam. Ergo non magis obstare poterit libertati obiecti quam formalis determinatio ipsiusmet obiecti.

Consequentia est evidens: nam formalis determinatio non obstat libertati, quia haec non requirit indifferentiam obiecti liberi, postquam existit - seu ipsi convenientem ex suppositione existentiae -, sed solum indifferentiam suae causae: ita, ut in illa nullam determinationem, sed omnimodam indifferentiam habeat. Ergo, si divina scientia nullam ante existentiam obiecti petit determinationem illius, sed solam determinationem existendi, aeque compatietur eius libertatem ac ipsa determinatio existentiae.

Quod confirmatur ex subsecutione scientiae ad liberam causam et operationem, quia libera causa per operationem determinat, ut Deus ipsam operationem praesciat, et per suspensionem operationis potest praescientiam impedire. Ergo non magis obstabit eius libertati praescientia aeternitate praecedens quam scientia, cum operatione ipsa incipiens, cuius ipsa operatio causa et motivum est. 
444. Solum obstare poterat, futurorum contingentium, quae praedefiniuntur praedefinitione causaliter efficaci, causam esse praescientiam ipsam absolutam. Ergo respectu horum non salvatur ratio concordiae, quam adduximus.

Respondetur, [907v] salvari: quia horum futurorum praescientia non alio modo potest esse causa, quam est „causa“ ipsa praedefinitio, in qua cognoscit futura. Haec autem est causa absoluta operationis non ut omnino praevia, sed ut aliquo modo consequens id ipsum, ad quod praecedit, ideoque non influit immediate in illud per se nec per medium aliquod determinatum, sed per media indifferentia: ita, ut petat nullam dari immediatam determinationem causalem obiecti contingentis nullamque remotam, quae sit omnino antecedens. Etenim praedefinitio efficax, qua Deus plura opera bona decernat, necessario praesupponit scientiam conditionatam operis praedefiniendi ut futuri per media indifferentia: ita, ut illis positis foret, etsi non ponerentur vi praeviae determinationis boni operis, sed per solam indifferentem Dei voluntatem. Hinc est, praefinitionem, quae hanc praescientiam supponit et opus bonum vult cum attemperatione ad illam, esse suppositionem consequentem et velle operationem solum ut faciendam eo modo, quo praevisa est, scilicet ut faciendam vi indifferentium mediorum, quibus fieret, etsi non praedefiniretur. Ideoque, tam ex ratione suppositionis consequentis quam ex negatione causalis determinationis, illi convenit tota ratio concordiae a nobis explicata: quia huic sufficit, nullam dari determinationem operis, quae sit immediata causa operationis, et quae non sit aliquo modo subsequens ad operationem. Utrumque praedefinitioni illi et praescientiae absolutae in illa fundatae - convenire, explicuimus saepe duobus libris praecedentibus (et latius explicabitur libro $7^{\circ}$ ).

\section{Ad quatuor libros praecedentes Appendix de divina voluntate praedefiniente actum liberum disiunctive ut efficiendum per aliquod medium indifferens}

445. Hac voluntate saepe usi sumus libris praecedentibus, praesertim libro $2^{\circ}$ capitibus $24^{\circ}, 26^{\circ}$ et $50^{\circ}$, et libro $3^{\circ}$ capitibus $18^{\circ}$ et $28^{\circ}$, ad explicandam dominativam Dei potestatem in nostros actus bonos eius exactam discussionem ad librum 5 et 7 remittentes. Nunc vero, post absolutum librum 4, quo primus hic tomus clauditur, a dulci studiorum otio Maiorum imperio avulsi molestis negotiis implicati veremur, libros illos serius lucem visuros quam hactenus sperabamus. Ideo de praedicta voluntate Dei, quia divino imperio et providentiae explicandis apprime inserviet et Aliorum scriptis hactenus illustrata non invenitur, nonnulla, etsi brevissime, adnotare decrevimus. 
446. Bonorum actuum, quia bona Dei sunt, [908r] oportet ipsum specialiori modo dominum esse, quam est dominus malorum: non, quia ex parte Dei perfectius sit dominium respectu alicuius obiecti creati quam alterius, sed, quia, cum „dominium" sit respectu eorum, quibus ad libitum uti possumus, magis proprie dicitur respectu eorum, quae magis immediate et per se terminare possunt libitum Dei. Hoc autem modo terminant Dei libitum bona, non autem mala. Nam ad haec ponenda solum ferri potest libitum divinum permissive: nolendo scilicet removere ea quibus impediretur eorum existentia. Ad bona autem ponenda fertur immediate volens positive et directe, quod sint. Et sic illis specialiori titulo et magis coniuncto divinae voluntati his utitur. Bonum ergo actum Deus, quia eius tanquam divini boni dominus est, debet posse velle. Quia tamen boni actus ratione libertatis sunt etiam bona, quae non nisi pro alterius domini libito obtineri possunt, oportet ita illos subiici libito Dei, ut non extrahantur a dominio creato, cui illos subiecit Deus - volens illos pro libito creati arbitrii vel poni vel impediri, prout ipsi placuerit -, et consequenter, quod non fiant nisi per media indifferentia, quorum determinatio ad operandum hoc potius quam illud committatur arbitrio creato tanquam determinanti, dependenter a divino concursu, praeviam indifferentiam ad opposita.

447. Ut haec dominia componantur, opus est,

$1^{\circ}$ Deum posse pro libito determinare ad actus boni existentiam ita, ut ad eius nutum et imperium hic efficiendus sit. Sic enim in propria bona dominari summe perfecte dominum necesse est, ut illi ad nutum inserviant quoad esse et non-esse, et consequenter, quod Deus possit ita velle, quod sint, ut eo volente non possint non esse.

Nec est, quod obiicias, Deum non posse ad nutum, cui resisti nequeat, dominari in bona sua, quorum voluit constituere alium dominum, pro cuius libito iis utendum sit.

Huic enim obiectioni occurritur facile, quia, Deum concedere creaturae, ut non nisi eius determinante electione fiat actus, nequaquam impedit, ne Deus decernat, quod creatura determinet et eligat hoc et non illud, dummodo per eadem immediata principia fiat actus - Deo illum decernente -, per quae fieret, etsi non decerneret efficaciter illum fieri; Deusque eius effectionem per illa principia decernat dependenter ab eo, quod praevideat, actum fore efficiendum per eademmet principia, quamvis non per intentionem determinativam actus, sed per intentionem indifferentem ad duo, conferrentur (ut saepe ostensum est et mihi videtur per se manifestum).

\section{Statuimus ergo}

$2^{\circ}$ Increati Domini libitum determinans ad unum - nempe ad esse actus boni non posse $[908 \mathrm{v}]$ determinare, quod fiat nisi per media illa, quibus positis fieret, 
etsi non per decretum determinans ad actum bonum, sed per omnino indifferens, ponerentur. Sic enim et relinquitur actus immediate determinandus in executione arbitrio creaturae, et pro libito Dei intendentis imperatur executio, et ad illam applicatur creatura munita ad operandum Dei virtute et indifferentis voluntatis divinae executivae concursu.

449. $3^{\circ}$ Statuimus, dupliciter posse Dei intentionem determinantem ad esse actus boni id decernere dependenter ab eo, quod idem efficeretur per eadem media, etsi non per determinantem, sed per indifferentem, intentionem ponerentur: $1^{\circ}$ ita, ut ante decretum Dei actum determinans existat praescientia conditionata contingens, qua Deus praevideat de medio, quod, si ponatur, obtinebit finem actus; $2^{\circ}$ ita, ut decretum non praesupponat illam praescientiam praecedentem natura ad sui existentiam, attamen petat, quod eiusmodi scientia praecedat ad executionem actus, quem decernit.

450. Primus modus dependendi a praescientia necessarius est decreto, quo Deus decernit actum ut efficiendum his mediis in singulari et sub his determinate circumstantiis: quia, cum contingens sit sub illis sumptis in singulari fieri et non fieri actum, non potest Deus decernere, quod, is positis absque ullo alio immediate influente, fiat infallibiliter actus, nisi praesciat, quod illis solis positis absque addito illo principio determinativo infallibile sit, actum per indifferentia illa esse efficiendum, si ponantur. Nam impossibile est Deum velle, quod per medium aliquod infallibiliter obtineatur finis, nisi prius de tali medio praecognoscat, quod, si ponatur, obtinebit infallibiliter. Nam qui huius conditionalis non praescius decerneret actum fieri per illud indifferens medium, decerneret finem obtineri infallibiliter absque infallibili medio. Quod aeque implicat. Nam velle finem hoc medio infallibiliter obtineri, est velle, quod medio posito infallibiliter sequatur finis; hoc autem nemo rationis compos velle potest, nisi praecognoscat, quod posito medio infallibile sit, sequuturum esse finem, vel, quia medium ex natura sua non potest non obtinere finem, vel, quia, etsi posset illum non obtinere, attamen infallibiliter praescitur, quod illum obtinebit; cum ergo natura medii indifferentis non petat sequi infallibiliter finem liberum, oportet, ut Deus, antequam decernat per tale medium fieri actum, praesciat - non per scientiam necessariam, quae comprehendit medii naturam, sed per contingentem, qua supercomprehendit pertingens usque ad eventus contingenter ab illa orituros -, praesciat, inquam, quod, si tale medium ponatur, obtinebit finem liberi actus.

451. Secundus vero modus dependendi a praescientia conditionata contingenti eventus liberi sufficit ad decretum, [909r] quo Deus actum infallibiliter fieri decernit, non tamen determinando, ut per hoc medium in singulari fiat, sed disiunctive respiciendo collectionem mediorum indifferentium, in qua necesse sit inveniri 
plura, de quibus praesciatur, quod, si ponantur, quamvis omnino indifferentia sint, obtinebunt infallibiliter finem. ${ }^{327}$ Etenim supposito, quod necesse sit (de quo statim

327. Dieser Prädefinitionsmodus war schon vorher öfter vorgekommen. Vgl. Lib. II cap. 50: [Fol. 427r] " $4^{\circ}$ arguitur, quia Deus potest sine praesuppositione ullius praescientiae contingentis, etiam conditionatae, decernere liberam operationem ut solius scientiae simplicis intelligentiae. Per hanc enim certo novit Deus, non posse deficere in collectione mediorum possibilium innumera, de quibus certum sit, quod, si ponantur, obtinebunt effectum, etiamsi, illis positis, possibile sit, illum non obtineri. Nam, $[427 \mathrm{v}]$ licet hac scientia non cognoscat de aliquo medio in particulari, quod, illo posito, obtinetur effectus liber - quia eiusmodi obiectum est contingens -, attamen, cum necesse sit, Deum habere actum aliquem scientiae contingentis conditionatae, qua de aliquibus mediis sciat, quod, si ponantur, obtinebunt effectum liberum - quia impossibile est, illa deficere in infinita mediorum collectione -, Deus per scientiam necessariam id cognoscere debet, sicut etiam per eandem cognoscit, quod impossibile sit, se ipsum non habere scientiam contingentem absolutam de aliquo ponendo, aut suspendendo, a divina libertate. Hoc posito, argumentor sic: Deus vi scientiae necessariae, qua cognoscit, impossibile esse, quod non habeat de aliquo medio indifferenti certam praescientiam conditionatam, qua certo sciat, actum bonum fore, si tale medium ponatur, potest decernere, quod existat talis actus: quia potest decernere medium aliquod poni, de quo praesciatur fore efficax ad talis actus existentiam. Quod est efficaciter decernere actus existentiam. - Respondeo concedendo eiusmodi decretum et negando, quod sit omnino antecedens operationem liberam. Nam, etsi antecedens sit in existendo, non tamen in operando et coexistendo voluntati ut proxime potenti elicere talem operationem, quia non potest ad operationem concurrere nisi determinando electionem medii, quod praesciatur fore efficax, si ponatur. Haec autem determinatio non est Deo possibilis nisi ex conditionatae praescientiae directione, et, consequenter, decretum illud - in operando id, quod concurrit ad operationem, et in coexistendo voluntati ut habenti illud - consequens est ad conditionatam praescientiam. Quod sufficit ad actus libertatem (ut cap. 24 dictum est et libro sequenti [sc. $3^{\circ}$ ] cap. 18 iterum ostendetur)." Vgl. auch das folgende Exzerpt aus Lib. III cap. 28 Explicatur suppositio consequens in aliis duobus modis praedestinandi liberos actus, et in praedestinatione ad gloriam ut coronam: [Fol. 73or] „Patet autem, dupliciter [...] ordinare Deum disiunctive media ad finem liberi actus ante efficacem ordinationem absolutam medii particularis ad illum - et huius [730v] praefinitionem per tale medium -, quia duplex esse potest intentio actus disiunctive respiciens media. Alia est absoluta omnino, quam S. Tномаs de facto semper supponi vult ad talem praefinitionem et praedestinationem: estque ordinatio absolute intendens, quod fiat actus per aliquod medium, quia collectio mediorum, circa quae versatur, disiunctio illius ordinationis talis est, ut non possent non includi in illa media aliqua, quae, si ponantur, habitura sint effectum. Secunda est ordinatio conditionata, qua Deus velit actum liberum fieri per aliquod ex collectione determinata mediorum, si in illa contineatur aliquod, cui homo libere consensurus praevideatur. Haec intentio sufficit ad actum in posteriori signo praedefiniendum absolute et, consequenter, ad praedestinationem praedefinitivam absolute actus liberi per determinatum medium exercendam. - Si autem quaeras, quae sit conditio, sub qua conditionata illa ordinatio disiunctiva vult fieri actum per aliquod medium ex contentis in collectione mediorum, ad quae divinae praeparationis misericordia se extendit? - respondeo, conditionem esse scientiam conditionatam actus liberi ut futuri per aliquod ex mediis in tali collectione contentis. Nam, vi talis ordinationis necesse est, Deum non velle exequi aliquod ex his mediis, nisi dependenter a praevisione eventus, quem quodlibet illorum, si ponatur, habebit, et quod, si praevideatur 
agemus), in collectione indifferentium mediorum invenienda esse plura, quibus positis infallibiliter obtinendus sit finis liberi actus, Deus antecedenter ad omnem praescientiam contingentem scit, non posse sibi deesse media aliqua quibus, si ponantur, obtinendus sit infallibiliter actus liber. Ergo vi huius scientiae, quin ulla contingens praecedat ad decretum, potest Deus decernere, quod existat actus, hunc respiciendo determinate, media vero, quibus effici potest, disiunctive. Ergo decretum efficax liberi actus non determinans medium hoc indifferens in particulari, sed disiunctive respiciens collectionem mediorum, in qua necesse sit inveniri plura infallibiliter illatura actum, si ponuntur, non potest dependere a praescientia conditionata contingenti tanquam a praecedente natura ad ipsum, sed solum tanquam a requisito essentialiter ad executionem actus, quem decernit.

452. Dependentia autem haec in eo fundatur, quod - cum eiusmodi decretum habeatur vi scientiae necessariae, qua novit Deus, non posse deesse media, de quibus ipse per contingentem scientiam praesciat, quod, si ponantur, efficient actum liberum - necesse est, tale decretum ad eius tantum medii executionem determinare, de quo prius fuerit praevisum per scientiam contingentem, quod, si ponatur, inferet infallibiliter effectum. Hac ergo scientia eget decretum illud ad actus, quem decernit, executionem eamque essentialiter petit in Deo dari, non quidem ut praeviam natura ad se ipsam, sed, ut praevie dirigat ad sui executionem. Haec enim fieri debet per electionem medii alicuius in singulari, per quod Deus velit fieri actum, quem sine unius medii prae alio determinatione decreverat. Non potest autem velle, quod infallibiliter fiat per medium hoc in singulari, cum quo - spectata medii

aliquod habiturum effectum, illud eligatur. Idem dicendum est de decreto disiunctivo, quo Deus statueret de unico tantum medio, illud vel dare, si profuturum esse videatur, vel omnino negare potestatem ad operandum, si videatur, hominem tali medio male usurum. Nam hoc decretum sufficit, ut possit Deus - et debeat - in collatione, et negatione, medii regulari per praescientiam eventus, et quod, data praescientia eventus boni, dare debeat ex illa tale medium, et negare, si sciatur oppositum. Attamen aliquam ex dictis ordinationibus disiunctivis praecedere, opus est, et quaevis sufficit ad praefinitionem et praedestinationem liberi actus ut exercendi per medium quodvis indifferens in particulari sumptum." - Zum zeitgenössischen Meinungsbild in bezug auf die Existenzannahme disjunktiver Willensdekrete vgl. die Übersicht bei ANTonius BERNALDo DE Quirós SJ.: Selectae Disputationes theologicae de Deo, Lyon 1654, 481b/82a: „Prima sententia negat. Ita obiter AlbertinUs tomo $1^{\circ} \mathrm{q} .3$ Theolog. fine in tertio Coroll. ex quarto principio Philosophico, Alvarez de Auxil. lib. $2^{\circ}$ disp. 13 n. 4 , et ex professo Alarcon tractatu $4^{\circ}$ de Praedest. cap. $7 \$ 2$ a n. 36 pro se citans SuAREz latissime impugnantem haec decreta vaga et disiunctiva opusc. $3^{\circ}$ de Auxil. cap. 17 n. 2 et 14 , libro $1^{\circ}$ de Praedest. cap. 13 et libro $3^{\circ}$ cap. 10. [...] Secunda sententia admittit volitionem disiunctivam. Ita Granados prima parte Controv. 3 tract. 3 disp. 5 sect. 3 a n. 19, Pater Ruiz disp. 11 de Voluntate sect. 8 n. 2 et sect. 10, et de Provident. disp. 8 sect. 4, Lugo disp. 7 de Incarnatione n. 39, Arriaga disp. 7 Logicae n. 66, Georgius Hemelman tom. $1^{\circ}$ in Primam partem titulo 7 d. 3 per totam latissime [...]. " Auch Bernaldo de Quirós selber tritt der zweiten Fraktion bei. 
natura - actus non est infallibiliter connexus nisi ex directione praecedentis scientiae contingentis, qua cognoscat infallibiliter ponendum actum, si medium illud ponatur, quia - sicut ad volendum, quod infallibiliter sequatur finis per medium, necesse est praenoscere, quod, si ponatur medium, erit finis, ita - ad volendum, quod infallibiliter sequatur finis ex hoc medio, necesse est praescire, quod, si hoc ponatur, sequetur finis. Ad finem ergo liberum volendum per hoc medium in particulari, necesse est, scientiam conditionatam contingentem - seu mediam praecedere ad Dei volitionem, [909v] quia contingens est, quod, medio illo posito, sequatur actus. At vero ad volendum, quod per aliquod medium contingens fiat, non est opus, quod praecedat ad Dei volitionem contingens praescientia conditionata: quia contingens non est, sed necessarium, quod Deus cognoscat, in collectione mediorum indifferentium reperienda esse plura media, quae, si ponantur, obtinebunt finem actus liberi. ${ }^{328}$

453. Decreti hoc tantum $2^{\circ}$ modo pendentis a scientia conditionata contingenti possibilitas et compossibilitas cum libertate actus decreti pendet ex impossibilitate resistendi toti collectioni vocationum et mediorum indifferentium, quibus Deus hominem movere potest ad quemlibet actum bonum. Ea enim impossibilitas probat, dari in Deo essentialem determinationem ad habendum de aliquibus mediis scientiam contingentem, qua infallibiliter cognoscat, quod, si ponantur, obtinebunt consensum liberum hominis. Haec autem essentialis determinatio cognita facit Deo possibilem volitionem determinativam nostri actus non determinantem, sed disiunctive respicientem, media quibus faciendus est; nam eo modo, quo novit Deus, sibi suppetere media infallibiliter illativa actus, potest hunc ut infallibiliter ponendum decernere. Cum ergo per scientiam necessariam sciat, sibi non posse deesse media infallibilia ad finem actus obtinendum, poterit vi talis scientiae - nulla contingenti scientia expectata - decernere, quod per aliquod illorum exerceatur actus, illumque per media indifferentia exequi eundemque operandi modum, quo operatur voluntas creata absque decreto determinativo Dei ad operandum applicata, retinere (ut inferius videbimus).

Si ergo semel statuatur in voluntate nostra impossibilitas resistendi toti collectioni auxiliorum indifferentium, quibus Deus illam ad quemcumque actum movere potest, facile concluditur, Deo ante omnem scientiam contingentem inesse potestatem decernendi efficaciter existentiam nostri actus liberi, dependenter tamen a contingenti praescientia exequendi.

328. Für diese Relativierungsstrategie der Scientia-Media-Hypothese vgl. Franciscus Albertinus: Corollaria, seu quaestiones theologicae quae deducuntur ex principiis Philosophicis complexis, Lyon 1610, p. 300 ; ebd. p. $328 \mathrm{aD} / \mathrm{bA}$. 
454. Impossibilitatem ergo illam stabiliamus. Eam non solum dari asserimus moralem, sed et metaphysicam, ${ }^{329}$ resistendi toti collectioni auxiliorum indifferentium: ac proinde essentialem necessitatem consentiendi innumeris.

Haec est communior sententia Doctorum, qui solis auxiliis indifferentibus Deum uti posse docent ad liberos actus. Eam tradit expresse Suarez lib. $3^{\circ} \mathrm{De}$ Auxiliis cap. 14 n. 16, quia „potest (inquiens) Deus infinitis modis hominem adiuvare et vocare; ideo simpliciter fieri non potest, quin praecognoscat Deus plures gratias seu auxilia, quibus de facto converteret hominem, si vellet illa praestare“.330 VÁzQuez tom. $1^{\circ}$ in Primam partem disp. 11 cap. 5 non solum de collectione auxiliorum ad bonum, sed de collectione etiam tentationum, asserit, impossibile esse, quod in illis non videantur innumerae, quibus homo deficeret, [910r] si illis urgeretur. ${ }^{331}$ FAsolus Prima parte q. 14 art. 13 n. 437, ubi ait: „Inter [...] infinitas gratias, quibus Deus movere potest Petrum ad fidem, non potest deesse aliqua, per quam Petrus crederet, et a Deo ad fidem eligi posset. “ 332 Et n ${ }^{\circ} 138$ : „Nego, Iudam esse impraedestinabilem, quia omnipotenti deesse non potest modus inducendi Iudam aut quemlibet alium multo peiorem - ad bene operandum. “"333 P. Ruiz tomo De Providentia tract. 2 disp. 11 sect. 4 n. 9 obiectioni, in qua assumitur hypothesis, in qua voluntas aliqua ita prava constituatur, ut in omni tempore et omni vocatione Deo repugnatura per scientiam conditionatam praevideatur, respondet, 334 hypothesim illam esse „impossibilem“ non minus, quam impossibile est, volitivam potentiam esse „intrinsece malam“. 335 P. Molina Prima parte q. 23 art. 4 et 5 disp. 1 membro 11 concl. 6,336 et in Concordia eadem quaestione et disputatione membro

329. Diese Zuspitzung von Augustins Position (s.u. \$456) ist vor Wadding unbezeugt. Genauso jedoch Antonius Perez: In Primam partem D. Thomae opus posthumum: De providentia Dei 5, 79, Rom 1656, 363a/b.

330. Franciscus Suarez: Opera omnia, Paris 1856-78, t.11, $230 a$.

331. Nicht verifizierbar. Vgl. jedoch Gabriel Vazquez: Commentaria ac Disputationes in Primam Secundae S. Thomae 189, 40, t.2, 295 a.

332. Hieronymus Fasolus: In Primam partem Summae D. Thomae commentaria, Lyon 1623-36, t.2, 259 b.

333. Nicht verifizierbar. Vgl. jedoch Hieronymus Fasolus: In Primam partem Summae D. Thomae commentaria Q. 14 art. 13, 440, Lyon 1623-36, t.2, 26ob/61a.

334. Didacus RuIZ de Montoya: Commentarii ac Disputationes ad quaestionem XXII et bonam partem quaestionis XXIII ex Prima parte S. Thomae: De providentia praedefiniente ac praebente praedestinationis exordium, Lyon 1631, 171b.

335. intentionalem corr.

336. Nicht verifizierbar. Vgl. jedoch Ludovicus Molina: Commentaria in Primam D. Thomae partem Q. 23 art. 4-5, 1, 11, 5, Cuenca 1592, 957-58. 
9 concl. etiam 6,337 et alibi saepe, supponit tanquam per se notum, Deum de quavis voluntate praescire innumeros modos movendi ad quemcumque actum, quibus positis infallibiliter novit Deus, talem actum exercendum esse. Idque pro indubitato supponunt omnes Nostri Doctores, quoties de potestate Dei ad humana corda, quo voluerit, inflectenda disserunt. Si autem possibile esset, in tota collectione mediorum indifferentium non praevideri ullum, quo posito obtineretur finis liberi actus, non possent illi Authores ut indubitabile supponere illam Dei praescientiam de mediis infallibilibus ad cuiuscumque actus effectionem.

455. Nam etsi dicat quis, eos ad id asserendum motos fuisse non ex eo, quod sit impossibile voluntatem nostram videri resistentem omnibus mediis possibilibus, sed quia Sacrae Literae, Sanctique Doctores docent, id de facto non videri a Deo - sed potius oppositum -, dum docent, Deo suppetere media et modos vocandi quibus infallibiliter quemlibet, quoties ipsi libuerit, convertere valet, -

Etsi, inquam, id dicat quis, non satisfaciet: quia eam potestatem infallibilem ad libitum convertendi Deo tribuunt et SCRIPTURAe et Patres ut praedicatum indefectibile illi conveniens, quia omnipotens est et humanarum voluntatum perfectus et supremus Dominus (ut ex inferius dicendis constabit).

456. Potestatem hanc ut per se notam supponit Divus Augustinus in Enchiridio cap. 98, quis - inquiens - tam impie desipiat, ut malas hominum voluntates neget Deum posse convertere, "quas voluerit, quando voluerit, ubi voluerit“?338 Et in lib. De Correptione et Gratia cap. 14: Deo, inquit, „,volenti salvum facere nullum humanum resistit arbitrium. Sic enim velle, et nolle in volentis [...] est potestate, ut divinam voluntatem non impediat, neque superet potestatem [...] De ipsis enim hominum voluntatibus facit, quod vult, et quando vult [...] habens humanorum cordium, quo voluerit, inclinandorum omnipotentissimam potestatem. “"339 Huius vero potestatis rationem seu expeditionem reducit ad impossibilitatem resistendi omnibus modis vocationum, quas Deus in omnipotentiae suae thesauris habet lib. $1^{\circ}$ Ad Simplicianum q. 2: "Cum unus sic, alius vero sic moveatur ad Fidem, eademque res uno modo dicta moveat, alio modo dicta non moveat, unum moveat, alium non moveat, etc., quis audeat dicere, defuisse Deo modum vocandi, quo etiam Esau ad eam Fidem mentem applicaret voluntatemque coniungeret, in qua Iacob iustificatus est?" ${ }^{340}$ His similia passim in ea quaestione et saepe alibi inculcat

337. Vielmehr Ludovicus Molina: Liberi arbitrii cum gratiae donis etc. Concordia Q. 23 art. 4-5, 1, 11, 20, ed. J. Rabeneck, Oña-Madrid 1953, 549-50.

338. Augustinus: Enchiridion 98, 25, PL 40, 277.

339. Augustinus: De correptione et gratia 14, 43. 45, PL 44, 942-43.

340. Augustinus: Ad Simplicianum I, 2, 14, PL 40, 119. 
Augustinus. Ergo, [910v] iuxta ipsum, foret audacia de nullo homine credibilis insaniaque et fatuitas negare, quod Deus habeat in thesauris suae omnipotentiae innumeros modos, quibus Esau - et quivis hominum - converteretur, si Deus illis uti vellet; illaque non suppetere, reputant iniuriam omnipotentis. Ergo omnipotentiae conceptus requirit, Deum habere modos vocandi, de quibus sciatur, iis adhibitis hominem esse convertendum, idque adeo evidens iudicat, ut non nisi ab amente aut fatuo negari possit. Non ergo contingens, sed essentialiter necessarium est - et Deo, et nobis -, quod ad ${ }^{341}$ actum conversionis ad Fidem et consequenter ad quemcumque alium actum liberum Deus habeat et praenoscat infinitos modos, quibus, si uti velit, ii actus obtinendi sunt.

457. Nec iuvat dicere, Deo essentiale esse, quod possit hominem convertere infallibiliter aliquo actu conversionis vel libero, si homo velit alicui ex indifferentibus auxiliis acquiescere, vel necessario, si omnibus illis repugnaturus cognoscatur.

Nam D. Augustinus loquitur de conversione ad Fidem et ad actus salutares, quibus homo ad gratiam disponatur et ad aeternam salutem tendere possit. Hos autem actus liberos esse oportet.

Deinde, ratio, qua Augustinus probat, Deum habere innumeros modos, quibus convertere hominem possit, inanis esset, si loqueretur de sola conversione necessaria. ${ }^{342}$ Ratio est: „Cum unus sic, alius sic moveatur ad Fidem, quis audeat dicere, defuisse Deo modum vocandi, quo Esau mentem ad Fidem applicaret, in qua Iacob iustificatus est?" 343 Ergo voluntas credendi, ad quam dicit non posse Deo deesse modum vocandi, quo obtineretur, est voluntas eius generis, ad quam unus sic, alius sic de facto moveretur: ac proinde est voluntas libera. Et sane ad necessariam voluntatem in nobis producendam nil refert, quod unus sic, alius sic libere moveatur ad Fidem; nam, etsi nullus ullo modo indifferenti libere movendus esset ad Fidem, Deo aeque possibile esset illum determinare ad Fidem necessariam ac possibile cognoscitur supposito, quod libere aliquibus auxiliis movendi sint. Nec ad probandum, quod Deo possibilis sit modus, quo ad Fidem necessario exercendam moveri possit homo, utilis probatio desumeretur ex eo, quod unus sic, alius sic moveatur ad Fidem. Hac ergo probatione Augustinus tantum utitur ad probandum, quod Deo non possint deesse plures modi vocandi quibus ad voluntatem liberam credendi moveretur Esau et quilibet alius ex hominibus.

458. Ratio autem, qua id probat Augustinus, est, quia, cum videamus unum hominem sic moveri, alium sic, unum moveri hoc modo, alium vero hoc modo, quia ipsi

341. quoad corr.

342. libera corr.

343. Augustinus: Ad Simplicianum I, 2, 14, PL 40, 119. 
congruens non est, non moveri, omnipotensque possit infinitis modis quemlibet ad quemcumque actum movere, sequitur manifeste, quod innumeros habeat modos, quibus quemlibet hominem possit Deus ad quemcumque actum movere.

Huius rationis vis non aliunde desumitur quam ex ipsa terminorum manifestatione, quae rem relinquit nulli rationabiliter dubitabilem. In infinitis namque modis adeoque variis et proportionatis movendi voluntatem tam facile hoc et illo modo mobilem nullum inveniri, qui actu profuturus ad movendum iudicetur, nec credibile nec possibile apparet. Videtur etiam omnino alienum a resistentia finita voluntatis comparata cum infinita motionum indifferentium [911r] multitudine, activitate et varietate. His enim repugnat semper frustrari posse a voluntate non habente resistentiam ex necessitate naturae, quae infinitae virtutis - et non propriae inconstantiae - determinatione resistit.

459. Nec dicas, finitudinem resistendi, si probet subiectionem ad Dei nutum, non probare subiectionem in exercitio libero, sed in necessario: cum necessarium sit quod exercetur sine potestate resistendi.

Concedo enim, quod oporteat fateri necessitatem aliquam in impossibilitate resistendi eo modo, quo impossibilitas est. Quod in omni sententia ut per se notum supponi debere, probavi libro $2^{\circ}$ capite $1^{\circ}$. Libero autem exercitio operationis non omnis necessitas contradicit, sed quae illud facit necessarium iis principiis, quibus „liberum“ dicitur; nam respectu horum oportet, quod non sit necessaria operatio, sed contingens. Principia autem, quibus dicitur contingens operatio „libera“, non sunt omnia, a quibus fieri potest, sed a quibus fit, nec omnia, a quibus utcumque fit, sed ea, quae ex sua natura petit aut in illam immediate et per se influunt. Quod autem non sit contingens - sed necessaria - respectu aliorum, nil refert. Hinc est, ex finita virtute resistendi voluntatis concedendum esse, eam non habere libertatem resistendi omnibus auxiliis divinis possibilibus collective sumptis ${ }^{344}$ sicut nec voluntati divinae determinanti, quod actus fiat, sed potius habere necessitatem consentiendi huic voluntati determinate sumptae et alicui ex collectione auxiliorum disiunctive sumpto: 345 quia voluntas Dei, cui nequit resistere, non est requisita ad actum liberum nec in illum per se influens, collectio vero auxiliorum non est principium, quod actu et singulariter influit, sed, quod influere potest per quamlibet talis collectionis partem. Quid ergo refert ad libertatem operandi per hoc particulare principium, quod necesse sit eam conditionate videri operantem per hoc vel per illud, quin ulla sit libertas ad operationis carentiam coniungendam in Dei praescientia cum omnibus auxiliis collective?

344. Zur Distinktion ,divisive / collective’ („Jedes Los kann gewinnen“: in der einen Beziehung ja, in der anderen nicht) vgl. $\$ 72$.

345. sumpta corr. 
46o. Probatur denique eadem impossibilitas resistendi omnibus auxiliis collective, quia repugnare videtur perfecto dominio, quo in humanas voluntates dominari Deum testantur SCRIPTURAe. Quae enim in illis inveniuntur de potestate Dei ad corda humana, quo voluerit et quando voluerit, convertenda, non contingens aliquod praedicatum, sed esse moralem perfectionem praedicant. Quod satis ostenditur illo Isaiae 14 [v. 24-27] „Iuravit Dominus exercituum, dicens: Si non, ut putavi, ita erit, et quomodo mente tractavi, ita eveniet [...] Dominus enim exercituum decrevit, et quis poterit infirmare?"Esse autem Dominum exercituum et universorum Dominum, perfectio essentialis est. Non loquor de dominandi exercitio, sed de potestate. Ergo ea perfectione essentiali probat SCRIPTURA, quod cuncta sint posita in Dei voluntate, et quod eius voluntati resisti nequeat. Cum ergo in cunctis, quae divinae voluntati subiiciuntur, includi necesse sit liberos nostros actus, ita ut neque in his resisti possit divinae voluntati, dicendum est, non esse Deo accidentale, sed essentiale, quod actus liberi subiiciantur nutui divino, cui nequeat resisti.

461. Confirmatur eadem probatio: quia potestatem [911v] erga libera, qua Deus possit de illis exercendis decernere ad nutum, cui nequeat resisti, convenire de facto Deo, constans est ex SCRIPTURIs; magis autem commendat divinam perfectionem, quod ea potestas Deo conveniat essentialiter quam accidentaliter, ut per se patet: sic ergo dicendum est, quod conveniat.

462. Oppones $1^{\circ}$, eam potestatem ut essentialiter Deo convenientem non consistere cum libertate: quia huic repugnat, quod possit inevitabiliter determinari actus liber. Si autem Deo essentiale esset, posse decernere actus liberi existentiam, posset hic inevitabiliter determinari, quia determinari posset per decretum Dei, cuius neque existentia neque executio evitari ab humana voluntate posset.

Huic obiectioni saepe satisfecimus, praesertim libro $2^{\circ}$ capite $^{346}$ et libro $3^{\circ} \mathrm{ca}-$ pite $18^{\circ}$. Summa responsionis est, decretum, quo Deus potest absque suppositione aliqua a nobis inimpedibili ${ }^{347}$ decernere actum nostrum liberum, non esse decretum, quo velit actum fieri per hoc principium in singulari, sed, quo velit illum fieri per aliquod ex possibilibus; ideoque actum non facit inevitabilem respectu voluntatis ut constituitur potens in singulari per hoc principium, quando datur a Deo, aut per aliud, quod Deus concedere vellet. Hinc est, decretum illud non esse determinationem inevitabilem nostri actus ut efficiendi per principium illud, quo voluntas constituitur actu et in singulari potens ad illum, licet sit determinatio et necessitas actus ut inevitabiliter efficiendi per aliquod principium. Quod non obstat libertati actus ut efficiendi per hoc determinate, ut per se patet, cum illum relinquat

346. Lacuna.

347. impedibili corr. 
contingentem respectu principii determinati seu singularis, a quo efficitur: quamvis nulla sit contingentia in eo, quod per aliquod principium efficiendus sit. Hanc autem contingentiam actus respectu singularis principii immediati, a quo efficitur, sufficere ad eius libertatem, saepe ostendimus ex eo, quod faciat immediatum principium eodem modo operari, ac si nulla esset disiunctiva necessitas operandi per hoc aut per illud principium immediatum: quia disiunctiva necessitas, quam imponit decretum illud Dei, est solum remoti principii et determinantis ad operandum per aliquod immediatum principium, quo operatura foret voluntas, etiamsi per decretum nullo modo determinativum actus, sed omnino indifferens, conferretur. Quod facit, eiusmodi decretum esse suppositionem consequentem: non in existendo, sed in operando et in coexistendo principio proximo, quo potens constituitur voluntas creata ad operandum, quia non potest ullum huiusmodi principium in voluntate ponere nisi ex praescientia conditionata, quod actus per ipsum producendus foret, etsi non a decreto determinante, sed indifferenter se habente, poneretur. De his vide caput $^{348}$ libri 2, et 18 libri 3 .

\section{[Obiectio]}

463. $2^{\circ}$ Oppones: Omne principium determinans ad unum obstare libertati, etsi remotum sit:

Tum, quia cum remoti determinatione ad unum non stat, proxima esse indifferentia ad duo: praesertim voluntatem executivam, qua Deus immediate concurrit, quia, cum haec oriatur ex cognitione remotorum praerequisitorum, a quibus oritur et per se ab illis dependeat, non potest non esse determinata ad unum, si ad illam praecedat remota aliqua voluntas Dei ad unum determinans.

Tum etiam, quia suppositio determinans, si praecedat natura - etiam remote -, non potest esse „consequens“: erit ergo omnino antecedens ac proinde - in nostris principiis - repugnans libertati.

Antecedens hoc solet multis suaderi, praesertim, quia, ut aliquod principium sit consequens ad operationem liberam, opus est, quod operatio pro statu, in quo praecedit ad tale principium, [912r] non supponat illud; nam, si pro eodem statu, in quo operatio praecedit ad principium aliquod sui, supponeret illud, non esset opus distinctione ulla statuum in operatione, ut ,praecederet' et ,subsequeretur' ad aliquod principium sui, sed posset - et deberet - pro eodem statu praecedere simul et subsequi. Quod Authores, qui suppositiones omnino praevias reiiciunt, 349 nequaquam admittunt, sed asserunt, vel mutuam prioritatem principii et operationis sumptae pro eodem statu implicatoriam esse, vel, si sit probabilis in diverso

348. Lacuna.

349. D.h. die Jesuiten. 
genere, ${ }^{350}$ non sufficere hoc mutuae prioritatis genus ad hoc, ut principium operationis, cui convenit, non sit suppositio omnino antecedens ad illam: quia suppositioni omnino antecedenti convenire potest. De physica enim praedeterminatione, quae omnino antecedens suppositio est, dicitur communiter, quod subsequens sit ad operationem in genere causae materialis, etsi procedat in genere efficientis.

\section{Tum sic:}

Principium determinans ad unum seu praedefinitivum operationis et praecedens ad illam in statu absoluto, non potest supponere operationem ut futuram in statu conditionato sine dependentia et subsecutione a principio praedefinitivo: ergo non potest praedefinitio esse ullo modo consequens, sed debet esse omnino antecedens.

Antecedens probatur. Imprimis in sententia Asserentium, quod praefinitio Dei sit essentialiter requisita ad absolutam operationis existentiam.

Implicat enim Dei conditionatam scientiam affirmare, operationem esse futuram, nisi sub conditione sufficienti ad absolutam existentiam illius: cum implicet fore sub conditione operationem, nisi possit sub illa esse; implicat autem posse sub illa esse, nisi conditio sufficiens sit ad tale esse sufficientiamve secum afferat vel supponat: Deus ergo affirmans, operationem fore, si ponatur conditio aliqua, cognoscere debet in conditione sufficientiam ad esse operationis ac proinde praefinitionem essentialiter inclusam in tali sufficientia, quin ab illa praescindere valeat conditionata Dei affirmatio. Ergo necesse est, ut praedefinitionem vel affirmet fore, si ponatur conditio, vel, quod sub illa tanquam sub conditione affirmet operationem.

Hoc secundum non potest dici, quia conditionata scientia contingens non affirmat operationem sub conditione ulla, cum qua essentialiter connectatur. Alias contingens scientia non esset, sed necessaria.

Nec etiam dici potest primum, quia conditio, sub qua affirmatur operatio, non est conditio ad praefinitionem operationis: ac proinde sub illa non potest affirmari praefinitio, et ideo Dei praefinitio non potest esse affirmata sub tali conditione.

465. Dices: Quod affirmat Deus fore per scientiam conditionatam de praefinitione sua, esse disiunctum quoddam, nempe, quod vel non existet conditio seu vocatio, vel existet per praefinitionem operationis. Quod est affirmare praefinitionem absolute sub quadam disiunctione conditionaliter explicata.

350. Die von Aristoteles bezogen auf verschiedene Gattungen der Kausalität - causa efficiens und causa finalis (Physik II, 3, 195a) - zugegebene Möglichkeit einer „mutua prioritas“ wurde in der Jesuitenscholastik häufig nicht zugegeben: GABRIEL VÁzQUEZ: Commentaria ac Disputationes in Tertiam partem S. Thomae 202, 11, Lyon 1620, t.3, 274a; Rodericus De Arriaga: Cursus philosophicus: Phys. 7, 101, Antwerpen 1632, 341a. Prädestinationstheologisch wurde sie vertreten von Antonius Bernaldo de Quiros: Selectae Disputationes theologicae de praedestinatione, Trinitate, et Angelis 9, 20, Lyon 1658, 61b. 


\section{Sed contra:}

$1^{\circ}$ Quia hoc non est videre aliquod humanae libertatis exercitium ut contingenter futurum, sed videre exercitium libertatis divinae: ad quod inevitabiliter sequatur humanum. Ergo non est praevisio faciens in divino decreto subsecutionem ad praevisam libertatem humanam. [912v]

$2^{\circ}$ Quia, conditionem vel non esse ponendam, vel ponendam esse per praefinitionem operationis, non homini, sed Deo soli, liberum est. Suam ergo, non hominis, libertatem in hoc disiuncto praevisum habet. Ergo non hominis, sed Dei libertas est, quae antecedit absolutam praefinitionem divinam, Deique libertas non quomodocumque sumpta, sed exercita absolute ex parte Dei conditionate seu disiunctive decernentis, conditionem non fore nisi per praefinitionem operationis.

$3^{\circ} \quad$ Hoc genus explicandi conditionatam scientiam - ut tendentem tam ad nostram operationem et Dei praefinitionem - a sententia Praedeterminantium nequaquam recedit: quia IPSI ante absolutam praefinitionem operationis dicunt, necessarium esse, quod Deus praesciat et decernat, vocationem non fore nisi per absolutam operationis praedefinitionem decernentem, quod, si vocatio extitura sit, oriatur a divino decreto praefiniente operationem et non ab alio. Ergo decretum, quod PraedeTERminantes defendunt respectu nostrae operationis, eandem habet praesuppositionem operationis humanae ac praedefinitivum decretum, quod in praedicta solutione defenditur.

466. Nec iuvat dicere, decretum Praedeterminantium supponere praevisionem operationis ut futuram per immediata principia determinantia ad unum, at vero decretum praedefinitivum, quod nunc defenditur ut necessarium ad liberam operationem absolutam, supponere praevisionem operationis ut futurae per immediata principia indifferentia.

Sed contra $1^{\circ}$, quia voluntas praedefinitiva, quae necessaria ab IIs Theologis dicitur, est requisitum proximum et immediatum - non remotum et mediatum -, quia aliqua Dei voluntas immediate influere debet in actum liberum; praedicti autem Theologi non admittunt distinctionem virtualem in actibus divinae voluntatis, praesertim circa idem obiectum: ergo, cum aliqua Dei voluntas immediate influat, necesse est, eam esse indistinctam a praefinitiva et, consequenter, si haec necessaria est, esse requisitum immediatum et non remotum.

467. Contra $2^{\circ}$, quia immediata principia non possunt esse indifferentia, si aliquod determinans sit necessarium etiam remote: quia eo ipso, quod essentialiter requiratur principium aliquod ad effectum, hic debet ab illo per se dependere ac proinde vel immediate vel medio aliquo, quod per se, et non per accidens, exigat tale principium. Nam, principium determinans esse essentialiter requisitum, facit, quod indifferens 
principium nec sufficiens nec aptum sit sola sua existentia producere actum, ad quem principium determinans requiritur: cum possit tota illa existentia dari sine principio determinante ad actum et cum determinatione ad oppositum. Ad effectum autem immediate concurrit principium ut aptum et sufficiens. Ergo determinans principium, quo aptitudo principii indifferentis ad influendum in actum constituitur, influere debet immediate in actum, sive sit tanquam efficiens, sive tanquam constituens efficiendi aptitudinem saltem per modum immediatae conditionis.

Deinde, probatur huius impugnationis assumptum ex eo, quod voluntas, qua Deus immediate concurrit ad actum nostrum, debet supponere omnia remotiora, quae essentialiter requiruntur ad actum, nisi alicuius carentiam ex suppositione consequenti positam supponat. Si ergo essentialiter requiri dicatur remotum principium [913r] determinans ad actus existentiam, necesse est, voluntatem, qua Deus immediate concurrit, supponere eiusmodi principium et consequenter esse determinatam ad unum.

Antecedens patet, quia voluntatem, qua Deus immediate et absolute vult applicare voluntatem liberam ad agendum, debet vel facere vel supponere, quod nullum detur impedimentum agendi. Ergo, cum defectus cuiusvis essentialiter requisiti ad agendum sit impedimentum actionis, oportet, voluntatem illam Dei immediate applicativam repugnare cum hoc defectu et consequenter connecti cum requisiti illius existentia.

468. Contra $3^{\circ}$, quia immediatum principium non potest esse conditio, sub qua, in se sola spectata, praevideri possit futurus actus, cum ipsa, secundum se spectata, non sit sufficiens ad actus existentiam, sed indifferens ad hoc, ut sit vel expedita ad illum ponendum (si supponat decretum determinans ad eius positionem) vel impedita (si supponat decretum oppositum). Ergo sub illa sola eiusque indifferentia non poterit videri actus futurus. Solum ergo videri potest futurus sub conditione principii immediati adiungendo mediatum: vel ponendo illud ex parte hypothesis - quod facit conditionalem non contingentem, sed omnino necessariam -, vel ponendo illud ex parte conditionati ${ }^{351}$ seu praedicati affirmati asserendo, conditionem principii immediati non extituram esse ${ }^{352}$ nisi per principium immediatum determinans: quod contingens quidem est, non tamen contingentia libertatis humanae, sed divinae decernentis, conditionem immediati principii, si ponenda sit, ponendam fore per mediatum determinans existentiam actus.

Tum sic argumentor: Ergo ad libertatem componendam cum decreto determinativo actus nostri parum refert, quod hic ante decretum praevideri dicatur futurus per immediatum principium indifferens.

351. hypothesis corr.

352. esse suppl. 


\section{Probatur consequentia:}

Nam imprimis, praevisio actus ut sic futuri debet esse in decreto Dei decernentis, non poni conditionem indifferentem nisi per decretum actus nostri exercendi. Per illam cognosci oportet futuram esse operationem nostram, si ponatur conditio: sicut in decreto praevidendum dicunt Moderni Thomistae, quod posita indifferenti conditione homo sit operaturus.

Deinde, aeque inimpedibilis a voluntate creata est suppositio huius decreti ac decreti de operatione nostra facienda per principium immediate determinans. Nam inimpedibile prorsus a nobis est, quod Deus praevideat, non fore ponendum immediatum principium indifferens nisi per decretum determinans ad operationem. Nam hoc soli Deo liberum est. Ipsi etiam soli liberum est velle poni conditionem illam. Ac proinde suppositio decreti, de quo agimus, aeque inimpedibilis a nobis est ac suppositio decreti determinantis immediate. Ergo, cum concordia, quam NosTRI Doctores defendunt inter libertatem creatam et divinam determinationem fundetur in eo, quod determinatio, ut est ad operandum per haec principia in singulari, sit impedibilis a voluntate - saltem in radice sui, nempe in scientia conditionata -, exclusi ab hac concordia manent qui decretum praedefinitivum actus volunt esse principium necessarium - etsi remote - ad actus existentiam: etenim neque necessitatem hanc principii determinantis cum eius impedibilitate componere possunt neque eius inevitabilitatem cum legibus concordiae Iesuiticae.

469. Denique impugnatur solutio [\$ 454], quia, voluntatem [913v] nostram esse aut praevideri - operantem per principia proxime indifferentia inevitabiliter impedita ad omissionem operationis, non potest sufficere ad libertatem; sed hoc tantum pacto operans praevidetur voluntas in solutione, quam impugnamus: ergo non praevidetur modo sufficienti ad libertatem.

Minor et consequentia evidentes sunt.

Maior autem patet. Nam imprimis S. Thomas docet: „Potestas ad opposita, quam requirit libertas, est potestas expedita.“

Deinde, voluntatem esse inevitabiliter determinatam ad ponendum unum extremum per principia quibus constituitur potens operari, et impeditam ad positionem alterius, est esse antecedenter et simpliciter impotentem ad hoc alterum ponendum. Hoc autem libertati obstare, inter Nostros indubitabile est.

Quod impeditio illa faciat impotentiam, per se notum est, cum impeditum ut impeditum poni impossibile sit. Quod autem faciat impotentiam antecedentem, aeque notum videtur, cum omne inevitabile antecedens sit. Quod denique faciat impotentiam simpliciter et sine addito, patet, quia haec est, quae aliquo simpliciter ante operationem requisito caret.

470. Nec sufficit dicere, nil proxime requisitum deesse: quia hoc non est, nil simpliciter requisitum deesse, sed nil deesse requisitum in genere aliquo determinato. 
Quod non sufficit ad libertatis expeditionem. Ut in requisitis remotis, quorum etsi nullum desit, non ideo verificabitur, nil deesse simpliciter requisitum: quia, etsi omnia remota adsint, potest aliquod proximum deesse. Et sane non video, quid referat, requisitum, si essentiale sit, esse „proximum“ potius quam esse „remotum“, ut eius defectus potius faciat defectum requisiti simpliciter quam defectus requisiti remoti: cum omne essentialiter requisitum eo ipso simpliciter et absolute requisitum sit.

471. Probationem hanc confirmare possumus ex eo, quod indifferentia principii proximi ad duo extrema efficienda, si ad unum ponendum egeat uno principio remoto et alio ad alterum, non est indifferentia activa ad opposita ponenda sub iisdem requisitis, sed ad unum ponendum, si detur unum requisitum, et ad aliud ponendum, si detur alterum. Ut per se patet. Hoc autem genus indifferentiae non est electivae nec constituentis libertatem, quia electiva et libera facultas est vis determinandi opposita sub eisdem requisitis. Nam potentia, quae solum sub diversis $^{353}$ requisitis est effectiva diversorum, neutrius electiva est, sed ex electione et determinatione ponentis requisitum operans. Est enim operatio unius extremi sub conditione, quod ponatur requisitum, quo tale extremum eget, nempe, divinum decretum de talis extremi existentia, quin aliter illud valeat operari, et est operativum alterius extremi sub conditione decreti oppositi, quin absque illo quicquam possit ad talis extremi positionem. Ergo indifferentia agendi nulla est nisi ea, quae ad conditionum diversarum positionem datur. Ergo ad effectum ${ }^{354}$ operationis, quae sub tali conditione dicitur possibilis, nulla datur indifferentia electiva et determinativa, sed indifferentia determinabilis, quae per unius conditionis positionem determinatur ad unum effectum, et ad alium per positionem conditionis diversae.

Consequentia haec manifesta videtur. Nam principium, quod tantum sub conditione operativum est, eo tantum modo operativum est, quo per conditionem illam operari valet; ac proinde, [914r] si conditio est determinate exigens unum tantum genus operationis, principium erit determinate operativum illius tantum sub tali conditione, et alterius tantum sub alia: ac proinde non elective nec libere, cum ad conditionum varietatem nullam habeat electionem aut libertatem.

472. His probatum manet obiectionis huius secundae [ $\$ 463]$ praecipuum assumptum, nempe, praedefinitivam Dei voluntatem et suppositionem quancumque natura antecedentem non posse esse consequentem, probatum, inquam, manet in sententia Asserentium, quod praedefinitiva illa voluntas sit principium essentialiter requisitum ad praefiniti actus existentiam.

353. eisdem corr.

354. defectum corr. 
In sententia vero negante, illam, etsi principium sit, esse necessarium, probatur imprimis omnibus huius sententiae impugnationibus, quibus praevidetur, nil existere posse, nisi a Deo decernatur. De his impugnationibus vide librum 2 cap., ${ }^{355}$ et 3 capite $18^{\circ}$ et $19^{\circ}$, et capite $26^{\circ}$ et sequentibus.

\section{[Responsio]}

473. Hac obiectione, quam satis fuse prosequuti sumus, id aperte probatum videtur, videlicet, decretum Dei scientiam mediam antecedens determinate aliquem humanae voluntatis actum decernens omnino laedere libertatem humanam ac tollere, si eiusmodi decretum asseratur esse essentialiter et necessario requisitum ad operationem. Verumtamen, si non dicatur esse necessarium, sed principiis necessariis - et remotis et proximis - ultro et pro libito Dei superadditum, nihil concludit facta obiectio.

Ad quam propterea respondendum est eadem illa solutione, quam primae obiectioni adhibuimus $[\$ 462]$, videlicet, non omne principium determinatum libertatem tollere, sed aliquod principium, etsi determinatum, si tamen nonnisi remotum sit neque ad operandum necessarium - ac propterea sit consequens saltem in operando (ut iam explico et explicui supra) -, cum libertate componi.

474. Dicendum ergo, illud decretum quasi materialiter et velut subiective esse antecedens, formaliter vero et quoad operationem humanam attinet, esse consequens. Etenim operationem nostram respicit illud decretum ut effectum faciendum. Sic autem respicit operationem nostram, quia solum respicit illam ut faciendam medio aliquo auxilio hoc vel illo vage; ut autem ita se vage habens nequit decretum operari nec incipere quidem operari: ergo, ut operetur, indiget, quod accedat scientia media et per illam sciat Deus, quodnam ex auxiliis determinate habiturum sit eventum et futurum efficax. Qua comperta efficacia ad opus exit conferendo auxilium quod praevisum est efficax. Suppositio ergo eius decreti nisi dependenter a consensu praeviso nihil agit atque adeo temperatur voluntati nostrae. Non ergo dicenda est simpliciter „,antecedens“, sed solum „,antecedens“ cum addito - quippe materialiter et in existendo -, et simpliciter „consequens“: formaliter consequens et in operando.

475. Reliqua vero, quae in obiectione continentur, contra istam solutionem carent vi, nam scientia media non opus est, ut videat nisi ea principia, quae necessaria sunt ad operationem - sive proxima, sive remota -, non autem ea, quae necessaria non sunt. Hoc patet in sententia communi SocietaTis, quae defendit praefinitiones

355. Lacuna. 
divinas, tametsi consequentes ad scientiam mediam. Nam hae praefinitiones nec ex parte hypothesis videri possunt - nam redderent scientiam mediam necessariam - [914v] nec ex parte conditionati, ut bene probat obiectio [\$468]: ab illis itaque praescinditur. Quod idem dicendum est de praedefinitione ista divina, quam modo defendimus.

476. Neque - ut alia praeteream quae ex dictis soluta manent - ex defectu vel praesentia eius decreti impediri potest libertas nostra. Quae scilicet manet potens ad opposita sub omnibus requisitis necessariis, secus sub non-necessariis et remotis ac modo explicato consequentibus. Quod fere idem respondent NosTRI communiter, dum necessario fateri cogantur - atque fateantur -, voluntatem, ut subest praefinitioni divinae etiam consequenti, omnino ut sic liberam non esse neque ad opposita (nec praedestinatum ut talem et in sensu reduplicativo „posse“ damnari), satque omnes ad libertatem putant, si voluntas specificative sit potens ad opposita seque determinet ad opposita.

Atque hic sit finis huius voluminis ad laudem et gloriam omnipotentis Dei, et Beatissimae Virginis Mariae conceptae absque labe originalis peccati, Evangelistae Lucae, Ignatii parentis, et Patricii Hibernorum Apostoli. ${ }^{356}$

356. Die Schlußformel von anderer Hand hinzugefügt. 



\section{Index scholasticus}

\section{(unter Angabe der Paragraphen)}

Diego (Didacus) Alarcon SJ. (1585-1634): Prima pars Theologiae scholasticae. Lyon 1633.

Tract. 2 disp. 2 cap. 7: 44

Diego (Didacus) Alvarez OP. (1550-1635): De auxiliis divinae gratiae et humani arbitrii viribus et libertate, ac legitima eius cum efficacia eorundem auxiliorum Concordia. Rom 1610: 425

Lib. 2 disp. 10 n. 4: 17, 20-24, 27, 33

Lib. 2 disp. 12: 5

Francesco Albertini SJ. (1552-1619): Corollaria, seu Quaestiones Theologicae, praecipue in Primam et Tertiam partem S. Thomae, quae deducuntur ex principiis Philosophicis complexis ( $\left.{ }^{1} 1606\right)$. Lyon 1629.

Pr. 4 phil. q. 2 theol.: $44-45$

Martín de Alviz (Albiz) OSA. (1573-1633): De altissima Scientia, inscrutabili Voluntate, investigabili Praedestinatione ac ineffabili Trinitate tractatus IV in Primam partem S. Thomae. Alcalá de Henares 1632.

Tract. 1 disp. 6 sect. 3: 171

Pedro de Arrúbal SJ. (1559-1608): Commentaria ac Disputationes in Primam partem D. Thomae. Madrid 1619-22, t.1.

Disp. 42: 44

Martin van der Beeck (Becanus) SJ. (1561-1624): Summa theologiae scholasticae ( $\left.{ }^{1} 1612\right)$. Rouen 1657.

Tract. 2 cap. 1 q. $11: 385$

Tract. 2 cap. 10 q. $7: 44$

Tract. 2 cap. 10 q. $8: 45$

Jean Cabrol (Capreolus) OP. ( $† 1444)$ : Defensiones theologiae D. Thomae Aquinatis. Herausgegeben von C. Paban / Th. Pègues, Tours 1900-07.

I Sent. dist. 38 q. 1 art. 2: 38,362
Girolamo Fasulo (Hieronymus Fasolus) SJ. (1568-1639): In Primam partem Summae S. Thomae commentaria. Lyon 1623-36, t.2.

Q. 14 art. 13: 426, 454

Q. 14 art. 13 dub. 9: 40, 44

Q. 14 art. 13 dub. 10: 45

Pedro da Fonseca SJ. (1528-96): Commentaria in Metaphysicorum Aristotelis Stagiritae libros. Köln 1615 / Repr. 1964, t.3.

Lib. 6 cap. 2 q. 4 sect. 7: 45

Juan González de Albelda OP. († 1622): Commentaria et Disputationes in Primam partem Angelici Doctoris D. Thomae. Alcalá 1621.

Disp. 43-44: 5

Diego (Iacobus) Granado SJ. (1571-1632): Commentarii in Summam Theologiae S. Thomae, Sevilla 1623.

Q. 14 art. 13: 44

VALENTín Herice SJ. (1573-1626): Quatuor tractatus in Primam partem S. Thomae. Pamplona 1623.

Tract. 1 disp. 6 cap. 2-3: 44

Pedro de Ledesma OP. (†1616): Tractatus de divinae gratiae auxiliis. Salamanca 1611: 38-40, 362, 425

Leonard Lessius SJ. (1554-1623): De gratia efficaci, decretis divinis, libertate arbitrii et praescientia Dei conditionata Disputatio apologetica. Antwerpen 1610: 266

Cap. 3 n. 24: 43, 44

Luis de Molina SJ. (1535-1600): Commentaria in Primam Divi Thomae partem. Cuenca 1592: 44, 56

Q. 14 art. 13 disp. 13: 249-58

Q. 14 art. 13 disp. $14(-15): 7,45,221,240$

Q. 23 art. 4-5 disp. 1 membr. 11: 454 
LuIS de Molina SJ.: Liberi arbitrii cum gratiae donis, divina praescientia, providentia, praedestinatione et reprobatione Concordia. Hg. von Johannes Rabeneck. Oña-Madrid 1953.

Q. 23 art. $4-5$ disp. 1 membr. $11 \S 20: 454$

Baltasar Navarrete OP.: Controversiae in D. Thomae et eius scholae defensionem. Valladolid 1605-09, t.1: 425

João Poinsot (IoAnnes a S. Thoma) OP. (15891644): Cursus theologicus in Primam partem D. Thomae. Alcalá 1637, t.1.

Disp. 19 art. 2: 33, 192-201

Disp. 20 art. 7: 363

Diego Ruizde Montoya SJ.(1562-1632): Commentarii ac Disputationes de Scientia, de Ideis, de Veritate, ac de Vita Dei. Ad Primam partem Sancti Thomae, a Quaestione 14. usque ad 18. Paris 1629.

Disp. 11 sect. 3: 56

Disp. 24 sect. 3: 45

Disp. 26: 426

Disp. 26 sect. 5 n. 10: 387

Disp. 26 sect. 5 n. 12: 385

Disp. 28: 202, 224, 258

Disp. 28 sect. 3: 259

Disp. 28 sect. 7: 126-27, 168, 193

Disp. 28 sect. 7-8: 259, 260-65, 387

Disp. 31 sect. 1 n. $11: 95$

Disp. 31 sect. 2: 95

Disp. 31 sect. 4: 95

Disp. 33: 44, 324, 364

Disp. 33 sect. 7: 362

Disp. 52 sect. 3 n. $2: 396$

Diego Ruiz de Montoya SJ.: Commentarii ac Disputationes ad Quaestionem XXII et bonam partem Quaestionis XXIII ex Prima parte S. Thomae: De Providentia praedefiniente ac praebente praedestinationis exordium. Lyon 1631.

Disp. 11 sect. 4 n. 9: 454

Francisco SuÁReZ SJ. (1548-1617): De concursu et efficaci auxilio Dei ad actus liberi arbitrii necessario, libri III. In: Varia opuscula theologica ('1599). Opera omnia. Paris $1856-78$, t.11.

Lib. 2 cap. 7 n. 11: 403, 435

Lib. 3 cap. 14 n. 16: 454
Francisco Suárez SJ.: De scientia, quam Deus habet de futuris contingentibus, libri II. In: Varia opuscula theologica $\left({ }^{1} 1599\right)$. Opera omnia. Paris 1856-78, t.11.

Lib. 1 cap. 4 n. 5: 45

Lib. 1 cap. 6 n. 1: 385

Lib. 1 cap. 6 n. 15: 426

Lib. 1 cap. 7 n. 2: 268

Lib. 1 cap. 8 n. 9-10: 127, 259, 267, 269

Francisco SuÁrez SJ.: Prolegomenum secundum: De scientia, quam Deus habet de liberis actibus sub conditione futuris prius ratione, quam absolute futura cognoscat. In: Tractatus de gratia Dei. P.I. Opera omnia. Paris 1856-78, t.7.

Cap. 8: 44

Cap. 9 n. 6: 31, 247

Cap. 9 n. $8: 385$

Adam Tanner SJ. (1572-1632): Universa Theologia scholastica. Ingolstadt 1626-27, t.1.

Disp. 2 q. 8 dub. 6: 44

Thomas de Aquino OP.: In Perihermeneias Aristotelis expositio

Lib. 1 lect. 13: 12, 176, 192

Thomas de Aquino OP.: In XII libros Metaphysicorum Aristotelis expositio, ed. R.M. Spiazzi, Turin 1964.

Lib. 5 lect. 13 n. $936: 107$

Thomas de Aquino OP.: Commentum in librum I Sententiarum

Dist. 38 q. 1 art. 5: 14, 55, 59

Dist. 39 q. 1 art. 1: 384

Thomas de Aquino OP.: Summa Theologica

I, Q. 14 art. 8: 94, 197

I, Q. 14 art. 9: 33, 36

I, Q. 14 art. 13: 11, 15, 33, 37, 45, 58, 62, 64, 174, 189, $192,197,219,230-34,357-58$

I, Q. 15 art. 3: 45

I, Q. 16 art. 7: 15, 33-34, 176, 198

I, Q. 19 art. 3: 21

I, Q. 19 art. 8: 372

I, Q. 26 art. 1: 352

I, Q. 57 art. 3: 12, 55

I, Q. 83 art. 4: 294

I, Q. 86 art. $4: 12$

II/II, Q. 171 art. 6: 14, 21, 57

II/II, Q. 174 art. 1: 57 
Thomas de Aquino OP.: Summa contra gentiles

Lib. 1 cap. 66: 12, 18, 23, 55, 215

Lib. 1 cap. 67: 16, 17, 24-26, 55, 362

Lib. 1 cap. $68: 27-28,45,362$

Lib. 2 cap. $30: 345$

Lib. 3 cap. $90: 352$

Thomas de Aquino OP.: Quaestiones disputatae de Veritate
Q. 2 art. 4:55
Q. 2 art. 6: 215
Q. 2 art. 7: 45
Q. 2 art. 11: 33
Q. 2 art. 12: 12, 15, 55, 192, 199, 202, 213-14, 359-60
Q. 3 art. 6: 45
Q. 12 art. 11: 33,35
Q. 22 art. 1: 52
Q. 23 art. 1: 52

Thomas De Aquino OP.: Quaestiones disputatae de Malo

Q. 16 art. 7: 2, 12, 15, 19, 21, 28, 29, 35, 37, 55, 174, $175,192,199,219,379,433$

Claude Tiphaine SJ. (1571-1641): De ordine deque priori et posteriori liber, ad varias et celebres Theologiae et Philosophiae quaestiones enodandas. Reims 1640.

Cap. 19 n. 10: $268-72$
Gregorio de VAlencia SJ. (1549-1603): Commentaria theologica in Summam Theologicam D. Thoma. Lyon 1609, t.1: 44, 266

Disp. 1 q. 14 punct. 5 n. $2: 7$

Gabriel VÁzQuez SJ. (1549-1604): Commentaria ac Disputationes in Primam partem S. Thomae. Opera omnia, hg. von Marcel Chossat. Paris 1905, t.1.

Disp. 65 n. 23: 385

Thomas de Vio Cardinalis Caietanus OP. (14691534): Commentaria in Primam partem Summae theologiae Angelici Doctoris S. Thomae Aquinatis, in Thomas Aquinas: Opera omnia ed. Leonina. Rom 1888ff., t.4-5.

Q.14 art. 13 n. 10: 248

Q. 14 art. 13 n. 14: 39

Q. 14 art. 13 n. 17: 45, 46, 67, 221, 274, 375

Q. 14 art. 13 n. 23: 39

Q. 57 art. 3 n. $4: 39$ 



\section{Index nominum ${ }^{*}$}

A

\author{
Abra de Raconis $\quad 98$ \\ Adam Wodeham OFM. 345 \\ Aegidius Romanus OSA. \\ 214, 368 \\ Agostini SJ. 35f., 57, 62, 70, 72f., \\ $81,89,112$
}

Aguilar SJ. 50, 59, 69, 87, 107

Alarcón SJ. 29, 37, 39, 42, 45, 53, 55ff., 59, 61, 66f., 71, 73, 79, $83,87,89,98 \mathrm{ff} ., 101,105,122$, 128, 218, 415

Albertini SJ. 42f., 55, 64, 94, 100, 117, 217f., $415 \mathrm{f}$.

Albertus Magnus 214, 218, 220, 346,368

Albus (White) 43f., 62

Aldrete SJ. 29, 31, 33f., 37, 42f., 49, 53, 57f., 6of., 69, 72, 74 , 75f., 78f., 81, 83, 84f., 86, 87ff., 92f., 95f., 101, 103, 104, 106, 108, 111, 113ff., 116, 118, 121, $141,161,168,172,313$

Alegambe SJ. 22

Aler SJ. 19, 65

Alexander de Hales 368

Alexandre OP. 17, 22, 27

Alfonso SJ. 72

Alva y Astorga OFM. 3

Alvarez OP. 3, 13, 15f., 18ff., 21ff., 39ff., 42, 74, 95, 109f., 123, 132f., 193, 202ff., 205ff., 208, 210, 401, 415, 431

Alviz OSA. 47, 121, 276

Amat de Graveson OP. 2, 7, 20

Ames 109

Amico SJ. 38, 49, 59, 8of., 94, 102, 114, 116

Amort CR. 68

Anfray IX
Annat SJ. 12, 14f., 18, 19, 21, 23, 44, 50, 68, 94

Anselmus Cantuariensis

79, 132, 280, 288, 346ff., 355ff., 358f., $368 \mathrm{f}$.

Antoine SJ. 27, 35, 48, 55, 61, $91,95,108$

Antonio de la Madre de

Dios OC. 3

Antonius Andreas OFM. 148

Aquaviva SJ. 30,126

Aranda SJ. 28f., 34f., 37, 50, 53, 67, 69, 74f., 77f., 80, 106, 116, 118

Araujo OP. 141

Araujo SJ. 45, 54, 56, 58f., 74, 84, 101, 104f., 123

Ariew XVI

Aristoteles 14ff., 19, 43, 46, 127, 240, 246, 248, 253, 266, 278,

$294,329,344,357,423$

Arnauld 2, 4, 21, 120, 139

Arriaga SJ. 28, 33, 37, 39, 44, 51, 53, 58, 60, 62f., 67, 7of., 73, 78f., 82ff., 87, 89, 93f., 10of., $118,148,157,168,173,215$, 225f., 251, 263, 329, 360, 391, 415, 423

Arrúbal SJ. 10, 56, 99f., 102, 217, 431

Astrain SJ. 172

Ps.-Athanasius 359

Augustinus xvII, iff., 4f., 7f., 11f., 14f., 22, 25f., 63, 110, 112, $121,144,146,221,246,251$, 255, 280, 288f., 293f., 319, 331, 344ff., 347, 358f., 371ff., 405, $417 \mathrm{ff}$.

Avendaño SJ. 42, 45, 54, 56, 72 , $85,95,101$
Avendaño y Eztenaga SJ. 52, 58, 85, 94f., 100, 103

Aversa CRM. 122

Ayleworth SJ. 51, 53, 119

B

Babenstuber OSB. $\quad 45,48,69$

Baciero SJ. 168

Bajus 22

Báñez OP. 16, 193, 213f., 367f., 401

Banholzer SJ. 50, 91, 108

Barberiis OFMCap. 94

Barbiano SJ. 140

Baron OP. 103, 126

Barrientos García XI

Bastida SJ. 2f., 28f., 33, 39, 60, $63,69,73,95,100$, 111f., 115, $117,119,161$

Bauer 109

Baumeister 123

Baumgarten, A.G. 37

Baumgarten, S.J. 123

Bayle 25, 120, 148, 168

Becanus SJ. 27, 31, 38, 57, 66, 71, 88, 94, 111, 217f., 38o, 431

Bechmann 44

Ps.-Beda 362

Bellarmin SJ. 62f., 69, 111, 217

Bene CR. 43, 102

Benedictus a S. Iacobo OSA. 68

Benedikt XIV. 7, 125

Benjumea OFM. 43, 102

Bereur de Dôle OFMCap. $4,37,66,68,74$

Bermudez SJ. 172

Bernaldo de Quirós SJ. 30, 33, 41f., 53, 59, 61, 64, 67, 69, 74ff., 79, 84ff., 89, 91, 93, 97, 106f., 115, 117, 16of., 172, 297, 415, 423

* Der Ausdruck „et passim“ besagt, daß der sonst stets berücksichtigte Fußnotenteil das in dem betreffenden Eintrag nicht ist. 
Bernique OFM. $16,50,88,106$

Berti OSA. 7f., 24

Billuart OP. 6, 12

Blanckenburg XII

Blanco SJ. 143

Blumenberg XIX, 166

Boethius 43, 293, 342, 362, 368

Bolzano 164

Bonae Spei (Crespin) OC.

34,56

Bonald 18

Bonartes (Barton) ex-SJ. 46

Bonaventura 94, 214, 218f., 224, 243, 346, 369

Borkenau XI

Borrull SJ. 104

Bossuet 2, 120

Boudart 32

Bourdaloue SJ. 120

Boursier 5, 23

Brüntrup SJ. 111

Budde 94

Bugis SJ. 51, 111

Buontempi OFMCap. 39, 94

Burman 30

\section{C}

Cabrera 34, 39, 41, 60, 71, 86, 89, 98ff., 114, 118

Cacherano CRSP. $\quad 45,109,125$

Campoverde SJ. $\quad 61,69,85,113$

Canz 124

Caramuel y Lobkowitz O.Cist. 40, 62, 103, 126, 169

Cardenas y Mendieta CR. $128 \mathrm{f}$.

Caruso 173

Casimirus Tolosanus OFMCap. 44

Caspe OFMCap. 56

Cattaneo SJ. 42

Cerf 81

Ceyssens 139

Channevelle SJ. 42, 90, 102, 119

Charleton 94

Chenu OP. 21

Chossat SJ. XVII, 104

Chrysippos 43

Cicero 16, 63, 344

Cienfuegos SJ. 29, 77

Clémencet OSB. 23
Clemens VIII. 3

Colbert 6

Collegium Complutense OP. 19

Collegium Salmanticense OCD. $3,21,23,40,46$

Comitibus (Conti) OSA. 50

Compton-Carleton SJ. 25, 44

Coninck SJ. 16, 37, 161

Contenson OP. 24, 109

Cornejo OC. 46

Craig 124

Crusius 70, 102, 123

Curiel 46

D

Dagens 2

Daniel SJ. XVII, 28, 95, 120

Dechamps SJ. 4, 19

Deckers SJ. 94

Der-Kennis SJ. 34, 59, 113

Descartes XVI, 146

Dionysius Carthusianus 368

Diotallevi $32,45 f$., $53,66,68$, 71f., 78f., 81f., 85, 88, 94, 101

Donoso Cortes 18

Doyle 52, 151, 173, 271

Drattenberger SJ. 51, 85

Driessens (Valerius Andreas) 17

Duhem 17

Dummermuth OP. 11

Dumont 139

Durandus a S. Porciano OP. $65,68 f$., 218, 224, 243, 342, 369

Durelle O.Minim. $\quad 43,47,55$

Dvořák $\mathrm{x}$

E

Eberhard 124

Eberstein 18, 126

Eck 30

Elbecque OP. 5, 7

Embry 48

Erath CRA. 34, 68, 96, 119

Erber SJ. 50, 54, 81

Escobar y Mendoza SJ. 172

Esparza y Artieda SJ. 42, 5of., 71, 85, 87f., 97f., 116, 180, 182

Esperabé Arteaga 173

Estrix SJ. 38
F

Faber (Fabbri) OFM. 90, 102, 112

Fabri SJ. 97

Fasolus (Fasulo) SJ. 27, 41, 47, 57, 62, 64, 77, 96ff., 10off., 104, 111, 118, 401f., 417, 432

Fasseau OP. 96

Felix OFM. 39, 57, 60, 71, 78, 126

Fénelon 2, 5ff., 9, 12ff., 19, $23 \mathrm{ff}$., 120

Ferre OP. 22, 126

Ferrier SJ. 50, 94, 103, 126

Feuerbach XIII

Fichte 163

Filorami O.Minim. 108

Fischer 110, 124

Fonseca SJ. 31-34, 42f., 56-59, 61, 71, 81, 90, 93f., 97, 113, 160, $219,233,432$

Fouillou 2, 6

Fourmestraux SJ. 63, 109, 125

Franceschi 1-26

Franciscus a S. Clara

(Davenport) OFM. 157

Franzelin SJ. 48

Froidmont 17

G

Gabriele di San Vincenzo OCD. 33, 37, 39f., 46, 48, 65, 109

Gale 20

Gamaché 15

Gener SJ. 81

Gengell SJ. 121

Gerberon OSB. 139

Germon SJ. 11, 15

Gesures (Gesvres) OSB. 5, 71

Gibbon de Burgo OSA. 119

Gibieuf OF. 15, 18, 32

Gilson 21

Gioberti $17 \mathrm{f}$.

Godart 100

Godoy OP. 43, 46, 48, 100, 103, 111

Gomarus 123

Gonet OP. 7, 17f., 23, 42, 46, 62,69

González de Albelda OP. 194, 432 
González de Rosende CRM. 22, 36, 42, 82f., 103, 108f., 120,122

González de Santalla SJ. 14, 17, 20, 22, 29, 33, 35, 41f., 44, 49ff., 54, 67, 73, 75f., 78f., 81, 84, 88, 94f., 97f., 101, 106, 108, $113,125,144,159,164 \mathrm{f}$.

Gormaz SJ. 41, 61, 74

Goudin OP. 19

Gracia 22

Granado SJ. 30, 42, 53, 60, 63, $82,88,99,101,110,114,116$, $217,415,432$

Gregorius Ariminensis OSA. 31 Gregorius Magnus 292

Groethuysen 8

Grou SJ. 26

Gualterus Burleus 294

Gualterus Chatton OFM. 256

Gufl OSB. 45, 70, 109

Guillelmus Ockham 43

Gunner 85

Gutierrez de la Sal SJ. 105, 114ff.

\section{$\mathrm{H}$}

Habert 24

Hanov 124

Haunold SJ. 77, 85, 100, 102, 115,157

Hazart SJ. 139

Hebenstreit 30

Heereboord 109

Hemelman SJ. 161, 415

Henao SJ. XIX, 21, 28, 31ff., 42-45, 49-53, 69, 73, 75f., 78f., 88, 90, 94ff., 98, 10of., 104, 106f., 118, 121ff., 126, 137, 139ff., 161, 170, 172

Henricus a S. Ignatio OC. 5,17 , 29, 56, 110, 122

Hentrich SJ. 71

Herice SJ. 34, 39, 50, 54, 56, 62, 65, 7off., 82, 87, 10of., 109, 115 , 118, 218, 432

Herinckx OFM. 110

Hermann OFM. 40

Hermann SJ. 59, $105 f$.

Herrera SJ. 36, 51, 54, 60, 65, $67,73,75,78 f ., 85,98$, 106f., $111,113,128$
Hieronymus 346,361

Hild 21

Höfler OSA. 31

Hoenen 242

Hogan SJ. 135ff., 140, 170, 179-84

Hübener XIX, 12, 38

Hugo de S. Victore 242, 370

Hurtado SJ. 89, 101

Hurtado de Mendoza SJ. 34f., 42, 44, 57, 59, 61, 63f., 85 , $88,90,99,101,116,118,157$, $161,169,171,184,282$

Huygens 108

I

Imbach XIX

Ioannes a S. Thoma (Poinsot) OP. 22, 31, 39f., 43, 6o, 65, 74f., 95f., 11of., 119, 121f., 141, 193, 203, 210ff., 285-302, 368, 433

Ioannes ab Annunciatione OC. 2

Ioannes Baconthorp OC. 133

Ioannes Buridanus 17

Ioannes Capreolus OP. 213, 218, 224, 243, 311, 366f., 385, 431

Ioannes Chrysostomus 346 , 36of.

Ioannes Damascenus 222, 326, $361 f$.

Ioannes Duns Scotus 137, 155, 169, 218, 220, 241, 318, 340, 375

Ioannes Maior $\quad 242,370$

Ps.-Iustinus 242

Izquierdo SJ. XIV, 14, 29, 32, 38f., 45, 47ff., 51-56, 58f., 61, $64,67,69,72,74,76,78,83$, 85, 87, 91f., 97, 10of., 107f., 122,164

\section{J}

Jäger $\quad 35,47,100$

Jamin 7

Jansenius 7, 14, 19f., $138 f$.

Jöcher 150

José de S. Maria OP. 17

Juaniz y Echalaz $173 \mathrm{f}$.

Junius (Young) SJ. 35f., 48, 55 , $60,69,78,81,85 f$., 88f., 92f., 98, 105f., 108, 115 f.

\section{K}

Kant 37

Kapp 121

Kilber SJ. 94

Kircher SJ. 170

Klein 17

Knebel xIII, XIV, XVIII, Xx, 24, 117, 139, 142ff., 151f., 155, 169,171

Knippenberg OP. $\quad$ 96, 108

Knittel SJ. 44

Kromayer 118

Krug 124

\section{L}

\section{L'Herminier 96,108}

La Broue 6

Lalemandet O.Minim. 31, 40, $49,65,70,74,90$

Lallemant SJ. 26

Lamparter SJ. 108

Launoy 3

Laville 26

Le Bachelet SJ. 12, 30, 34, 36, $62 f ., 65,82,86,94,100,115$, $118,122,168$

Le Blanc Beaulieu 13

Le Moyne 4

Ledesma OP. 15f., 18f., 28, 32, 34, 39, 41ff., 46f., 56f., 70, 74 $103,107,110,118,213 f$., 367 , 401, 432

Leibniz IX, 18, 38f., 58, 70, 74f., 79, 91, 100, 102, 110f., 121, 124

Leinsle $135,157,168$

Lemos OP. 3, 7, 13, 15, 17f., 19, 22, 31, 39f., 43, 46, 57, 95, 97, 100, 109f., 114, 119, 121, 126, 234

León OSA. 29

Lessius SJ. 29, 31, 33f., 36f., 43, 46, 63ff., 71f., 82, 94, 97, 100, $111,115,216,319,432$

Leydecker $\quad 43,107,112$

Lilao Franca 131, 140, 171

Lorca O.Cist. 100

Lossius 124

Loyola SJ. $\quad 158$

Lubac SJ. 5

Lugo SJ., F. $\quad 45,174$ 
Lugo SJ., J. $\quad 38,113,144,161$, 168f., 415

Luis SJ. $\quad 33,94$

Lumbier OC. 49, 102

Lüthy XVI

Lyncaeus (Lynch) SJ. $\quad 83,101$, 104, 115, 140f., 172f., 175f., 187-90, 217

\section{M}

Mabillon OSB. 5

Macedo ex-SJ. 55, 72, 82, 94f., $110,112,118,126$

Maderni CRSP. $\quad 33,72,87,89$, 103, 110

Maeratius SJ. $\quad 89,315$

Magalhaes OP. 10, 45f., 56, 126

Malebranche 2

Mamachi OP. 8

Manso OSA. 22

Manuel de la Concepción O.SS.T. $33,36,58 f$., $65,85,98,104$, $109 f$.

Marandé 120

Maresius (Desmarets) 19, 119

Mariales OP. 19

Marín SJ. 36, 85, 118

Maritain 5

Mármol SJ. XVII, XVIII

Marsilius de Inghen $\quad 242,345$, 371

Marti 123

Martínez SJ. 27, 33f., 39, 41f., 49f., 53ff., 57, 6off., 67, 69f., 73, 75, 79f., 82, 85, 87-90, 95, 104, $106,110,123,160$

Martinez Bara 138

Martínez de Prado OP. 16

Martínez de Ripalda SJ. 17, 22f., 8o, 84, 139, 168

Martinon SJ. 19, 60, 87, 89, 107,114

Mascarenhas 94, 100

Massoulié OP. 2, 6f., 13f., 18

Mastri da Meldola OFM. 27, $33,40,43,65,69,96 f ., 102$, $121,146,225$

Mauro SJ. 32, 36, 38, 41, 51f., 58, 71, 79, 81, 87, 91, 103, 105f., 116

Mayr SJ. $\quad 34,36,39,55,59,84$, 91, 105f., 112

Meindl SJ. 77
Mendizabal 136

Mendoza OSA. 31, 39, 41f., 57,88

Mendoza SJ. 184

Merinero OFM. 105

Merlin SJ. 25

Meron OFM. 44

Mersenne O.Minim. 120

Meyer (Meyere) SJ. 15, 21, 28, 95, 108, 112, 161

Michel 45

Micraelius 100

Miczka XIx/xx

Miranda SJ. 41, 88, 98, 114, 121

Modestus a S. Amabili OC. 39

Molina SJ. IX, XI, XVI, 1, 3, 7, 1of., 21f., 28, 39, 42, 44, 49, 62, 65-68, 71, 79, 87-90, 93, 95, 97, 99f., 104, 109, 111, 113, 115f., $121,126,132,159,162,169,190$, 194, 217f., 224, 300, 307, 311f., 315f., 417, 432 et passim

Molinaeus 74

Moncé SJ. 27, 42, 72, 82f., 89, 99ff.

Monschein SJ. 47, 49, 67, 72, 79, 91

Monzon SJ. 122

Moore SJ. 128

Morán SJ. 132, 140, 169, 171, 173,187

Morasch 70

Morawski SJ. 36, 65, 107

Mougenot OSB. 7

Muniesa (Muniessa) SJ. 34, 53, $78,93,98,101,116,118,126$

Muñoz Delgado OM. 39

$\mathrm{N}$

Navarrete OP. 31, 40, 46, 78, 112, 401, 432

Nazarius (Nazzari) OP. 119

Nethen vide Voet

Neuhauser SJ. 120

Neumayr SJ. 112

Newton 120

Nicole 2, 4f., 21

Noailles 6, 23

Nugent SJ. 180

Nuñez Coronel OSA. 108

Nuño Cabezudo OP. 15f., 19, 110
O

O'Connor 136

Olivares SJ. 168

Opstraet 110

Orcibal 138

Origenes 31

Ortega SJ. 15, 50, 80, 101, 114, 140

Oviedo SJ. 14, 43f., 50f., 53, 58, 64-69, 76, 78f., 115, 117, 157, 161,263

\section{$\mathbf{P}$}

Palanco OM. 43

Pallavicino SJ. 31, 52, 58, 88, 91 Para du Phanjas ex-SJ. 120

Parra OP. 19

Pascal 1, 4, 21, 172

Paul V. 3

Péligry 172

Peñafiel SJ., I. 43

Peñafiel SJ., L. $\quad 67,94,114 f ., 117 f$.

Pennotto CR. 16, 29, 39, 72

Peralta SJ. 35, 45, 57f., 60, 62, 73, 76f., 84, 102, 104, 106, 115

Perez OP. 45, 107

Perez SJ. 31, 33, 51, 53f., 67, 77, 85, 92 fff., 105, 139, 160, 166f., $172,250,255,282,323,337$, 405, 417

Perez de Quiroga OFM. 100

Perez de Unánoa SJ. 91f., 98

Perez Goyena 138

Perlín SJ. XVII, 116, 161

Perrimezzi O.Minim. 48, 72, 102,109

Pesanzio 46f.

Pesch SJ. 45

Petavius (Petau) SJ. 17

Petrus a S. Ioseph (Comagère)

O.Cist. 44

Petrus Thomae OFM. 194

Peynado SJ. 48, 74, 98

Piccinardi OP. 43, 45, 60, 69, $85,98,101,109$

Pimentel SJ. 171-74

Piña SJ. $\quad 135,170,173,187$

Pinto Ramirez SJ. $\quad 107$

Piny OP. 75

Piro $\mathrm{x}$

Pius (Ituren) SJ. 65 
Plantinga 124

Platel SJ. $\quad 51,53,62,76,81$

Pluta XIX/XX

Polizzi SJ. 52, 55, 58, 72, 84

Poncius Legionensis (de León) OSA. 139

Poncius (Punch) OFM. 66, 68 Praepositus (Prévost) SJ. 113, 122

Prideaux 4of., 57, 94, 109, 119, 126

Prosperus Aquitanus $\quad 346,353$

\section{Q}

Quadros SJ. 23

Quenstedt 34,80

Quesnel 2, 4ff., 22

\section{R}

Racine, B. $8,12,23$

Racine, L. 109

Ragusa SJ. 35

Ram 95, 97, 99, 116

Ramirez SJ. 33, 45, 47, 50, 52, 58, 6o, 67f., 72, 75f., 78f., 81, 85, 87f., 93, 98, 104-07

Ramis Barceló $146 f$.

Raynaud SJ. 16, 47, 57, 68f., 84, $122,161,408$

Recupito SJ. $38,47,52,57,60$, 95, 99-102, 113f., 116

Redmond 143

Reginaldus (Regnault) OP. 7,16

Reguera SJ. 184

Rehlinger SJ. 116

Reid 123

Reinhardt 33, 94

Reusch $123 \mathrm{f}$.

Rhodes SJ. 33, 82

Ribadeneira (Rivadeneyra) SJ. 28, 57, 59, 72, 75, 78, 84, 91ff., 103f., 107, 111, 115

Ribas SJ. $\quad 66,101$

Ricardus de Mediavilla OFM. 311, 368

Richard Fitzralph (Armachanus) 369

Ripert de Monclar 25

Rispolis OP. 90, 94, 99, 119f.

Robert Holkot OP. 247

Robles SJ. 255
Romaeus OP. $\quad 215$

Ruiz de Montoya SJ. XI, XVI, 14, 16f., 24, 33f., 38f., 42f., 47f., 56ff., 64f., 67, 69, 71, 73f., 75, 80, 86, 88, 95, 102, 109, $112-17,121,134,164,174,196$, 206, 210, 218ff., 224ff., 229, 237, 241ff., 251, 256ff., 275, 287, 292, 301, 316-19, 329, 345f., 353 , 355f., 359-62, 365-71, 373, 379-82, 386, 390, 402, 415, $417,423,433$

Rutherford 123

\section{S}

Saénz de Aguirre OSB. 22, 140 Saguens O.Minim. 29, 37, 39, $41,43,60,113$

Saléon 7

Salmeron SJ. 217

Sanctius (Santi) SJ. 30

Sarasa SJ. 110ff., 120, 123 f.

Schabel XVIII, 29, 37

Schad CR. 24

Scheeben 151

Scheffler (Angelus Silesius) 167

Schertzer 34, 103, 107

Schleiermacher 40

Schmutz X, XIV, XV, 21, 48f., 132, 136, 139, 164, 166f., 169

Schneemann SJ. 31

Schoock 14, 17, 110

Schuler 123

Schüssler XI

Schwane 100

Schwarz OSB. 121

Sébille OP. 17

Sedlmayr OSB. $\quad 39,105$

Semery SJ. 72

Sendin Calderón OFM. 16, 56

Serna OM. 44

Serra OP. 17

Serry OP. 7, 11, 15, 21, 23, 94, $112,122,126,161$

Sherlog SJ. 13, 42, 45, 95f., 122, 133, 136, 170f., 173, 179, 181-84, 190, 315, 375

Silva y Pacheco OSB. $30,34,37$, 46, 59, 70, 95f., 102f., 105, 119

Simonnet SJ. 35

Sinnich 23
Sirenio 63

Slevogt 44

Smising OFM. 99

Soares SJ. 28, 71, 79, 98, 101

Söder 241

Soliani 139

Sommervogel SJ. 120

Soto OP. 16, 57

Sotwellus (Southwell) SJ. 119

Spaemann 9

Specht 61

Stattler SJ. 70

Sterzinger SJ. 53, 62, 91, $104 \mathrm{f}$.

Stillingfleet 170

Stone $\mathrm{xIx} / \mathrm{xx}$

Strang $17,59,80,110$

Stromeyer 93

Stümel OFM. 95, 119

Suárez SJ. 1, 10, 12, 18, 22, 42, 44, 46f., 49f., 56f., 64-68, 70, 74, 76, 79f., 85, 87, 9of., 95, 10of., 103, 110f., 113f., 117, 125f., 134f., 142, 144ff., 163, 174, 209, 217, 219, 224, 257f., 310, 316, 319ff., 380, 386, 390, 402, 406, 417, 433f. et passim

Sylvestris Ferrariensis OP. 206f., 213, 224, 365

$\mathrm{T}$

Talbot OSA. $\quad 181$

Tanner SJ. $\quad 35,87,96,218,434$ Tapolcsanyi SJ. 92, 108

Taubes XIX

Tellez SJ. 100

Thomas ab Argentina OSA. 29, 369

Thomas de Aquino xIV, 1, 8, 14, 25f., 133, 160, 175f., 192, 196-214, 218f., 222ff., 226f., 230, 241f., 248, 278f., 282, 284-92, 296f., 299-305, 311, $316,331,346,357,361,363$, 365-68, 373ff., 377, 379f., 397, 405, 426, 434f. et passim

Thomas de Vio (Caietanus) OP. 213f., 218, 220, 224, 231f., 300, 311f., 315f., 322, 345, 364-67, $375,386,435$

Thomas Waldensis OC. 32 Thomas Wylton 29 
Thomassin 24

Tiedemann 17

Timmermans 26

Tiphaine SJ. 30, 90, 122, 157, 161, 319, 435

Tolomei (Ptolemaeus) SJ. $36,45,86,104$

Tolstoi 58

Torrecilla OFMCap. 68

Turretini 108

Turrianus (Torres) SJ. 47

Twisse 15, 17f., 42, 46, 57, 102ff., 109f., 123

\section{$\mathrm{U}$}

\section{Ugolinus ab Urbe Veteri} (Orvieto) OSA. 408

Ulloa SJ. 28, 33f., 36, 41, 52, 54, 58-61, 64, 67, 73-77, 81, 84, 9off., 97, 104, 106, 111

Ulrich 111

Uriarte SJ. 179

\section{$\mathrm{V}$}

Valencia SJ. 3, 71, 435

Vallio SJ. 44

Vansteenberghe 10, 41, 45

Vargas SJ. 35, 69, 76, 104, 106
Vázquez SJ. XIV, XVII, 22, 27, 31, Wadding (Godinez) SJ., M. 42f., 47, 56f., 59, 64, 66f., 74 , 136,158 78ff., 82-86, 10of., 111, 115, 117, 121, 126, 128, 134f., 159, 210,

Wadding SJ., P. $\quad 35,61,72,82$, $118,135,137 \mathrm{f}$. 217f., 220, 224, 302, 311, 319, Wadding OSA., R. 135 $380,386,417,423,435$

Veith SJ. $\quad 17,24$

Veken SJ. 39, 52, 58, 84, 101, $103,113,121$

Ventura de Raulica 18

Verdu OP. 111

Viou OP. 7

Vita OP.vazque 125

Vitoria OP. 16

Viva SJ. 51, 114, 116

Vives OP. 46, 95, 99, 123

Voetius (Voet) $32,40,43,57, \quad \mathrm{Y}$ $69,71,79,81,87,90,94,103, \quad$ Ysambert 16,56 109, 111-14, 118

Vona xvI

Vulpius (Volpi) OFM. 99

\section{W}

Wadding (Gaudin) SJ., A. 135

Wadding OFM., L. $135 \mathrm{ff}$.

Wadding SJ., L. $\quad 77,131-210$ et passim
Wale 123

Walsh SJ. 161

Weigel 12O, 124

Weise 124

Weiss 172

Werner 9

White SJ. 179

Wietrowski SJ. 41, 98

Windheim 124

Wolff 7o, 124, 146

Z

Zedler 124, 169

Zumel OM. 16, 31, 34, 39, 43, $46,57,71,75,89,95,99,101$, $111,118,214$

Zuniga SJ. 161 
Molinismus ist heute ein Kapitel Philosophie. Das Thema dieses Buchs ist jedoch nicht die Renaissance der Scientia Media-Hypothese in der modernen angloamerikanischen Religionsphilosophie, sondern ihre scholastische Ausgestaltung in dem auf Molina folgenden Jahrhundert: Ohne den Kalkül mit den möglichen Welten z.B. kein Leibniz mit seinem Optimismus. Die vorliegende Studie bahnt sich den Weg durch die Gnadenstreitigkeiten zur Metaphysik des Faktenwissens. Hier zeigt sich die Grundlagenkrise des Molinismus.

Das molinistische Faktum hat drei Merkmale: Es ist kontingent, es ist Teil einer möglichen Welt, es ist vom Allwissenden notwendig gewußt. Traditionell beruht die Lehre von Gottes Faktenwissen auf dem Dogma vom Vorsprung der göttlichen Willensaktivität. Dieses Dogma ist durch die Scientia Media-Hypothese erschüttert. Worauf beruht es aber dann, daß Gott A vorherweiß, nicht nonA?

Der Streit der Schulrichtungen wird zusätzlich durch eine lateinische Textedition illustriert. Von dem Jesuiten Luke Wadding (1593-1651), dem Autor dieses schwierigen

Texts, ist bisher nur bekannt, daß er der Lehrer des Scientia Media-Historikers Gabriel de Henao gewesen ist.

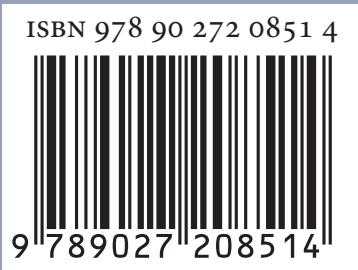

